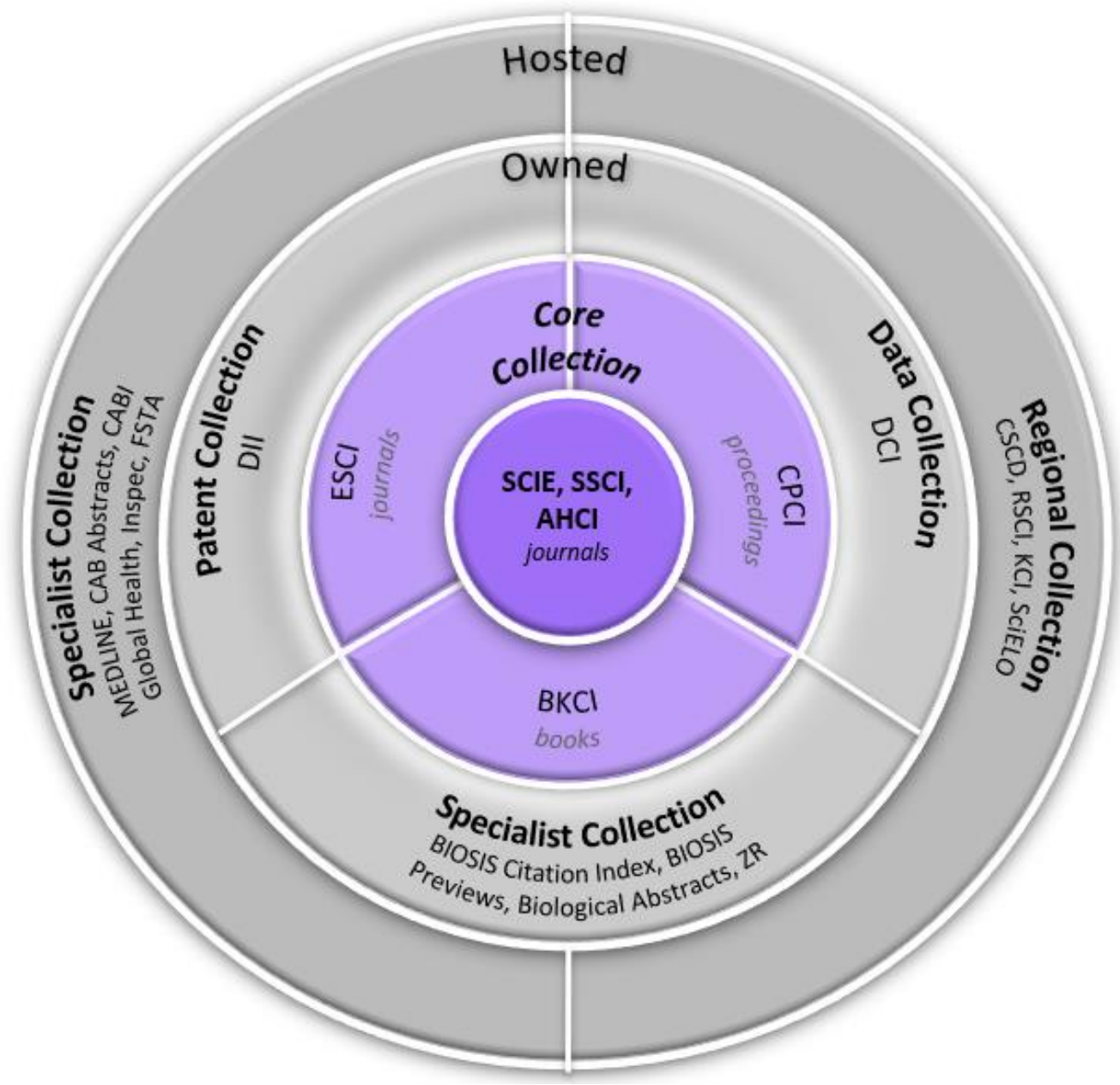

Herramientes para descubrir:

- La Colección Principal de la Web

of Science

- Medline

- Scielo

- Korean Journal Database

Kopernio

\title{
EndNote $^{\mathrm{TM}}$
}

Herramientas de identificación de autores y revisores

- Publons

- ORCID

- ResearcherID

publons ORCID

\section{ase}

(2)


Derechos Reservados $@ 2019$ Web of Science Group. ${ }^{\circledR}$

A los clientes de Web of Science Group se les otorga aquí mediante permiso para hacer copias de esta guía para su propio uso dentro de su organización. Todas las copias reproducidas deberán contener el aviso de Derechos Reservados de Web of Science Group (incluyendo copias parciales). Otras reproducciones requerirán la aprobación explícita de Web of Science Group.

\section{Reconocimientos de la Reimpresión}

El extracto de "Measurement of transient out-of-plane displacement gradients in plates using double-pulsed subtraction TV shearography" por Antonio Fernández, Ángel F. Doval, Guillermo H. Kaufmann, Abundio Dávila, Jesus Blanco-García, Carlos Pérez-López, y José L. Fernandez se reimprime con el permiso de Optical Engineering, Volumen 39, agosto de 2000, páginas 2106-2113. Copyright (C2000 SPIE- The International Society for Optical Engineering.

El extracto de "Epistemological aspects of modern painting"se reimprime con permiso de Filozofia 55 (8) 601-619 2000. C Filozofický ústav SAV, Bratislava 2000. 
RECURSOS ADICIONALES Y MÁS INFORMACIÓN DE WEB OF SCIENCE GROUP

INTRODUCCIÓN A WEB OF SCIENCE COLECCIÓN PRINCIPAL.................................13

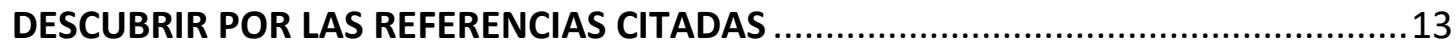

SELECCIÓN DE PUBLICACIONES, PRODUCCIÓN Y EXTRACCIÓN DE LA BASE DE DATOS

NUESTRA HISTORIA Y CONTROL DE CALIDAD DE LA SELECCIÓN DEL CONTENIDO ..15

TIPOS DE DOCUMENTOS INDEXADOS

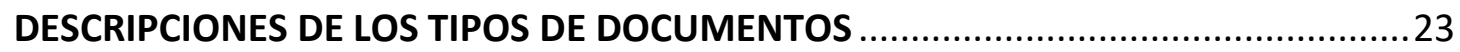

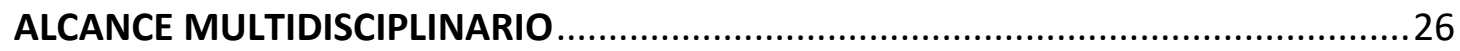

CATEGORÍAS DE LA COLECCIÓN PRINCIPAL DE LA WEB OF SCIENCE .......................27

COBERTURA SELECTIVA EN ARTS \& HUMANITIES CITATION INDEX Y SOCIAL

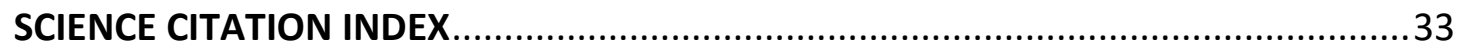

EJEMPLO DE UN ARTÍCULO INDEXADO EN EL SCI EXPANDED ${ }^{\circledR} \ldots \ldots \ldots \ldots \ldots \ldots \ldots \ldots \ldots . . . . . . . . . . . . . . . . . . .33$

REGISTRO DE UN DOCUMENTO SCI EN LA COLECCIÓN PRINCIPAL DE LA WEB OF SCIENCE.

LAS REFERENCIAS CITADAS DE UN REGISTRO SCI

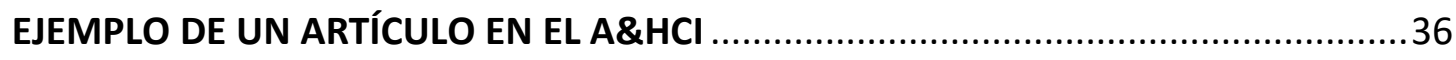

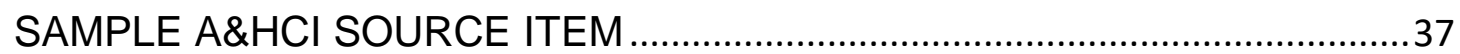

REGISTRO DE UN DOCUMENTO A\&HCI EN LA COLECCIÓN PRINCIPAL DE LA WEB OF SCIENCE

LAS REFERENCIAS CITADAS DE UN ARTÍCULO DE A\&HCI

ACCESO A LA WEB OF SCIENCE

PÁGINA PRINCIPAL DE LA WEB OF SCIENCE.

WEB OF SCIENCE COLECCIÓN PRINCIPAL: PÁGINA DE BÚSQUEDA. 


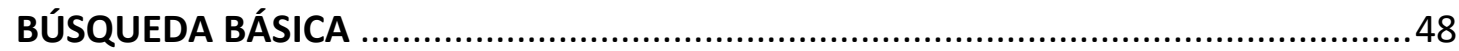

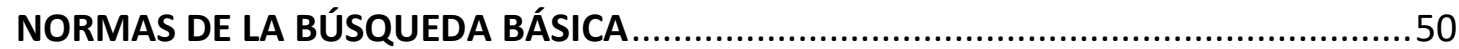

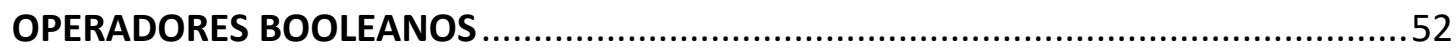

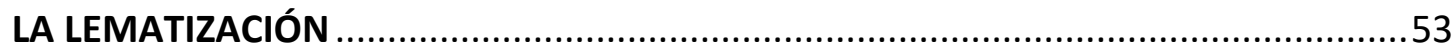

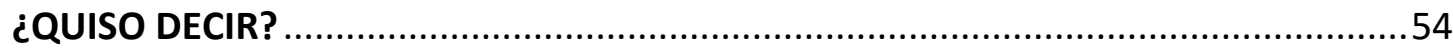

BÚSQUEDA POR UNA FRASE Y LOS OPERADORES DE PROXIMIDAD ......................55

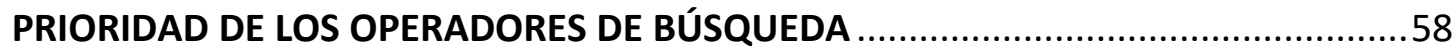

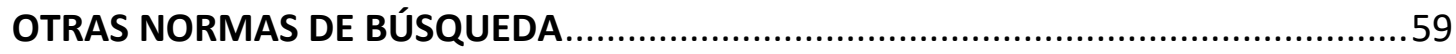

RESULTADOS DE UNA BÚSQUEDA-ORDENAR, REFINAR Y ANALIZAR ..................60

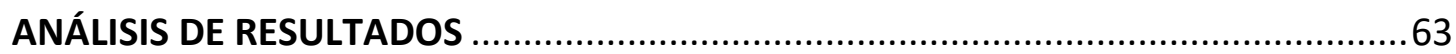

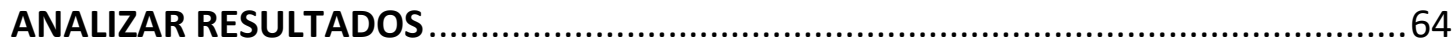

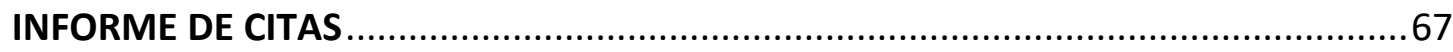

ESTADÍSTICAS AGREGADAS DEL INFORME DE CITAS ..........................................68

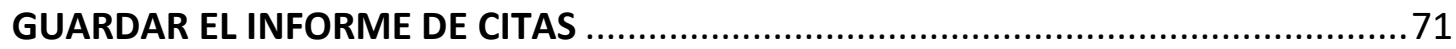

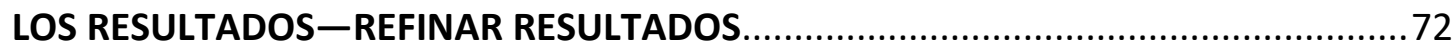

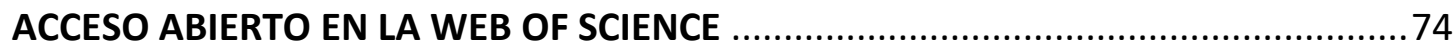

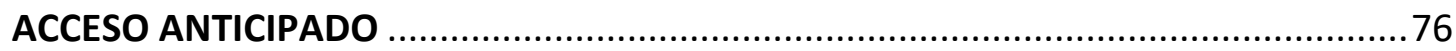

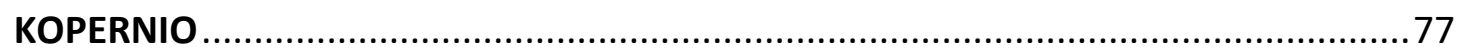

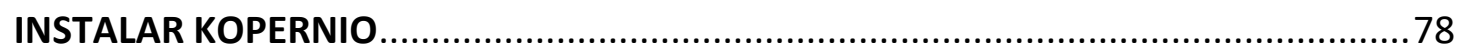

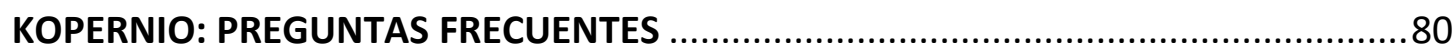




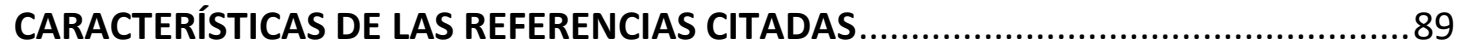

DESCUBRIR Y NAVEGAR POR LA LA RED DE CITAS................................................

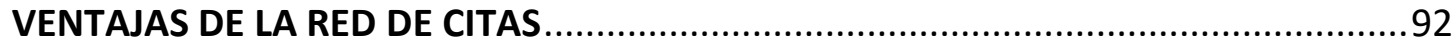

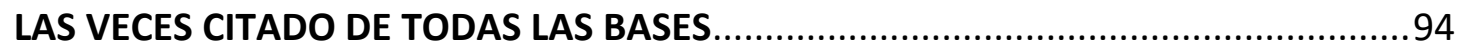

UNA BÚSQUEDA EN TODAS LAS BASES DE DATOS ..............................................95

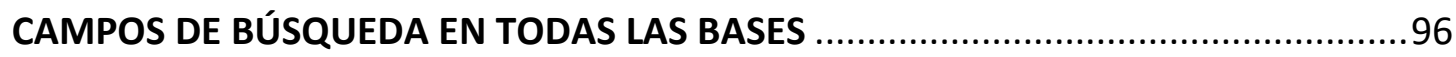

RESULTADOS DE UNA BÚSQUEDA POR TODAS LAS BASES ................................97

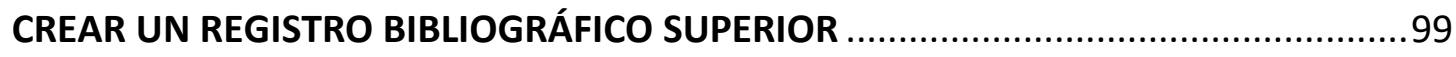

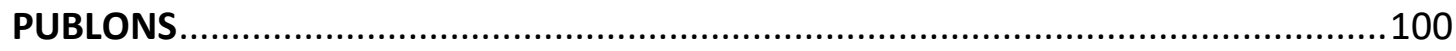

UTILIDADES DE PUBLONS: BÚSQUEDA Y AGRUPACIÓN DE REVISORES .................102

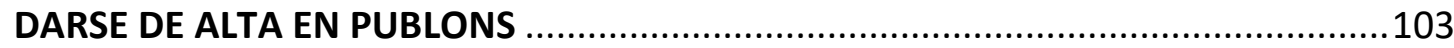

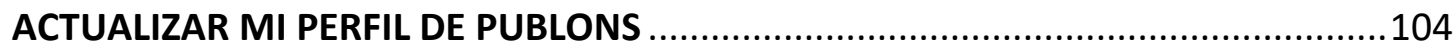

MIS REGISTROS: IMPORTAR PUBLICACIONES A PUBLONS.....................................105

IMPORTAR MIS PUBLICACIONES A PUBLONS: RECLAMAR MIS PUBLICACIONES EN

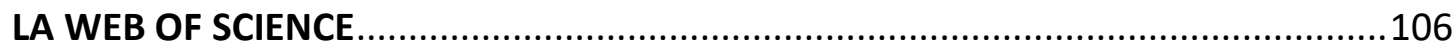

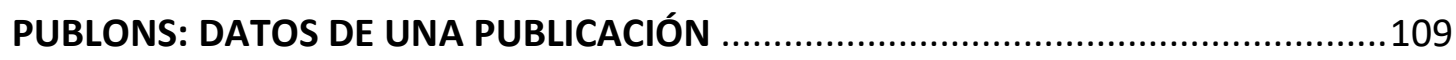

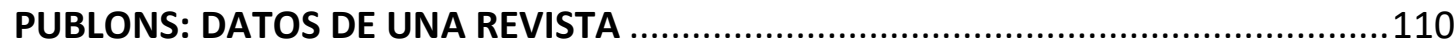

MI PERFIL COMPLETO Y VERIFICADO DE PUBLONS ........................................111

ANÁLISIS DE PUBLONS: MÉTRICAS DE MIS REVISIONES....................................113

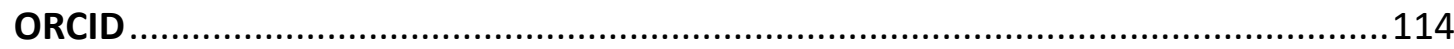


CREACIÓN DE UN PERFIL EN RESEARCHERID DENTRO DE LA WEB OF SCIENCE .....116

ACTUALIZAR UN PERFIL EN RESEARCHERID.COM .........................................118

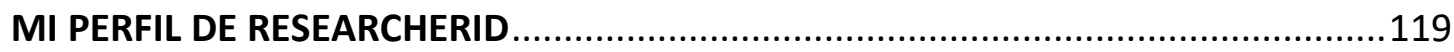

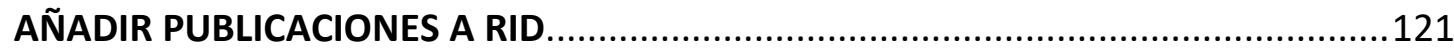

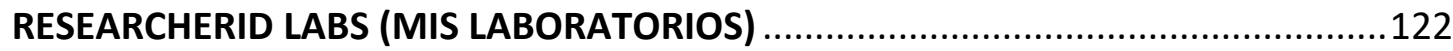

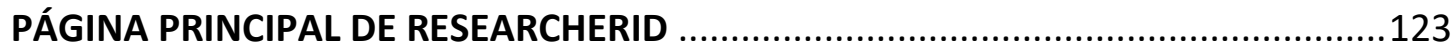

BÚSQUEDA AVANZADA EN LA COLECCIÓN PRINCIPAL DE LA WEB OF SCIENCE ....125

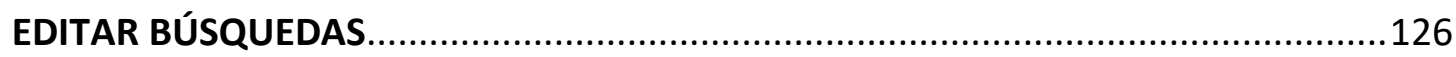

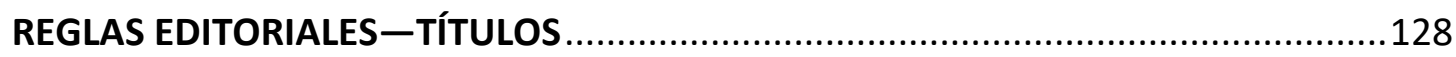

BÚSQUEDA POR AUTOR-NORMAS GENERALES............................................... 130

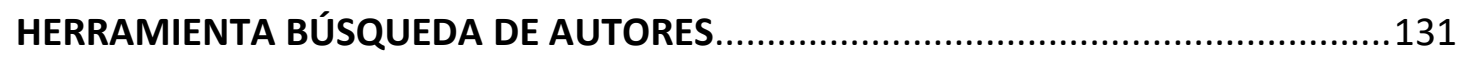

SISTEMA DE GRUPOS DE PUBLICACIONES DE UN AUTOR ..................................134

BÚSQUEDA POR TÍTULO DE LA PUBLICACIÓN ...................................................136

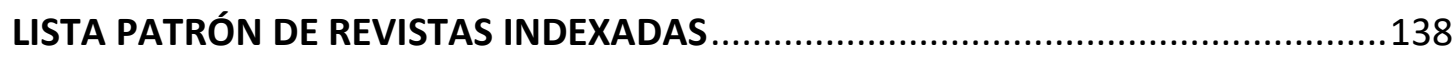

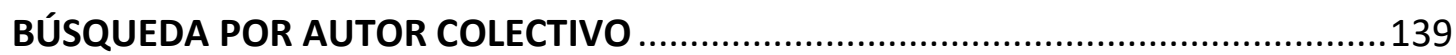

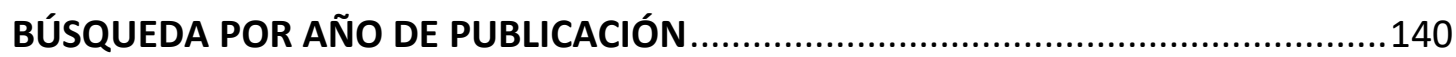

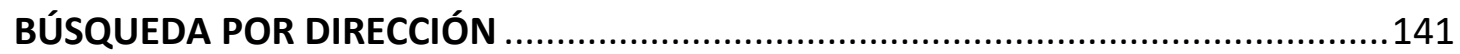

MEJORA EN LA CALIDAD DE DATOS: NOMBRE MEJORADO DE UNA ORGANIZACIÓN 
BÚSQUEDA POR REFERENCIAS CITADAS

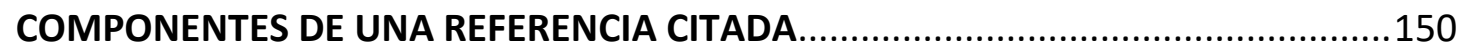

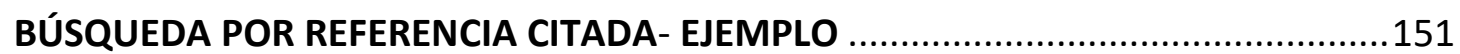

BÚSQUEDA POR REFERENCIAS CITADAS: LISTA DE REFERENCIAS ........................152

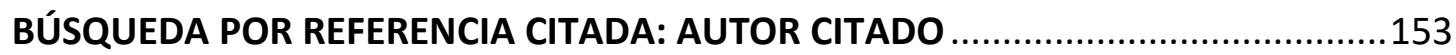

BÚSQUEDA POR REFERENCIA CITADA: AUTOR SECUNDARIO CITADO ...................155

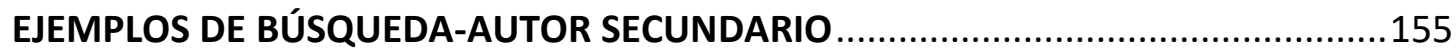

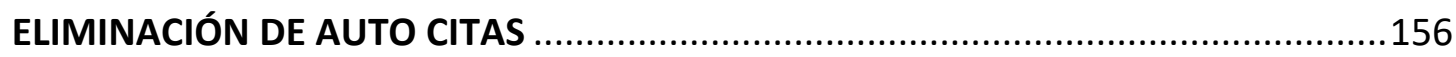

BÚSQUEDA POR REFERENCIAS CITADAS-VARIACIONES .................................156

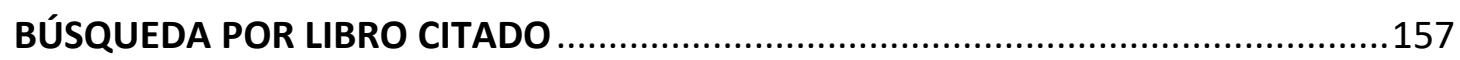

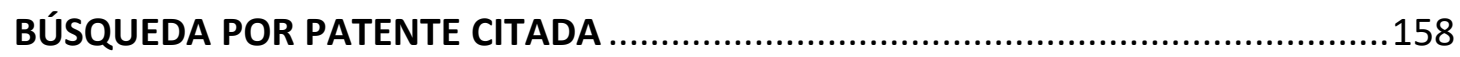

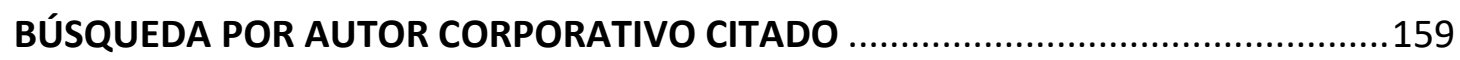

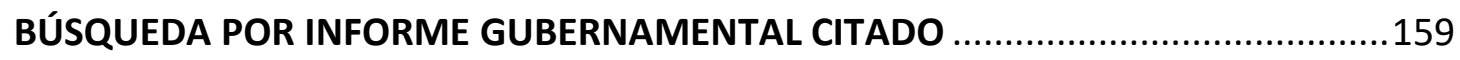

BÚSQUEDA POR REFERENCIAS CITADAS EN ARTS \& HUMANITIES CITATION INDEX

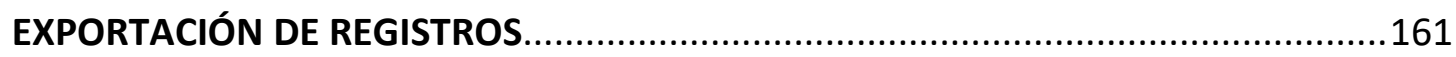

LA LISTA MARCADA: MARCAR REGISTROS Y GUARDAR LISTAS MARCADAS .........163

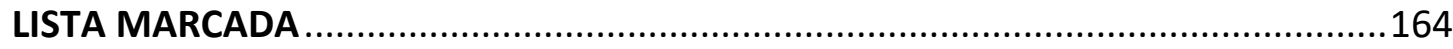

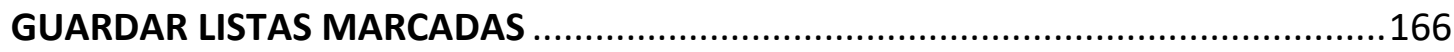

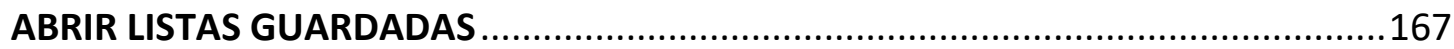


AÑADIR NUEVOS REGISTROS A UNA LISTA GUARDADA

COMBINAR LISTAS GUARDADAS

GUARDADO DE HISTORIALES Y CREACIÓN DE ALERTAS

GUARDADO DEL HISTORIAL EN EL SERVIDOR DE WEB OF SCIENCE

CREAR UNA ALERTA DE HISTORIAL DE BÚSQUEDA

CREAR ALERTA DE BÚSQUEDAS DIRECTAMENTE EN LA PÁGINA DE RESULTADOS 172

EJECUCIÓN DE HISTORIALES GUARDADOS

EN LA PÁGINA PRINCIPAL DE LA WEB OF SCIENCE

EN LA PÁGINA HISTORIAL DE BÚSQUEDA/ BÚSQUEDA AVANZADA 176

ABRIR HISTORIALES GUARDADOS 176

RECEPCIÓN DE ALERTAS 178

MIS ALERTAS DE CITAS 178

ENDNOTE BASIC (VERSIÓN EN LÍNEA) 179

COMPARACIÓN DE LAS VERSIONES DE ENDNOTE. 180

ENDNOTE (VERSIÓN EN LÍNEA) 181

PÁGINA PRINCIPAL DE ENDNOTE BASIC.

CITE WHILE YOU WRITE (CITAR MIENTRAS SE ESCRIBE) Y APLICAR FORMATO A UN MANUSCRITO

APÉNDICE A 192

BÚSQUEDA EN ARTS \& HUMANITIES: GUÍA DE BÚSQUEDA DE ESCRITURAS SAGRADAS

APÉNDICE B-CAMPOS DE BÚSQUEDAS 193

INTRODUCCIÓN A INCITES JOURNAL CITATION REPORTS 198 
USOS DE INCITES JCR

USOS PRINCIPALES DE JOURNAL CITATION REPORTS

INTEGRACIÓN DE DATOS DE IMPACTO DE JCR EN LA WEB OF SCIENCE 200

PÁGINA DE INICIO NUEVA DE INCITES JCR 201

ACCESO A LA PÁGINA NUEVA DEL PERFIL DE UNA REVISTA 202

PÁGINA NUEVA DEL PERFIL DE UNA REVISTA. 203

INFOGRAFÍA DE DATOS DE TENDENCIA DEL FACTOR DE IMPACTO 203

GRAFICA DE LA DISTRIBUCIÓN DE LAS VECES CITADO POR PUBLICACIÓN 204

EL FACTOR DE IMPACTO 205

VER INFORMACIÓN DEL DENOMINADOR DEL IF EN LA WEB OF SCIENCE COLECCIÓN PRINCIPAL 206

VER INFORMACIÓN DEL NUMERADOR DEL IF EN LA WEB OF SCIENCE COLECCIÓN PRINCIPAL

CALCULO DEL FACTOR DE IMPACTO 208

EL FACTOR DE IMPACTO DE 5 AÑOS 209

AUTO CITAS DE LA REVISTA 210

ÍNDICE DE INMEDIATEZ. 211

SUSPENSIÓN DE REVISTAS DE JCR 211

EVALUAR REVISTAS EN UNA CATEGORÍA 212

PERSONALIZAR LA LISTA RESUMEN 214

PERFIL ANTIGUA DE UNA REVISTA 216

RANKING DE UNA REVISTA 
LA VIDA MEDIA DE CITAS RECIBIDAS (CITED HALF-LIFE DATA) .........................218

LA VIDA MEDIA DE CITAS INCLUIDAS (CITING HALF-LIFE DATA) ........................219

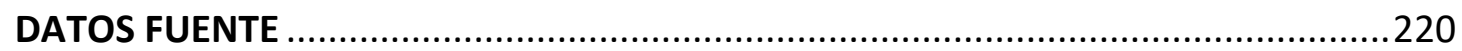

REVISTA CITADA: LA REVISTA SELECCIONADA RECIBE CITAS POR LAS REVISTAS DE LA LISTA

LA REVISTA DA CITAS A OTRAS REVISTAS: LA REVISTA SELECCIONADA CITA A LAS REVISTAS DE LA LISTA

COMPARAR REVISTAS 223

JOURNAL RANKING .224

DIAGRAMA DE CAJAS 225

EIGENFACTOR METRICS 226

EIGENFACTOR ${ }^{\text {TM }}$ SCORE 227

ARTICLE INFLUENCETM SCORE: 228

INTRODUCCIÓN A INCITES ESSENTIAL SCIENCE INDICATORS. 229

UMBRALES DE CITAS PARA INCLUIRSE EN ESI. 232

INTEGRACIÓN DE INDICADORES DE 'INCITES ESSENTIAL SCIENCE INDICADORES' EN LA COLECCIÓN PRINCIPAL DE WEB OF SCIENCE.

INCITES ESSENTIAL SCIENCE INDICATORS: CONSULTAS 234

FIELD BASELINES. 239

MEDLINE 242

PÁGINA DE INICIO DE MEDLINE. 243

BÚSQUEDAS DE MEDLINE . .244

PÁGINA DE RESULTADOS MEDLINE 245 
UN REGISTRO COMPLETO EN MEDLINE

EL TESAURO DE MEDLINE.

SCIELO CITATION DATABASE 249

SOBRE SCIELO 250

SCIELO CARACTERÍSTICAS 250

PÁGINA DE BÚSQUEDA DE SCIELO 251

NORMAS DE UNA BÚSQUEDA EN SCIELO 252

PÁGINA DE RESULTADOS DE SCIELO 255

REGISTRO COMPLETO DE SCIELO 256

BÚSQUEDA AVANZADA DE SCIELO 257

KOREAN JOURNAL DATABASE 258 


\section{Recursos Adicionales y más Información de Web of Science Group}

Materiales para formación descargables:

http://clarivate.libguides.com/home

Calendario para formación en línea:

http://clarivate.libcal.com/calendar/wos-incites-training

Formación grabada en línea:

https://www.youtube.com/user/WoSTraining

Información para contactar Soporte Técnico:

https://support.clarivate.com/s/

El proceso para la selección de revistas:

https://clarivate.com/essays/journal-selection-process/

Lista patrón de las revistas indexadas en la Colección Principal y en otras bases de datos de Web of Science:

http://mjl.clarivate.com/\#journal_lists

Descripciones de las categorías de las revistas:

http://mjl.clarivate.com/\#scope notes

Formulario electrónico para recomendar una revista:

http://mjl.clarivate.com/journal-submission/

Enlace para solicitar el cambio de datos incorrectos:

http://ips.Web of Science Group.com//techsupport/datachange/

Página web del equipo editorial

http://ips.clarivate.com//techsupport/datachange/

Gestores bibliográficos

http://endnote.com y www.myendnoteweb.com

API y servicios web de la Web of Science

https://developer.clarivate.com/apis

Web of Science

https://clarivate.com/products/web-of-science/

Selección de los Conference Proceedings

http://wokinfo.com/products tools/multidisciplinary/webofscience/cpci/cpciess

av/

Recursos para bibliotecas

http://clarivate.libguides.com/webofscienceplatform/introduction 


\section{Introducción a Web of Science Colección Principal}

Disponible a través de la plataforma Web of Science, La Colección Principal de la Web of Science ofrece acceso mediante la Web a los índices de citas 'Web of Science Core Collection Citation Indexes'. La Colección Principal de la Web of Science contiene información sobre investigación multidisciplinaria de alta calidad publicada en revistas líderes mundiales en las ciencias, ciencias sociales, artes y humanidades. Este manual está diseñado para guiarlo paso a paso a través de las funciones de La Colección Principal de la Web of Science. Si tiene alguna pregunta, no dude de ponerse en contacto con nosotros a través de las direcciones indicadas en la página 12.

Web of Science Group identifica e indexa las publicaciones más importantes en todas las áreas de las ciencias, ciencias sociales y las artes y las humanidades. Se identifican e indexan todos los documentos significativos contenidos en dichas publicaciones. Esto quiere decir que además de artículos pueden buscarse cartas, correcciones, adiciones, editoriales o revisiones que hayan aparecido en una revista. La Colección Principal de la Web of Science es una base de datos bibliográfica, por lo tanto, los registros contienen información tal como títulos, autores, palabras claves, resúmenes, referencias citadas y otros detalles. Sin embargo, también es posible conectarse al texto completo de miles de publicaciones dependiendo de la suscripción de su institución a las revistas electrónicas y por herramientas integradas de Web of Science Group, por ejemplo, Kopernio y filtrar resultados por Acceso Abierto.

La Colección Principal de la Web of Science consiste en bases de datos separadas que pueden utilizarse por separado o conjuntamente. Para ver más datos sobre la cobertura de la La Colección Principal de la Web of Science vaya a la página a continuación.

\section{Descubrir por las Referencias Citadas}

La indexación de citas permite utilizar las referencias citadas en los artículos publicados como términos de índice temáticos. Este tipo de indexación aprovecha los vínculos que existen entre los trabajos establecidos por los propios autores. La búsqueda por referencia citada ofrece la función exclusiva de encontrar información nueva basada en información conocida.

La información proporcionada por los Índices de Citas de Web of Science Group puede utilizarse de diversas maneras. Por ejemplo, se puede emplear para descubrir quién está citando sus trabajos de investigación y cómo éstos influyen sobre nuevos proyectos; puede también ser útil para descubrir en qué direcciones está progresando la investigación basándose en estudios anteriores. También permite conocer los trabajos de colegas e identificar las fuentes de información que los competidores nacionales o internacionales consultan. 
Adquisición de Revista/ Libro en impresión, PDF o html
Digitalizar $y$

OCR
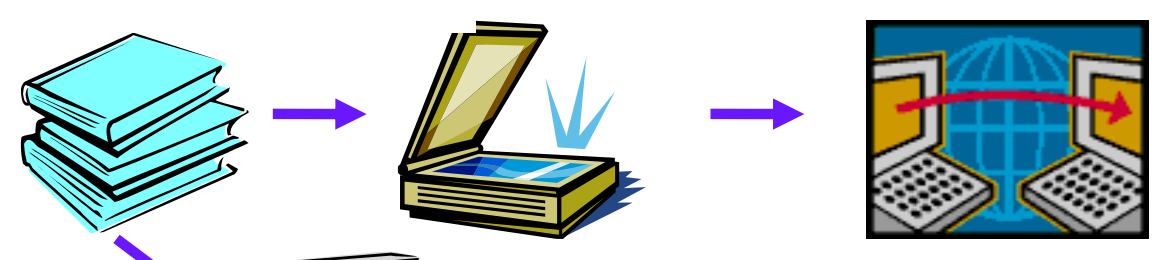

Aparición de registros de documentos en los productos de WOS
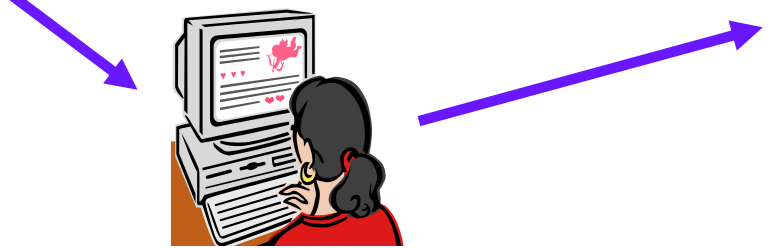

Selección de Artículos y Captura de Datos

Trabajo Manual de Creación de Índices. Web of Science Group traduce títulos de idiomas distintos de inglés al inglés estadounidense y adicione más información a algún contenido de la base de Artes \& Humanidades para que sea mejor recuperado

\section{Tiempo de Procesamiento: +/-10 días \\ La Colección Principal de la Web of Science actualiza cada día (de lunes a viernes)}

\section{Selección de Publicaciones, Producción y Extracción de la Base de Datos}

La selección de publicaciones a ser indexadas en Web of Science Colección Principal se realiza según los siguientes criterios: Para más información visite:

\section{https://clarivate.com/essays/journal-selection-process/}

\section{¿Por Qué Ser Selectivo?}

Al parecer, para ser exhaustivo, se espera que un índice de la literatura de revistas académicas cubra todas las revistas publicadas. Sin embargo, se ha demostrado que un número relativamente pequeño de revistas publican la mayoría de los resultados académicos significativos. Este principio se refiere a menudo como la Ley de Bradford.

SC Bradford se dio cuenta de que la literatura principal para cualquier disciplina científica dada estaba compuesta por menos de 1,000 revistas. De estas 1,000 revistas, hay relativamente pocas con una relevancia muy fuerte para el tema dado, mientras que hay muchas con una relevancia más débil para él. Sin embargo, aquellos con una relevancia débil para la disciplina o tema dado, típicamente tienen una fuerte relevancia para alguna otra disciplina. Por lo tanto, la literatura científica principal puede formarse en torno a varios temas, con revistas individuales que se vuelven más o menos relevantes según el tema. Bradford comprendió que un núcleo esencial de revistas forma la base bibliográfica para cada disciplina y que la mayoría de los artículos importantes se publican en relativamente pocas revistas. 


\section{Nuestra Historia y Control de Calidad de la Selección del Contenido}

1. Proceso editorial para seleccionar y evaluar revistas.

The Web of Science Core Collection

Improving speed and transparency through an updated journal evaluation process

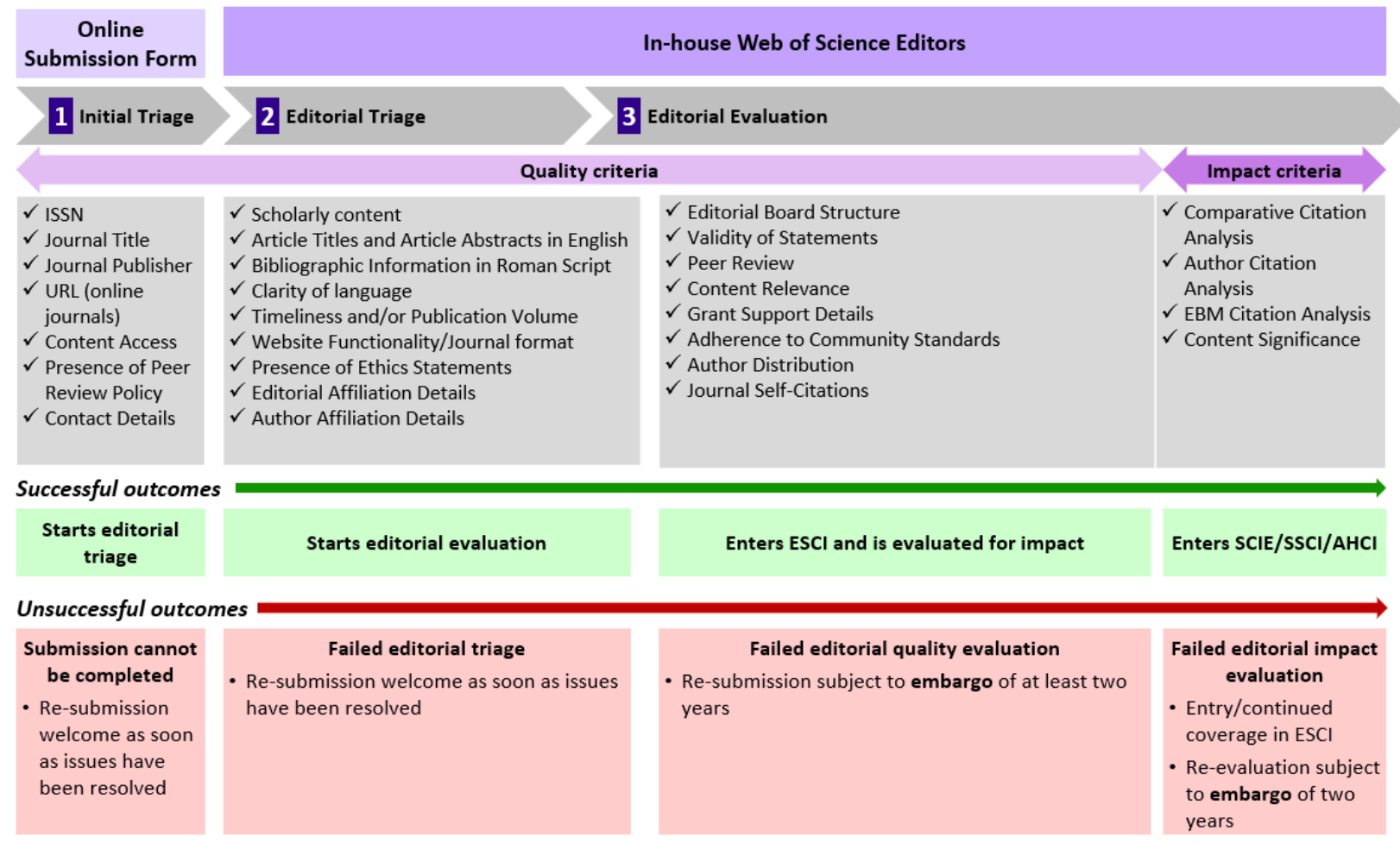

2. Historia y evolución de las herramientas de descubrimiento y análisis de investigación.

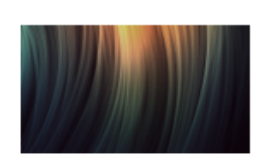

Science Citation Index

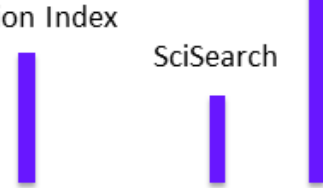

Journal Citation Reports

\section{Custom citation projects \&} national indicators (mainframe)

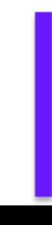

\section{0 | 1960 | 1965 | 1970 | 1970}

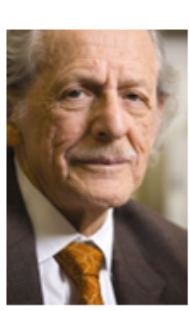

Social Sciences Citation Index

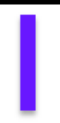

Arts \& Humanities Citation Index

PC-based citation sets and indicators for journals, nations, and institutions

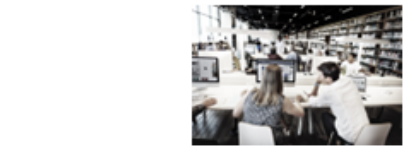

Book Citation

Index

Web of Science

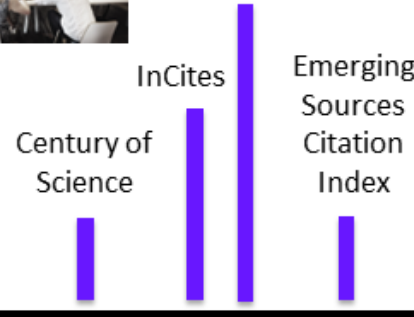

$2000 \mid 2005$ | 2010 | 2015

Change to Clarivate Analytics

Essential Science Indicators Century of Social

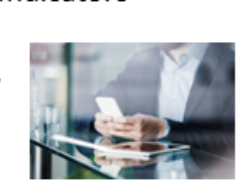

Science

\section{1) Clarivate Analytics}




\section{Content Set}

\section{La Verdad de la Web of Science}

\section{WEB OF SCIENCE DISCOVERY PLATFORM}

\section{All}

Includes journals in the WoS Core Collection, BIOSIS databases, Zoological Records, RCls and hosted products of MEDLINE, CABI, FSTA, Inspec

Number of journals globally (as of 7/2018)

Number of subject categories

Number of Open Access journals (DOAJ) (as of 7/2018)

Number records in total (including $\mathrm{BkCl}, \mathrm{CPCl}, \mathrm{DCl}$ )

\section{WEB OF SCIENCE CORE COLLECTION}

All Journal Editions

Includes: Journal titles indexed in $\mathrm{SCIE}, \mathrm{SSCl}, \mathrm{AHCl}, \mathrm{ESCl}$

Number of journals globally

Number of disciplines (WoS Categories)

Number of Open Access journals (DOAJ)

Number of cited references journal editions (SCIE, SSCl, $\mathrm{AHCl}, \mathrm{ESCl}$ )

Number of cited references all editions ( $\mathrm{SCIE}, \mathrm{SSCl}, \mathrm{AHCl}, \mathrm{ESCl}, \mathrm{BKCl}$, (PCI)

$1,485,309,419$

Year coverage starts

Science Citation

Includes: Journal titles indexed in SCIE

Index Expanded

Number of actively publishing journals

Number of disciplines

Number of Open Access journals (DOAJ)

Number records in total 


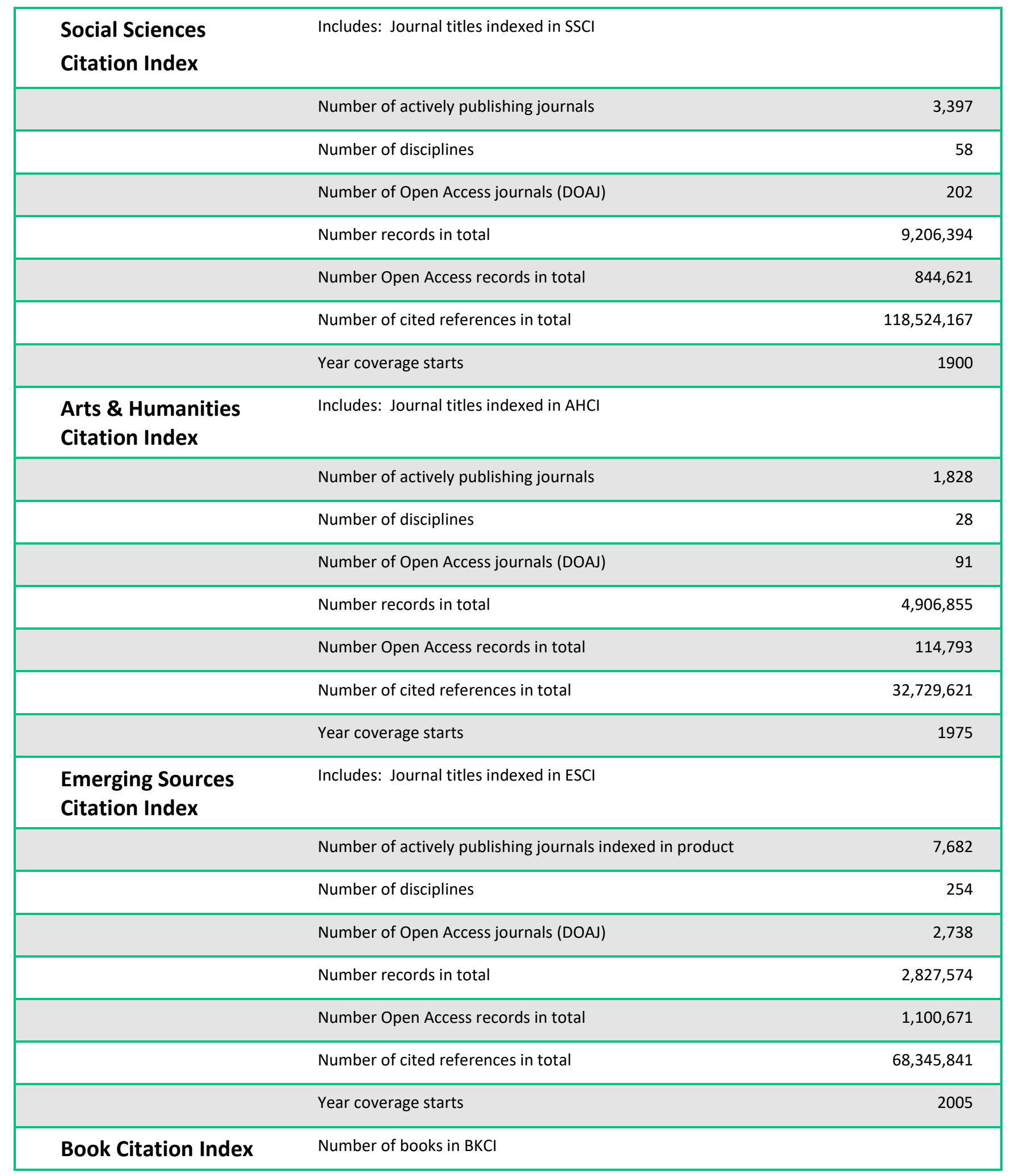




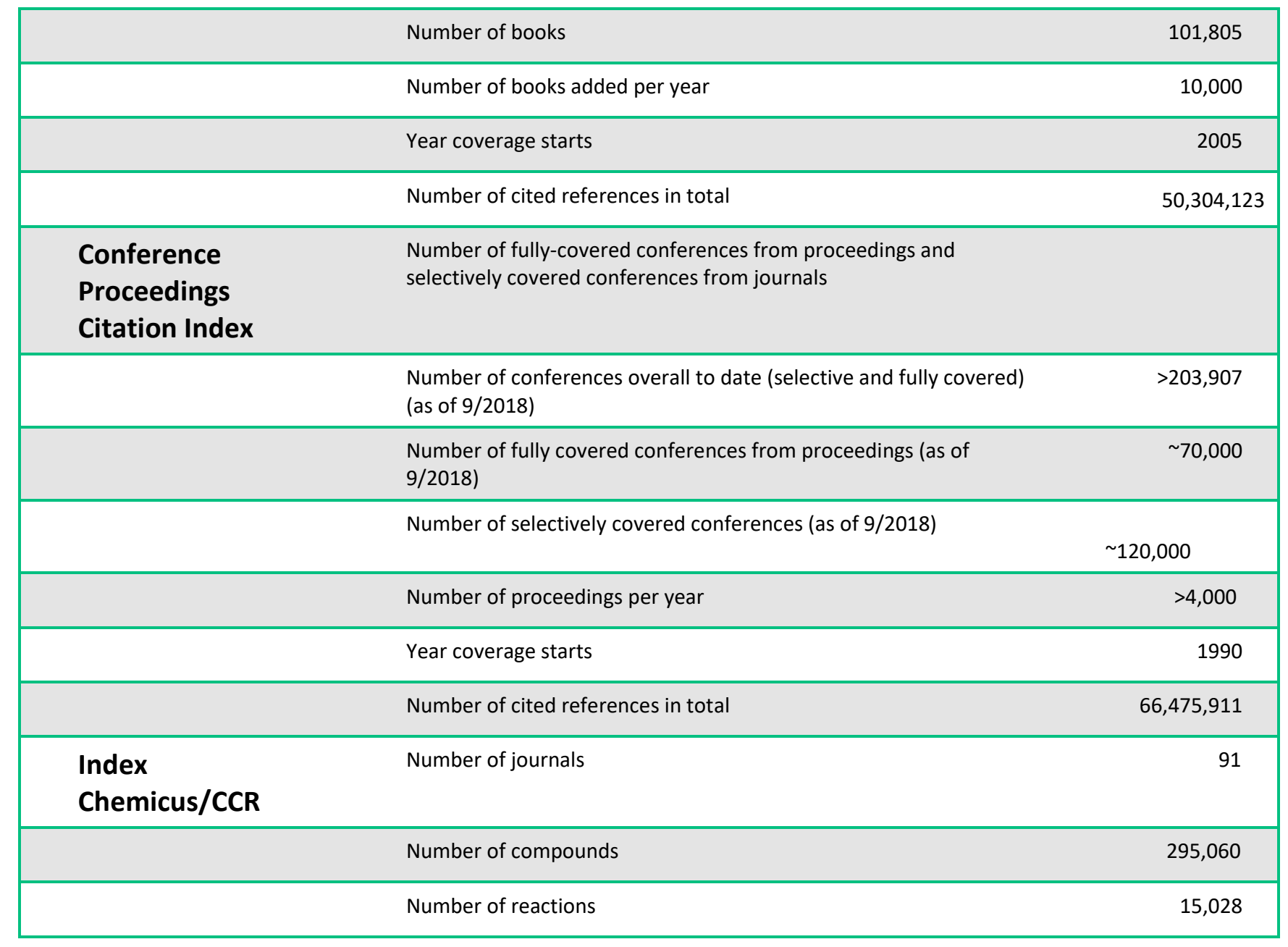

\section{REGIONAL COLLECTION}

\section{SciELO Citation}

Index

Number of journals (as of 2017)

Number records in total

Year coverage starts

KCI Korean Journal

Database (Index)

Number of journals (as of 2017)

\section{Russian Science} Citation Index 


\begin{tabular}{|llc|}
\hline & Number of journals (as of 2017) & 503,299 \\
\hline & Number records in total & 2005 \\
\hline $\begin{array}{l}\text { Chinese Science } \\
\text { (Index) }\end{array}$ & Year coverage starts & 1,587 \\
\hline & Number of journals (as of 2017) & $5,101,703$ \\
\hline & Number records in total & 1989 \\
\hline
\end{tabular}

\section{SPECIALIST COLLECTION}

Biological Abstracts

Number of journals

4,316

Number records in total

$17,866,569$

Year coverage starts

BIOSIS Previews

Number of journals

Number records in total

Year coverage starts

\section{CAB Abstracts}

Number of journals

CABI Global Health

CABI Global Health titles are included in CAB Abstracts

\section{Food Science and}

\section{Technology}

Abstracts (FSTA)

\section{INSPEC}




\begin{tabular}{|c|c|c|}
\hline & Number of journals (as of 10/2018) & 4,517 \\
\hline & Number records in total & $19,132,786$ \\
\hline & Year coverage starts & 1898 \\
\hline \multicolumn{3}{|l|}{ MEDLINE } \\
\hline & Number of journals (as of $3 / 2018$ ) & 5,237 \\
\hline & Number records in total & $28,975,619$ \\
\hline & Year coverage starts & 1950 \\
\hline \multicolumn{3}{|c|}{ Zoological Record } \\
\hline & Number of serials & 4,664 \\
\hline & Number records in total & $4,441,558$ \\
\hline & Year coverage starts & 1864 \\
\hline \multirow{4}{*}{$\begin{array}{l}\text { BIOSIS Citation } \\
\text { Index }\end{array}$} & Same coverage as BIOSIS Previews & \\
\hline & Number of journals and serials & 5,313 \\
\hline & Number records in total & $27,484,631$ \\
\hline & Year coverage starts & 1926 \\
\hline \multicolumn{3}{|c|}{ PATENT COLLECTION } \\
\hline \multicolumn{3}{|c|}{$\begin{array}{l}\text { Derwent } \\
\text { Innovations Index }\end{array}$} \\
\hline & Number of patent families & $39.3 \mathrm{M}$ \\
\hline & Number of individual patent documents & $80 \mathrm{M}+$ \\
\hline & Number of patent issuing authorities covered & 52 \\
\hline & Number of patents added in last year & $6 \mathrm{M}$ \\
\hline & Year coverage starts & 1963 \\
\hline \multicolumn{3}{|c|}{ DATA COLLECTION } \\
\hline \multicolumn{3}{|c|}{ Data Citation Index } \\
\hline & Number of repositories & 357 \\
\hline & Number of datasets & $7,315,119$ \\
\hline & Number of data studies & $1,106,934$ \\
\hline
\end{tabular}




\section{ANALYTICAL RESOURCES AND IDENTIFIERS}

Essential Science

Indicators

Journal Citation

Reports
Essential Science Indicators is the ideal resource for conducting complex analyses of scientific literature so you can understand research performance, significant trends in research, rank top countries, determine research output and evaluate potential employees. It provides you with access close to 12 million articles from over 12,000 journal titles from around the world.

Offers a systematic, objective means to critically evaluate the world's leading journals, with quantifiable, statistical information based on citation data. JCR helps to measure research influence and impact at the journal and category levels, and shows the relationship between citing and cited journals.

Number of journals currently included in JCR

\section{InCites}

\section{Benchmarking and}

Analytics

Year data starts

Organizations

12,730

Funders

Countries/Regions

ResearcherID

Introduced in 2008 , it is an identifying system for scientific authors, including links to dynamic citation metrics and collaboration networks. 


\section{Tipos de Documentos Indexados}

Web of Science Group indexa todos los elementos significativos de cada una de las revistas seleccionadas.

\begin{tabular}{|c|c|}
\hline $\begin{array}{l}\text { Todos los tipos de documentos } \\
\text { Artículo } \\
\text { Abstract de elemento publicado } \\
\text { Crítica de exposición de arte } \\
\text { Bibliografía } \\
\text { Elemento bibliográfico } \\
\text { Libro } \\
\text { Capítulo de libro } \\
\text { Reseña bibliográfica } \\
\text { Cronología } \\
\text { Corrección } \\
\text { Corrección, Adición } \\
\text { Crítica de espectáculo de danza } \\
\text { Artículo de datos } \\
\text { Reseña de base de datos } \\
\text { Debate } \\
\text { Acceso anticipado (solo en la Colección principal } \\
\text { de Web of Science) } \\
\text { Material editorial } \\
\text { Extracto } \\
\text { Ficción, Prosa creativa } \\
\text { Crítica de cine } \\
\text { Reseña de hardware } \\
\text { Artículo sobre una persona } \\
\text { Carta } \\
\text { Abstract de reunión } \\
\text { Resumen de reunión } \\
\text { Crítica de actuación musical } \\
\text { Partitura musical } \\
\text { Crítica de partitura musical } \\
\text { Artículo informativo } \\
\text { Nota } \\
\text { Poema } \\
\text { Proceedings Paper } \\
\text { Crítica de grabación } \\
\text { Reimpresión } \\
\text { Retractación de publicación } \\
\text { Retractación } \\
\text { Revisión } \\
\text { Guión } \\
\text { Reseña de software } \\
\text { Crítica de TV, Crítica de radio }\end{array}$ & $\begin{array}{l}\text { Prosa Creativa } \\
\text { Críticas de Cine } \\
\text { Críticas de Espectáculos Musicales } \\
\text { Partituras de Música } \\
\text { Críticas de Partitura de Música } \\
\text { Poesía } \\
\text { Críticas de Disco } \\
\text { Guiones } \\
\text { Críticas de Teatro } \\
\text { Críticas de Televisión } \\
\text { Críticas de Radio }\end{array}$ \\
\hline
\end{tabular}


Crítica de TV, Crítica de radio, Crítica de video

Crítica de teatro

Críticas de Libros - en Science Citation Index Expanded, sólo se incluyen aquellas Críticas de libros que aparecen en Science, Nature y The Scientist. En Social Sciences Citation Index y en Arts \& Humanities Citation Index se incluyen todas las Críticas de libros de todas las revistas.

En Science Citation Index Expanded se incluyen las actas que aparecen en las 900 revistas más importantes (clasificadas por factor de impacto).

Se identifican los artículos como artículos de revisión si son publicados en una revista de revisión o si incluyen más de 100 referencias citadas. Además, debe haber alguna indicación de que el artículo es de revisión como por ejemplo las palabras Review (Revisión) u Overview (Resumen) en el índice o en el artículo en sí.

\section{Descripciones de los Tipos de Documentos}

Artículo: informes de investigación sobre trabajos originales. Incluye artículos de investigación, artículos periodísticos, comunicaciones breves, informes de casos, notas técnicas, cronologías y artículos completos que fueron publicados en una revista o presentados en un simposio o conferencia.

Abstract del elemento publicado: solo datos bibliográficos sobre un artículo publicado. Busca generalmente registros que datan de 1974 o de años anteriores.

Crítica de exposición de arte: críticas de exposiciones de obras de arte en galerías o museos.

Bibliografía: una lista, a menudo con notas críticas o descriptivas, de escritos relacionados con una materia específica.

Elemento biográfico: obituarios, artículos centrados en la vida de una persona y artículos que son homenajes o conmemoraciones de una persona.

Libro: una monografía o publicación escrita sobre un tema específico.

Capítulo de libro: una monografía o publicación escrita sobre un tema específico en una división principal de un libro.

Reseña bibliográfica: una valoración crítica de un libro (a menudo refleja la recomendación u opinión personal del crítico) que evalúa aspectos como, por ejemplo, la organización y el estilo de escritura, el posible atractivo en el mercado y su significado literario, político y cultural.

Cronología: una revisión de eventos sobre una materia o tema específico en el orden en que sucedieron en el tiempo.

Corrección: corrección de los errores detectados en artículos que fueron publicados previamente y que se dieron a conocer luego de que el artículo se publicara. Incluye adiciones, fe de erratas y retractaciones.

Corrección, Adición: corrección de los errores detectados en artículos que fueron publicados previamente y que se dieron a conocer luego de que el artículo se publicara. Incluye adiciones, fe de erratas y retractaciones. 
Crítica de espectáculo de danza: críticas de recitales de danza en solitario, producciones de danza completas, programas de danza formados por varias obras y otros tipos de bailes escénicos.

Artículo de datos: una publicación académica en la que se describe un conjunto de datos específico o una recopilación de conjuntos de datos y que se suele publicar en forma de artículo revisado por expertos en una revista académica. El principal objetivo de un artículo de datos es ofrecer hechos sobre los datos (metadatos como, por ejemplo, recopilación de datos, acceso, funciones, etc.) en vez del análisis y la investigación que sustentan dichos datos, como es el caso de un artículo de investigación convencional. Reseña de base de datos: una valoración crítica de una base de datos que a menudo refleja la recomendación u opinión del revisor. Se refiere a una colección estructurada de registros o datos que se almacenan en un sistema informático.

Debate: un artículo o documento que trata cuestiones en un debate abierto y normalmente informal. Busca generalmente registros que datan de 1996 o de años anteriores.

Acceso anticipado: Un artículo que se publicó electrónicamente en una revista antes de asignarlo a un volumen y un número específicos.

Material editorial: un artículo que ofrece las opiniones de una persona, un grupo o una organización. Incluye editoriales, entrevistas, comentarios y debates entre personas, debates sobre artículos, simposios en torno a mesas redondas y conferencias clínicas.

Extracto: una selección procedente de una obra literaria o musical (o un fragmento de la misma) que no se puede considerar como una obra independiente por derecho propio.

Ficción, Prosa creativa: incluye historias breves y otras obras de prosa creativa.

Crítica de cine: crítica de un largometraje.

Reseña de hardware: una valoración crítica del hardware de computadoras que a menudo refleja la recomendación u opinión del evaluador. Hace referencia a objetos que se pueden tocar realmente como, por ejemplo, discos duros, teclados o impresoras.

Artículo sobre una persona: una reseña de la(s) obra(s) de un personaje célebre en un campo de estudio específico.

Carta: aportaciones o correspondencia de los lectores al editor de una revista con relación a material publicado previamente.

Abstract de reunión: un resumen general de los artículos completos que se presentaron en un simposio o conferencia.

Resumen de reunión: un artículo que abarca varios abstracts de reuniones en una variedad de materias.

Crítica de actuación musical: crítica de una actuación musical en directo (recital, concierto y ópera).

Partitura musical: transcripción de la partitura original y completa de una composición musical o de un arreglo que incluye las partes específicas de los diferentes instrumentos o voces y que se escribe en pentagramas alineados unos encima de otros.

Crítica de partitura musical: revisión de una composición musical o colección de composiciones musicales.

Artículo informativo: noticias, eventos actuales y acontecimientos recientes.

Nota: un documento que cita o hace referencia a un artículo publicado sobre una materia específica. Busca generalmente registros que datan de 1996 o de años anteriores. 
Poesía: composiciones en verso escritas en forma métrica.

Proceedings Paper: literatura publicada de conferencias, simposios, seminarios, coloquios, talleres y convenciones sobre una amplia gama de disciplinas. Publicado generalmente en un libro de actas de conferencias.

Los registros incluidos en los dos índices de actas de conferencias ( $\mathrm{CPCl}-\mathrm{S}$ y $\mathrm{CPCl}-\mathrm{SSH}$ ) se identifican como Proceedings Paper. Sin embargo, los mismos registros incluidos en los tres índices $(\mathrm{SCl}-\mathrm{E}, \mathrm{SSCl}$ y $\mathrm{A} \& \mathrm{HCl})$ se identifican como Artículo cuando se publican en una revista.

Crítica de grabación: críticas de un discurso u obra musical grabados.

Reimpresión: artículo publicado previamente.

Retractación de publicación: artículo retirado por un autor, institución, editor o editorial debido a errores o a datos no confirmados.

Retractación: aviso público que indica que un artículo se debería retirar debido a errores o a datos no confirmados

Revisión: estudio renovado de material estudiado previamente. Incluye encuestas y artículos de revisión de literatura publicada anteriormente. Normalmente no presentará ninguna información novedosa sobre un tema.

Guión: incluye guiones cinematográficos y guiones para radio, televisión y obras de teatro.

Reseña de software: una valoración crítica de un software de computadoras que a menudo refleja la recomendación u opinión del revisor. Hace referencia a programas, procedimientos y normas, junto con documentación asociada relacionada con el funcionamiento de un sistema informático.

Crítica de teatro: crítica de una representación teatral.

Crítica de TV, Crítica de radio: críticas de programas de radio y televisión.

Crítica de TV, Crítica de radio, Crítica de video: críticas de videos y programas de radio y televisión. 


\section{Alcance Multidisciplinario}

\section{SCIENCE CITATION INDEX EXPANDED}

Agricultura \& Tecnología de Alimentos

Astronomía

Ciencias del Comportamiento

Bioquímica

Biología

Ciencias Biomédicas

Química

Informática

Electrónica

Ingeniería

Ciencias Ambientales

Genética

Geociencias

Instrumentación

Ciencia de Materiales

Matemáticas

Medicina

Microbiología

Ciencias Nucleares

Farmacología

Física

Psiquiatría \& Psicología

Estadística \& Probabilidad

Tecnología \& Ciencias

Aplicadas

Veterinaria

Zoología
SOCIAL SCIENCES CITATION

INDEX

Antropología

Arqueología

Estudios de Áreas

Negocios \& Finanzas

Comunicación

Criminología

Demografía

Economía

Educación

Estudios Ambientales

Ergonomía

Estudios Étnicos

Estudios de Familia

Geografía

Geriatría

Salud \& Rehabilitación

Relaciones Industriales \&

Laborales

Biblioteconomía y Ciencias

de la Información

Relaciones Internacionales

Derecho

Lingüística

Administración

Enfermería

Investigación de

Operaciones

Planificación \& Desarrollo

Ciencias Políticas

Psiquiatría

Psicología

Administración Pública

Sociología

Estudios Urbanos

Estudios de la Mujer
ARTS AND HUMANITIES CITATION INDEX

Arqueología

Arquitectura

Arte

Estudios Asiáticos

Clásicos

Danza

Cine

Asuntos Folclóricos

Historia

Humanidades

Idiomas

Lingüística

Críticas Literarias

Literatura

Música

Filosofía

Poesía

Religión

Televisión \& Radio

Teatro 


\section{Categorías de la Colección Principal de la Web of Science}

- 254 categorías en total

- Categoría nueva en 2019- Quantum Science \& Technology (Tecnología y ciencia cuántica

- Cambios de categoría. La categoría 'Planning \& Development' se ha convertido en dos categorías: 1. Development Studies 2. Regional \& Urban Planning.

\begin{tabular}{|c|c|c|c|}
\hline $\begin{array}{l}\text { Acoustics } \\
\text { (Acústica) }\end{array}$ & $\begin{array}{l}\text { Electrochemistry } \\
\text { (Electroquímica) }\end{array}$ & Literature (Literatura) & $\begin{array}{l}\text { Physics, Fluids \& Plasmas } \\
\text { (Física, Fluidos y Plasmas) }\end{array}$ \\
\hline $\begin{array}{l}\text { Agricultural } \\
\text { Economics \& Policy } \\
\text { (Política y } \\
\text { Economía Agrícola) }\end{array}$ & $\begin{array}{l}\text { Emergency } \\
\text { Medicine (Medicina } \\
\text { de Emergencia) }\end{array}$ & $\begin{array}{l}\text { Literature, African, } \\
\text { Australian, Canadian } \\
\text { (Literatura, Africana, } \\
\text { Australiana, Canadiense) }\end{array}$ & $\begin{array}{l}\text { Physics, Mathematical } \\
\text { (Física, Matemática) }\end{array}$ \\
\hline $\begin{array}{l}\text { Agricultural } \\
\text { Engineering } \\
\text { (Ingeniería } \\
\text { Agrícola) }\end{array}$ & $\begin{array}{l}\text { Endocrinology \& } \\
\text { Metabolism } \\
\text { (Endocrinología y } \\
\text { Metabolismo) }\end{array}$ & $\begin{array}{l}\text { Literature, American } \\
\text { (Literatura, Americana) }\end{array}$ & $\begin{array}{l}\text { Physics, Multidisciplinary } \\
\text { (Física, Multidisciplinar) }\end{array}$ \\
\hline $\begin{array}{l}\text { Agriculture, Dairy } \\
\text { \& Animal Science } \\
\text { (Ciencia de los } \\
\text { Animales, } \\
\text { Productos Lácteos } \\
\text { y Agricultura) }\end{array}$ & $\begin{array}{l}\text { Energy \& Fuels } \\
\text { (Energía y } \\
\text { Combustibles) }\end{array}$ & $\begin{array}{l}\text { Literature, British Isles } \\
\text { (Literatura, Islas } \\
\text { Británicas) }\end{array}$ & $\begin{array}{l}\text { Physics, Nuclear (Física, } \\
\text { Nuclear) }\end{array}$ \\
\hline $\begin{array}{l}\text { Agriculture, } \\
\text { Multidisciplinary } \\
\text { (Agricultura, } \\
\text { Multidisciplinar) }\end{array}$ & $\begin{array}{l}\text { Engineering, } \\
\text { Aerospace } \\
\text { (Ingeniería, } \\
\text { Aeroespacial) }\end{array}$ & $\begin{array}{l}\text { Literature, German, Dutch, } \\
\text { Scandinavian (Literatura, } \\
\text { Alemana, Holandesa, } \\
\text { Escandinava) }\end{array}$ & $\begin{array}{l}\text { Physics, Particles \& Fields } \\
\text { (Física, Partículas y } \\
\text { Campos) }\end{array}$ \\
\hline $\begin{array}{l}\text { Agronomy } \\
\text { (Agronomía) }\end{array}$ & $\begin{array}{l}\text { Engineering, } \\
\text { Biomedical } \\
\text { (Ingeniería, } \\
\text { Biomédica) }\end{array}$ & $\begin{array}{l}\text { Literature, Romance } \\
\text { (Literatura, Romance) }\end{array}$ & Physiology (Fisiología) \\
\hline Allergy (Alergia) & $\begin{array}{l}\text { Engineering, } \\
\text { Chemical } \\
\text { (Ingeniería, } \\
\text { Química) }\end{array}$ & $\begin{array}{l}\text { Literature, Slavic } \\
\text { (Literatura, Eslava) }\end{array}$ & Plant Sciences (Botánica) \\
\hline $\begin{array}{l}\text { Anatomy \& } \\
\text { Morphology } \\
\text { (Anatomía y } \\
\text { Morfología) }\end{array}$ & $\begin{array}{l}\text { Engineering, Civil } \\
\text { (Ingeniería, Civil) }\end{array}$ & Logic (Lógica) & Poetry (Poesía) \\
\hline $\begin{array}{l}\text { Andrology } \\
\text { (Andrología) }\end{array}$ & $\begin{array}{l}\text { Engineering, } \\
\text { Electrical \& } \\
\text { Electronic } \\
\text { (Ingeniería, } \\
\text { Eléctrica y } \\
\text { Electrónica) }\end{array}$ & Management (Gestión) & $\begin{array}{l}\text { Political Science (Ciencias } \\
\text { Políticas) }\end{array}$ \\
\hline $\begin{array}{l}\text { Anesthesiology } \\
\text { (Anestesiología) }\end{array}$ & $\begin{array}{l}\text { Engineering, } \\
\text { Environmental } \\
\text { (Ingeniería, } \\
\text { Ambiental) }\end{array}$ & $\begin{array}{l}\text { Marine \& Freshwater } \\
\text { Biology (Biología Marina y } \\
\text { de Agua Dulce) }\end{array}$ & $\begin{array}{l}\text { Polymer Science (Ciencia } \\
\text { de Polímeros) }\end{array}$ \\
\hline
\end{tabular}




\begin{tabular}{|c|c|c|c|}
\hline $\begin{array}{l}\text { Anthropology } \\
\text { (Antropología) }\end{array}$ & $\begin{array}{l}\text { Engineering, } \\
\text { Geological } \\
\text { (Ingeniería, } \\
\text { Geológica) }\end{array}$ & $\begin{array}{l}\text { Materials Science, } \\
\text { Biomaterials (Ciencia de } \\
\text { los Materiales, } \\
\text { Biomateriales) }\end{array}$ & $\begin{array}{l}\text { Primary Health Care } \\
\text { (Atención Primaria de } \\
\text { Salud) }\end{array}$ \\
\hline $\begin{array}{l}\text { Archaeology } \\
\text { (Arqueología) }\end{array}$ & $\begin{array}{l}\text { Engineering, } \\
\text { Industrial } \\
\text { (Ingeniería, } \\
\text { Industrial) }\end{array}$ & $\begin{array}{l}\text { Materials Science, } \\
\text { Ceramics (Ciencia de los } \\
\text { Materiales, Cerámica) }\end{array}$ & Psychiatry (Psiquiatría) \\
\hline $\begin{array}{l}\text { Architecture } \\
\text { (Arquitectura) }\end{array}$ & $\begin{array}{l}\text { Engineering, } \\
\text { Manufacturing } \\
\text { (Ingeniería, } \\
\text { Fabricación) }\end{array}$ & $\begin{array}{l}\text { Materials Science, } \\
\text { Characterization \& Testing } \\
\text { (Ciencia de los Materiales, } \\
\text { Caracterización y Testeo) }\end{array}$ & Psychology (Psicología) \\
\hline $\begin{array}{l}\text { Area Studies } \\
\text { (Estudios de Área) }\end{array}$ & $\begin{array}{l}\text { Engineering, Marine } \\
\text { (Ingeniería, Marina) }\end{array}$ & $\begin{array}{l}\text { Materials Science, } \\
\text { Coatings \& Films (Ciencia } \\
\text { de los Materiales, } \\
\text { Revestimientos y Película) }\end{array}$ & $\begin{array}{l}\text { Psychology, Applied } \\
\text { (Psicología, Aplicada) }\end{array}$ \\
\hline Art (Arte) & $\begin{array}{l}\text { Engineering, } \\
\text { Mechanical } \\
\text { (Ingeniería, } \\
\text { Mecánica) }\end{array}$ & $\begin{array}{l}\text { Materials Science, } \\
\text { Composites (Ciencia de los } \\
\text { Materiales, Compuestos) }\end{array}$ & $\begin{array}{l}\text { Psychology, Biological } \\
\text { (Psicología, Biológica) }\end{array}$ \\
\hline $\begin{array}{l}\text { Asian Studies } \\
\text { (Estudios Asiáticos) }\end{array}$ & $\begin{array}{l}\text { Engineering, } \\
\text { Multidisciplinary } \\
\text { (Ingeniería, } \\
\text { Multidisciplinar) }\end{array}$ & $\begin{array}{l}\text { Materials Science, } \\
\text { Multidisciplinary (Ciencia } \\
\text { de los Materiales, } \\
\text { Multidisciplinar) }\end{array}$ & $\begin{array}{l}\text { Psychology, Clinical } \\
\text { (Psicología, Clínica) }\end{array}$ \\
\hline $\begin{array}{l}\text { Astronomy \& } \\
\text { Astrophysics } \\
\text { (Astronomía y } \\
\text { Astrofísica) }\end{array}$ & $\begin{array}{l}\text { Engineering, Ocean } \\
\text { (Ingeniería, } \\
\text { Oceánica) }\end{array}$ & $\begin{array}{l}\text { Materials Science, Paper \& } \\
\text { Wood (Ciencia de los } \\
\text { Materiales, Papel y } \\
\text { Madera) }\end{array}$ & $\begin{array}{l}\text { Psychology, } \\
\text { Developmental } \\
\text { (Psicología, del } \\
\text { Desarrollo) }\end{array}$ \\
\hline $\begin{array}{l}\text { Audiology \& } \\
\text { Speech-Language } \\
\text { Pathology } \\
\text { (Audiología y } \\
\text { Patología del Habla } \\
\text { y del Lenguaje) }\end{array}$ & $\begin{array}{l}\text { Engineering, } \\
\text { Petroleum } \\
\text { (Ingeniería, } \\
\text { Petróleo) }\end{array}$ & $\begin{array}{l}\text { Materials Science, Textiles } \\
\text { (Ciencia de los Materiales, } \\
\text { Textil) }\end{array}$ & $\begin{array}{l}\text { Psychology, Educational } \\
\text { (Psicología, Educativa) }\end{array}$ \\
\hline $\begin{array}{l}\text { Automation \& } \\
\text { Control Systems } \\
\text { (Sistemas de } \\
\text { Control y } \\
\text { Automatización) }\end{array}$ & $\begin{array}{l}\text { Entomology } \\
\text { (Entomología) }\end{array}$ & $\begin{array}{l}\text { Mathematical \& } \\
\text { Computational Biology } \\
\text { (Biología Computacional y } \\
\text { Matemática) }\end{array}$ & $\begin{array}{l}\text { Psychology, Experimental } \\
\text { (Psicología, } \\
\text { Experimental) }\end{array}$ \\
\hline $\begin{array}{l}\text { Behavioral } \\
\text { Sciences (Ciencias } \\
\text { del } \\
\text { Comportamiento) }\end{array}$ & $\begin{array}{l}\text { Environmental } \\
\text { Sciences (Ciencias } \\
\text { Ambientales) }\end{array}$ & $\begin{array}{l}\text { Mathematics } \\
\text { (Matemáticas) }\end{array}$ & $\begin{array}{l}\text { Psychology, } \\
\text { Mathematical } \\
\text { (Psicología, Matemática) }\end{array}$ \\
\hline $\begin{array}{l}\text { Biochemical } \\
\text { Research Methods } \\
\text { (Métodos de } \\
\text { Investigación } \\
\text { Bioquímica) }\end{array}$ & $\begin{array}{l}\text { Environmental } \\
\text { Studies (Estudios } \\
\text { Ambientales) }\end{array}$ & $\begin{array}{l}\text { Mathematics, Applied } \\
\text { (Matemáticas, Aplicadas) }\end{array}$ & $\begin{array}{l}\text { Psychology, } \\
\text { Multidisciplinary } \\
\text { (Psicología, } \\
\text { Multidisciplinar) }\end{array}$ \\
\hline $\begin{array}{l}\text { Biochemistry \& } \\
\text { Molecular Biology } \\
\text { (Bioquímica y } \\
\text { Biología Molecular) }\end{array}$ & $\begin{array}{l}\text { Ergonomics } \\
\text { (Ergonomía) }\end{array}$ & $\begin{array}{l}\text { Mathematics, } \\
\text { Interdisciplinary } \\
\text { Applications } \\
\text { (Matemáticas, }\end{array}$ & $\begin{array}{l}\text { Psychology, } \\
\text { Psychoanalysis } \\
\text { (Psicología, Psicoanálisis) }\end{array}$ \\
\hline
\end{tabular}




\begin{tabular}{|c|c|c|c|}
\hline & & $\begin{array}{l}\text { Aplicaciones } \\
\text { Interdisciplinares) }\end{array}$ & \\
\hline $\begin{array}{l}\text { Biodiversity } \\
\text { Conservation } \\
\text { (Conservación de } \\
\text { la Biodiversidad) }\end{array}$ & Ethics (Ética) & Mechanics (Mecánica) & $\begin{array}{l}\text { Psychology, Social } \\
\text { (Psicología, Social) }\end{array}$ \\
\hline Biology (Biología) & $\begin{array}{l}\text { Ethnic Studies } \\
\text { (Estudios Étnicos) }\end{array}$ & $\begin{array}{l}\text { Medical Ethics (Ética } \\
\text { Médica) }\end{array}$ & $\begin{array}{l}\text { Public Administration } \\
\text { (Administración Pública) }\end{array}$ \\
\hline $\begin{array}{l}\text { Biophysics } \\
\text { (Biofísica) }\end{array}$ & $\begin{array}{l}\text { Evolutionary } \\
\text { Biology (Biología } \\
\text { Evolutiva) }\end{array}$ & $\begin{array}{l}\text { Medical Informatics } \\
\text { (Informática Médica) }\end{array}$ & $\begin{array}{l}\text { Public, Environmental \& } \\
\text { Occupational Health } \\
\text { (Salud Pública, Ambiental } \\
\text { y Ocupacional) }\end{array}$ \\
\hline $\begin{array}{l}\text { Biotechnology \& } \\
\text { Applied } \\
\text { Microbiology } \\
\text { (Biotecnología y } \\
\text { Microbiología } \\
\text { Aplicada) }\end{array}$ & $\begin{array}{l}\text { Family Studies } \\
\text { (Estudios de } \\
\text { Familia) }\end{array}$ & $\begin{array}{l}\text { Medical Laboratory } \\
\text { Technology (Tecnología } \\
\text { Médica de Laboratorio) }\end{array}$ & $\begin{array}{l}\text { Quantum Science \& } \\
\text { Technology (Tecnología y } \\
\text { ciencia cuántica) }\end{array}$ \\
\hline $\begin{array}{l}\text { Business } \\
\text { (Negocios) }\end{array}$ & $\begin{array}{l}\text { Film, Radio, } \\
\text { Television (Radio, } \\
\text { Televisión y Cine) }\end{array}$ & $\begin{array}{l}\text { Medicine, General \& } \\
\text { Internal (Medicina, } \\
\text { General e Interna) }\end{array}$ & $\begin{array}{l}\text { Radiology, Nuclear } \\
\text { Medicine \& Medical } \\
\text { Imaging (Radiología, } \\
\text { Imagen Médica y } \\
\text { Medicina Nuclear) }\end{array}$ \\
\hline $\begin{array}{l}\text { Business, Finance } \\
\text { (Negocios, } \\
\text { Finanzas) }\end{array}$ & $\begin{array}{l}\text { Fisheries } \\
\text { (Pesquería) }\end{array}$ & $\begin{array}{l}\text { Medicine, Legal (Medicina, } \\
\text { Legal) }\end{array}$ & $\begin{array}{l}\text { Regional \& Urban } \\
\text { Planning (Planificación } \\
\text { urbana y regional) }\end{array}$ \\
\hline $\begin{array}{l}\text { Cardiac \& } \\
\text { Cardiovascular } \\
\text { Systems (Sistemas } \\
\text { Cardiaco y } \\
\text { Cardiovascular) }\end{array}$ & Folklore (Folclore) & $\begin{array}{l}\text { Medicine, Research \& } \\
\text { Experimental (Medicina, } \\
\text { Experimental y de } \\
\text { Investigación) }\end{array}$ & $\begin{array}{l}\text { Rehabilitation } \\
\text { (Rehabilitación) }\end{array}$ \\
\hline $\begin{array}{l}\text { Cell \& Tissue } \\
\text { Engineering } \\
\text { (Ingeniería de } \\
\text { Tejidos y Células) }\end{array}$ & $\begin{array}{l}\text { Food Science \& } \\
\text { Technology (Ciencia } \\
\text { y Tecnología de los } \\
\text { Alimentos) }\end{array}$ & $\begin{array}{l}\text { Medieval \& Renaissance } \\
\text { Studies (Estudios } \\
\text { Renacentistas y } \\
\text { Medievales) }\end{array}$ & Religion (Religión) \\
\hline $\begin{array}{l}\text { Cell Biology } \\
\text { (Biología Celular) }\end{array}$ & $\begin{array}{l}\text { Forestry (Ingeniería } \\
\text { de Montes) }\end{array}$ & $\begin{array}{l}\text { Metallurgy \& Metallurgical } \\
\text { Engineering (Metalurgia e } \\
\text { Ingeniería Metalúrgica) }\end{array}$ & $\begin{array}{l}\text { Remote Sensing } \\
\text { (Teledetección) }\end{array}$ \\
\hline $\begin{array}{l}\text { Chemistry, } \\
\text { Analytical } \\
\text { (Química, } \\
\text { Analítica) }\end{array}$ & $\begin{array}{l}\text { Gastroenterology \& } \\
\text { Hepatology } \\
\text { (Gastroenterología } \\
\text { y Hepatología) }\end{array}$ & $\begin{array}{l}\text { Meteorology \& } \\
\text { Atmospheric Sciences } \\
\text { (Meteorología y Ciencias } \\
\text { de la Atmósfera) }\end{array}$ & $\begin{array}{l}\text { Reproductive Biology } \\
\text { (Biología Reproductora) }\end{array}$ \\
\hline $\begin{array}{l}\text { Chemistry, Applied } \\
\text { (Química, } \\
\text { Aplicada) }\end{array}$ & $\begin{array}{l}\text { Genetics \& Heredity } \\
\text { (Genética y } \\
\text { Herencia Genética) }\end{array}$ & $\begin{array}{l}\text { Microbiology } \\
\text { (Microbiología) }\end{array}$ & $\begin{array}{l}\text { Respiratory System } \\
\text { (Sistema Respiratorio) }\end{array}$ \\
\hline $\begin{array}{l}\text { Chemistry, } \\
\text { Inorganic \& } \\
\text { Nuclear (Química, } \\
\text { Inorgánica y } \\
\text { Nuclear) }\end{array}$ & $\begin{array}{l}\text { Geochemistry \& } \\
\text { Geophysics } \\
\text { (Geoquímica y } \\
\text { Geofísica) }\end{array}$ & Microscopy (Microscopía) & $\begin{array}{l}\text { Rheumatology } \\
\text { (Reumatología) }\end{array}$ \\
\hline $\begin{array}{l}\text { Chemistry, } \\
\text { Medicinal }\end{array}$ & $\begin{array}{l}\text { Geography } \\
\text { (Geografía) }\end{array}$ & Mineralogy (Mineralogía) & Robotics (Robótica) \\
\hline
\end{tabular}




\begin{tabular}{|c|c|c|c|}
\hline $\begin{array}{l}\text { (Química, } \\
\text { Medicinal) }\end{array}$ & & & \\
\hline $\begin{array}{l}\text { Chemistry, } \\
\text { Multidisciplinary } \\
\text { (Química, } \\
\text { Multidisciplinar) }\end{array}$ & $\begin{array}{l}\text { Geography, Physical } \\
\text { (Geografía, Física) }\end{array}$ & $\begin{array}{l}\text { Mining \& Mineral } \\
\text { Processing (Minería y } \\
\text { Tratamiento de Minerales) }\end{array}$ & $\begin{array}{l}\text { Social Issues (Asuntos } \\
\text { Sociales) }\end{array}$ \\
\hline $\begin{array}{l}\text { Chemistry, Organic } \\
\text { (Química, } \\
\text { Orgánica) }\end{array}$ & Geology (Geología) & $\begin{array}{l}\text { Multidisciplinary Sciences } \\
\text { (Ciencias } \\
\text { Multidisciplinarias) }\end{array}$ & $\begin{array}{l}\text { Social Sciences, } \\
\text { Biomedical (Ciencias } \\
\text { Sociales, Biomédica) }\end{array}$ \\
\hline $\begin{array}{l}\text { Chemistry, Physical } \\
\text { (Química, Física) }\end{array}$ & $\begin{array}{l}\text { Geosciences, } \\
\text { Multidisciplinary } \\
\text { (Ciencias de la } \\
\text { Tierra, } \\
\text { Multidisciplinar) }\end{array}$ & Music (Música) & $\begin{array}{l}\text { Social Sciences, } \\
\text { Interdisciplinary (Ciencias } \\
\text { Sociales, Interdisciplinar) }\end{array}$ \\
\hline Classics (Clásicos) & $\begin{array}{l}\text { Geriatrics \& } \\
\text { Gerontology } \\
\text { (Geriatría y } \\
\text { Gerontología) }\end{array}$ & Mycology (Micología) & $\begin{array}{l}\text { Social Sciences, } \\
\text { Mathematical Methods } \\
\text { (Ciencias Sociales, } \\
\text { Métodos Matemáticos) }\end{array}$ \\
\hline $\begin{array}{l}\text { Clinical Neurology } \\
\text { (Neurología } \\
\text { Clínica) }\end{array}$ & $\begin{array}{l}\text { Gerontology } \\
\text { (Gerontología) }\end{array}$ & $\begin{array}{l}\text { Nanoscience \& } \\
\text { Nanotechnology } \\
\text { (Nanociencia y } \\
\text { Nanotecnología) }\end{array}$ & $\begin{array}{l}\text { Social Work (Trabajo } \\
\text { Social) }\end{array}$ \\
\hline $\begin{array}{l}\text { Communication } \\
\text { (Comunicación) }\end{array}$ & $\begin{array}{l}\text { Green \& } \\
\text { Sustainable Science } \\
\text { \& Technology } \\
\text { (Tecnología y } \\
\text { ciencia de ecología } \\
\text { y sostenibilidad) }\end{array}$ & $\begin{array}{l}\text { Neuroimaging } \\
\text { (Neuroimagen) }\end{array}$ & Sociology (Sociología) \\
\hline $\begin{array}{l}\text { Computer Science, } \\
\text { Artificial } \\
\text { Intelligence } \\
\text { (Informática, } \\
\text { Inteligencia } \\
\text { Artificial) }\end{array}$ & $\begin{array}{l}\text { Health Care } \\
\text { Sciences \& Services } \\
\text { (Servicios y Ciencias } \\
\text { de la Salud) }\end{array}$ & $\begin{array}{l}\text { Neurosciences } \\
\text { (Neurociencias) }\end{array}$ & $\begin{array}{l}\text { Soil Science (Ciencia del } \\
\text { Suelo) }\end{array}$ \\
\hline $\begin{array}{l}\text { Computer Science, } \\
\text { Cybernetics } \\
\text { (Informática, } \\
\text { Cibernética) }\end{array}$ & $\begin{array}{l}\text { Health Policy \& } \\
\text { Services (Servicios y } \\
\text { Política Sanitaria) }\end{array}$ & $\begin{array}{l}\text { Nuclear Science \& } \\
\text { Technology (Ciencia y } \\
\text { Tecnología Nuclear) }\end{array}$ & $\begin{array}{l}\text { Spectroscopy } \\
\text { (Espectroscopia) }\end{array}$ \\
\hline $\begin{array}{l}\text { Computer Science, } \\
\text { Hardware \& } \\
\text { Architecture } \\
\text { (Informática, } \\
\text { Hardware y } \\
\text { Arquitectura) }\end{array}$ & $\begin{array}{l}\text { Hematology } \\
\text { (Hematología) }\end{array}$ & Nursing (Enfermería) & $\begin{array}{l}\text { Sport Sciences (Ciencias } \\
\text { de la Actividad Física) }\end{array}$ \\
\hline $\begin{array}{l}\text { Computer Science, } \\
\text { Information } \\
\text { Systems } \\
\text { (Informática, } \\
\text { Sistemas de } \\
\text { Información) }\end{array}$ & History (Historia) & $\begin{array}{l}\text { Nutrition \& Dietetics } \\
\text { (Nutrición y Dietética) }\end{array}$ & $\begin{array}{l}\text { Statistics \& Probability } \\
\text { (Estadística y } \\
\text { Probabilidad) }\end{array}$ \\
\hline $\begin{array}{l}\text { Computer Science, } \\
\text { Interdisciplinary } \\
\text { Applications }\end{array}$ & $\begin{array}{l}\text { History \& } \\
\text { Philosophy of } \\
\text { Science (Historia y }\end{array}$ & $\begin{array}{l}\text { Obstetrics \& Gynecology } \\
\text { (Obstetricia y Ginecología) }\end{array}$ & $\begin{array}{l}\text { Substance Abuse (Abuso } \\
\text { de Sustancias) }\end{array}$ \\
\hline
\end{tabular}




\begin{tabular}{|c|c|c|c|}
\hline $\begin{array}{l}\text { (Informática, } \\
\text { Aplicaciones } \\
\text { Interdisciplinares) }\end{array}$ & $\begin{array}{l}\text { Filosofía de la } \\
\text { Ciencia) }\end{array}$ & & \\
\hline $\begin{array}{l}\text { Computer Science, } \\
\text { Software } \\
\text { Engineering } \\
\text { (Informática, } \\
\text { Ingeniería de } \\
\text { Software) }\end{array}$ & $\begin{array}{l}\text { History of Social } \\
\text { Sciences (Historia } \\
\text { de las Ciencias } \\
\text { Sociales) }\end{array}$ & $\begin{array}{l}\text { Oceanography } \\
\text { (Oceanografía) }\end{array}$ & Surgery (Cirugía) \\
\hline $\begin{array}{l}\text { Computer Science, } \\
\text { Theory \& Methods } \\
\text { (Informática, } \\
\text { Teoría y Métodos) }\end{array}$ & $\begin{array}{l}\text { Horticulture } \\
\text { (Horticultura) }\end{array}$ & Oncology (Oncología) & $\begin{array}{l}\text { Telecommunications } \\
\text { (Telecomunicaciones) }\end{array}$ \\
\hline $\begin{array}{l}\text { Construction \& } \\
\text { Building } \\
\text { Technology } \\
\text { (Construcción y } \\
\text { Tecnología de la } \\
\text { Edificación) }\end{array}$ & $\begin{array}{l}\text { Hospitality, Leisure, } \\
\text { Sport \& Tourism } \\
\text { (Hospitalidad, Ocio, } \\
\text { Deporte y Turismo) }\end{array}$ & $\begin{array}{l}\text { Operations Research \& } \\
\text { Management Science } \\
\text { (Ciencia de la Gestión e } \\
\text { Investigación de } \\
\text { Operaciones) }\end{array}$ & Theater (Teatro) \\
\hline $\begin{array}{l}\text { Criminology \& } \\
\text { Penology } \\
\text { (Criminología y } \\
\text { Penología) }\end{array}$ & $\begin{array}{l}\text { Humanities, } \\
\text { Multidisciplinary } \\
\text { (Humanidades, } \\
\text { Multidisciplinar) }\end{array}$ & $\begin{array}{l}\text { Ophthalmology } \\
\text { (Oftalmología) }\end{array}$ & $\begin{array}{l}\text { Thermodynamics } \\
\text { (Termodinámica) }\end{array}$ \\
\hline $\begin{array}{l}\text { Critical Care } \\
\text { Medicine } \\
\text { (Medicina } \\
\text { Intensiva) }\end{array}$ & $\begin{array}{l}\text { Imaging Science \& } \\
\text { Photographic } \\
\text { Technology } \\
\text { (Tecnología } \\
\text { Fotográfica y } \\
\text { Ciencias de la } \\
\text { Imagen) }\end{array}$ & Optics (Óptica) & Toxicology (Toxicología) \\
\hline $\begin{array}{l}\text { Crystallography } \\
\text { (Cristalografía) }\end{array}$ & $\begin{array}{l}\text { Immunology } \\
\text { (Inmunología) }\end{array}$ & Ornithology (Ornitología) & $\begin{array}{l}\text { Transplantation } \\
\text { (Trasplante) }\end{array}$ \\
\hline $\begin{array}{l}\text { Cultural Studies } \\
\text { (Estudios } \\
\text { Culturales) }\end{array}$ & $\begin{array}{l}\text { Industrial Relations } \\
\text { \& Labor (Trabajo y } \\
\text { Relaciones } \\
\text { Laborales) }\end{array}$ & Orthopedics (Ortopedia) & $\begin{array}{l}\text { Transportation } \\
\text { (Transporte) }\end{array}$ \\
\hline Dance (Baile) & $\begin{array}{l}\text { Infectious Diseases } \\
\text { (Enfermedades } \\
\text { Infecciosas) }\end{array}$ & $\begin{array}{l}\text { Otorhinolaryngology } \\
\text { (Otorrinolaringología) }\end{array}$ & $\begin{array}{l}\text { Transportation Science \& } \\
\text { Technology (Ciencia y } \\
\text { Tecnología del } \\
\text { Transporte) }\end{array}$ \\
\hline $\begin{array}{l}\text { Demography } \\
\text { (Demografía) }\end{array}$ & $\begin{array}{l}\text { Information Science } \\
\& \text { Library Science } \\
\text { (Ciencias de la } \\
\text { Información y } \\
\text { Biblioteconomía) }\end{array}$ & $\begin{array}{l}\text { Paleontology } \\
\text { (Paleontología) }\end{array}$ & $\begin{array}{l}\text { Tropical Medicine } \\
\text { (Medicina Tropical) }\end{array}$ \\
\hline $\begin{array}{l}\text { Dentistry, Oral } \\
\text { Surgery \& } \\
\text { Medicine } \\
\text { (Odontología, } \\
\text { Medicina y Cirugía } \\
\text { Oral) }\end{array}$ & $\begin{array}{l}\text { Instruments \& } \\
\text { Instrumentation } \\
\text { (Instrumentos e } \\
\text { Instrumentación) }\end{array}$ & $\begin{array}{l}\text { Parasitology } \\
\text { (Parasitología) }\end{array}$ & $\begin{array}{l}\text { Urban Studies (Estudios } \\
\text { Urbanos) }\end{array}$ \\
\hline $\begin{array}{l}\text { Dermatology } \\
\text { (Dermatología) }\end{array}$ & $\begin{array}{l}\text { Integrative \& } \\
\text { Complementary }\end{array}$ & Pathology (Patología) & $\begin{array}{l}\text { Urology \& Nephrology } \\
\text { (Urología y Nefrología) }\end{array}$ \\
\hline
\end{tabular}




\begin{tabular}{|c|c|c|c|}
\hline & $\begin{array}{l}\text { Medicine (Medicina } \\
\text { Complementaria e } \\
\text { Integral) }\end{array}$ & & \\
\hline $\begin{array}{l}\text { Development } \\
\text { Studies (Estudios } \\
\text { de desarrollo) }\end{array}$ & $\begin{array}{l}\text { International } \\
\text { Relations } \\
\text { (Relaciones } \\
\text { Internacionales) }\end{array}$ & Pediatrics (Pediatría) & $\begin{array}{l}\text { Veterinary Sciences } \\
\text { (Ciencias Veterinarias) }\end{array}$ \\
\hline $\begin{array}{l}\text { Developmental } \\
\text { Biology (Biología } \\
\text { del Desarrollo) }\end{array}$ & $\begin{array}{l}\text { Language \& } \\
\text { Linguistics (Lengua } \\
\text { y Lingüística) }\end{array}$ & $\begin{array}{l}\text { Peripheral Vascular } \\
\text { Disease (Enfermedad } \\
\text { Vascular Periférica) }\end{array}$ & Virology (Virología) \\
\hline Ecology (Ecología) & Law (Derecho) & $\begin{array}{l}\text { Pharmacology \& Pharmacy } \\
\text { (Farmacología y Farmacia) }\end{array}$ & $\begin{array}{l}\text { Water Resources } \\
\text { (Recursos Hídricos) }\end{array}$ \\
\hline $\begin{array}{l}\text { Economics } \\
\text { (Economía) }\end{array}$ & $\begin{array}{l}\text { Limnology } \\
\text { (Limnología) }\end{array}$ & Philosophy (Filosofía) & $\begin{array}{l}\text { Women's Studies } \\
\text { (Estudios de la Mujer) }\end{array}$ \\
\hline $\begin{array}{l}\text { Education \& } \\
\text { Educational } \\
\text { Research } \\
\text { (Educación e } \\
\text { Investigación } \\
\text { Educativa) }\end{array}$ & $\begin{array}{l}\text { Linguistics } \\
\text { (Lingüística) }\end{array}$ & $\begin{array}{l}\text { Physics, Applied (Física, } \\
\text { Aplicada) }\end{array}$ & Zoology (Zoología) \\
\hline $\begin{array}{l}\text { Education, } \\
\text { Scientific } \\
\text { Disciplines } \\
\text { (Educación, } \\
\text { Disciplinas } \\
\text { Científicas) }\end{array}$ & $\begin{array}{l}\text { Literary Reviews } \\
\text { (Críticas Literarias) }\end{array}$ & $\begin{array}{l}\text { Physics, Atomic, Molecular } \\
\text { \& Chemical (Física, } \\
\text { Atómica, Molecular y } \\
\text { Química) }\end{array}$ & \\
\hline $\begin{array}{l}\text { Education, Special } \\
\text { (Educación, } \\
\text { Especial) }\end{array}$ & $\begin{array}{l}\text { Literary Theory \& } \\
\text { Criticism (Crítica y } \\
\text { Teoría de la } \\
\text { Literatura) }\end{array}$ & $\begin{array}{l}\text { Physics, Condensed } \\
\text { Matter (Física, Materia } \\
\text { Condensada) }\end{array}$ & \\
\hline
\end{tabular}




\section{Cobertura Selectiva en Arts \& Humanities Citation Index y Social Science Citation Index}

Consiste en la selección de determinados documentos de las revistas indexadas en Science Citation Index Expanded (SCIE) para ser incluidos en Social Science Citation Index (SSCI) o en Arts \& Humanities Citation Index (A\&HCl). La cobertura selectiva se lleva a cabo mediante un algoritmo y posterior evaluación por el Departamento Editorial para determinar si está apropiado para la inclusión en $\mathrm{SSCl}$ o $\mathrm{A} \& \mathrm{HCl}$.

En el ejemplo que continúa, la revista completa Trends in Cognitive Sciences se indexa en SCIE, sin embargo, ciertos artículos como el que se presenta, se indexan también en $\mathrm{A} \& \mathrm{HCl}$.

\section{Ejemplo de un Artículo Indexado en el SCI Expanded ${ }^{\circledR}$}

\section{Measurement of transient out-of-plane displacement gradients in plates using double-pulsed subtraction TV shearography}

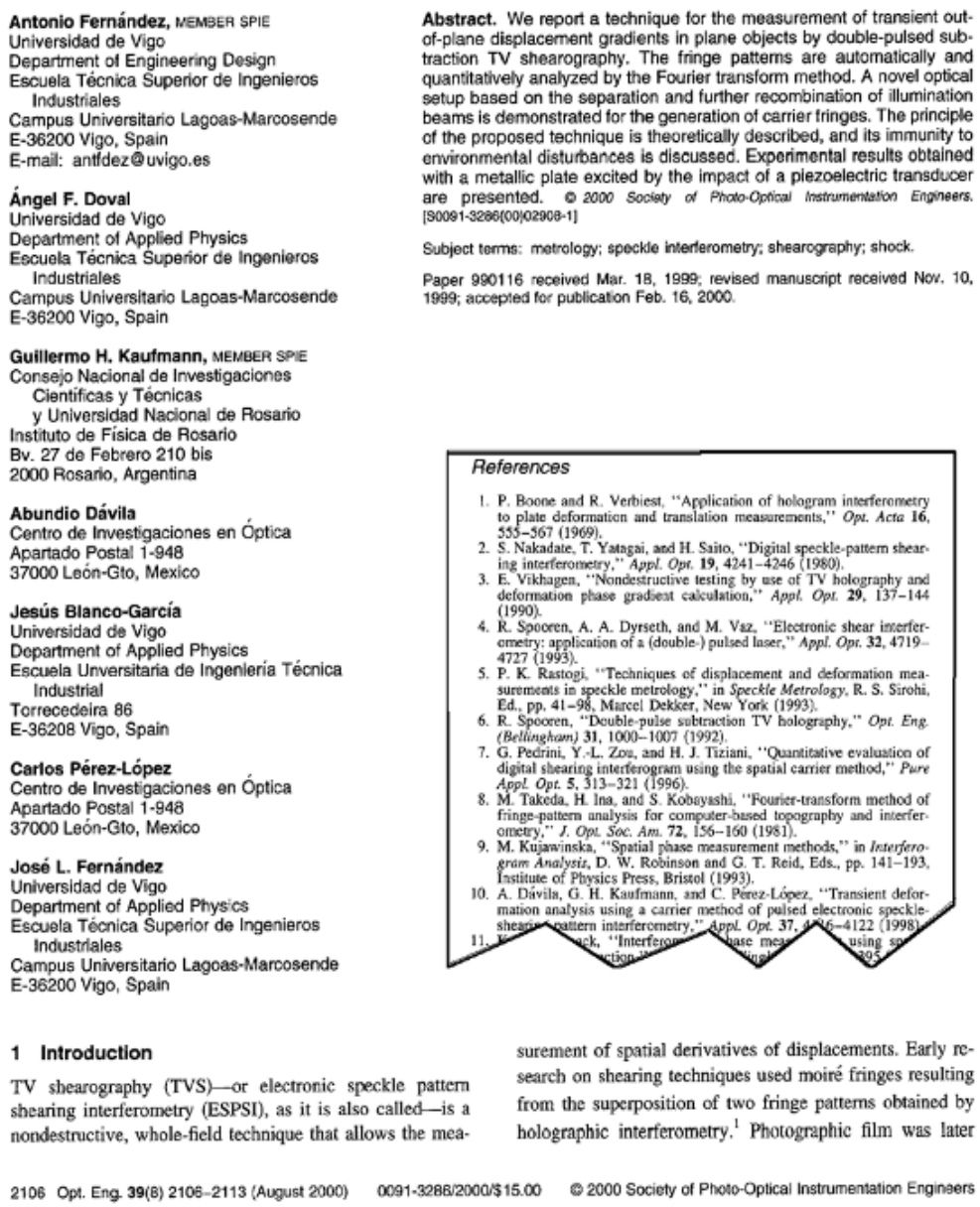

TV shearography (TVS)-or electronic speckle pattern

TV shearography (TVS)-Or electronic speckle pattern

nondestructive, whole-field technique that allows the mea-

Abstract. We report a technique for the measurement of transient outof-plane TV shearography. The fringe patterms are automatically and quantitatively analyzed by the Fourier transform method. A novel optical setup based on the separation and further recombination of illumination beams is demonstrated for the generation of carrier fringes. The principle of the proposed technique is theoretically described, and its immunity to with a metallio plate excith by the impact of a piezoelectric traneducer with a metalic plate excited by the impact of a plezoelectric transducer [S0091-3280600/02908-1]

Subject terms: metrology; speckle interterometry; shearcography; shock. Pager 990116 received Mar. 18, 1999, revised manuscript received NOr. 10. 


\section{Registro de un Documento SCl en la Colección Principal de la Web of Science}

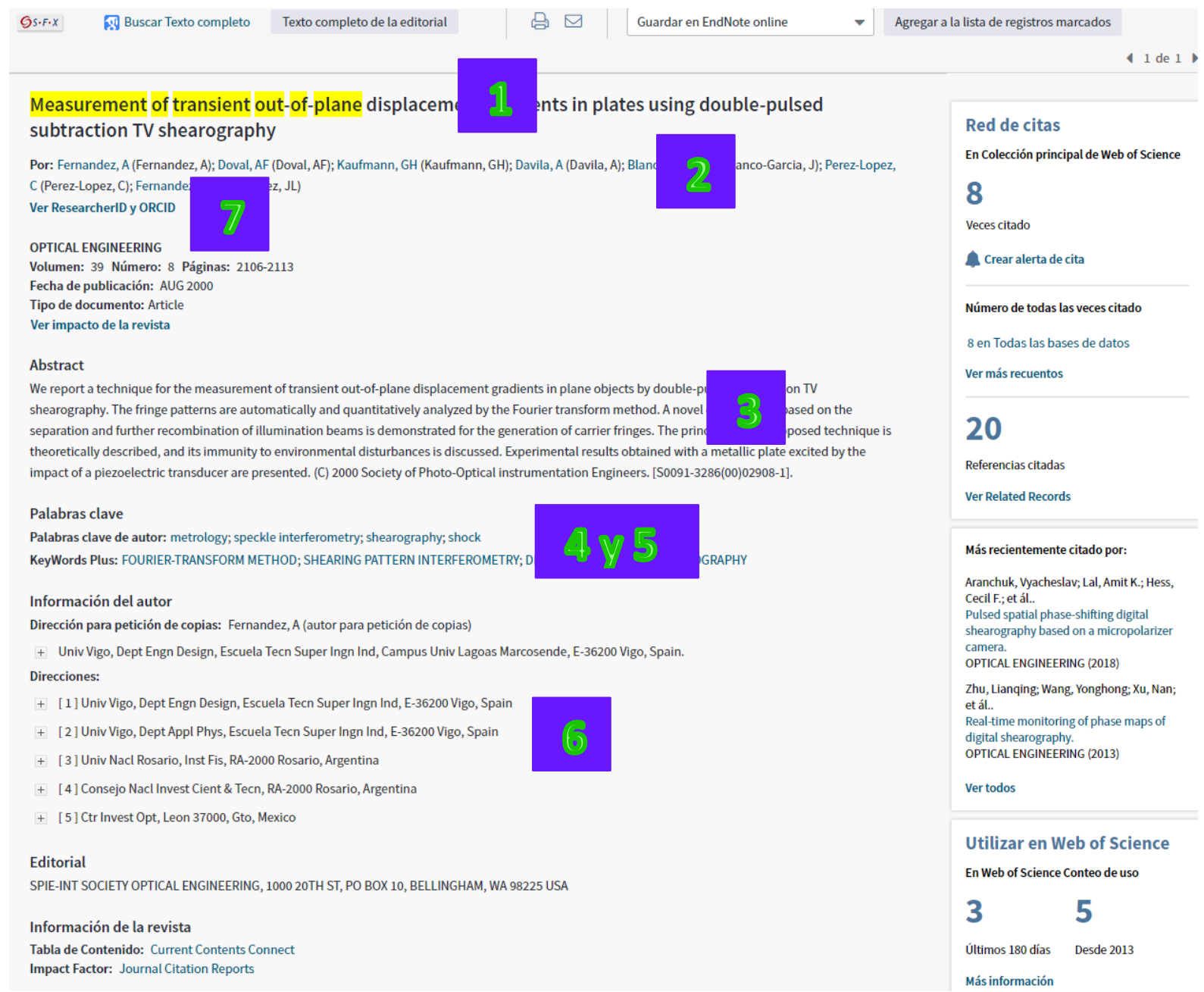

1. Se indexa el título completo del documento original y sirve para hacer búsquedas. Se traducen los títulos de artículos de idiomas extranjeros al inglés estadounidense.

2. Los nombres de los autores se indexan incluyendo el apellido y hasta cinco iniciales. Se incluyen los nombres de todos los autores y todos sirven para hacer búsquedas. Para autores indexados después de 2006 se presentan sus nombres completos si están previstos en el documento original. El nombre completo del autor también sirve como una búsqueda por autor.

3. Se indexa el resumen completo del autor. Los resúmenes se indexan cuando están provistos en inglés por la propia revista. Web of Science Group no traduce ni escribe los resúmenes.

4. Se incluyen las palabras clave si son provistas por el autor del artículo.

5. "Keywords Plus" originan de los títulos de las referencias citadas. No todos los artículos tienen palabras clave o resúmenes.

6. Se captura todas las afiliaciones de los autores si son provistas en el documento original. Para artículos indexados después de 2008 se puede ver la afiliación de lo cual está afiliado un autor según el número indicado después de su nombre. Para los artículos indexados antes de 2008 solamente el autor que provee las separatas o reimpresiones aparece vinculado a su dirección. Se incluirá el correo electrónico del autor si está provisto en el documento original. 
7. En el campo 'Identificadores de autores' se pueden ver los usuarios de la comunidad www.researcherid.com o de ORCID que han añadido esta misma publicación a sus listas de publicaciones. Visite www.researcherid.com o www.orcid.org para más información.

\section{Las Referencias Citadas de un registro SCI}

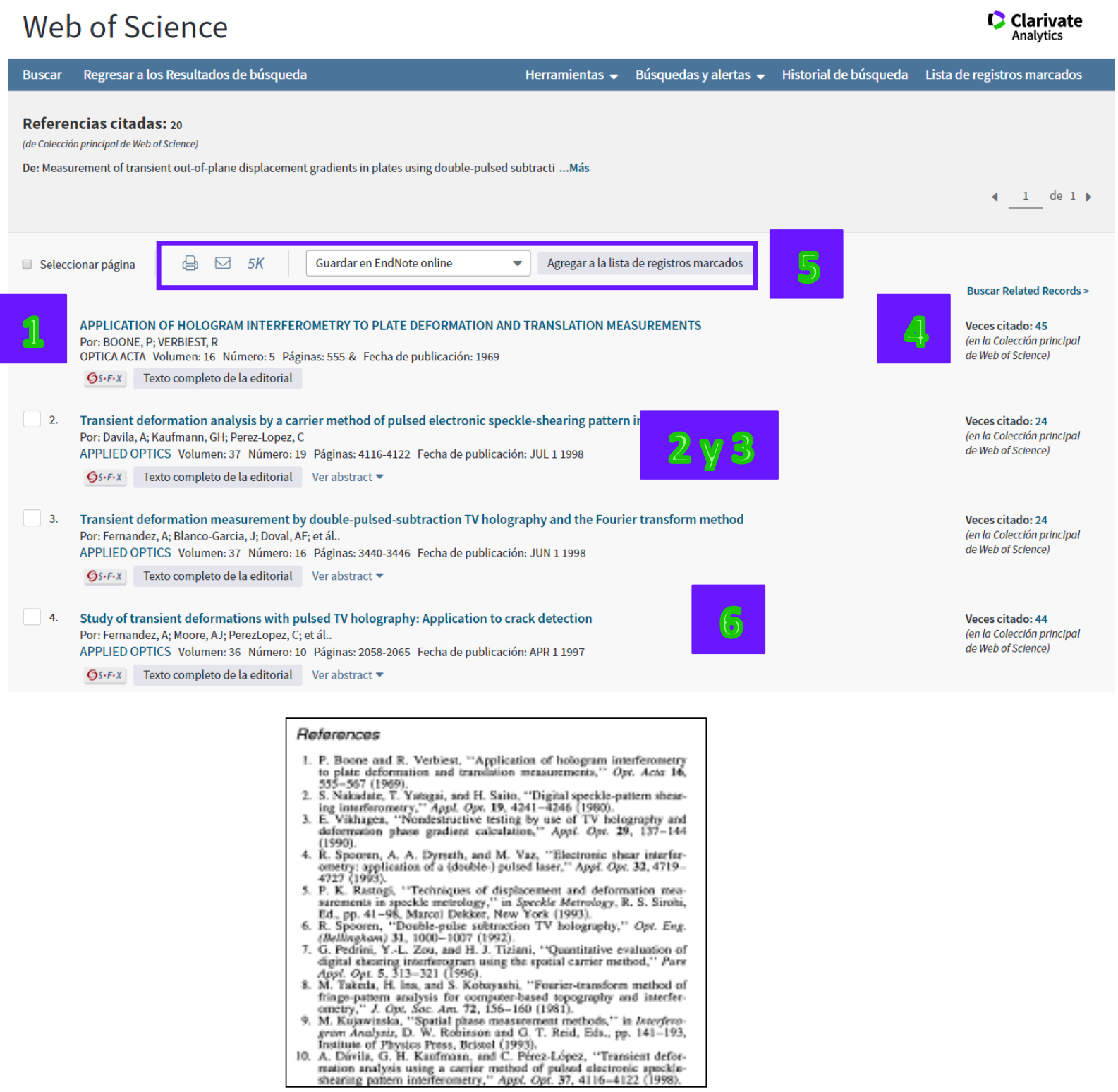

1. Las referencias citadas se orden por un orden alfabético por primer autor de la publicación.

2. Los títulos de las referencias citadas en azul (hiperenlace) están vinculados a sus registros completos en la Web of Science.

3. Se indexan todas las referencias citadas tal y como publicadas. Observe que los títulos de revistas y libros pueden ser abreviados.

4. Se muestra las veces citado (de la colección principal) para las referencias citadas indexadas en la Web of Science. 
5. Es posible exportar las referencias que vinculan a sus registros fuentes en la WOS. Para exportar las referencias hace falta seleccionar sus casillas correspondientes en la columna a mano izquierda. Viste la sección 'Exportar registros' para leer más sobre las opciones de exportación en la WOS.

6. Se indexa la referencia en completo

\section{Ejemplo de un Artículo en el $\mathrm{A} \& \mathrm{HCl}$}

ST A TE

FILOZOFIA

Roc. 55, 2000, c. 8

\section{EPISTEMOLOGICKÉ ASPEKTY MODERNÉHO MALIARSTVA}

LADISLAVV KVASZ, Katedra humanistiky MFF-UK, Bratislava

KVASZ, L.: The Epistemological Aspects of Modern Painting

FILOZOFIA 55, 2000, No 8, p. 601

The aim of the paper is to analyse the geometrical aspects of a series of modem paintings and to show the parallel between them and the development of modem geometry. It starts with El Greco, offering a geometrical explanation of his painting the figures in a prolonged manner. Further the analogy between the imnerseinoie way of creating space (in the works of Turner, Monet and Se cal idea of Cayley to use projective space as a basis for nonreconstructed. Next the paper describes the parallel betweer in the paintings of Cezanne and Picasso and the concept topology. In conclusion the paper deals with the analogy be stract paintings and the set-theoretical foundations of geome

Predkladaná stat' nadväzuje na clánok Epistemologické aspekty v ktorom sme sa pokúsili načrtnút' paralelu spájajúcu geometrické as liarstva od renesancie po baroko s dejinami geometrie od Desargua po rom článku bola téza, že existuje paralela medzi formálnou štruktúrc barokového maliarstva a štruktúrou obrázkov $\mathrm{v}$ textoch neeuklidovsk sa podarilo predíżit' paralelu medzi geometriou a maliarstvom, ktorej v obmedzuje na obdobie renesancie, aj za hranice tejto epochy. $Z$ teor bol rovnako dôležitý opis príkladu vetvenia formy jazyka, ked' sme u spektivistickú formu existovali tri rôzne spôsoby nadviazania - deskrił jektivna forma a anamorfická forma. To ukazuje, ako možno rekonštr discipliny oslobodit' od tendencie linearizácie jej vývinu. V tejto stati na predošlé analýzy a predížit' výklad geometrických aspektov maliars abstraktného umenia. Sledovat' budeme líniu Turner, Monet, Seurat,

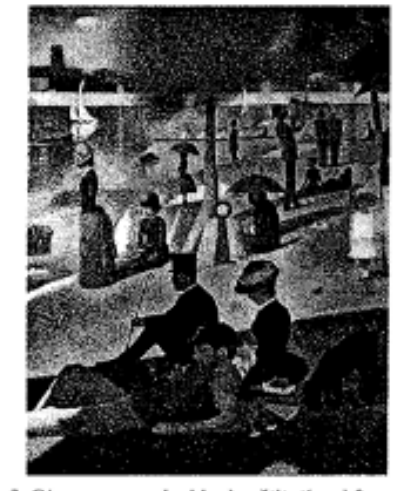

Kandinskij a pokúsime sa ukázat' jej paralely v dejinách geometrie. Pritom obmedzenia, o ktorých sme hovorili v úvode predošlého článku, platia ešte vo văčšej miere pre náš pohlad do dejín moderného maliarstva. Ked'že v modernom maliarstve hrá farebnost', expresívnost' a gestickost' stále významnejłiu úlohu, ostáva stále menej obrazov, pri interpretácii ktorých je ústredným motívom ich geometrická struktúra. Preto náš exkurz do dejín mo bude zau nia, pove článku. K LITERATÚRA

[1] AGoSTON, M.: Algebraic Topology, a First Course. New York, Marcel Dekker 1976 2) BLATT, S. J.: Continuity and Change in Art.. New Jersey, Lawrence Erlbaum Associates Publishers 1984

[3] BUGÁR, P. : Mandalické myslenie. In: Mojżis, J. (ed.): Archetyp, mýtus, utópia. Bratislava, 1998, s. $114-143$

[4] CANTOR, G. (1883): Grundlagen einer allgemeinen Mannigfaltigkeitslehre. Leipzig, Teubner. Ruský preklad in: Georg Kantor, Trudy po teorii mnozestv. Moskva, Nauka 1985

[5] KELEMEN, P.: El Greco revisited. New York, The Macmillan Company 1961.

[6] KVASZ, L.: Nacrt analytickej teórie subjektu. In: Filosofický Casopis 1996/4, s. 617-640

[7] KVASZ, L.: Dejiny nábozenstva a matematika. In: Hieron II., 1997, s. 115-129.

8] KVASZ, L.: Epistemologické aspekty dejin maliarstva. In: Filozofia 1998/10, s. 658-681.

[9] KVASZ, L.: Gramatika zmeny. Bratislava, Chronos 1999.

[10] LORAN, E. (1943): Cezanne's composition. Berkeley, University of California Press 1983

[11] MERLEAU-PONTY, M: Oko a đuch a jiné eseje. Praha, Obelisk 1971.

[12] WITTGENSTEIN, L. (1921): Tractatus Logico-philosophicus. Frankfurt am Main, Suhrkamp 1989. 


\section{Registro de un documento $A \& H C l$ en la Colección Principal de la Web of Science}

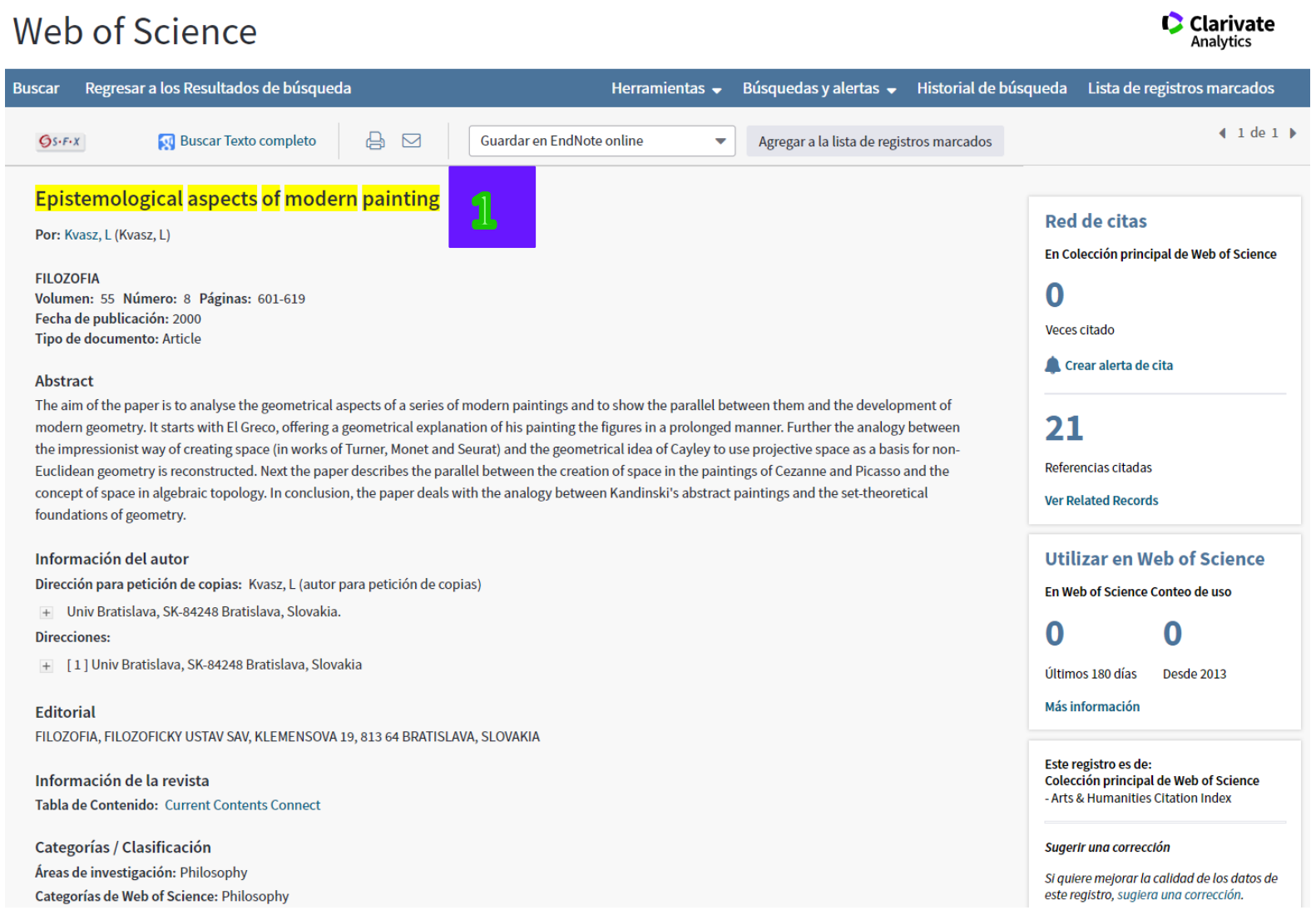

1. Observe que el resumen está en inglés, mientras que el idioma del artículo es esloveno. Los resúmenes se indexan cuando son provistos en inglés por la propia revista. Web of Science Group no los traduce. 


\section{Las Referencias Citadas de un artículo de A\&HCI}

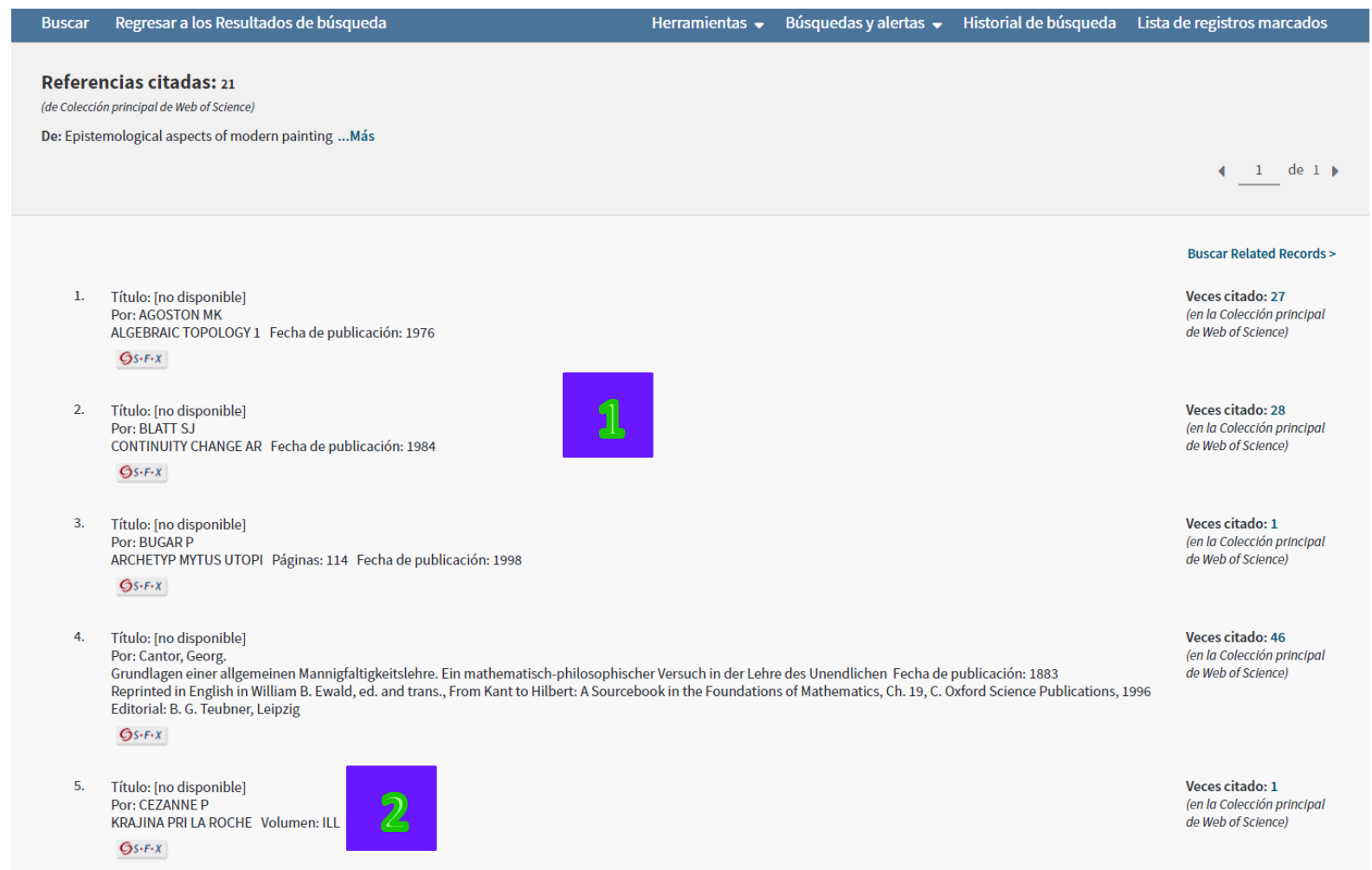

1. El número de referencias que presentan enlaces con los registros completos es menor en $\mathrm{A} \& \mathrm{HCl}$ que en $\mathrm{SCIE}$ y SSCl debido a que los tipos de documento más frecuentemente citados en las artes y humanidades (por ejemplo: libros) no son indexados en Web of Science.

Las referencias que incluyen una "ilustración" al lado del año indican que una ilustración se presenta en el artículo. Se indexan el autor citado y los nombres de los trabajos citados del título incluido en la ilustración. Cuando se incluye una ilustración en un artículo, está representada por 'ILL' en el campo del volumen en el resumen de una búsqueda por referencias citadas. 


\section{Acceso a la Web of Science}

Existen varios tipos de acceso que le permiten acceder a la Web of Science desde cualquier sitio y en cualquier momento.

\section{Google Académico}

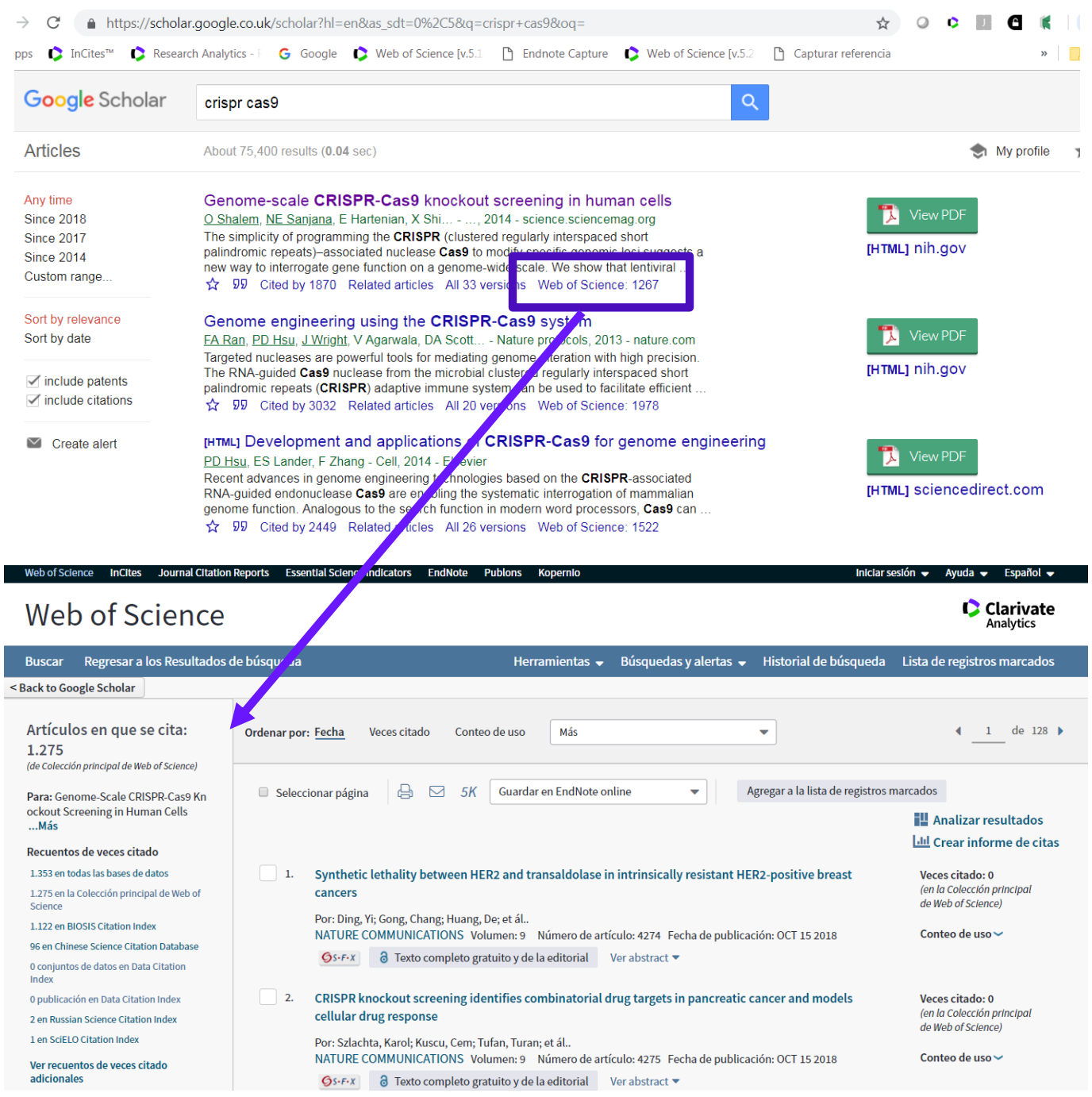

2. Búsqueda rápida en el navegador Google Chrome

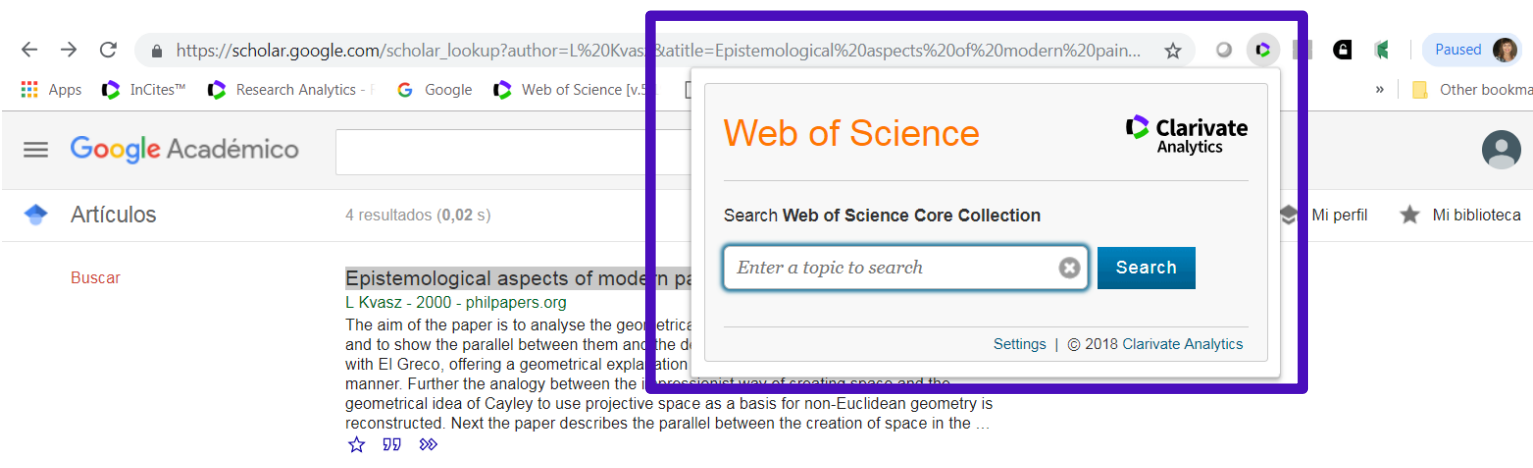

https://chrome.google.com/webstore/detail/web-of-science-quicksear/nemobobcigeaigadamdpegpjkklkoeae 
3. Catálogo de las bases de datos electrónicas de su biblioteca institucional

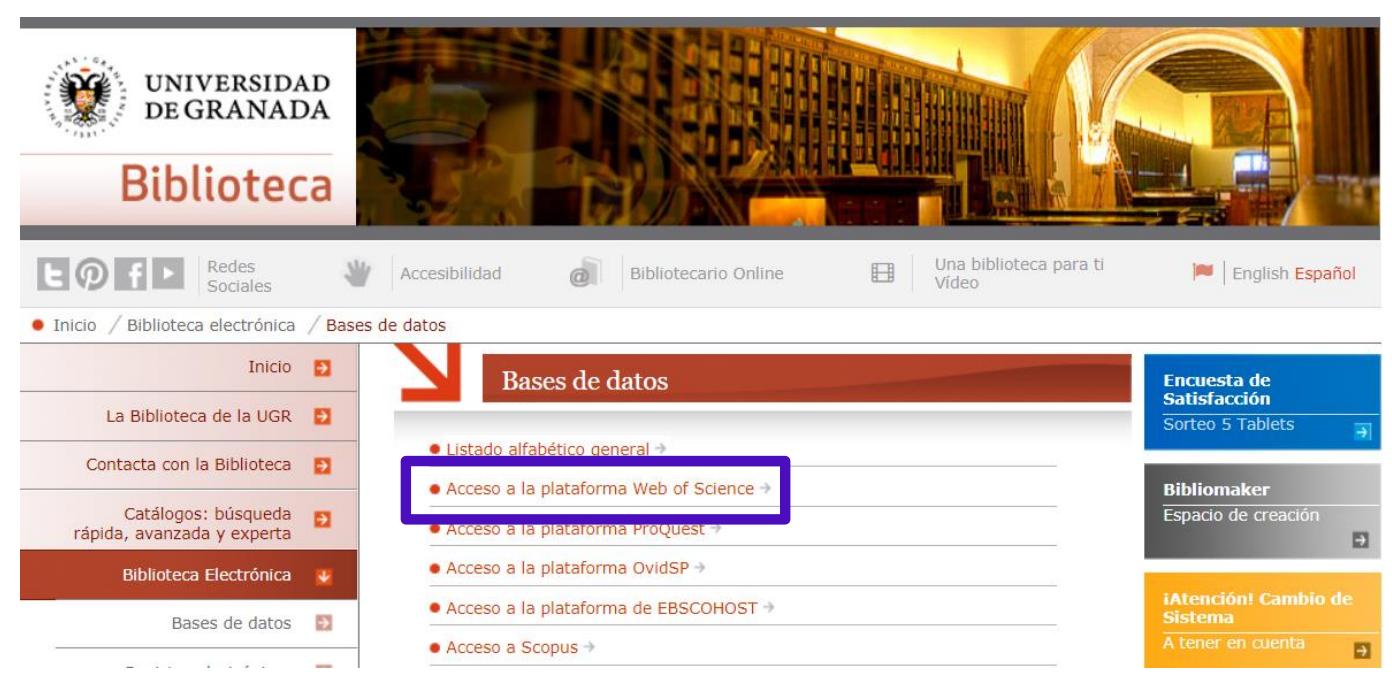

4. https://roaming.webofscience.com

Acceso desde fuera de su institución/campus

1. Acceso para los usuarios de Shibboleth. Selecciona 'Inicia de sesión para usuarios de instituciones'. Busca su institución en el menú desplegable de instituciones (Federation of Spain by FECYT) luego pulse en 'Go'.

2. Acceso para los usuarios registrados (perfil de Web of Science). Selecciona 'inicia de sesión para usuarios registrados'. Introduce las credenciales de su perfil luego 'iniciar sesión'.

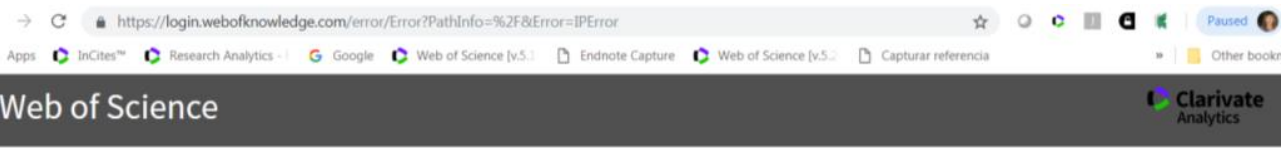

Please Sign In to Access Web of Science

REGISTERED USERS SIGN IN

Sign in with your Web of Science account. Note that you must have recently signed in while

at your institution in order to sign in with roaming

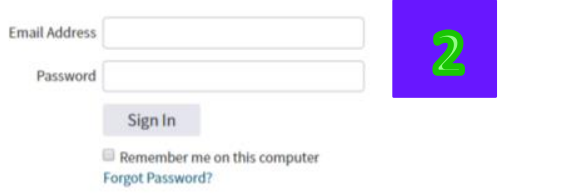

INSTITUTIONAL USERS SIGN IN

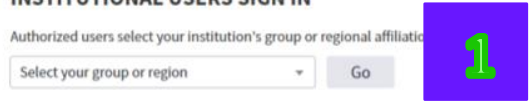

NEED ASSISTANCE

Contact your institution with questions about signing in and registering for an account

Contact Technical Support

Your IP address is: 213.120.141.2

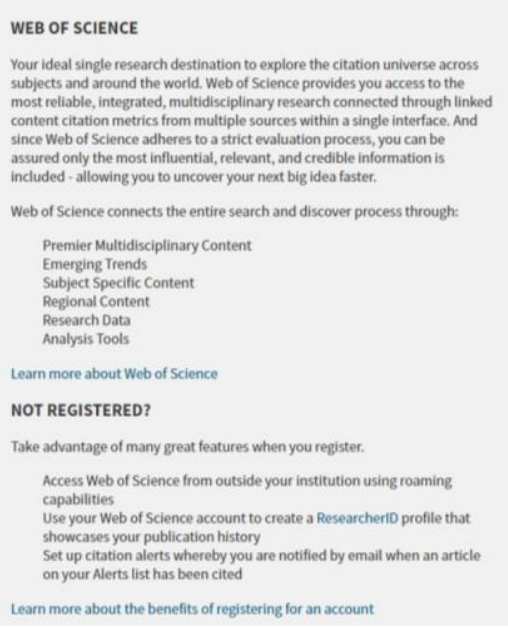




\section{Página Principal de la Web of Science}

La interfaz de Web of Science consiste en una lista de bases de datos que le permite desplazarse fácilmente entre los recursos contratados según la suscripción de su institución.

Desde la página inicial se puede ir directamente a un determinado producto, hacer una búsqueda en varios productos simultáneamente $\mathrm{o}$ abrir historiales guardados con anterioridad.

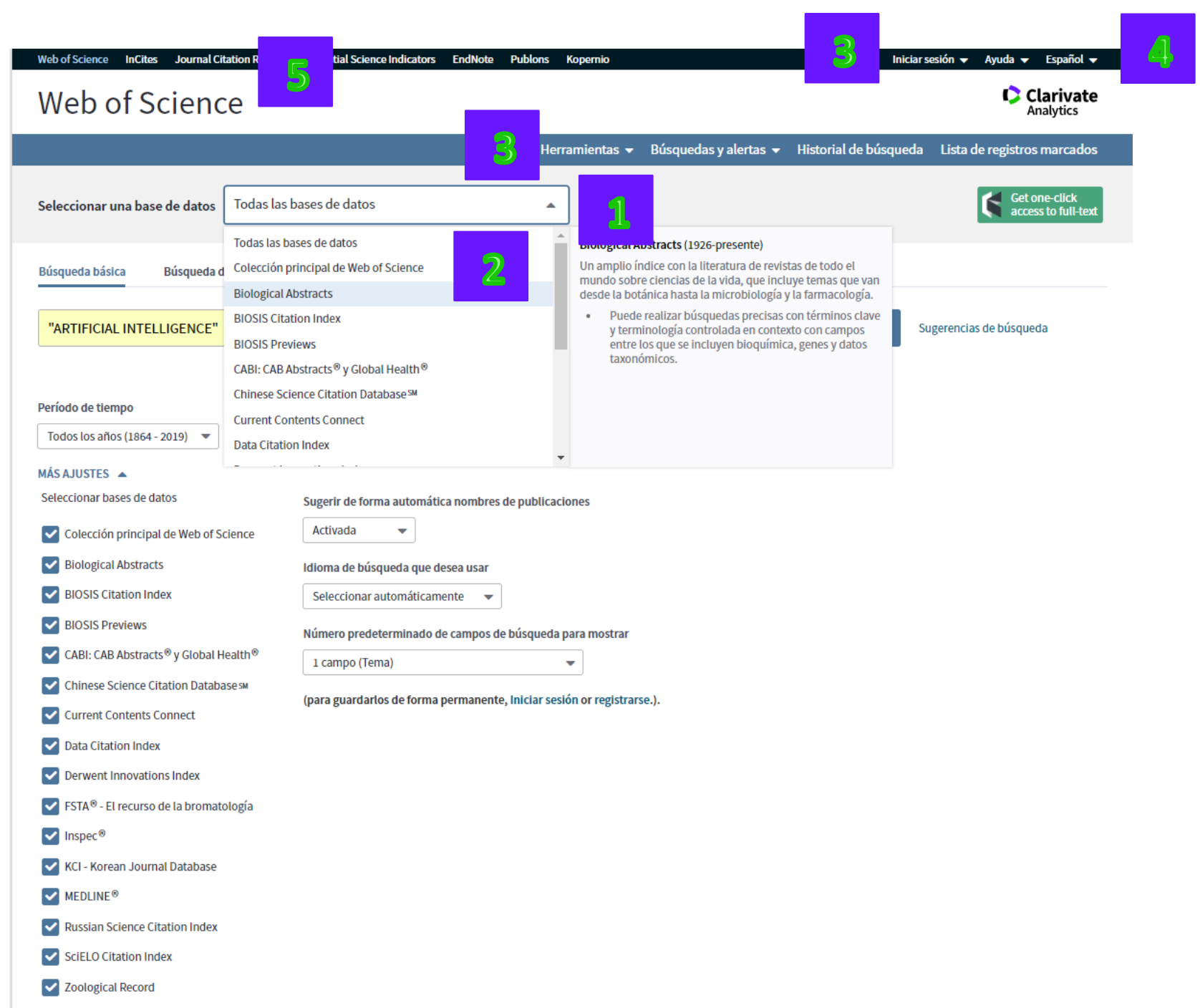

1. Utilice la búsqueda 'Todas las bases de datos' para hacer una búsqueda simultánea de todos los productos de Web of Science contratados.

2. Utilice 'Colección Principal de Web of Science' para buscar en los índices de citas tradicionales de la Web of Science Colección Principal.

3. Haga clic en 'Iniciar Sesión' y/o 'Mis Herramientas' para guardar sus búsquedas, crear alertas de citas y de consultas, acceder a su perfil de Researcher ID o acceder al gestor de referencias Endnote versión de la web.

4. Seleccione en la parte superior el idioma de la interfaz (inglés, español, portugués, china, japonés) 
5. Lanza Incites Journal Citation Reports e Incites Essential Science Indicators en la parte superior.

6. Con respecto a la búsqueda Todas las Bases de Datos, es posible personalizar las bases incluidas en la búsqueda. Marque las casillas de verificación de las bases que deseas incluir en la búsqueda.

\section{Web of Science Colección Principal: Página de Búsqueda}

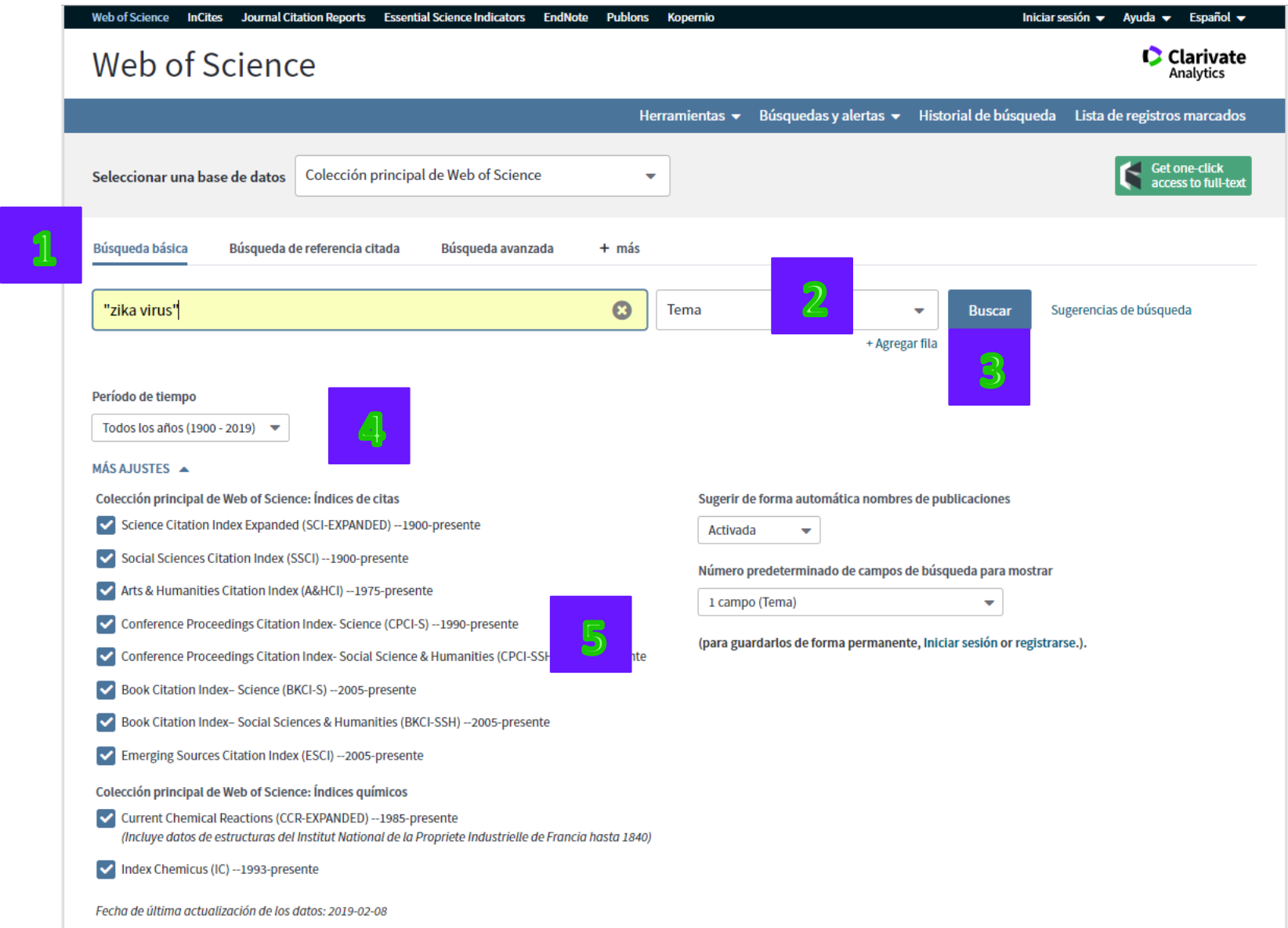

1. De primera decisión, es obligatorio seleccionar el tipo de búsqueda que se desea realizar entre las opciones siguientes; una búsqueda básica, una búsqueda de Referencia Citada, una búsqueda Avanzada, una búsqueda de autores y una búsqueda de estructura.

2. De segunda decisión, es necesario seleccionar el campo de búsqueda en el menú desplegable. Para ver más ejemplos de búsqueda y las reglas visite el índice de soporte.

3. Puede añadir más campos de búsqueda en la página haciendo clic en el enlace 'Agregar otro campo'

4. Período de tiempo. Selecciona los años/fechas para incluir en la búsqueda. El período de búsqueda corresponde al año de publicación de la revista. La Web of Science Colección Principal actualiza cada día (menos el fin de semana). Puede visualizar la última fecha de actualización en la parte inferior de la sección 'Mas ajustes'. 


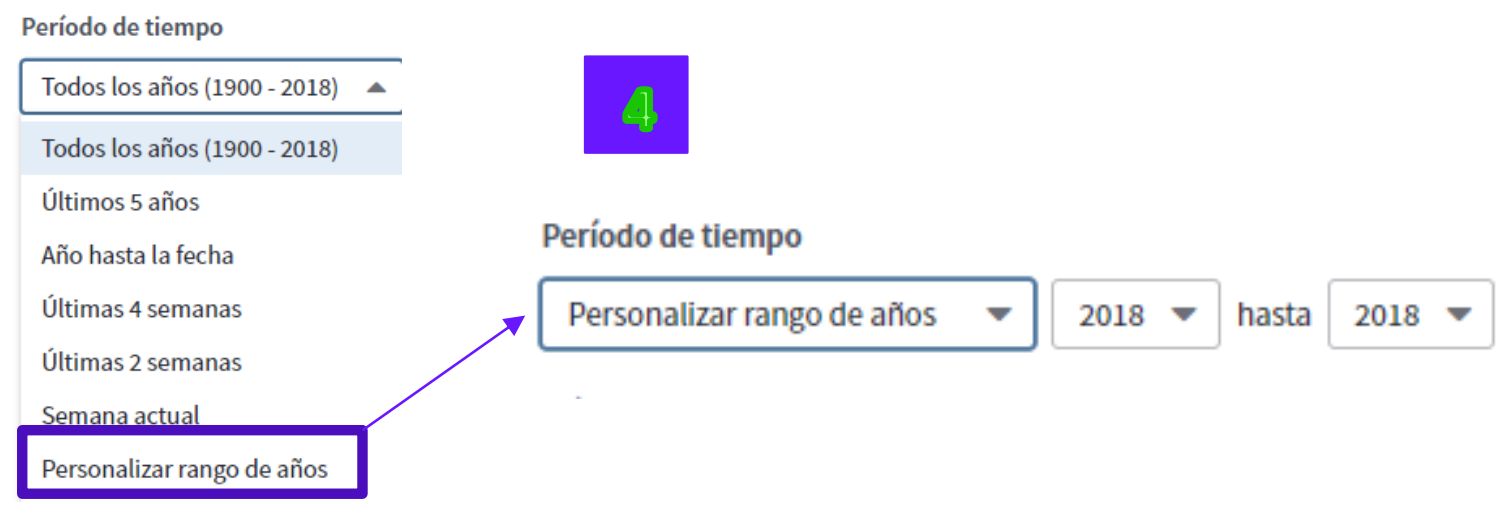

5. Índices de citas. Puede seleccionar aquí los índices de citas para incluir en la búsqueda.

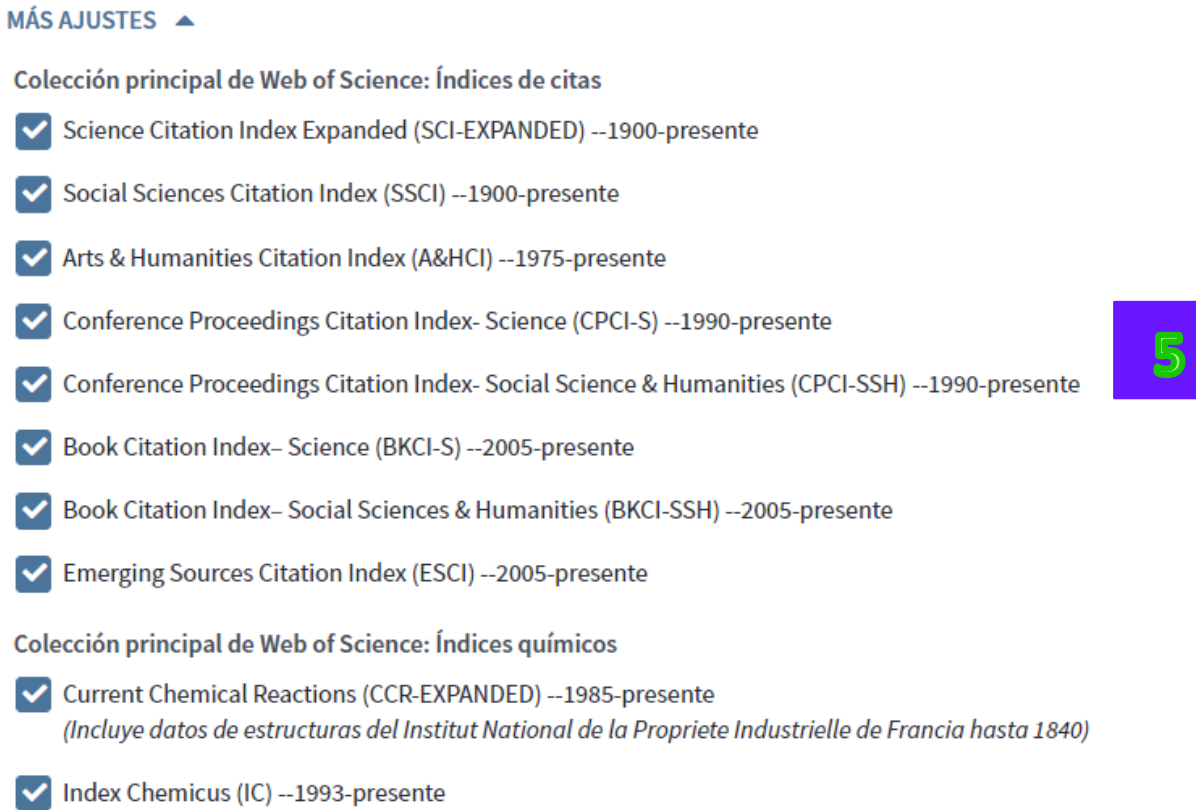

Fecha de última actualización de los datos: 2018-10-24

6. Configuración de la página de búsqueda. Selecciona aquí para activar o desactivar la herramienta que muestra sugerencias de los títulos de las revistas/publicaciones. Y selecciona el número determinado de campos de búsqueda para mostrar. Para guardar los cambios de forma permanente hay que iniciar una sesión o registrarse.

Sugerir de forma automática nombres de publicaciones

Activada $\quad \nabla$

Número predeterminado de campos de búsqueda para mostrar

\begin{tabular}{|l|}
\hline 1 campo (Tema) \\
\hline 1 campo (Tema) \\
3 campos (Tema, Autor, Nombre de publicación)
\end{tabular}




\section{Campos de Búsqueda en la Colección Principal Web of Science}

\begin{tabular}{|c|c|c|}
\hline \multicolumn{2}{|l|}{$\begin{array}{l}\text { Campo de } \\
\text { Búsqueda }\end{array}$} & Índice \\
\hline Topic (tema) & $\begin{array}{l}\text { Recupera sus términos de búsqueda en: } \\
\text { - Título } \\
\text { - Abstract } \\
\text { - Palabras clave de autor } \\
\text { Introduce los términos de búsqueda en } \\
\text { cualquier orden. Las siguientes } \\
\text { búsquedas son equivalentes: } \\
\text { Para buscar una frase exacta, use } \\
\text { comillas. Ejemplo: "radioactive decay" }\end{array}$ & ¿Quiso decir? \\
\hline Title (título) & $\begin{array}{l}\text { Recupera sus términos de búsqueda en } \\
\text { los títulos de los registros únicamente }\end{array}$ & ¿Quiso decir? \\
\hline Author (autor) & $\begin{array}{l}\text { Introduce el apellido y hasta } 5 \text { iniciales o } \\
\text { el nombre completo (apellido seguido } \\
\text { por primer nombre) del autor de interés. } \\
\text { También introduce variaciones posibles. }\end{array}$ & $\begin{array}{l}\text { Búsqueda de autores } \\
\text { Índice de autores }\end{array}$ \\
\hline $\begin{array}{l}\text { Autor Identifier } \\
\text { (Identificadores de } \\
\text { autores) }\end{array}$ & $\begin{array}{l}\text { Introduce identificador: } \\
\text { RID ej. B-6117-2008 o el identificador de } \\
\text { ORCID 0000-0003-4722-491X }\end{array}$ & $\begin{array}{l}\text { www.researcherid.com } \\
\text { www.orcid.org }\end{array}$ \\
\hline $\begin{array}{l}\text { Group Author } \\
\text { (Autoria conjunta) }\end{array}$ & $\begin{array}{l}\text { Introduce el título de la autoría colectiva } \\
\text { Ej. 'HUMAN GENOME ORG ETHICS COMM' } \\
\text { Introduce el nombre completo o } \\
\text { nombre parcial utilizando los comodines } \\
\text { (wildcards: * ? \$).. }\end{array}$ & Si \\
\hline Editor (editor) & Goldman A & \\
\hline $\begin{array}{l}\text { Publication Name } \\
\text { (título de la } \\
\text { publicación) }\end{array}$ & $\begin{array}{l}\text { Introduce título completo de la revista. } \\
\text { Ej. revista española de cardiología }\end{array}$ & $\begin{array}{l}\text { Índice de publicaciones } \\
\text { Auto sugerencia }\end{array}$ \\
\hline DOI & $\begin{array}{l}\text { Identificador del objeto digital } \\
10.1038 / \text { nature } 09798\end{array}$ & \\
\hline $\begin{array}{l}\text { Year Published } \\
\text { (año de } \\
\text { publicación) }\end{array}$ & $\begin{array}{l}\text { Introduce un año o rango de años. } \\
\text { Máximo rango de años limitado a } 10 \\
\text { años. }\end{array}$ & \\
\hline
\end{tabular}




\begin{tabular}{|c|c|c|}
\hline $\begin{array}{l}\text { Address } \\
\text { (Dirección) }\end{array}$ & $\begin{array}{l}\text { Introduce la dirección de interés. Se } \\
\text { puede introducir una institución, } \\
\text { departamento, código postal, ciudad, } \\
\text { región o país. } \\
\text { Introduce el nombre completo o parcial } \\
\text { de una institución o ubicación de la } \\
\text { dirección de un autor. Por } \\
\text { ejemplo, Univ y University busca } \\
\text { instituciones en las que el término } \\
\text { "Univ" aparece en el campo Dirección de } \\
\text { un registro. ingrese } \\
\text { Cuando nombres } \\
\text { completos, no use artículos (a, an, the) ni } \\
\text { preposiciones (of, in, for) en el nombre. } \\
\text { Por ejemplo, la búsqueda de UNIV } \\
\text { Pennsylvania es correcta, pero si } \\
\text { introduce University of Pennsylvania, } \\
\text { aparecerá un mensaje de error. } \\
\text { Tenga en cuenta que los términos de } \\
\text { direcciones habituales pueden estar } \\
\text { abreviados en la base de datos del } \\
\text { producto. Por ejemplo, la palabra } \\
\text { Department puede estar abreviada } \\
\text { como Depto Dep. }\end{array}$ & $\begin{array}{l}\text { Consulta la sección } \\
\text { 'Abreviaturas de } \\
\text { direcciones' } \\
\text { en el archivo de soporte }\end{array}$ \\
\hline $\begin{array}{l}\text { Organización } \\
\text { Enhanced } \\
\text { (Organización- } \\
\text { nombre preferido) }\end{array}$ & $\begin{array}{l}\text { Buscar una organización por su nombre } \\
\text { mejorado. Consulte el índice para } \\
\text { examinar el listado de organizaciones } \\
\text { incluidas en este proyecto. } \\
\text { Busca variantes en las direcciones de las } \\
\text { organizaciones unificadas a un nombre } \\
\text { único. Web of Science Group unifica las } \\
\text { variantes de las organizaciones a un } \\
\text { nombre principal. }\end{array}$ & $\begin{array}{l}\text { Consulte la lista de } \\
\text { nombres mejoradas }\end{array}$ \\
\hline $\begin{array}{l}\text { Conference } \\
\text { (conferencia) }\end{array}$ & $\begin{array}{l}\text { El campo Conferencia le permite buscar } \\
\text { en los siguientes campos de un registro } \\
\text { de documentos de actas de conferencia. } \\
\text { - Título de la conferencia } \\
\text { - Ubicación de la conferencia } \\
\text { - Fecha de la conferencia } \\
\text { - Patrocinador de la conferencia }\end{array}$ & \\
\hline
\end{tabular}




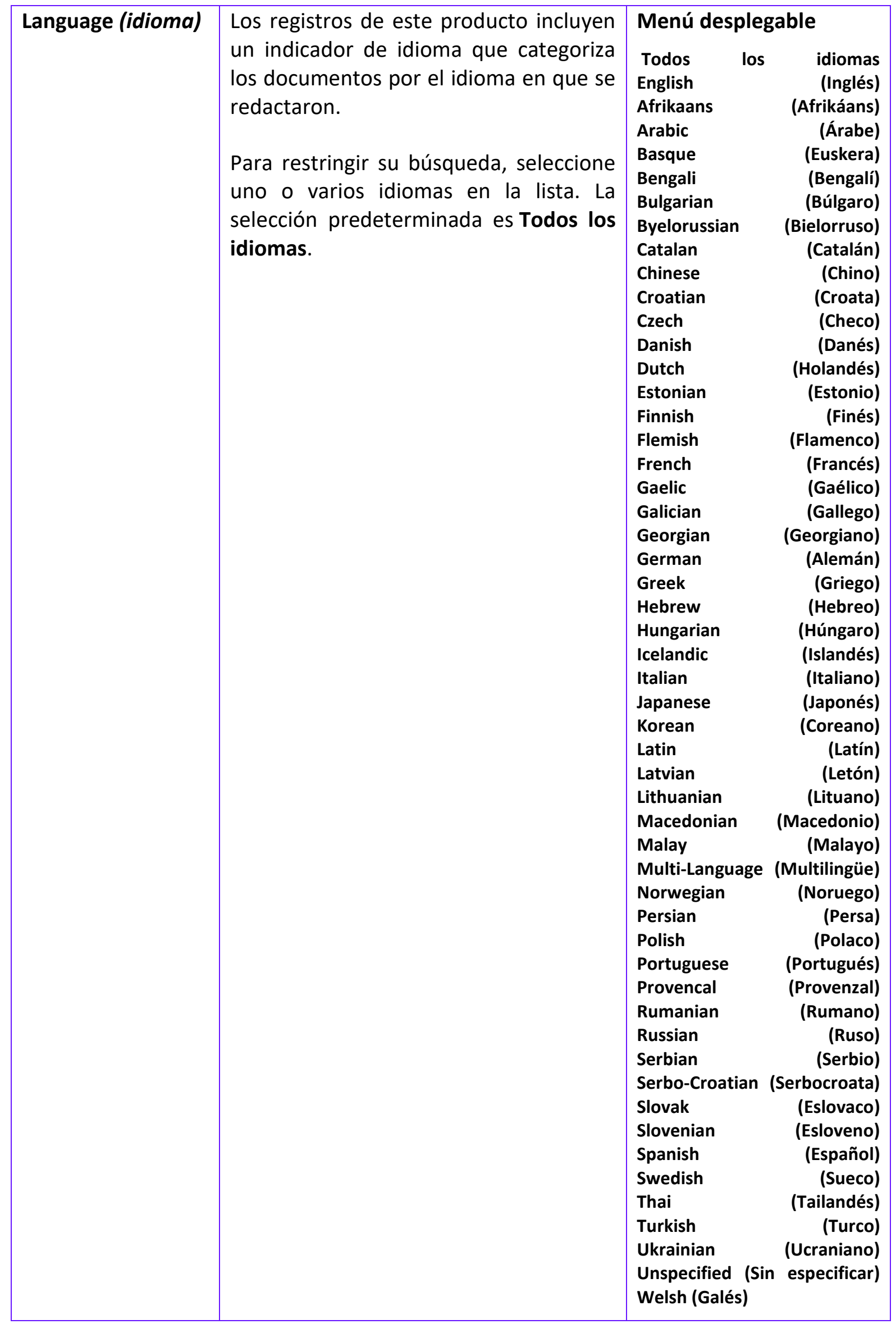




\begin{tabular}{|c|c|c|}
\hline $\begin{array}{l}\text { Document Type } \\
\text { (tipo de } \\
\text { documento) }\end{array}$ & $\begin{array}{l}\text { Seleccione un tipo de documento del } \\
\text { listado de tipos disponibles. } \\
\text { Automáticamente todos los tipos de } \\
\text { documentos están seleccionados. Se } \\
\text { puede seleccionar más de un tipo de } \\
\text { documento a la vez. }\end{array}$ & Menú desplegable \\
\hline $\begin{array}{l}\text { Funding Agency } \\
\text { (Entidad } \\
\text { financiadora) }\end{array}$ & $\begin{array}{l}\text { Ingrese el nombre de una entidad } \\
\text { financiadora para buscar en el campo } \\
\text { Entidad financiadora de la tabla } \\
\text { Reconocimiento de financiación de un } \\
\text { registro. } \\
\text { Ej. 'comunidad madrid'. } \\
\text { Para artículos indexados en } 2008 \text { y } \\
\text { adelante. } \\
\text { En 2016, la Colección principal de Web of } \\
\text { Science Web of Science empezó a } \\
\text { complementar la información de } \\
\text { concesión con números y agencias de } \\
\text { concesión desde MEDLINE y } \\
\text { researchfish }{ }^{\circledR} \text {. Los registros que ya } \\
\text { incluyen información de concesión no se } \\
\text { modificarán. Los registros que no } \\
\text { incluían información de concesión se } \\
\text { actualizaron con información de } \\
\text { concesión procedente de MEDLINE y } \\
\text { researchfish }{ }^{\circledR} \text {. }\end{array}$ & \\
\hline $\begin{array}{l}\text { Grant Number } \\
\text { (Numero de } \\
\text { subvención) }\end{array}$ & $\begin{array}{l}\text { Introduce número de a subvención. Ej. } \\
\text { F30602-00-2-0620. Para artículos } \\
\text { indexados en } 2008 \text { y adelante }\end{array}$ & \\
\hline ID de Pubmed & $\begin{array}{l}\text { Identificador de Pubmed } \\
\text { Ej. PMID: } \mathbf{2 5 3 5 0 9 8 4}\end{array}$ & \\
\hline
\end{tabular}




\section{Búsqueda Básica}

Los campos bibliográficos que se buscan en una búsqueda por temas son:

$\begin{array}{llll}\text { Palabras de los títulos } & \begin{array}{l}\text { SCIE } \\ \text { Todos los } \\ \text { años }\end{array} & \begin{array}{l}\text { SSCI } \\ \text { Todos los } \\ \text { años }\end{array} & \begin{array}{l}\text { AHCI } \\ \text { Todos los } \\ \text { años }\end{array} \\ \text { Palabras clave } & 1991 \rightarrow & 1991 \rightarrow & 1991 \rightarrow \\ \text { KeyWords Plus } & 1991 \rightarrow & 1991 \rightarrow & 1991 \rightarrow \\ \text { Resumen de autor } & 1991 \rightarrow & 1992 \rightarrow & 2000 \rightarrow\end{array}$

Para buscar artículos que se tratan del tema 'olive oil' e incluyen por lo menos una dirección española en las direcciones, hace falta combinar la búsqueda por tema con la búsqueda por una dirección.

\section{Tema= "olive oil" \\ Dirección = spain}

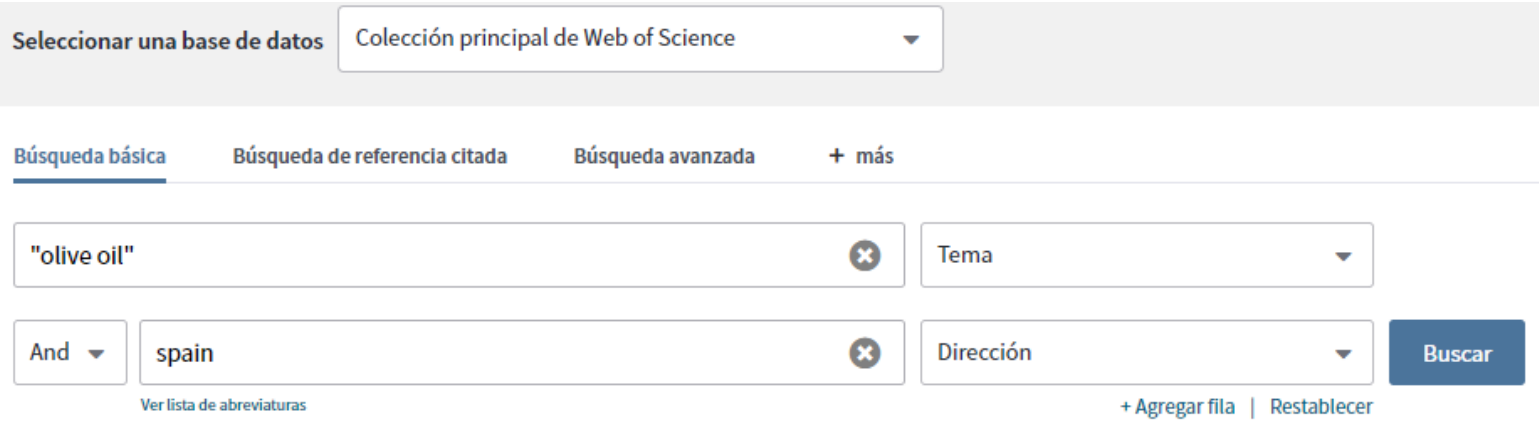

Período de tiempo

Todos los años (1900 - 2019) $\quad$ V

1. Consulte la sección "Reglas de búsqueda" para leer una explicación sobre los operadores booleanos, símbolos de truncamiento y otras reglas de búsqueda en la Colección Principal de Web of Science. O consulte el archivo de soporte (Help file) en el producto.

2. Para limitar la búsqueda de términos solamente a los títulos del registro, seleccione la búsqueda 'título'.

3. Es posible limitar la búsqueda a uno o más idiomas y/o otros tipos de documentos seleccionando los idiomas / tipos de documentos de interés del menú desplegable a la derecha. Todos los títulos que no estén en inglés se traducen al inglés estadounidense.

4. Las búsquedas se introducen en inglés.

5. Haga clic en Buscar para ejecutar su búsqueda.

6. El registro recupero coincide con la búsqueda: incluye 'olive oil' por lo menos en el título, resumen y las palabras claves. E incluye por lo menos una dirección española. 
Quality assessment of olive oils based on temperature-ramped HS-GC-IMS and sensory evaluation: Comparison of different processing approaches by LDA, kNN, and SVM

Por: Gerhardt, N (Gerhardt, Natalie) ${ }^{[1]}$; Schwolow, S (Schwolow, Sebastian) ${ }^{[1]}$; Rohn, S (Rohn, Sascha) ${ }^{[2]}$; Perez-Cacho, PR (Ruiz Perez-Cacho, Pilar) ${ }^{[3]}$ Galan-Soldevilla, H (Galan-Soldevilla, Hortensia) ${ }^{\left[{ }^{[3]}\right.}$; Arce, L (Arce, Lourdes) ${ }^{[4]}$; Weller, P (Weller, Philipp) ${ }^{[1]}$ Ocultar ResearcherID y ORCID

\begin{tabular}{|l|l|l|}
\hline Autor & ResearcherlD & Número ORCID \\
\hline Ruiz Perez-Cacho, Pilar & $0-4537-2018$ & http://orcid.org/0000-0001-9697-2821 \\
\hline ARCE, LOURDES & & http://orcid.org/0000-0002-7130-8446 \\
\hline
\end{tabular}

FOOD CHEMISTRY

Volumen: 278 Páginas: $720-728$

DOl: $10.1016 /$ J.foodchem.2018.11.095

Fecha de publicación: APR 252019

Tipo de documento: Articl

Ver impacto de la revista

Abstract

For the first time, this study describes a HS-GC-IMS strategy for analyzing non-targeted volatile organic compounds (VOCs) profiles to distinguish between virgin olive oils of different classification. Correlations among measured flavor characteristics and sensorv attributes evaluated by a test panel were determined by applying unsupervised (PCA, HCA) and supervised (LDA, kNN and SVM) chemor stric techniques. PCA nd HCA were applied for natura clustering of the samples and cons investigated samples, LDA, kNN, and SVM models correctly classified $83.3 \%, 73.8 \%$, and $88.1 \%$ of the samples, respectively.

This suggests that mathematical correlations of HS-GC-IMS $3 \mathrm{D}$ fingerprints with the sensory analysis may be appropriate for calculating a good predictive value to classify virgin olive oils.

\section{Palabras clave}

Palabras clave de autor: Olive oils; Ion mobility; Chemometry; Classification; VOC profiling; Gas chromatography; PCA; LDA

KeyWords Plus: ION-MOBILITY SPECTROMETRY; SOLID-PHASE MICROEXTRACTION; VOLATILE COMPOUNDS; HEADSPACE; CLASSIFICATION; EXTRACTION; ODORANTS; TONGUE; NOSE; TIME

\section{Información del autor}

Dirección para petición de copias: Weller, $\mathrm{P}$ (autor para petición de copias)

Mannheim Univ Appl Sci, Inst Instrumental Analyt \& Bioanal, D-68163 Mannheim, Germany. Direcciones:

[1] Mannheim Univ Appl Sci, Inst Instrumental Analyt \& Bioanal, D-68163 Mannheim, Germany

+ [2] Univ Hamburg, Hamburg Sch Food Sci, Inst Food Chem, D-20146 Hamburg, Germany

- [3] Univ Cordoba, Dept Bromatol \& Tecnol Alimentos, Lab Estudios Sensoriales, GrupoSens, Campus Rabanales, Cordd a 14070, Spain Nombres mejorados para organizaciones

Universidad de Cordoba

- [4] Univ Cordoba, Dept Analyt Chem, Inst Fine Chem \& Nanochem, Campus Rabanales, Marie Curie Annex Bldg, E-1407, Nombres mejorados para organizaciones Universidad de Cordoba

Direcciones de correo electrónico: p.weller@hs-mannheim.de
Red de citas

En Colección principal de Web of Science

Veces citado

Crear alerta de cita

\section{9}

Referencias citadas

Ver Related Records

Utilizar en Web of Science En Web of Science Conteo de uso

73

73

Últimos 180 días Desde 2013

Más información

Este registro es de: Colección principal de Web of Science Science Citation Index Expanded

Sugerir una corrección

Si quiere mejorar la calidad de los datos de este registro, sugiera una corrección. 


\section{Normas de la Búsqueda Básica}

\section{Comodines}

Los comodines se pueden usar en todos los campos de búsqueda que permitan palabras y frases. Se pueden usar en una consulta de búsqueda para representar caracteres desconocidos. Solo son válidos en consultas de búsqueda en inglés.

1. El asterisco $\left({ }^{*}\right)$ representa cualquier grupo de caracteres, incluida la ausencia de caracteres.

2. El signo de interrogación (?) representa cualquier carácter único.

3. El signo del dólar (\$) representa la presencia de un carácter o la ausencia de caracteres.

\section{Truncamiento (*)}

- Truncamiento izquierdo (*saccharide) le permite recuperar variaciones a mano izquierda de un termino

- Truncamiento derecho (enzy*) le permite recuperar variaciones a mano derecha de un termino

$$
\begin{aligned}
& \text { ? = un carácter solamente } \\
& * \text { = cero o más caracteres } \\
& \$=\text { cero o un carácter }
\end{aligned}
$$

\begin{tabular}{|c|c|c|c|}
\hline \multicolumn{2}{|c|}{ Truncamiento derecho/izquierdo } & \multicolumn{2}{|c|}{ Truncamiento interno (Comodines) } \\
\hline symptom* & $\begin{array}{l}\text { symptom } \\
\text { symptoms } \\
\text { symptomatic }\end{array}$ & lap*roscop* & $\begin{array}{l}\text { laparoscopic } \\
\text { laproscopic } \\
\text { laparoscopy }\end{array}$ \\
\hline gene* & $\begin{array}{l}\text { gene } \\
\text { genes } \\
\text { general } \\
\text { generation }\end{array}$ & dosto?evsk* & $\begin{array}{l}\text { dostoyevsky } \\
\text { dostoievsky } \\
\text { dostoievski } \\
\text { dostoyevskii }\end{array}$ \\
\hline cell\$ & $\begin{array}{l}\text { cell } \\
\text { cells } \\
\text { cello }\end{array}$ & behavio $\$ r^{*}$ & $\begin{array}{l}\text { behavior } \\
\text { behaviour } \\
\text { behavioral }\end{array}$ \\
\hline *saccharide & $\begin{array}{l}\text { polysaccharide } \\
\text { monosaccharide }\end{array}$ & & \\
\hline
\end{tabular}




\section{Comodines, guiones y apóstrofes}

El motor de búsqueda trata los guiones (-) y los apóstrofes (') de los nombres como espacios. Por ejemplo:

$\mathbf{A U}=\mathbf{O}$ Brien devuelve el mismo número de resultados que $\mathbf{A U}=\mathbf{0}$ 'Brien.

Intente buscar nombres con o sin espacio. Por ejemplo, $\mathrm{AU}=\mathrm{OB}$ rien $\mathrm{OR} \mathbf{A U}=\mathbf{0}$

Brien devuelve las dos variantes del nombre.

Al buscar términos de consulta con guiones, ingrese el término con y sin comodines. Por ejemplo:

TS=hydro-power devuelve registros que contienen los términos "hydro-power" y "hydro power".

TS=hydro*power devuelve resultados que contienen los términos "hydropower" $\mathrm{y}$ "hydroelectricpower".

TS=hydro power devuelve registros que contienen los términos "hydro" y "power" en cualquier posición en el registro, como "hydro-power", "hydro-electrical power" y "hydromechanical power

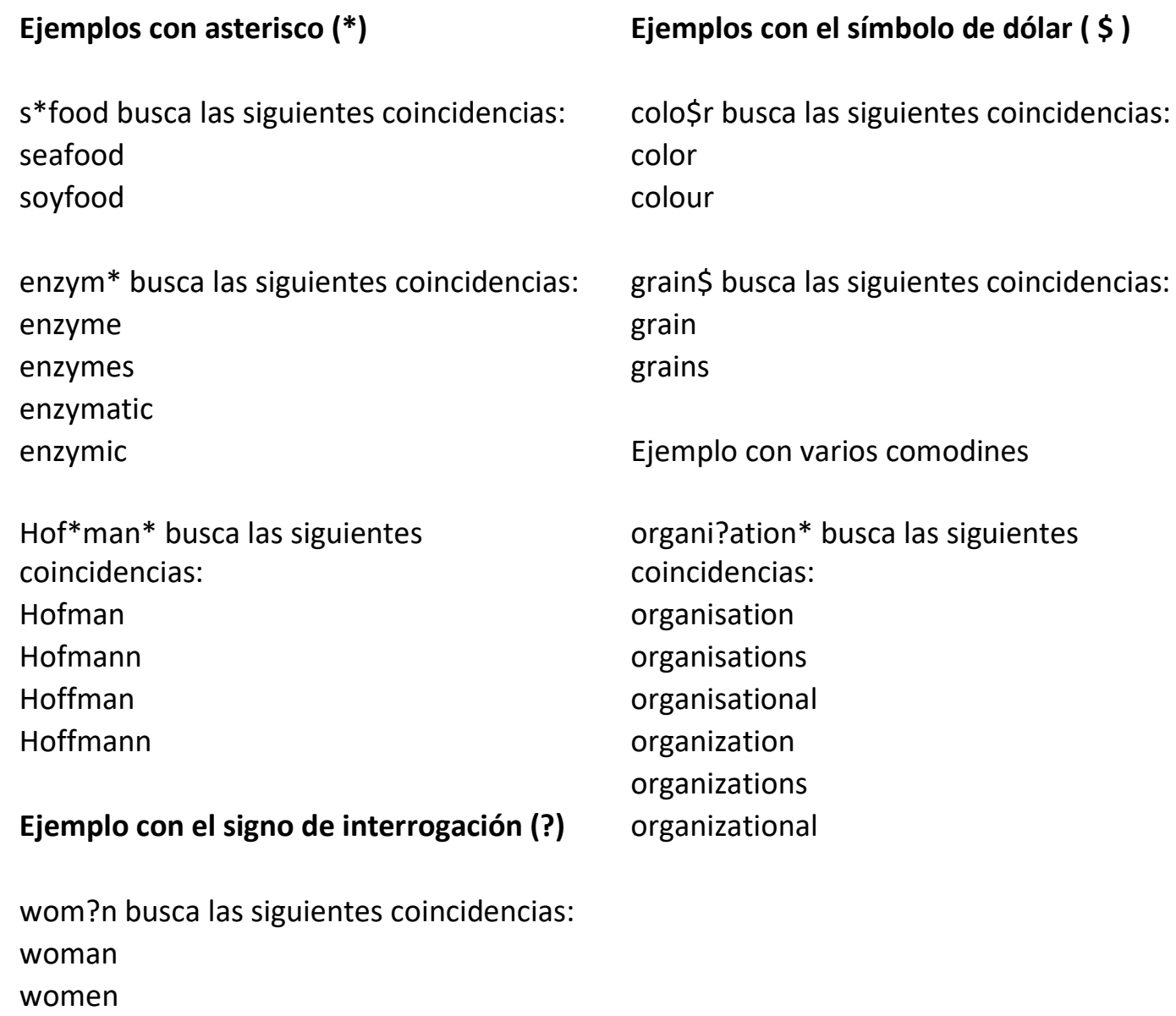




\section{Operadores Booleanos}

Puede usar hasta 49 operadores booleanos en una única consulta de búsqueda. No puede usar más de 49 operadores en una consulta en un único campo o entre campos de la página de búsqueda. Los operadores implícitos no cuentan.

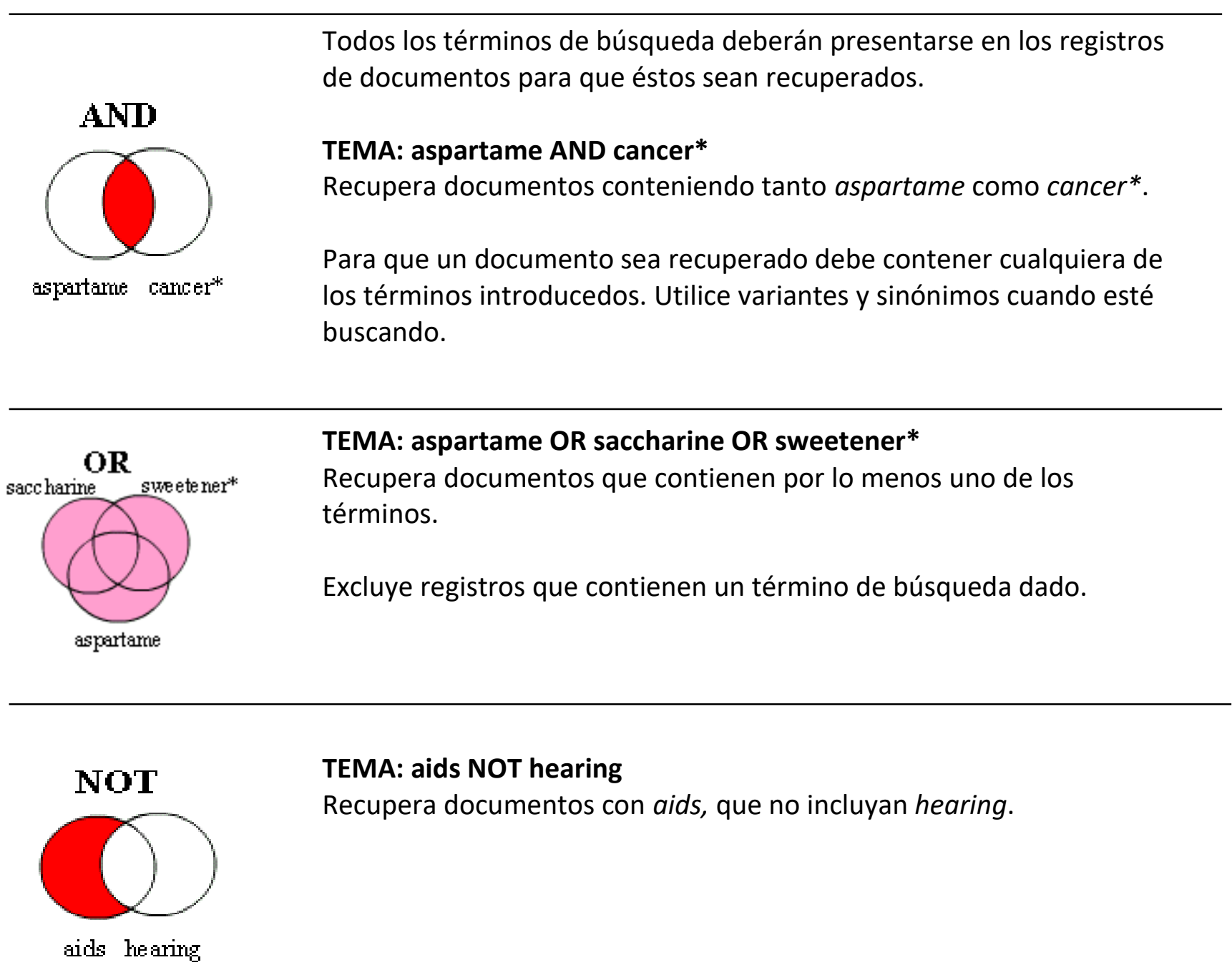

Todos los términos de búsqueda deberán presentarse en los registros

TEMA: aspartame AND cancer

Para que un documento sea recuperado debe contener cualquiera de los términos introducedos. Utilice variantes y sinónimos cuando esté buscando.

TEMA: aspartame OR saccharine OR sweetener* términos.

Excluye registros que contienen un término de búsqueda dado.

Para determinar la proximidad de un término a otro.

NEAR/ $x$

\section{TEMA "climate change" NEAR/5 desertification}

Para recuperar documentos en los que el término "climate change" aparece muy próximo al término 'desertification' con un máximo de 5 palabras separando los dos términos en títulos, abstract y palabras clave 


\section{La Lematización}

1. La lematización facilita la recuperación automática de variaciones de los términos introducidos.

Consiste de un diccionario propietario de términos que optimizan la búsqueda. El diccionario incluye variantes según los temas siguientes:

- tiempos de verbos (run, runs, running, ran)

- la palabra en forma singular y en forma plural (mouse y mice)

- grados de comparación (loud, louder, loudest)

- la palabra en inglés británica o en inglés americana y mucho más.

2. Automáticamente está activada 'on' pero si hace falta recuperar resultados más precisos a los términos introducidos hace falta encerrar el término de búsqueda entre las comillas.

"behaviour" busca behaviour pero no behavior

Más ejemplos

- defense recupera defense y defence

- immunize recupera immunise y immunize

- color recupera color y colour

3. Para recuperar la palabra exacta hace falta encerrarla entre las comillas por ejemplo "mouse". Cuando se encierre un término entre las comillas desactiva la lematización (OFF). 


\section{¿Quiso Decir?}

Las bases de datos de la Web of Science Colección Principal incluyen ahora un corrector ortográfico que permite comparar sus consultas con ortografías comunes y sus variantes para determinar si existe una ortografía alternativa que pueda mejorar sus resultados de búsqueda.

Si existe una ortografía alternativa, aparecerá un cuadro de texto ¿Quiso decir? sobre su consulta ofreciéndole una consulta alternativa. La herramienta comprueba términos completos, no términos truncados o con comillas. Para no corregir su término hace falta encerrarla entre las comillas " “

La herramienta ¿Quiso decir? usa un diccionario personalizado de términos y palabras clave de uso frecuente en la Colección Principal de Web of Science para ofrecer sugerencias relacionadas con el campo en el que está buscando actualmente.

Web of Science $\quad$ sclarivate Herramientas - Búsquedas y alertas - Historial de búsqueda Lista de registros marcados

Seleccionar una base de datos Colección principal de Web of Science

$\checkmark$

Búsqueda básica Búsqueda de referencia citada Búsqueda avanzada + más 


\section{Búsqueda por una Frase y los Operadores de Proximidad}

\begin{tabular}{|c|c|}
\hline $\begin{array}{l}\text { Búsqueda por una } \\
\text { frase }\end{array}$ & $\begin{array}{l}\text { Automáticamente el motor de búsqueda implica el operador 'AND' entre } \\
\text { los términos introducidos. No es necesario introducir 'AND' entre todos } \\
\text { los términos para que todos estén recuperados. Una búsqueda con } \\
\text { varios términos recupera registros que contienen todos los términos en } \\
\text { los campos de los títulos, resúmenes o campos de palabras clave. Para } \\
\text { recuperar la frase o palabra compuesta exacta es necesario encerrar la } \\
\text { misma en comillas (“"). } \\
\text { Para buscar una frase exacta, escriba la frase entre comillas. Por ejemplo, } \\
\text { la consulta "energy conservation" recuperará registros que contengan la } \\
\text { frase exacta energy conservation. Esto se aplica solo a las búsquedas por } \\
\text { tema y título. } \\
\text { Si introduce una frase sin comillas, el motor de búsqueda recuperará } \\
\text { registros que contengan todas las palabras que ingresó. Las palabras } \\
\text { pueden o no aparecer juntas. Por ejemplo, energy conservation recupera } \\
\text { registros que incluyen la frase exacta energy conservation. También } \\
\text { buscará registros que incluyan la frase conservation of energy. } \\
\text { Si introduce dos palabras separadas por un guión, un punto o una coma, } \\
\text { el término se interpretará como una frase exacta. Por ejemplo, el } \\
\text { término de búsqueda waste-water buscará registros que contengan la } \\
\text { frase exacta waste-water o la frase waste water. No buscará } \\
\text { coincidencias con water waste, waste in drinking water o water extracted } \\
\text { from waste. } \\
\text { Puede usar comodines en una consulta de búsqueda de frase exacta. Por } \\
\text { ejemplo, "energy conserv*" coincide con energy conservation, al mismo } \\
\text { tiempo que con energy conserving. No coincide con conservation of } \\
\text { energy. La búsqueda "m\$croeconomic theory" coincide } \\
\text { con macroeconomic theory y con microeconomic theory. No coincide } \\
\text { con pricing theory using macroeconomic variables ni con microeconomic } \\
\text { problems studied by portfolio theory. } \\
\text { comillas. }\end{array}$ \\
\hline
\end{tabular}




\begin{tabular}{|c|c|}
\hline $\begin{array}{l}\text { Same } \\
\text { (Operador de } \\
\text { proximidad) }\end{array}$ & $\begin{array}{l}\text { En las búsquedas de direcciones, use el operador SAME para } \\
\text { restringir su búsqueda a términos que aparezcan en la misma } \\
\text { dirección en un registro completo. Use paréntesis para agrupar sus } \\
\text { términos de direcciones. Por ejemplo: } \\
\text { AD=(McGill Univ SAME Quebec SAME Canada) busca registros en los } \\
\text { que McGill University aparece en el campo Direcciones de un registro } \\
\text { completo junto con "Quebec" y "Canada". } \\
\text { AD=(Portland SAME Oregon) busca registros en los que "Portland", } \\
\text { "Oregon" u "OR" (abreviatura del estado) aparecen en el campo } \\
\text { Direcciones de un registro. } \\
\text { Tenga en cuenta que el operador SAME funciona exactamente como } \\
\text { AND cuando se usa en otros campos (por ejemplo, en los campos } \\
\text { Tema y Título) y cuando los términos aparecen en el mismo registro. } \\
\text { Por ejemplo: } \\
\text { TS=(cat SAME mouse) devuelve los mismos resultados que TS=(cat } \\
\text { AND mouse). }\end{array}$ \\
\hline $\begin{array}{l}\text { NEAR } \\
\text { (operador de } \\
\text { proximidad ) }\end{array}$ & $\begin{array}{l}\text { Use NEAR/x para buscar registros en los que los términos unidos por } \\
\text { el operador aparezcan con una distancia entre ellos de un número } \\
\text { específico de palabras. } \\
\text { Reemplace la x por un número para especificar el número máximo de } \\
\text { palabras que separan los términos. } \\
\text { Si usa NEAR sin /x, el sistema encontrará registros en los que los } \\
\text { términos unidos por NEAR aparecen con una distancia de } 15 \text { palabras } \\
\text { entre ellos. Por ejemplo, estas búsquedas son equivalentes: } \\
\text { salmon NEAR virus } \\
\text { salmon NEAR/15 virus } \\
\text { Tenga en cuenta que... } \\
\text { No puede usar el operador AND en las consultas que incluyen el } \\
\text { operador NEAR. Por ejemplo, la siguiente consulta no es válida: } \\
\text { TS = (Germany NEAR/10 (monetary AND union)) } \\
\text { Sin embargo, el operador NEAR se puede utilizar para encontrar una } \\
\text { palabra o frase en X número de palabras de una frase. Las siguientes } \\
\text { consultas son válidas: } \\
\text { TS = (Germany NEAR/10 "monetary union") } \\
\text { TS = (Germany NEAR/10 (monetary NEAR/0 union)) } \\
\text { NEAR/0 determina que las palabras unidas por el operador deberían } \\
\text { ir juntas. } \\
\text { Cuando la palabra NEAR aparece en un título } \\
\text { Escriba siempre la palabra NEAR entre comillas (" ") cuando la palabra } \\
\text { aparezca en el título de un elemento fuente como, por ejemplo, una } \\
\text { revista, un libro, un acta u otro tipo de trabajo. Por ejemplo, la } \\
\text { siguiente consulta es válida: } \\
\text { Atomistic simulations of a solid/liquid interface: a combined force } \\
\text { field and first principles approach to the structure and dynamics of } \\
\text { acetonitrile "near" an anatase }\end{array}$ \\
\hline
\end{tabular}




\begin{tabular}{|l|l|}
\hline & $\begin{array}{l}\text { Si omite las comillas, el sistema devolverá el siguiente mensaje de } \\
\text { error: "Error de búsqueda: uso no válido del operador NEAR." }\end{array}$ \\
\hline
\end{tabular}




\section{Prioridad de los operadores de búsqueda}

Si usa diferentes operadores en su búsqueda, la búsqueda se procesará según este orden de prioridad:

1. NEAR/x

2. SAME

3. NOT

4. AND

5. OR

Use paréntesis para anular la prioridad de los operadores. Por ejemplo:

- influenza OR flu AND avian busca registros que incluyen la palabra influenza. También buscará registros que incluyan tanto flu como avian.

- (influenza OR flu) AND avian busca registros que incluyen tanto influenza como avian o ambas flu y avian.

Si introduce copper OR lead AND algae, obtendrá todos los registros en los que están presentes los términos "lead AND algae", así como todos los registros en los que aparece la palabra "copper".

Si introduce (copper OR lead) AND algae, obtendrá todos los registros en los que está presente la palabra "algae" junto con las palabras "copper" o "lead". 
Utilice paréntesis para reemplazar el orden de precedencia cuando use múltiples operadores booleanas y/o de proximidad. En una búsqueda pueden utilizarse hasta cincuenta operadores booleanas.

\section{Otras Normas de Búsqueda}

\section{Sinónimos}

Utilice sinónimos en las estrategias incluyendo lenguaje natural, siglas y jerga como posibles términos. Conecte los términos con el operador Booleano OR.

\section{Ejemplo: honey bee* OR honeybee* OR apis mellif*}

\section{Truncamiento}

Considere formas variantes de términos de búsqueda tales como plurales, distinta ortografía y términos derivados. Consulte la sección de la búsqueda general para más información sobre truncamientos y comodines.

Ejemplo: enzym*

Recupera enzyme, enzymes, enzymatic, enzymology

\section{Búsquedas de términos que contienen puntuación}

Se pueden reemplazar los signos de puntuación por espacios (aunque no es necesario). En los registros recuperados la puntuación aparecerá.

\section{Ejemplos:}

Introducer $\mathbf{2} \mathbf{4}$ dinitrotoluene recupera resultados que contienen el término 2,4dinitrotoluene

Introducer xray or $\mathbf{x}$ ray recupera $\mathbf{x}$-ray y xray

\section{Búsqueda de nombres propios}

Con excepción de los resúmenes, el resto de los campos pueden presentar los nombres propios tanto con el nombre primero y luego el apellido como viceversa (primero el apellido y luego el nombre). Por lo tanto es necesario utilizar el operador SAME para recuperar todas las variaciones:

\section{Ejemplo: Churchill SAME (winston o w*)}

\section{Búsqueda de términos que contienen letras griegas}

Escriba el nombre de la letra griega en inglés.

Ejemplo: beta carotene AND alpha omega recuperará:

Electroabsorption spectroscopy of $\boldsymbol{\beta}$-carotene and $\boldsymbol{\alpha}, \boldsymbol{\omega}$-bis(1,1-dimethylheptyl)$1,3,5,7,9,11,13,15$-hexadecaoctaene 
Resultados de una Búsqueda-Ordenar, Refinar y Analizar

Web of Science InCites Journal Citation Reports Essential Science Indicators EndNote Publons Kopemio $\quad$ Iniciar sesión - Ayuda - Español V

Web of Science

1 Clarivate

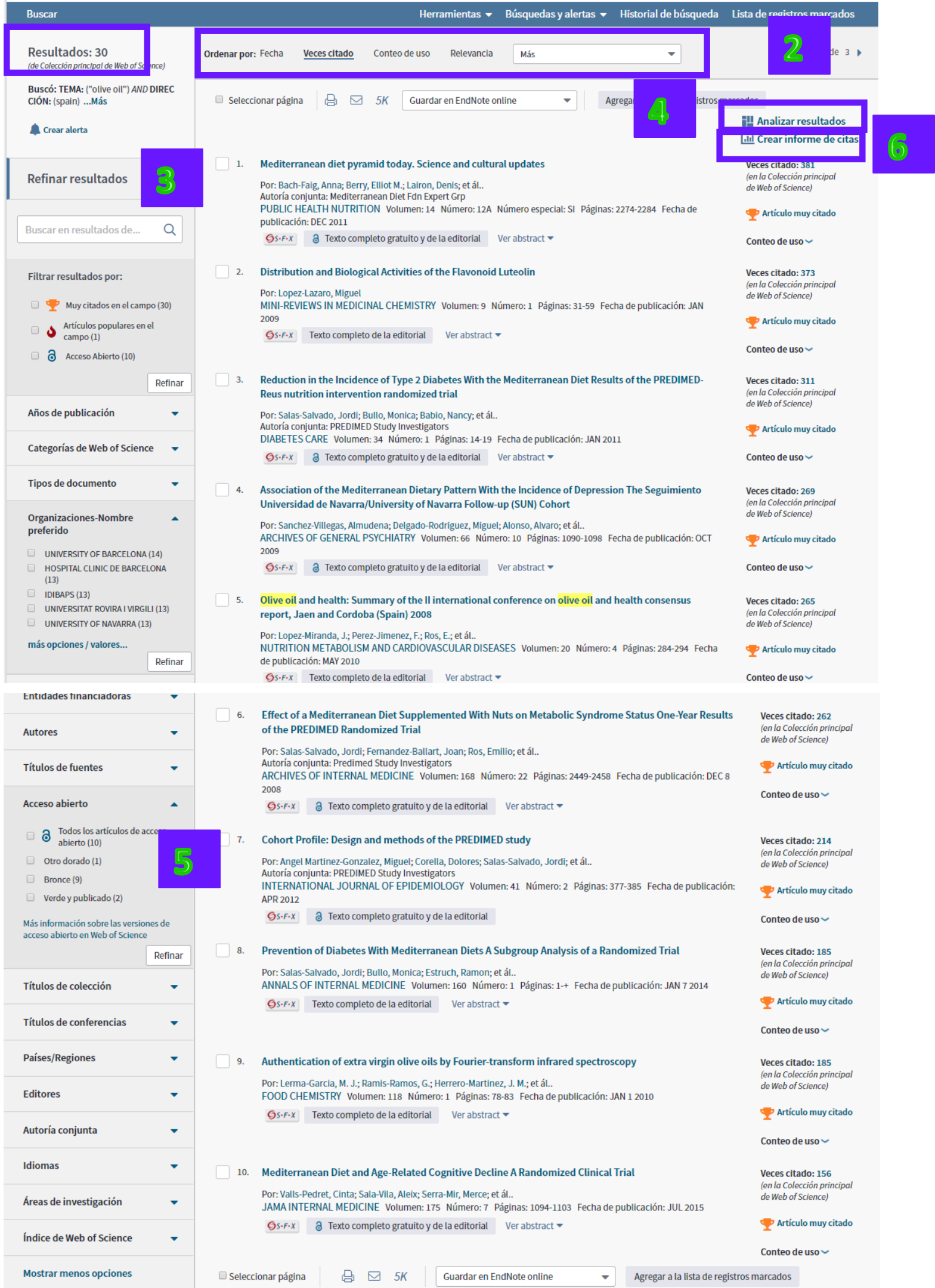


1. Aquí se observa el número total de registros que coinciden con sus términos de búsqueda. Se recupera todos los resultados que corresponden a la búsqueda.

2. Automáticamente los registros ordenan por la fecha de publicación (de lo más actual a lo más antigua). Los registros recuperados pueden ordenarse de distintas maneras según lo indica el menú desplegable. Nota que se pueden ordenar los registros por:

- Fecha de publicación- de lo más actual a lo más antiguo

- Fecha de publicación- de lo más antigua a lo más actual

- Fecha de indexación- de lo más actual a lo más antigua

- Fecha de indexación - de lo más antigua a lo más actual

- Las veces citado (de lo más citado a lo menos o de lo menos citado a lo más citado)

- Conteo de uso- últimos 180 días, de lo más alto a lo más bajo

- Conteo de uso- desde 2013, de lo más alto a lo más bajo

- Relevancia. Ordene los registros según la frecuencia de aparición de su término en el registro (título, abstracto o palabras clave).

- Primer autor por el orden a-z o z-a

- Título de la fuente (título de la publicación)

- Título de la conferencia

3. Utilice 'Refinar Resultados' para clasificar los resultados según varias áreas temáticas. También se puede realizar una búsqueda (por tema) dentro de la página de los resultados (buscar en los resultados) para concentrar la búsqueda original sin salir de los resultados.

Se puede refinar todos los resultados por:

- Trabajos altamente citados

- Trabajos populares

- Acceso abierto

- Datos asociados

- Años de publicación

- Categorías de la Web of Science

- Tipos de documento

- Organización nombre mejorado

- Entidad financiadora

- Autor

- Título de la fuente

- Acceso abierto (los niveles)

- Título de la colección

- Título de la conferencia

- País/región

- Editor

- Autoría conjunta

- Idiomas

- Áreas de investigación 
- Índice de la Web of Science Colección Principal

4. Utilice la herramienta 'Analizar' para realizar un análisis más completo sobre los resultados. Sus pasos en Analizar se guardan en su historial.

5. Acceso al Texto Completo. Se pueden configurar enlaces al texto completo para las revistas a que su institución se suscribe o conectar a los mecanismos de conexión a sus colecciones de biblioteca. Para apoyar la ciencia en abierto, Web of Science Group identifica textos completos abiertos en la página web de la editorial (dorado) y textos completos depositados en un repositorio (verde).

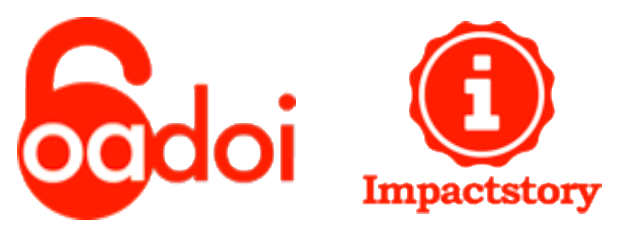

6. Para ver métricas de citas basadas en los resultados, ejecute el Informe de Citas (crear informe de citas) 


\section{Análisis de Resultados}

La herramienta 'Análisis de resultados' sirve para clasificar un conjunto de resultados de búsqueda según categorías como Autor, Organización, Organización-nombre preferido, Países/Territorios, Año de Publicación, Título Fuente, Tipo de Documento, Idioma, Categoría de la Web of Science y Agencias de Financiación.

Análisis de resultados le ayuda a detectar tendencias y patrones que no pueden identificarse de forma inmediata, pero que resultan cruciales para obtener una visión del conjunto de la investigación.

Con ella podrá analizar todos sus resultados sin verse limitado por el máximo de 100.000 registros, gracias a lo cual sabrá con exactitud quiénes con los autores más prestigiosos en su área de interés, así como las principales instituciones y las revistas que publican la información que más le interesa, entre otras muchas más.

También podrá conocer las tendencias que indican qué temas están de actualidad o revisar el historial de un área de estudio en particular.

Se puede lanzar 'Analizar Resultados' en todas las páginas de resultados de búsqueda de la página de Registros Relacionados, de la lista marcada y del informe de citas. La herramienta 'Análisis de Resultados' es la mejor manera para limitar sus resultados a un conjunto de registros más precisos.

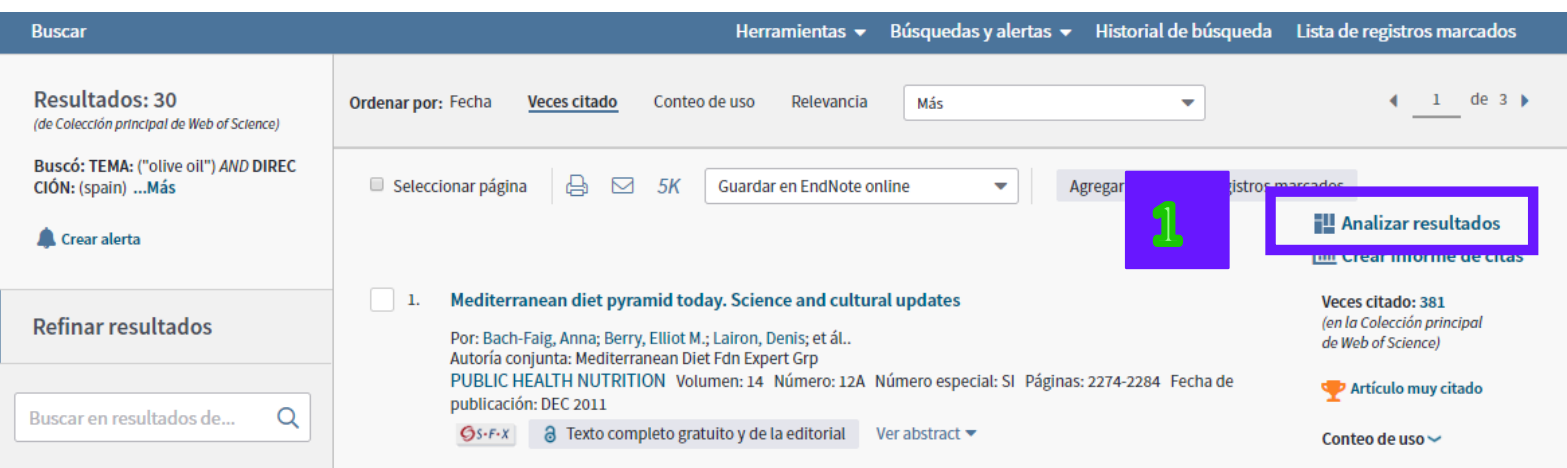




\section{Analizar Resultados}

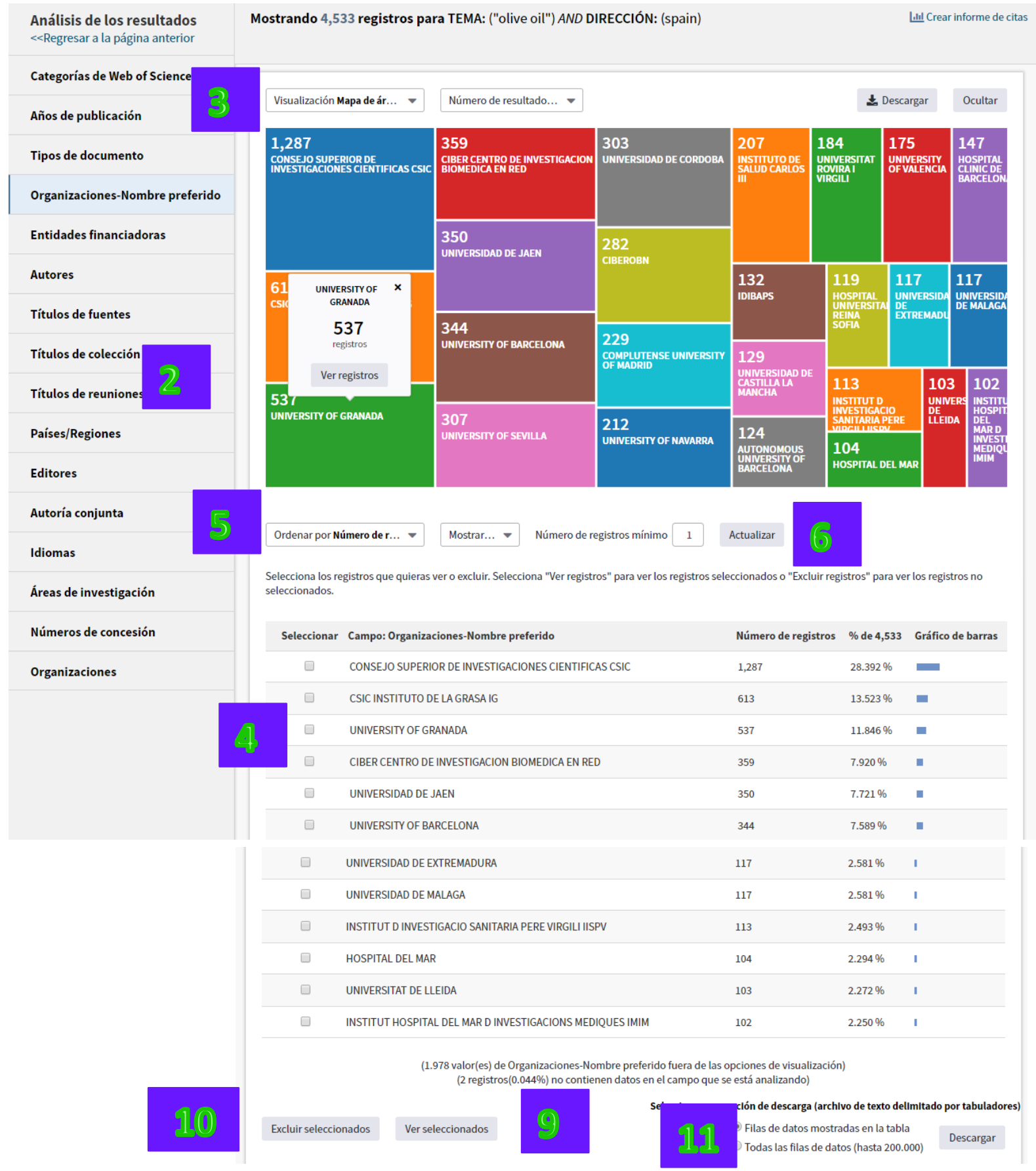

1. Haga clic en Analizar resultados en cualquier página de resultados para acceder a la página Analizar resultados. De forma predeterminada, el sistema analizará basándose en el primer campo incluido en el menú de campos. En la parte superior de la página se muestra un gráfico con los principales valores de campo, y bajo esa imagen se incluye una tabla de datos con los principales valores de campo. Los principales valores del campo seleccionado se muestran junto al número de registros correspondientes. 
2. Seleccione el campo que quiera analizar en la lista de menú de campos situada a la izquierda.

3. Visualización: En la visualización de la parte superior de la página se muestran un máximo de 25 valores. Puede cambiar de un mapa de árbol a un gráfico de barras, descargar una imagen JPG de la visualización y ocultar la visualización si desea centrarse en la tabla de datos.

4. Tabla de datos: La tabla de datos situada debajo de la visualización muestra hasta 500 valores. También puede cambiar el orden y establecer el número de registros mínimo.

5. Orden. El orden seleccionado en la tabla de datos también cambiará el orden de los valores en la visualización.

6. El número de registros clasifica los valores de mayor a menor, según el número de registros en los que aparece cada valor (número de registros mínimo).

7. El campo seleccionado ordena la lista en orden alfabético ascendente (A-Z) o numérico (0-9).

8. Número de registros mínimo (umbral). Para que se muestre en la tabla de resultados y en la visualización, un valor debe aparecer al menos "este" número de veces en el conjunto. Ejemplo: Si selecciona Autor y establece un umbral de 4, el nombre del autor se incluirá en la tabla de resultados si aparece en un mínimo de 4 registros.

Ejemplo: si selecciona Autor y los $\mathbf{1 0}$ mejores, el producto busca los 10 mejores autores en función del número de registros mínimo.

\section{Ver registros de la página de resultados}

Para ver registros que incluyan valores de campos que aparezcan en el informe de resultados, siga estos pasos:

I. Seleccione la casilla de verificación de cada uno de los valores de campo que quiera ver.

II. Haga clic en el botón Ver seleccionados situado en la parte inferior de la tabla para acceder a la página Resultados, donde podrá ver los registros que contienen los valores de campo seleccionados.

\section{Excluir registros de la página de resultados}

Para eliminar registros que incluyan valores de campos de la lista de resultados, siga estos pasos:

I. Seleccione la casilla de verificación de cada uno de los valores de campo que quiera excluir.

II. Haga clic en el botón Excluir seleccionados, situado en la parte inferior de la tabla, para acceder a la página Resultados, donde podrá ver los registros que no contienen los valores de campo seleccionados.

Por ejemplo, imagine que está analizando los resultados por el campo Autor. Si hay algunos autores cuyos trabajos quiere excluir, seleccione la casilla de verificación correspondiente a estos autores y luego haga clic en el botón Excluir seleccionados. 


\section{Guardar datos del análisis en un archivo}

Para guardar los resultados que aparecen en la tabla de resultados, siga estos pasos:

I. Seleccione el número de filas que desea descargar. Puede elegir entre descargar solo las filas que se muestran en la página, todas, o un máximo 200.000 filas.

II. Haga clic en el botón Descargar para descargar el archivo llamado "analyze.txt".

(132 valor(es) de Categorías de Web of Science fuera de las opciones de visualización

Excluir seleccionados

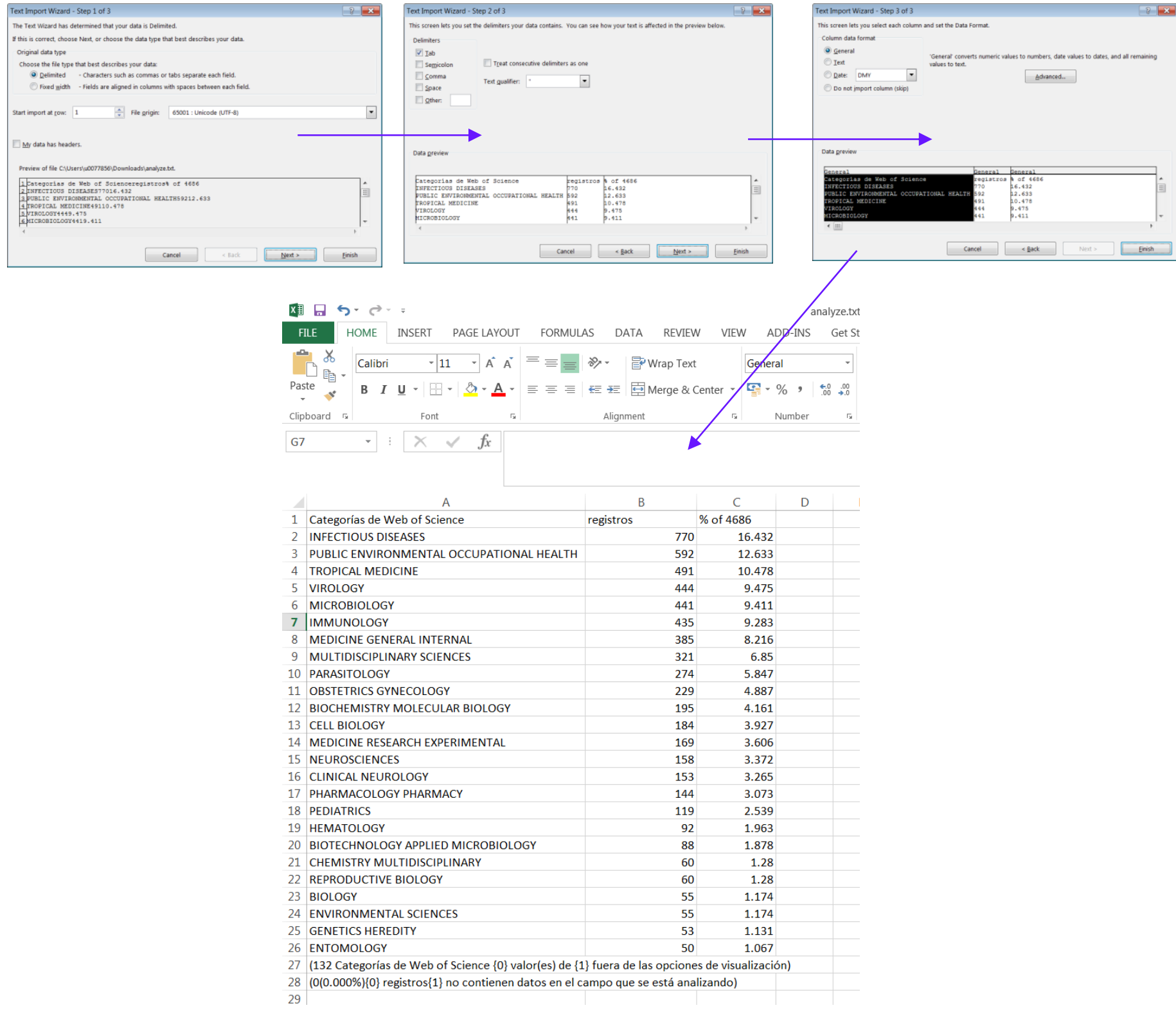




\section{Informe de Citas}

Para un conjunto de resultados inferior a los $\mathbf{1 0 . 0 0 0}$ registros se puede ejecutar el Informe de Citas. El Informe de Citas le proporciona con métricas de citas basadas en los resultados recuperados e incluye el índice $h$.

Web of Science

I) Clarivate

Buscar Regresar a los Resultados de búsqueda

Informe de citas 30 resultados de Colección principal de Web of Science entre \begin{tabular}{lll|l|l|l|}
1900 & Ir
\end{tabular}

BUSCó: IDENTIFICADORES DE AUTORES: (0000-0002-6660-4996) ...Más

Este informe refleja las citas de los elementos origen indexados dentro de Colección principal de Web of Science. Hacer una búsqueda de referencia citada para incluir citas de elementos no indexados dentro de Colección principal Web of Science.

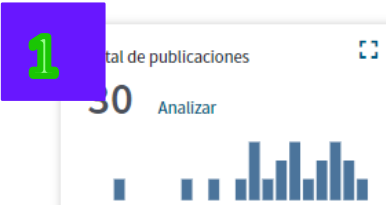

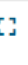

h-index
19
Promedio de citas por elemento
124,47

(1)

124,47

Exportar datos: $\quad$ Guardar en archiv... $>$

Número de veces citado al año

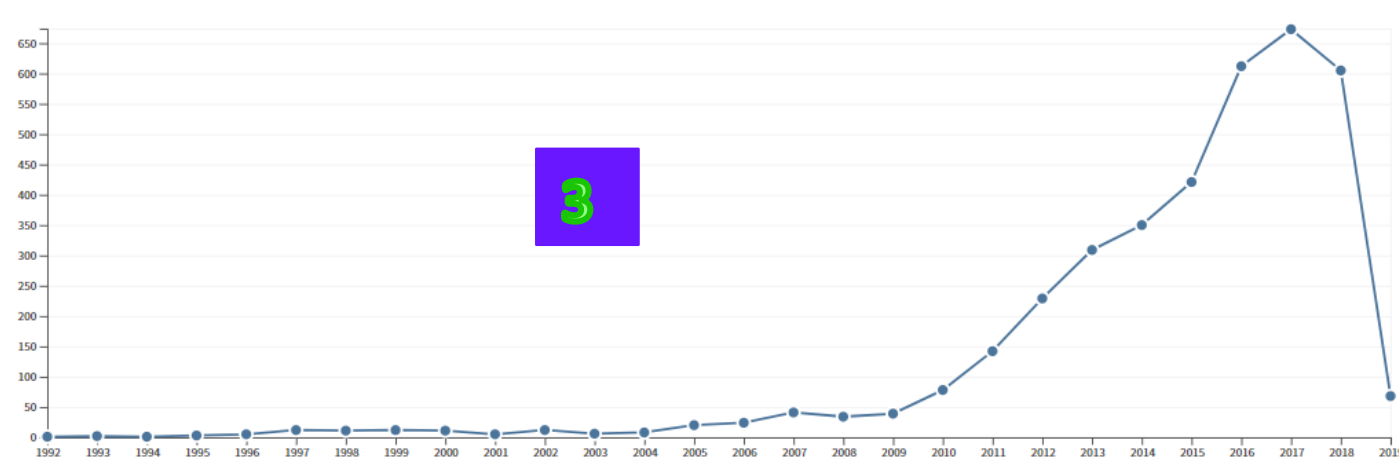

Ordenar por: Veces citado Fecha Más

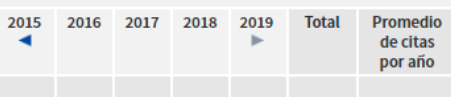

Use las casillas de verificación para eliminar elementos individuales de este informe de citas

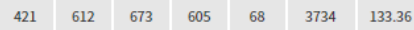

o restrinja la búsqueda a elementos publicados entre $1900 \rightarrow$ y 2019 -

Evolution and classification of the CRISPR-Cas systems

Por: Makarova, Kira S.; Haft, Daniel H.; Barrangou, Rodolphe; et ál.

NATURE REVIEWS MICROBIOLOGY Volumen:9 Número: 6 Páginas: 467-477 Fecha de publicación: JUN 2011

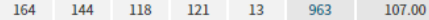

Intervening sequences of regularly spaced prokaryotic repeats derive from foreign genetic elements

Por: Mojica, EJM: Diez-Villlsenor, C; Garcia-Martinez, tjet át.

Páginas: 174-182 Fecha de publicación: FEB 2005

Short motif sequences determine the targets of the prokaryotic CRISPR defence system

Por: Mojica, F. J. M. Diez-Villasenor, C.; Garcia-Martinez, J.; et ál.

MICROBIOLOGY-SGM Volumen: 155 Páginas: 733-740 Fecha de publicación: MAR 2009

4. An updated evolutionary classification of CRISPR-Cas systems

Por: Makarova, Kira S.; Wolf, Yuri l;; Alkhnbashi, Omer S.; et ál..

NATURE REVIEWS MICROBIOLOGY Volumen: 13 Número: 11 Páginas: $722-736$ Fecha de publicación: NOV 2015

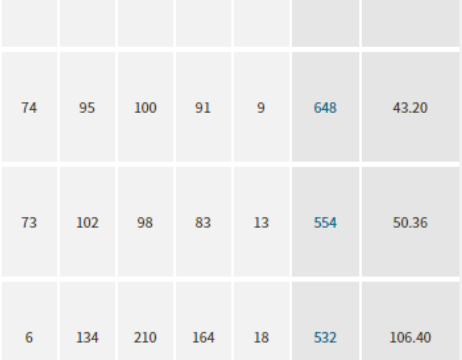


1. En la parte superior se presentan dos gráficas. Una gráfica el permite ver total de publicaciones al largo de los años. La otra grafica le permite ver el numero veces citado de citas al año.

2. El informe de citas proporciona estadísticas de citas agregadas para un conjunto de resultados de búsqueda. Estas estadísticas incluyen los siguientes datos:

- El número total de resultados encontrados (campo Resultados encontrados)

- El número total de veces que se citaron todos los registros (campo Total de veces citado)

- El número total de citas de todos los resultados encontrados en el conjunto de resultados menos las citas procedentes de artículos incluidos en el conjunto (campo Total de veces citado sin citas propias)

- El número total de citas de cualquiera de los elementos del conjunto de resultados de búsqueda (campo Artículos en que se cita)

- El número de artículos en que se cita menos los artículos que aparecen en el conjunto de resultados de búsqueda (campo Artículos totales en que se cita sin citas propias)

- El promedio de veces que se citó un registro (campo Promedio de citas por elemento)

- El número total de veces que se citó un registro en todos los años del conjunto de resultados (columna Total)

- El número de h-index que se basa en la lista de publicaciones clasificadas en orden descendente por el número de veces citado.

\section{Estadísticas agregadas del informe de citas}

\section{Resultados encontrados}

Este campo muestra el número total de registros encontrados en el conjunto de resultados. Se basa en el período de tiempo que seleccionó para realizar la búsqueda original. Por ejemplo, si selecciona Todos los años, puede recuperar 250 resultados; sin embargo, si selecciona Año hasta la fecha, es posible que solo recupere 50 resultados.

\section{Total de veces citado}

Este campo muestra el número de citas totales (referencias citadas) en todos los elementos encontrados en el conjunto de resultados. Esta es la suma de la columna Total, que muestra el número total de artículos en que se cita para todos los años en la tabla Informe de citas.

\section{Total de veces citado sin citas propias}

Este campo muestra el número de citas totales (referencias citadas) en todos los elementos encontrados en el conjunto de resultados menos cualquier cita de los artículos del conjunto. 
Por ejemplo, Smith AJ publicó siete artículos que fueron citados un total de nueve veces. Sin embargo, dos de estos artículos citaron tres de los artículos del conjunto de resultados. El campo Total de veces citado sin citas propias se calcula en seis.

Número de veces citado $=9$

Referencias citadas $=3$ (citas propias)

Total de veces citado $\sin$ citas propias $=6$

\section{Artículos en que se cita}

Este campo muestra el número total de artículos en que se cita de todos los elementos del conjunto de resultados de búsqueda. Haga clic en el enlace Web Artículos en que se cita para mostrar los artículos en que se cita.

Recuerde que el número de artículos en que se cita recuperado puede ser inferior al total del número de veces citado, ya que un artículo puede citar más de un elemento en el conjunto de resultados de búsqueda.

Por ejemplo, tiene seis artículos en el informe de citas. Un autor puede haber citado en su artículo tres de los artículos. En este caso, el sistema recupera cuatro artículos en que se cita, no seis. Esto se debe a que un artículo en que se cita solo se muestra una vez.

\section{Artículos totales en que se cita sin citas propias}

Este campo muestra el número total de artículos en que se cita menos cualquier artículo que aparezca en el conjunto de resultados de búsqueda del informe de citas. Haga clic en el vínculo Artículos totales en que se cita sin citas propias para ver una lista de estos resultados.

\section{Promedio de citas por elemento}

Este campo muestra una fórmula sencilla que calcula el promedio de artículos en que se cita para todos los elementos de un conjunto. Es el total del número de veces citado dividido entre el número de resultados encontrado. Por ejemplo:

Total de veces citado: 967

Resultados encontrados: 55

$967 / 55=17.58$ 


\section{h-index $1^{1}$}

Este campo muestra el número de h-index que se basa en una lista de publicaciones clasificadas en orden descendente por el número de veces citado.

El h-index se indica mediante una línea horizontal de color naranja trazada a través de las columnas Año y Total al año. El número de elementos que se encuentran por encima de esta línea, que es " $h$ ", tienen al menos " $h$ " citas. Por ejemplo, un $h$-index de 20 significa que existen 20 elementos que tienen 20 citas o más. Este indicador resulta útil debido a que reduce la ponderación desproporcionada de los artículos que se citan con mucha frecuencia o de los artículos que todavía no han sido citados.

Calcular el valor de h-index: el factor h-index se basa en el número de años de su suscripción al producto y en el período de tiempo seleccionado. Los elementos que no aparezcan en la página de resultados no se tendrán en cuenta en el cálculo. Si el número de años de su suscripción es 10 , el valor de h-index se basará en este número, aunque un autor específico pueda haber publicado artículos hace más de 10 años. Además, en el cálculo solo se incluyen elementos de su producto (no se tienen en cuenta libros y artículos de revistas no incluidas en él).

3. Las publicaciones en la lista de resultados están ordenadas por veces citado (de lo más citado al menor citado) por defecto. Es posible ordenarlas por fecha de publicación, primer autor, título de publicación y título de la conferencia.

4. Para cada publicación se puede ver el total de citas recibidas, el promedio de veces citado por año y el número de citas recibidas por año separado. Es posible ver información retrospectiva haciendo clic en la flecha azul que le permite retroceder en los años.

5. Se puede personalizar el informe de citas. Es posible limitar a un período de tiempo preferido o excluir resultados. El informe de citas actualizará para corresponder a los nuevos límites.

6. Es posible exportar el informe de citas a un archivo de Excel. En la parte inferior de la página seleccione el modo de exportación 'Enviar a archivo de Excel' y luego selecciona el rango de registros.

${ }^{1}$ 1. El h-index es un indicador desarrollado por J.E. Hirsch y publicado en la revista Proceedings of the National Academy of Sciences of the United States of America 102 (46): 16569-16572 November 152005. 


\section{Guardar el Informe de Citas}

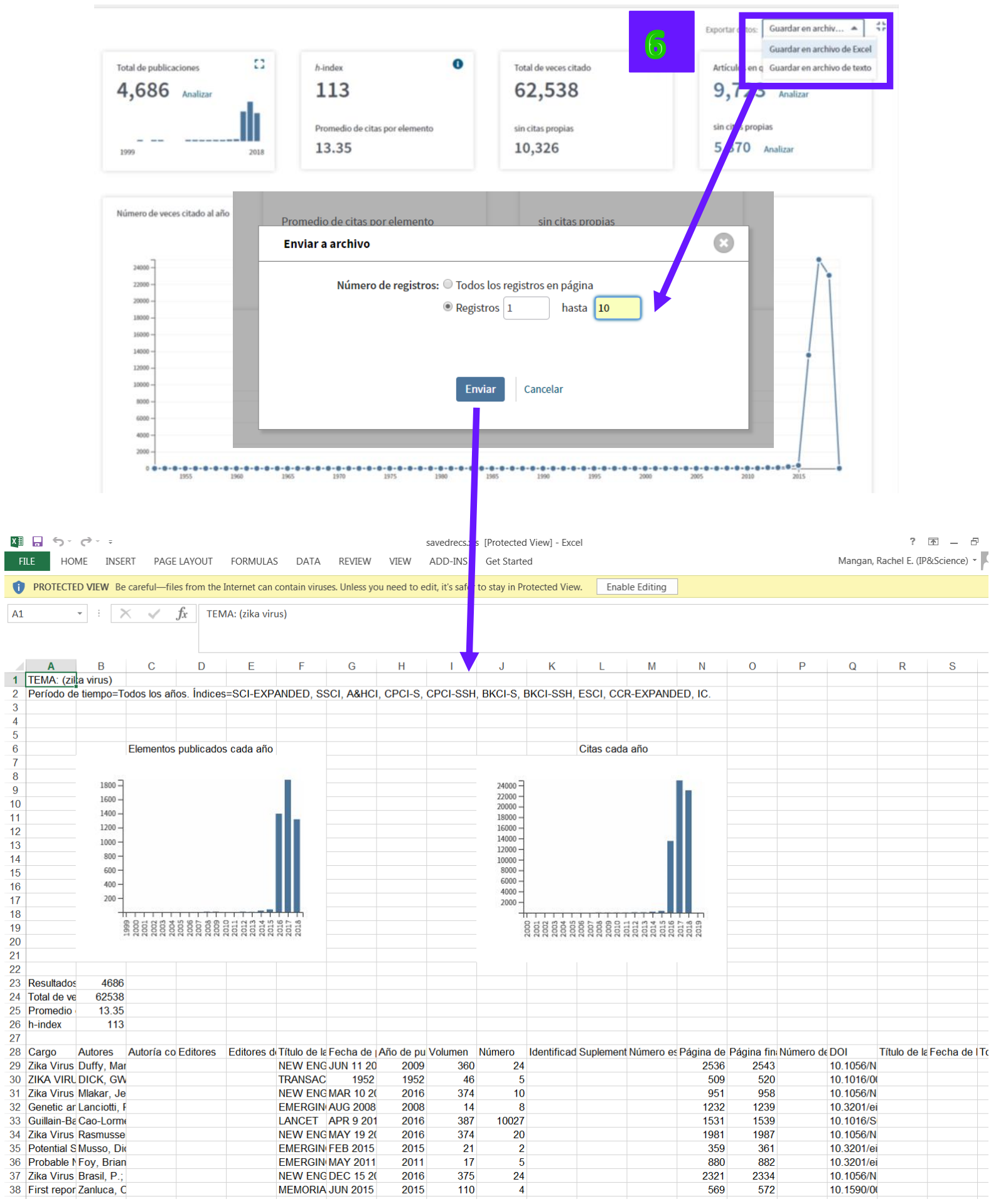




\section{Los Resultados-Refinar Resultados}

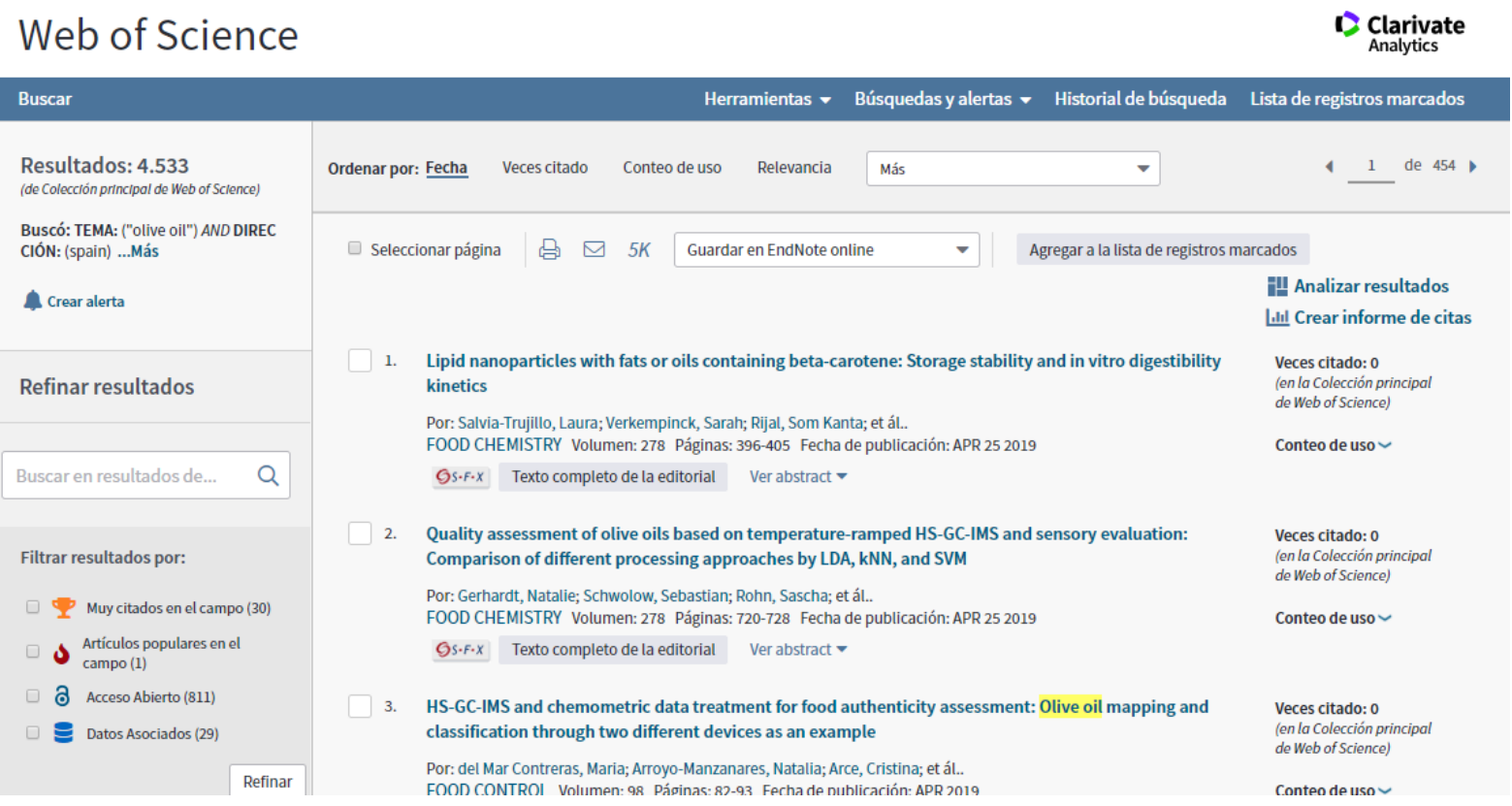

1. Se puede refinar los resultados por varios temas/datos bibliográficos. Para desplegar los resultados clasificados por un tema haga clic sobre los iconos representados por las flechas situadas a mano derecha de las clasificaciones.

2. Desde Refinar es posible priorizar investigación limitando los resultados por:

- Trabajos altamente citados

- Trabajos populares

- Acceso abierto

- Datos asociados

- Años de publicación

- Categorías de la Web of Science

- Tipos de documento

- Organización nombre mejorado

- Entidad financiadora

- Autor

- Título de la fuente

- Acceso abierto (los niveles)

- Título de la colección

- Título de la conferencia

- País/región

- Editor

- Autoría conjunta

- Idiomas

- Áreas de investigación

- Índice de la Web of Science Colección Principal 
3. Haga clic en 'más opciones/valores' para examinar hasta un máximo de 100 resultados de la categoría seleccionada. También con esta función se puede excluir resultados u organizarlos por un orden alfabético/cronológico.

4. Seleccione los temas de interés con sus casillas correspondientes y haga clic en "Refinar" para ver su búsqueda clasificada por los mismos temas de interés.

5. Nota: categorías temáticas de la Web of Science se asignan al nivel de la revista. Las revistas pueden presentarse en una o más categorías. Los artículos heredan las mismas categorías temáticas asignadas a la revista donde fueron publicados.

6. Sus pasos en Refinar se mantienen en la página de resultados en la parte superior y se guardan en su historial.

\begin{tabular}{|c|c|}
\hline Web of Science & $\begin{array}{l}\text { Clarivate } \\
\text { Analytics }\end{array}$ \\
\hline
\end{tabular}

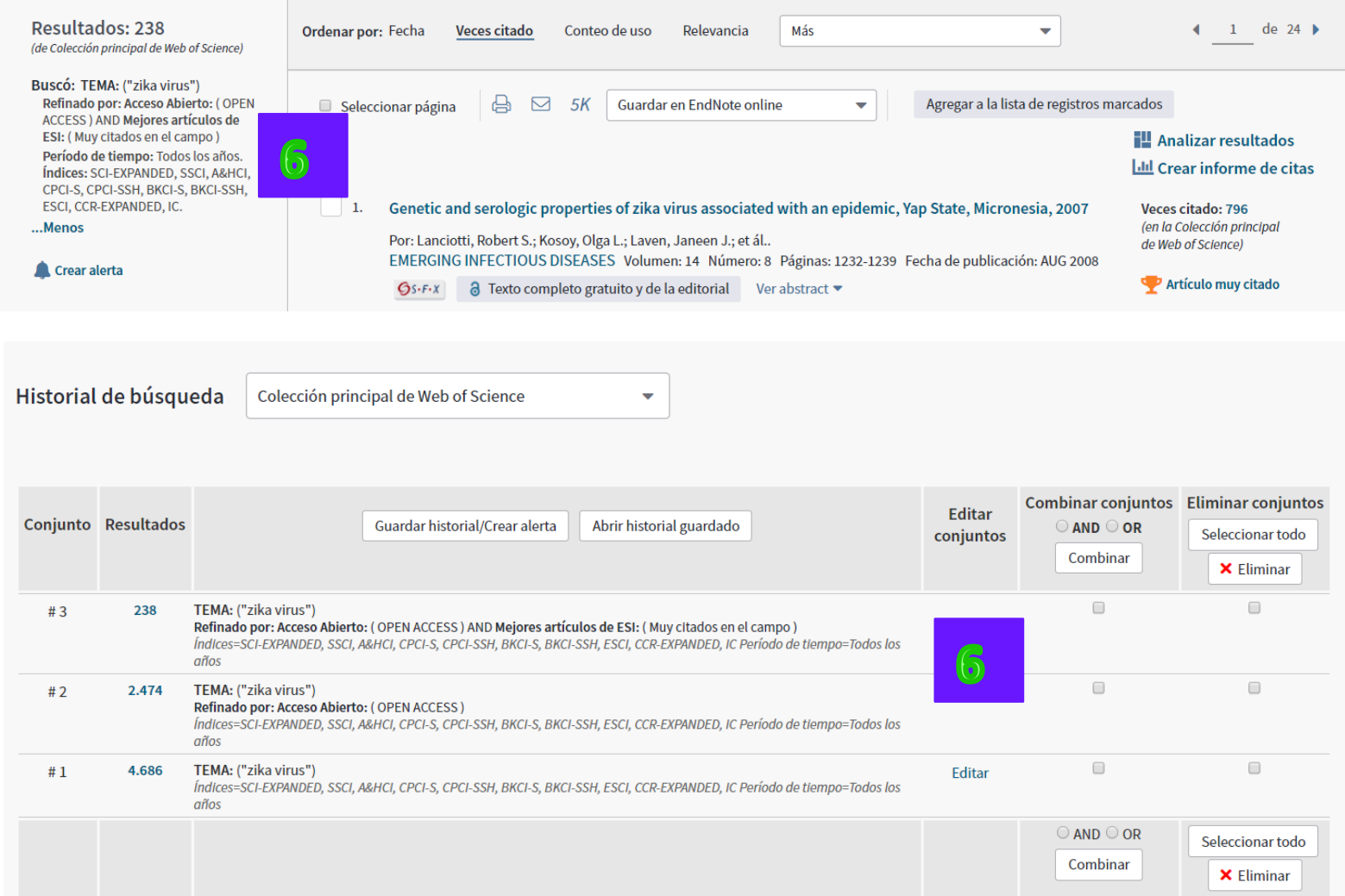




\section{Acceso Abierto en la Web of Science}

La plataforma Web of Science ofrece el estado Acceso abierto como resultado de la asociación con Impactstory, una organización sin ánimo de lucro que acaba de publicar una base de conocimiento con contenido de acceso abierto (OA). Gracias a esta base de conocimiento, se puede acceder a contenido OA legal dorado o bronce (contenido libre en el sitio web de la editorial) y verde (por ejemplo, archivado por el autor en un repositorio). Esta asociación mejora la visibilidad y el acceso a las versiones OA en el nivel de artículos no solo al agregar más vínculos al contenido $O A$, sino también al priorizar los vínculos a las mejores versiones de contenido OA cuando existen varias versiones del artículo. Consulte siempre los derechos de autor del propietario para saber si desea volver utilizar el producto o solicitar alguna licencia. Si desea obtener más información sobre OA en Web of Science, consulte http://info.clarivate.com/openaccess.

El estado OA de un documento puede ser uno de los siguientes:

- Dorado: acceso gratuito a la versión final de un artículo. Los artículos se encuentran en el sitio web de la editorial en uno de los siguientes formatos:

- Una revista que solo pública artículos de acceso abierto.

- Una revista que permite a los artículos individuales tener acceso abierto en una revista en la que es necesaria una suscripción.

- Bronce: acceso gratuito a la versión final de un artículo. Estos elementos pueden reflejar contenido promocional o archivado, así como contenido que el editor decide que sea de lectura gratuita por el bien del público. El contenido OA bronce de Web of Science puede incluir versiones de "acceso público" protegido por derechos de autor de lectura gratuita y versiones de lectura gratuita en las que la información de licencia no se pudo identificar.

- Verde: una versión gratuita y accesible de un artículo ubicada en un repositorio por materia, como PubMed Central o un repositorio institucional. Esta versión del artículo puede variar del manuscrito que los expertos revisan y aceptan a la versión final publicada, según las políticas de la revista. Dado que los manuscritos aceptados pueden ser diferentes a las versiones finales publicadas, se asigna la etiqueta Verde y aceptada y Verde y publicado respectivamente.

Una ventaja importante de la asociación con Impactstory es la capacidad de priorizar los vínculos a los accesos abiertos para que el usuario vea en primer lugar la versión del registro en el sitio web de la editorial, seguida por la versión final en un repositorio y, en último lugar, el manuscrito aceptado en el repositorio. Solo se proporciona un vínculo de acceso abierto.

Los usuarios pueden filtrar los resultados para identificar los artículos de acceso abierto, de forma que puedan leerlos sin tener en cuenta las colecciones de la biblioteca.

Los siguientes valores de OA están disponibles como parte del archivo exportado del registro completo 
- Dorado: para elementos de revistas que el DOAJ identificó como dorados completos y que están disponibles en el sitio web del editor

- Dorado o bronce: para elementos que son dorados híbrido o bronce ("acceso público") y que están disponibles en el sitio web del editor

- Verde editado: para elementos que reflejan la versión publicada de un artículo que está disponible en un repositorio

- Verde aceptado: para elementos que reflejan la versión aceptada de un artículo que está disponible en un repositorio

\section{Refinar resultados para acceso abierto}

El panel Refinar resultados de Web of Science proporciona dos métodos para filtrar un conjunto de resultados de búsqueda de manera que se muestre únicamente contenido de acceso abierto.

El filtro de Open Access del panel principal "Filtrar resultados por" situado en la parte superior izquierda de la página Resultados de búsqueda-Resumen limitará los resultados de la búsqueda a todos los elementos identificados como acceso abierto de cualquier tipo.

El panel Refinar resultados de la izquierda también permite a los usuarios limitar la búsqueda por tipo de OA:

- $\quad$ "Todo el acceso abierto" limitará los resultados de la búsqueda a todos los elementos identificados como acceso abierto de cualquier tipo.

- "Dorado o bronce" limitará los resultados de la búsqueda a todos los elementos identificados como dorado (de cualquier tipo) o bronce ('acceso público'). Estas publicaciones se identificarán con un enlace para acceder a "Texto completo gratuito y de la editorial."

- "Verde y publicado" limitará los resultados de la búsqueda a todos los elementos identificados con un enlace para acceder a "Artículo del repositorio gratuito y publicado."

- "Verde y aceptado" limitará los resultados de la búsqueda a todos los elementos identificados con un enlace para acceder a "Artículo del repositorio gratuito y aceptado."

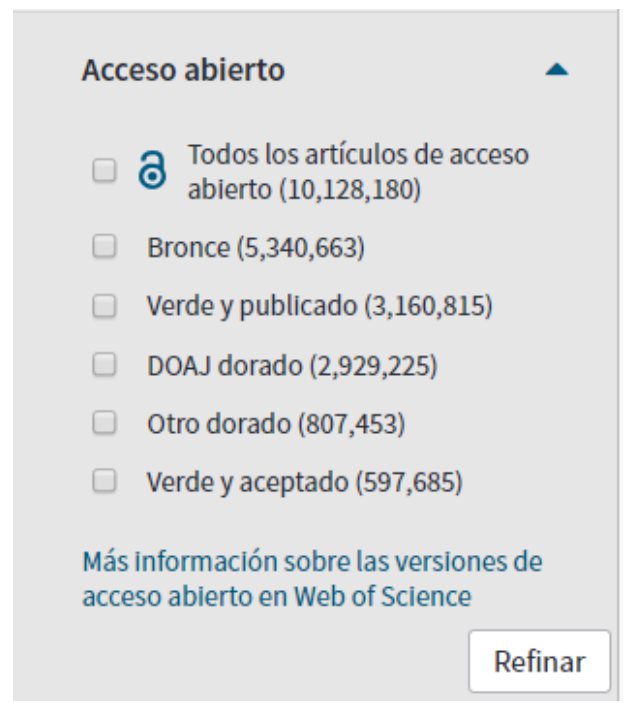




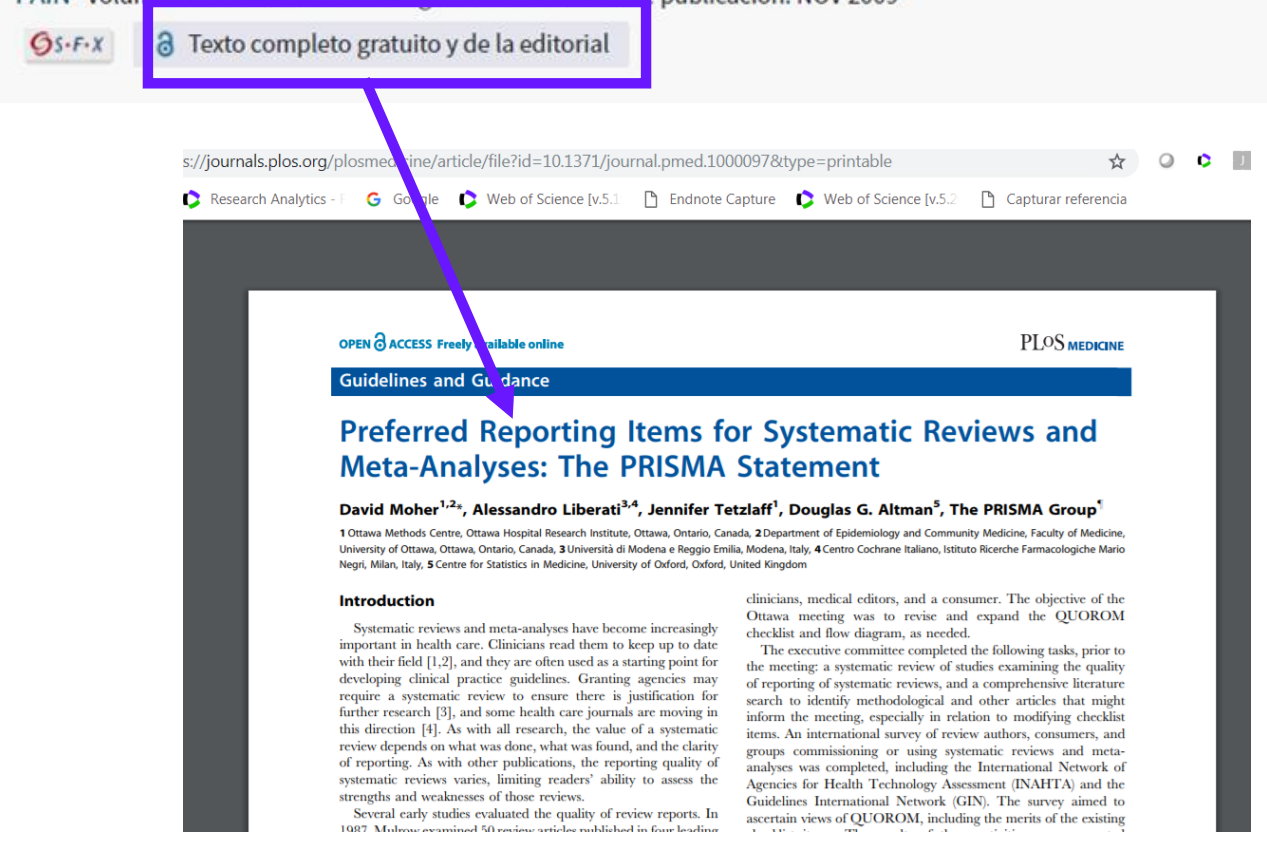

\section{Acceso Anticipado}

La función Acceso anticipado indica que un artículo se publicó electrónicamente en una revista antes de asignarlo a un volumen y un número específicos. Estos artículos también se conocen como "artículos en prensa" o "publicar antes de imprimir", en función de la marca del editor.

Estos artículos se pueden encontrar con antelación y están completamente indexados, incluyendo una fecha de publicación en línea para el editor. Estos artículos acumulan el número de veces que se citaron en esta fase inicial de publicación, por lo que se conserva el impacto completo del artículo. También se incluye la función Web of Science total, que incluye opciones de alertas y exportación. 


\section{Kopernio}

\section{¿Que es Kopernio?}

Kopernio es un complemento del navegador que encuentra el mejor PDF disponible de un artículo académico mientras navegas. Detrás de escena, Kopernio buscará bases de datos abiertas y (donde sea posible) las suscripciones de la universidad para encontrar la mejor versión del documento para usted. El mejor artículo PDF nunca es más que un clic de distancia.

Kopernio se integra con servidores proxy de biblioteca para recuperar artículos de investigación de las suscripciones de biblioteca. Si su biblioteca es compatible, Kopernio lo configurará automáticamente. Kopernio también indexa un rango de fuentes de datos adicionales de las que se pueden recuperar los archivos PDF:

- Publicadores de acceso abierto

- Repositorios institucionales

- Servidores de reimpresión

- Google Académico

- Tu historial de búsqueda de Kopernio

\begin{tabular}{|c|c|c|}
\hline & $\begin{array}{l}\text { 1. Impulsar tu búsqueda } \\
\text { bibliográfica }\end{array}$ & $\begin{array}{l}\text { Acceso con un clic a archivos } \\
\text { PDF. No más VPN, formularios de } \\
\text { inicio de sesión, redirecciones, } \\
\text { búsqueda desesperada de Google y } \\
\text { búsqueda de enlaces rotos }\end{array}$ \\
\hline & 2. Navegar paywalls & $\begin{array}{l}\text { Busque automáticamente } \\
\text { suscripciones a bibliotecas } \\
\text { universitarias, servidores de } \\
\text { preimpresión y repositorios } \\
\text { institucionales para archivos PDF. }\end{array}$ \\
\hline & $\begin{array}{l}\text { 3. Trabajar fuera del } \\
\text { campus }\end{array}$ & $\begin{array}{l}\text { Lleva la biblioteca de la universidad } \\
\text { contigo a donde vayas; En casa, en } \\
\text { conferencias, en la playa. }\end{array}$ \\
\hline & 4. Guardar para más tarde & $\begin{array}{l}\text { Kopernio guarda automáticamente } \\
\text { los archivos PDF que lee en su } \\
\text { propio Kopernio Locker } \\
\text { privado. Vuelve y léelos de nuevo } \\
\text { más tarde, en cualquier lugar, en } \\
\text { cualquier momento. }\end{array}$ \\
\hline
\end{tabular}




\section{Instalar Kopernio}

Para instalar Kopernio, siga los pasos a continuación:

1. Vaya a https://www.kopernio.com/

2. Haga clic sobre el botón en color verde 'Add to Chrome'

3. Es necesario crear una cuenta (darse de alta) a Kopernio para obtener acceso a tu espacio personalizado (Locker)

4. La extensión instala en el navegador

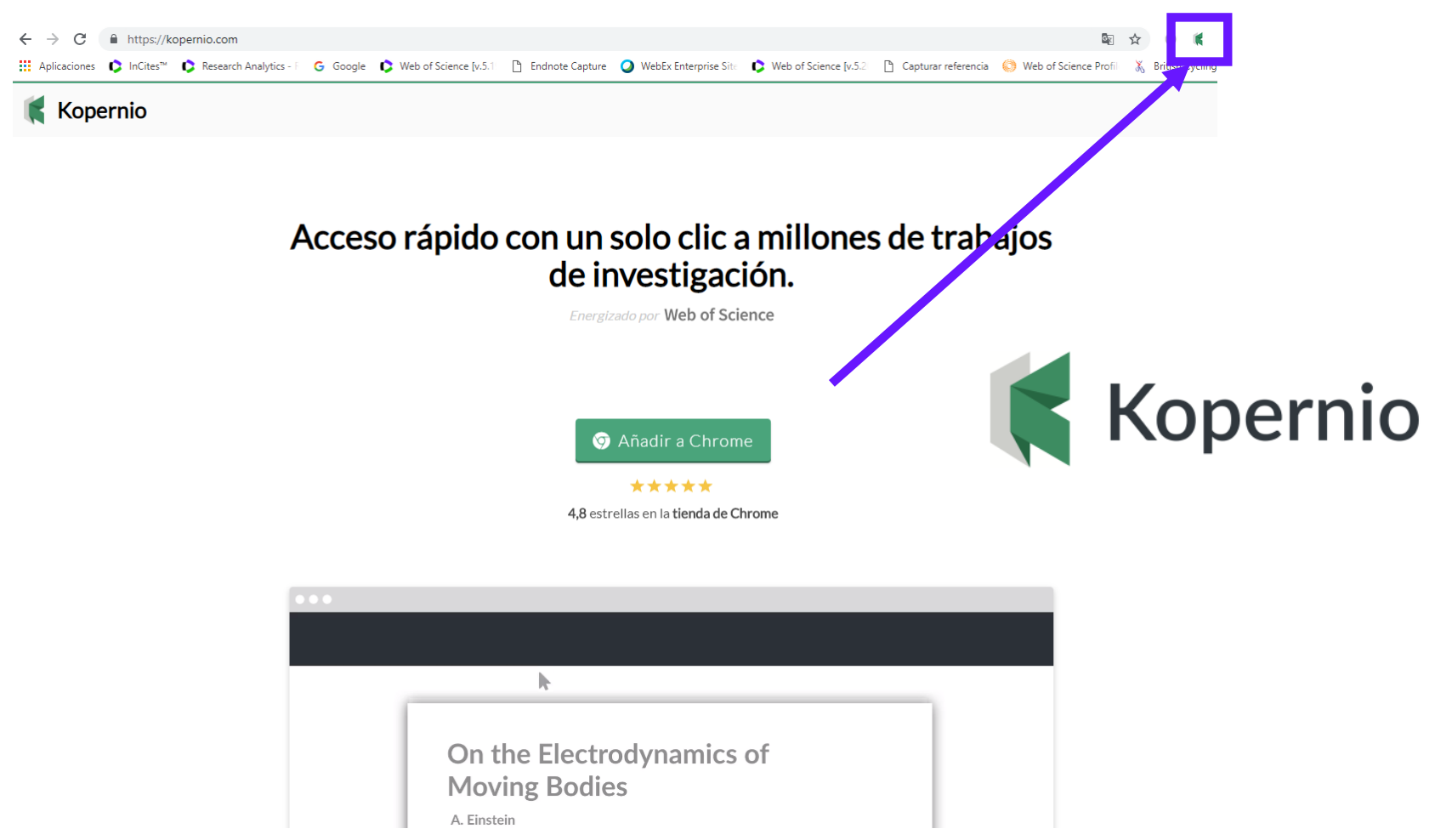

5. Vaya a una base de datos (Web of Science por ejemplo) y ejecute una búsqueda. 
6. Hace falta abrir un registro completo. La extensión de Kopernio intenta localizar un texto completo legal de las fuentes incluidas. Si tiene éxito, Kopernio le comunicará que ha recuperado un PDF.

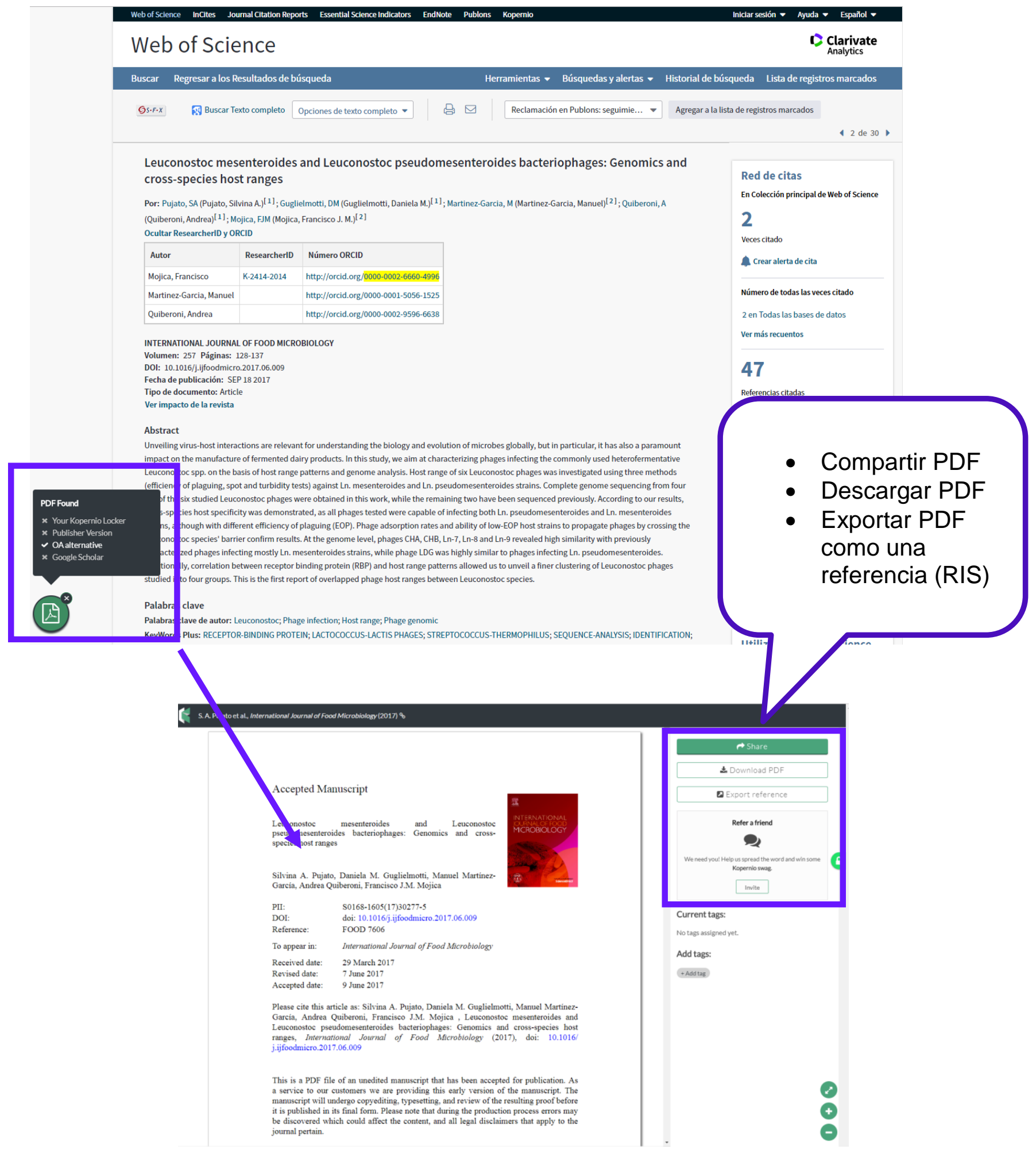

- http://clarivate.libguides.com/webofscienceplatform/kopernio

- https://www.kopernio.com/ 


\section{Kopernio: Preguntas Frecuentes}

\section{¿Necesito una dirección de correo electrónico de la universidad?}

Puedes registrarte con cualquier dirección de correo electrónico. Sin embargo, las funciones que requieren la integración de bibliotecas solo funcionan si nos dice el nombre de su institución.

\section{No puedo encontrar mi institución en su lista, ¿qué debo hacer?}

Verifique las diferentes variantes del nombre de su institución (por ejemplo, la Universidad China de Hong Kong puede guardarse como "Universidad China de Hong Kong" ). En algunos casos, el nombre en inglés puede usarse en lugar del nombre local (por ejemplo, la Universidad Federal de São Paulo puede guardarse como "Universidad Federal de Sao Paulo").

\section{¿De dónde obtiene Kopernio los archivos PDF?}

Kopernio se integra con servidores proxy de biblioteca y sistemas de autenticación de biblioteca para recuperar artículos de investigación a través de suscripciones de biblioteca. Si su biblioteca es compatible, Kopernio configurará esto por usted automáticamente. A continuación, se muestra una lista de recursos a los que Kopernio intenta acceder y de los cuales se pueden recuperar los archivos PDF:

- Editores (tanto para la suscripción como para el contenido de OA): Kopernio siempre intenta obtener el artículo de la revista primero desde la plataforma del editor original.

- Otras fuentes, por ejemplo, repositorios (por ejemplo, repositorios institucionales), bases de datos (por ejemplo, JSTOR), servidores de preimpresión (por ejemplo, Arxiv), Google Scholar: si no podemos recuperar una versión original del editor, Kopernio indexa este rango de fuentes de datos adicionales.

Kopernio está configurado para priorizar, buscar y devolver artículos de sus suscripciones de biblioteca. Si la búsqueda de ese contenido no genera resultados, o si no tiene una suscripción a la biblioteca, Kopernio buscará de forma predeterminada la siguiente jerarquía de fuentes: historial del usuario, editores de acceso abierto y contenido de terceros (por ejemplo, Google Scholar). Sin embargo, puede configurar esta jerarquía si desea hacerlo.

\section{¿Qué quiere decir con la "mejor" versión PDF?}

Cuando sea posible, Kopernio recuperará la versión final publicada del artículo de la revista. Para los artículos de acceso no abierto que no están disponibles a través de su suscripción institucional, Kopernio intentará encontrar una versión alternativa en su lugar. Las versiones alternativas incluyen preimpresos y manuscritos de autores depositados en repositorios institucionales. 


\section{¿Qué haces con mis datos?}

Puede encontrar nuestros Principios de datos "simples en inglés" aquí que establecen qué datos recopila Kopernio y por qué.

\section{¿Puedo usar Kopernio fuera del campus?}

¡Sí! ¡Kopernio puede proporcionar acceso con un solo clic a artículos dentro y fuera del campus! Si su biblioteca ofrece un servicio proxy, Kopernio puede conectarse a ella , reconocer sus derechos y recuperar archivos PDF para usted cuando está fuera del campus (es decir, fuera del rango de IP de su institución). La primera vez que intente acceder a un PDF fuera del campus utilizando Kopernio, podrá ver la página de inicio de sesión de su biblioteca y deberá autenticarse de la manera habitual. Sin embargo, una vez que se haya autenticado (solo necesita hacerlo una vez), puede continuar accediendo a las suscripciones de su biblioteca con un solo clic desde cualquier lugar.

\section{¿Kopernio trabaja con EndNote?}

Kopernio puede exportar archivos .RIS que son compatibles con la mayoría de los administradores de referencia (incluido EndNote). Simplemente haga clic en el botón Exportar referencia cuando se encuentre en el visor de PDF de Kopernio.

\section{¿Por qué necesito registrarme?}

El registro solo toma unos segundos y nos permite brindar una experiencia mucho mejor, incluido el acceso con un clic a las revistas desde sus suscripciones institucionales. Una vez que se haya registrado, los archivos PDF a los que accede a través de Kopernio se almacenan en la nube en su "Casillero" personal, se sincronizan automáticamente entre dispositivos y se pueden compartir fácilmente con sus colegas.

\section{¿Qué hace Kopernio con las credenciales de mi biblioteca?}

Cuando se autentica contra el proxy de su biblioteca por primera vez, sus detalles se almacenan localmente dentro del complemento Kopernio. Esto es muy similar a cómo funcionan los administradores de contraseñas como LastPass. Para garantizar su seguridad, todos los detalles confidenciales se cifran mediante algoritmos de cifrado estándar de la industria. Todo el procesamiento de las credenciales se realiza localmente y su contraseña nunca se transmite ni se almacena en los servidores de Kopernio.

\section{¿Qué pasa con la autenticación de dos factores?}

Kopernio es capaz de soportar instituciones con autenticación multifactor. Cuando se autentique por primera vez en su biblioteca, deberá proporcionar sus credenciales junto con los factores de autenticación adicionales. Por lo general, su biblioteca no necesitará proporcionar los factores de autenticación adicionales durante algún tiempo, durante los 
cuales Kopernio podrá usar sus credenciales habituales para autenticarlo. Tenga en cuenta que, para que esto funcione correctamente en su institución, es posible que debamos asegurarnos de que se realicen cambios en nuestra configuración, por lo que podría valer la pena pedirle a su bibliotecario que se ponga en contacto con el equipo de Kopernio si encuentra algún problema.

\section{¿Qué pasa si cambio o abandono mi institución?}

Puede seguir usando Kopernio, solo actualice su afiliación en la página de configuración . Es probable que su biblioteca revoque el acceso a las suscripciones institucionales, momento en el que ya no podrá acceder al contenido suscrito a través de Kopernio.

\section{¿Qué editores / plataformas son compatibles?}

El complemento Kopernio se activa en una lista blanca de más de 20,000 plataformas, incluidas:

- Publicadores de acceso abierto

- Editores pagados

- Resumen de bases de datos incluyendo Pubmed, Scopus y Web of Science.

- Servidores de preimpresión como el arXiv.

- Repositorios institucionales y temáticos seleccionados.

Constantemente estamos agregando a esta lista y siempre estamos abiertos a sugerencias para nuevos lugares donde el complemento Kopernio sería útil. Envíenos un correo electrónico a help@kopernio.com si desea ver el soporte de Kopernio en un sitio nuevo.

\section{¿Qué navegadores soporta Kopernio?}

En este momento, admitimos Chrome, Firefox y Opera, aunque estamos trabajando en extender esto a otros navegadores. Puede ayudarnos a decidir en qué navegador trabajaremos a continuación, activando su navegador favorito:

1. Upvote Safari 宜

2. Upvote Edge 目

3. Sugerir otro navegador 宜

¿Por qué Kopernio necesita permisos de navegador cuando está instalado?

Al igual que con cualquier aplicación, las extensiones de navegador necesitan su permiso para funcionar. Para su privacidad y seguridad, Kopernio solicita los permisos mínimos necesarios. Estos son necesarios para que Kopernio encuentre sus suscripciones institucionales, para agregar el botón PDF de Kopernio a las páginas mientras navega y para ayudarlo a descargar archivos PDF. 
Internamente, Kopernio usa una lista blanca de páginas web para ayudar a su navegador a decidir si activa o no el botón Kopernio, de modo que Kopernio solo se activa cuando está en una plataforma de investigación y no de otra manera. Revisamos regularmente los permisos y la lista blanca de Kopernio para asegurarnos de que respetamos su privacidad en línea y seguimos todas las mejores prácticas de seguridad.

\section{¿En qué se diferencia Kopernio de OA Button, Unpaywall, etc.?}

Apoyamos todos los proyectos que hacen que la investigación de OA sea más fácil de encontrar y más accesible, y nos complace ver tantas iniciativas trabajando juntas en este importante problema. De hecho, Kopernio utiliza varias fuentes de datos de OA, incluidos repositorios institucionales, servidores de preimpresión como arXiv y bioRxiv, Unpaywall Data y Pubmed Central.

Sin embargo, también es importante reconocer que el contenido de OA actualmente constituye solo la minoría de la investigación publicada (en algún lugar entre el 25 y el 40\% de los artículos). Para poder acceder al 60-75\% restante de los artículos, es necesario hacer uso de las suscripciones a revistas que a menudo se brindan a través de universidades y otras instituciones de investigación.

Kopernio lo hace singularmente sencillo al integrarse automáticamente con las suscripciones institucionales para entregar sin problemas la OA y el contenido suscrito con un solo botón. De esta manera, siempre puede obtener acceso a la mejor versión de artículo disponible para usted, sin importar dónde se encuentre en línea, tanto dentro como fuera del campus.

Los manuscritos y las preimpresiones pueden ser alternativas útiles para los artículos con muros de pago, pero no se garantiza que contengan cambios de los comentarios del revisor o las correcciones posteriores a la publicación que la versión de registro del editor hace. Esto puede causar problemas de reproducibilidad, por lo que Kopernio hace todo lo posible para asegurarse de obtener la mejor versión disponible del artículo.

También tenemos muchas funciones prácticas exclusivas de Kopernio que incluyen almacenamiento en la nube para sus documentos, funciones para compartir artículos e integraciones con más de 20,000 plataformas en línea. También somos la única herramienta para garantizar el acceso con un solo clic directamente al PDF (sin páginas abstractas, inicios de sesión, redirecciones u otros obstáculos).

La mejor manera de ver la diferencia es descargar Kopernio y probar por ti mismo.

Si no encuentra una respuesta a su pregunta, no dude en enviarnos un correo electrónico a help@kopernio.com . 


\section{Un Registro Completo de la Colección Principal de Web of Science}

Web of Science

\section{Busci} sar a los Resultados de búsqueda 1

\section{9}

I) Clarivate Analytics

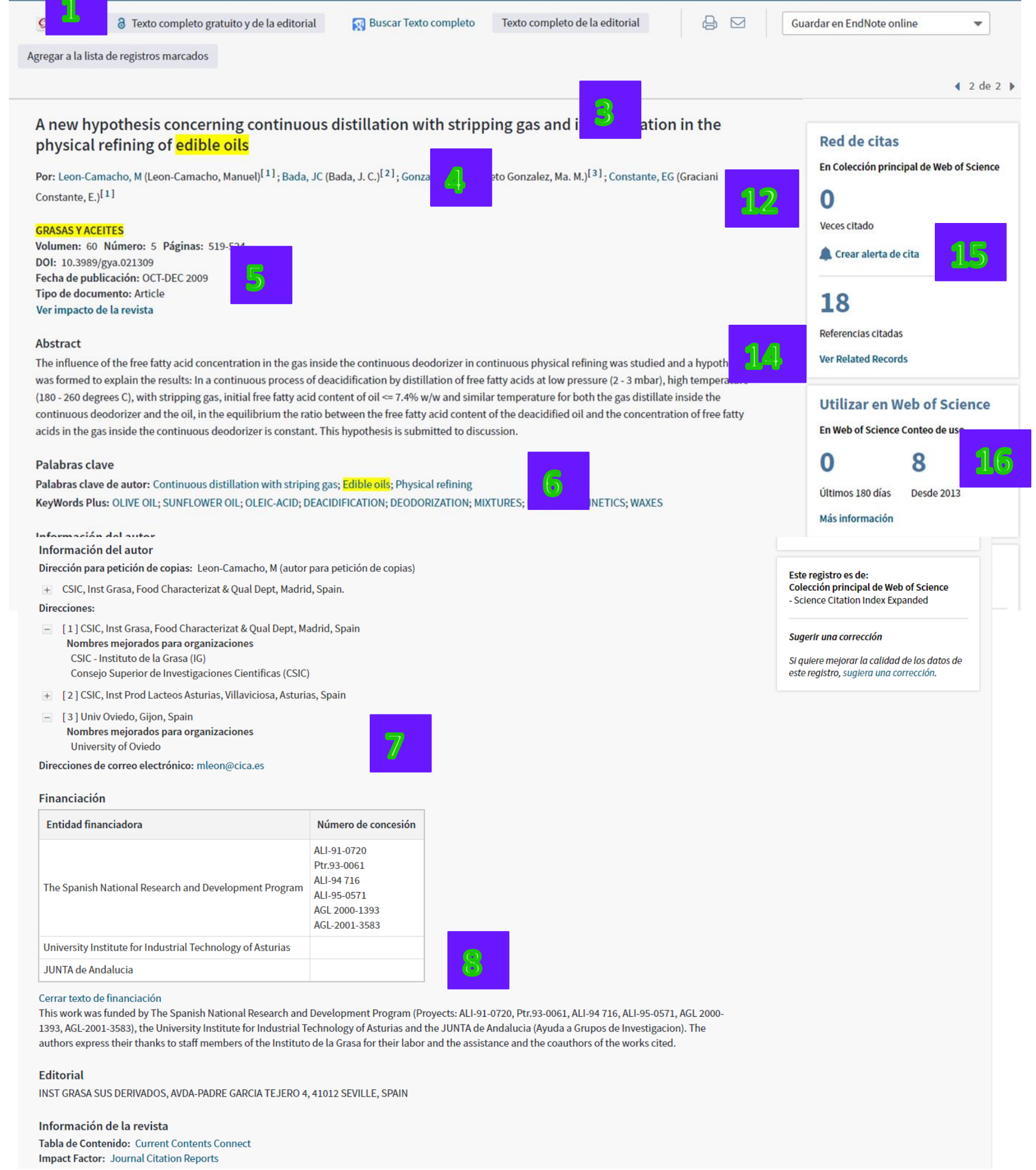




\section{Opciones de acceso al Texto completo}

2. Buscar el texto completo en Google Académico

3. Título original del artículo. Web of Science Group traduce los títulos al inglés estadounidense cuando se publican en otro idioma.

4. Autores: - Los nombres de todos los autores en el documento original. Web of Science Group normaliza los nombres de los autores y se presentan en dos formatos. El formato principal consiste en el apellido seguido por los iniciales. El segundo formato consiste en el nombre completo del autor si está disponible en el documento original. Para artículos indexados después de 2008 puede aparecer un número en superíndice después del nombre de un autor. Esto significa que hemos encontrado una asociación entre el nombre y la dirección del autor. Cuando haga clic en el enlace Web del número, el sistema le llevará al campo Direcciones, donde podrá consultar la dirección del autor.

En algunos casos, un autor puede estar asignado a varias direcciones y verá más de un número en superíndice. En otros casos, es posible que un autor no se asigne a una dirección, mientras que otros autores del mismo artículo sí estén asignados a una. Esto sucede cuando no podemos determinar qué dirección está asociada a un autor.

El producto mantiene la asociación entre autor y dirección cuando imprime, envía por correo electrónico, guarda o exporta registros. En el campo Dirección de su documento de salida, busque el nombre del autor antes de la dirección.

5. Información de la revista: - datos de la publicación. Haga clic en 'Ver información de la revista' para mostrar métricas de impacto de la revista de Incites Journal Citation Reports.

6. Palabras claves: - Existen dos tipos de palabras clave, las del autor y Keywords Plus. Es posible lanzar una nueva búsqueda por tema basándose en cualquier de los términos.

7. Direcciones: - Web of Science Group indexa todas las direcciones proporcionadas por los autores en la publicación original. Por debajo de la dirección indexada se puede ver el nombre mejorado de la organización.

\section{Información de Financiación: -}

Este campo incluye información financiera proporcionada por el documento fuente. La Colección principal de Web of Science ha estado recopilando información financiera desde 2008 en SCl-Expanded y, desde 2015, en SSCI.

En 2016 Web of Science empezó a complementar la información de concesión con números y agencias de concesión desde Researchfish ${ }^{\circledR}$

\section{Número de concesión}

La información de financiación suele incluir un código o número de identificación asignado por las entidades financiadoras para un proyecto de financiación específico. Ejemplos de estos números de concesión, números de proyectos y números de programas. 
En la Colección principal de Web of Science, este identificador se denomina un número de concesión.

Es posible encontrar una organización de financiación sin números de concesión.

\section{Texto de financiación}

Haga clic en el vínculo Ver texto de financiación para ver el agradecimiento al apoyo conseguido a través del documento fuente.

El artículo fuente permite identificar las fuentes de financiación que apoyaron la investigación. Por lo general, esta información se incluye en la sección de agradecimientos que suele estar presente antes de las referencias que se incluyen al final del artículo. La información de financiación también puede estar disponible al final del abstracto o con la información de direcciones.

\section{Número de concesión}

La información de concesión procede de artículos de revistas incluidas en la Colección principal de Web of Science. La indexación de la información de concesión comenzó en 2008.

La información de concesión se encuentra disponible públicamente en numerosos sitios web como, por ejemplo, PubMed. Puede encontrar información adicional ingresando el número de concesión al realizar una búsqueda. Por ejemplo, una búsqueda sobre "Swiss National Science Foundation" en PubMed busca artículos escritos por investigadores de instituciones financiadas por esta organización.

En 2016, la Colección principal de Web of Science Web of Science empezó a complementar la información de concesión con números y agencias de concesión desde MEDLINE y researchfish ${ }^{\circledR}$. Los registros que ya incluyen información de concesión no se modificarán. Los registros que no incluían información de concesión se actualizaron con información de concesión procedente de MEDLINE y researchfish ${ }^{\circledR}$.

Para buscar dentro del texto original de financiación, hace falta realizar la búsqueda avanzada e introducir la etiqueta $(\mathrm{ft}=$ ). Ej. $\mathrm{ft}=$ European Regional Development Fund 
9. Clasificación de la revista- puede ver aquí las clasificaciones de la revista en Web of Science CC y estas mimas categorías coinciden con las en JCR.

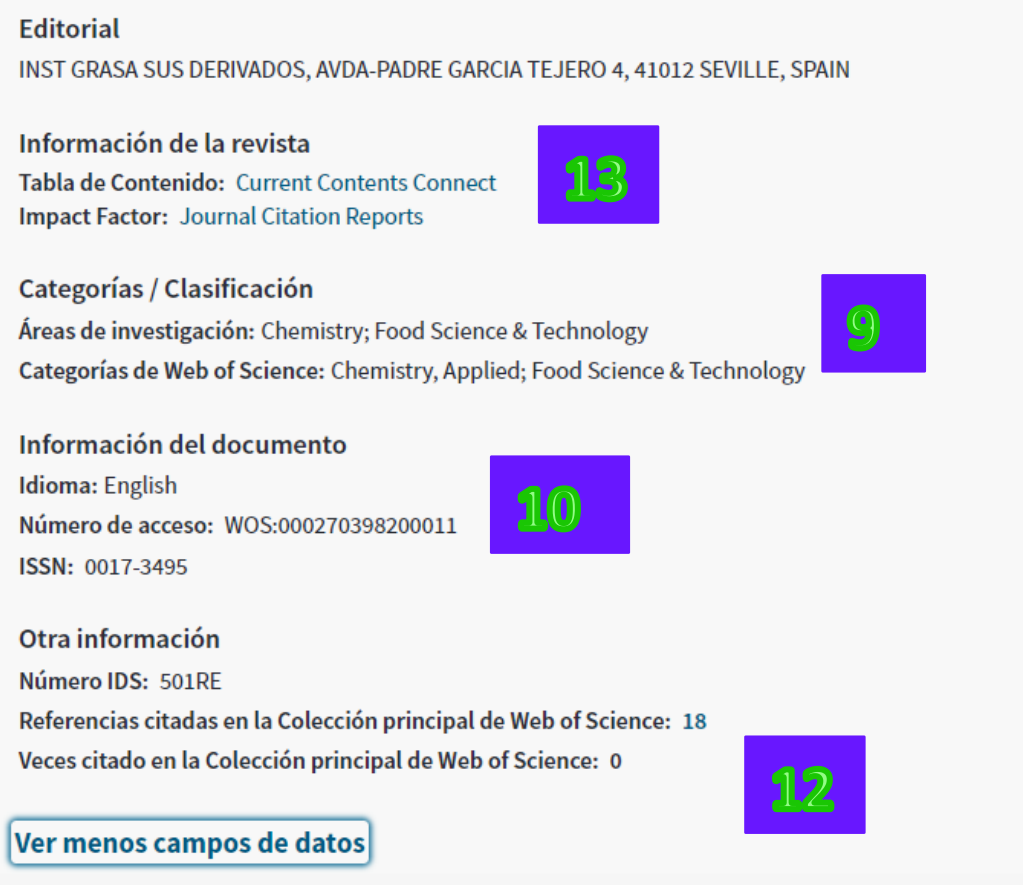

10. Información del documento:- puede ver aquí el tipo de documento, el idioma de publicación de la revista y el número de acceso.

11. Información de la revista - puede ver datos de Current Content Connect (suscripción necesaria) o ir al perfil de la revista en Incites Journal Citation Reports.

12. Otra información:- accede aquí la bibliografía (Referencias Citadas) del artículo.

13. Las Veces Citado:- Observe aquí las veces citado de la Web of Science Core Collection y las veces citado de Todas las Bases

Note: Los artículos que aparecen en los totales son aquellos que citan el artículo correctamente. Puede haber referencias adicionales al artículo que no aparecen aquí debido a variaciones en la cita., (p. Ej. número incorrecto de página, volumen, año citado, o nombre del autor citado incorrectamente). Para recuperar documentos que contienen variaciones o errores de citación, la búsqueda debe realizarse en la opción Búsqueda por Referencias Citadas

14. Buscar por Registros Relacionados es una búsqueda que recupera otros documentos en la base que comparten al menos una referencia citada con las referencias en la bibliografía de este mismo documento. Una búsqueda por registros relacionados le permite recuperar más registros que coinciden con el tema de búsqueda sin añadir más vocabulario específico a su búsqueda. También se pueden descubrir artículos relevantes que no se recuperaron con su estrategia original de búsqueda.

15. Alerta de citas - Puede crear una alerta de citas para hacer un seguimiento de las nuevas citas a este artículo. Se pueden tener tantas alertas como desee, pero es necesario crear un perfil dentro de Web of Science para poder utilizar esta herramienta. 


\section{6. Índice de Uso del artículo:-}

El índice de uso es una medida del nivel de interés en un artículo específico que se calcula diariamente usando un algoritmo pendiente de patente.

Este algoritmo cuenta el número de veces que el artículo cubrió las necesidades informativas de un usuario

- Hacer clic sobre 'texto completo' (No se considera el botón 'buscar texto completo en Google Académico)

- Guardar la referencia en cualquier formato (guardar en Endnote, Refworks, otros tipos de archivo)

El índice de uso tiene en cuenta la actividad llevada a cabo por todos los usuarios de Web of Science, no solo la actividad realizada por los usuarios de su institución.

Últimos 180 días. Este resultado cuenta el número de veces que se accedió al texto completo de un registro o que un registro se guardó a un gestor de referencias los últimos 180 días. Este resultado puede fluctuar a medida que avanza la fecha de finalización del período establecido.

Todos los tiempos. Este resultado cuenta el número de veces que se accedió al texto completo de un registro o que un registro se guardó a un gestor de referencias desde el 1 de febrero de 2013. Este resultado puede aumentar o permanecer estático a lo largo del tiempo

El conteo de uso considera el uso de un registro en cualquier formato de cómo existe en la plataforma. Por ejemplo, un usuario puede hacer clic sobre 'texto completo' en un registro de SciELO. Si el mismo registro también se indexa tanto en SciELO como en la WOS CC, el registro de WOS CC también recibe un aumento en su índice de uso. El índice de uso de los registros en la plataforma es homogéneo. 


\section{Características de Las Referencias Citadas}

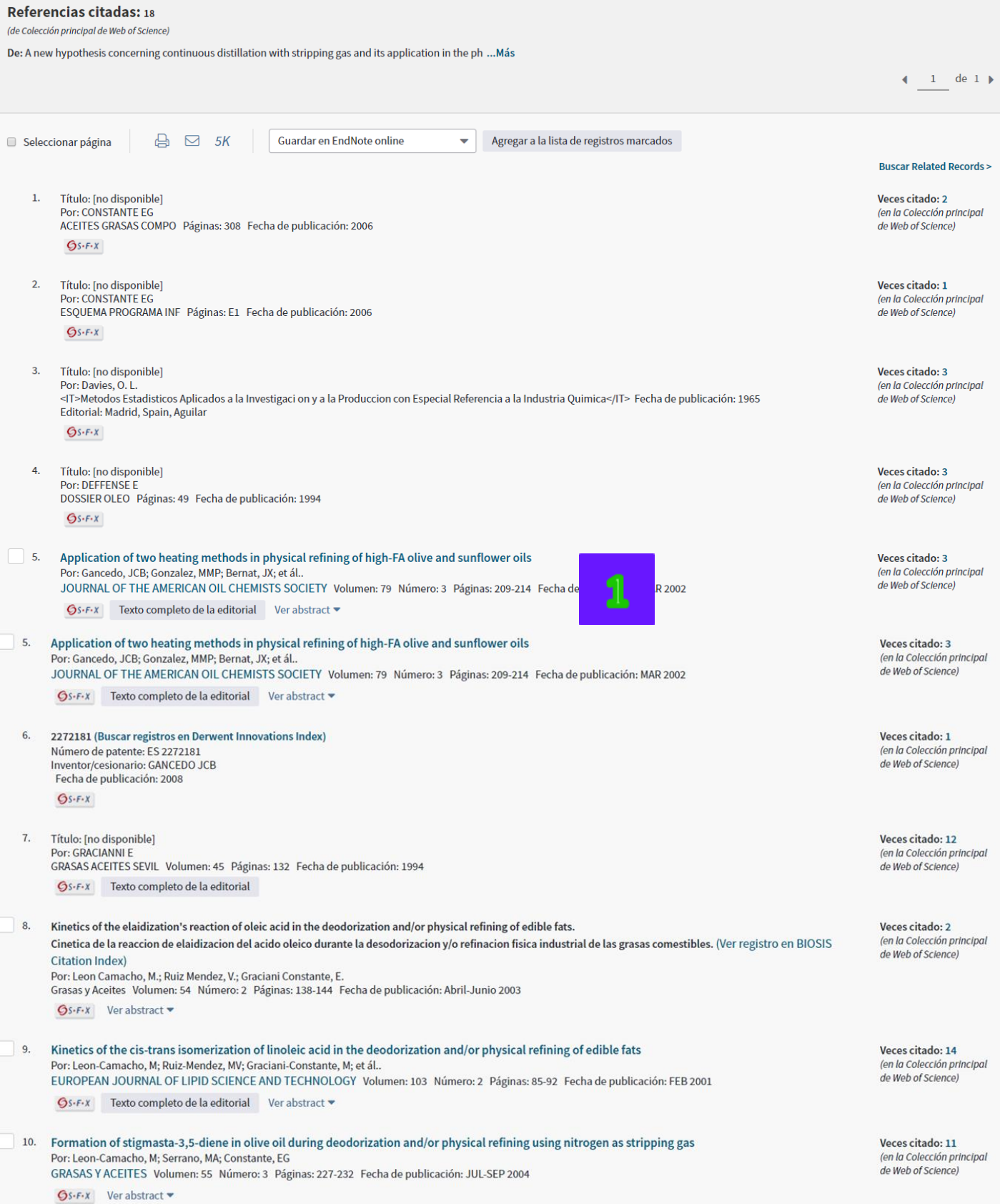

8. Kinetics of the elaidization's reaction of oleic acid in the deodorization and/or physical refining of edible fats. Cinetica de la reaccion de elaidizacion del acido oleico durante la desodorizacion y/o refinacion fisica industrial de las grasas comestibles. (Ver registro en BIOSIS Citation Index)

10. Formation of stigmasta-3,5-diene in olive oil during deodorization and/or physical refining using nitrogen as stripping gas Por: Leon-Camacho, M; Serrano, MA; Constante, EG GRASASY ACEITES Volumen: 55 Número: 3 Páginas: 227-232 Fecha de publicación: JUL-SEP 2004 OS.F.X Ver abstract .

1. Haga clic en el título con hiperenlace (en azul) de la referencia para ir al registro completo de la referencia.

2. Se presenta el título completo de la fuente para registros indexados en Web of Science.

3. Es posible exportar las referencias citadas (imprimir, enviar por correo electrónico, enviar a un gestor de referencias)

4. Web of Science Group indexa la referencia en completo, tal y como publicado en la publicación original.

5. Algunas referencias aparecen sin enlace al registro del documento. Por ejemplo:

- Monografías tales como libros y tesis

- Artículos citados "in press" (en prensa) 
- Cualquier artículo no indexado en la base de datos

- Variantes de la referencia (datos incompletos o datos erróneos)

- Citas a trabajos publicados en años anteriores a su suscripción 


\section{Descubrir y Navegar por la La Red de Citas}

\section{Web of Science}

Por: Mlakar, J (Mlakar, Jernej) ${ }^{[1]}$; Korva, M (Korva, Misa) ${ }^{[2]}$; Tul, N (Tul, Natasa) ${ }^{[3]}$; Popovic, M (Popovic, Mara) ${ }^{[1]}$; Poljsak-Prijatelj, M (Poljsak-Prijatelj, Mateja $^{\left[{ }^{[2]}\right.}$; Mraz, J (Mraz, Jerica) ${ }^{[1]}$; Kolenc, M (Kolenc, Marko) ${ }^{[2]}$; Rus, KR (Rus, Katarina Resman) ${ }^{[2]}$; Vipotnik, TV (Vipotnik, Tina Vesnaver) ${ }^{[4]}$; Vodusek,

VF (Vodusek, Vesna Fabjan) ${ }^{[3]} \ldots$...Más

NEW ENGLAND JOURNAL OF MEDICINE

Volumen: 374 Número: 10 Páginas: 951-958

DOI: 10.1056/NEJMoa1600651

Fecha de publicación: MAR 102016

Tipo de documento: Article

Ver impacto de la revista

\section{Abstract}

A widespread epidemic of Zika virus (ZIKV) infection was reported in 2015 in South and Central America and the Caribbean. A major concern associated with this infection is the apparent increased incidence of microcephaly in fetuses born to mothers infected with ZIKV. In this report, we describe the case of an expectant mother who had a febrile illness with rash at the end of the first trimester of pregnancy while she was living in Brazil. Ultrasonography performed at 29 weeks of gestation revealed microcephaly with calcifications in the fetal brain and placenta. After the mother requested termination of the pregnancy, a fetal autopsy was performed. Micrencephaly (an abnormally small brain) was observed, with almost complete agyria, hydrocephalus, and multifocal dystrophic calcifications in the cortex and subcortical white matter, with associated cortical displacement and mild focal inflammation. ZIKV was found in the fetal brain tissue on reverse-transcriptase-polymerase-chain-reaction (RT-PCR) assay, with consistent findings on electron microscopy. The complete

En un registro de la Web of Science se observa dos totales de las veces citado.

Según el artículo ejemplo:

1. Total de las veces citado que origina de artículos indexados en la Colección Principal de Web of Science (856)

¿Cómo se cuentan los artículos en que se cita en la colección principal de Web of Science?

Contamos citas de la lista de referencias de revistas, actas de conferencias, colecciones y otros documentos indexados en Web of Science.

El número de artículos en que se cita corresponde a todos los años (desde 1900 hasta la actualidad) y a los siete índices de Web of Science (no únicamente al año actual y a los índices incluidos en su suscripción, cuyo número puede ser menor). Los índices de citas son los siguientes:

- Science Citation Index Expanded

- Social Sciences Citation Index

- Arts \& Humanities Citation Index

- Conference Proceedings Citation Index - Science

- Conference Proceedings Citation Index - Social Sciences \& Humanities

- Book Citation Index-Science

- Book Citation Index-Social Sciences \& Humanities 
Además, no contamos la misma referencia (citas duplicadas) más de una vez en una única fuente. Por ejemplo, si un autor cita un trabajo cinco veces en el cuerpo de un artículo (citas abreviadas dentro de texto), solo procesamos y contamos la referencia una vez.

La metodología para calcular el número de veces que se cita un trabajo se aplica a todos los registros de Web of Science y a todas las suscripciones de Web of Science. Si consulta las Veces citado de un registro en cualquier parte del mundo, el valor será siempre el mismo.

2. Número de todas las veces citado (910)

El número de todas las veces citado muestra el número de veces que el registro fue citado por otros elementos de todos los productos que se clasifican como índices de citas.

Los registros duplicados en los índices de citas solo se cuentan una vez. Sin embargo, un registro de un documento puede aparecer en varias bases de datos de productos. Los índices de citas incluyen:

- Colección principal de Web of Science

- BIOSIS Citation Index

- Chinese Science Citation Database

- Data Citation Index

- Russian Science Citation Index

- SciELO Citation Index

\section{Ventajas de la Red de Citas}

- La red de citas nos permite descubrir investigación por las conexiones establecidas por los autores.

- Es posible observar tendencias de investigación y seguir la evolución de un tema.

- La red de citas nos permite descubrir investigación anterior o las antecedentes de un tema.

\section{Las Referencias Citas-datos disponibles}

Los datos bibliográficos y de abstractos están disponibles en la extracción de los registros seleccionados en la página Referencias citadas. Los datos de referencias citadas y del registro completo no están incluidos en la extracción.

Para extraer datos de la página Referencias citadas, el registro debe ser un registro fuente indexado en nuestros productos y su institución debe tener derechos de suscripción al producto.

Dispone de dos opciones si desea ver y extraer datos de referencias citadas y del registro completo de un registro específico. 
1. Haga clic en el enlace Título de un registro fuente para acceder a la página de registro completo. En la página de registro completo, seleccione los datos que desee imprimir, enviar por correo electrónico, guardar o exportar.

2. Haga clic en la casilla de verificación que aparece en la columna situada más a la izquierda de un registro. Haga clic en el botón Agregar a la lista de registros marcados para agregar registros seleccionados a su lista de registros marcados. En la página Lista de registros marcados, seleccione los datos que desee imprimir, enviar por correo electrónico, guardar o exportar.

\section{Registros Relacionados}

Haga clic en el vínculo Buscar Related Records para recuperar registros de documentos que citan las mismas referencias.

Al buscar en Related Records, se asume que los documentos que citan los mismos trabajos están relacionados por materia, independientemente de que su texto o sus títulos contengan los mismos términos. Cuantas más referencias citadas compartan dos documentos, más estrecha será su relación por materia.

Este concepto de una relación por materia es 'la asociación de ideas' creada por Eugene Garfield.

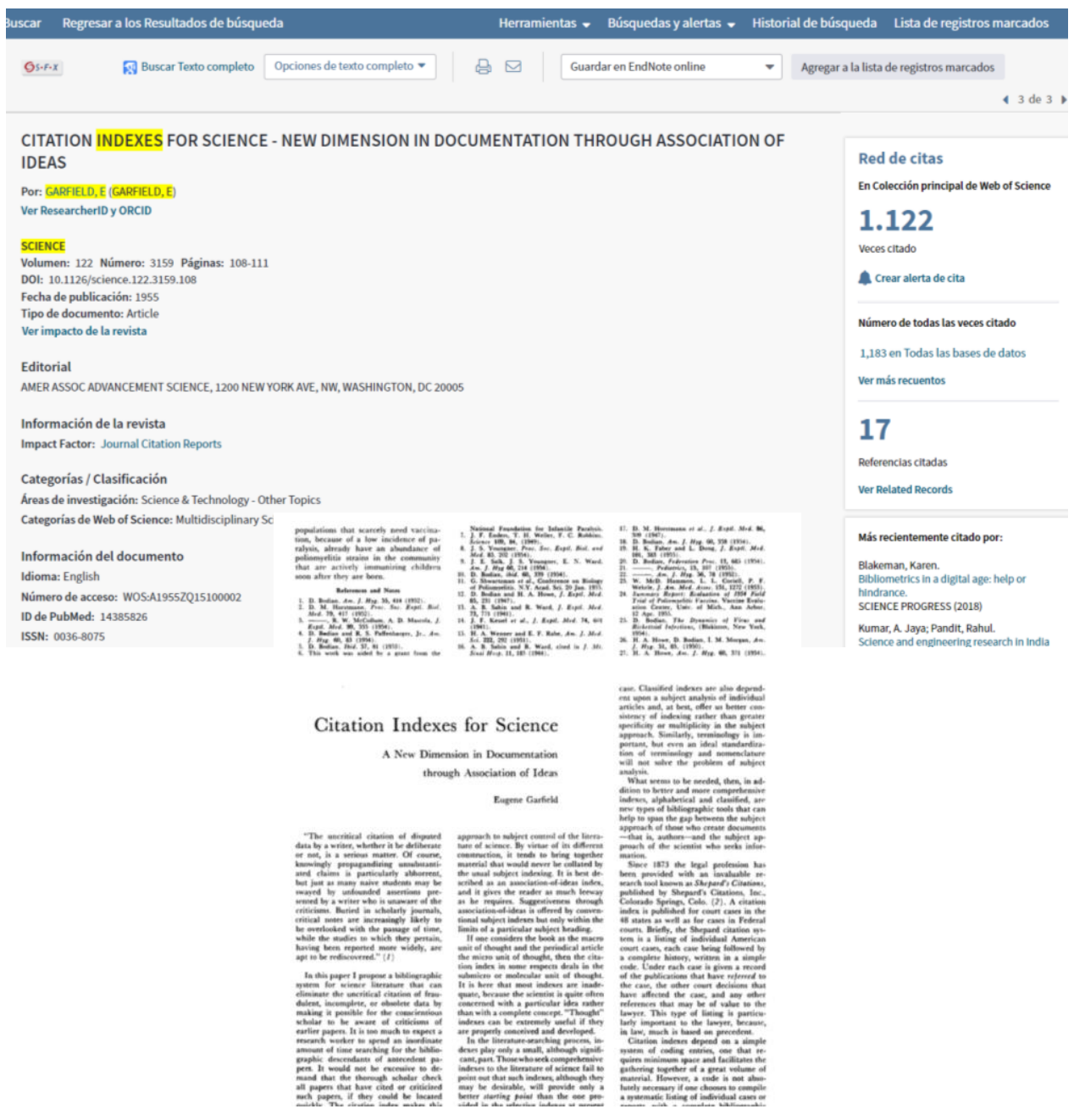




\section{Las Veces Citado de Todas Las Bases}

- La Web of Science incluye otras bases que también indexan las bibliografías de los documentos indexados.

- Estas bases contribuyen al total de citas de un artículo y así se establece un total de citas global que reúne todas las referencias citadas en la WOS a un artículo.

- Esta conexión de citas le permite entender mejor la repercusión y el impacto de un artículo en el ámbito científico indexado en la Web of Science.

- Las veces citado de la Web of Science recoge citas de la Colección Principal de Web of Science, el Biosis Citation Index, el Chinese Science Citation Index, el Data Citation Index, el índice de citas de SciELO y el Russian Science Citation Index.

- Este total de las veces citado es completo para todos los usuarios, no depende de la suscripción de su institución.

\section{Web of Science}

I) Clarivate

Buscar Regresar a los Resultados de búsqueda Herramientas - Búsquedas y alertas - Historial de búsqueda Lista de registros marcados

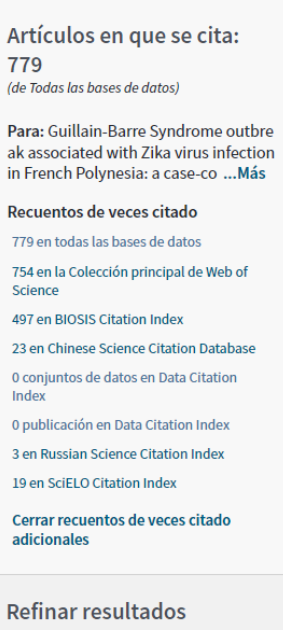

Número de todas las veces citado

779 en Todas las bases de datos

754 publicación(es) en Colección principal de Web of Science

708 en Science Citation Index Expanded (SCIE), Social Science Citation Index (SSCI) y Arts \& Humanities Citation Index (A\&HCI)

42 en Emerging Sources Citation Index (ESCl)

8 en Conference Proceedings Citation Index - Science (CPCI-S); Conference Proceedings Citation Index-Social Science \& Humanities (CPCI-SSH)

8 en Conference Proceedings Citation Index - Science (CPCI-S)

0 en Conference Proceedings Citation Index - Social Science \& Humanities (CPCI-SSH)

- 6 en Book Citation Index-Science (BKCI-S); Book Citation Index-Social Sciences \& Humanities (BKCI-SSH)

6 en Book Citation Index-Science (BKCI-S)

1 en Book Citation Index-Social Sciences \& Humanities (BKCI-SSH)

497 publicación(es) en BIOSIS Citation Index

23 publicación(es) en Chinese Science Citation Database

o conjunto(s) de datos en Data Citation Index

o publicación(es) en Data Citation Index [i]

3 publicación(es) en Russian Science Citation Index

19 publicación(es) en SciELO Citation Index

4. Se puede examinar donde originan las citas al nivel de la base y del índice. El número total de todas las bases es sin duplicación. Para las bases incluidas en su suscripción las citas se presentan en el color azul y el número está vinculado a los registros. 


\section{Una Búsqueda en Todas Las Bases de Datos}

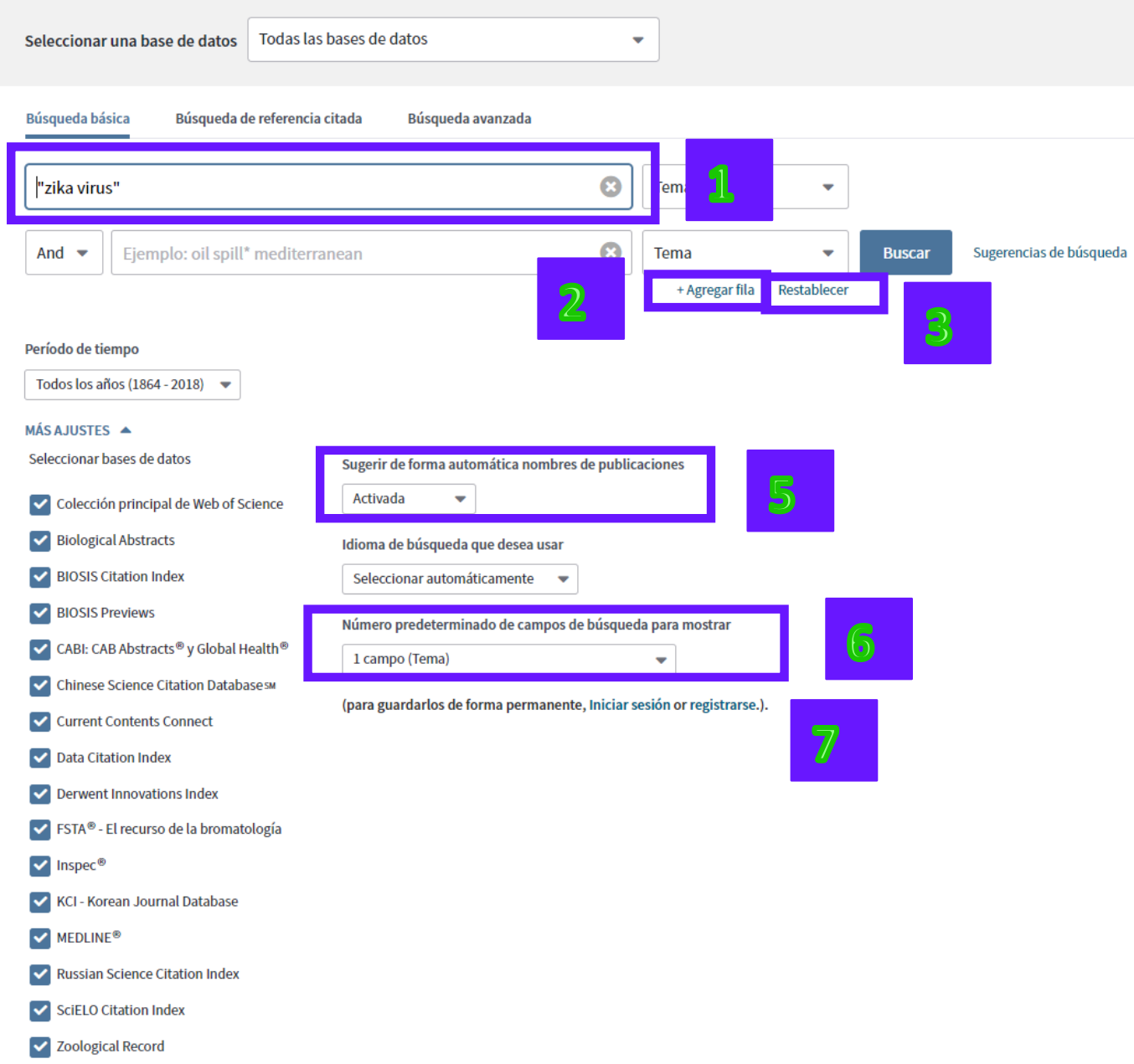

La búsqueda en Todas las bases de datos le permite consultar simultáneamente todas las bases contratadas por su institución.

Pasos de una búsqueda básica en Todas las Bases de Datos.

1. Ingrese sus términos de búsqueda en uno o varios campos de búsqueda.

2. El enlace Agregar otro campo le permite agregar más campos de búsqueda a la página Búsqueda básica.

3. El enlace Restablecer formulario le permitirá borrar cualquier consulta de búsqueda que haya introducido. Esta acción restablece la página de búsqueda a los campos de búsqueda originales. Esta acción se aplica a la búsqueda de autor y a la búsqueda de referencia citada.

4. En enlace Seleccionar del índice le permite seleccionar un elemento (por ejemplo, el nombre de una publicación o el nombre de un autor) cuando realice una búsqueda de autor o de nombre de publicación.

5. La opción Sugerir de forma automática nombres de publicaciones le permite activar o desactivar sugerencias para nombres de publicaciones. Cuando la función esté activada, el producto ofrece una lista de nombres de publicaciones basados en los 
caracteres que introduce en el campo de búsqueda. Por ejemplo, si introduce CANC, el producto muestra una lista de publicaciones que empiezan con estos cuatro caracteres como, por ejemplo, Cancer Biology Therapy y Cancer Investigation.

6. La opción Número predeterminado de campos de búsqueda para mostrar le permite seleccionar solo el campo Tema o puede seleccionar los campos Tema, Autor y Nombre de publicación.

7. La opción Guardar configuración le permite guardar su configuración para futuras sesiones de búsqueda.

8. Haga clic en Buscar para acceder a la página de resultados.

\section{Campos de Búsqueda en Todas Las Bases}

- Tema:

$>$ Título

$>$ Abstract

$>$ Palabras clave de autor

$>$ KeyWords Plus

> Campos de indexación especializadas de bases especializadas (Por ejemplo MeSH, Derwent Class Codes...)

Ingrese los términos de búsqueda en cualquier orden. Las siguientes búsquedas son equivalentes:

- radioactive decay

- decay radioactive

Para buscar una frase exacta, use comillas. Ejemplo: "radioactive decay"

Utilice comodines $(* \$$ ?) para buscar las formas singular y plural de las palabras.

Utilice los operadores de búsqueda (AND, OR, NOT, SAME, NEAR) para prescribir una relación entre los términos como, por ejemplo, equivalencia, exclusión o proximidad.

- Título

- Autor

- Identificadores de autores (www.researcherid.com o www.orcid.org)

- Autoría conjunta

- Editor

- Nombre de publicación

- DOI

- Año de publicación

- Dirección 


\section{Resultados de una Búsqueda por Todas Las Bases}

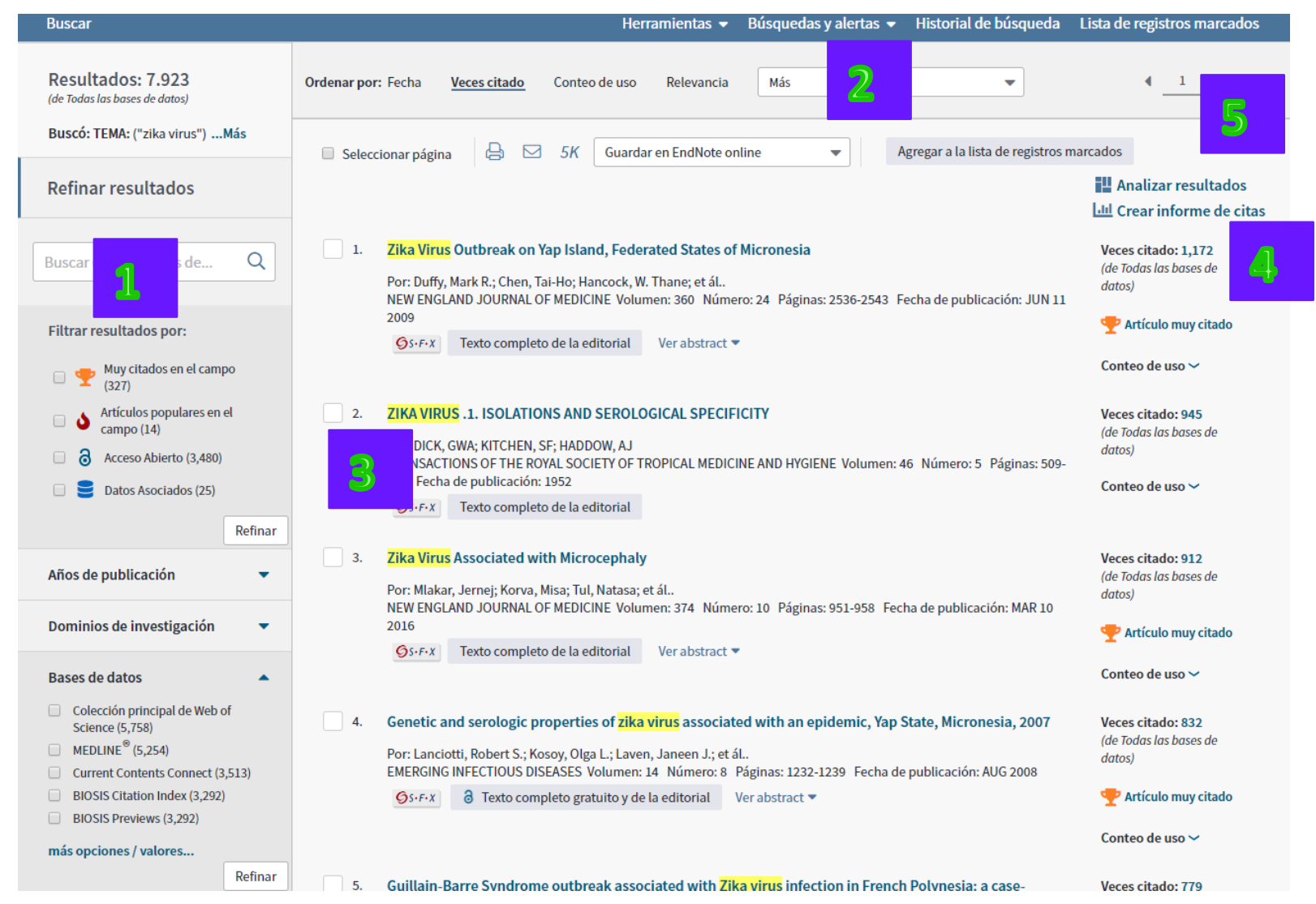

1. Filtrar resultados le permite clasificar los resultados por los campos siguientes:

- Artículo muy citado

- Artículo popular

- Acceso Abierto

- Datos asociados (hace falta tener una suscripción de la base Data Citation Index)

- Dominios de investigación (ciencia y tecnología, ciencias sociales, artes y humanidades)

- Bases de Datos

- Áreas de investigación (de la Web of Science, 150 en total)

- Tipo de documento

- Autor

- Autor Colectivo

- Editor

- Entidades financiadoras

- Títulos de las publicaciones

- Títulos de conferencias

- Años de publicación

- Idioma (de publicación de la revista)

- País/territorio 
2. Ordenar los resultados por las opciones en el menú desplegable. Automáticamente los resultados ordenan por la fecha de publicación, de lo más actual a lo más antiguo.

3. Se puede marcar registros para enviarlas a la lista marcada seleccionado las casillas de verificación. Se puede guardar las listas marcadas a su perfil de WOS y abrirlas en sesiones posteriores.

4. Se puede ejecutar el informe de citas sobre los resultados recuperados (menos de 10.000). Haga clic en 'Informe de citas' a mano derecha.

5. Analizar los resultados para identificar tendencias de investigación 


\section{Crear Un Registro Bibliográfico Superior}

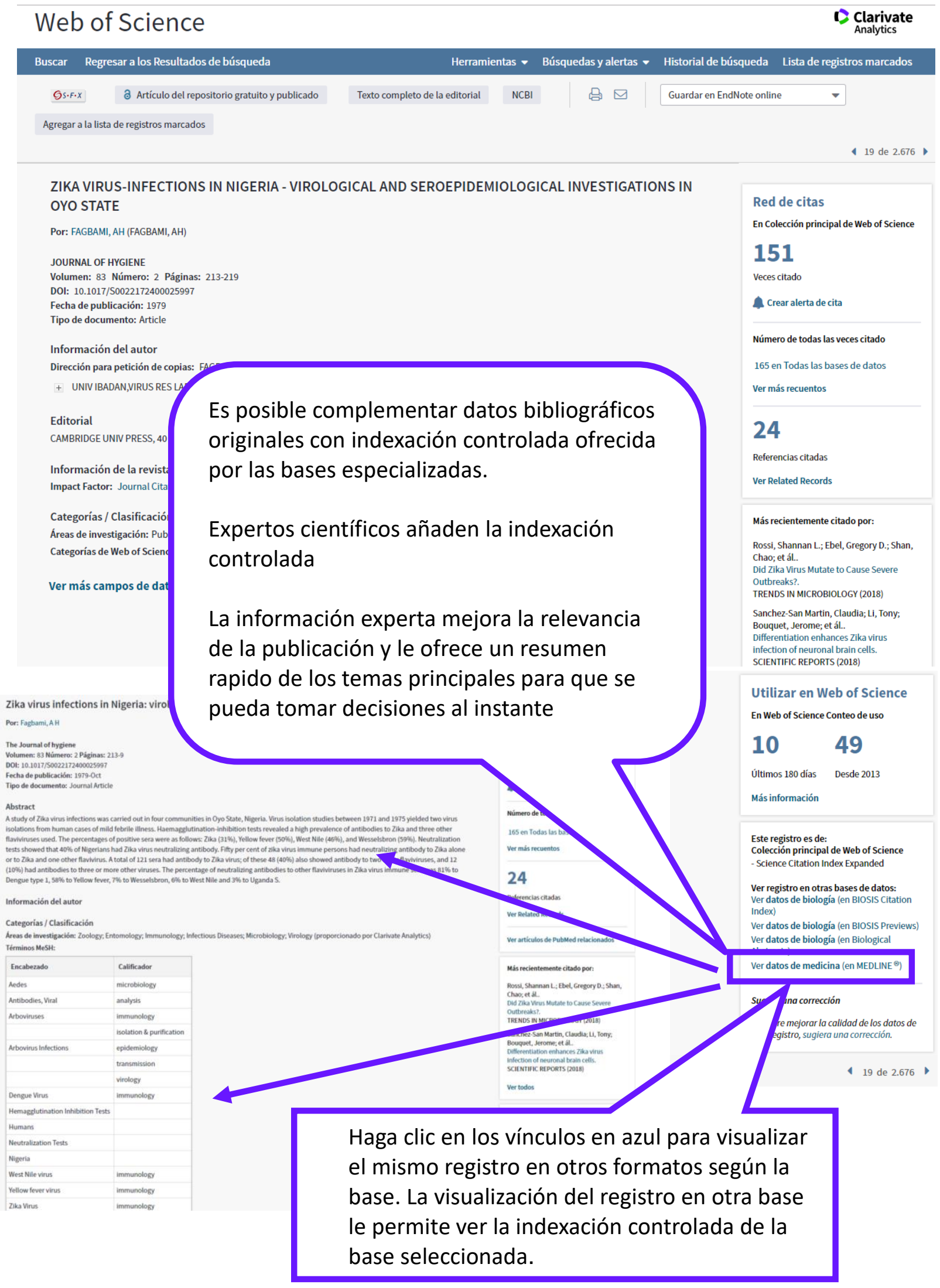




\section{Publons}
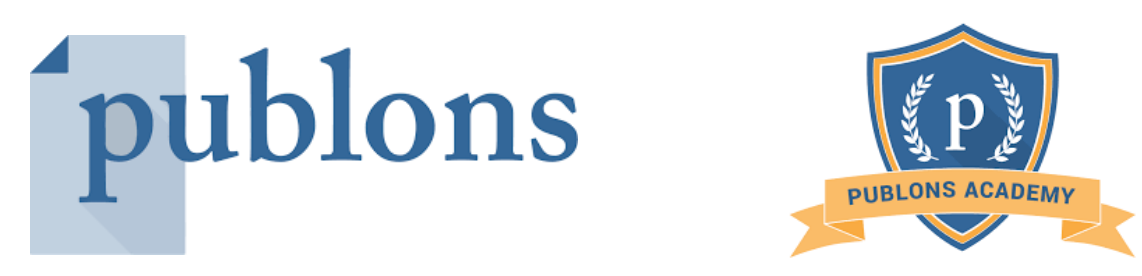

- ¿Que es? Una base de datos social y gratuita donde los autores y las revistas registran las revisiones científicas.

- ¿Cuándo? Es un concepto neozelandés a partir del año 2013 y fue adquirida por Web of Science Group en 2017

- ¿Para quién? El principal objetivo de Publons son los autores y las revistas, y en adición ofrece servicios adicionales (Publons Academy- la docencia de Peer Review)

- ¿Cuantas? El primer registro de revisiones que permite ser validadas asi como otras aplicaciones derivadas.

$>571.866$ investigadores

> 2.777 revistas oficiales participan en Publons

$>204.513$ revistas y actas en total

$>5.066$ instituciones

> 222 países

- ¿Por qué?

El Peer Review es el garante de la calidad de una revista, el corazón del sistema de evaluación. Es un trabajo que requiere una máxima especialización, que normalmente es confidencial y que normalmente no es reconocido de forma pública.

Publons trata de poner en valor este trabajo y optimizar ciertos aspectos, como la búsqueda de revisores, desde el año 2013.

\section{Objectivos del Peer Review}

- Prevenir la publicación de trabajos malos, filtrar aquellos estudios que provienen de ideas pobres o han sido pobremente planificados y ejecutados.

- Comprobar que la investigación se ha ejecutado de forma sistemática y con procedimientos lógicos y no existen defectos en su diseño.

- Asegurar que los resultados se comunican correctamente y de forma inequívoca, contextualizados con la investigación conocida.

- Confirmar que los resultados han sido interpretados correctamente y se han tenido en cuenta todas las interpretaciones posibles.

- Asegurarse de la solidez de los resultados, evitando los resultados especulativos o preliminares, pero al mismo tiempo sin bloquear nuevas líneas de investigación o teorías. 
- Seleccionar trabajos de gran interés para los lectores de la revista.

- Proveer al editor de evidencias sobre la calidad del trabajo, para facilitarle una valoración científica y justa que le ayude en la toma de decisiones.

- Incrementar la calidad y legibilidad de los trabajos.

Publons ofrece:

- Un perfil público con sus revisiones validadas, así como de contactar con las revistas.

- Mantener una historia verificada de su revisiones y trabajo como editor para las revistas más importantes en el mundo.

- Aprende como hacer la revisión por pares con el módulo 'Publons Academy'.

- Descarga un registro verificado de su trabajo de revisión, de editor y publicaciones en un CV.

- A las revistas les ofrece la posibilidad de gestionar su cartera de revisores, crear perfiles públicos de revisores, así como de contactar con nuevos revisores 'probados'.

El poder de Web of Science llega a Publons

Publons anuncia en 2018 un perfil de Publons mejorado, impulsado por integraciones con Web of Science.

Publons ahora combina sus publicaciones, las métricas de citas, el historial de revisión por pares y el trabajo de edición de revistas en un perfil único y fácil de administrar, lo que le ayuda a realizar un seguimiento de su impacto en la investigación.

- Todas sus publicaciones, importadas de Web of Science, ORCID o su administrador de referencias bibliográficas (por ejemplo, EndNote o Mendeley)

- Métricas de citas de confianza, importadas automáticamente desde Web of Science

- Su historial verificado de revisión por pares y edición de revistas, impulsado por asociaciones con miles de revistas académicas

- Registro descargable que resume su impacto académico como autor, editor y revisor.

El nuevo perfil de Publons es fácil de mantener, le permite administrar su identidad de investigador en línea y le ahorra tiempo en la preparación de evaluaciones, para que pueda volver a lo que es importante: hacer investigación 


\section{Utilidades de Publons: Búsqueda y Agrupación de Revisores}

\section{Buscar revisores por:}

- Nombre

- Líneas de investigación

- Revista

- Publicaciones

- Organizaciones

- Países

\section{Ordenar/ filtrar por:}

- Número total de revisiones verificadas

- Numero de revisiones en los últimos 12 meses

- Investigador altamente citado (Highly Cited Reseacher en Essential Science Indicators)

- Registros verificados de editor

\section{Identificar}

- Los mejores revisores en el mundo

- Los mejores revisores en un campo científico

- Los mejores revisores en un país

- Los mejores revisores en una organización

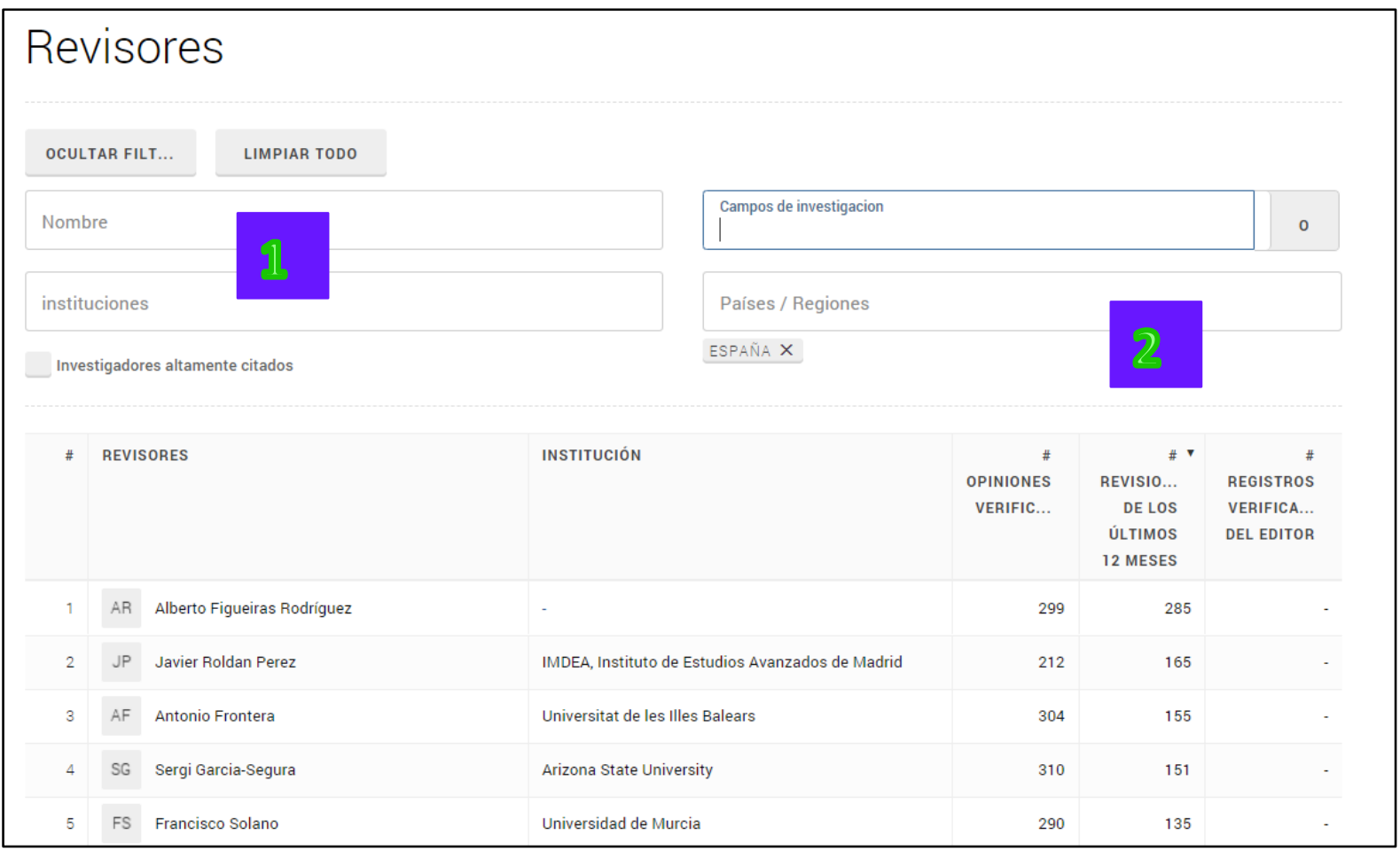




\section{Darse de alta en Publons}

1. Vaya a https://publons.com y haga clic en 'Register'.

2. Ahora puede iniciar sesión en Publons, EndNote, Web of Science e Researcher ID con una dirección de correo electrónico y una contraseña

3. Le recomendamos que inicie sesión en Publons con su dirección de correo electrónico habitual y restablezca su contraseña. Esto actualizará su contraseña para Publons, EndNote, Web of Science e ResearcherID

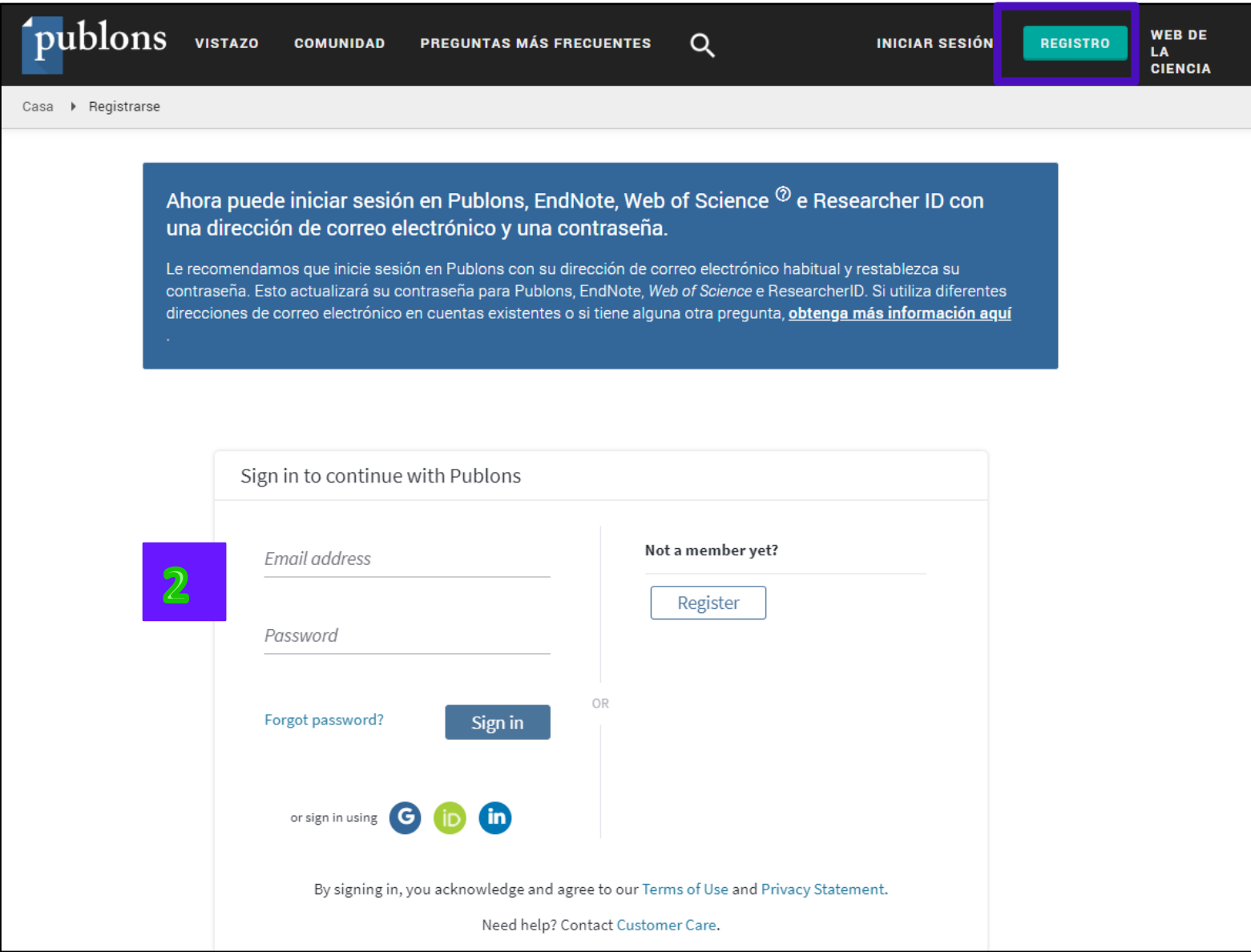




\section{Actualizar mi perfil de Publons}

1. Mi Panel de Control: azulejos

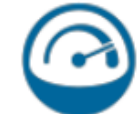

Rastrear mis citas

Obtenga los recuentos de citas de la Colección principal de Web of Science para sus publicaciones.

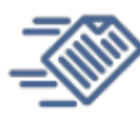

Administrar mis comentarios

Agregue opiniones de pares nuevas o anteriores para mostrar su experiencia.

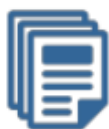

Mira mi perfil Mira cómo se ve tu perfil para otras personas en Publons.
Exportar mi registro

Descarga tu registro para

aplicaciones de

financiación o promoción.

2. Mi Panel de Control: mis actividades y mis módulos

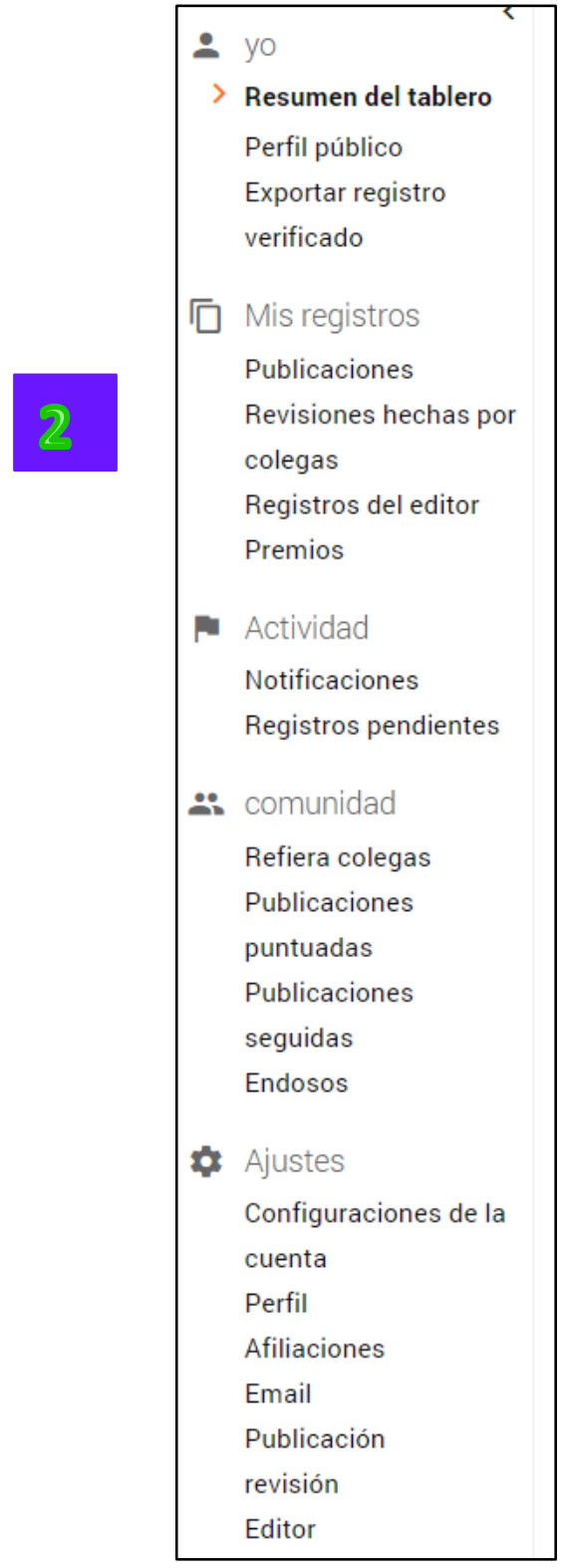

- Mis Registros: añadir revisiones y publicaciones

- Ajustes: Mi información personal (nombre, afiliaciones correos electronicios y campos de investigación) 


\section{Mis Registros: Importar Publicaciones a Publons}

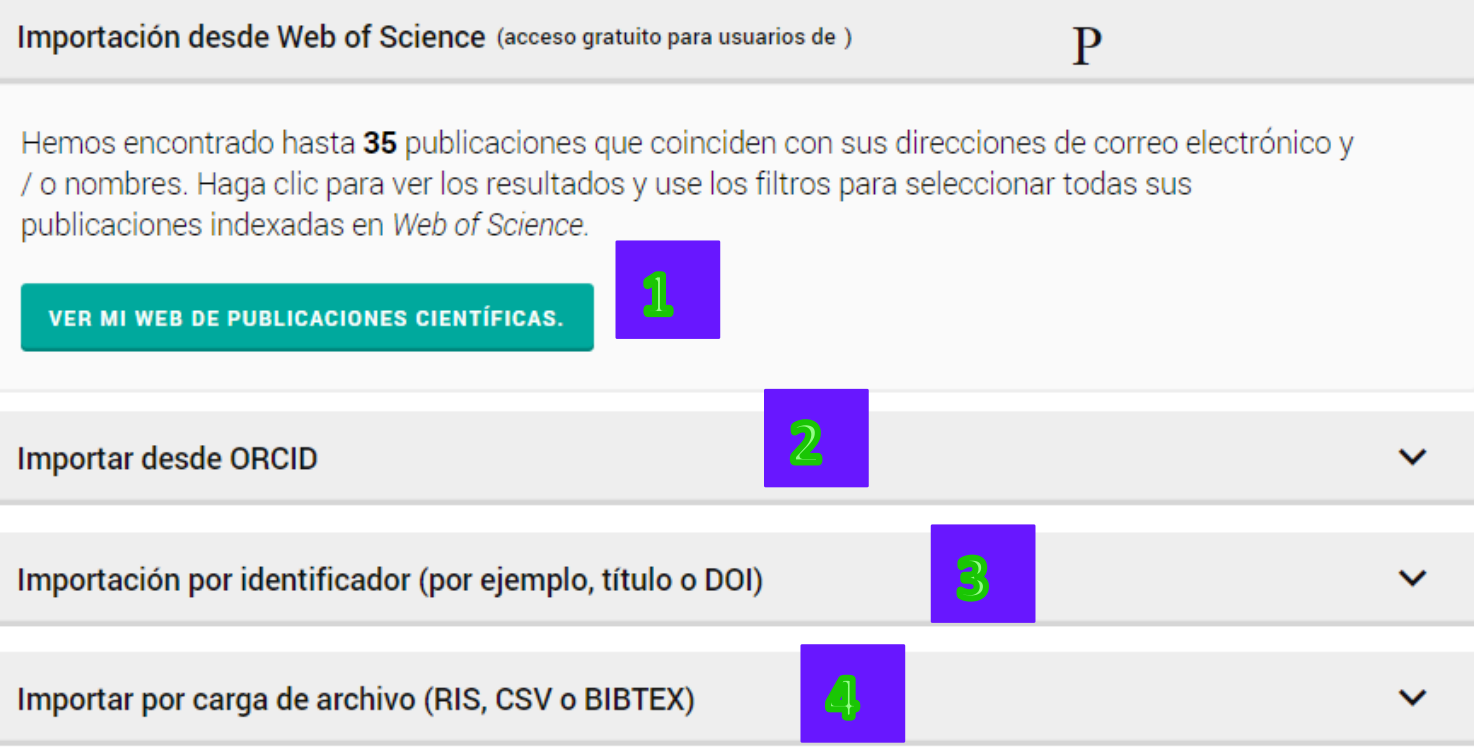

Existen 5 opciones para añadir publicaciones:

1. Importar publicaciones de la Web of Science según coincidencias con el correo electrónico y nombre en mi perfil de Publons.

2. Importar publicaciones incluidas en mi perfil de ORCID.

3. Importar publicaciones por un identificador (DOI)

4. Importar publicaciones por la subida de un archivo (RIS, CSV, BIBTEX).

5. Reclamar mis publicaciones en Web of Science y enviarlas a mi perfil de Publons. 


\section{Importar mis publicaciones a Publons: Reclamar mis publicaciones en la Web of Science}

El poder de Web of Science llega a Publons. Ahora es posible buscar tus publicaciones en WOS y enviarlas directamente a tu perfil en Publons. Esta mejora aporta la capacidad de buscar tus publicaciones por una variedad de opciones (nombre, RID/ORCID) y usar los filtros y/o análisis de resultados de Web of Science para precisar los resultados antes de reclamarlas.

1. Busco mis publicaciones por nombre o por buscador de autores o por DAIS (grupos)

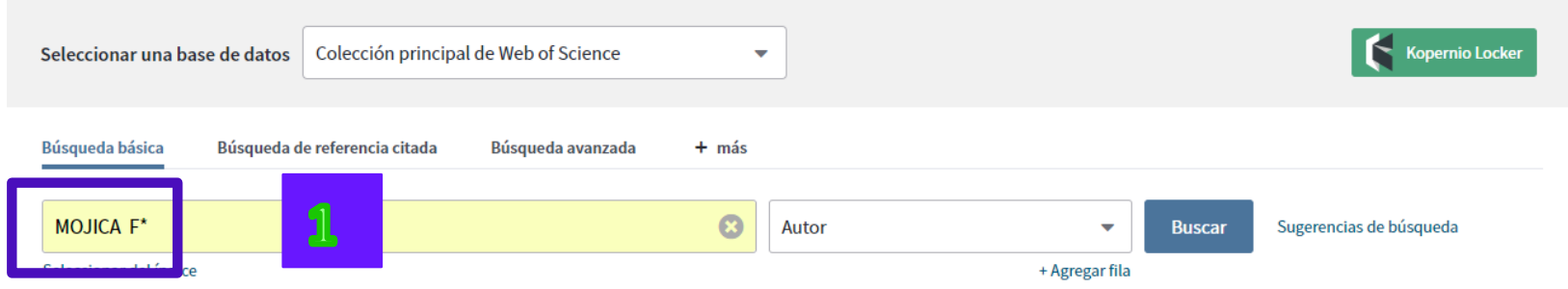

2. Busco publicaciones por identificadores (RID o ORCID)

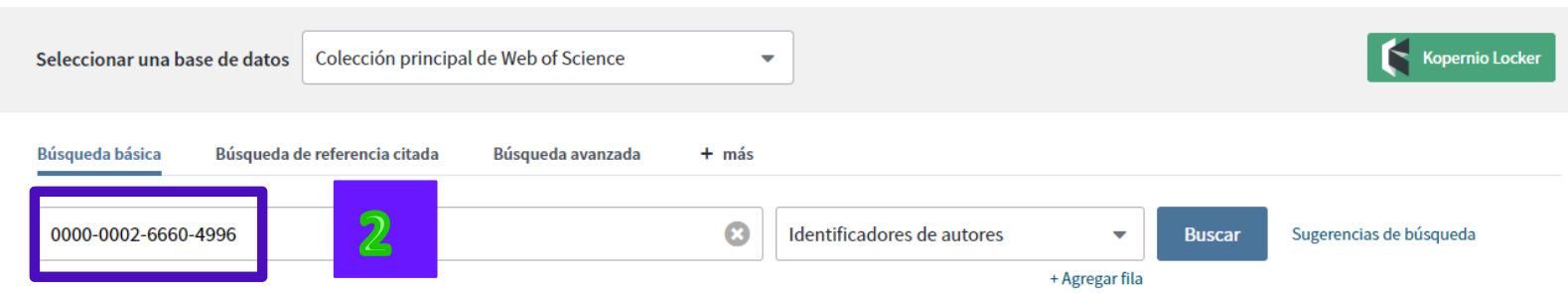

3. En la página de resultados, abre el menú desplegable de las opciones de exportación y seleccione 'Reclamación en Publons- enviar a Publons'

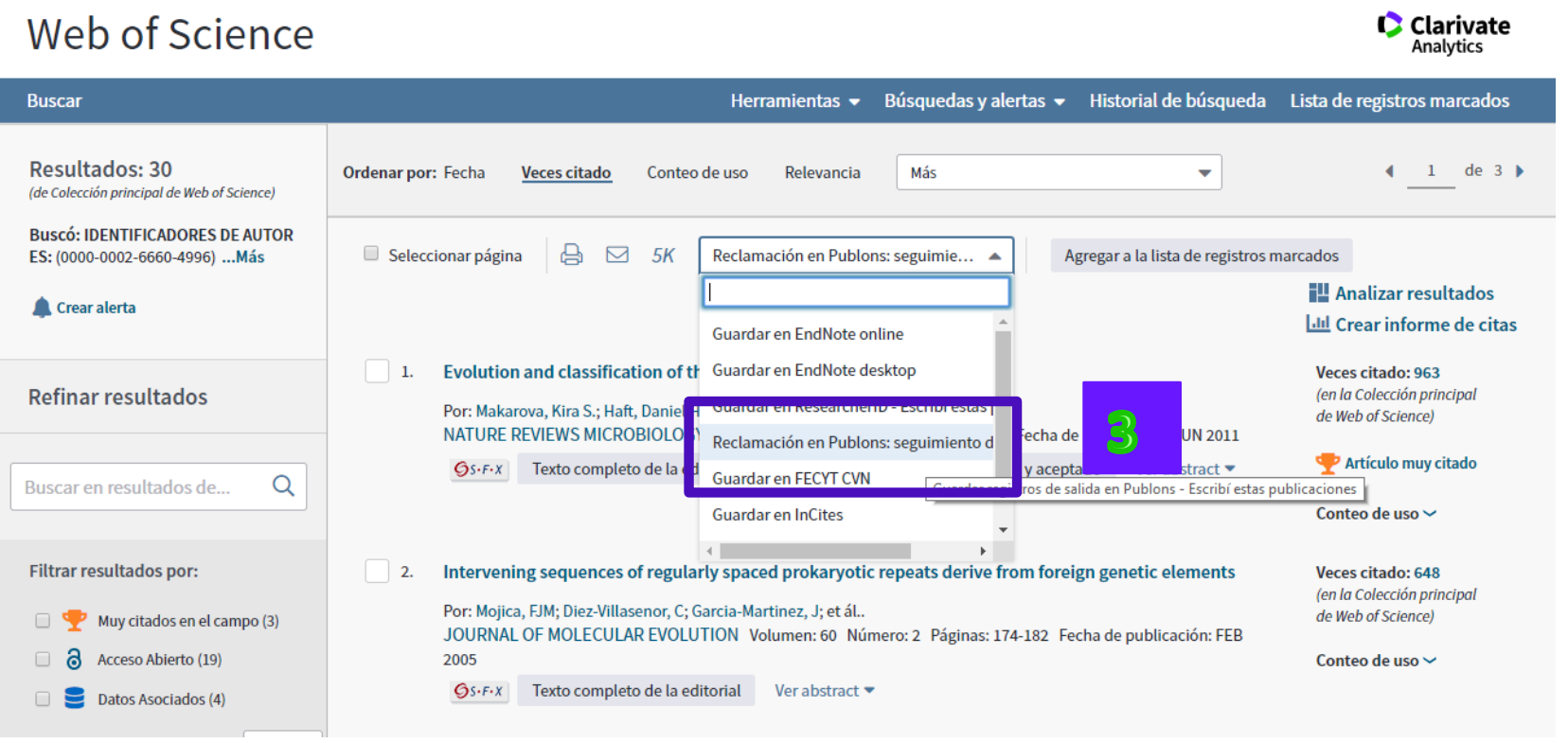


4. El sistema te pide aceptar que eres el autor de las publicaciones seleccionadas. Este paso de control intenta advocar el uso correcto de la exportación de publicaciones en WOS a Publons.

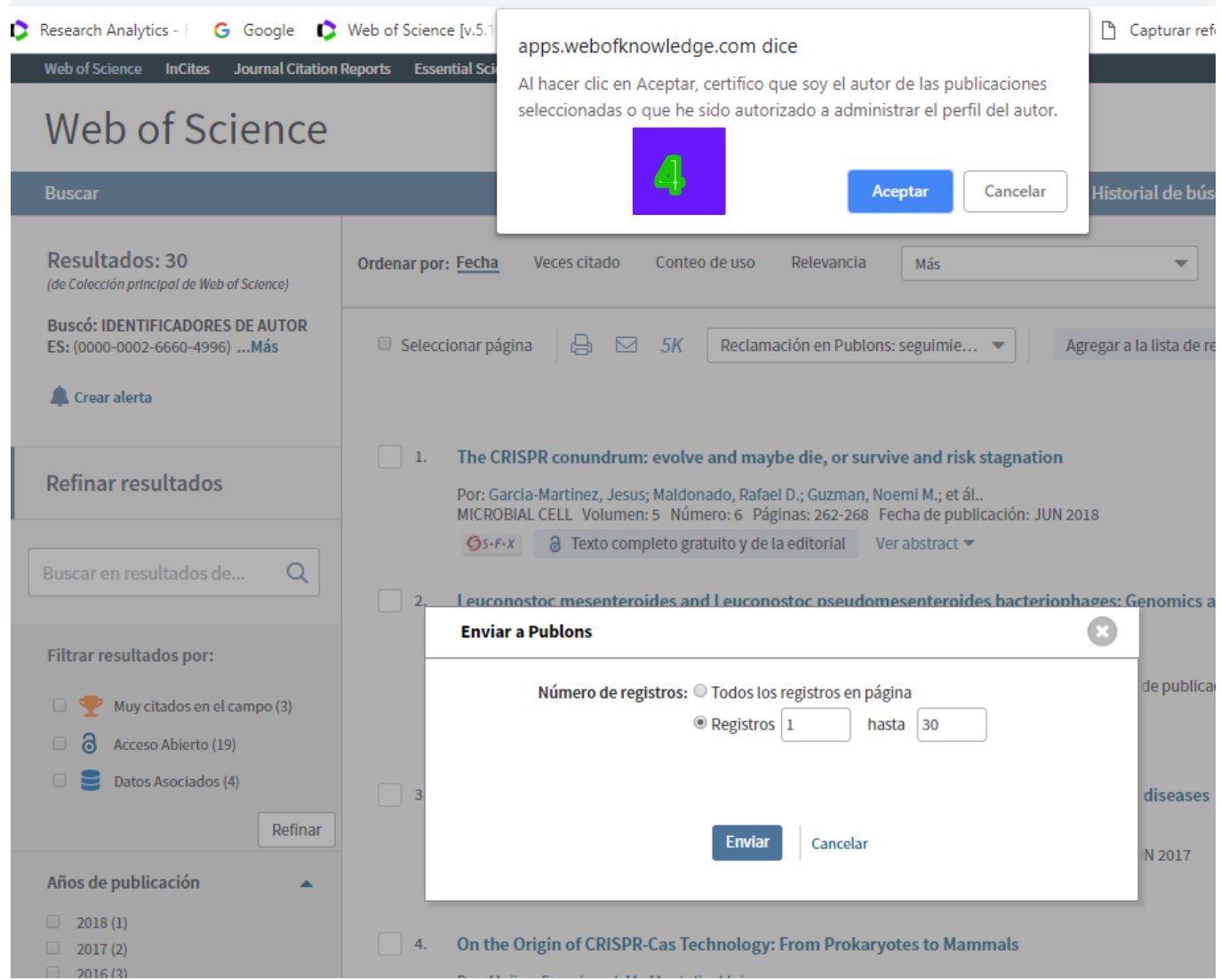

4. El sistema le dirige a la página de Publons y le pide confirmar la importación de la Web of Science.

\section{publons vistazo comunidad preguntas más frecuentes $Q$}

Importar desde la web de la ciencia

\section{Confirma tu importación de Web of Science}

Haga clic en el botón de abajo para importar sus registros.

COMENZAR A IMPORTAR 


\section{Importando 30 registros de Web of Science ...}

Sus registros se están importando, esto solo debería tomar unos segundos.

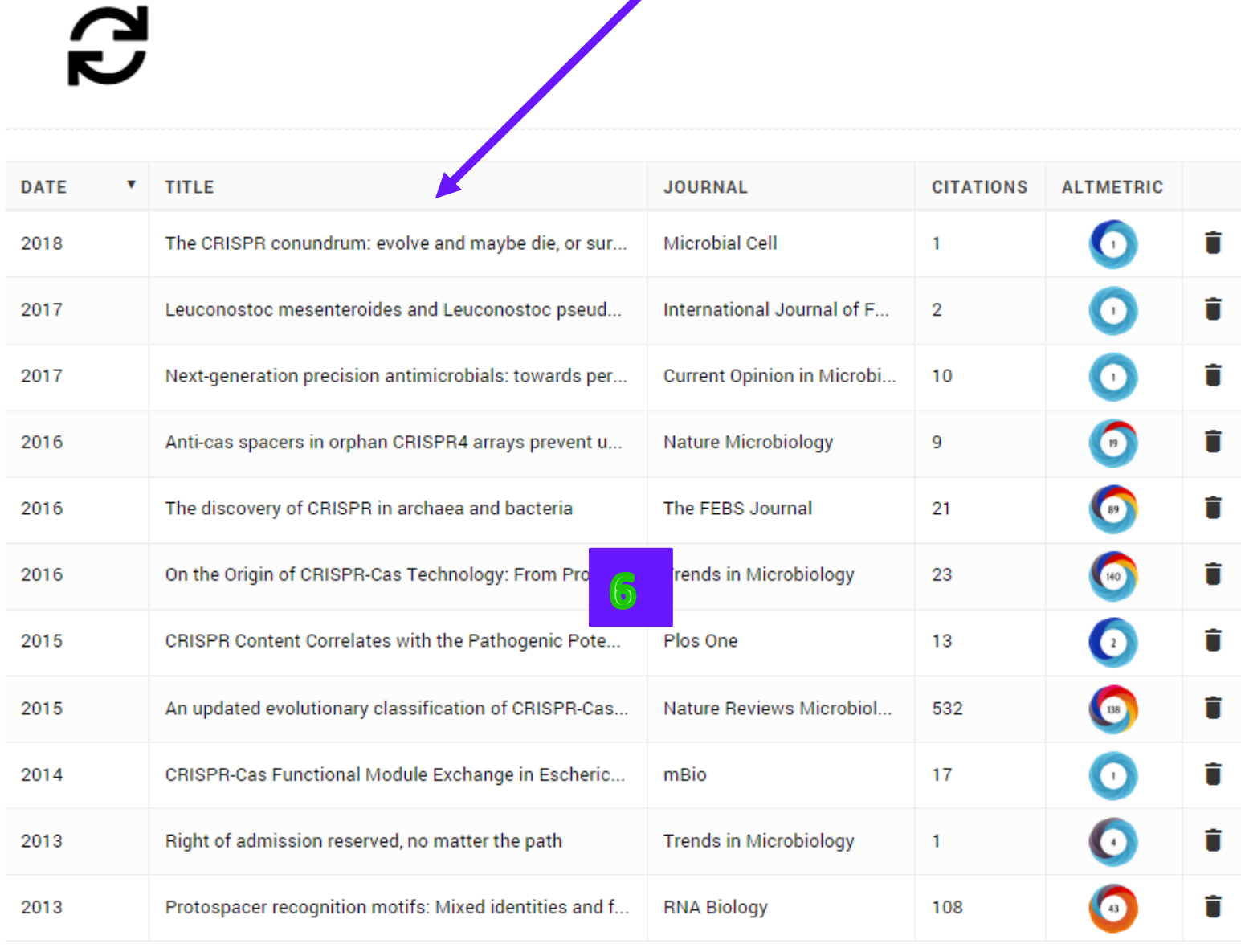

5. Las publicaciones seleccionadas en WOS se incorporan en el perfil. La información de Publons muestra:

- El año de publicación

- El título del articulo

- La revista

- Las veces citado (de la Colección Principal de la Web of Science)

- Datos del proveedor 'Altmetric'

- Icono del papelero para eliminar la publicación. 


\section{Publons: Datos de una Publicación}

El sistema de Publons genera un perfil único a cada publicación en la base. Este perfil proporciona información tal y como las veces citado de la Colección Principal de la Web of Science, información del proveedor Altmetric y conexiones a los perfiles de otros autores y de la revista en Publons.




Publons: Perfil de una Revista

\section{publons vistazo comunidad preguntas más frecuentes $Q$}

Revistas / Conferencias • Detalles de la revista / conferencia

REVISTA / CONFERENCIA

\section{Revista Española de Cardiología}

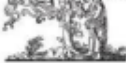

ELSEVIER

ACERCA DE

Revista Española de Cardiología, Revista Bilingüe Científica Internacional, Publicación de la Sociedad

Española de Cardiología.

CAMPO

\section{Cardiología y Medicina Cardiovascular}

VISITA LA PÁGINA WEB

PUBLICADO POR

I. Elsevier

PROPIEDAD DE

DU Sociedad Española de Cardiología

POLÍTICA DE REVISIÓN EN PUBLONS

- No permite que las revisiones se muestren públicamente.

- Sólo permite que los revisores muestren la revista que revisaron

OPINIONES

\section{Total: 44}

¿INTERESADO EN REVISAR PARA ESTA REVISTA?

Su interés en la revisión se comparte con revistas o conferencias cuando se asocian con nosotros. Más información.

HAGA CLIC PARA QUE SEPAN

MIEMBROS DE LA JUNTA EDITORIAL EN PUBLONS

Los usuarios de Publons han indicado que forman parte del consejo editorial de Revista Española de Cardiologia, pero no podemos verificar estas afirmaciones. Si usted es administrador de Revista Española de Cardiología, póngase en contacto para averiguar cómo puede verificar las contribuciones de los miembros de su consejo editorial y más.

LOS MEJORES REVISORES EN PUBLONS (MANUSCRITOS REVISADOS EN LOS ÚLTIMOS 12 MESES)
(16) Pablo Avanzas Ferná..
RA (2) Rafa Alonso
JG (2) Juan C Garcia-Rubira
JB (2) Javier Bermejo

AVALADO POR

NP.

JG 


\section{Mi Perfil Completo y Verificado de Publons}

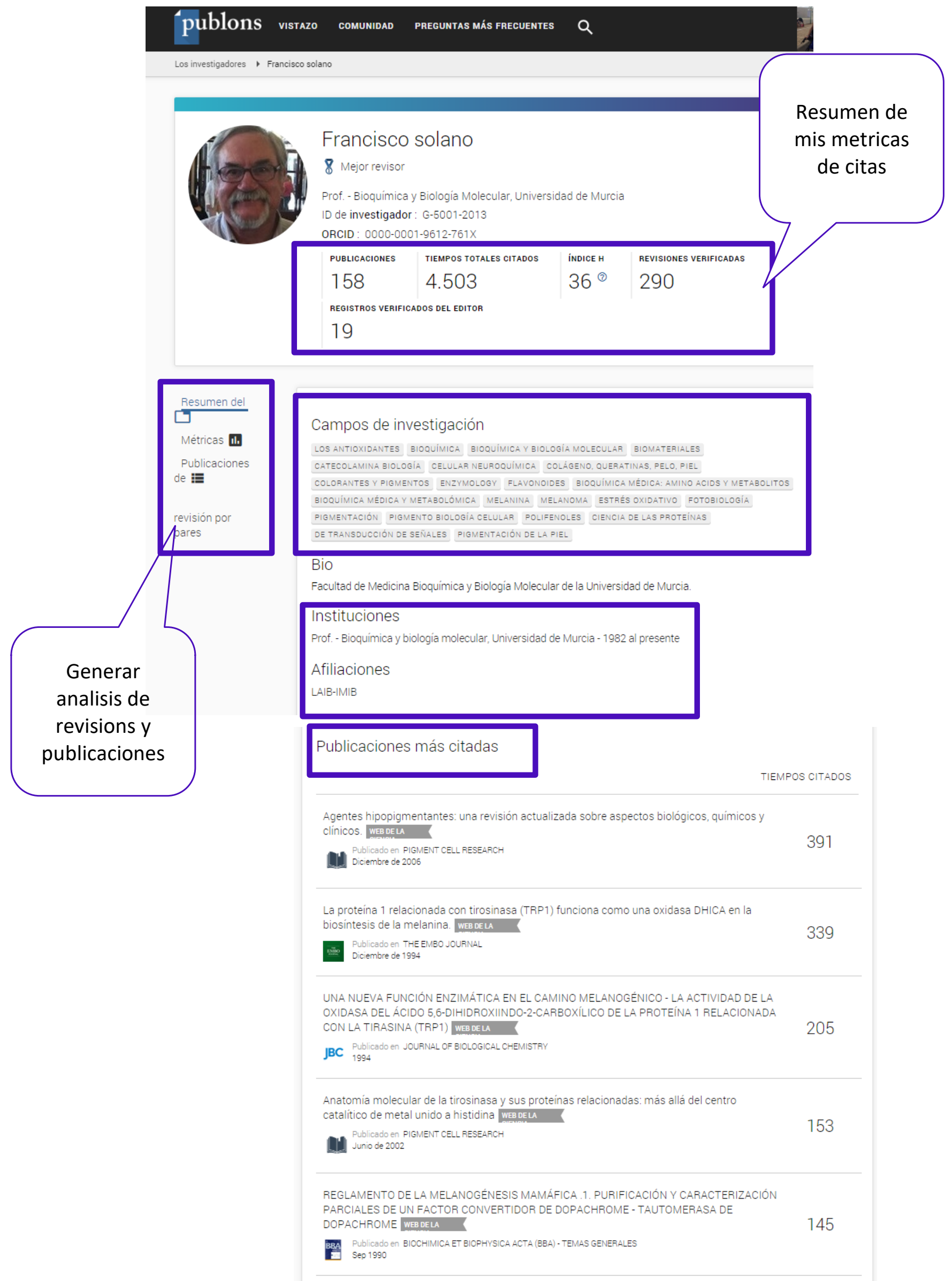




\section{Revistas publicadas en}

D. (26) Investigación de células de pigmento

DU (10) Biochimica et Biophysica Acta (BBA) - Te

(6) El diario FEBS

Wos

(4) Comunicaciones de investigación bi.

(4) La revista internacional de bioquímica.
Las revistas en las cual he publicado mis artículos

(5) Diario de Química Biológica

(4) Cartas de Microbiología FEMS

(3) Microbiología Aplicada y Biotecnolo.

El impacto de Francisco Solano en el tiempo.

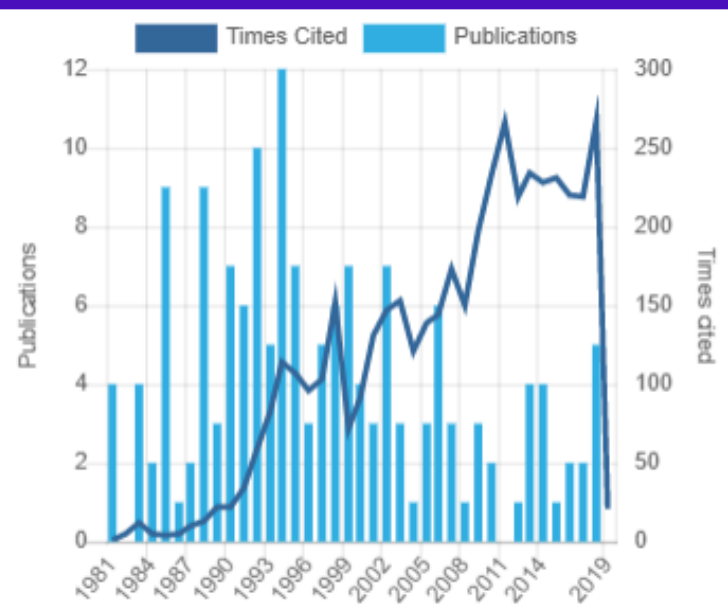

Year
Resumen de mis metricas de citas

Las estadísticas se calculan basándose únicamente en la información que se ha enviado a Publons Lea más sobre ellos aquí.

\section{Métricas de publicación}

\begin{tabular}{|c|c|c|c|c|}
\hline PUBLICACIONES EN & SUMA DE VECES & & PROMEDIO DE CITAS & PROMEDIO DE CITAS \\
\hline WEB OF SCIENCE & CITADA * & ÍNDICE H * & * POR ARTÍcULo & * POR AÑo \\
\hline
\end{tabular}

\section{7




\section{Análisis de Publons: Métricas de mis revisiones}

REVISIONES VERIFICADAS OPINIONES VERIFICADAS (ÚLTIMOS 12 MESES) REVISAR A RELACIÓN DE PUBLICACIÓN
290
Mediana: 3
135
Mediana: 1
2. 7 Mediana: $0.7: 1$

sión por pares

Opiniones por mes

Month

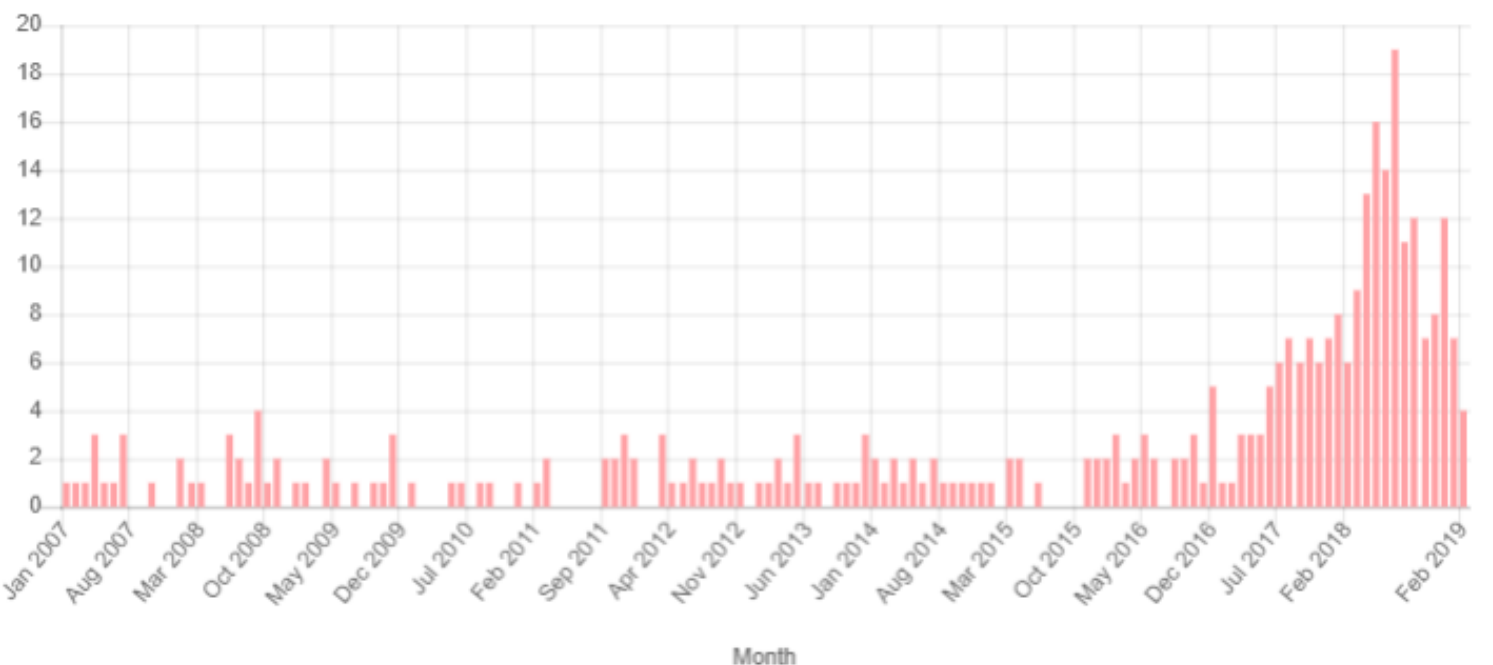

Longitud de revisión promedio

El número promedio de palabras por revisión (para el cual tenemos contenido), en comparación con el promedio de todos los revisores de campos y el promedio de revisores en instituciones afiliadas.

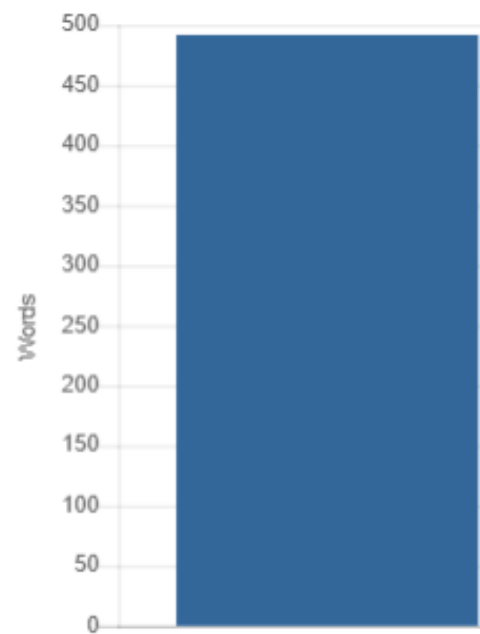

Francisco Solano

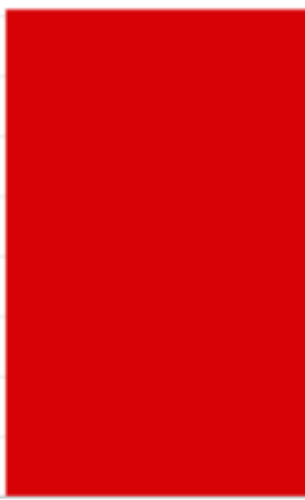

All reviewers

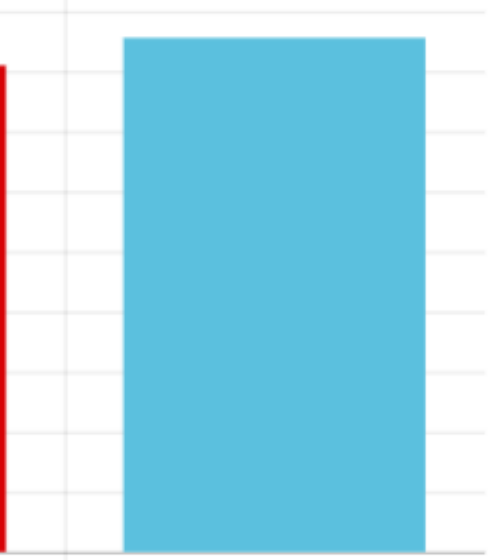

Universidad de Murcia 


\section{ORCID}

\section{¿Que es Orcid?}

- Es el proyecto Open Researcher and ContributorID (Orcid) que intenta resolver el problema de la identificación, ambigüedad y duplicidad en los nombres de los investigadores (autores y colaboradores) mediante la creación de un registro único (URL).

- Éste estará conectado con otros sistemas actuales de identificación de autor como Author Resolver, Inspire, IraLIS, RePEc, ResearcherID, Scopus Author Identifier y VIVO, entre otros.

- Orcid se vinculará a la producción de los investigadores facilitando conocer sus publicaciones, identificando colaboradores y revisores y en definitiva, favoreciendo el proceso de descubrimiento científico.

- Nació a finales del año 2009, a propuesta del Nature Publishing Group y de Web of Science Group y con el que se quiere conseguir un instrumento beneficioso para toda la comunidad científica: autores, universidades, agencias de financiación, sociedades profesionales, agencias gubernamentales y editores.

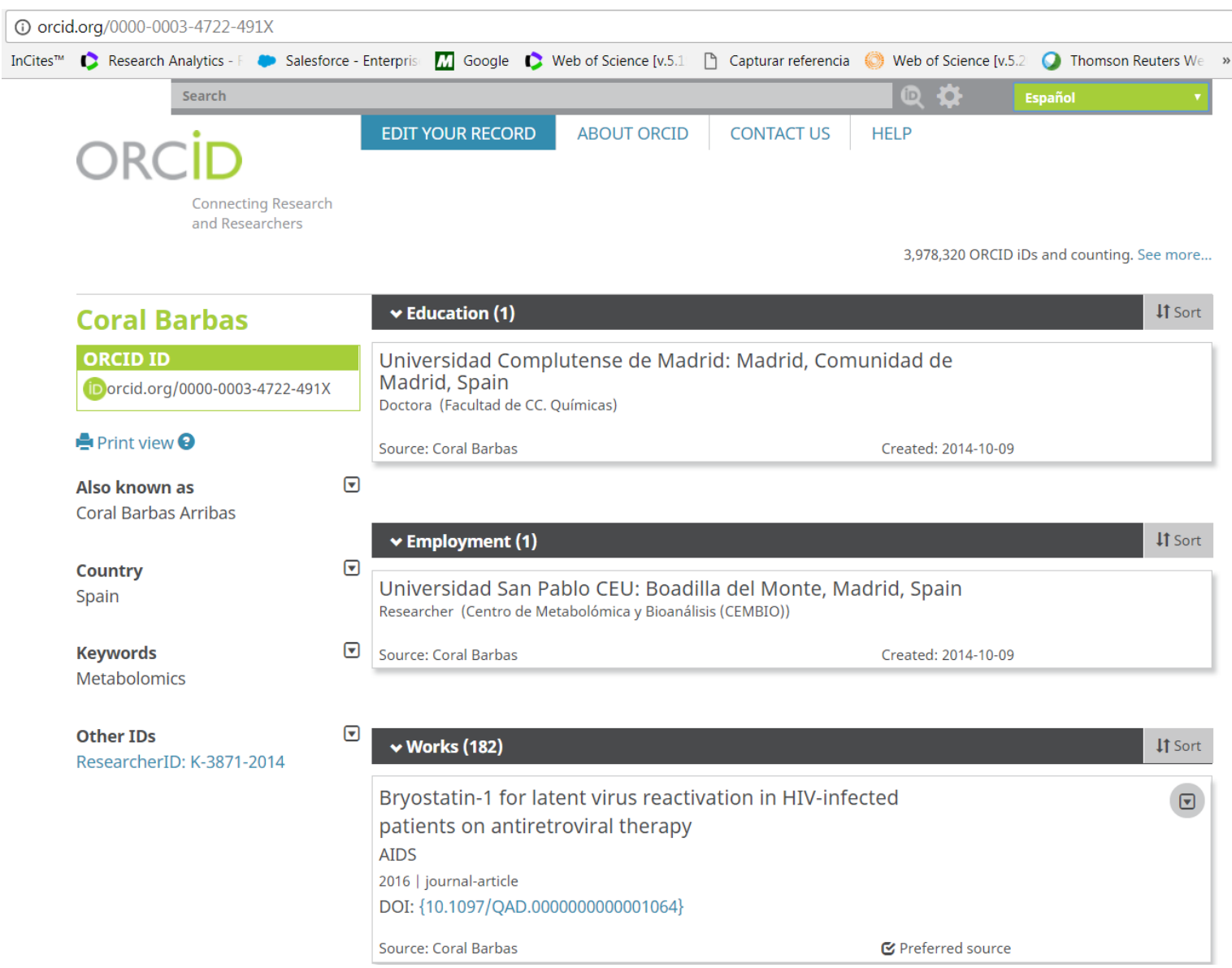




\section{ResearcherID}

\section{¿Qué es ResearcherID?}

\section{ResearcherID}

ResearcherID.com es un recurso disponible de forma gratuita para la comunidad de investigación académica global y multidisciplinar. Luego de registrarse, se le asignará un número de ID individual que estará con usted durante el transcurso de su carrera, con independencia de los cambios en los nombres o en la afiliación de su institución.

ResearcherID le permite crear un perfil en línea para mostrar su historial de publicaciones. Está diseñado para establecer una asociación eficiente entre usted y su trabajo académico, garantizando un registro preciso de resultados y atribuciones. De esta forma, se facilita una puerta de enlace para que sus colegas puedan localizar rápidamente su trabajo publicado e identificarle como colaborador potencial.

\section{Características:}

- Accesible desde cualquier sitio (www.researcherid.com).

- Le permite crear un listado de su producción científica en la Web.

- Se puede compartir su perfil con el público o mantenerse como privado.

- Usuarios no suscritos a Web of Science pueden buscar perfiles y encontrar colaboradores potenciales, oradores y revisores.

- Es posible buscar investigadores por cualquiera combinación de los criterios siguientes: nombre, identificación individual, palabra clave o institución o por país.

- Se puede introducir publicaciones de la Colección Principal y otras bases de datos de Web of Science a que su institución está suscrita, Endnote y otros gestores de referencias en el formato (RIS).

- Compatible con Unicode UTF8.

- Se presentan términos claves (keywords) sugeridos basados en términos que ya existen en el registro.

- Se muestran enlaces al registro completo para registros introducidos desde Web of Science (depende de su suscripción) y enlaces a la revista electrónica (DOI).

- Ejecute 'Los Laboratorios' (Research Labs) para explorar redes de colaboración y de citas según autor, categoría, país o institución. Se puede visualizar las redes en un mapa mundial interactivo.

- Genera métricas de citas basadas en las publicaciones introducidas de la Colección Principal de Web of Science:
o Índice $h$
- Distribución de citas por año
- Total de las veces citado
- Promedio de las veces citado 


\section{Creación de un Perfil en ResearcherID dentro de la Web of Science}

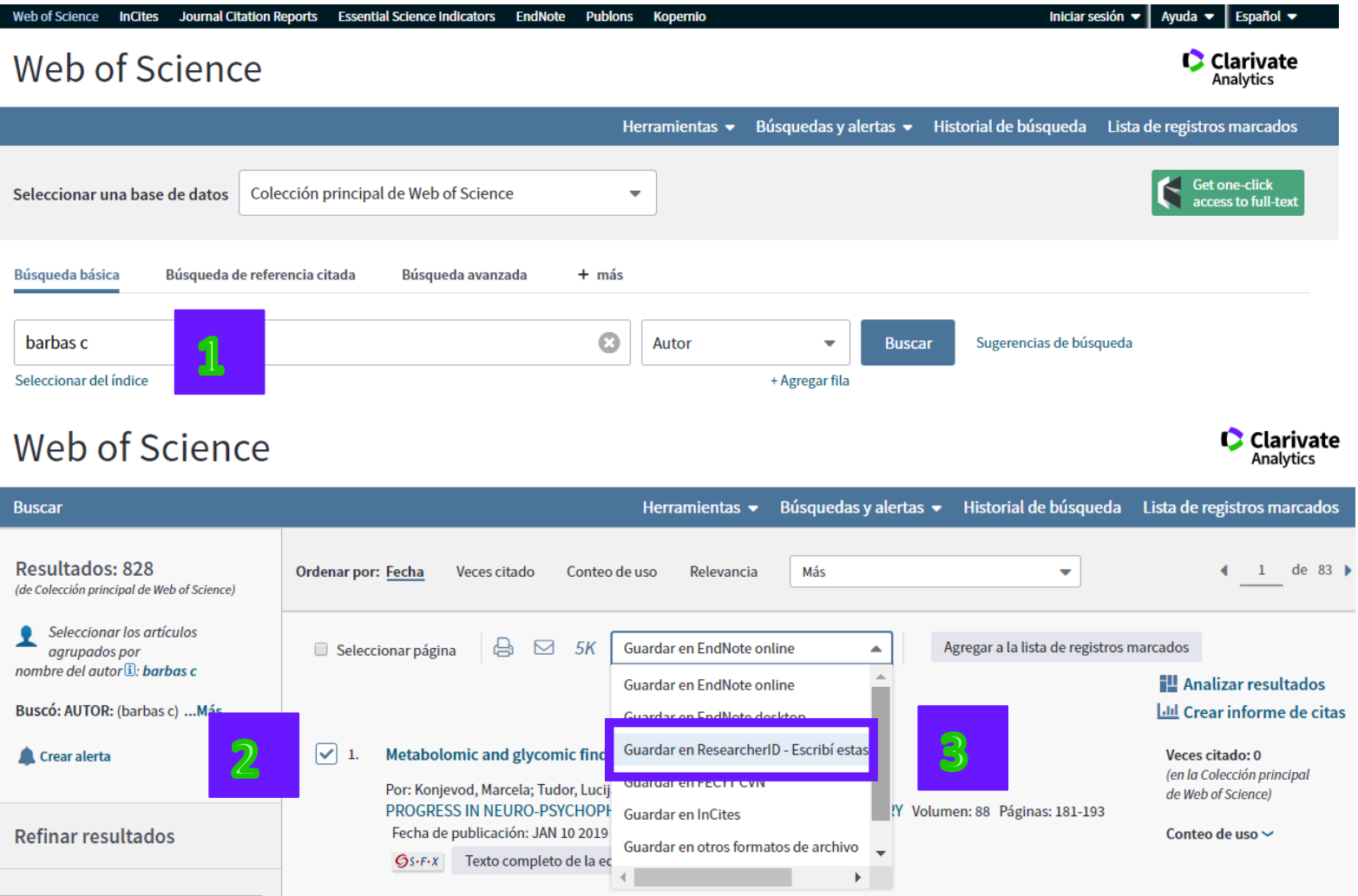

1. Busca sus publicaciones en la Colección Principal (o en cualquier otra base contratada) por una búsqueda por nombre de autor o por la herramienta búsqueda de autor. Para recuperar mejores resultados, es recomendable introducir todas firmas posibles de un nombre y combinar un nombre con otros datos científicos por ejemplo las áreas de investigación y todas afiliaciones.

2. Seleccione sus publicaciones para enviar a su perfil.

3. En el menú de las opciones para enviar a un destino, selecciona 'ResearcherIDEscribí estas publicaciones'.

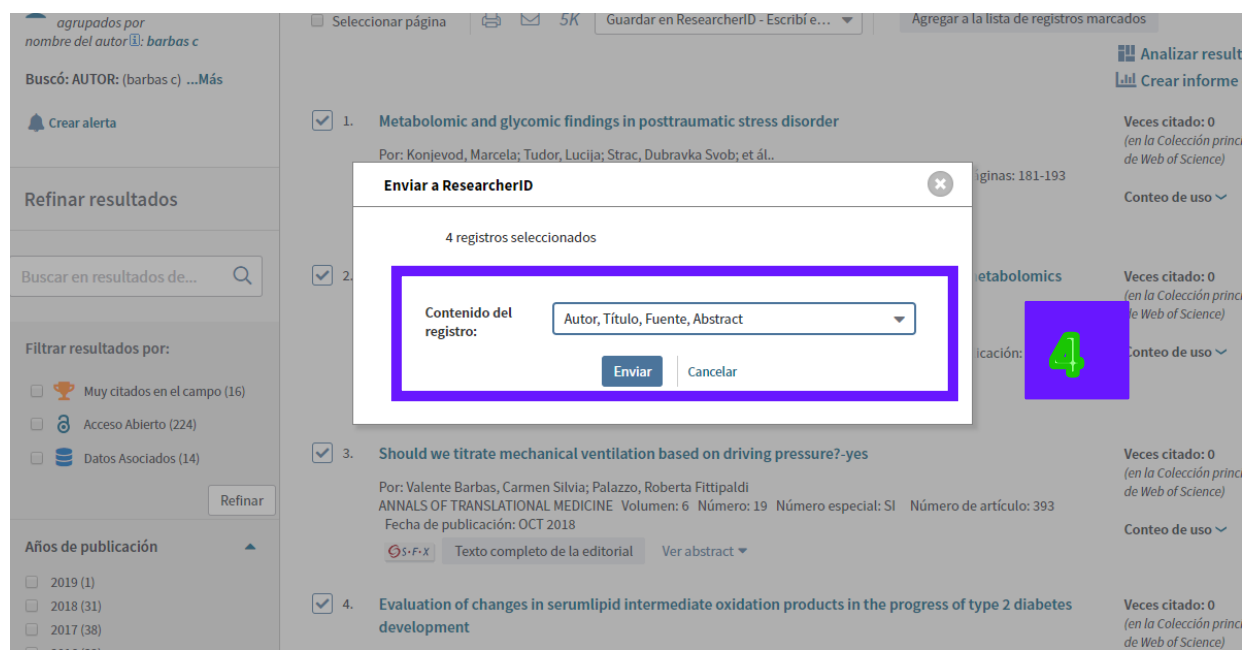


4. Seleccione el número de referencias para enviar a RID y los campos bibliográficos.

5. Hace falta declarar que las publicaciones seleccionadas están suyas o que le ha sido autorizado a administrar el perfil de ReseacherID del autor.

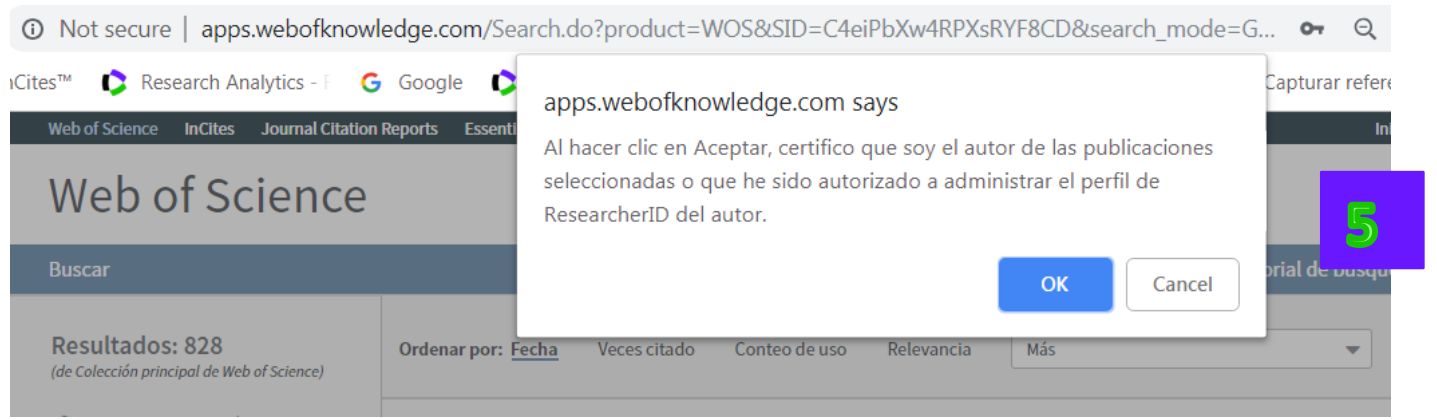

6. En la página a continuación se puede introducir sus credenciales de su perfil de RID o haga clic en 'Registrarse en ReseacherID' para iniciar el proceso del registro (6).

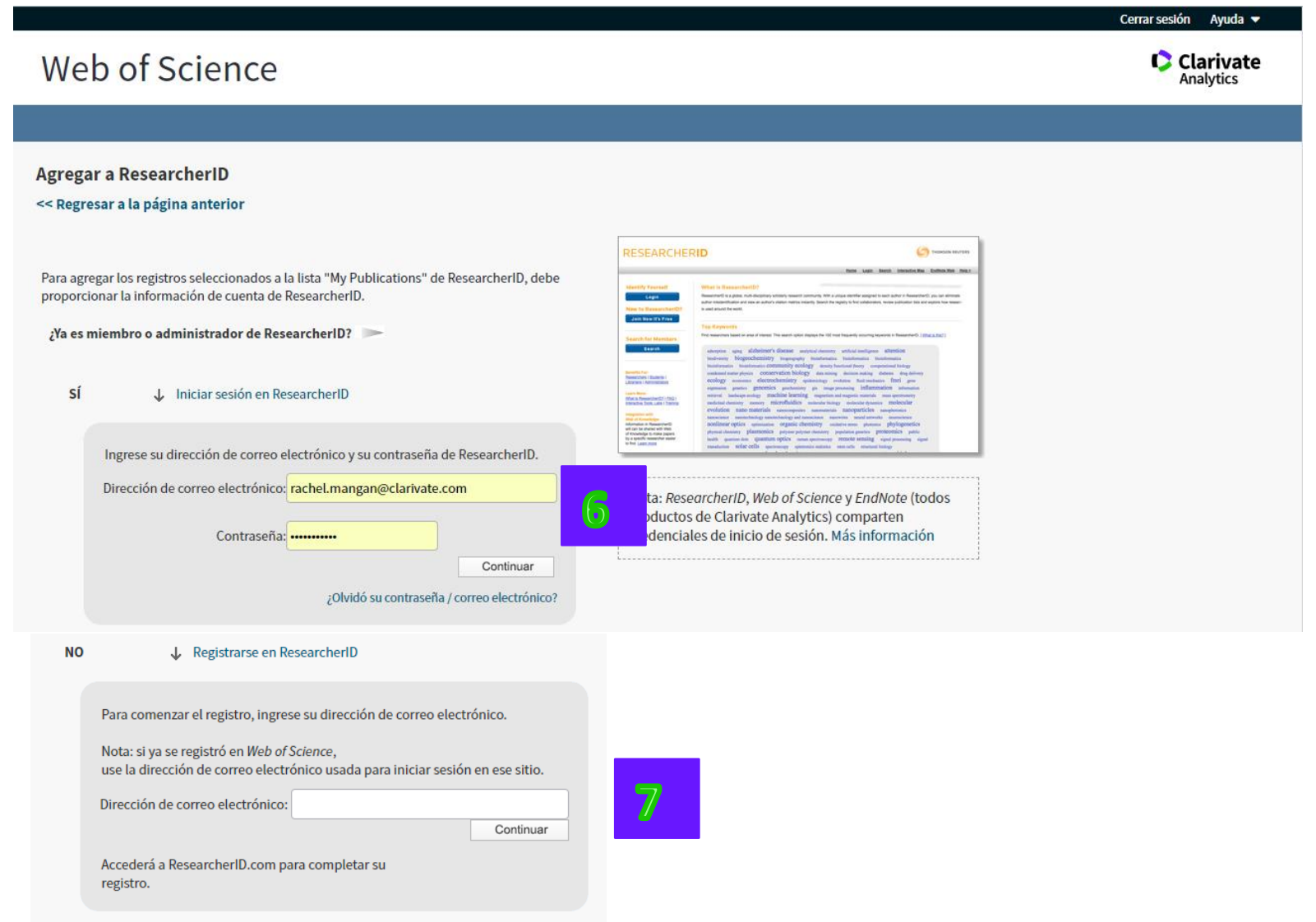

7. Para darse de alta en RID.com, en primer lugar, hace falta introducir su correo electrónico. Si ya cuenta con un perfil de la Web of Science se puede introducir este mismo correo electrónico y la misma contraseña. Haga clic en 'Continuar' para seguir los pasos del registro. 


\section{Actualizar un Perfil en ResearcherID.com}

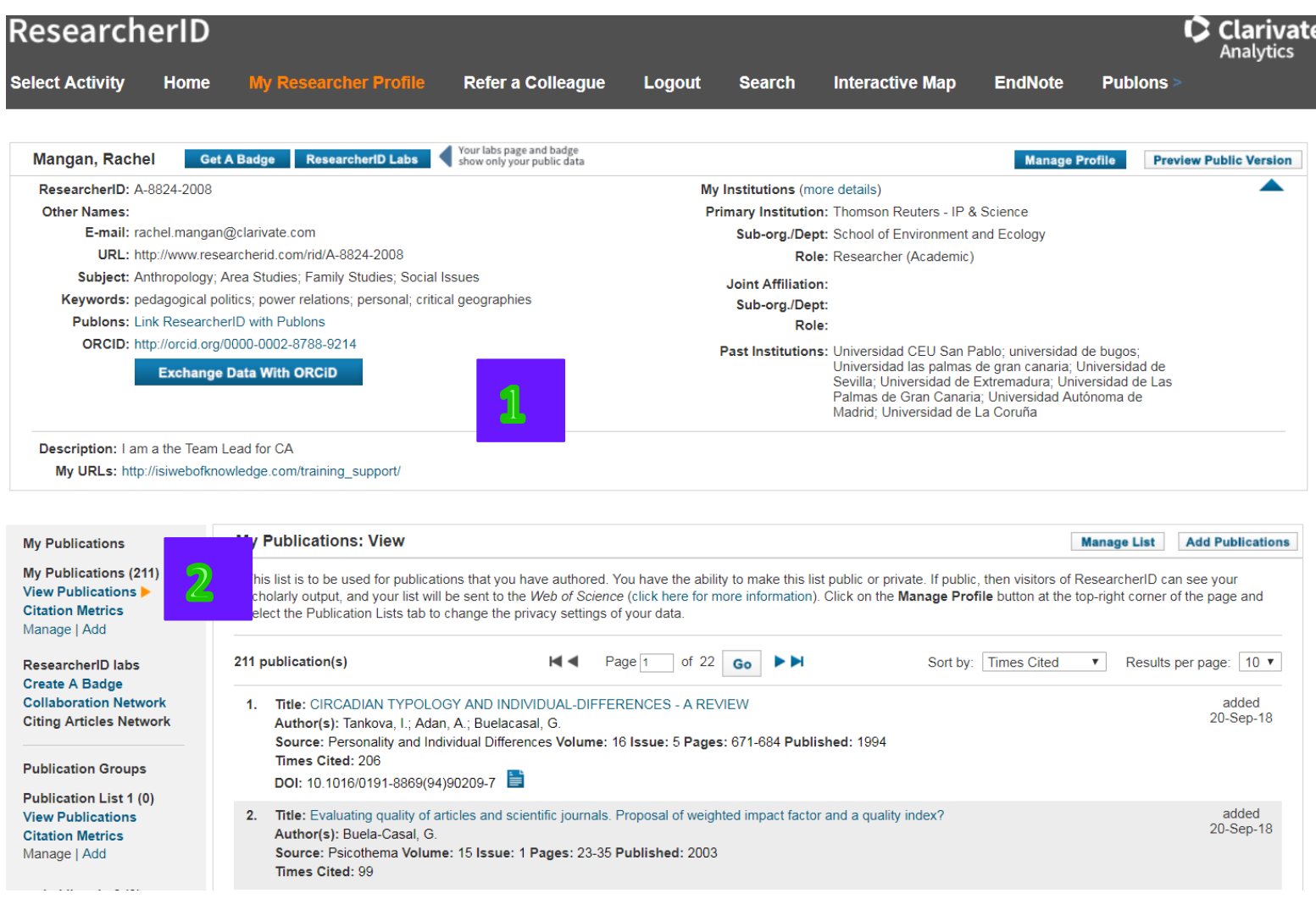

1. El perfil por encima es un perfil ejemplo de RID. Se puede actualizar el perfil con los datos siguientes:

- Variantes en su nombre (buela-casal g, buelacasal g, casal gb, Gualberto buela casal).

- Sus temas de investigación.

- Las palabras claves que describen su campo de investigación.

- Una descripción de su trabajo (proyectos actuales, otras afiliaciones y campos de interés).

- Su institución principal, un departamento y su cargo.

- Otras afiliaciones.

- Afiliaciones anteriores

- Conectar RID con ORCID

- Conectar RID con PUBLONS

2. Por debajo de la sección titulada 'My Publications' se observará tres listados de publicaciones. Se puede añadir publicaciones a cualquier de los tres listados. El listado titulado 'My Publications' es el único listado que está integrado con la Web of Science. Introduce sus publicaciones en este listado para hacerlas conectadas a su número de RID en la Web of Science. 


\section{Mi Perfil de ResearcherID}

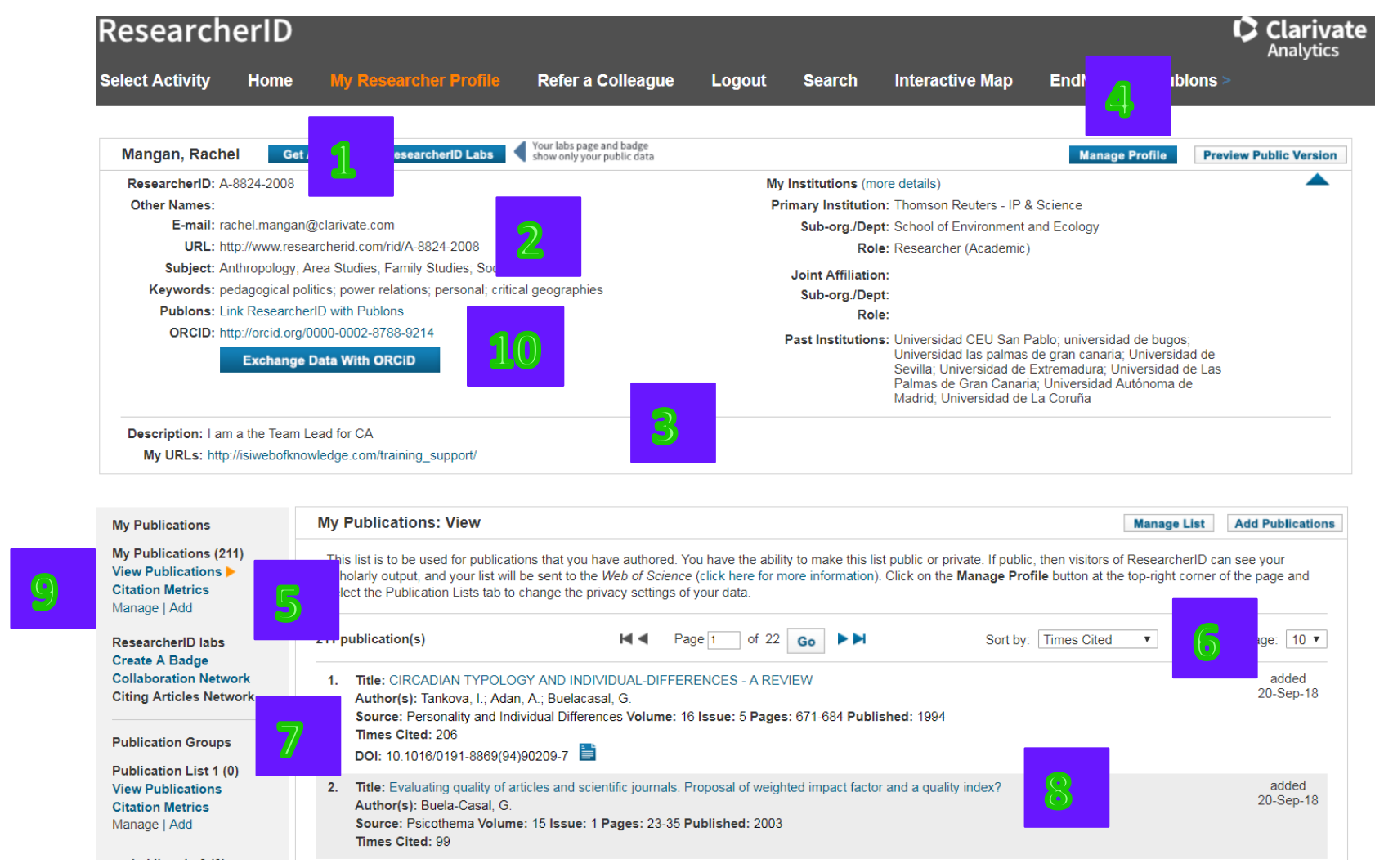

1. Aquí se presenta su número de identificación individual (RID)

Su perfil incluirá una URL que es única por su página de ResearcherID. Se puede usar este enlace para dirigir personas a su perfil de RID.

2. Aquí se puede anunciar sus datos profesionales, por ejemplo; su cargo, sus áreas temáticas, unas palabras clave que describen su área de investigación, afiliaciones actuales y anteriores y una descripción.

3. Para modificar cualquier elemento de su perfil haga clic en el enlace 'Manage profile' (manejar su perfil). Se puede optar para hacer su información pública o mantenerse como privado. Su perfil puede incluir palabras clave que describen su área de investigación o áreas temáticas designadas. También se puede escribir una descripción para explicar su área de investigación o área de interés. Los otros usuarios de Researcher ID pueden buscar por área temática y encontrar su listado de publicaciones. Una vez actualizado su perfil haga clic en el botón 'Submit Changes' (Realizar cambios).

4. Para introducir sus publicaciones a su perfil haga clic en el enlace 'Add Publications' (añadir sus publicaciones). Existen 3 opciones para crear su listado de publicaciones.

I. Busque en Web of Science para publicaciones individuales.

II. Busque en Web of Science para grupos de artículos usando la herramienta 'Distinct Author Sets' (Sistema de Identificación de Autores Distintos). Es necesario ser afiliado a una institución que suscribe a Web of Science para que pueda utilizar estas características.

III. También podrá copiar archivos generados de Endnote, Endnote en línea o Reference Manager en el formato RIS. 
5. Abre el menú para cambiar el orden de visualización de las publicaciones añadidas por las opciones siguientes: las veces citado, título del artículo o fecha de entrada.

6. Existen 3 listados de publicaciones.

I. My Publications (conecta a la Web of Science y a Endnote Web)

II. Publication List 1(conecta a la Web of Science y a Endnote online)

III. Publication List 2 (conecta a la Web of Science y a Endnote online)

Haga clic sobre 'View Publications List' para ver sus publicaciones añadidas.

7. Para artículos introducidos desde Web of Science $\mathrm{CC}$ o de otras bases de datos de Web of Science, sus títulos llevan un hiperenlace para que se pueda ir directamente a su registro completo. Para artículos que incluyen su DOI (identificador del objeto digital) al hacer clic en el icono de la cartita se puede ir al formato electrónico de la publicación.

8. Haga clic sobre 'Citation Metrics' para ver métricas de citas automáticamente calculados basados en las publicaciones introducidas desde Web of Science CC. Verá el total de las citas, la media de las citas y el índice $h$. Tenga en cuenta que las publicaciones subidas de los archivos RIS no contienen información de citas y por lo tanto no figuran en los métricos de citas.

9. Identificador de ORCID (vaya a www.ORCID.org para más información) 


\section{Añadir Publicaciones a RID}

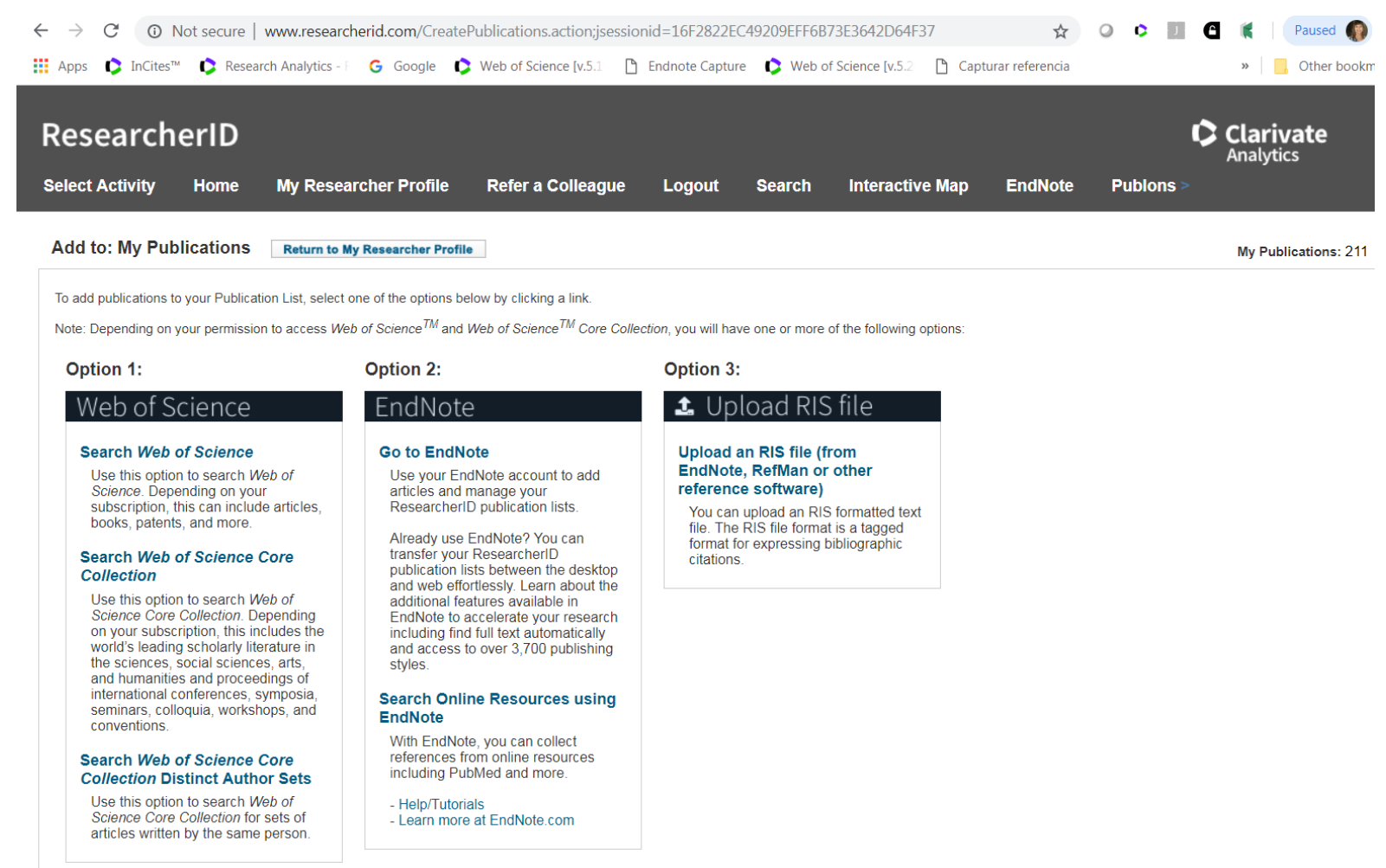

Existen 3 opciones para crear su listado de publicaciones.

\section{Opción 1}

- Busque en la Colección Principal de Web of Science para publicaciones individuales (por su nombre, tema, revista, o institución)

- Busque en las bases de datos de Web of Science dentro de su suscripción.

- Busque en Web of Science para grupos de artículos usando la herramienta 'Distinct Author Sets' (Sistema de Identificación de Autores Distintos).

- Es necesario ser afiliado a una institución que suscribe a Web of Science para que pueda utilizar estas características.

\section{Opción 2}

- Conecte a su biblioteca de Endnote online y añada publicaciones a los listados de publicaciones 1 \& 2. Desde la biblioteca de Endnote online se puede manejar estos listados de publicaciones. Endnote online conecta a bases de datos en línea y catálogos de las bibliotecas. También le permite crear una referencia manualmente o importar referencias.

\section{Opción 3}

- Haga clic sobre el enlace para importar archivos guardados a su ordenador generados de Endnote, Reference Manager u otros gestores de referencias en el formato RIS. 


\section{ResearcherID Labs (Mis Laboratorios)}

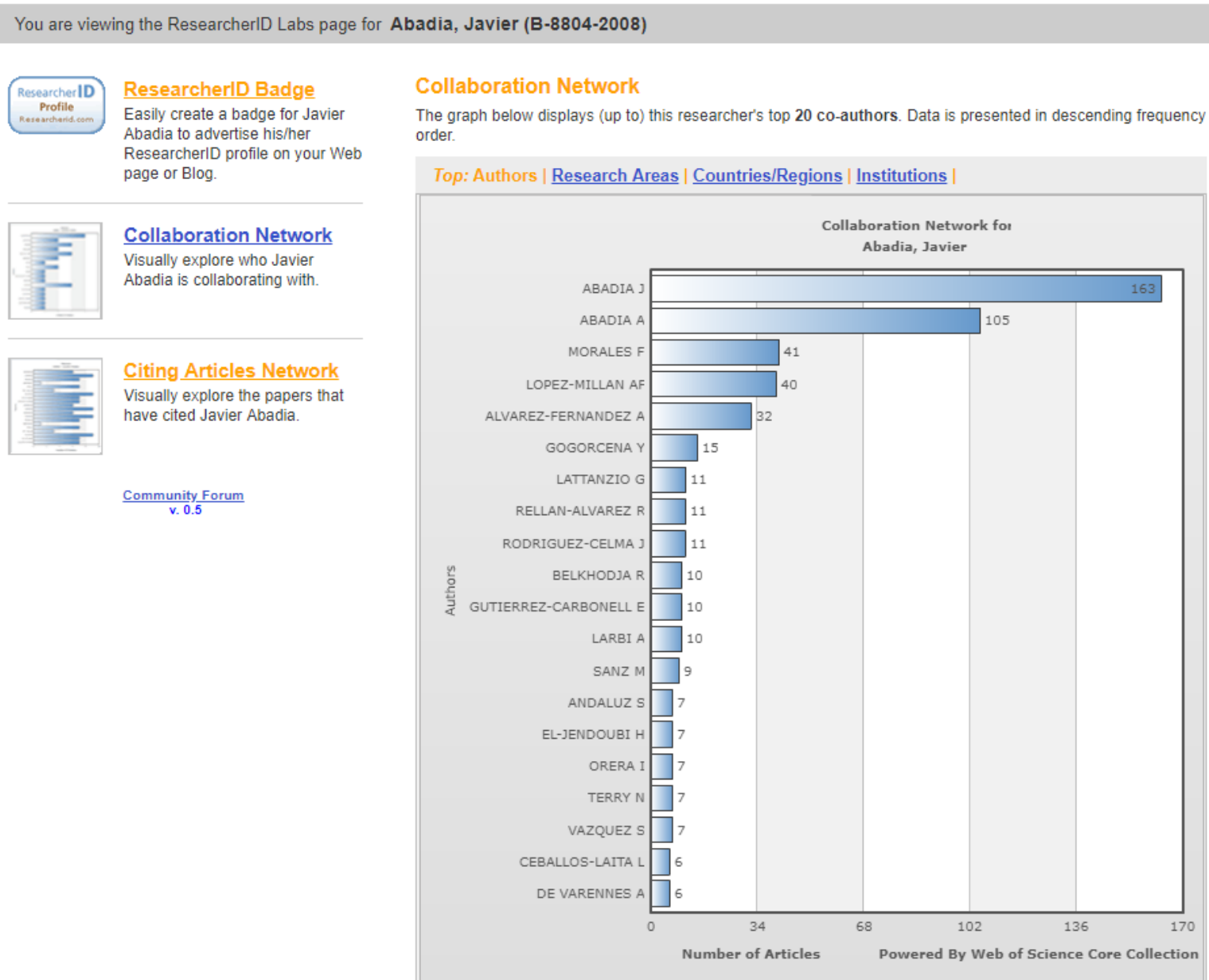

1. 'Mis Laboratorios' le permite generar y visualizar de una manera interactiva unas redes de colaboración para que pueda explorar con quién colabora el científico.

2. Se puede clasificar la red por los coautores/colaboraciones, área temática, país, institución.

3. También se puede generar unas redes de citas para explorar de una manera interactiva de donde origina el impacto de la investigación del autor. Se puede clasificar la red por autor, área temática, país, institución y por año de publiacion. 


\section{Página Principal de ResearcherID}

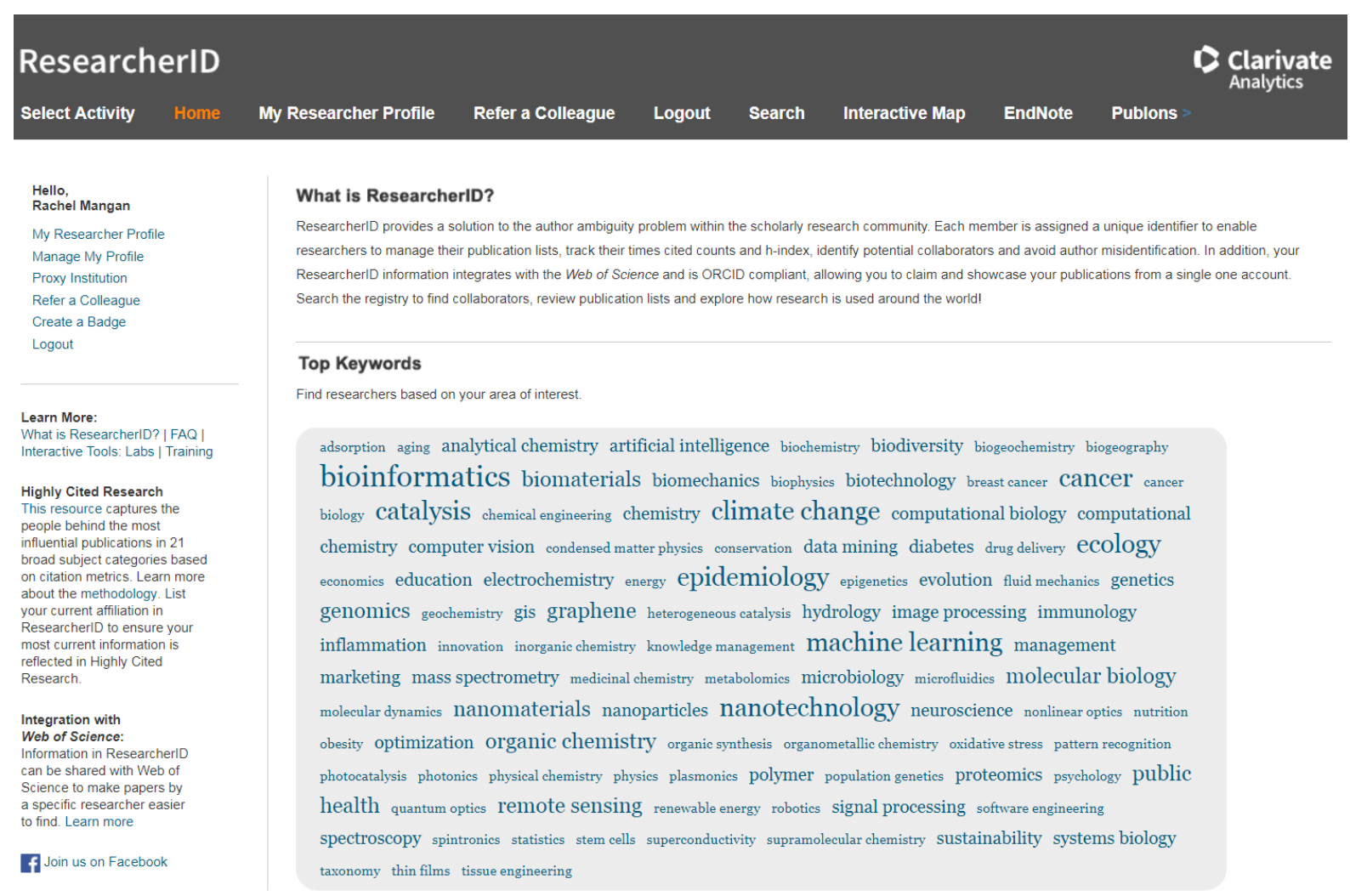

\section{Introduce la URL www.researcherid.com}

1. Haga clic en el enlace 'Login' para inscribirse e ir a su perfil.

2. Haga clic en el botón 'Join Now Its Free' para crear un perfil de RID

3. Haga clic en 'Search' para iniciar una búsqueda de perfiles.

4. También se puede buscar perfiles asociados a una palabra temática. En la página principal de ResearcherID se muestran las 20 principales palabras claves basadas en las palabras introducidas por los usuarios.

5. Explore el mapa mundial interactivo para buscar perfiles según un país. 


\section{Una Búsqueda dentro de ResearcherID.com}

ResearcherID
Select Activity $\quad$ Home $\quad$ My Researcher Profile $\quad$ Refer a Colleague $\quad$ Logout $\quad$ Search Interactive Map EndNote Publons

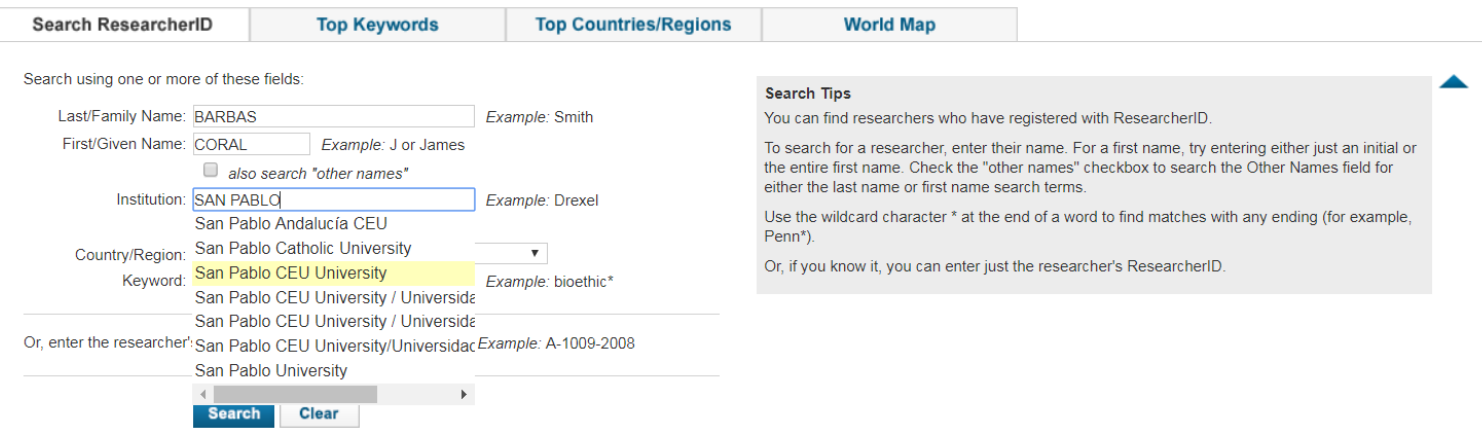

1. Se puede buscar investigadores según los criterios siguientes:

-Apellido o nombre del investigador

-Institución (incluso institución anterior)

-Palabras clave

-Países principales

-Mapa mundial interactivo

2. Al introducir términos en los campos de búsqueda por institución y por las palabras clave verá términos sugeridos basados en términos que ya existen en el registro.

3. Haga clic en la pestaña 'Top Keywords' para ver un listado de las palabras claves más utilizadas en el registro.

4. Haga clic en 'World Map' para lanzar el mapa mundial interactivo.

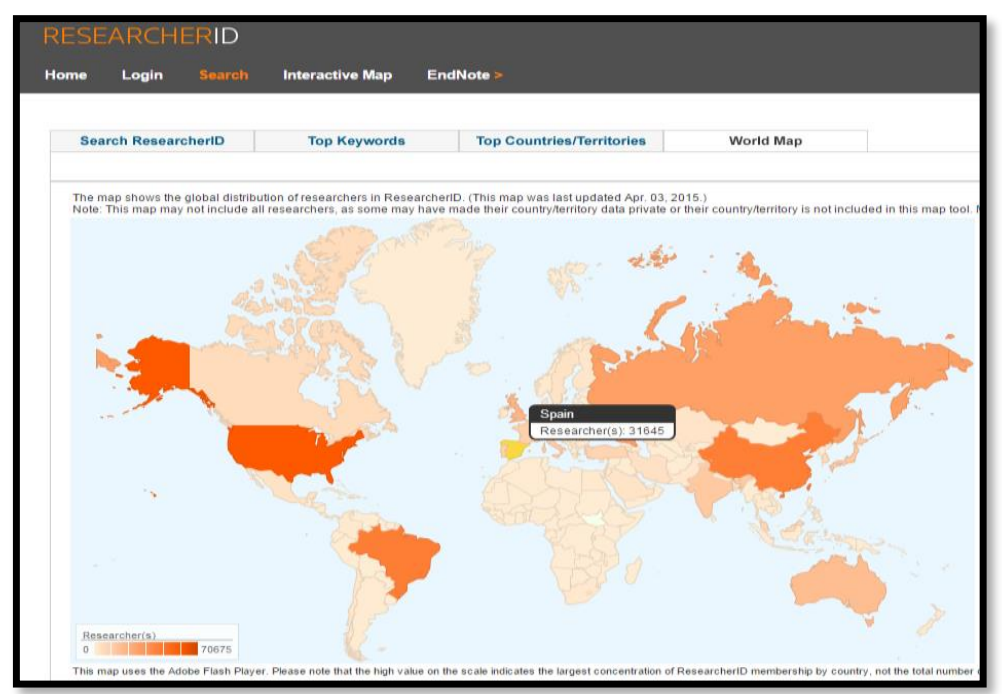




\section{Búsqueda Avanzada en la Colección Principal de la Web of Science}

La Búsqueda Avanzada le permite crear más consultas complejas mediante el uso de etiquetas (o abreviaturas) de campo de dos caracteres, operadores booleanos y combinaciones de conjuntos en su historial.

Reglas de búsqueda de combinación de conjuntos

- Incluya un símbolo de número (\#) delante de cada número de conjunto.

- Incluya operadores booleanos (AND, OR, NOT) en las combinaciones de conjuntos.

- No utilizar comodines en combinaciones de conjuntos.

- Use paréntesis para anular la prioridad de los operadores.

\section{Web of Science}

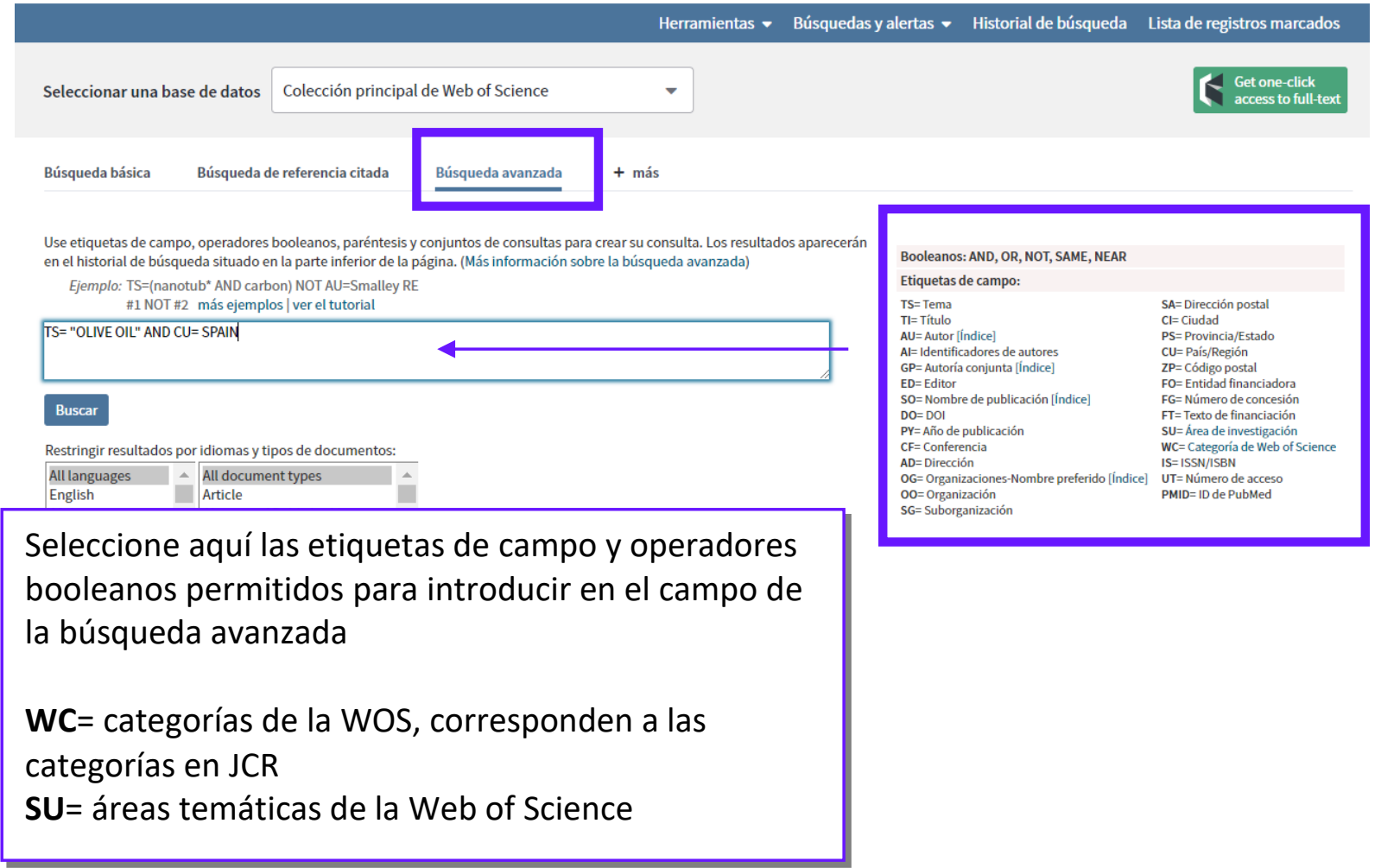

\section{Guardar historial de búsqueda}

1. Esta función le permite guardar sus consultas de búsqueda en un archivo de historial de búsqueda que puede recuperar y abrir posteriormente.

2. Haga clic en el botón Guardar historial/Crear alerta para acceder al cuadro de diálogo de superposición Guardar historial de búsqueda, donde podrá guardar su trabajo en el servidor host o en su estación de trabajo local.

3. Puede guardar hasta 40 conjuntos de búsqueda de la tabla de historial de búsqueda. El historial de búsqueda incluye la consulta de búsqueda y las opciones seleccionadas para cada consulta de búsqueda. 
4. Al intentar borrar una estrategia que forma parte de una combinación de estrategias recibirá el mensaje siguiente:

Al menos uno de los conjuntos que ha seleccionado para borrar forma parte de una combinación. Hemos señalado las combinaciones afectadas. Verifique las marcas de comprobación y haga clic en DELETE para borrar dichos conjuntos

\section{Editar Búsquedas}

En la Colección Principal de la Web of Science es posible editar las búsquedas guardadas en su historial. Para editar una búsqueda hace falta ir a la búsqueda Avanzada y hacer clic en 'Editar' a mano derecha de la búsqueda que desea editar.
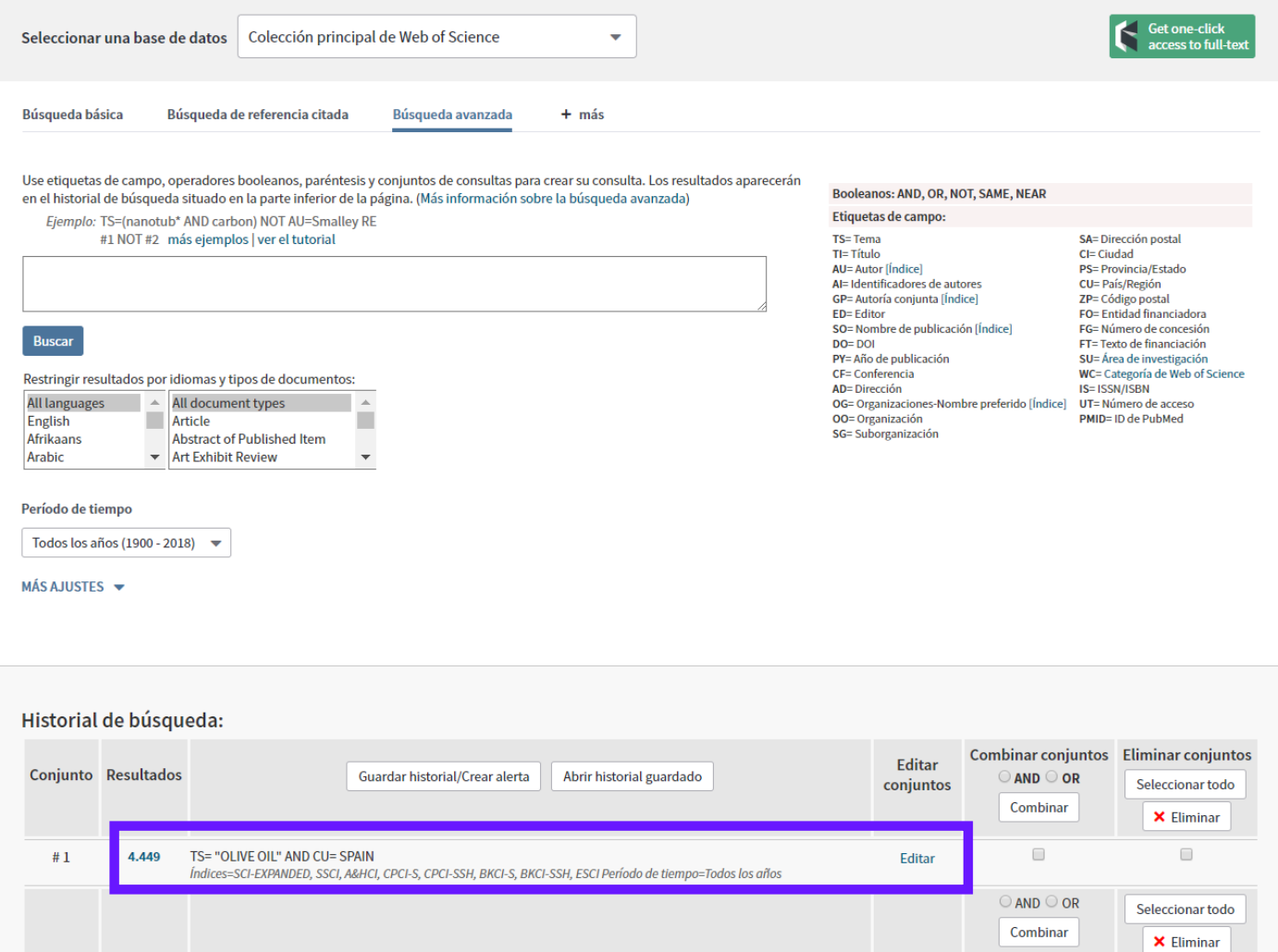
[EDITANDO CONJUNTO N. ${ }^{\circ} 1$ ]

Use etiquetas de campo, operadores booleanos, paréntesis y conjuntos de consultas para crear su consulta. Los resultados aparecerín en el historial de búsqueda situado en la parte inferior de la página. (Más información sobre la búsqueda avanzada) Ejemplo: TS=(nanotub* AND carbon) NOT AU=Smalley RE

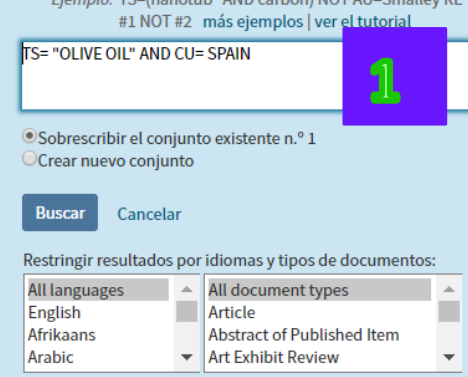

Booleanos: AND, OR, NOT, SAME, NEAR Etiquetas de campo:

$\mathrm{TS}=$ Tema
$\mathrm{T}=$ Titulo

$\mathrm{Tl}=$ Titulo
$\mathrm{AU}=$ Autor [índice]

$\mathrm{A}=$ Autor
$\mathrm{A}=$ Idindicel

$G P=$ Autoria

$\mathrm{ED}=$ Editor

$\mathrm{SO}=\mathrm{Nomb}$
$\mathrm{DO}=\mathrm{DOI}$

$\mathrm{PY}=\mathrm{A}$ ก̃o de publicació

$\mathrm{CF}=$ Conferencia
$\mathrm{AD}=$ Dirección

AD = Dirección

$\mathrm{OG}=$ Organizaciones
$\mathrm{OO}=$ Organización

$\mathrm{OO}=$ Organización
$\mathrm{SG}=$ Suborganización
SA= Dirección postal

$\mathrm{Cl}=$ Ciudad

CU=Pais/Región ZP= Código postal $\mathrm{FO}=$ Entidad financiadora
$\mathrm{FG}=$ Número de concesión FT= Texto de financiación IS=ISSN/ISBN UT= Número de acceso

Periodo de tiempo

Todos los años $(1900-2018)$

MÁSAJUSTES -

Historial de búsqueda:

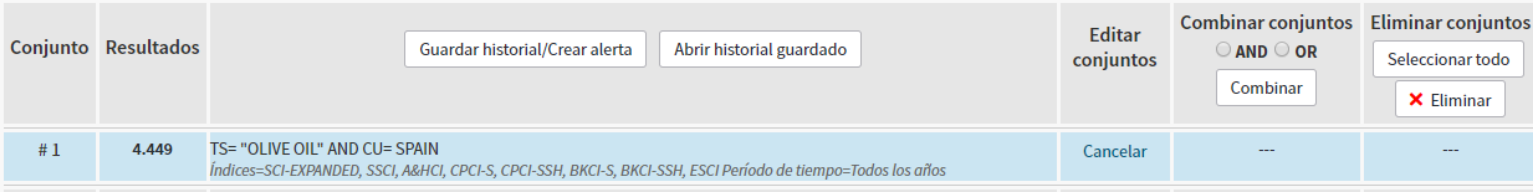

La función Editar le permite modificar una consulta existente o crear una nueva a partir de la consulta realizada previamente.

Use esta función para restringir el número de resultados que el sistema devolvió originalmente o para corregir errores sintácticos de la consulta original.

1. Haga clic en el enlace Editar situado en la columna Editar conjuntos de la tabla de historial de búsqueda. El producto le dirigirá a un cuadro de texto situado en la parte superior de la página.

2. Acceda a la sección Más ajustes de la página si necesita cambiar su configuración.

3. Seleccione Sobrescribir el conjunto existente (opción predeterminada) para editar el conjunto de búsqueda existente o seleccione Crear nuevo conjunto para crear un nuevo conjunto a partir del conjunto existente.

4. Ingrese su consulta de búsqueda en el cuadro de texto usando etiquetas de campo de dos caracteres.

5. Haga clic en Buscar para completar el proceso. Haga clic en Cancelar para detener la operación.

6. En la tabla de historial de búsqueda, haga clic en el enlace Web de la columna Resultados para ver los resultados de su búsqueda. 


\section{Reglas Editoriales-Títulos}

\section{Traducciones:}

Los títulos que no están en inglés se traducen al inglés estadounidense cuando la revista no provee una traducción.

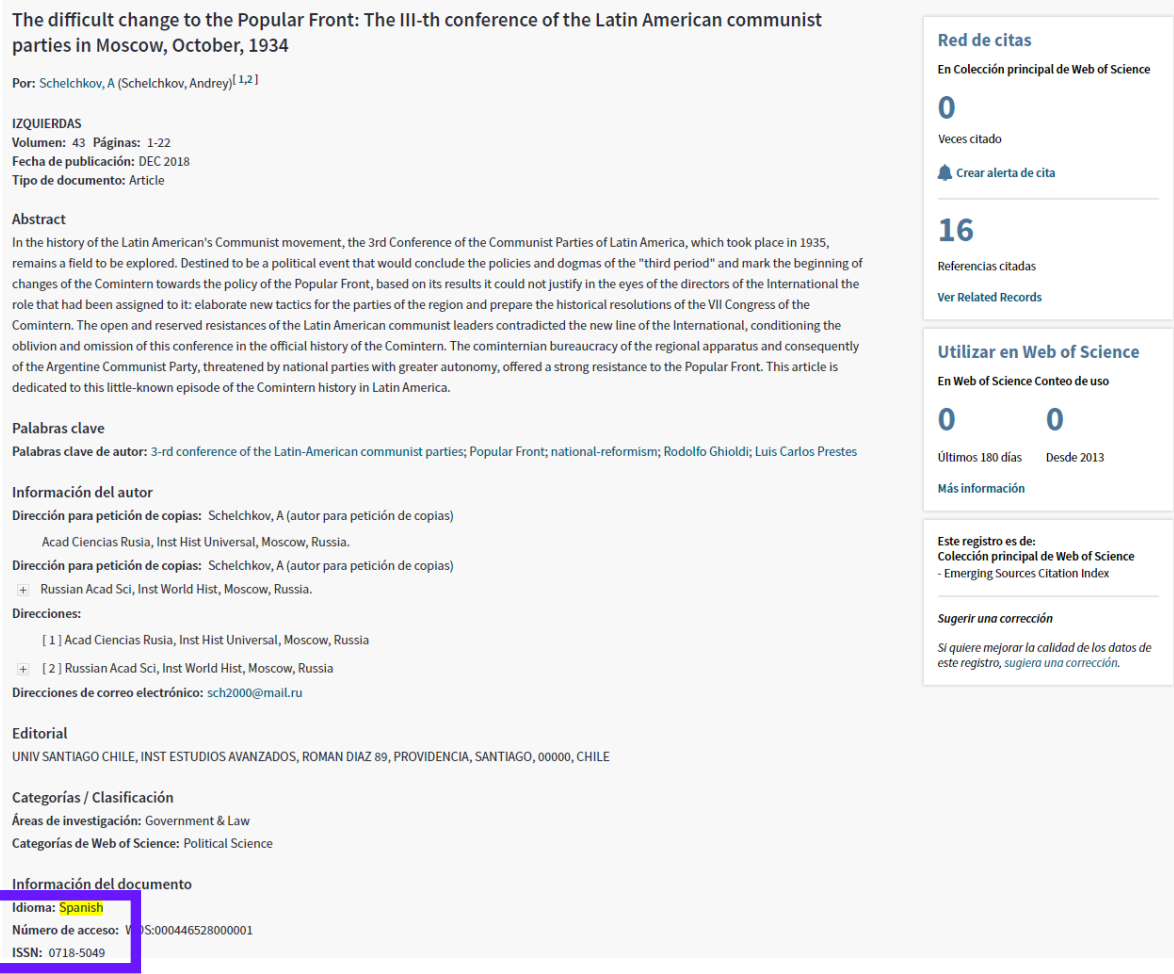

\section{Obras Creativas:}

Los títulos de obras creativas permanecen en el idioma original.

Web of Science

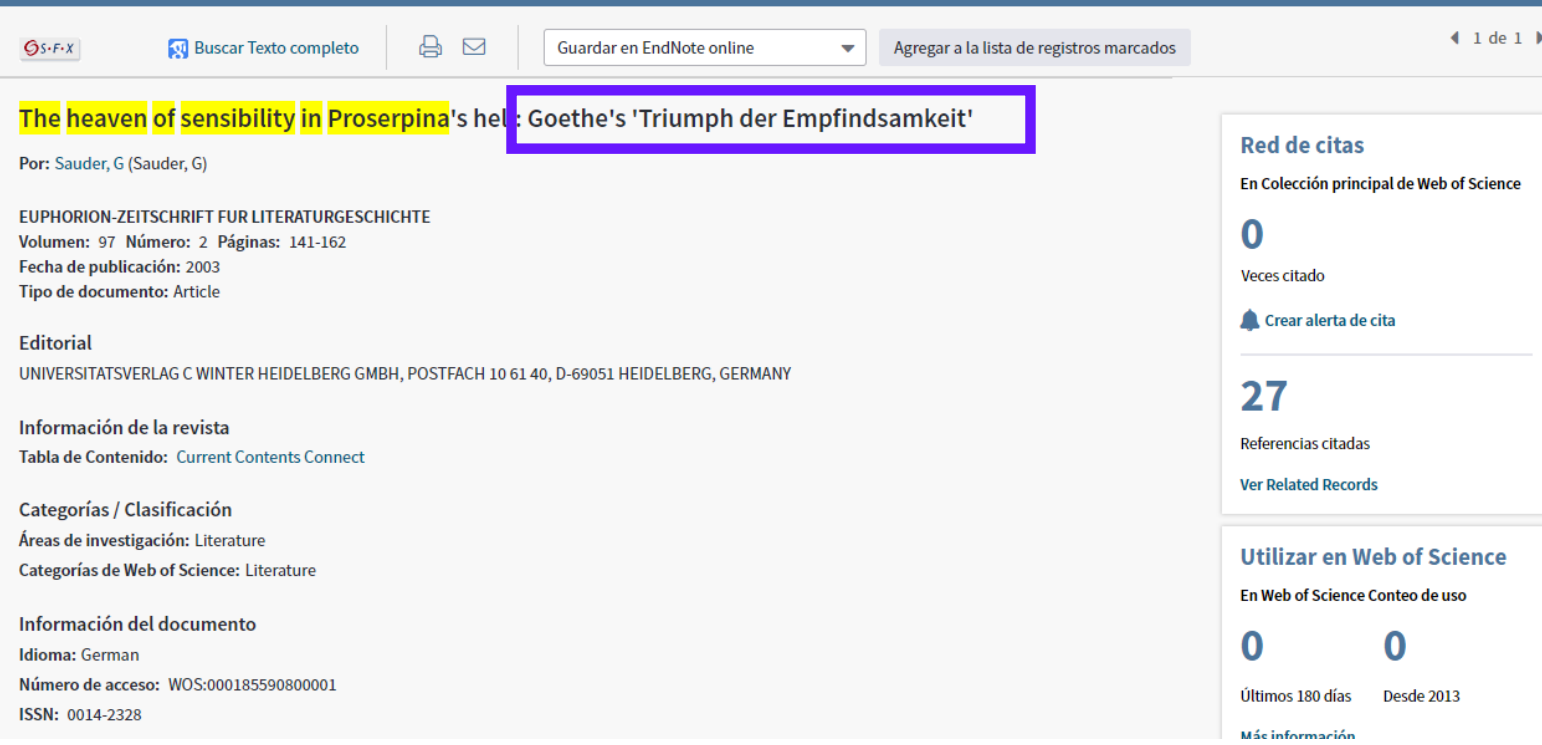




\section{Aclaración de Títulos:}

En la base Arts \& Humanities Citation Index, los títulos poco descriptivos son aclarados. Dicha aclaración aparece continuando al título y está delimitada por signos (+) o paréntesis.

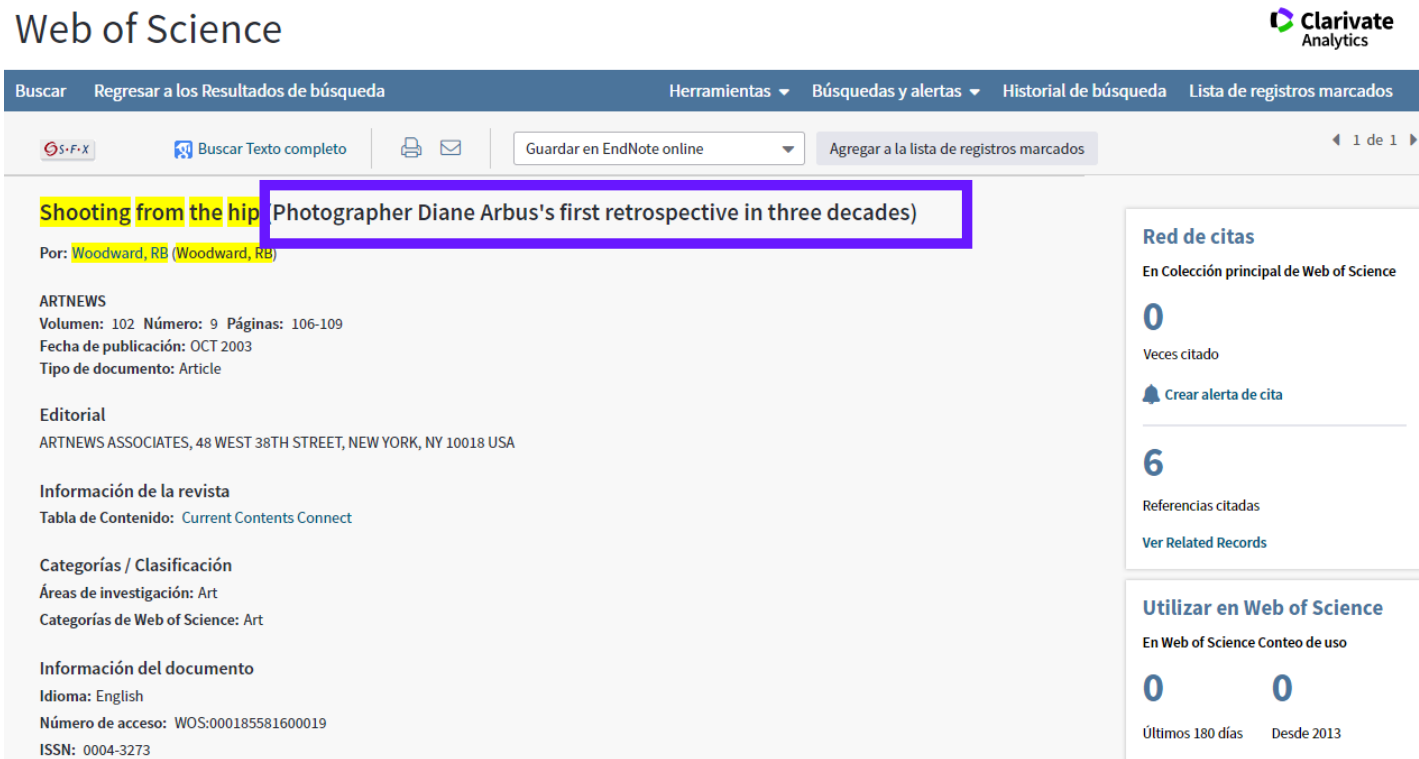




\section{Búsqueda por Autor-Normas Generales}

Web of Science Group indexa TODOS los Autores por lo tanto las búsquedas pueden realizarse utilizando el nombre de cualquiera de ellos.

\section{Regla General}

Introduce el apellido seguido por un espacio y hasta 5 iniciales. También se puede introducir el nombre completo (nota que se indexa los nombres completos cuando está incluido en el documento original y desde el año 2006 y adelante.

\begin{tabular}{|l|l|l|}
\hline \multicolumn{1}{|c|}{ Documento Fuente } & \multicolumn{1}{|c|}{ Base de Datos } & \multicolumn{1}{c|}{ Búsqueda por: } \\
\hline J.R.W. Yates & Yates JRW & $\begin{array}{l}\text { yates } \mathrm{j}^{*} \text { or } \\
\text { yates jrw }\end{array}$ \\
\hline
\end{tabular}

\section{Variaciones de nombre}

Utilice variantes en la búsqueda cuando el nombre de familia puede o no ser utilizado como apellido.

\begin{tabular}{|l|l|l|}
\hline \multicolumn{1}{|c|}{ Documento Fuente } & \multicolumn{1}{|c|}{ Base de Datos } & \multicolumn{1}{c|}{ Búsqueda por: } \\
\hline Sheng-Horng Yen & $\begin{array}{l}\text { Yen SH } \\
\text { Horng YS } \\
\text { Yen Sheng horng }\end{array}$ & $\begin{array}{l}\text { yen sh or } \\
\text { horng ys or } \\
\text { yen sheng horng }\end{array}$ \\
\hline Uzonyi Kiss Sandor & $\begin{array}{l}\text { Uzonyi KS } \\
\text { Sandor UK } \\
\text { Kiss SU }\end{array}$ & $\begin{array}{l}\text { uzonyi ks or sandor uk or } \\
\text { kiss su }\end{array}$ \\
\hline
\end{tabular}

\section{Nombres compuestos}

Antes de 1997 los nombres compuestos se indexaban fusionados. Por lo tanto, para que la recuperación sea completa la búsqueda debe incluir las dos formas, la compuesta y la fusionada.

\begin{tabular}{|l|l|l|}
\hline \multicolumn{1}{|c|}{$\begin{array}{c}\text { Documento Fuente } \\
\text { D. Lagadic- }\end{array}$} & \multicolumn{1}{c|}{$\begin{array}{c}\text { Base de Datos } \\
\text { Lossmann }\end{array}$} & \multicolumn{1}{c|}{ Búsqueda por: } \\
\hline $\begin{array}{l}\text { Geraldo Felipe de la } \\
\text { Fuente }\end{array}$ & $\begin{array}{l}\text { De la Fuente GF } \\
\text { DelaFuente GF } \\
\text { De la fuente- Felipe, Geraldo }\end{array}$ & $\begin{array}{l}\text { lagadic gossmann } \text { d* }^{*} \text { or } \\
\text { lagadicgossmann } \text { d* }^{*}\end{array}$ \\
\hline M. D'Angelo & $\begin{array}{l}\text { D Angelo M } \\
\text { de la fuente g* or } \\
\text { delafuente } \text { g }^{*} \text { or }\end{array}$ \\
\hline
\end{tabular}

\section{Títulos}

Los títulos de rango, las designaciones generacionales Junior y Senior y los títulos académicos no deben incluirse en las búsquedas. 


\begin{tabular}{|l|l|l|}
\hline Documento Fuente & Base de Datos & Búsqueda por: \\
\hline Lord Duvall Edwards & Edwards D & edwards d* $^{*}$ \\
\hline W. Brumfitt, Jr. & Brumfitt W & brumfitt w* \\
\hline
\end{tabular}

\section{Herramienta Búsqueda de Autores}

La función Búsqueda de autores ofrece una forma sencilla de identificar y recuperar todos los trabajos de un autor específico. Esta función se centra en la información que usted conoce sobre el autor y permite separar trabajos de autores diferentes que tienen el mismo nombre.

Los nombres de autores aparecen en el siguiente formato: apellido(s) seguido(s) de hasta cuatro iniciales. Los apellidos pueden contener guiones, espacios o apóstrofes. Por ejemplo:

- Wilson SE

- O'Grady AP

- De La Rosa JM

- Ruiz-Gomez M

- Van der Waals JE

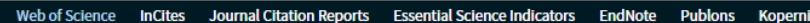

Ingresar nombre de autor Seleccionar dominio de investig Seleccionar organización

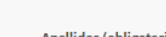

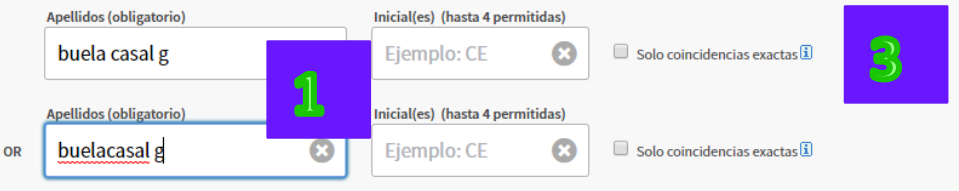

+ Agregar variante del nombre de autor | Borrar

La herramienta 'Búsqueda de Autores' incorpora el sistema de identificación de autores distintos (DAIS). Es un sistema de 'desambiguamiento' que resuelva el problema de la similitud de_nombres de autores. El sistema distingue los autores que se llaman igual y agrupa la bibliografía de un autor, aunque su nombre aparezca con varios formatos diferentes, incluso completo. 


\section{Buscar un nombre de autor con la herramienta 'Búsqueda de Autores'}

1. Ingrese el (los) apellido(s) del autor en el campo Apellidos.

2. Ingrese un máximo de cuatro iniciales en el campo Iniciales.

Haga clic en el vínculo Agregar variante del nombre de autor para mostrar otra fila de campos Apellidos e Iniciales. Esta función le permite buscar múltiples variantes de nombres de autores. Puede buscar hasta cinco variantes del nombre de autor.

Por ejemplo: Fila 1 = De La Rosa JM y Fila 2=DeLaRosa JM. El sistema encuentra todos los registros en los que el autor puede haber publicado artículos con estas dos variantes.

3. Seleccione la casilla de verificación Solo coincidencias exactas. Este paso es opcional. Esta función restringe la búsqueda a nombres de autores que coincidan de forma exacta con el que usted ingresó.

4. Haga clic en Seleccionar dominios de investigación para acceder a la página Dominios de investigación. Este paso es opcional.

5. En la página Dominios de investigación, haga clic en Seleccionar organizaciones para acceder a la página Seleccionar organización. Este paso es opcional.

6. Selecciona en el último paso las organizaciones relacionadas con el autor. Haga clic en 'Numero de registros' para ordenar las organizaciones por el número de registros. Es recomendable examinar en completo las organizaciones porque puede que existan variaciones en los nombres de las organizaciones. Selecciona las organizaciones actuales y anteriores del autor

7. Haga clic en Finalizar búsqueda para acceder directamente a la página de resultados.

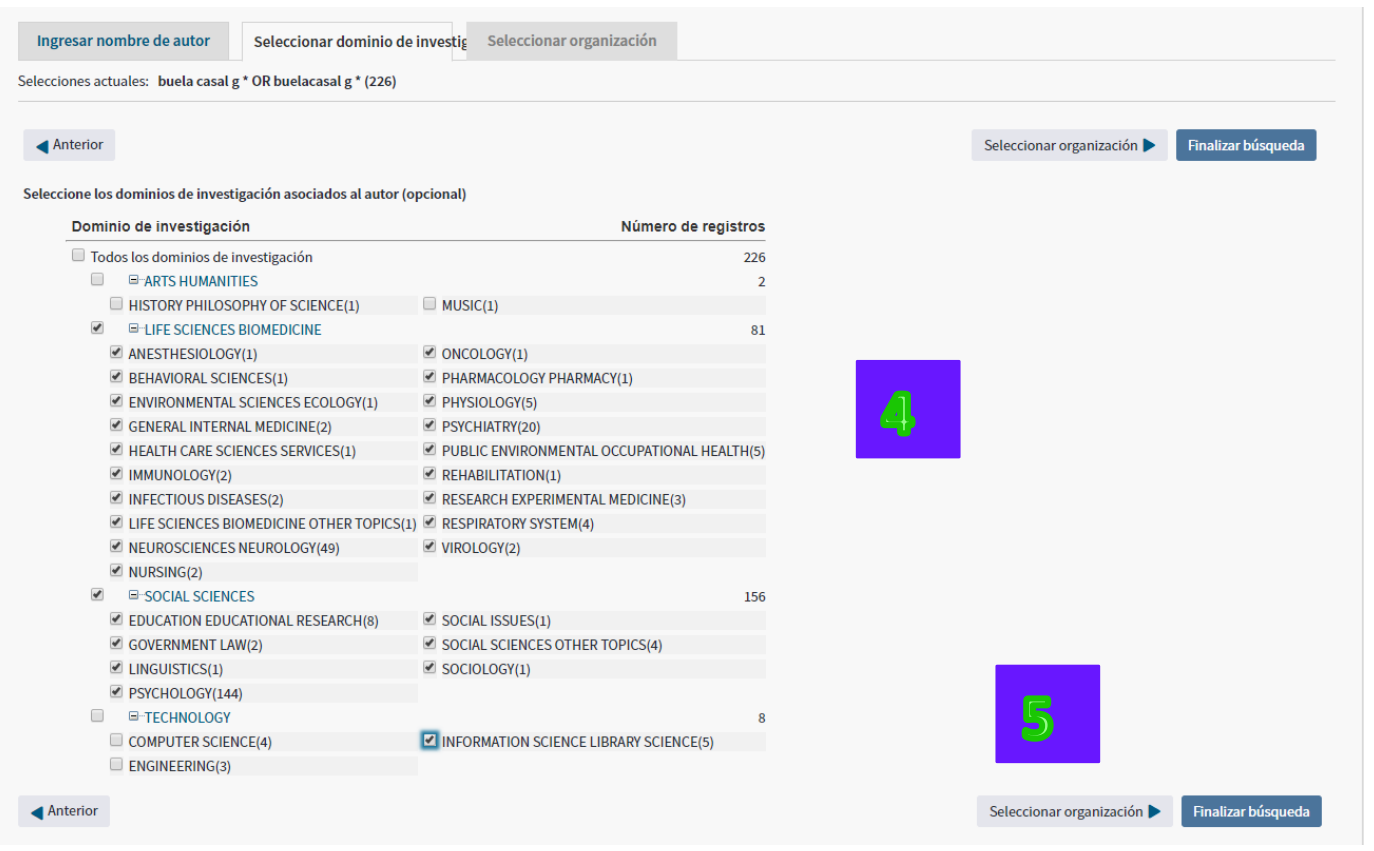




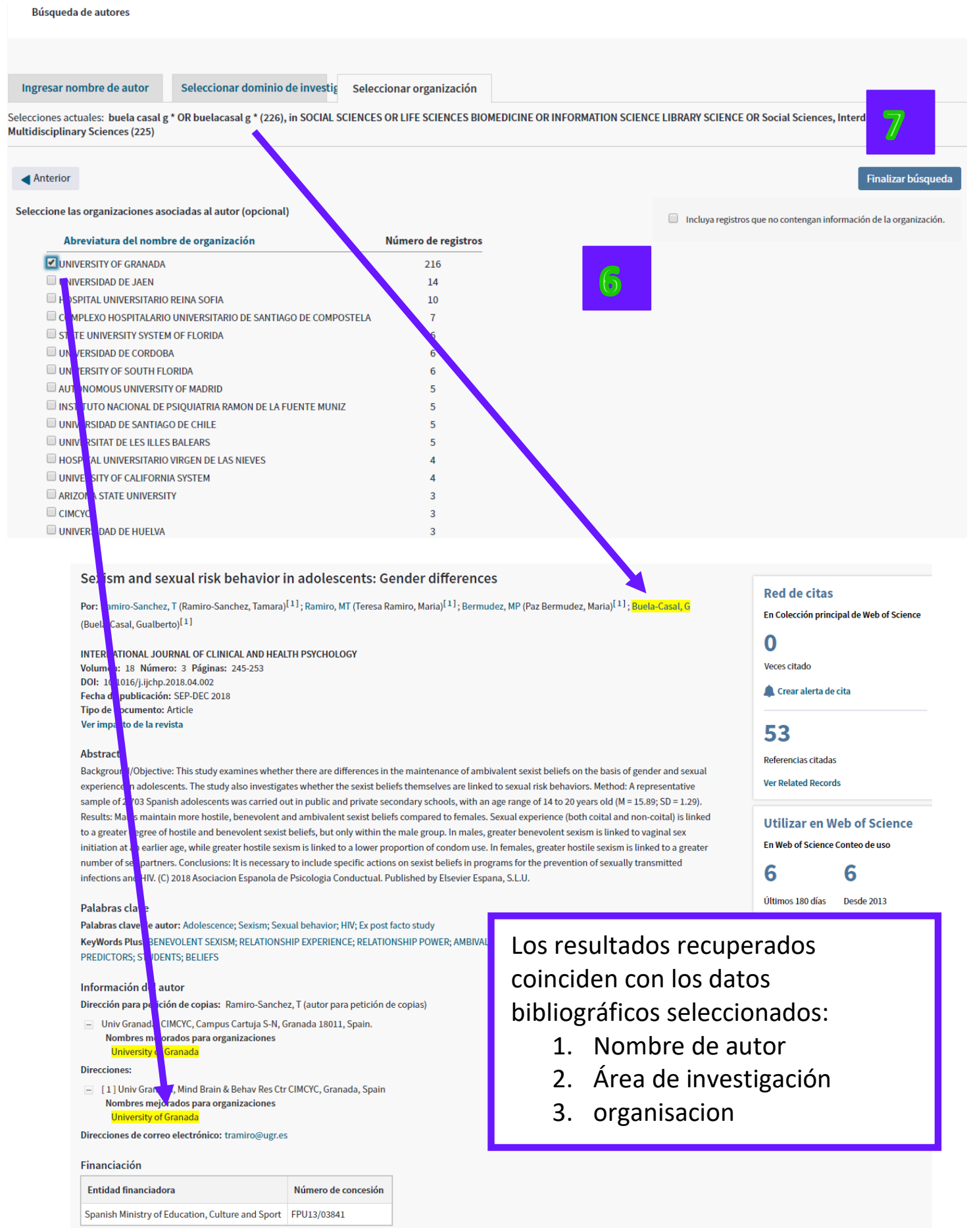




\section{Sistema de Grupos de Publicaciones de un Autor}

Un grupo de artículos es un conjunto de artículos escritos por la misma persona. Los grupos de artículos son generados por un algoritmo de propiedad que identifica y examina los elementos de datos compartidos como, por ejemplo, nombres de autores, nombres de instituciones y relaciones entre autores que citan y autores citados.

Los grupos de artículos se muestran ordenados por tamaño. El grupo con el mayor número de artículos aparece en la parte superior de la tabla.

\section{Web of Science}

\section{Buscar}

Herramientas - Búsquedas y alertas - Historial de búsqueda Lista de registros marcados

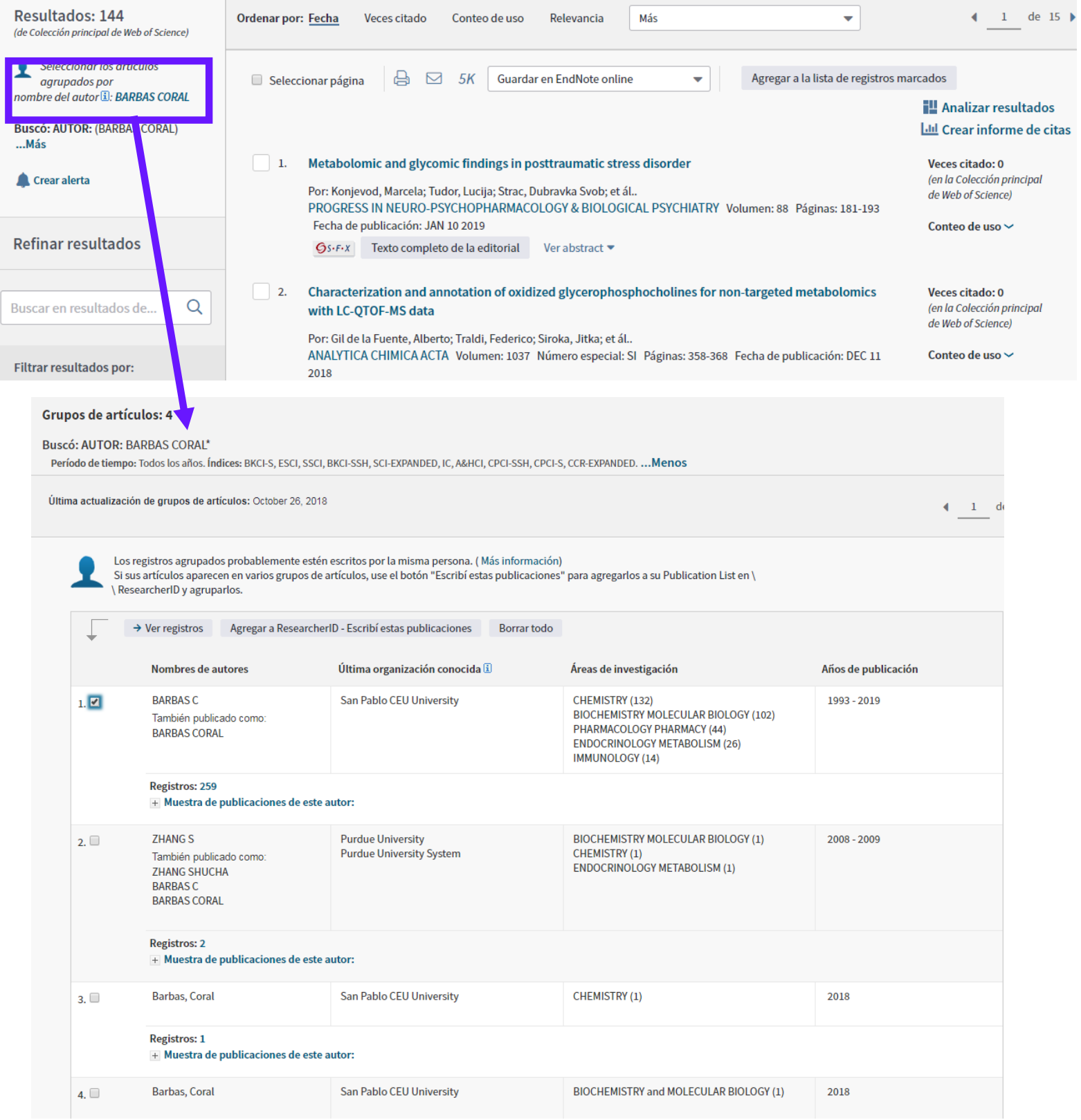


Para ver los registros de un grupo, seleccione la casilla de verificación y, a continuación, haga clic en el botón Ver registros. Puede ver los registros en más de un grupo de forma simultánea.

Puede que un autor esté asociado a varios grupos por estas razones:

- Es posible que el autor haya cambiado la institución o ubicación.

- Es posible que el autor esté trabajando en diferentes áreas de investigación

- Es posible que el autor esté citando una amplia variedad de trabajos en diferentes artículos publicados en años distintos

\section{Guardar en ResearcherID - Escribí estas publicaciones}

Esta función le permite a usted (o a un administrador autorizado) agregar sus trabajos publicados a su Publication List de ResearcherID. Use esta función si encuentra registros que desea reclamar como sus trabajos.

1. Seleccione el (los) registro(s) que desee incluir en su Publication List de ResearcherID.

2. Seleccione la opción Guardar en ResearcherID - Escribí estas publicaciones para abrir un cuadro de diálogo que muestra un mensaje solicitándole que certifique que usted es el autor (o proxy designado) del (de los) documento(s) seleccionado(s).

3. Puede producirse una de las siguientes acciones:

- Si ya inició sesión, el sistema le llevará a una superposición de procesamiento y agregará el (los) registro(s) seleccionado(s) a su Publication List.

- Si no inició sesión, haga clic en el enlace Web Iniciar sesión en ResearcherID. Ingrese sus credenciales y luego presione Continuar. El sistema le enviará a una superposición de procesamiento y agregará el (los) registro(s) seleccionado(s) a su Publication List.

- Si no es miembro registrado de ResearcherID, haga clic en el enlace Web Registrarse en ResearcherID. Ingrese una dirección de correo electrónico válida y luego presione Continuar para completar el proceso. 


\section{Búsqueda por Título de la Publicación}

Introduce un nombre de publicación para buscar en el campo Fuente de un registro. El producto recupera:

1. Títulos de revistas

2. Libros

3. Títulos de libros

4. Títulos de colecciones

5. Subtítulos de libros

6. Subtítulos de colecciones

7. Y mucho más...

Ingrese el nombre completo o parcial de una publicación seguido de un comodín(* ? \$). Por ejemplo: Cell Biology* busca:

- Cell Biology International

- Cell Biology International Reports

- Cell Biology Research Progress

Escriba los títulos de revistas entre comillas (" ") para encontrar el título exacto de la revista citada. Por ejemplo, "Journal of Agricultural and Food Chemistry" solo devuelve registros de artículos publicados en Journal of Agricultural and Food Chemistry.

Utilice el operador booleano OR para buscar registros de artículos publicados en cualquiera de las publicaciones especificadas. Por ejemplo, "Forensic Toxicology" OR "Drug Testing and Analysis" busca registros de artículos publicados en Forensic Toxicology o Drug Testing and Analysis.

Sugerir de forma automática nombres de publicaciones

Puede encontrar rápidamente una revista específica (o nombres de revistas similares que pueden ser útiles para su investigación) si selecciona la opción ACTIVAR de Sugerir de forma automática nombres de publicaciones en la sección Modificar configuración de la página de búsqueda. El producto muestra hasta 10 sugerencias a medida que ingresa al menos 3 caracteres sin espacios al principio. La lista se actualiza automáticamente a medida que ingresa más de 3 caracteres.

Escriba GENE en el campo Nombre de publicación para ver publicaciones como, por ejemplo:

- gene

- gene amsterdam

- gene expression omnibus

- Y mucho más...

Escriba GENE THERAPY en el campo Nombre de publicación para ver: 
- gene therapy

- gene therapy and gene delivery systems

- gene therapy and molecular biology

- Y mucho más...

Puede ocultar temporalmente las sugerencias automáticas presionando la tecla Esc a medida que ingresa caracteres en el campo Nombre de publicación.

Las sugerencias de búsqueda están basadas en la suscripción de su organización. El nombre de la revista seleccionado no siempre garantiza que el sistema encuentre registros, ya que el período de tiempo de búsqueda que seleccione puede excluir artículos adecuados.

1. Selecciona la búsqueda 'nombre de publicación'.

2. Introduce los términos del título de la publicación.

3. Se presentan sugerencias que corresponden con los términos introducidos (a medida que se introduce 3 caracteres).

4. Puede lanzar el índice para obtener más opciones de búsqueda.

Web of Science

Búsqueda básica Búsqueda de referencia citada Búsqueda avanzada + más

\begin{tabular}{|l|l|l|}
\hline REVISTA ESPANOLA & Nombre de publicación - \\
revista espanola de cardiologia \\
revista espanola de derecho constitucional \\
revista espanola de enfermedades digestivas \\
revista espanola de fisiologia
\end{tabular}

MÁS AJUSTES -

Normas (sin usar auto- sugerencia)

Biochemical and biopsy's*

Recuperate:

BIOCHEMICAL AND BIOPHYSICAL RESEARCH COMMUNICATIONS

No recuperate:

JOURNAL OF BIOCHEMICAL OR BIOPHYSICAL METHODS

\section{Polímero}

Sólo recupera:POLYMER 


\section{Lista Patrón de Revistas Indexadas}

Para ver la lista completa de revistas indexadas por Web of Science Group diríjase a:

http://mil.clarivate.com/

Los listados incluyen un archivo con los últimos cambios de publicaciones.

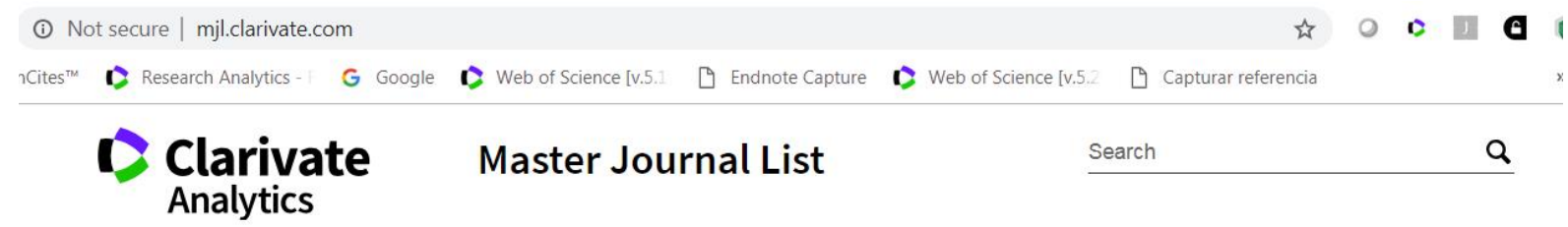

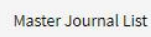

Journal Lists for Searchable Databases

Web of Science Core Collection

Arts \& Humanities Citation Index

Science Citation Index Expanded

Social Sciences Citation Index

Emerging Sources Citation Index

Subject Indexes on the Web of Science platform

Biological Abstracts

BIOSIS PREVIEWS

Biological Abstracts/RRM

Zoological Record

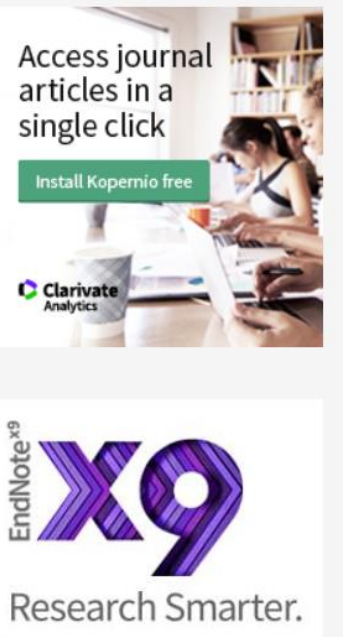




\section{Búsqueda por Autor Colectivo}

Una autoría conjunta es una organización o institución a la que se le atribuye la autoría de una publicación fuente como, por ejemplo, un artículo, un libro, un acta u otro tipo de trabajo. Los datos para el Autor Colectivo están disponibles de 1995 al presente

Introduce el nombre de una autoría conjunta para buscar en los siguientes campos de un registro completo: Autoría corporativa y Autoría conjunta del libro.

Introduce nombres completos o parciales usando comodines (* \$ ?). Por ejemplo, la búsqueda de Worldwide* encuentra autorías conjuntas como, por ejemplo:

- Worldwide Network Blood \& Marrow T

- Worldwide Wave Investigators

- Worldwide Study Grp

- Y mucho más...

Se puede introducir el nombre en el campo del autor colectivo o utilizar el índice del autor colectivo para ayudarle a localizar el nombre. En ambos casos, considere las variaciones posibles de un nombre de autor colectivo, utilizando siglas, abreviaturas y truncamiento para construir su búsqueda.

Ejemplo: Para buscar registros por autores afiliados con GIMEMA Grupo, introduce:

\section{Gímeme* ir grep* tal* mal* ir grupo* tal* mal*}

\section{Web of Science}

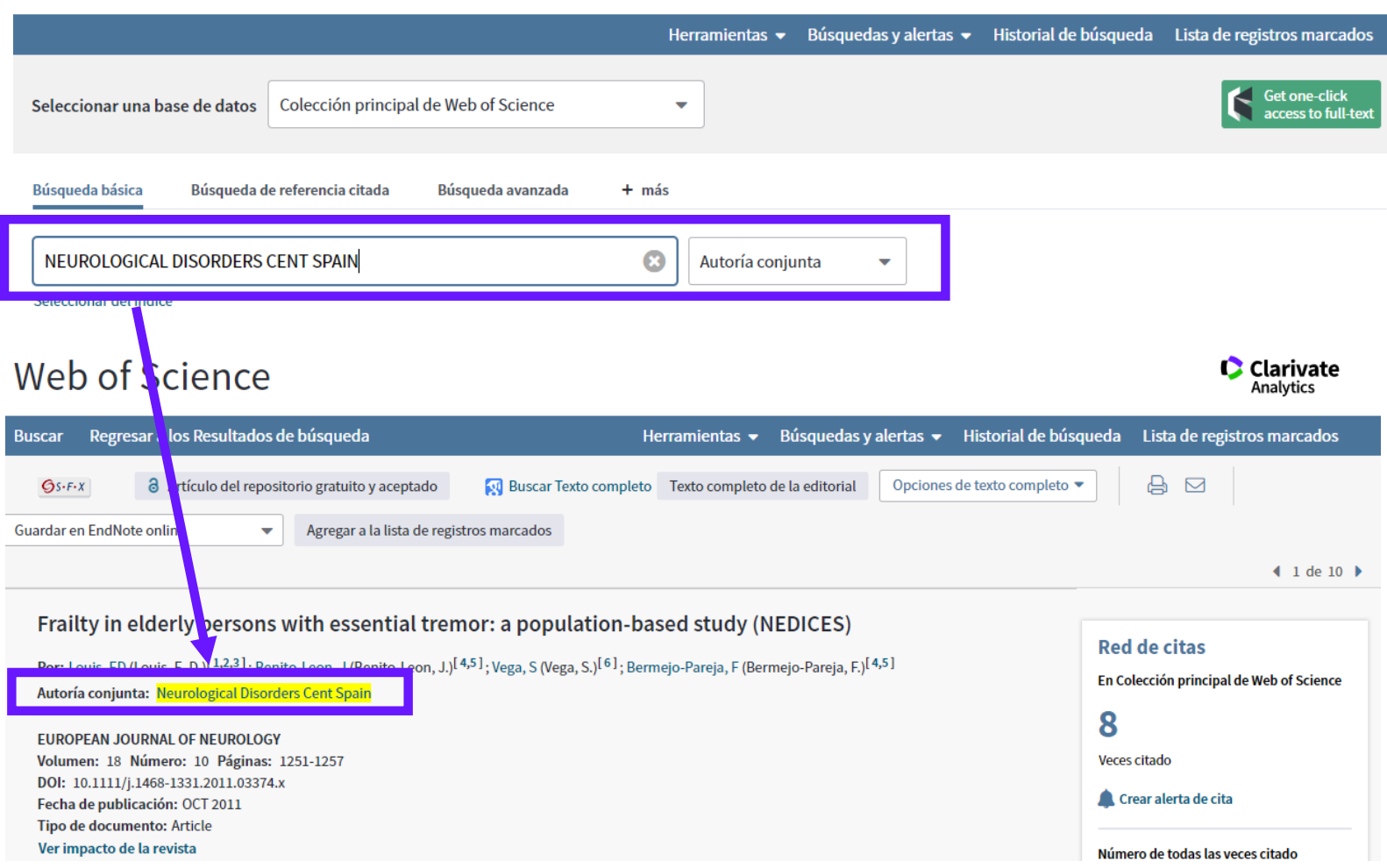




\section{Búsqueda por Año de Publicación}

Ingrese un año de cuatro dígitos o un rango de años. Por ejemplo:

- 2015

- 2010-2015

Siempre debe combinar una por año de publicación con una búsqueda por otro campo como, por ejemplo, Tema, Autor o Nombre de publicación.

Si su búsqueda por Año de publicación no devuelve ningún resultado, compruebe la configuración del período de tiempo. La configuración del período de tiempo puede excluir registros en el rango de años especificado.

Ejemplo: Año de publicación $=1999$ ir 2001-2004

Autor $=$ Henderson $\mathrm{G}^{*}$

Web of Science

Búsqueda básica

Búsqueda de referencia citada

Búsqueda avanzada + más

$1900-2018$

And
Ejemplo: O'Brian C* OR OBrian C*

Seleccionar del índice
Año de publicación

\section{Autor}




\section{Búsqueda por Dirección}

\section{Indexación de direcciones}

Se indexan las direcciones de TODOS los autores desde 1900. Cualquiera de ellas puede ser utilizada en las búsquedas. Se puede imprimir y/o exportar todas las direcciones. Web of Science Group normaliza las direcciones originales. En primer lugar indexa la organización principal, luego las otras organizaciones y por último la ciudad, el código postal y el país.

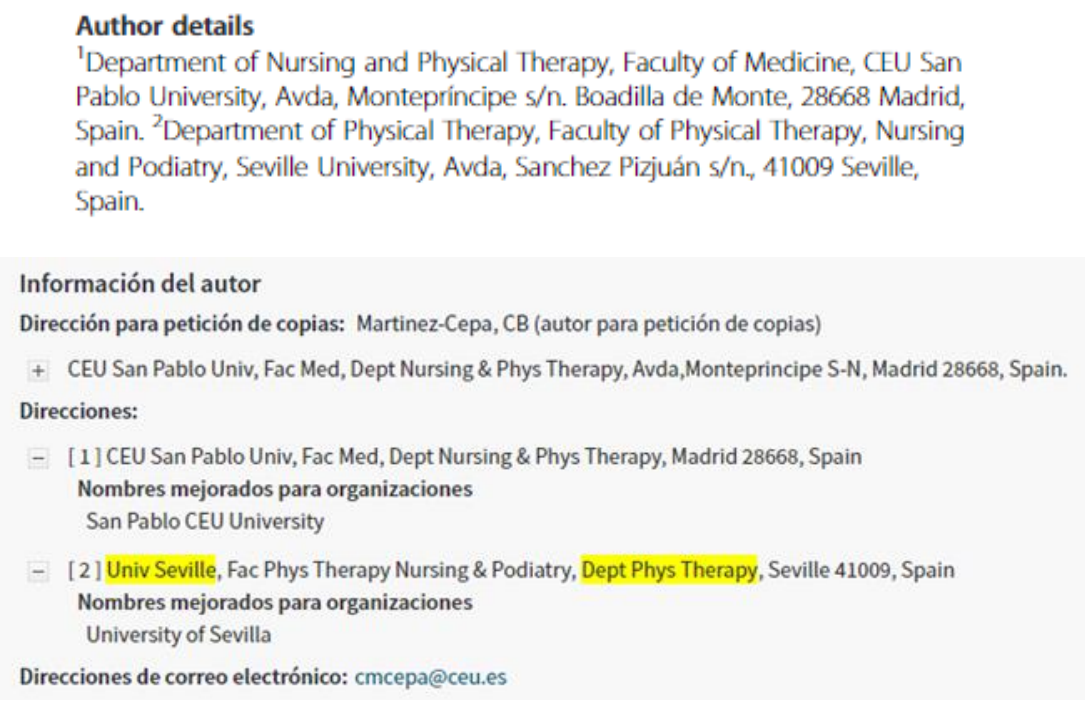

\section{Autor de reimpresión vinculado con su dirección}

El autor a quien se le solicitan reimpresiones está listado primero vinculado a su dirección. En cambio, para los otros autores se listan las direcciones sin establecer la asociación con el correspondiente autor.

\section{Abreviaturas}

Web of Science Group asigna términos de direcciones abreviados a términos de direcciones completos conocidos y viceversa. Esta función le permite usar términos de direcciones abreviados o completos para realizar búsquedas de registros que incluyan el término abreviado y el término completo. Haga clic en HELP para ver e identificar términos abreviados. Dado que no se trata de una lista exhaustiva, se recomienda truncar las abreviaturas para obtener resultados más completos.

- http://images.webofknowledge.com/WOKRS530AR16/help/es_LA/WOS/hp_address _abbreviations.html

- Web of Science Group también abrevia algunos nombres corporativos, de estados y de países. Para ver estas abreviaturas, utilice el enlace Help y luego Corporate $\boldsymbol{\&}$ Institution Abbreviations.

- Algunas abreviaturas por ejemplo "univ" e "inst" ocurren tan frecuentemente en la dirección que es necesario buscarlas en combinación con otros términos significativos de la dirección 


\section{Términos de búsqueda en el campo Dirección}

Se pueden realizar búsquedas por institución, departamento, calle, ciudad, estado, provincia, país, código postal o cualquier combinación de estos componentes.

\section{Introducir el título completo de la organización}

Una búsqueda por 'university Seville' es la misma que 'univ seville'

Colección principal de Web of Science

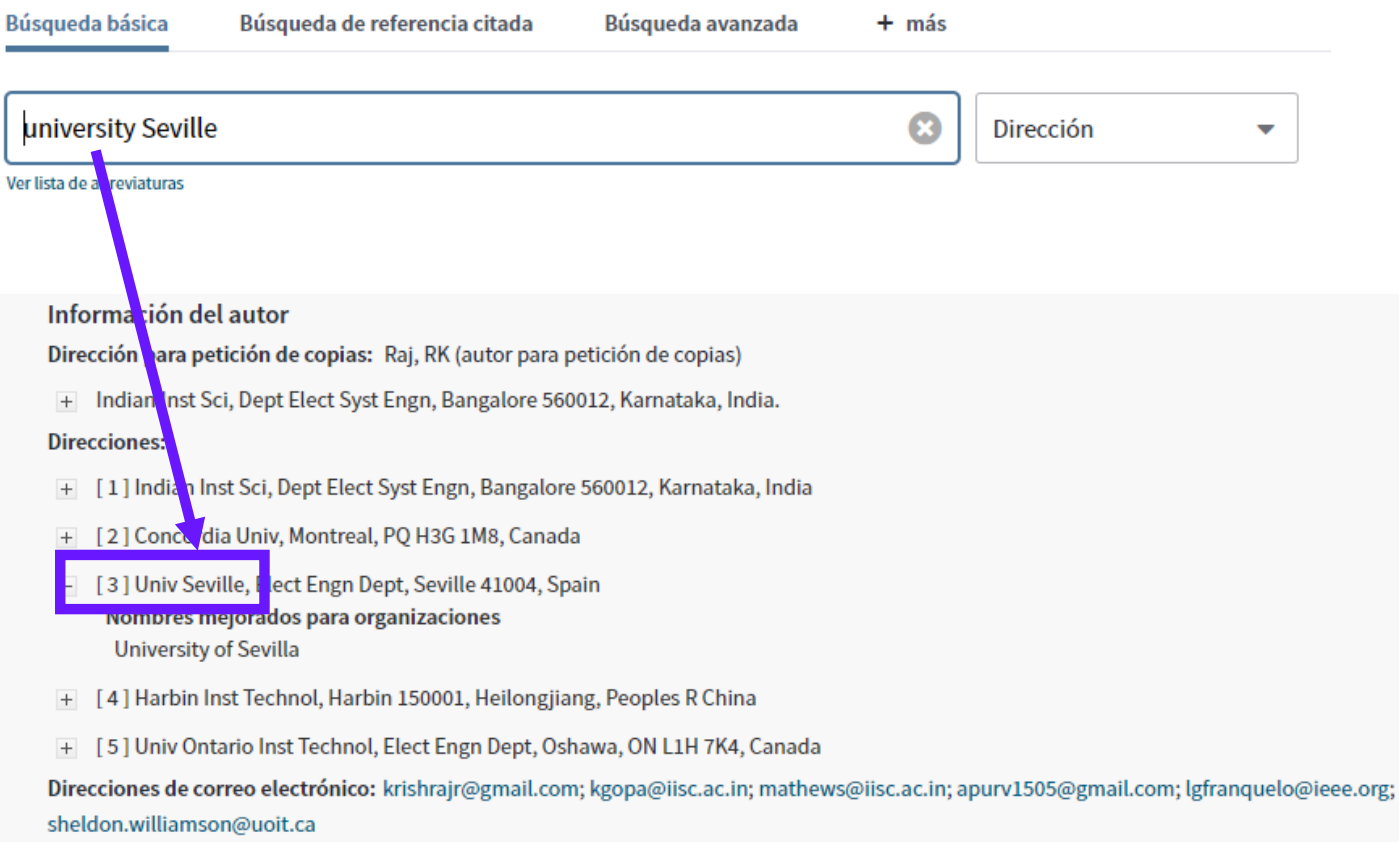




\section{Ejemplos}

Para localizar obras de coautores de Espana, Polania y Alemania introduce:

\section{spain and poland and germany}

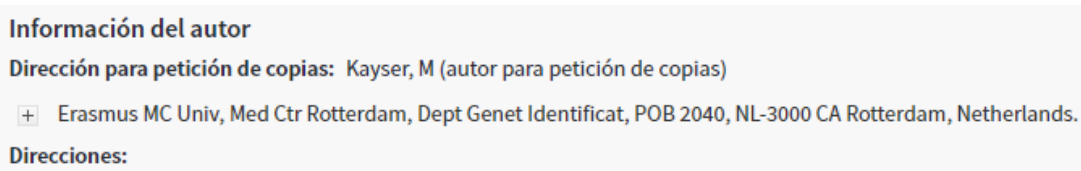

Para recuperar registros de documentos publicados por autores con código postal LS2 9JT, introduzca: LS2 9JT

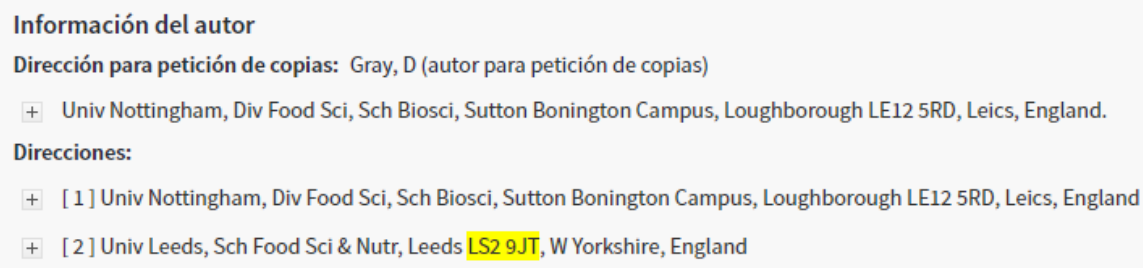

\section{Uso del operador SAME en la búsqueda por direcciones}

Para recuperar artículos escritos por científicos que trabajan en un campus especifico de una universidad o en un departamento específico use el operador SAME para recuperar registros que contengan dos o más términos en la misma dirección.

\section{univ sevilla same Dept Phys Therapy}


[1] Escuela Osteopatia Madrid, Madrid, Spain SAME aparecen en la misma

[2] Univ Catolica Avila, Dept Phys Therapy, Avila, Spain dirección.

+ [3 ] Univ Balearic Isl, Dept Nursing \& Physiotherapy, Carretera Valldemossa Km 7-5, Palma De Mallorca 07122, Spain

+ [4] Univ Balearic Isl, Univ Inst HIth Sci Res IUNICS IdISPa, Palma De Mallorca, Spain

+ [5] Univ Seville, Dept Phys Therapy, Fac Nursing Physiotherapy \& Podiatry, Seville, Spain

+ [6] Univ Seville, Dept Phys Therapy, EU Francisco Maldonado, Osuna, Spain

\section{Búsqueda avanzada - opciones adicionales de búsqueda}

Se puede buscar los elementos adicionales del campo de dirección al utilizar las siguientes etiquetas de campo disponibles en la página de búsqueda avanzada.

OG=Organization

SA $=$ Street Address

PS=Province/State

ZP=Zip/Postal Code
SG=Suborganization

$\mathrm{Cl}=$ City

$\mathrm{CU}=$ Country

Ejemplo: $\mathbf{O G}=$ univ Cordoba and $\mathbf{C U}=$ SPAIN 


\section{Mejora en la calidad de datos: Nombre Mejorado de una Organización}

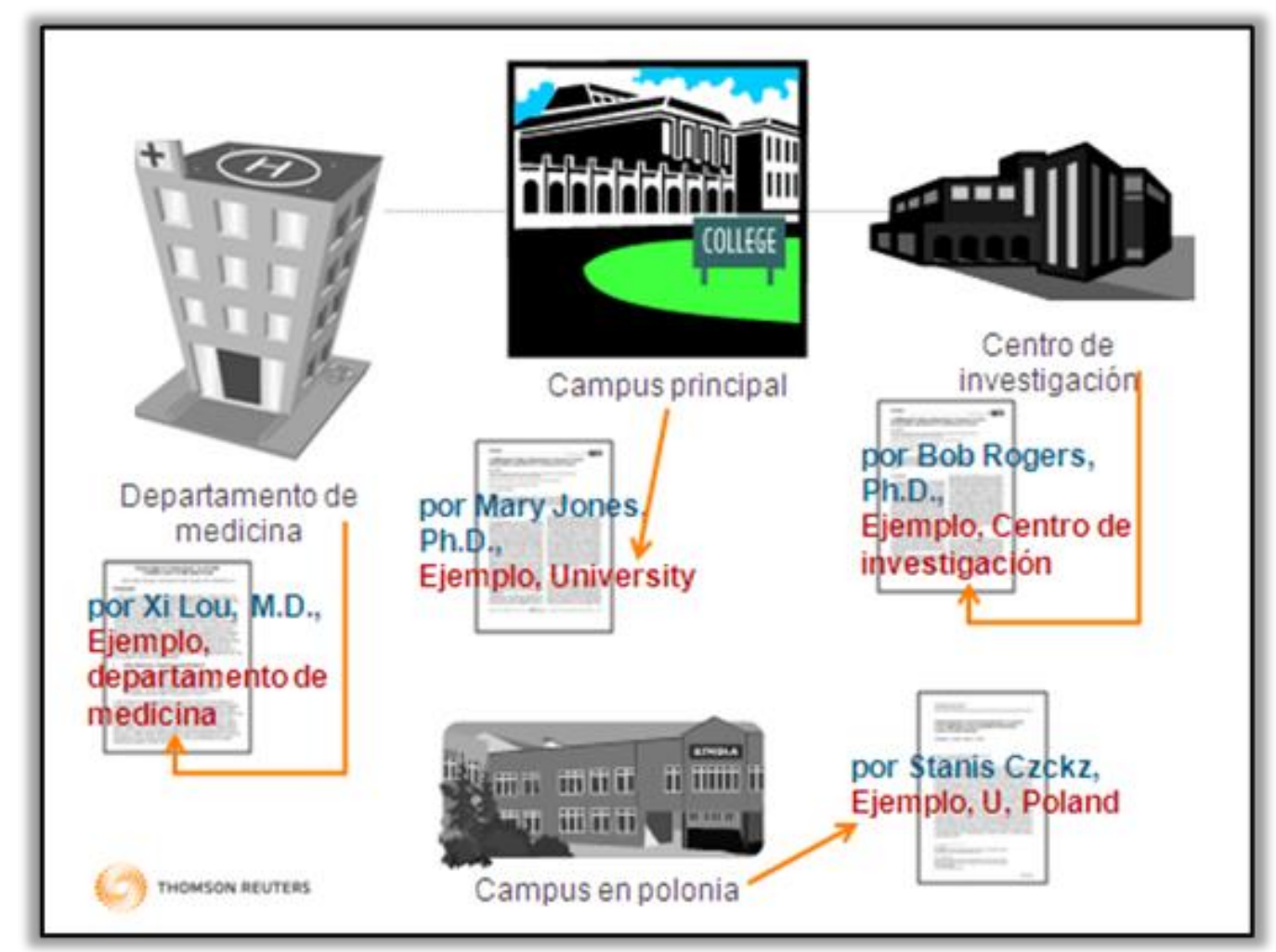

\section{Dificultades en la búsqueda por una organización}

- Existen variaciones en los nombres de las organizaciones porque los autores hacen referencia a su organización usando formas diferentes.

- Web of Science Group indexa las direcciones tal y como publicado y las variantes se presentan en las direcciones de los registros.

- Una búsqueda por una organización puede resultar en variaciones que pueden quedarse fuera de una búsqueda o puede resultar en organizaciones no de interés incluidas en los resultados.

\section{La Solución: Unificación de las direcciones}

- El campo de la Organización-nombre preferido

- Le permite buscar por un nombre preferido o unificado de una organización o por una variante/ nombre más específico.

- Listado incluye más de 12.679 instituciones unificadas

- La investigación de estas instituciones unificadas resulta en más de 49 millones de registros en la Web of Science

- La unificación es un trabajo continuo.

- Póngase en contacto con el equipo técnico de Web of Science Group para solicitar la unificación de su organización.

https://support.clarivate.com/s/ 


\section{Una Búsqueda por Una Organización-nombre mejorado}

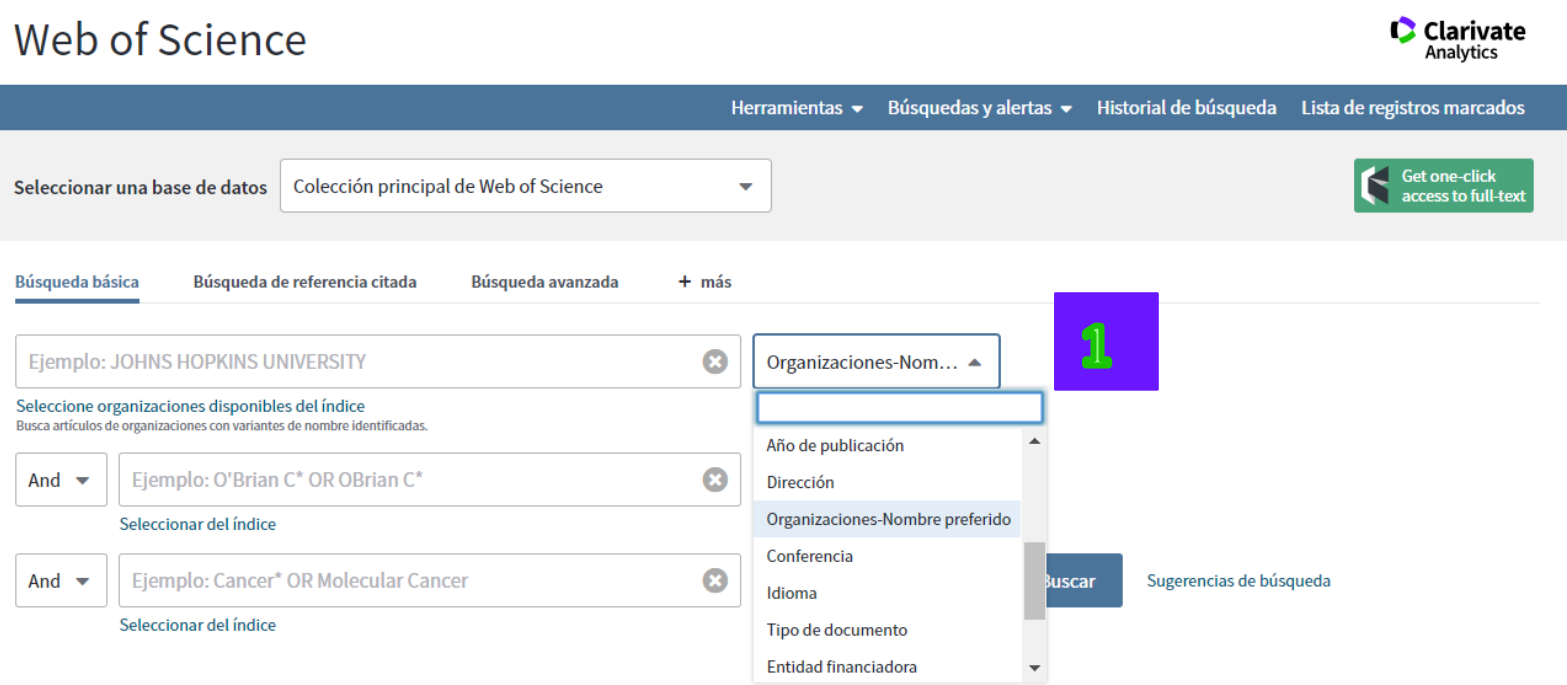

1. En la Colección Principal de la Web of Science, selecciona en el menú desplegable la búsqueda 'Organizaciones-Nombre Preferido' y abre el índice (Seleccione organizaciones disponibles del índice).

Este índice le permite buscar nombres de organizaciones de preferencia o sus variantes de nombre para agregarlos a su consulta de búsqueda. Puede seleccionar varios nombres de preferencia o variantes de nombre.

2. Para buscar organizaciones se puede examinar el índice alfabético o se puede realizar una búsqueda. Introduce la organización en la casilla de búsqueda y haga clic en 'Buscar'.

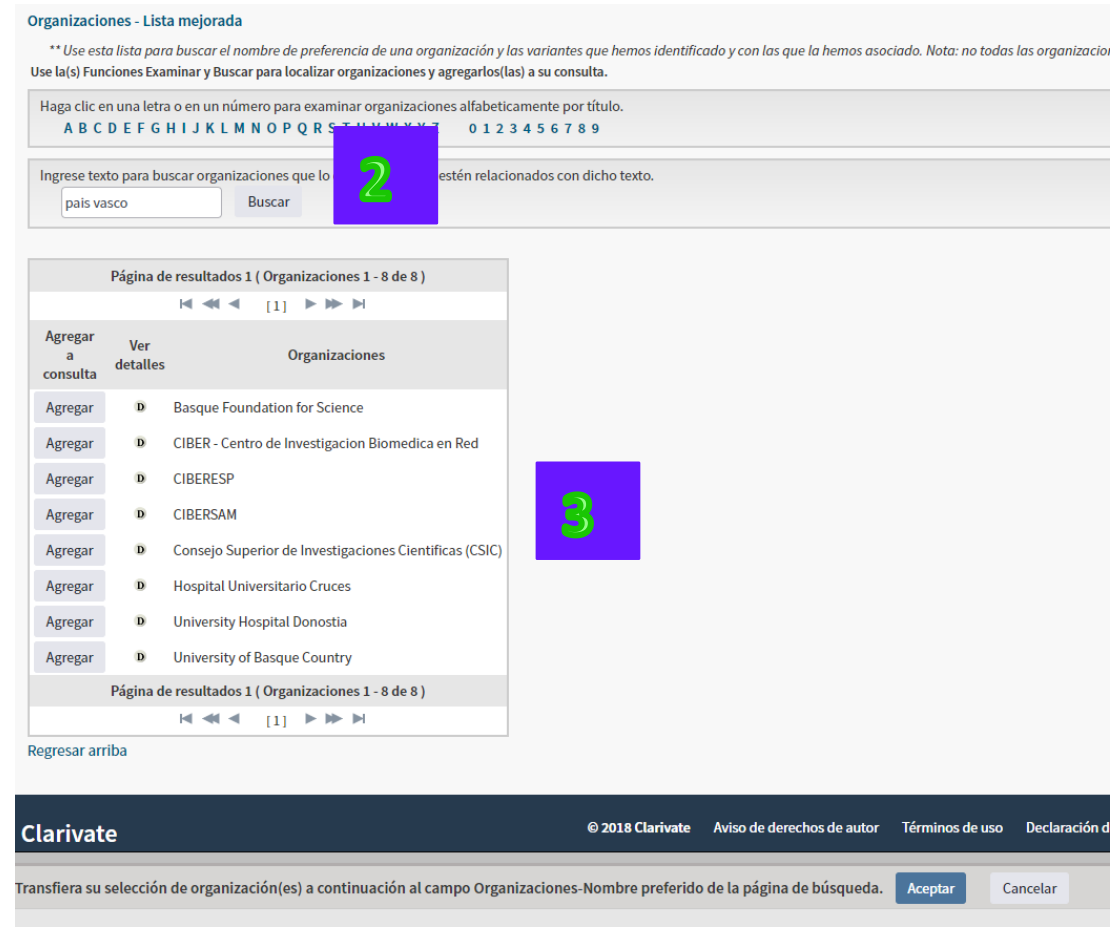


3. Las organizaciones recuperadas son los nombres preferidos de las organizaciones incluidas en el índice. Selecciona la organización de interés. Para examinar las variantes unificadas al nombre preferido haga clic en el icono ' $D$ ' para ver los detalles.

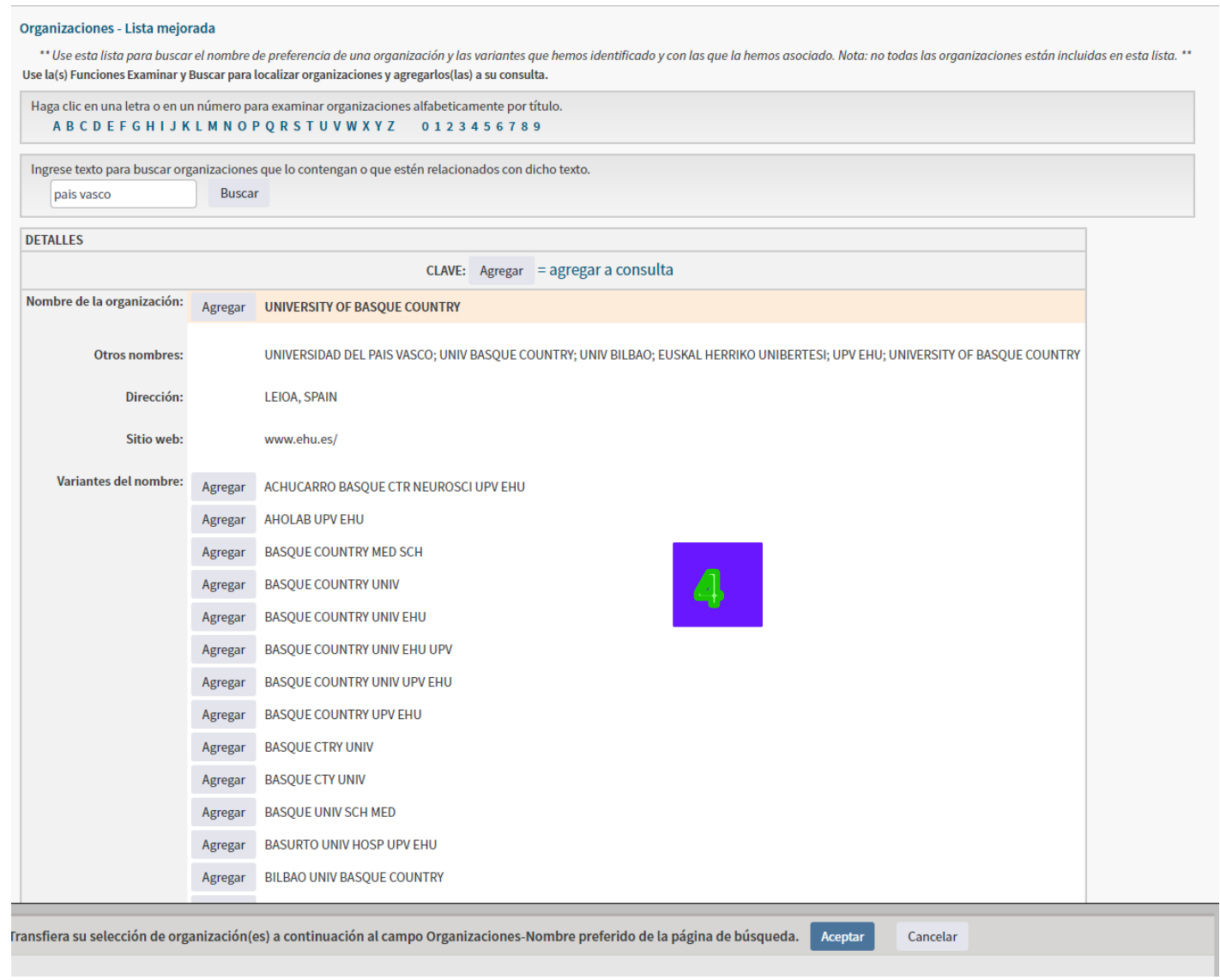

4. Las variantes relacionadas con la organización se presentan por un orden alfabético. En la parte superior se puede ver los detalles de la organización (dirección, página web). Para buscar todas las variantes unificadas al título principal, haga clic en el botón 'Agregar' a mano izquierda del título principal. La selección se presenta en la casilla de búsqueda en la parte inferior y haga clic en 'Aceptar' para volver a la página de búsqueda general.

5. Para buscar las variantes por separado, haga clic en 'Añadir' a mano izquierda de la variante deseada.

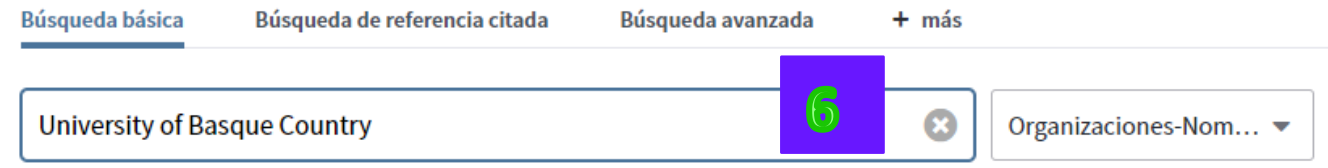

Seleccione organizaciones disponibles del índice

Busca artículos de organizaciones con variantes de nombre identificadas. 
6. El título preferido de la organización se presenta en el campo de búsqueda. Haga clic en 'Buscar' para lanzar la búsqueda.

7. Para examinar el número de registros que pertenecen a cada variante, hace falta ANALIZAR los resultados. En la herramienta Analizar Resultados, selecciona analizar por 'Organizaciones'

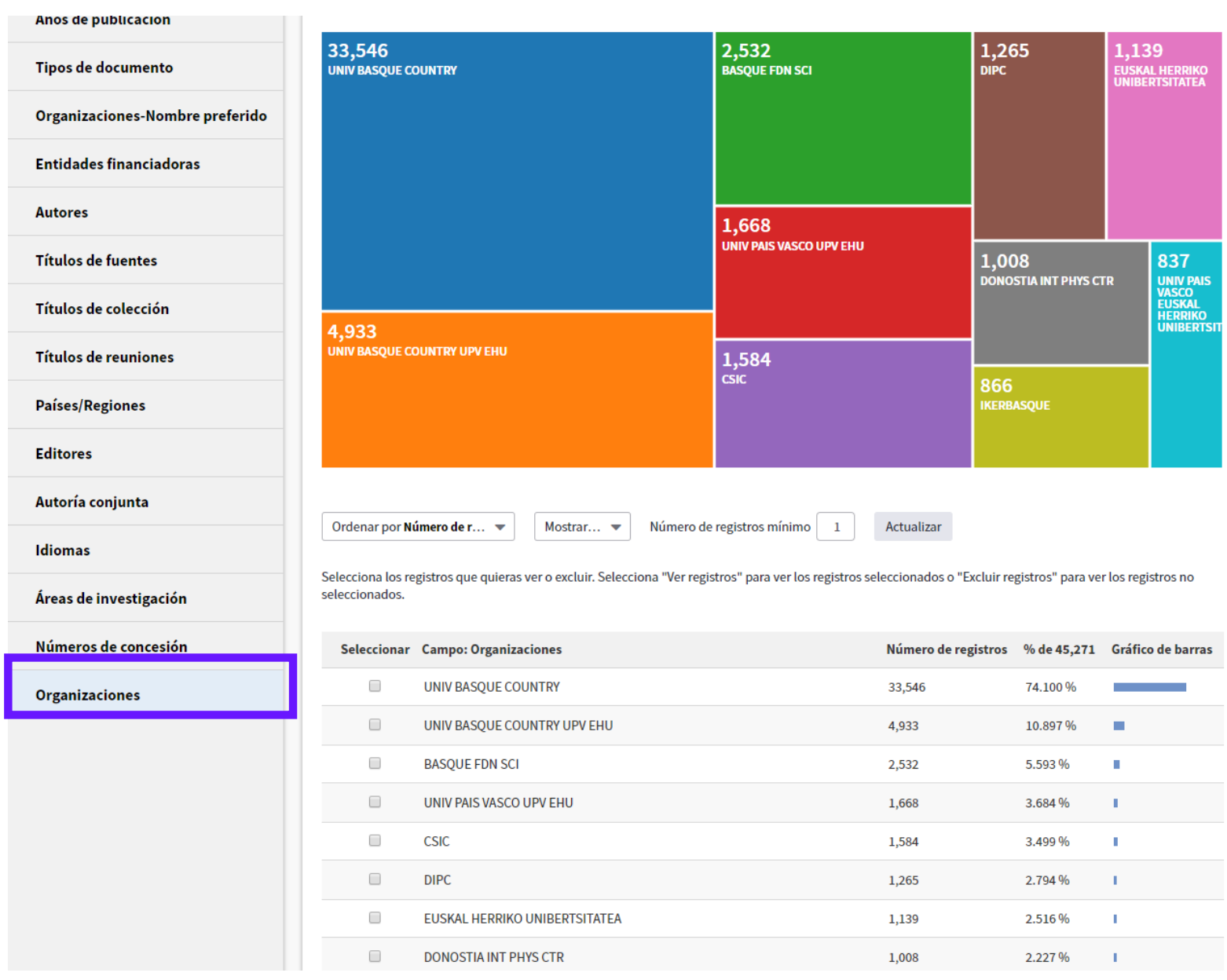




\section{Búsqueda por Referencias Citadas}

\section{Principios y Usos de la Búsqueda por Referencias Citadas}

La indexación de referencias citadas permite utilizar las citas como términos de búsqueda. Hace uso de las relaciones entre trabajos establecidos por los mismos autores.

La relación entre citas ofrece una capacidad única de encontrar información nueva o desconocida basada en información más antigua y conocida.

Una búsqueda de referencia citada permite descubrir cómo se confirmó, aplicó, mejoró, amplió o corrigió una innovación o una idea conocidas. Descubra quién cita sus investigaciones y el impacto que tiene su trabajo en otros investigadores del mundo.

En Arts \& Humanities Citation Index, la búsqueda de referencia citada le permite buscar artículos que incluyen o hacen referencia a una ilustración de una obra de arte o de una partitura musical. Estas referencias se denominan citas implícitas.

Ejemplos de usos de la información derivada de la Búsqueda por Referencia Citada:

1. Permite hallar quien está citando sus trabajos de investigación o los de un colega.

2. Facilita la identificación de la información que los competidores nacionales e internacionales consultan para desarrollar investigación.

3. Ayuda a elaborar un historial objetivo de un área de investigación, una invención o un descubrimiento. La indexación de citas muestra los vínculos que revelan el impacto y la influencia científica de las investigaciones.

4. Puede utilizarse para justificar políticas de adquisición de revistas determinando el uso de cada revista por parte de la comunidad científica.

5. En las artes y humanidades permite localizar artículos que contienen representaciones completas o parciales de arte o de música. 


\section{Componentes de una Referencia Citada}

\section{Elementos bibliográficos de un artículo citado}

Cited Author Apellido del primer autor (hasta 15 caracteres), un espacio y hasta 3 iniciales.

Cited Work Título del trabajo abreviado a 20 caracteres. La lista de títulos de publicaciones citadas en la página de búsqueda contiene sólo las abreviaturas de las publicaciones indexadas como revistas fuente la Colección Principal

Cited Year Año de publicación (tal y como se cita).

Volume Número del volumen, limitado a 4 caracteres

Cited Issue Edición citada (tal y como se cita)

Page Número de la primera página, limitado a 5 caracteres

Cited Title Título de la referencia (tal y como publicado)

\section{Consejos para realizar búsquedas}

Utilice variaciones o trunque el nombre del autor citado después de la primera inicial. También se puede localizar los nombres de autores en el índice del autor citado (Author Seach Aid)

1. Trunque los términos en el campo del trabajo citado para encontrar las formas diferentes de un título de una revista o libro abreviado. Trunque la abreviatura del trabajo citado incluso si está seleccionado a partir de la lista de abreviaturas.

2. Las referencias sin enlaces en el registro son documentos no indexados por TR (ejemplo, artículos fuera del alcance de su suscripción o variaciones de referencias citadas etc.). 


\section{Búsqueda por Referencia Citada- Ejemplo}

Si desea recuperar los artículos que han citado un trabajo en particular, selecciona una búsqueda por referencia citada en la página de inicio . A continuación, se presenta un ejemplo de una búsqueda por referencia citada para el artículo siguiente:

K. Anand, J. Ziebuhr, P. Wadhwani, J.R. Mesters, R. Hilgenfeld. "Coronavirus main proteinase (3CL(pro)) structure: Basis for design of anti-SARS drugs." SCIENCE, 300 (5626): 1763-1767, Jun. 13, 2003.

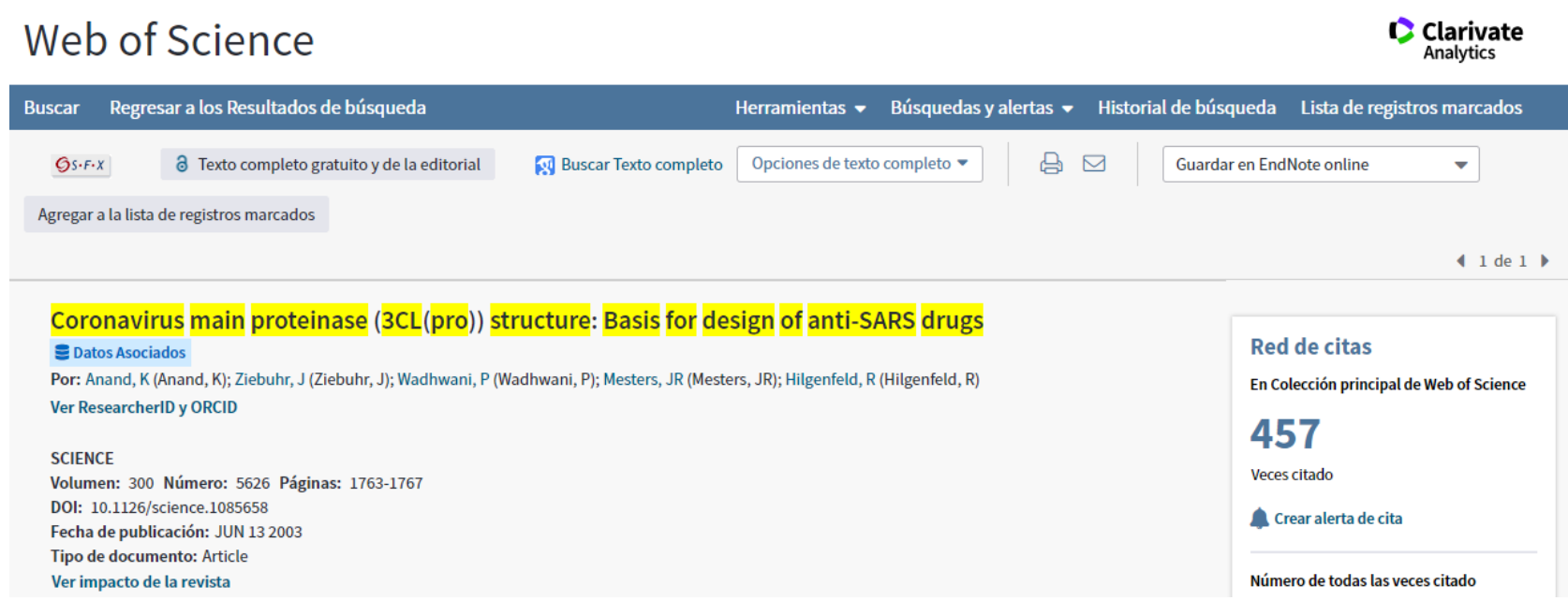

Para recuperar referencias citadas de artículos que citan al trabajo ejemplo introduce los términos de búsqueda siguientes:

Consejo: para recuperar variaciones (referencias que citan un trabajo incorrectamente o que faltan citar los datos bibliográficos completamente), es mejor introducir datos generales y usar el asterisco.

Web of Science $\quad$ clarivate

Búsqueda básica Búsqueda de referencia citada Búsqueda avanzada + más

Encuentre los artículos en los que se cita el trabajo de una persona.

\begin{tabular}{|c|c|c|c|c|c|}
\hline anand $^{*}$ & $\boldsymbol{x}$ & Autor citado & $\checkmark$ & & \\
\hline science $^{\star}$ & $\boldsymbol{x}$ & Trabajo citado & $\checkmark$ & & \\
\hline \multicolumn{6}{|l|}{$\begin{array}{l}\text { Selecccionar del intrice } \\
\text { Ver lista de abreviaturas }\end{array}$} \\
\hline Ejemplo: 1943 or $1943-1945$ & $\boldsymbol{x}$ & Año(s) de cita & $\checkmark$ & Buscar & $\begin{array}{l}\text { Consulte nuestro tutorial } \\
\text { de búsqueda de } \\
\text { referencia citada }\end{array}$ \\
\hline
\end{tabular}




\section{Búsqueda por Referencias Citadas: Lista de Referencias}

El índice de referencias citadas a continuación presenta todas las referencias que citan el trabajo publicado por 'Anand $K$ ' en la revista Science.

1. Si está buscando una referencia citada específica puede localizarla mediante el número del volumen, de la primera página y el año según la información bibliográfica original del artículo.

2. Observe que se ha citado este artículo por varias maneras. Variaciones de citas ocurren por que la referencia original cita incorrectamente el volumen, página o año de un artículo o puede incluir datos incompletos.

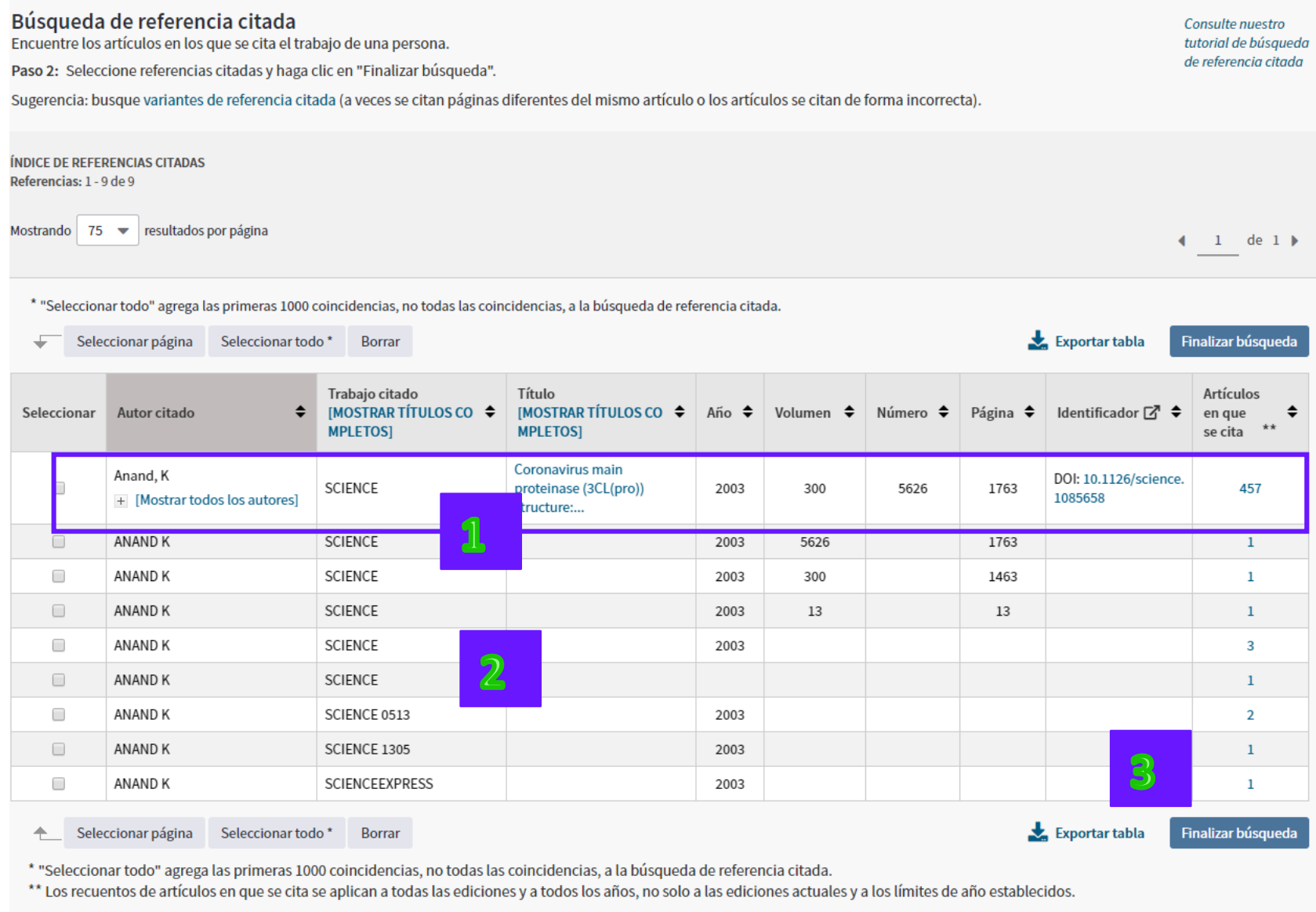

3. Para examinar todos los artículos indexados que citan citan el trabajo de búsqueda selecciona sus casillas a mano izquierda o selecciona todo, luego haga clic en 'Finalizar búsqueda'.

4. Los resultados recuperados son artículos que en sus referencias citadas exhiben una referencia que cita al autor 'Anand K, publicado en la revista Science.

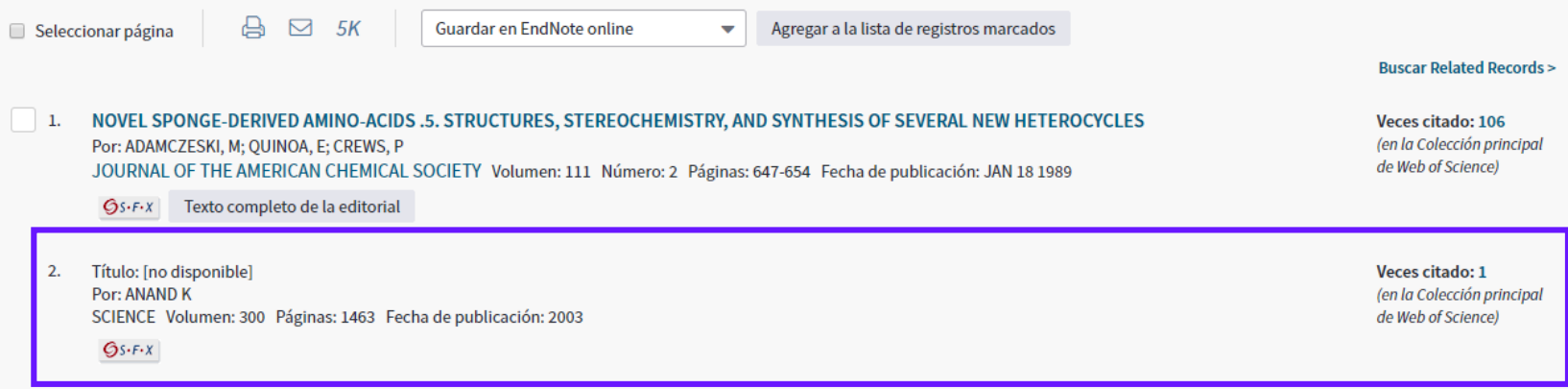




\title{
Búsqueda por Referencia Citada: Autor Citado
}

Para recuperar referencias que citan los trabajos de un autor citado de interés siga los pasos siguientes.

1. Para recuperar referencias que citan el autor 'Enrique Garcia-Berro' introduce la consulta siguiente:

\author{
Web of Science
}

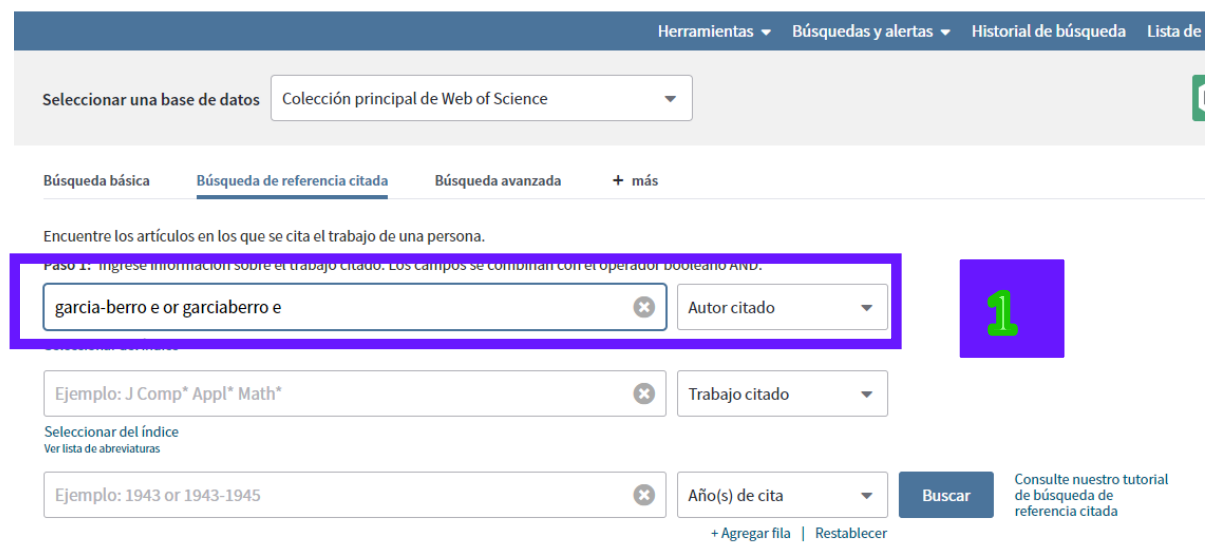

\begin{tabular}{|c|c|c|c|c|c|c|c|c|c|}
\hline \multirow{2}{*}{\multicolumn{9}{|c|}{$\begin{array}{l}\text { Búsqueda de referencia citada } \\
\text { Encuentre los artículos en los que se cita el trabajo de una persona. } \\
\text { Paso 2: Seleccione referencias citadas y haga clic en "Finalizar búsqueda". }\end{array}$}} & $\begin{array}{l}\text { Consulte nuestro } \\
\text { tutorial de búsqueda } \\
\text { de referencia citada }\end{array}$ \\
\hline & & & & & & & & & Sugerencia: busque variantes de referencia citada (a veces se citan páginas diferentes del mismo artículo o los artículos se citan de forma incorrecta). \\
\hline \multicolumn{10}{|c|}{$\begin{array}{l}\text { ÍNDICE DE REFERENCIAS CITADAS } \\
\text { Referencias: } 1 \text { - } 75 \text { de } 377\end{array}$} \\
\hline Mostrando 75 & resultados por página & & & & & & & 4 & de 6 . \\
\hline \multicolumn{10}{|c|}{ * "Seleccionar todo" agrega las primeras 1000 coincidencias, no todas las coincidencias, a la búsqueda de referencia citada. } \\
\hline$\checkmark$ Sele & cionar página Seleccionar toc & $0^{*}$ Borrar & & & & & & Exportar tabla & Finalizar búsqueda \\
\hline Seleccionar & Autor citado & $\begin{array}{l}\text { Trabajo citado } \\
\text { [MOSTRAR TíTULOS CO } \\
\text { MPLETOS] }\end{array}$ & $\begin{array}{l}\text { Título } \\
\text { [MOSTRAR TítULOS CO } \\
\text { MPLETOS] }\end{array}$ & Año $\triangleq$ & Volumen $\bullet$ & & Página $\rightleftharpoons$ & Identificador $\square \div$ & $\begin{array}{l}\text { Artículos } \\
\text { en que } \\
\text { se cita }\end{array} *$ \\
\hline$\square$ & $\begin{array}{l}\text { Althaus, L....Garcia-Berro, E. } \\
+ \text { [Mostrar todos los autores] }\end{array}$ & ARXIV12043565ASTROPH & & & & 15 & & & 2 \\
\hline$\square$ & $\begin{array}{l}\text { Althaus, L....Garcia-Berro, E. } \\
+[\text { Mostrar todos los autores] }\end{array}$ & P 7 PATR WORKSH AXW & $\begin{array}{l}\text { White dwarfs as physics } \\
\text { laboratories:the case of } \\
\text { axions }\end{array}$ & 2012 & & & 1 & & 1 \\
\hline$\square$ & $\begin{array}{l}\text { Althaus, L. G....Garcia-Berro, E. } \\
+ \text { [Mostrar todos los autores] }\end{array}$ & ASTRON ASTROPHYS & & 2015 & 576 & & 9 & & 1 \\
\hline$\square$ & $\begin{array}{l}\text { Althaus, L.G....Garcia-Berro, E. } \\
+ \text { [Mostrar todos los autores] }\end{array}$ & ASTRON ASTROPHYS & $\begin{array}{l}\text { White dwarf evolutionary } \\
\text { sequences for... }\end{array}$ & 2015 & 516 & & A9 & & 1 \\
\hline$\square$ & $\begin{array}{l}\text { Althaus, L. G....Garcia-Berro, E. } \\
+ \text { [Mostrar todos los autores] }\end{array}$ & ASTRON ASTROPHYS & & 2009 & & & 1021 & & 1 \\
\hline$\square$ & $\begin{array}{l}\text { Althaus, L. G....Garcia-Berro, E. } \\
+ \text { [Mostrar todos los autores] }\end{array}$ & A AR & & 2010 & & & 8 & & 1 \\
\hline$\square$ & $\begin{array}{l}\text { Althaus, L. G....Garcia-Berro, E. } \\
+ \text { [Mostrar todos los autores] }\end{array}$ & APJ IN PRESS & & 2010 & & & & & 2 \\
\hline$\square$ & $\begin{array}{l}\text { Althaus, L. G....Garcia-Berro, E. } \\
+ \text { [Mostrar todos los autores }]\end{array}$ & ASTRON ASTR IN PRESS & & 2010 & & & & & 3 \\
\hline$\square$ & $\begin{array}{l}\text { Althaus, L. G....Garcia-Berro, E. } \\
+ \text { [Mostrar todos los autores] }\end{array}$ & ASTRON ASTROPHYS & $\begin{array}{l}\text { New phase diagrams for } \\
\text { dense carbon-oxygen } \\
\text { mixtures... }\end{array}$ & 2012 & 537 & & & $\begin{array}{l}\text { DOI: } 10.1051 / 0004-63 \\
61 / 201117902\end{array}$ & 20 \\
\hline
\end{tabular}


2. Estas referencias si incluyen en el índice de referencias de una búsqueda por un autor citado pero no son registros fuentes indexadas en la Colección Principal, por este motivo no exhiben vínculos a registros en la Colección Principal. 


\section{Búsqueda por Referencia Citada: Autor Secundario Citado}

Es posible hacer una búsqueda por referencia citada utilizando el nombre de un autor secundario siempre y cuando el registro de tal documento haya sido indexado en la base y en los años de su suscripción. Por ejemplo, es posible buscar las citas hechas al mismo artículo utilizando los nombres de K. Anand, J. Ziebuhr, P. Wadhwani, J.R. Mesters, \& R. Hilgenfeld al introducir ziebuhr $j^{*}$ or wadwhani $p^{*}$ or mesters $j^{*}$ or hilgenfeld $r^{*}$ como autor citado. Sin embargo, para poder recuperar todas las variaciones y citas con errores deberá realizar una búsqueda por referencias citada con el nombre del primer autor listado.

\section{Ejemplos de Búsqueda-Autor Secundario}

\section{Web of Science}

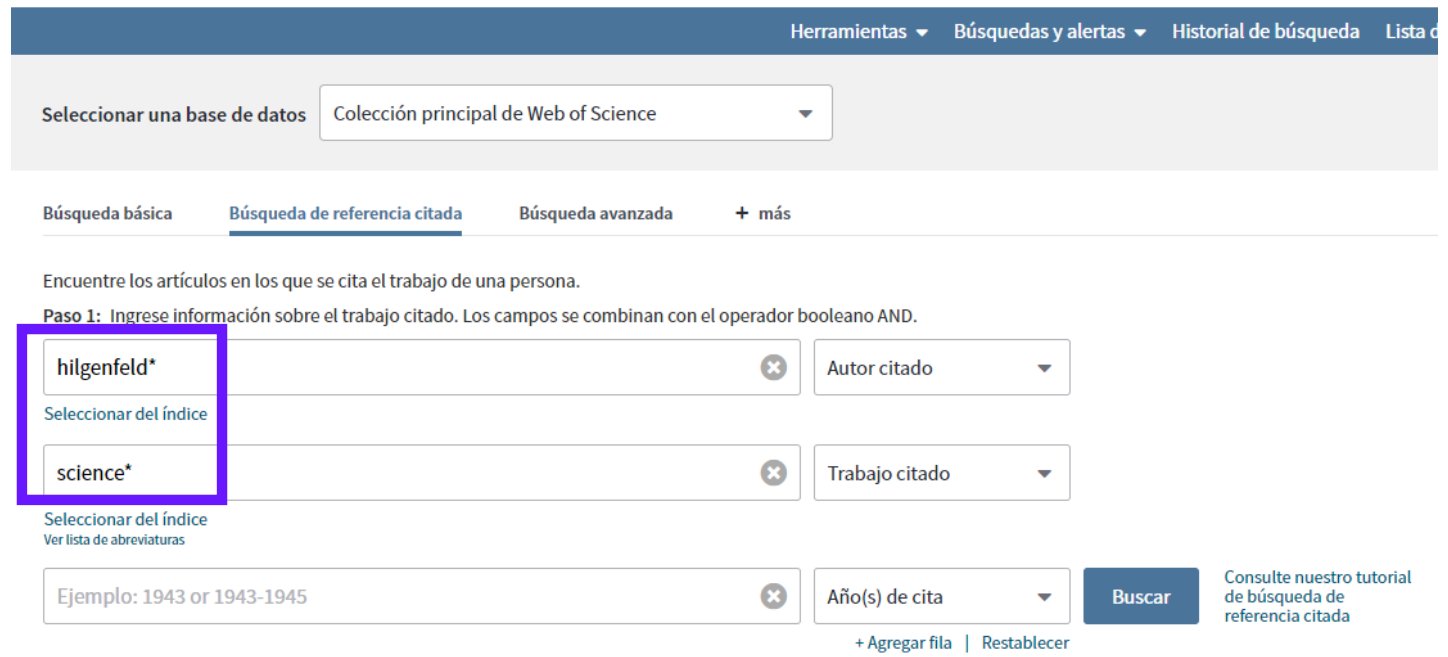

Búsqueda de referencia citada

Encuentre los artículos en los que se cita el trabajo de una persona.

Paso 2: Seleccione referencias citadas y haga clic en "Finalizar búsqueda".

Consulte nuestro

Sugerencia: busque variantes de referencia citada (a veces se citan páginas diferentes del mismo artículo o los artículos se citan de forma incorrecta).

INDICE DE REFERENCIAS CITADAS

Referencias: 1 - 5 de 5

Mostrando 75 resultados por página

* "Seleccionar todo" agrega las primeras 1000 coincidencias, no todas las coincidencias, a la búsqueda de referencia citada.

$\downarrow$ Seleccionar página Seleccionar todo * Borrar

\pm Exportar tabla

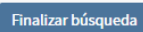

Trabajo citado MPLETOS:

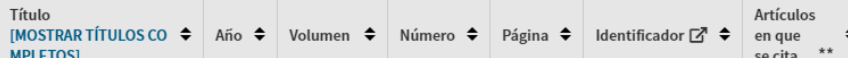

Autor citado

\begin{tabular}{|c|c|c|c|c|c|c|c|c|}
\hline $\begin{array}{l}\text { Anand, K...Hilgenfeld, } R \\
+[\text { Mostrar todos los autores] }\end{array}$ & SCIENCE & $\begin{array}{l}\text { Coronavirus main } \\
\text { proteinase (3CL(pro)) } \\
\text { structure:... }\end{array}$ & 2003 & 300 & 5626 & 1763 & $\begin{array}{l}\text { DOI: } 10.1126 / \text { science. } \\
1085658\end{array}$ & 457 \\
\hline $\begin{array}{l}\text { Anard, K....Hilgenfeld, } \mathrm{R} \\
+ \text { [Mostrar todos los autores] }\end{array}$ & SCIENCE & & 2003 & 300 & & 1763 & & 2 \\
\hline
\end{tabular}

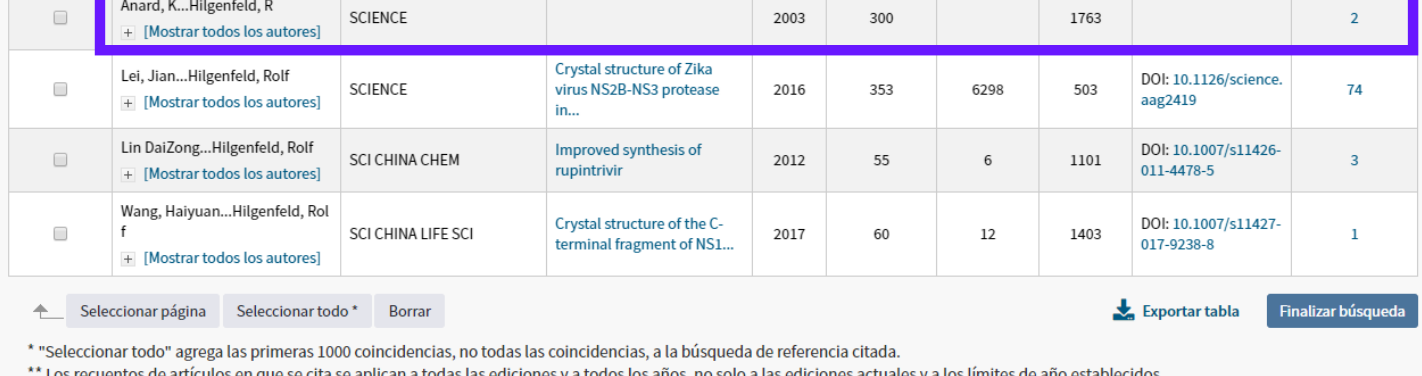


1. El nombre del primer autor (Anand $\mathrm{K}$ ) del artículo aparece en primer lugar, seguido por unos puntos y luego el nombre del autor secundario introducido (Hilgenfeld R)

2. Las variaciones y errores de referencias citadas sólo se recuperan buscando con el primer autor listado del artículo.

3. El autor secundario recuperará citas siempre y cuando el documento cuyo nivel de citas se busca esté indexado en la base (determinada por el alcance de su suscripción).

\section{Eliminación de Auto Citas}

Para eliminar las auto citas de un autor, realice en primer lugar una búsqueda de referencias citadas en Cited Reference Search. Seleccione todas las referencias que pertenecen al autor específico y haga clic en Finalizar búsqueda para crear un conjunto. Luego, vaya a la página de inicio de Web of Science para realizar una búsqueda por autor. Por último, en la Búsqueda Avanzada combine los dos conjuntos de búsqueda con el operador booleano NOT.

(Resultados de la búsqueda de referencias citadas) NOT (resultados de la búsqueda por autor)

\section{Búsqueda por Referencias Citadas-Variaciones}

La publicación (Cited Work) indexa hasta un máximo de 20 caracteres. Use abreviaturas y trunque para recuperar posibles variaciones del título.

\section{Consejos de búsqueda}

1. Para las revistas indexadas por Web of Science Group consulte el listado titulado 'Journal Abbreviations List' como guía.

2. Use truncamiento incluso para las abreviaturas seleccionadas de la lista de abreviaturas de revistas.

3. También se recomienda conocer las posibles abreviaturas y/o el acrónimo de una revista para descubrir las variaciones de una referencia citada. En el ejemplo se buscan las citas hechas a los artículos de R.N. Kostoff en Journal of the American Society for Information Science and Technology.

Cited Author $=$ kostoff $r^{* *}$

Cited Work = jasis* or j am soc inf* 


\section{Búsqueda por Libro Citado}

\section{Elementos bibliográficos de un libro citado}

Cited Author Apellido del autor (hasta 15 caracteres), un espacio y hasta 3 iniciales. Separe los apellidos de los autores con el operador OR.

Cited Work Título de la obra, abreviado a 20 caracteres. Existen normalmente variantes en las citas de libros (diferentes páginas, ediciones, traducciones, reimpresiones citadas). Trunque el título de la obra citada para obtener todas las variaciones.

Cited Year $\quad$ Año de publicación del libro.

Cita a un libro:

Gabriel García Márquez. Cien años de Soledad. (One hundred years of solitude). Buenos Aires: Editorial Sudamericana, 1967.

Para encontrar artículos que citan a este libro introduzca los siguientes términos de búsqueda:

Cited Author: garciamarquez* or marquez*

Cited Work: cien* or hundred* or cent* or $100^{*}$ or one*

\section{Consejos de Búsqueda:}

1. Trunque la primera palabra del título del libro.

2. No olvide buscar palabras de títulos extranjeros originalmente publicados en ediciones no inglesas.

3. Excluya palabras innecesarias (ej. And, the, with, of) de la abreviatura del título.

4. No limite por año. Los autores suelen citar la edición a mano, que puede resultar en una variación amplia en el campo de año citado. 


\section{Búsqueda por Patente Citada}

\section{Elementos Bibliográficos de una patente citada}

Cited Author Persona u organización que recibe la concesión de patente.

Cited Work Número de Patente. No incluya el código de país. (El código de país aparece pero no se utiliza en la búsqueda).

Cited Year Año en que la patente fue publicada.

Ejemplo:

Número de W09623010-A (otros Números de Patente excluidos)

Patente:

Título: $\quad$ Polyolefin for use as elastomers, moulding resins, adhesives etc. contains methyl, ethyl, propyl, butyl, amyl, hexyl and longer branches, and is obtd. in presence of novel transition metal catalyst

Nombres de JOHNSON L K, KILLIAN C M, ARTHUR S D, FELDMAN J, MCCORD E F, Inventores: MCLAIN S J, KREUTZER K A, BENNETT M A, COUGHLIN E B, ITTEL S D, PARTHASARATHY A, TEMPEL D J, BROOKHART M S, PARTHASARTHY A, BROOKHART M C, MCCORD E, ITTEL S, BENNETT A M A, WANG L, YANG $Z$, TEMPLE D J, WANG Y, MORKEN P A, COTTS P M, GUAN Z

Cesionario DU PONT DE NEMOURS \& CO E I (DUPO)

de Patente: $\quad$ UNIV NORTH CAROLINA (UYNC-Non-standard)

Introduzca 9623010* en el campo Cited Work para determinar cuáles artículos han citado esta patente.

\section{Consejos de búsqueda:}

1. El código del país aparece bajo Volumen en la tabla de consultas de las referencias citadas.

2. Ocurren muchas variaciones en el campo Cited Author porque algunos autores usaron el nombre del inventor como el autor citado, mientras que otros usaron el Cesionario de Patente. 


\section{Búsqueda por Autor Corporativo Citado}

\section{Elementos Bibliográficos de un Autor Corporativo Citado}

Cited Author Siglas o nombre de la compañía. Estos nombres aparecen precedidos por un asterisco en la tabla "Look Up" que no debe incluirse en la búsqueda.

Cited Work Nombre dado al informe.

Cited Year Año en que el trabajo fue publicado.

Un autor corporativo puede ser una empresa como por ejemplo Intel o IBM. También puede ser un cuerpo de autores o un grupo de investigación que asume un asunto de investigación. En éste último caso, sus conclusiones se reportan como un grupo no como un autor individual. Por ejemplo, el Writing Group for the PEPI Trial se consideraría como un autor corporativo. Se puede buscar de la siguiente manera:

Cited Author: writ* group pepi* OR pepi tr*

\section{Búsqueda por Informe Gubernamental Citado}

\section{Elementos bibliográficos de un informe gubernamental citado}

Cited Author Persona o institución responsable por el informe. El nombre o las siglas aparecen precedidos de un asterisco en la tabla de búsqueda y no debe incluirse en la búsqueda.

Cited Work Número del informe, frecuentemente fusionado a las siglas de la institución. Puede también ser citado con el título del informe.

Cited Year Año de publicación.

\section{Ejemplo:}

Zimbler, L.J. U.S. Department of Education. National Center for Educational Statistics. Faculty and instructional staff: who are they and what do they do? (NCES \#94346.) Washington: GPO, 1994.

Introduzca:

Cited Author: nces* or nat* ctr* ed* or us* dep* ed* or dep* ed* or zimbler

Cited Work: fac* inst* or $94346 *$ or nces $94346 *$ or nces* $94346 *$ 
Búsqueda por Referencias Citadas en Arts \& Humanities Citation Index

\section{ILUSTRACIONES}

Cuando un artículo incluye una representación de una obra de arte, la abreviatura "ILL" aparece en el campo de volumen citado.

Ejemplo: Guernica de Pablo Picasso

Cited Author: picasso

Cited Work: guernica*

\section{PARTITURAS MUSICALES}

Cuando un artículo incluye un fragmento de una partitura musical la abreviatura "MUS" aparece en el campo de volumen citado.

Ejemplo: Préludes by Frédéric Chopin

\section{Cited Author: chopin}

Cited Work: prelud*

\section{CITAS IMPLICITAS}

El indexadores de artes y humanidades identifican en los documentos las referencias a obras que no han sido incluidas en la bibliografía o en las notas de pie página. Estas citas implícitas se indican con la abreviatura "IMP" en el campo de volumen citado.

Ejemplo: Cervantes Saavedra, Miguel de. Don Quixote. 1605.

Cited Author: cervantes*

Cited Work: don* or advent* or qui* 


\section{Exportación de Registros}

Desde la página de resultados, un registro completo y la lista marcada verán opciones para exportar los artículos según las maneras siguientes:

- Impresión de registros.

- Envío de registros por correo electrónico.

- Exportación de registros a Endnote (en línea y de ordenador)

- Exportación de registros a otros programas de gestión bibliográfica (Reference Manager y Refworks).

- Guardar en ResearcherID-Escribí estas publicaciones

- Reclamación en Publons

- Guardar en FECYT CVN

- Guardar en Incites (hace falta tener una suscripción)

- Otros formatos de archivo (html, Bibtex, sin formato, delimitado por tabulador etc...)

- Exportar registros a su perfil de ResearcherID (Escribí estas publicaciones.)

- Marcar registros para crear una lista marcada.

- Descarga rápida de $5 \mathrm{~K}$ registros

Un ejemplo de exportación de artículos de la página de resultados.

\section{Web of Science}

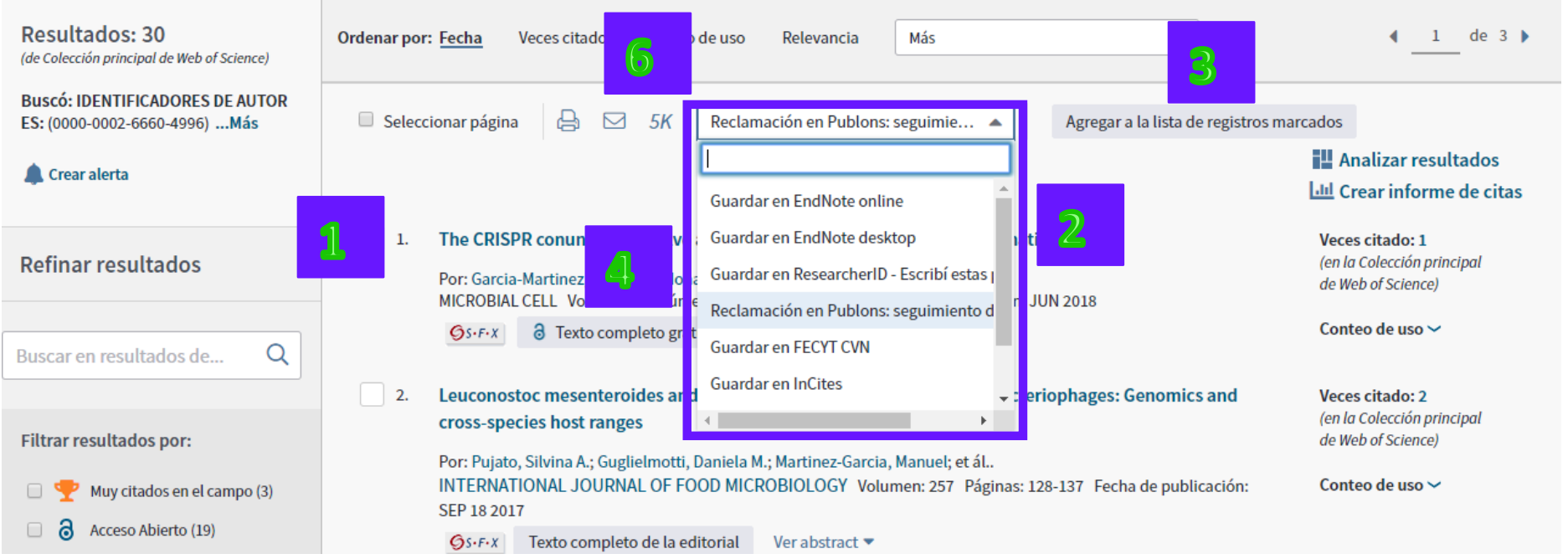

1. Selecciona los artículos en la página que desee exportar marcando las casillas de verificación a mano izquierda de los artículos.

2. Selecciona la manera en la que desee exportar los artículos.

a. Para enviar los resultados por correo electrónico, pulse en el icono de la carta.

b. Para imprimir los resultados, pulse en el icono de la impresora.

c. Para enviar los resultados a un destino, abra el menú desplegable para examinar las opciones de exportación.

3. Para enviar a la lista marcada haga clic en el botón 'Agregar a la lista de registros marcados'. 
4. Para enviar sus publicaciones al CVN de FECYT selecciona 'Guardar de FECYT CVN'

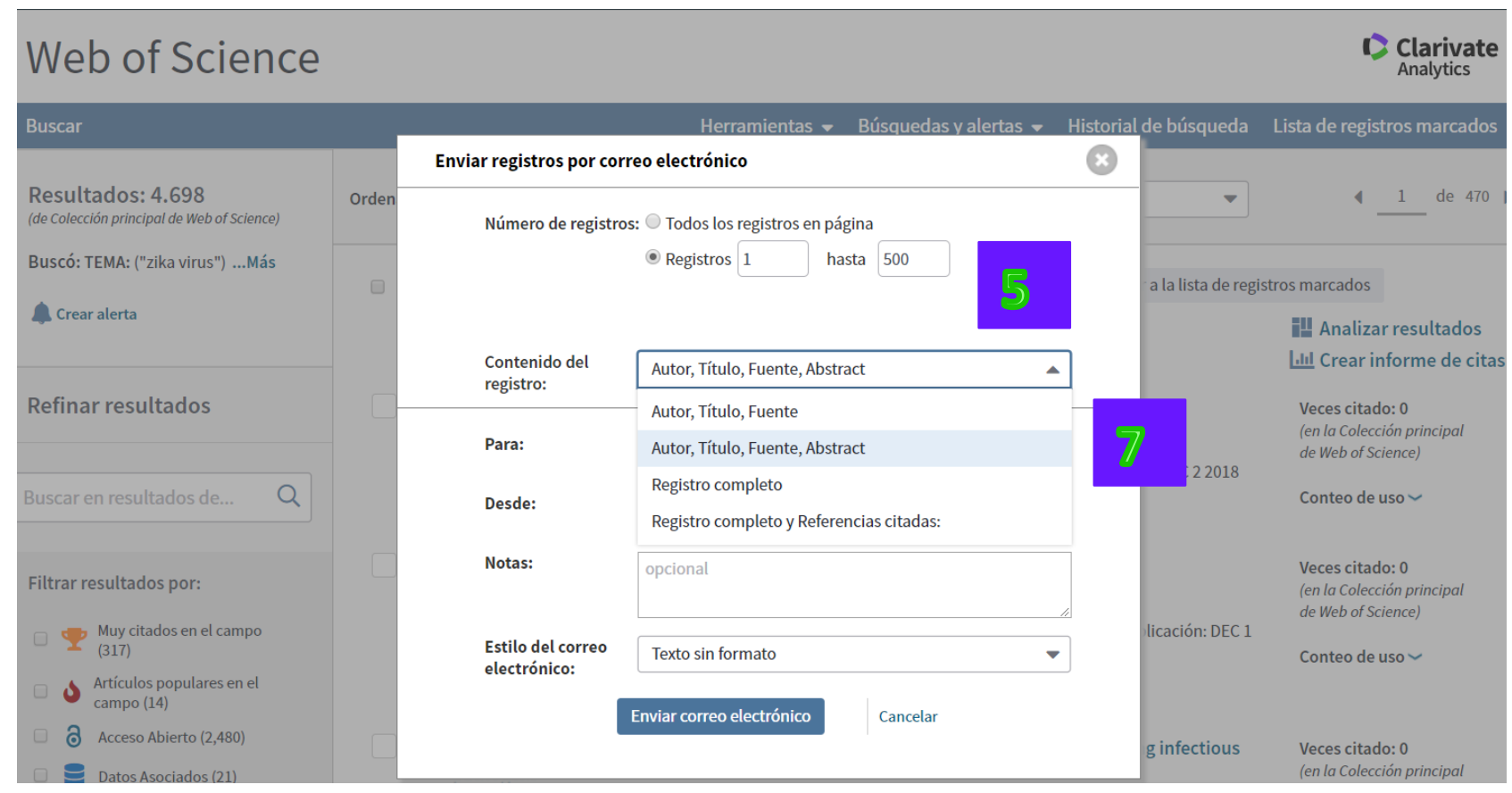

5. Selecciona el rango de registros (máximo limitado a 500 registros) o selecciona todos los registros en la página.

6. Existe la opción de hacer una exportación rápida de 5.000 registros (5K).

7. Selecciona los campos bibliográficos que desee exportar. Es posible exportar hasta el registro completo y las referencias citadas. 


\section{La Lista Marcada: Marcar Registros y Guardar Listas Marcadas}

Es posible enviar registros individuales o un rango de registros a la lista marcada.

Las listas marcadas ahora se guardan para utilizarlas en sesiones posteriores.

1. Se puede marcar registros individuales en la página o seleccionar todos los registros en la página (seleccionar página).

2. Para seleccionar un rango de registros (máximo 5.000), haga clic sobre 'Agregar a la lista de registros marcados' e introduce el rango (limitado a 5.000 registros).

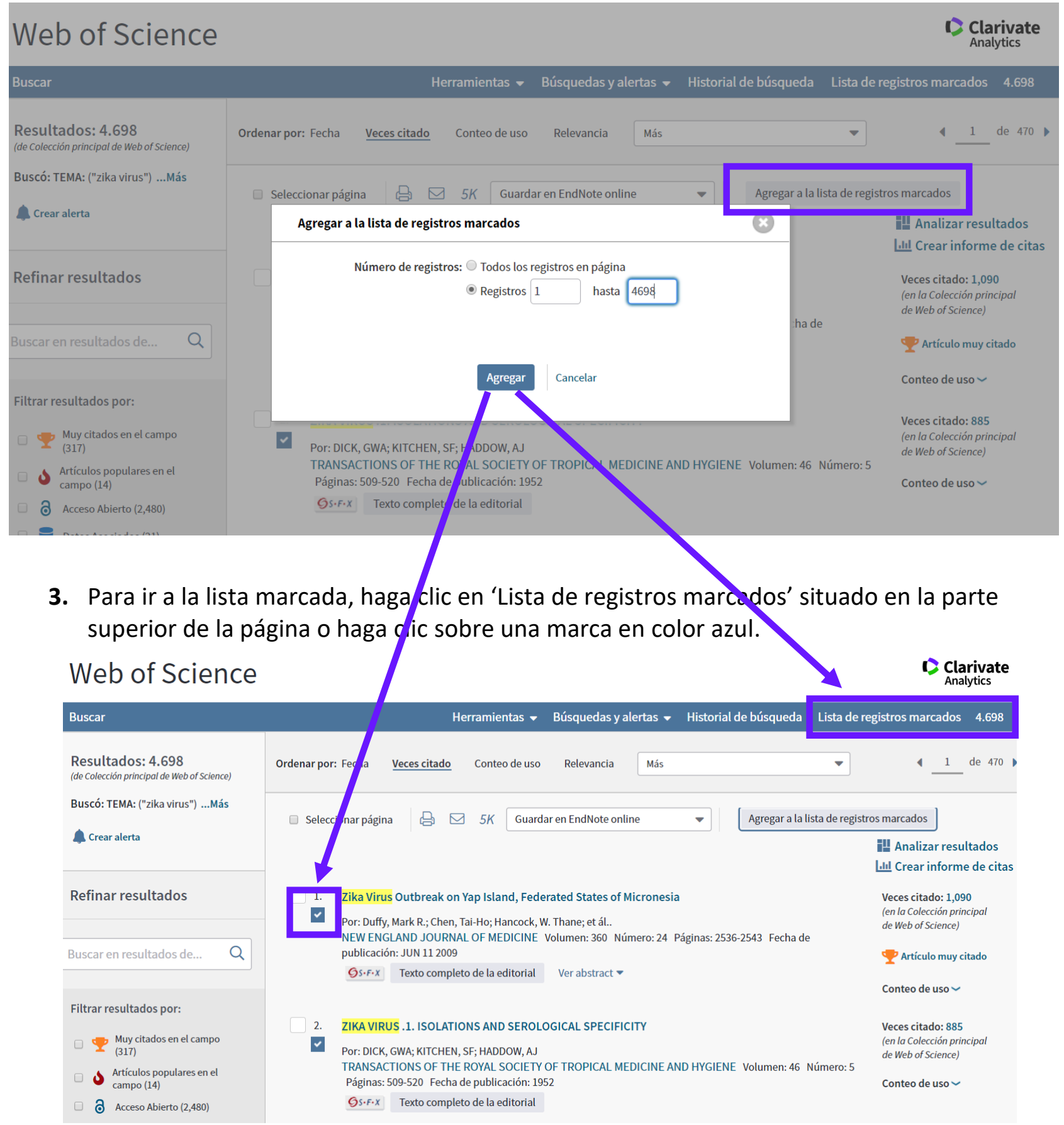




\section{Lista Marcada}

La página Lista de registros marcados muestra los registros que marcó en la página de resultados o en la página de registro completo.

Para guardar los resultados de la búsqueda, seleccione los registros y haga clic en Agregar a la lista de registros marcados en la página Resultados o bien en Agregar a la lista de registros marcados en la página de registro completo. El usuario puede agregar hasta 50.000 registros a la lista de registros marcados sin tener que registrarse ni iniciar sesión.

Los usuarios que estén registrados e inicien sesión pueden guardar hasta 50 listas de registros marcados, cada una con un máximo de 50.000 registros. Las listas marcadas que tengan 50.000 publicaciones se deben guardar y borrar antes de que se agreguen más registros.

Para extraer registros, puede seleccionar registros de la lista de registros marcados de Todas las bases de datos o también puede seleccionar registros de la lista de registros marcados de cada producto.

Extraer registros [ - Ocultar opciones de salida ] । $5 K$

\begin{tabular}{l|l} 
Paso 1: Seleccionar registros & Paso 2: Seleccionar contenido
\end{tabular}

- Todos los registros en esta lista (hasta 500) Seleccionar de los siguientes campo

Todos los registros en página

Paso 3: Seleccionar destino [Más información sobre cómo guardar co enido en un programa de gestión bibliográfica]

음 Guardar en EndNote online

Registros $\square$ hasta

Seleccionar todo Restablecer $\mid$ Guardar configuración personalizada

Autor(es)(Editor(es)

Título

Referencias citadas

$\checkmark$ Veces citado

Número de referencias citadas

Direcciones

- ISSN/ISBN

$\square$ Número IDS

$\checkmark$ Idioma

Número de acceso

$\checkmark$ ID de Pubmed $\square$ Acceso Abierto

*Al seleccionar estos elementos, el tiempo de procesamiento aumentará.

$\checkmark$ Fuente

Tipo de documento

Palabras clave

Abrev. de fuente

Categorías de Web of Science

$\checkmark$ Identificadores de autores

$\checkmark$ Artículo popular

- Articulo popula

Información sobre la conferencia
Patrocinadores de la conferencia
Información sobre la editorial
Número de páginas/Número de capítulos
Conteo de investigación
Muy citado

Muycitado

1. En la página 'Lista de registros marcados' se puede dar formato a los registros para imprimirlos, envirarlos a un correo electrónico o exportarlos directamente Endnote Online, Endnote, Refworks, a otro gestor de referencias o guardarlos a un archivo (ordenador). 
2. También se puede analizar o ejecutar el informe de citas sobre los registros marcados y/o realizar 'Analizar Resultados'.

3. Observará también en el menú a mano izquierdo unas opciones que le permite ordenar los registros marcados por las veces citado entre otras opciones.

Para exportar la Lista de registros marcado:

1. Selecciona el rango de registros para enviar

a. Todos los registros en la lista (hasta un máximo de 500)

b. Todos los registros en la página

c. Un rango (limitado a 500)

d. Descarga rápida de $\mathbf{5 K}$ (5.000). Tenga en cuenta que los campos siguientes solo se incluyen en el resultado si se utiliza esta opción: Autor, Título y Fuente; y que las opciones de los resultados tienen formato delimitado por tabulador (Mac o Windows).

2. Selecciona los campos bibliográficos que se desea exportar al marcar las casillas de verificación.

Seleccionar todo | Restablecer | Guardar configuración personalizada

Autor(es)/Editor(es)

Título

Fuente

$\square$ Abstract* $^{*}$

Referencias citadas

Tipo de documento

Direcciones

$\checkmark$ Veces citado

Palabras clave

Número de referencias citadas

Abrev. de fuente

Categorías de Web of Science

Número IDS

Idioma

Identificadores de autores

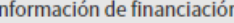

$\checkmark$ Número de acceso

Artículo popular

Información sobre la conferencia

Patrocinadores de la conferencia

Información sobre la editorial

Número de páginas/Número de capítulos

Áreas de investigación

Conteo de uso

$\checkmark$ ID de PubMed

Muy citado

*Al seleccionar estos elementos, el tiempo de procesamiento aumentará.

3. Selecciona el destino del envío (Endnote online, Endnote, Publons, ResearcherID, Incites, FECYT CVN, Refworks y otros tipos de archivo)

4. Abra el menú desplegable para ver ordenar los registros marcados. También es posible realizar un análisis sobre la lista marcada (Analizar resultados) o ejecutar el informe de citas sobre ello (Crear informe de citas).

5. Es posible eliminar registros en la lista. Haga clic en la cruz roja a mano izquierda del registro. 


\section{Guardar Listas Marcadas}

- Ahora es posible guardar sus listas marcadas y abrirlas en sesiones posteriores. Esta novedad le permite mantener conjuntos personalizados de registros durante sus sesiones en la Web of Science. Luego se podría exportar estos conjuntos personalizados al CVN de FECYT, a Incites (hace falta tener una suscripción) o a su perfil de Publons.

- Se puede guardar hasta 50 listas por cuenta de Web of Science. Cada lista puede guardar hasta 50.000 registros.

- Es posible editar listas (añadir/eliminar registros) y combinar listas.

\section{Web of Science $\quad$ clarivate}

Buscar Regresar a los Resultados de búsqueda Herramientas - Búsquedas y alertas - Historial de búsqueda Lista de registros marcados 4.698

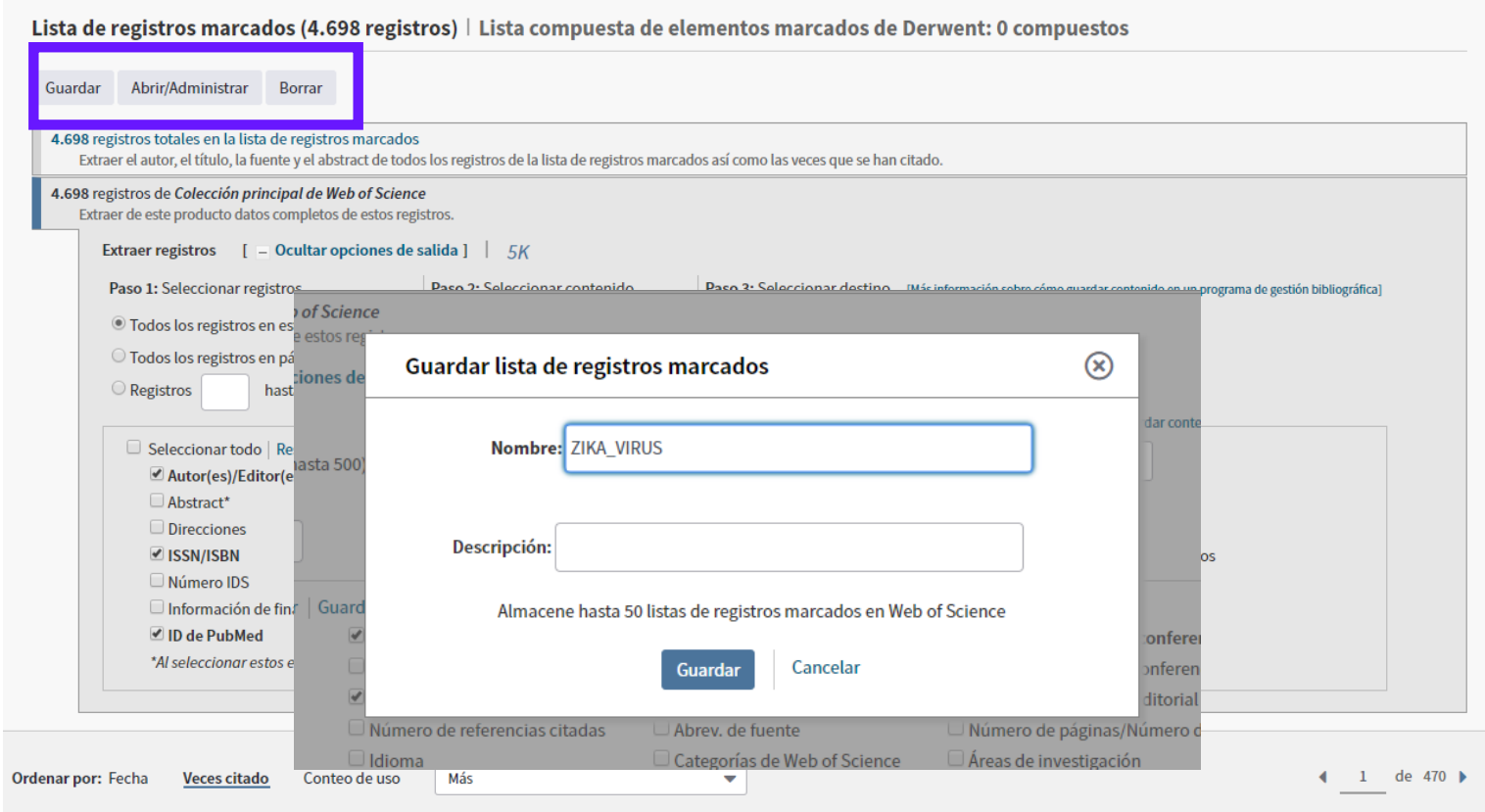

1. Para guardar una lista marcada hace falta hacer clic sobre 'guardar'. Luego hace falta iniciar una sesión personalizada. Introduce las credenciales de su perfil de WOS. Si no se ha registrado con anterioridad tendría que registrarse.

2. Introduce un título de la lista marcada y una descripción (opcional). Haga clic sobre 'guardar' para guardar la lista de forma permanente y mantenerla en su perfil. 


\section{Abrir Listas Guardadas}

1. Para abrir una lista marcada guardada hace falta iniciar una sesión personalizada. Luego vaya a 'lista de registros marcados'

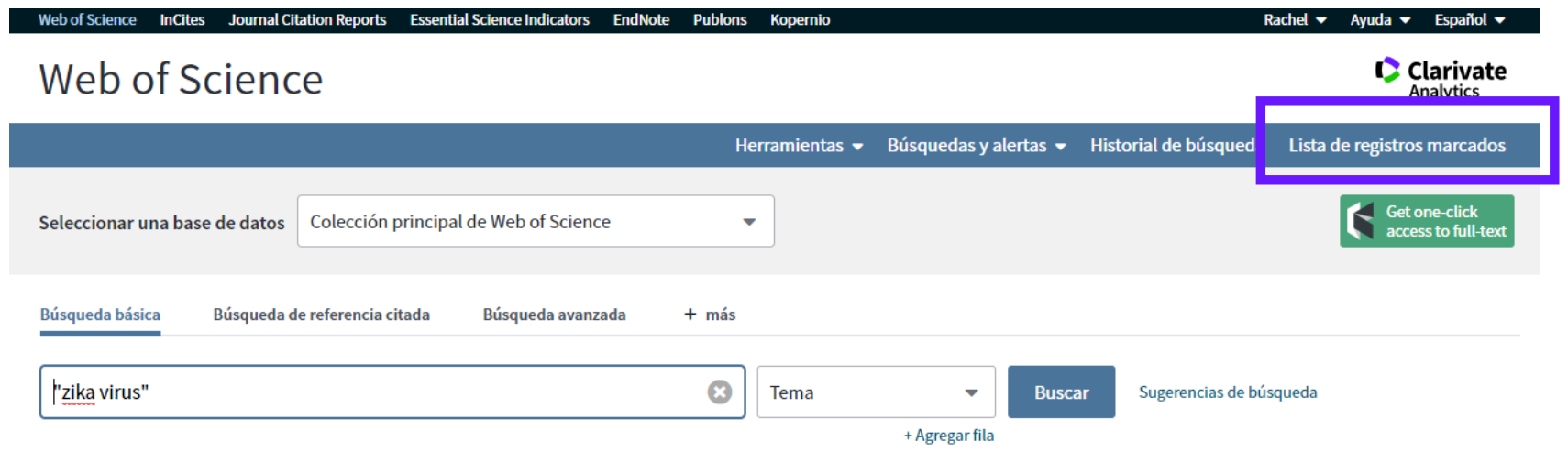

2. Luego haga clic sobre 'abrir/administrar'. Haga clic sobre el nombre de la lista para abrirlas.

\section{Web of Science

Lista de registros marcados (0 registro) | Lista compuesta de elementos marcados de Derwent: 0 compuestos

Web of Science

Abrir/Administrar listas de registros marcados guardadas

$\ll$ Regresar a la página anterior

\begin{tabular}{|c|c|c|c|c|c|}
\hline Seleccionar todo & \multicolumn{5}{|l|}{ Eliminar } \\
\hline & Nombre & Descripción & Número & Última modificación & Editar \\
\hline$\square$ & ZIKA_VIRUS & & 4698 & $10-30-2018$ & Editar \\
\hline$\square$ & radcliffe_journal & & 75 & 06-27-2018 & Editar \\
\hline$\square$ & bayer & & 645 & 09-05-2018 & Editar \\
\hline
\end{tabular}

$\square$ Seleccionar todo Eliminar 


\section{Añadir Nuevos Registros a una Lista Guardada}

Para añadir nuevos registros a una lista marcada que ya existe sigue los pasos siguientes:

- Asegurarse que la lista a la cual deseas añadir nuevos registros ya está abierta.

- En la página de resultados marca los registros de interés y hace clic sobre 'añadir a la lista marcada'.

- Vaya a lista marcada y haga clic sobre 'Guardar'.

- Introduce el título de la lista a la cual deseas añadir los registros.

- Le preguntará si desea reemplazar la lista que ya existe. Hace falta hacer clic sobre 'enviar' para confirmar la instrucción.

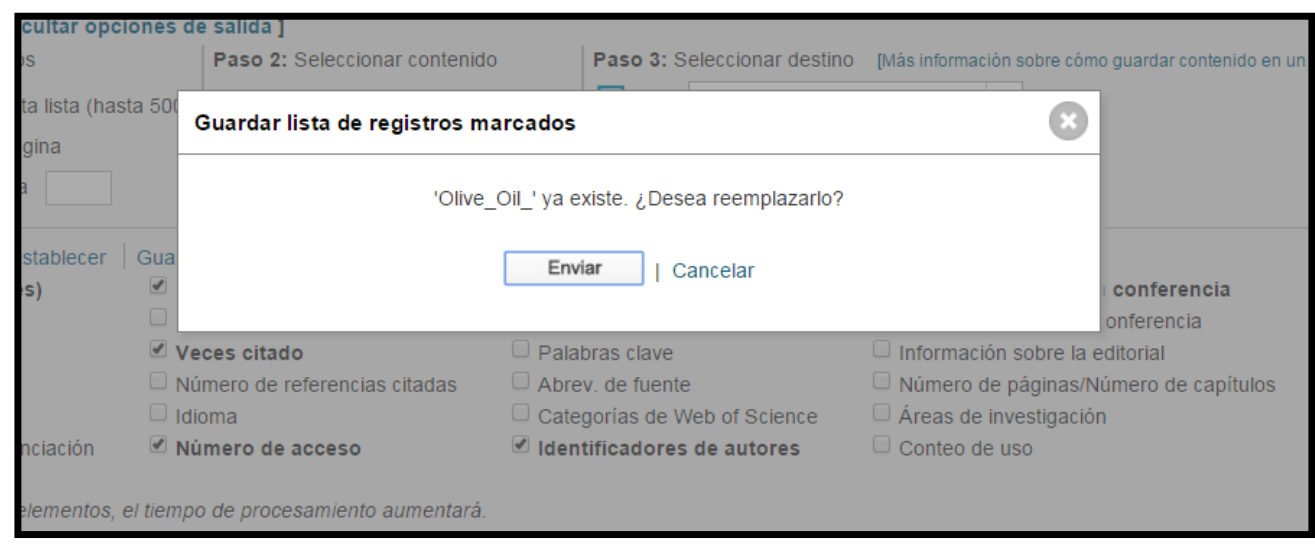

\section{Combinar Listas Guardadas}

Para combinar listas guardadas sigue los pasos siguientes

- Vaya sus listas guardadas. Haga clic sobre 'abrir/administrar'.

- Abra una de las listas que deseas combinar con otra

- Luego vuelva a sus listas guardadas y haga clic sobre el título de la lista a la que deseas combinar con la lista abierta.

\section{Abrir lista de registros marcados}

Tiene registros en la lista de registros marcados abierta actualmente. ¿Desea agregar o reemplazar estos registros de la lista?

Nota: Será necesario guardar cualquier cambio que haga.

\section{\begin{tabular}{|l|l|l|}
\hline Reemplazar & Agregar \\
\hline
\end{tabular}}

- Haga clic sobre 'reemplazar' luego 'guardar'. Introduce un nuevo título para esta lista combinada.

- Vaya a 'abrir/administrar' para ver la lista combinado guardado en su perfil. 


\section{Guardado de Historiales y Creación de Alertas}

Un historial de búsqueda es una consulta de búsqueda o varias consultas de búsqueda que usted guarda en nuestro servidor o en el disco duro de su computadora. No hay ningún límite para el número de historiales de búsqueda que puede guardar. Para guardar un historial de búsqueda en nuestro servidor, debe estar registrado como usuario e iniciar sesión

Guardar en el servidor de Web of Science le permite abrir y administrar sus historiales de búsquedas como así también programar alertas. Este proceso se refiere a la búsqueda general y búsqueda por referencia citada.

\section{Guardado del Historial en el Servidor de Web of Science}

Para guardar una búsqueda en el servidor de Web of Science siga estos pasos:

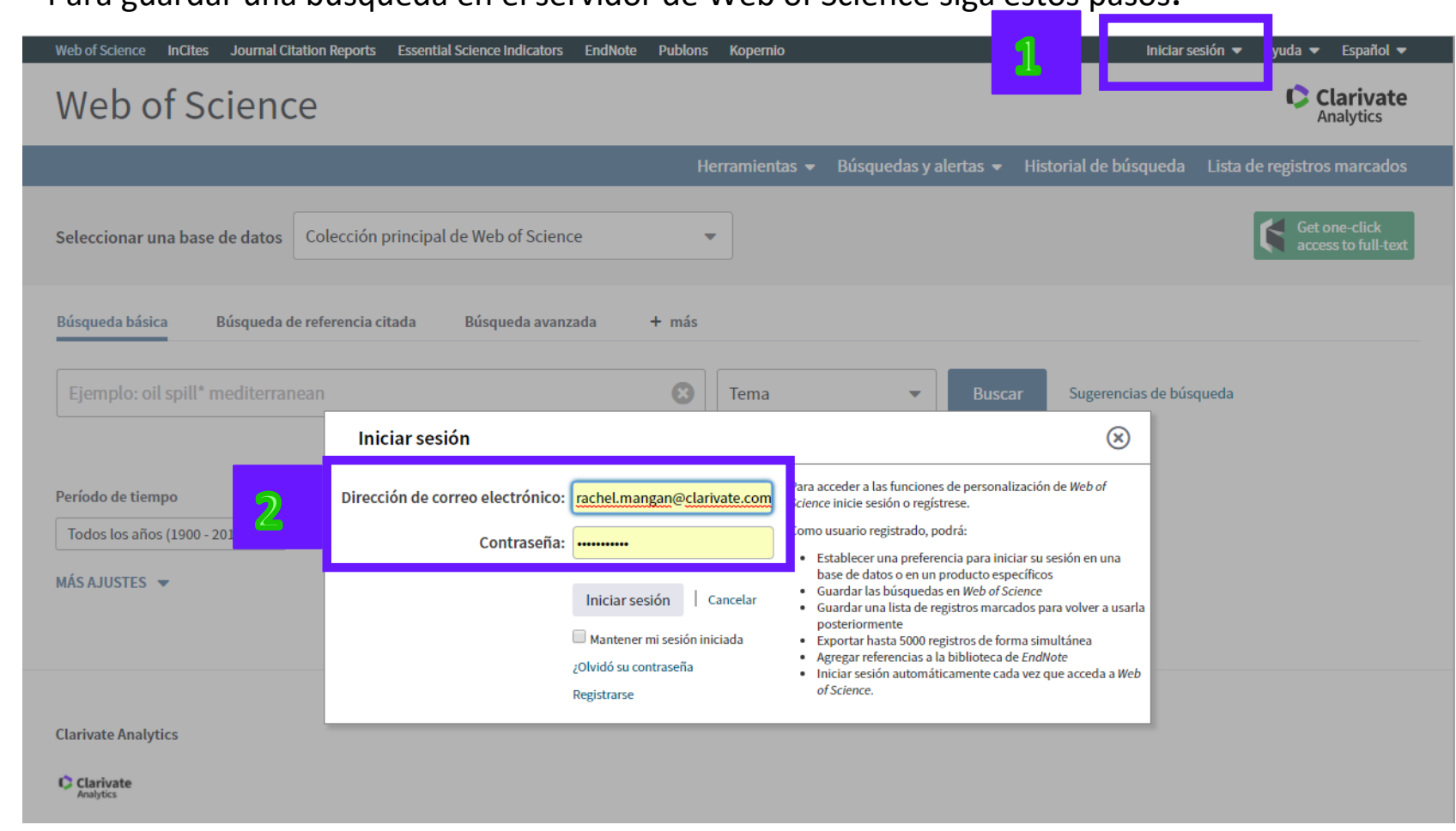

1. Inicie una sesión personalizada por medio del enlace 'Iniciar sesión' ubicado la parte superior de cualquiera página.

2. Introduzca sus credenciales. Nota: Si no se ha registrado se pedirá que lo haga cuando intente guardar su historial de búsqueda.

3. Ejecute una búsqueda

4. Diríjase a la página Historial de búsqueda o la página Búsqueda avanzada. 


\begin{tabular}{|c|c|c|c|c|c|c|c|}
\hline Conjunto & Resultados & & & & Combinar conjuntos \\
AND
\end{tabular}

\section{Haga clic en el botón Guardar Historial/ Crear alerta.}

6. Sus pasos en Refinar y Analizar se mantienen en su historial.

7. Introduzca un nombre a la historial y una descripción (opcional) luego haga clic en Guardar.

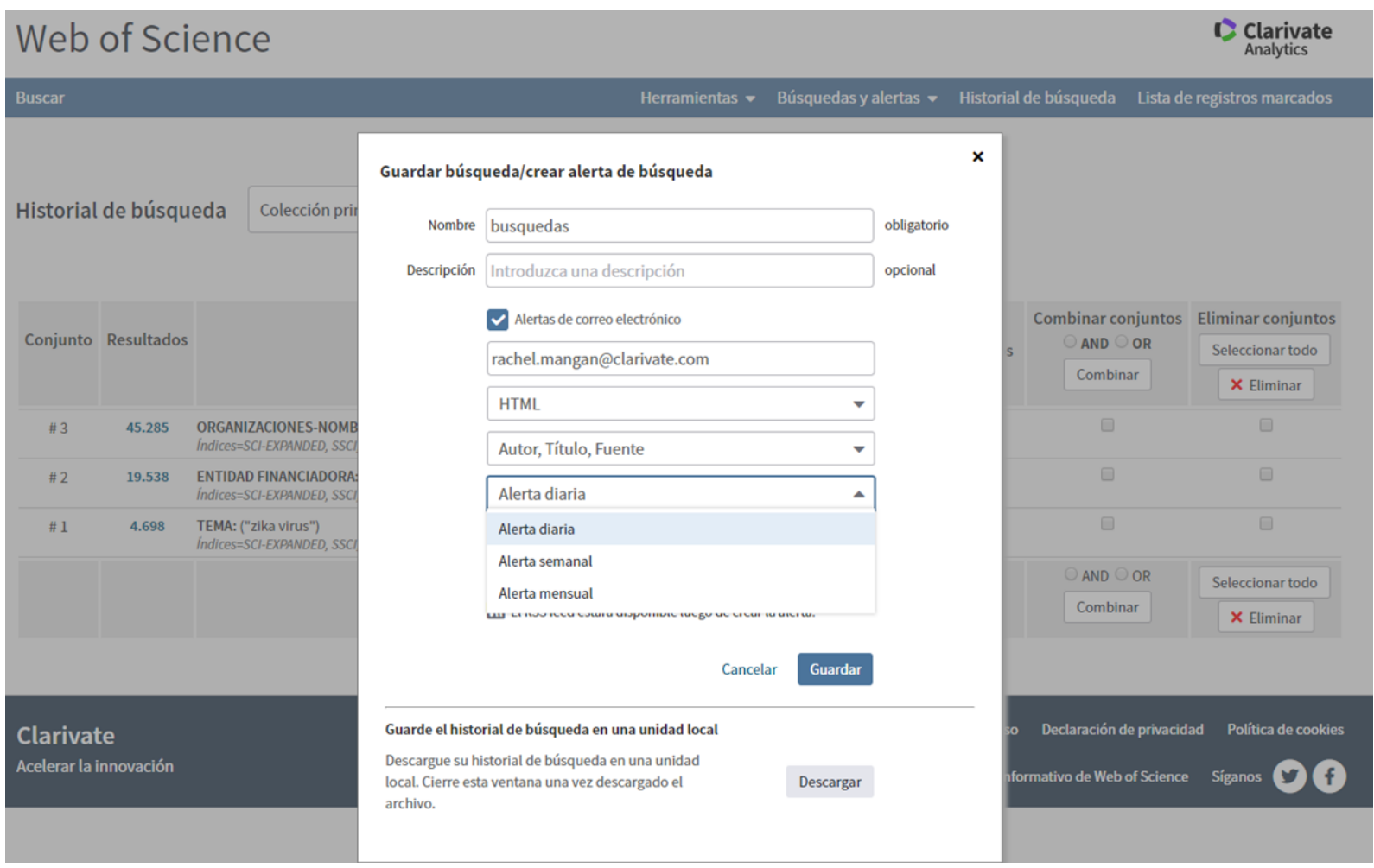




\section{Crear una Alerta de Historial de Búsqueda}

Debe crear una alerta cuando guarde su historial de búsqueda. El producto no guarda automáticamente el historial de búsqueda como una alerta.

1. Desde la página Historial de búsqueda, haga clic en el botón Guardar historial/Crear alerta para acceder a la página Guardar historial de búsqueda. Tenga en cuenta que debe iniciar sesión para acceder a esta página.

2. Seleccione la casilla de verificación Alertas por correo electrónico.

3. Ingrese una dirección de correo electrónico en el campo Dirección de correo electrónico. Use un punto y coma (;) y un espacio para separar varias direcciones. El valor predeterminado para este campo es su dirección de correo electrónico de inicio de sesión y registro. Puede ingresar hasta 255 caracteres en este campo.

4. Seleccione un tipo de alerta (es posible que algunos tipos de alertas no estén disponibles para algunos productos). El valor predeterminado suele ser Autor, Título, Fuente.

5. Seleccione un Formato de correo electrónico (es posible que algunos formatos no estén disponibles para algunos productos).

6. Seleccione una opción de Frecuencia de correo electrónico.

7. Haga clic en el botón Guardar para guardar la alerta en nuestro servidor y acceder a la página Guardar historial de búsqueda. No guarde el archivo de historial en su estación de trabajo porque no recibirá alertas de correo electrónico cuando se agreguen nuevos registros a la base de datos del producto.

8. Haga clic en el botón Cerrar cuando haya terminado.

Nota: si ve un mensaje de error que indica que se alcanzó el límite para el número de alertas, significa que su institución no compró la función Alertas o que alcanzó el número máximo de alertas compradas. Póngase en contacto con el administrador de su sistema si está interesado en crear alertas.

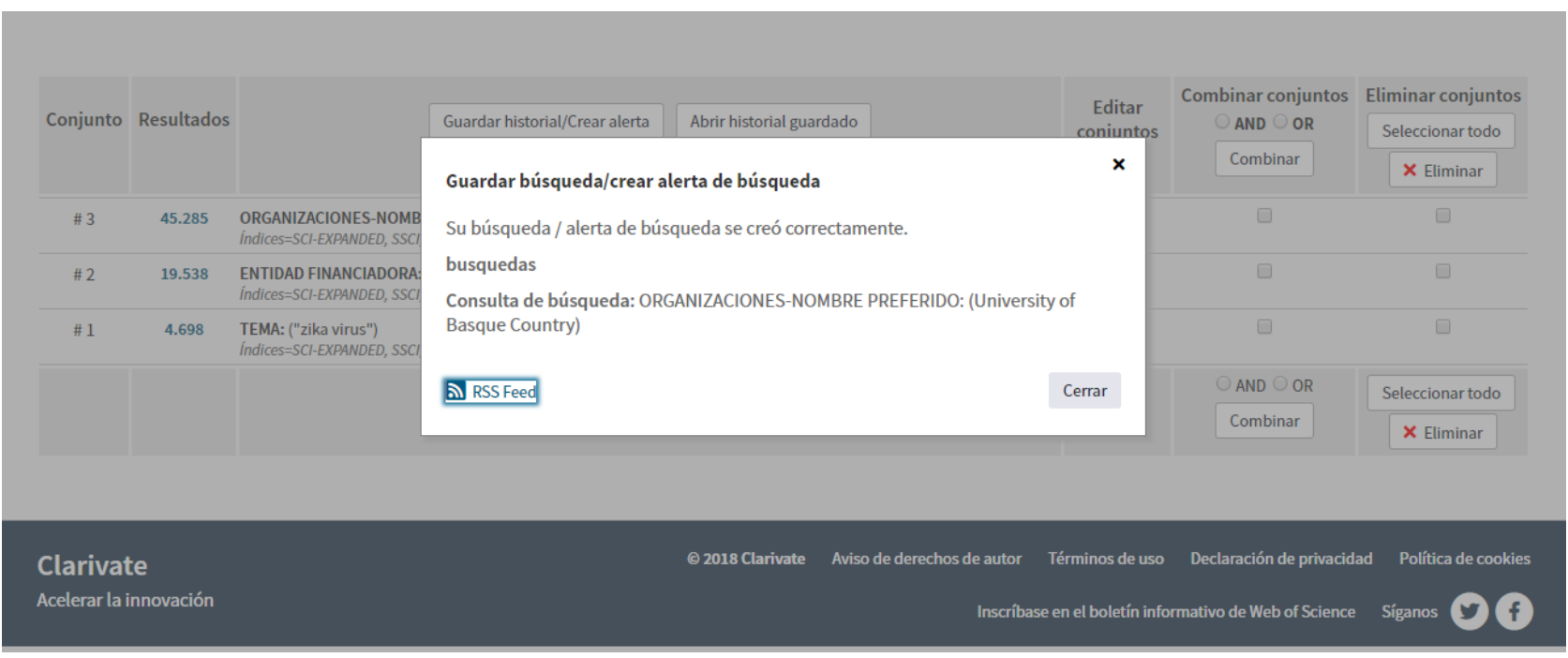




\section{Crear Alerta de Búsquedas Directamente en la Página de Resultados}

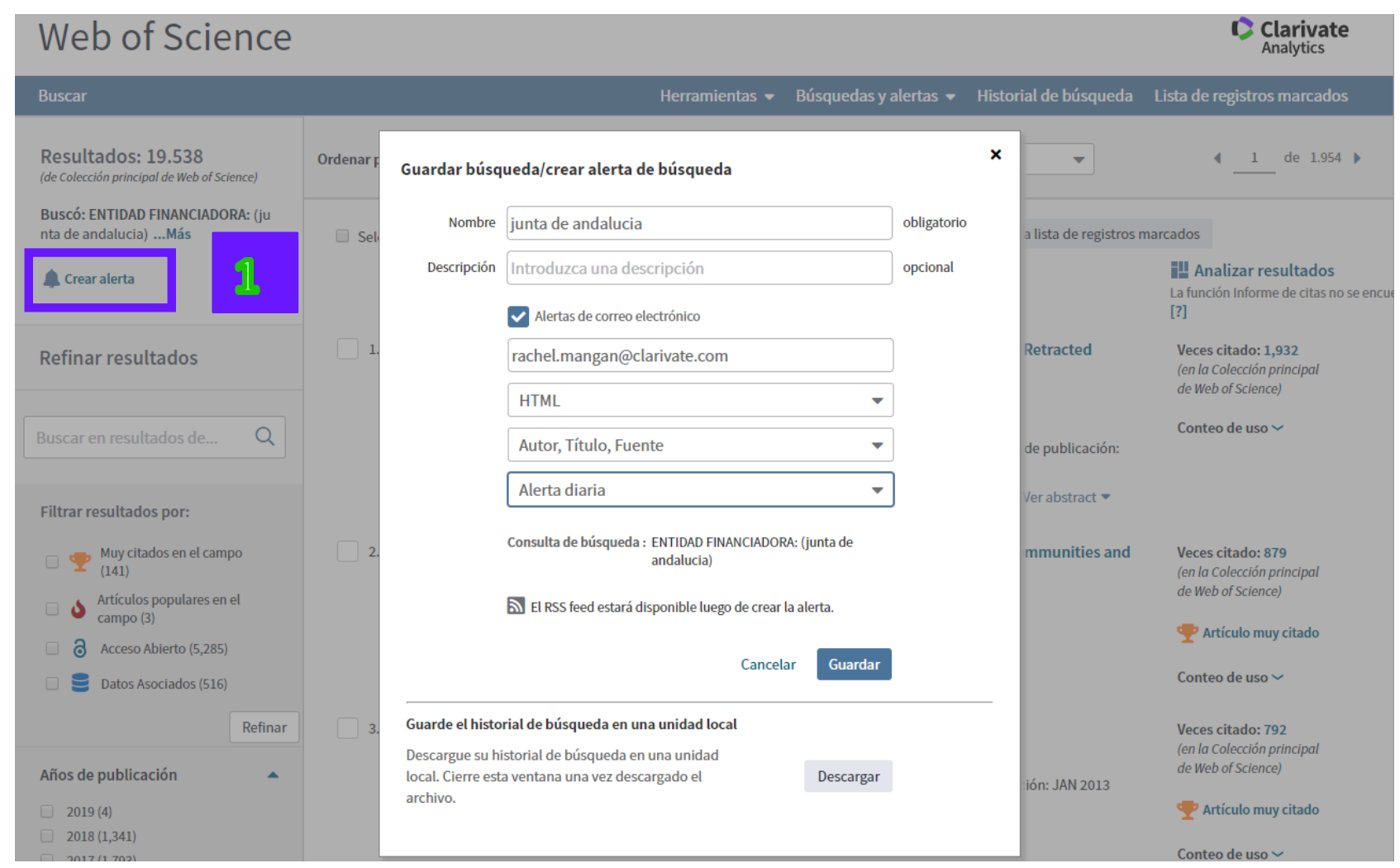

1. Para crear una alerta de resultados y guardar la búsqueda a un historial haga clic en el botón 'Crear Alerta'.

2. Introduce las credenciales de su perfil de Web of Science para guardar la búsqueda y crear una alerta de nuevos resultados. Si no se ha registrado con anterioridad, sería necesario registrarse para poder guardar la consulta y crear una alerta de resultados.

Tipos de Alerta

\begin{tabular}{|l|l|}
\hline Notificar solo & $\begin{array}{l}\text { Notificación de que los resultados de esta semana están } \\
\text { disponibles. Si los resultados están disponibles, inicie sesión } \\
\text { en Web of Science y luego abra y ejecute el historial de } \\
\text { búsqueda. Tenga en cuenta que es posible que el número de } \\
\text { resultados reportados en el correo electrónico no sea igual al } \\
\text { número de resultados que obtendrá al realizar la búsqueda } \\
\text { debido a que puede haber seleccionado ajustes de bases de } \\
\text { datos diferentes o un período de tiempo distinto antes de } \\
\text { ejecutar la alerta. }\end{array}$ \\
\hline Futor, Título, & $\begin{array}{l}\text { La información bibliográfica incluye nombres de autores, títulos } \\
\text { de artículos, información de la fuente, tipo de documento, } \\
\text { idioma y números ISSN o ISBN. Esta es la opción } \\
\text { predeterminada. }\end{array}$ \\
\hline
\end{tabular}




\begin{tabular}{|l|l|}
\hline $\begin{array}{l}\text { Autor, Título, } \\
\text { Fuente } \\
\text { y Abstract }\end{array}$ & Información bibliográfica y abstract del autor. \\
\hline $\begin{array}{l}\text { Registro } \\
\text { completo }\end{array}$ & $\begin{array}{l}\text { Información bibliográfica, abstract del autor, palabras clave, } \\
\text { información sobre direcciones e información sobre la editorial. }\end{array}$ \\
\hline
\end{tabular}

\section{Formatos del correo electrónico}

\section{Texto sin formato}

Un archivo de texto ASCII.

\section{HTML}

Lenguaje de marcado hipertextual. Este formato es adecuado para que se pueda mostrar correctamente en un navegador web.

\section{EndNote}

Un formato delimitado por campos que se puede importar directamente a una aplicación de gestión de referencia como, por ejemplo:

- EndNote ${ }^{\odot}$

- Reference Manager ${ }^{\circledR}$

- RefWorks

- Sente

- Biblioscape

\section{Campo etiquetado}

Un formato delimitado por campos adecuado para usarse con aplicaciones de gestión de referencia como, por ejemplo:

- EndNote

- Reference Manager

Si usa uno de estos productos, le recomendamos que seleccione el formato Campo etiquetado para simplificar el proceso de importación. 
Frecuencia de recepción de correo electrónico

\begin{tabular}{|c|c|}
\hline Diariamente & $\begin{array}{l}\text { Seleccione esta opción para recibir un correo electrónico si } \\
\text { la búsqueda recupera registros agregados desde la } \\
\text { actualización del día anterior. } \\
\text { Solo disponible para Colección principal de Web of } \\
\text { Science y Current Contents Connect. }\end{array}$ \\
\hline Semanalmente & $\begin{array}{l}\text { Seleccione esta opción para recibir un correo electrónico } \\
\text { una vez a la semana que le informe sobre los nuevos } \\
\text { registros que se agregaron a la base de datos del producto } \\
\text { desde la fecha del correo electrónico anterior. }\end{array}$ \\
\hline Mensualmente & $\begin{array}{l}\text { Seleccione esta opción para recibir un correo electrónico } \\
\text { una vez al mes que le informe sobre los nuevos registros } \\
\text { que se agregaron a la base de datos del producto desde la } \\
\text { fecha del correo electrónico anterior. }\end{array}$ \\
\hline $\begin{array}{l}\text { Cada } \\
\text { actualización }\end{array}$ & $\begin{array}{l}\text { Seleccione esta opción para recibir un correo electrónico } \\
\text { cada vez que la base de datos Derwent Innovations Index se } \\
\text { actualice. } \\
\text { Esta opción solo está disponible para los clientes } \\
\text { de Derwent Innovations Index. }\end{array}$ \\
\hline $\begin{array}{l}\text { Cada } 4 \\
\text { actualizaciones }\end{array}$ & $\begin{array}{l}\text { Seleccione esta opción para recibir un correo electrónico } \\
\text { cada cuatro actualizaciones de la base de datos Derwent } \\
\text { Innovations Index. } \\
\text { Esta opción solo está disponible para los clientes } \\
\text { de Derwent Innovations Index. }\end{array}$ \\
\hline
\end{tabular}




\section{Ejecución de Historiales Guardados}

Puede abrir y ejecutar un historial guardado desde varios sitios en la Web of Science

En la página principal de la Web of Science

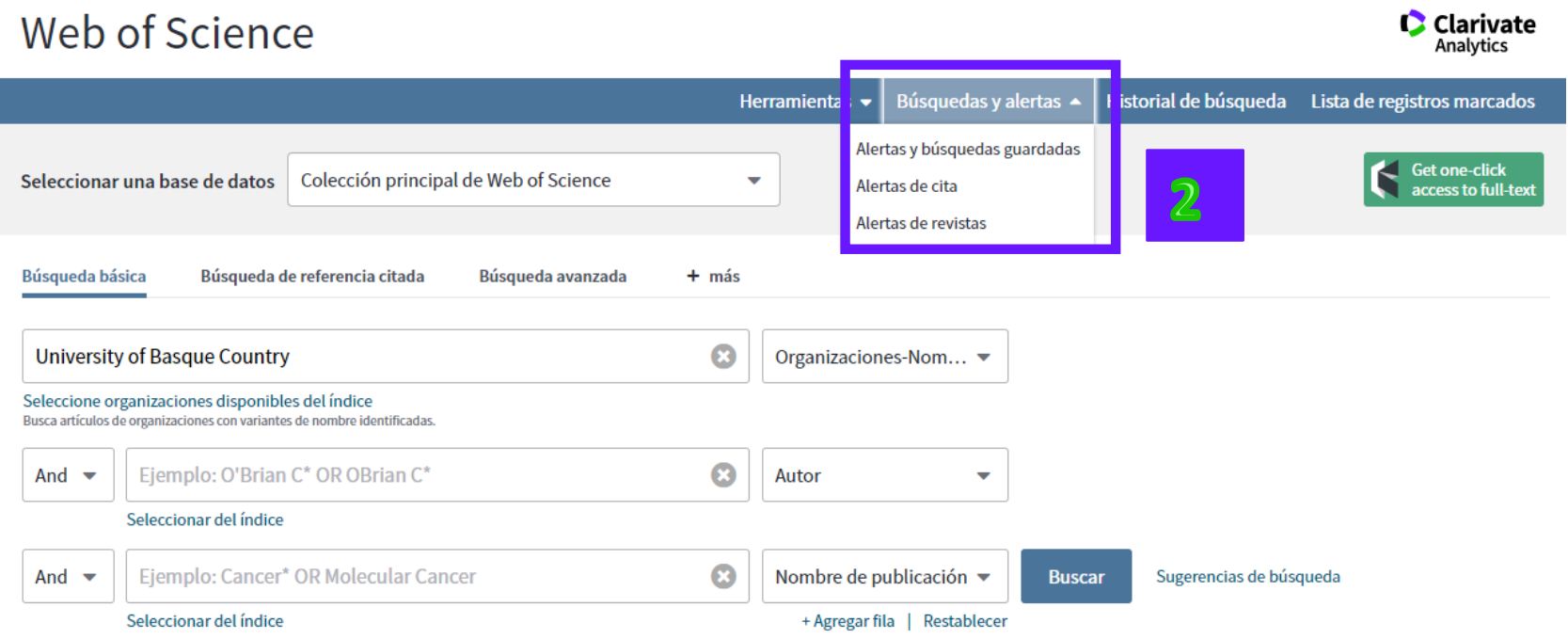

Período de tiempo

Todos los años $(1900$ - 2018) -

MÁS AJUSTES -

1. Necesitará iniciar una sesión personalizada en el Web of Science para abrir historiales guardados en el Servidor de Web of Science.

2. Haga clic 'Busquedas y alerta y luego 'Alertas de búsquedas guardadas'.

Web of Science

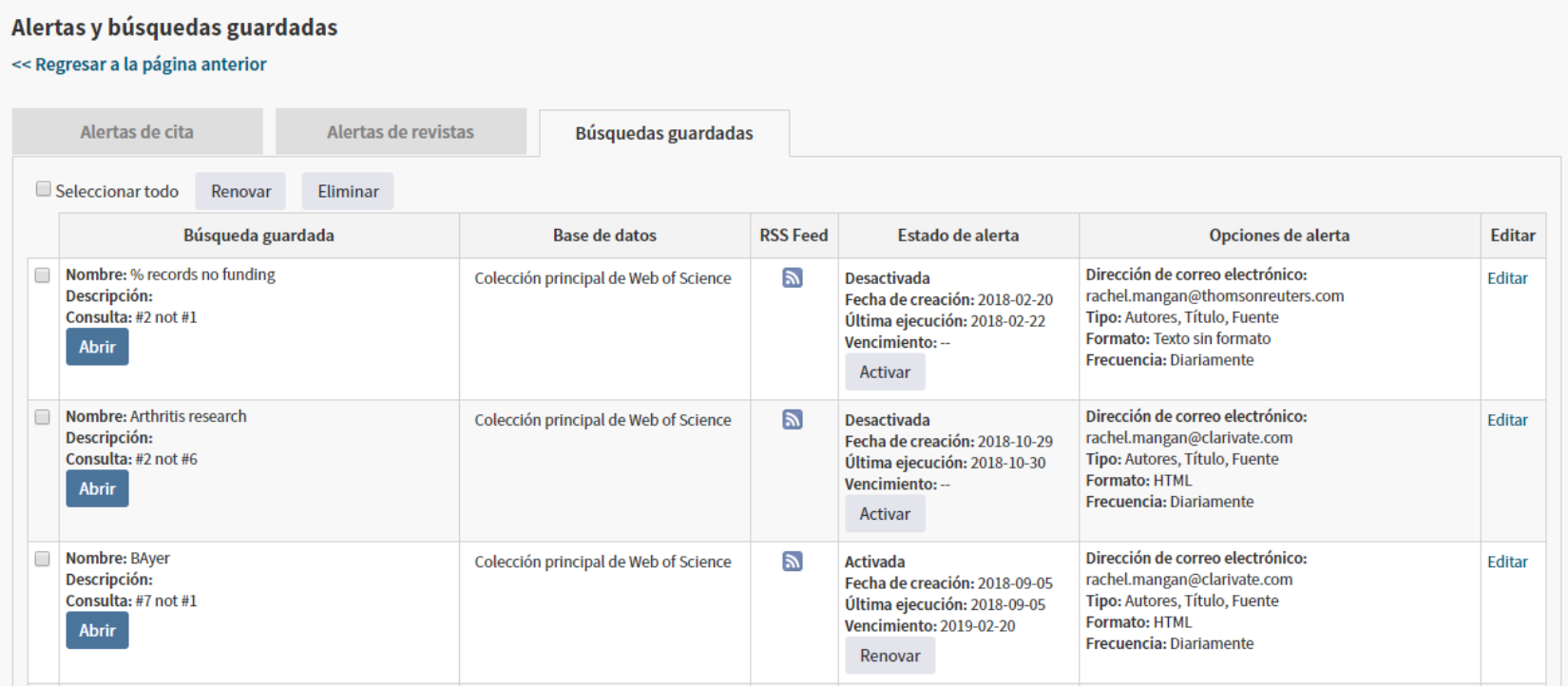




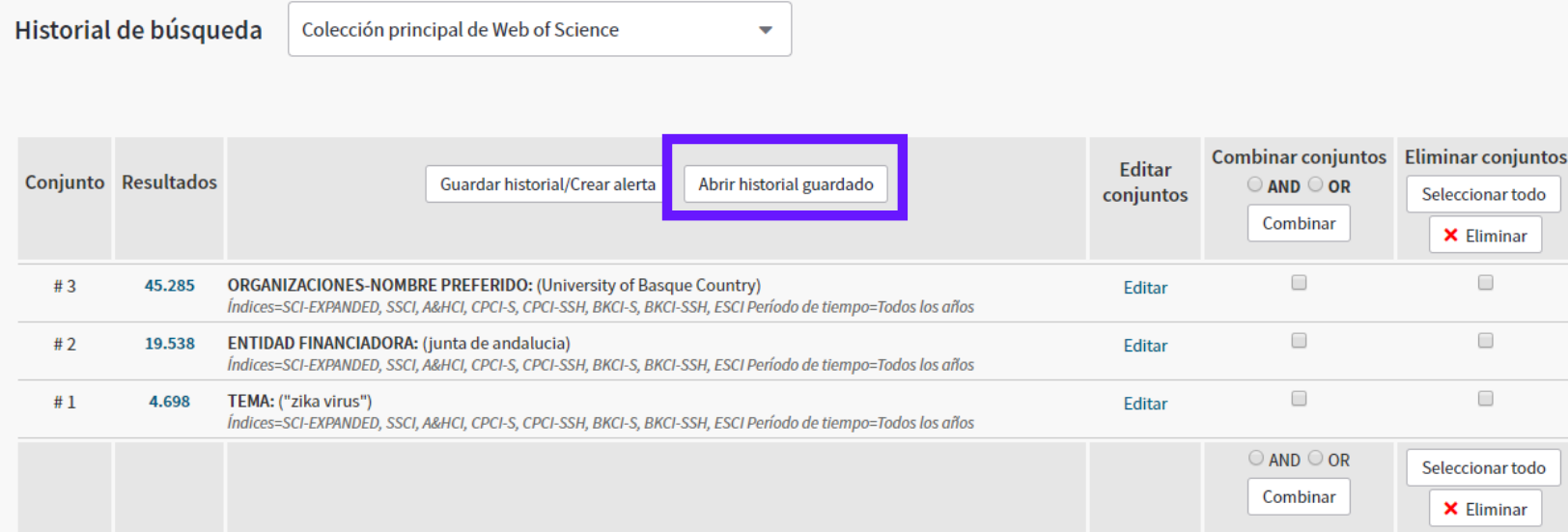

El botón Abrir historial guardado en la página Historial de búsqueda/búsqueda avanzada de Web of Science. Puede usar esta opción si su historial está guardado localmente o guardado en el servidor de Web of Science.

Nota: Cuando se abre y se ejecuta un historial guardado, se reemplazará cualquier búsqueda en su sesión actual.

\section{Abrir Historiales Guardados}

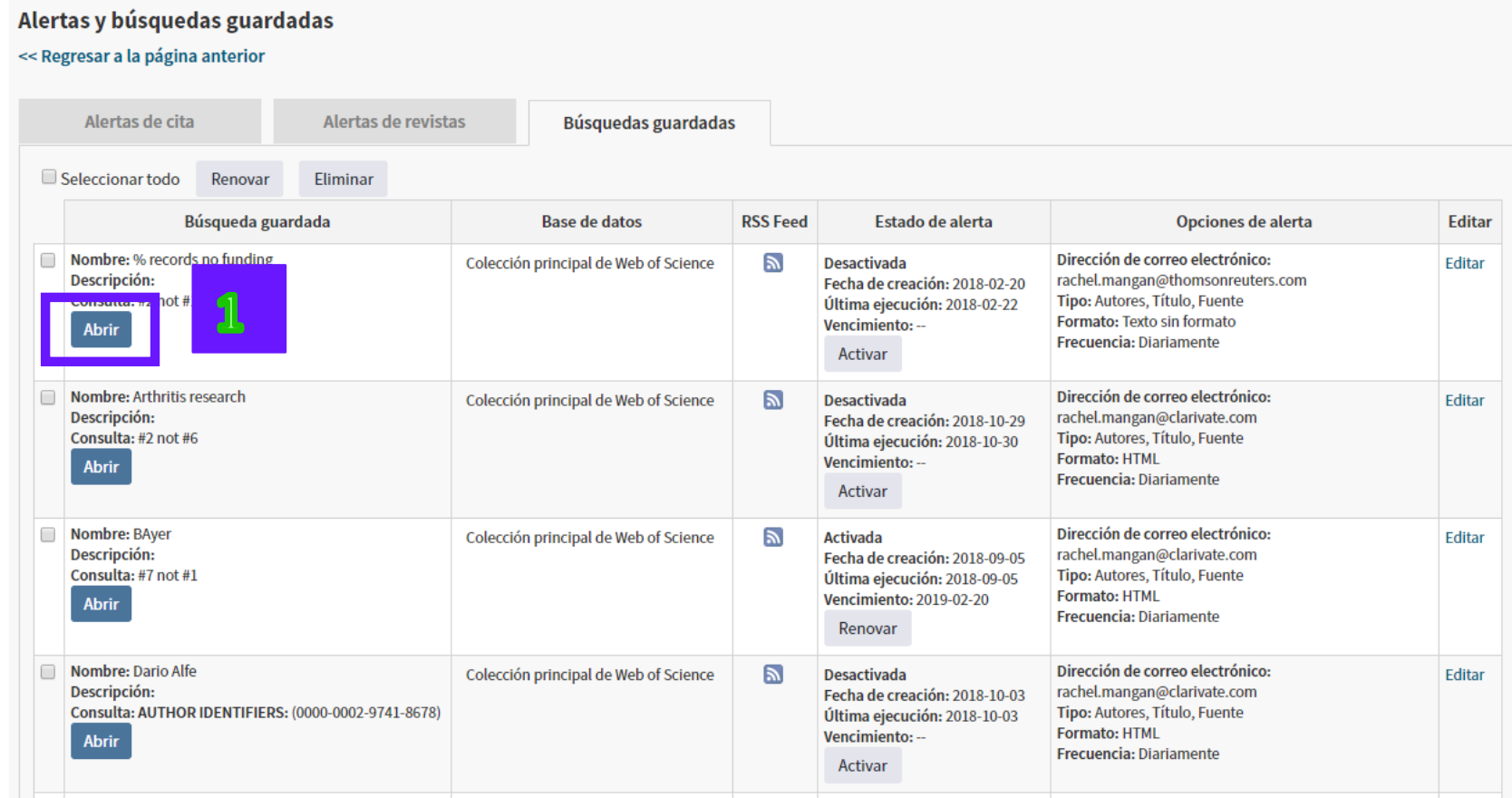

1. Haga clic en 'Abrir' para abrir de nuevo las consultas guardadas.

2. Las búsquedas guardadas se presentan a continuación.

3. Haga clic sobre 'Ejecutar búsqueda'. 
4. Antes de ejecutar las búsquedas es posible modificar los límites de búsqueda. Es posible cambiar el período de búsqueda y/o los índices incluidos en la búsqueda. Después de modificar la búsqueda si hace falta, haga clic en 'Continuar' para ir a los resultados.

$\ll$ Atres

\begin{tabular}{|c|c|}
\hline Conjunto & $\begin{array}{l}\text { le Web of Science } \\
\text { la - " Dario Alfe" }\end{array}$ \\
\hline H5 & $\begin{array}{l}\text { AUTHOR IDENTIFIERS: (0000-0002-9741-8678) } \\
\text { Tipos de documento=Todos los tipos de documentos; Idiomas=Todos los idiomas; }\end{array}$ \\
\hline$\# 4$ & $\begin{array}{l}\text { YEAR PUBLISHED: (1900-2018) } \\
\text { Tipos de documento=Todos los tipos de documentos; Idiomas=Todos los idiomas; }\end{array}$ \\
\hline$\# 3$ & $\begin{array}{l}\text { AUTHOR IDENTIFIERS: (0000-0002-9741-8678) } \\
\text { Refinado por: Open Access: (ALL OPEN ACCESS) } \\
\text { Tipos de documento=Todos los tipos de documentos; ldiomas=Todos los idiomas; }\end{array}$ \\
\hline$\# 2$ & $\begin{array}{l}\text { AUTHOR IDENTIFIERS: (0000-0002-9741-8678) } \\
\text { Tipos de documento=Todos los tipos de documentos; Idiomas=Todos los idiomas; }\end{array}$ \\
\hline$\# 1$ & $\begin{array}{l}\text { AUTHOR IDENTIFIERS: (0000-0002-4083-3248) } \\
\text { Tipos de documento=Todos los tipos de documentos; Idiomas=Todos los idiomas; }\end{array}$ \\
\hline
\end{tabular}

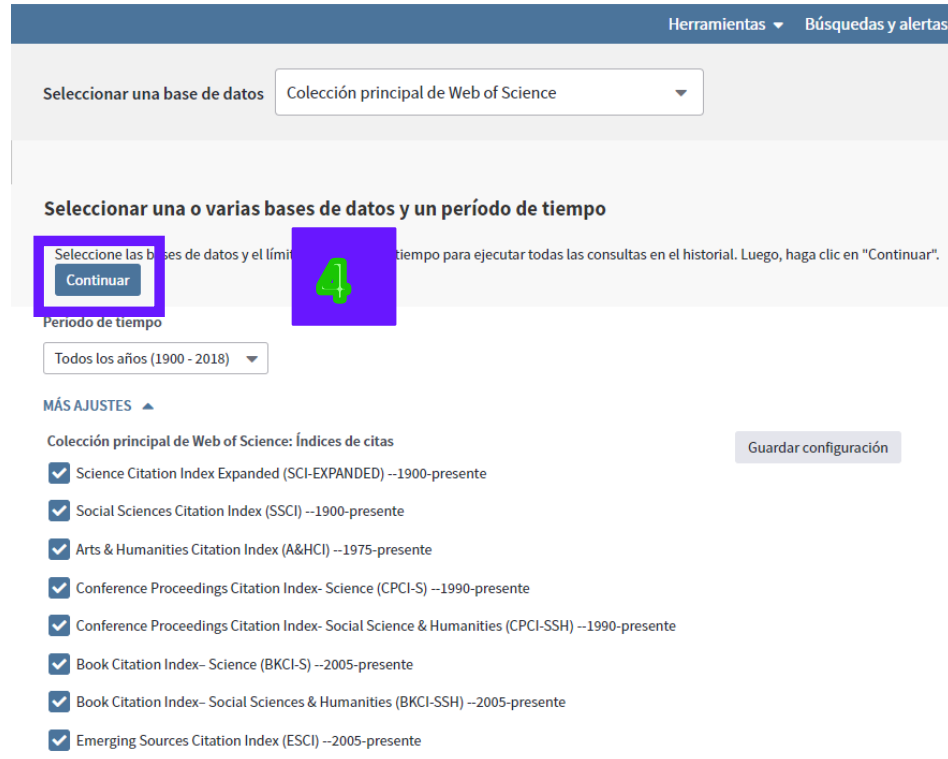




\section{Recepción de Alertas}

Cada día, semana o mes (según haya elegido) recibirá un correo electrónico que contiene los resultados que corresponden a sus criterios de búsqueda. Para las alertas de citas recibirá una notificación sólo cuando el artículo seleccionado haya sido citado.

1. Cada referencia en su correo electrónico está vinculada al registro completo en Web of Science.

2. Su alerta estará activa por 24 semanas. Hacia el final de este período, recibirá una notificación de expiración. Para extender esta alerta, acceda Alerta de Citas en la página principal de Web of Science y haga clic en el botón de Renovar sobre la alerta que desea extender.

3. Nota: La alerta de cita está activa por un año.

\section{Mis Alertas de Citas}

\section{Web of Science}

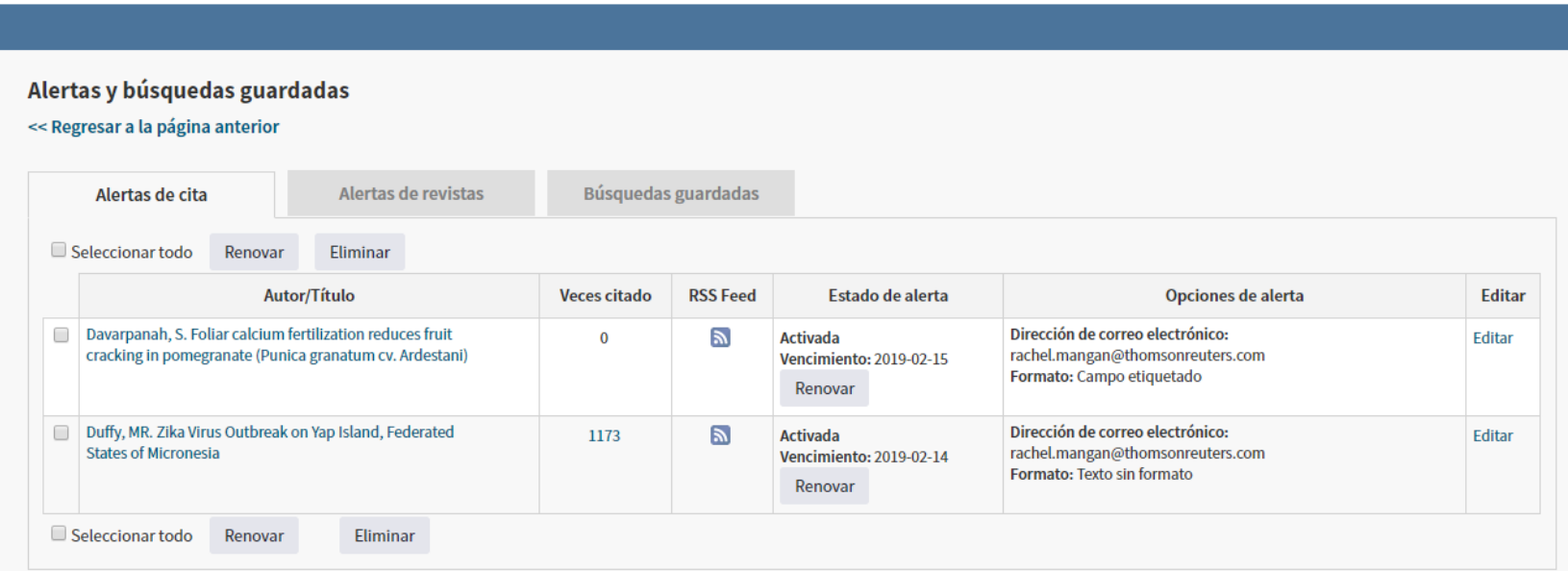

1. Desde 'Búsquedas y alertas' y luego ‘Alertas de citas' se puede ver sus alertas de citas.

2. Haga clic en 'Renovar' para recibir la alerta durante un año más.

3. Haga clic en 'editar' para desactivar la alerta, cambiar el formato de la alerta e introducir otros correos electrónicos.

4. Haga clic en 'Eliminar' para eliminar la alerta de su lista. 


\section{Endnote Basic (versión en línea)}

Endnote Basic (versión en línea) es un gestor de referencias integrado en la plataforma de Web of Science. Está diseñado para ayudar a los estudiantes e investigadores en el proceso de escritura de un trabajo de investigación. Acceso a una biblioteca de Endnote Basic individual está disponible a todos los usuarios de Web of Science que han creado con anterioridad un perfil de usuario de la Web of Science.

Endnote (versión en línea) le permite.....

- Buscar en Web of Science, PubMed y cientos de catálogos de bibliotecas en línea (OPAC's).

- Importar referencias de cientos de bases de datos en línea y organizar una biblioteca de referencias en idiomas múltiples (observe las notas sobre compatibilidad en Unicode).

- Almacenar referencias sin límite.

- Editar una referencia, añadir notas, palabras clave, modificar cualquier campo bibliográfico o crear una nueva referencia manualmente.

- Elegir entre más de 3,300+ estilos de bibliografía para formatear citas temporales y las bibliografías.

- Cite While You Write ${ }^{\mathrm{TM}}$ (Citar mientras se escribe) en Microsoft Word (es necesario descargar el plug-in) le permite introducir y formatear los documentos inmediatamente.

- Formatear documentos de otros procesadores utilizando archivos de RTF.

- Facilitar colaboración con colegas- compartir carpetas de Endnote (web) y designar el acceso de lectura y escritura a carpetas EndNote compartidas.

- Usar la barra de herramientas de Microsoft Internet Explorer y Mozilla ${ }^{\circledR}$ para que pueda acceder su biblioteca con un solo pulso y capturar datos de citas fácilmente en una página Web.

- Sincronizar la versión web con la versión de ordenador (Endnote Desktop X9)

- Se puede exportar resultados directamente de bases de datos de EBSCO HOST y otros proveedores.

- Conectar a su perfil de investigación de ResearcherID e introducir sus publicaciones. (Hace falta registrarse en ResearcherID para poder utilizar esta funcionalidad).

- Capturar referencias audiovisuales en la Web (You Tube por ejemplo).

- Se puede añadir archivos adjuntos a las referencias hasta un máximo de 5GB.

- Los usuarios de Endnote Desktop podrán añadir archivos adjuntos a sus referencias sin límite. 


\section{Comparación de las Versiones: Endnote Basic y Endnote X9}

\begin{tabular}{|c|c|c|}
\hline & EndNote basic & EndNote X9 \\
\hline How to access & Free account $>$ & Buy on EndNote.com > \\
\hline \multirow[t]{3}{*}{ Platforms } & Web browser & Macintosh \\
\hline & & Windows \\
\hline & & iPad app \\
\hline Reference storage & 50,000 & Unlimited \\
\hline Attachment storage & $2 \mathrm{~GB}$ & Unlimited \\
\hline Full Library sharing & & with 100 users \\
\hline Private group sharing & $\checkmark$ & $\checkmark$ \\
\hline Shared library activityfeed & & $\checkmark$ \\
\hline Recently added group & & $\checkmark$ \\
\hline Sync library with the iPad app & $\checkmark$ & $\checkmark$ \\
\hline Citation report (with your Web of Science subscription) & & $\checkmark$ \\
\hline Manuscript Matching and publication recommendations & $\checkmark$ & $\checkmark$ \\
\hline Automatic and bulk reference updating & & $\checkmark$ \\
\hline Advanced reference organization with smart and combined groups & & $\checkmark$ \\
\hline Online database searching & 5 & $6000+$ \\
\hline Send references directly from online databases & 9 & $500+$ \\
\hline Create a list of favorite styles & $\checkmark$ & $\checkmark$ \\
\hline Create custom groups of references & $\checkmark$ & $\checkmark$ \\
\hline Create smart groups of references for instant sorting & & $\checkmark$ \\
\hline One click find full text & & $\checkmark$ \\
\hline Annotate and highlight pdfs in application & & $\checkmark$ \\
\hline Search PDF text, notes, annotations & & $\checkmark$ \\
\hline PDF auto-import folder & & $\checkmark$ \\
\hline Smart reference creation from extracted DOIs and other metadata & & $\checkmark$ \\
\hline Integrated with Microsoft Word 2016 & $\checkmark$ & $\checkmark$ \\
\hline Predefined bibliographic formatting styles & 21 & $6000+$ \\
\hline Create or customize your own bibiliographic formatting styes & & $\checkmark$ \\
\hline Multiple bibliographies in a single document for book chapters & & $\checkmark$ \\
\hline Subheading and category bibliographies & & $\checkmark$ \\
\hline Composite references & & $\checkmark$ \\
\hline Field substitutions & & $\checkmark$ \\
\hline Journal abbreviation recognition and standardization & & $\checkmark$ \\
\hline Custom options to add more database providers & & $\checkmark$ \\
\hline Number of reference fields & 53 & 56 \\
\hline Number of reference types & 48 & 48 \\
\hline Unicode compliant & $\checkmark$ & $\checkmark$ \\
\hline Sync with the iPad app & $\checkmark$ & $\checkmark$ \\
\hline
\end{tabular}




\section{Endnote (versión en línea)}

- Para acceder a una biblioteca de Endnote Básico (www.myendnoteweb.com) es necesario inscribirse con sus claves de acceso correspondientes a su perfil de usuario de Web of Science. No es necesario crear un registro nuevo.

- Para los usuarios que no han creado ya un perfil de usuario deberían hacerlo al hacer clic en el enlace 'Cree una cuenta' y luego completar el formulario de registro.

https://access.clarivate.com/login?app=endnote

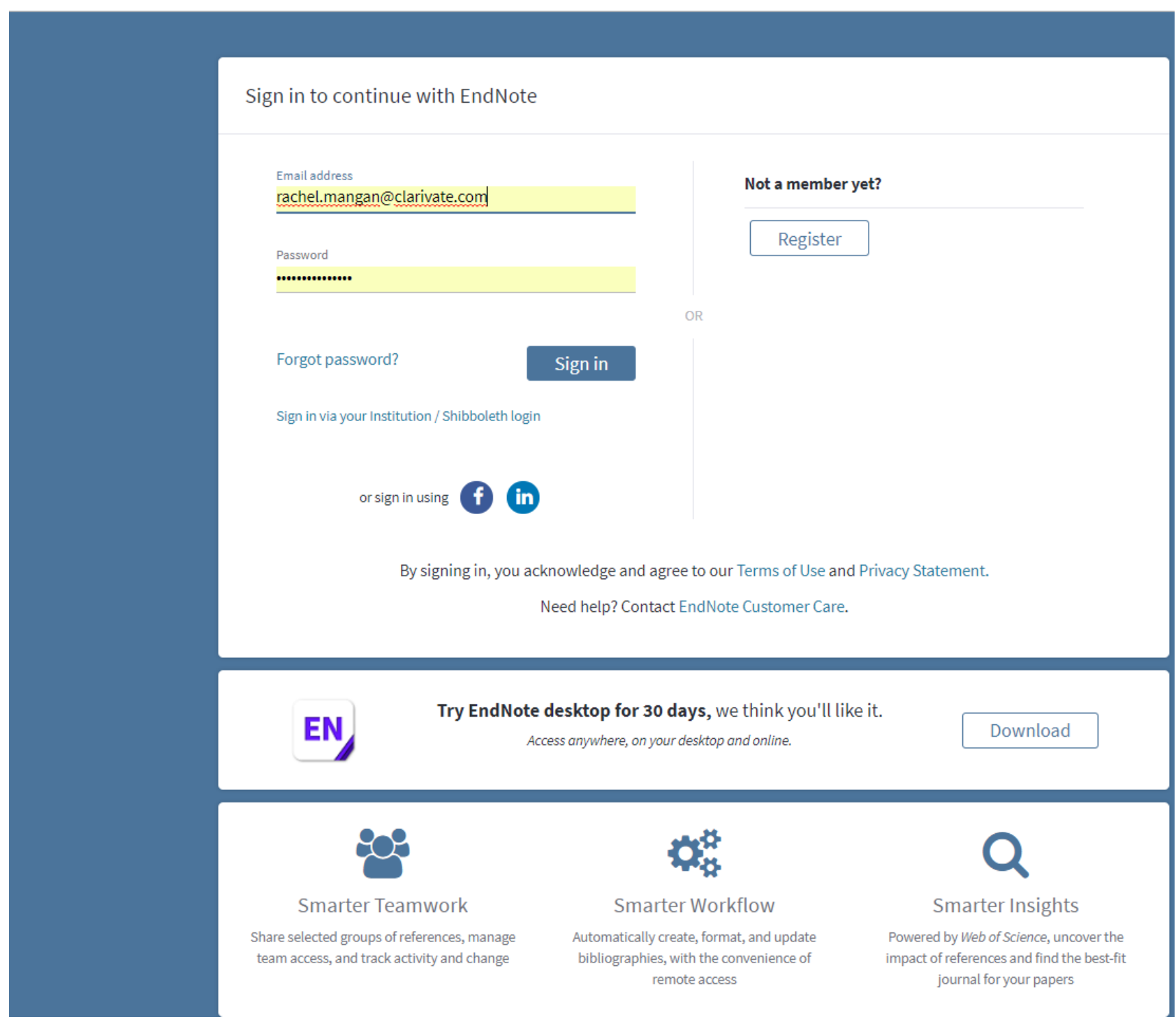

1. Introduzca sus claves de acceso correspondientes a su perfil de usuario en los campos y haga clic en 'iniciar sesión' para ir a su biblioteca.

2. Haga clic en 'Sign Up' para crear un perfil de usuario. El enlace le llevará a un formulario. En la página de registro es necesario completar como mínimo una serie de campos obligatorios (indicados con una estrella roja) sin utilizar acentos o guiones. Al finalizar el registro, pulse el botón 'Enviar datos' a fin de completar el proceso de registro.

3. Es posible iniciar una sesión por las credenciales de redes sociales 


\section{Página Principal de Endnote Basic}

La interfaz de la biblioteca de Endnote Basic se caracteriza por una serie de pestañas que correspondan a las funcionalidades principales del gestor de referencias.
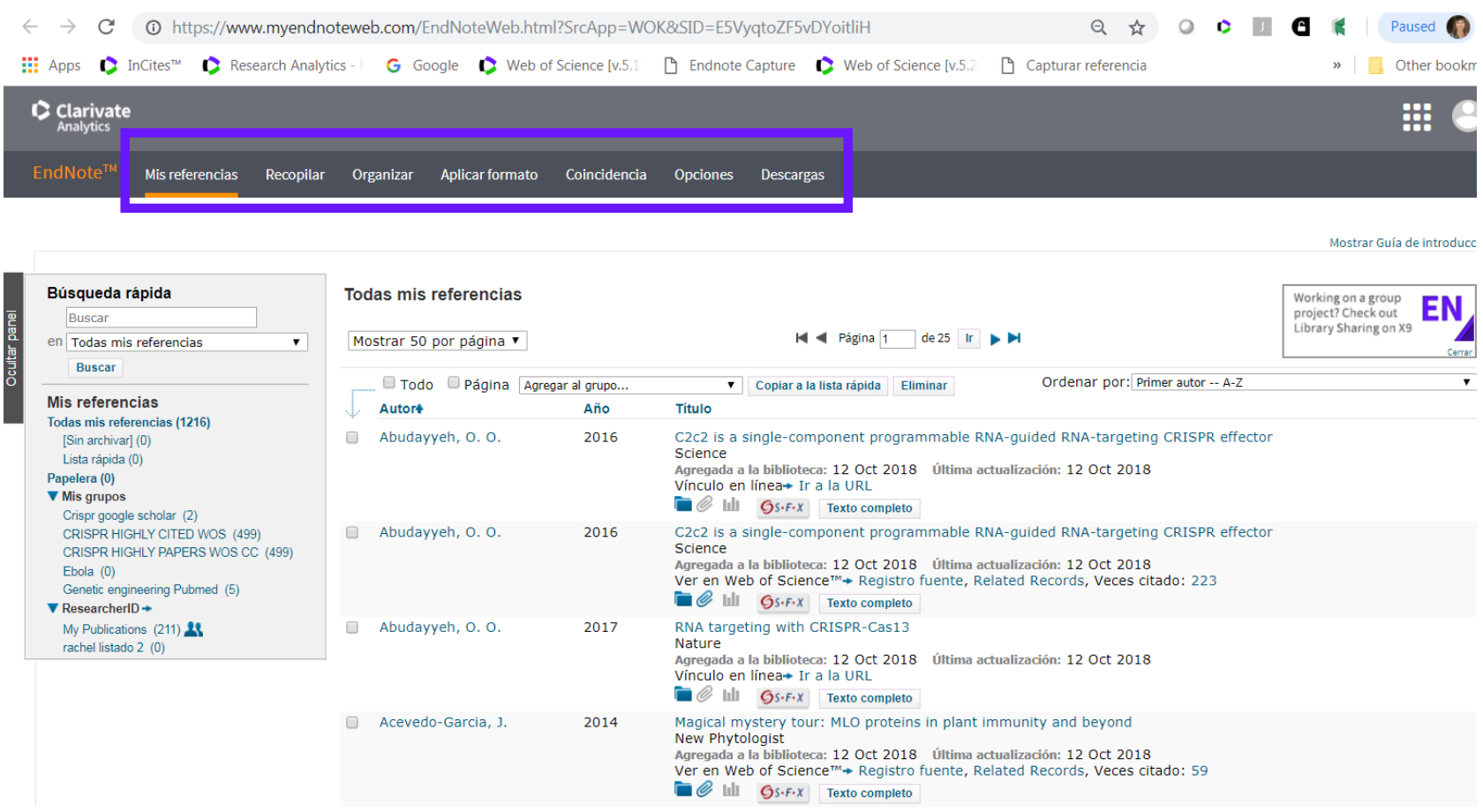

\section{Mis Referencias}

\section{Mis Grupos y Grupos de Researcher ID}

Esta pestaña le permite ver todas las referencias gestionadas en su biblioteca. También verá sus grupos individuales y grupos que otros usuarios compartidos con usted (grupos compartidos por otros usuarios). En el caso de que haya creado un registro en ResearcherID, verá sus listados de publicaciones 'My Publicaciones' y 'Publication List 1 \& 2' procedentes de ResearcherID. Es posible consultar de manera rápida las referencias en su biblioteca al realizar una búsqueda rápida.

Se puede cambiar el orden de visualización de las referencias seleccionado cualquier de los temas en el menú desplegable a mano derecha.

\section{Incorporar (Recopilar) Referencias}

Existen tres opciones para incorporar referencias a su biblioteca:

A. Una búsqueda en línea en bases de datos y catálogos de las bibliotecas desde Endnote.

B. Crear una nueva referencia manualmente

C. Importar referencias. 

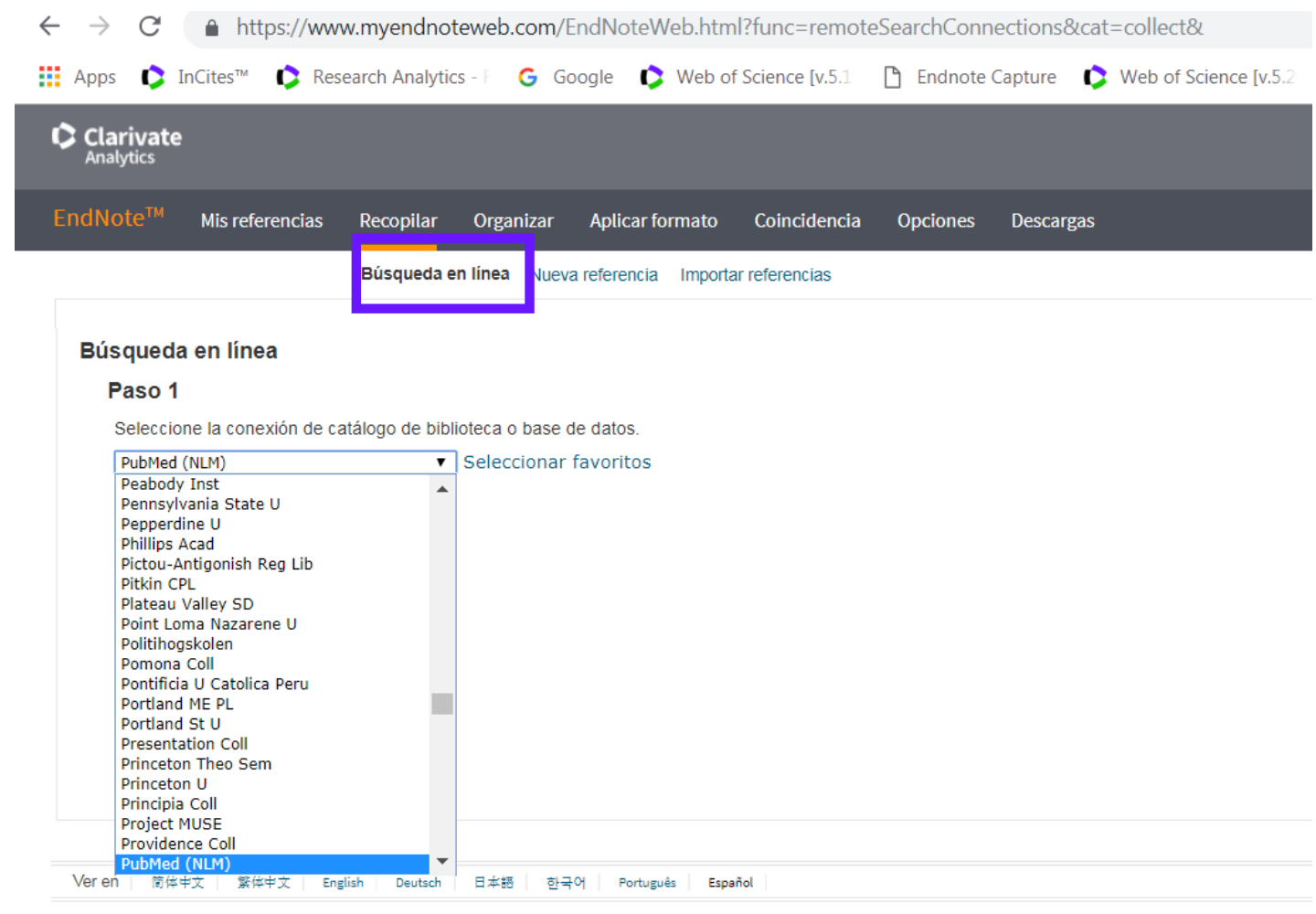

\section{A. Una Búsqueda en línea de bases de datos o catálogos desde Endnote}

Endnote le permite buscar en cientos de bases de datos y catálogos de bibliotecas Ej. Pubmed y Web of Science

- Seleccione el catálogo o la base desde el menú desplegable. Luego haga clic en 'Conectar' para conectarse a la base.

- Aparece una pantalla en la que se puede introducir los términos de búsqueda en varios campos. Haga clic sobre 'buscar' para lanzar la búsqueda.

- Verá una notificación del número de registros recuperados. Se puede seleccionar un rango de registros o todos.

- Haga clic sobre 'Recuperar' para incorporar los registros deseados en su biblioteca

- Una vez recuperados es necesario guardar los registros en un grupo nuevo o existente.

\section{B. Crear una nueva referencia manualmente}

Es posible introducir una nueva referencia de modo manual. Haga clic sobre 'Nueva referencia y aparecerá un formulario. Es obligatorio rellenar los campos bibliográficos indicados con la estrella roja.

Para introducir datos en los campos, hace falta hacer clic dentro del campo y escribir. 


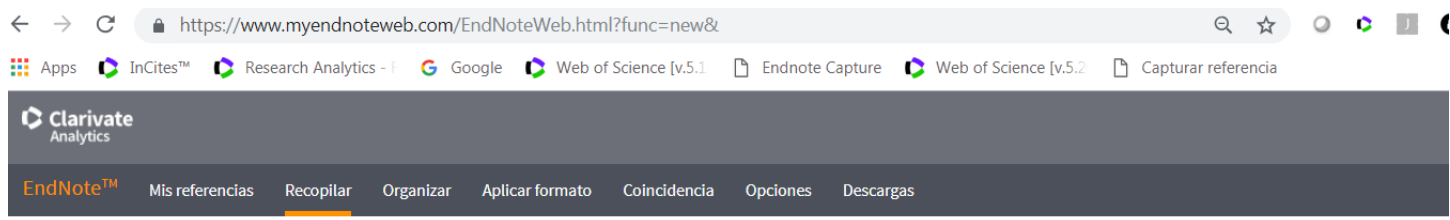

Búsqueda en línea Nueva referencia Importar referencias

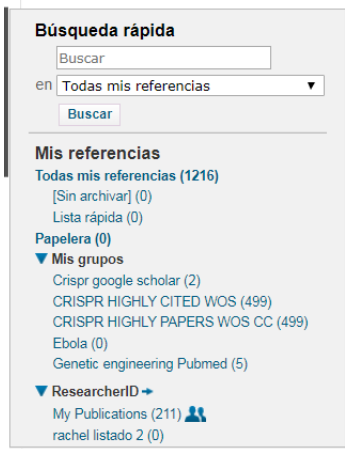

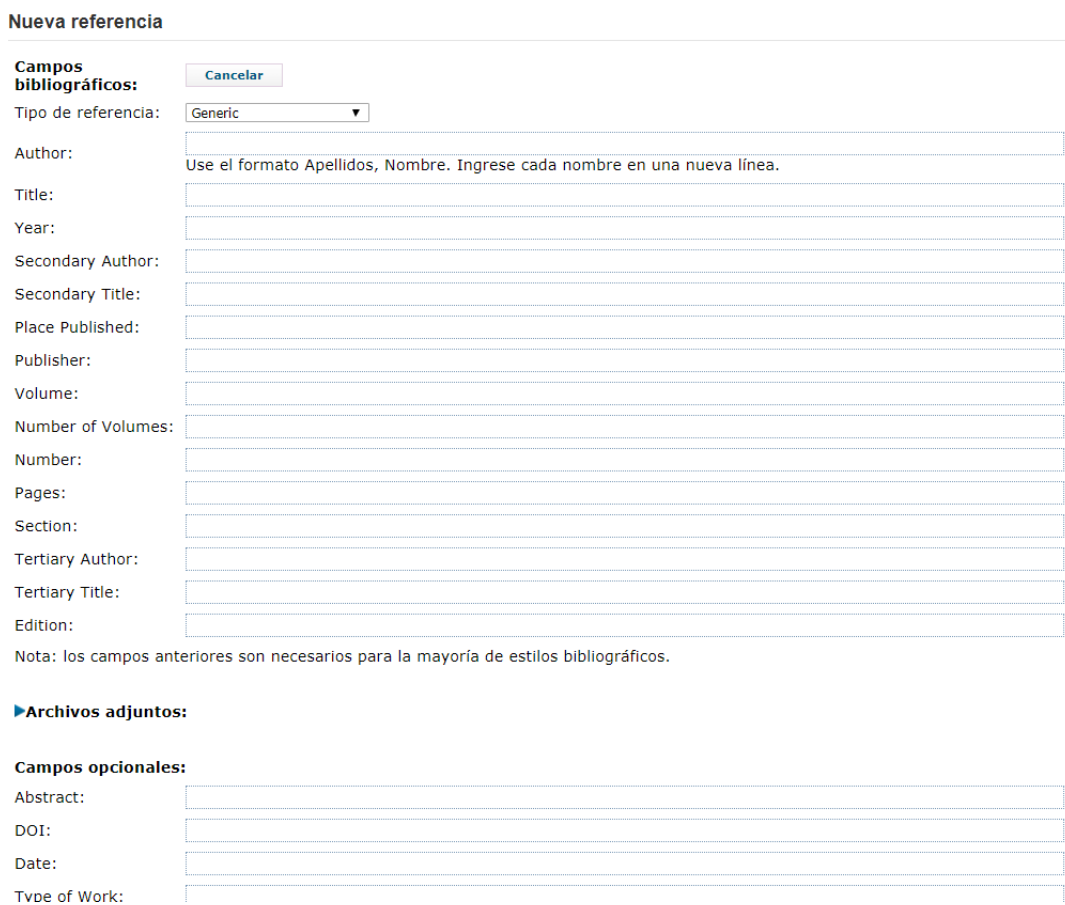

Una vez completado, haga clic en el botón 'Guardar' para incorporar la referencia a un nuevo grupo o a un grupo existente.

\section{Importar Referencias}
$\leftarrow \rightarrow C$
- https://www.myendnoteweb.com/EndNoteWeb.html?func=import\%20citations\&
:\# Apps 1 InCites ${ }^{\mathrm{TM}}$
1) Research Analytics
G Google
1. Web of Science [v.5.
D Endnote Capture I) We

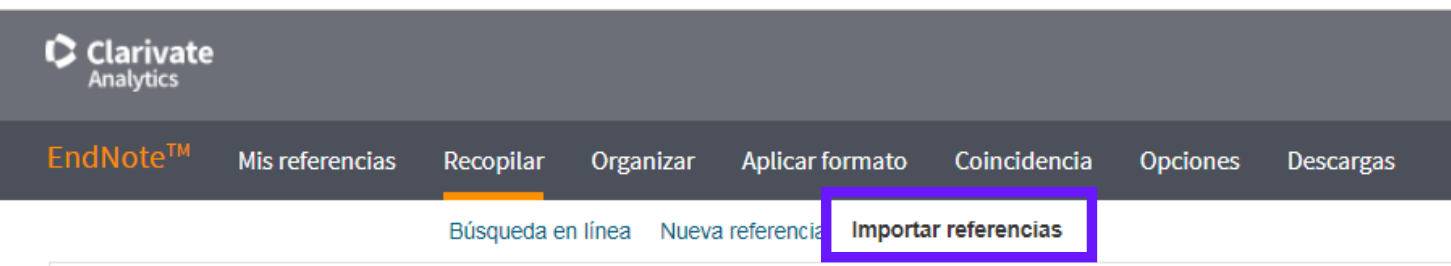

Importar referencias

¿Desea importar desde EndNote?

Archivo: Choose File No file chosen

Opción de importación: Seleccionar... v Seleccionar favoritos

A: Seleccionar...

Importar

Es posible introducir referencias en su biblioteca mediante la realización de búsquedas bibliográficas directamente desde bases de datos externas (Google Académico y Pubmed por ejemplo) o catálogos de bibliotecas. Sigan los pasos siguientes: 
1. Consulte los formatos de importación correspondientes a su proveedor.

2. Abra el índice de soporte para encontrar la sección 'Import Formats'.

\begin{tabular}{|c|c|c|}
\hline WwW.apa.0rg & $\begin{array}{l}\text { Select the text, then copy and paste it into a text editor, saving the } \\
\text { file it as plain text (".txt). }\end{array}$ & पासाप्रा \\
\hline PubMed ${ }^{\circ}$ & $\begin{array}{l}\text { 1. Display your search results in the MEDLNNE format by } \\
\text { choosing MEDLINE from the Display drop-down list box. } \\
\text { 2. Select File from the Send to drop-down list box. } \\
\text { 3. Save the file as a plain text (".txt) file. }\end{array}$ & PubMed (NLM) filter \\
\hline RefWorks & $\begin{array}{l}\text { In RefNorks: } \\
\text { 1. Select the references to export. } \\
\text { 2. Select the RefWorks Tagged format. } \\
\text { 3. Click the Export to Text File button. } \\
\text { 4. Save the file in a location that will be accessible when } \\
\text { importing later. } \\
\text { 5. In EndNote Web, follow the Importing References instructions } \\
\text { using the RefWorks Import filter. }\end{array}$ & RefWorks Import \\
\hline
\end{tabular}

3. Realice la búsqueda en la base o catálogo deseado y guarde los resultados a su ordenador en el formato adecuado.

4. Haga clic sobre el enlace 'Importar referencias'.

5. Seleccione el archivo adecuado.

6. Seleccione el filtro de importación adecuado. Se puede predefinir los filtros que se usa más frecuentemente a través de la opción 'personalizar estilo de importación'.

7. Haga clic en el botón 'Importar' para importar los resultados recuperados.

8. Los resultados se encuentran importados en el grupo de referencias temporales 'Sin archivar'.

9. Guarde las referencias en un nuevo grupo o adiciónelos a un grupo existente. 


\section{Exportar Referencias directamente de bases de datos de EBSCO HOST}

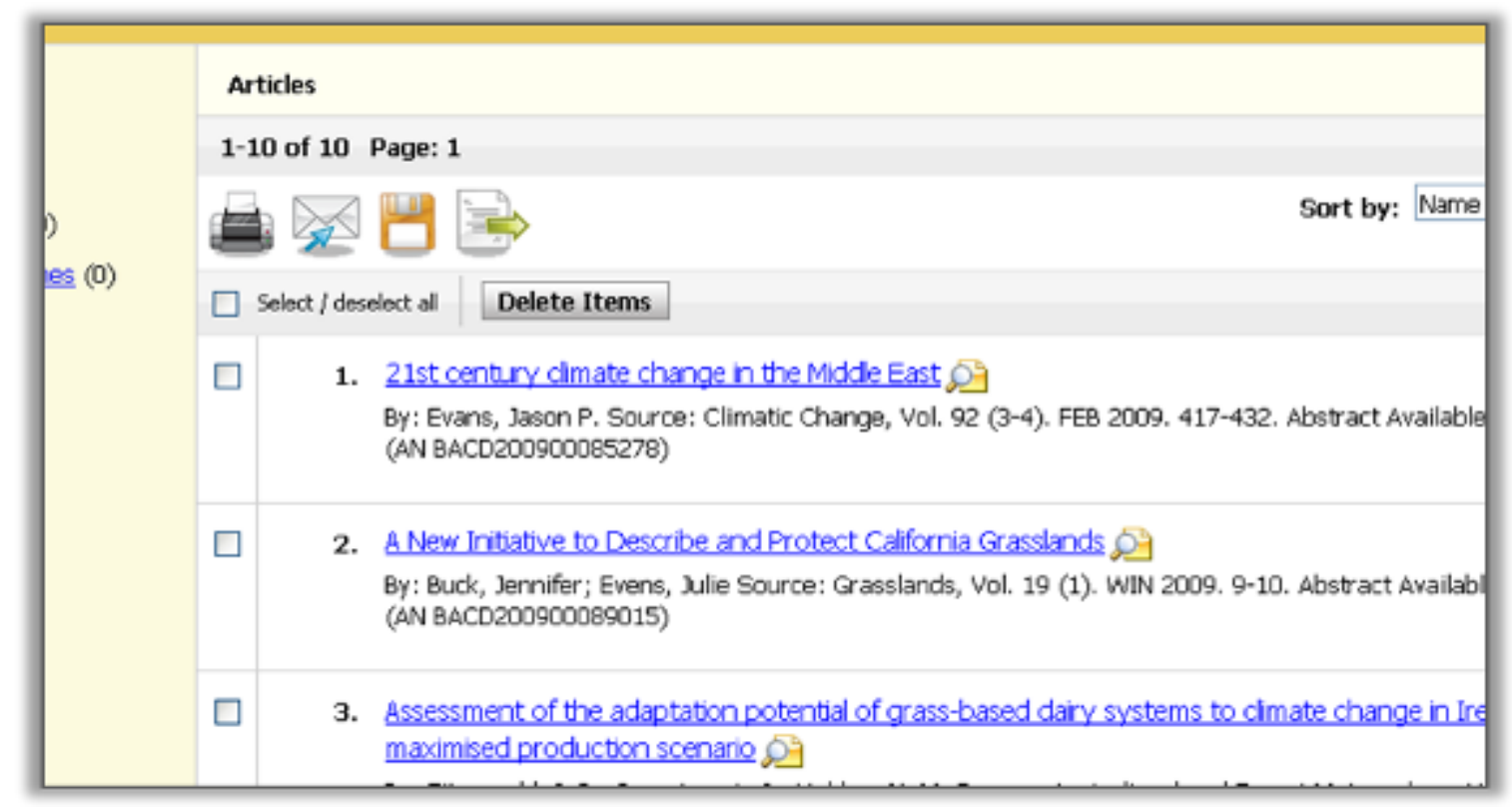

1. Después de realizar una búsqueda en EBSCO HOST y haber marcado los resultados de interés a un archivo, vaya al archivo y seleccione los resultados que desea exportar a su biblioteca de Endnote.

2. Luego haga clic sobre el icono de la cartita para ir a la página de exportación.

\begin{tabular}{|c|l|}
\hline Save E-mall & \\
\hline Number of items to be saved: 10 & \\
\hline Semove these items from folder after saving & Save citations to a file formatted for: \\
\hline Save & Direct Export to EndNote, Procite, or Reference Manager \\
\hline & Direct Export to EndNote Web \\
\hline & Generic bibliographic management software \\
& Citations in BibTeX format \\
& Citations in MARC21 format \\
\hline
\end{tabular}

3. Seleccione la opción 'Direct Export to Endnote Web' para exportar sus resultados directamente a su biblioteca de Endnote Web. 


\section{Organizar sus Referencias}

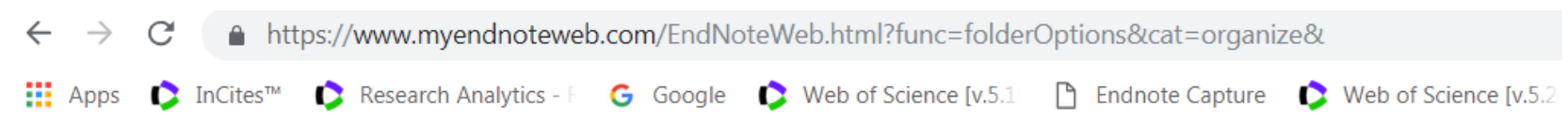

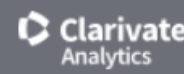

EndNote ${ }^{\mathrm{TM}}$ Mis referencias Recopilar Oroanizar Anlicarformatn Cnincidenria Oncinnes necraroas

Administrar mis grupos

\begin{tabular}{|c|c|c|c|c|c|}
\hline \multirow{2}{*}{$\begin{array}{l}\text { Mis grupost } \\
\text { Crispr google scholar }\end{array}$} & \multirow{2}{*}{$\begin{array}{l}\text { Número de } \\
\text { referencias } \\
2\end{array}$} & \multicolumn{2}{|c|}{ Compartir } & \multirow[b]{2}{*}{ Cambiar el nombre } & \multirow[b]{2}{*}{ Eliminar } \\
\hline & & $\square$ & Administrar uso compartido & & \\
\hline CRISPR HIGHLY CITED WOS & 499 & $\square$ & Administrar uso compartido & Cambiar el nombre & Eliminar \\
\hline CRISPR HIGHLY PAPERS WOS CC & 499 & $\square$ & Administrar uso compartido & Cambiar el nombre & Eliminar \\
\hline Ebola & 0 & $\square$ & Administrar uso compartido & Cambiar el nombre & Eliminar \\
\hline Genetic engineering Pubmed & 5 & $\square$ & Administrar uso compartido & Cambiar el nombre & Eliminar \\
\hline \multicolumn{6}{|l|}{ Mis grupos de ResearcherlD4 } \\
\hline 1) My Publications & 211 & $\checkmark$ & Administrar uso compartido & & \\
\hline rachel listado 2 & 0 & $\square$ & Administrar uso compartido & Cambiar el nombre & Eliminar \\
\hline
\end{tabular}

\section{Administrar Grupos}

- Selecciona la pestaña 'Organizar' y luego 'administrar mis grupos'. Aquí se puede compartir, crear, eliminar o cambiar el nombre de sus grupos. También se puede encontrar y eliminar referencias duplicadas y ver grupos de otras personas.

- Para eliminar grupos de referencias haga clic sobre el botón correspondiente 'eliminar'. Las referencias en un grupo a borrar pasarán al grupo de referencias temporales 'sin archivar'.

- Para compartir un grupo seleccione la casilla correspondiente en la columna Compartir y luego el botón 'administrar uso compartido'. En la pantalla siguiente, haga clic sobre el enlace 'empiece a compartir este grupo'. Luego abrirá una nueva ventana en el que se puede introducir los correos electrónicos de las personas con las que querrá compartir el grupo. Los correos electrónicos deberían ser las mimas con las que dichas personas están registradas a Endnote. Se puede designar el acceso de leer solamente o leer y escribir las referencias en las carpetas EndNote compartidas.

\section{Grupos de otros usuarios}

Haga clic sobre este enlace para ver grupos que otros usuarios comparten con usted. Es posible optar para visualizar estos grupos en la sección 'Mis Referencias' u ocúltalos.

\section{Buscar duplicados}

Para identificar y eliminar fácilmente los registros duplicados.

Se puede cambiar el nombre de sus listados de publicaciones $1 \& 2$ de ResearcherID. Simplemente haga clic sobre el listado deseado y luego 'cambiar el nombre'. El título del listado se actualizará en 
Endnote también. Hace falta crear un perfil dentro de ResearcherID para tener acceso a estos listados.

\section{Administrar archivos adjuntos}

Puede adjuntar hasta 5GB de archivos adjuntos. Haga clic en 'administrar archivos adjuntos' para ver los detalles.

\section{Aplicar Formato}

En la sección 'Aplicar formato' se puede elegir entre varias opciones para la creación y/o exportación de una bibliografía.

\section{Creación de una Bibliografía al instante}

La creación de una bibliografía consiste en 4 pasos.
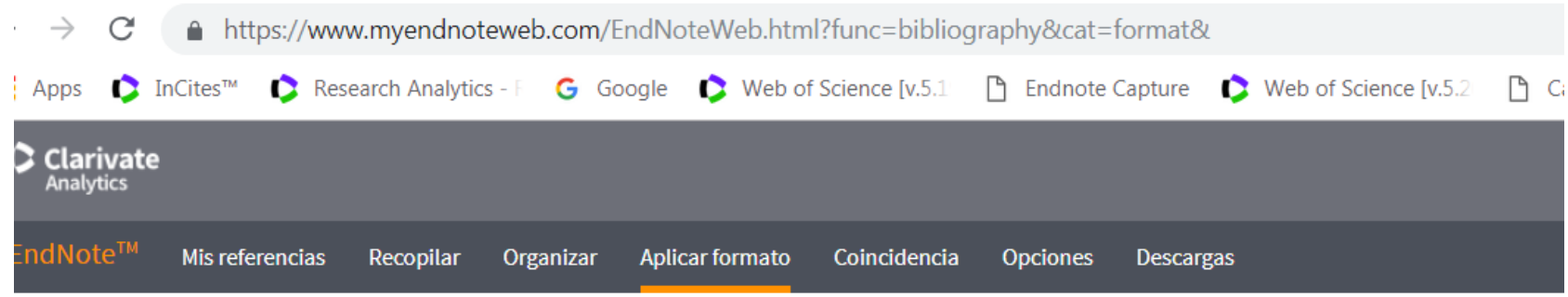

Bibliografia Plug-in de Cite While You Write ${ }^{\mathrm{TM}}$ Aplicar formato al artículo Exportar referencias

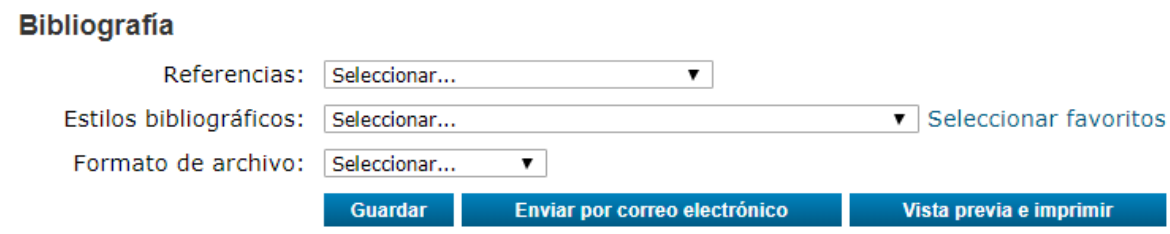

1. Seleccione el grupo con el que desea crear la bibliografía.

2. Seleccione el estilo de bibliografía entre 3.300 estilos. A mano derecha se muestra en un cuadro ejemplos de los estilos comunes para campos de investigación.

3. Seleccione el formato del archivo (HTML, texto pleno o texto enriquecido).

4. Finalmente seleccione una opción de exportación entre guardar, enviar por correo electrónico o visualización e impresión. 


\title{
Cite While you Write (Citar Mientras Se Escribe) y aplicar formato a un Manuscrito
}

Existen dos formas de incluir las citas y referencias en un manuscrito:

\section{Introducir citas y referencias con el plug-in "Cite While You Write"}

En primer lugar, es necesario descargar e instalar el plug in. Haga clic sobre 'Descargar instaladores' situado en la parte inferior de la página y sigan las instrucciones.

Una vez instalado verá una nueva barra de herramientas en MS Word que es la conexión entre el documento de Word con su biblioteca de Endnote. A continuación, se observa la barra de herramientas de CWYW en varias versiones de MS Word.

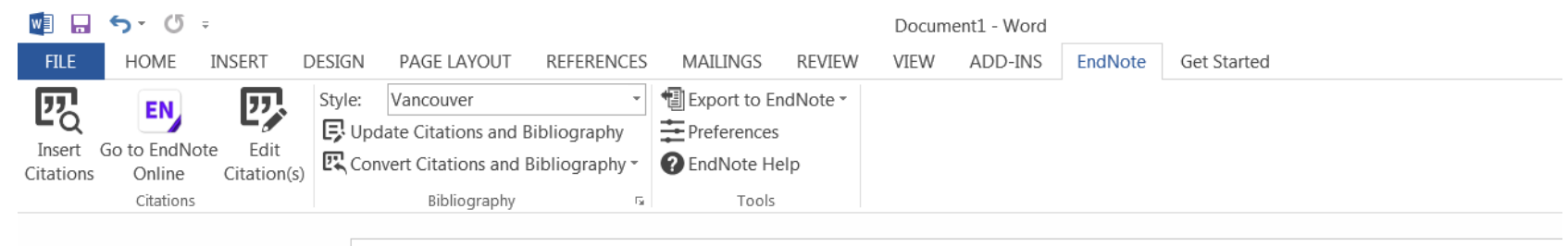

\begin{abstract}
In 2007, physicians on Yap Island reported an outbreak of illness characterized by rash, conjunctivitis, and arthralgia. Although serum from some patients had IgM antibody against dengue virus, the illness seemed clinically distinct from previously detected dengue. Subsequent testing with the use of consensus primers detected Zika virus RNA in the serum of the patients but no dengue virus or other arboviral RNA. No previous outbreaks and only 14 cases of Zika virus disease have been previously documented.

METHODS

We obtained serum samples from patients and interviewed patients for information on clinical signs and symptoms. Zika virus disease was confirmed by a finding of Zika virus RNA or a specific neutralizing antibody response to Zika virus in the serum. Patients with IgM antibody against Zika virus who had a potentially crossreactive neutralizing-antibody response were classified as having probable Zika virus disease. We conducted a household survey to estimate the proportion of Yap residents with IgM antibody against Zika virus and to identify possible mosquito vectors of Zika virus.

RESULTS

We identified 49 confirmed and 59 probable cases of Zika virus disease. The patients resided in 9 of the 10 municipalities on Yap. Rash, fever, arthralgia, and conjunctivitis were common symptoms. No hospitalizations, hemerrhagic manifestations, or deaths due to Zika virus were reported. We estimated that $73 \%$ (95\% confidence interval, 68 to 77 ) of Yap residents 3 years of age or older had been recently infected with Zika virus. Aedes hensilli was the predominant mosquito species identified. CONCLUSIONS

This outbreak of Zika virus illness in Micronesia represents transmission of Zika virus outside Africa and Asia. Although most patients had mild illness, clinicians and public health officials should be aware of the risk of further expansion of Zika virus transmission.
\end{abstract}

La barra de herramientas de Endnote Cite While You Write le permite:

A. Buscar referencias guardadas en su biblioteca e introducirlas en el texto, elaborando una bibliografía al final del texto.

B. Conectarse de un solo pulso a su biblioteca de Endnote.

C. Formatear una bibliografía a un estilo preferido

D. Editar citas

E. Cambiar el formato de citas 
F. Borrar códigos de campo

G. Personalizar las teclas de función rápida y seleccionar las aplicaciones dentro de Word

H. Exportar Referencias de un manuscrito a su biblioteca de Endnote

I. Es posible trabajar con Cite While You Write de las dos versiones (Endnote Web o Endnote de ordenador). Seleccione su preferencia en 'Preferences' y luego 'Application'.

\section{Formatear citas temporales en un manuscrito de texto enriquecido RTF}

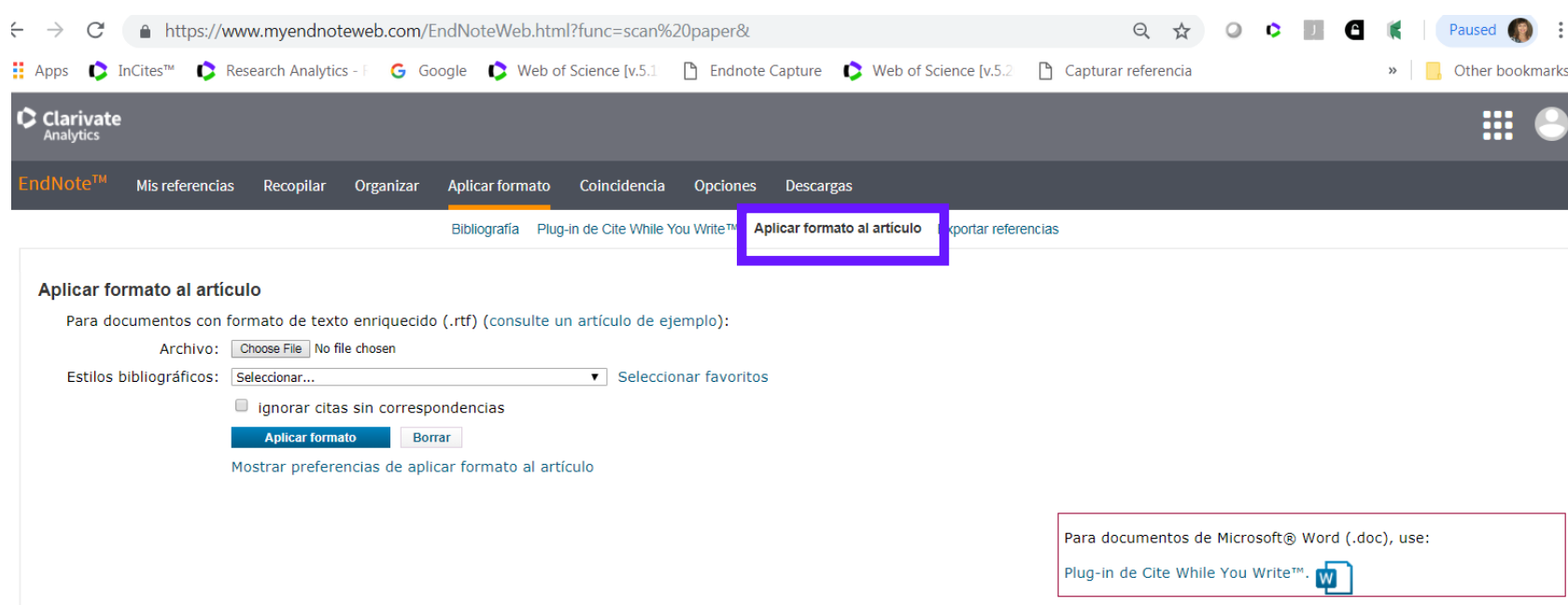

Se puede formatear citas temporales en un manuscrito de texto enriquecido. Sigan los pasos siguientes:

1. Localice el documento en su ordenador.

2. Seleccione un estilo de bibliografía.

3. Se puede ignorar citas no emparejadas.

\section{Exportar Referencias}

Endnote Web le permite exportar referencias desde su biblioteca a otros gestores bibliográficos (Endnote, Reference Manager...) y a otras herramientas.

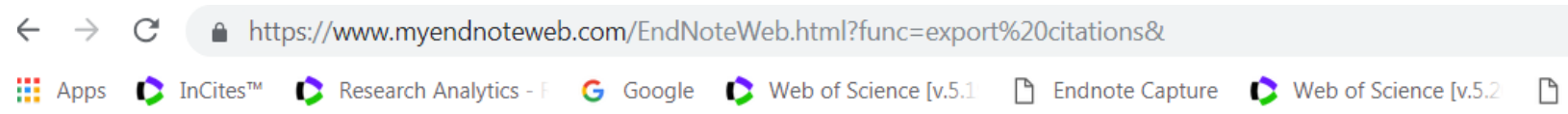

\section{Exportar referencias}

Referencias: - CRISPR HIGHLY PAPERS WOS CC $\nabla$

Estilo de exportación:

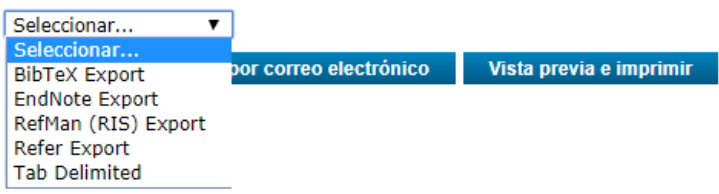


1. Seleccione las referencias/grupos.

2. Luego seleccione el formato de exportación. Para importar referencias a su perfil dentro de ResearcherID el estilo de exportación preferido es 'RefMan RIS'

3. Haga clic en el botón 'Guardar' para guardar el archivo a su ordenador. También es posible enviarlo por correo electrónico o visualizarlo e imprimirlo. 


\section{Apéndice $A$}

Búsqueda en Arts \& Humanities: Guía de Búsqueda de Escrituras Sagradas

\begin{tabular}{llll}
\hline Escrituras Sagradas & $\begin{array}{l}\text { Término de } \\
\text { búsqueda en el } \\
\text { campo Cited } \\
\begin{array}{l}\text { Author (Autor } \\
\text { Citado) }\end{array}\end{array}$ & $\begin{array}{l}\text { Elementos de } \\
\text { búsqueda en el } \\
\text { campo Cited } \\
\text { Work (Trabajo } \\
\text { Citado) }\end{array}$ & Ejemplos de Búsqueda \\
\hline Bible & BIBLE & Book & $\begin{array}{l}\text { Cited Author: BIBLE } \\
\text { Cited Work: GENESIS }\end{array}$ \\
Koran & Surah & $\begin{array}{l}\text { Cited Author: KORAN } \\
\text { Cited Work: SURAH }\end{array}$ \\
\hline \hline
\end{tabular}

\section{Literatura Talmúdica}

Mishna

Tosefta

Babylonian \&

Palestinian

(Jerusalem)

Talmuds

Dead Sea Scrolls

Nag Hammadi

Library

Miscellaneous

Judeo-Christian

Sacred Writings

Miscellaneous Non-

Judeo-Christian-

Islamic Sacred

Writings
MISHNA Tractate

TOSEFTA

SCRIPTURES

$\mathrm{BT}^{*}$ or JT*

Tractate

DSS*

SCRIPTURES

SCRIPTURES

$\mathrm{NH}^{*}$

Cited Author:

SCRIPTURES

Cited Work: NH

SCRIPTURES

Cited Title

Cited Author:

SCRIPTURES

Cited Work: TARGUM

Cited Title

Cited Work: I CHING 


\section{Tema}

Introduzca palabras o frases que puedan aparecer en el título del artículo, el resumen o las listas de palabras claves.

\section{Norma}

1. Para buscar dos palabras o más en serie, el motor de búsqueda aplicará el operador 'AND' entre las palabras.

2. Para buscar una frase, ingrese la frase entre comillas ("'). Se buscan términos adyacentes en el orden introducido.

3. Utilice el operador SAME para especificar que dos términos deben aparecer en la misma oración en cualquier orden.

4. Utilice sinónimos (lenguaje natural, siglas, jerga); combínelos con el operador OR.

5. Trunque para recuperar términos plurales y derivados.

6. Utilice comodines internos para recuperar variantes.

7. Introduzca un espacio al buscar un término que contenga puntuación.

8. Utilice el operador SAME al buscar una frase que contenga un posesivo.

9. Busque palabras con guión, fusionadas y no fusionadas.

10. Busque nombres propios utilizando el operador SAME.

\section{Ejemplo}

Introduzca avian influenz* $\mathbf{h} 5 \mathrm{n} 1$ para recuperar registros con al menos una aparición de cada palabra en los títulos, palabras clave o resúmenes en cualquier orden.

Introduzca "reduc* sodium" para recuperar reduced sodium, reducing sodium, etc.

Introduzca reduc* SAME sodium para recuperar reduced sodium, reducing sodium, sodium intake of experimental group was reduced, etc.

Introduzca heart* OR coronar* OR cardio* OR cardia* para recuperar heart, hearts, heartbeat, coronary, cardiovascular, cardiotonic, cardiopulmonary, cardiac, etc.

Introduzca angioplast* para recuperar angioplasty, angioplasties, angioplastic, etc.

Introduzca wom?n para recuperar woman o women. Introduce labo $\mathbf{\$} r$ para recuperar labor o labour.

Introduzca alfa $\mathbf{2}$ beta $\mathbf{2}$ para recuperar alfa(2)beta(2).

Introduzca kaposi* SAME sarcom* para recuperar Kaposi sarcoma, Kaposis-sarcoma, Kaposis sarcoma, Kaposi's sarcoma.

Introduzca cd rom OR cdrom para recuperar $C D-R O M, C D R O M$, etc...

Introduzca churchill same (winston OR w) para recuperar Winston Churchill; Churchill,Winston; Churchill, W., etc. 
11. Los títulos que no estén en inglés se traducen al inglés (EE.UU.) cuando no se provee una traducción por parte de la revista.

12. Los títulos de obras creativas permancen en el idioma original.
The continuous quality improvement process in mental health services management Massa JLP

Actas Luso-Españolas De Neurología Psiquiatría Y Ciencias Afines 24: (1) 49-57 JAN-FEB 1996

The Barbizon School - L'auberge Ganne' Laverroux N

Oeil-Magazine International D Art (477) S2-S2 DEC 1995

13. Las modificaciones en los títulos se indican mediante un signo (+) o por paréntesis (sólo Arts \& Humanities Citation Index).

\section{Regla}

1. Para nombres con puntuación o espacios, ingrese las versiones fusionadas y no fusionadas.

1. Busque variantes de nombres introduciendo el apellido de diversas formas.

2. Títulos de rango, designaciones generacionales tales como Junior o Senior y grados académicos se ignoran.

Speech After Long Silence + The Poesía de Haines,John

Berry W

Sewanee Reseña

104: (1) 108-110 WIN 1996

Ejemplo

Introduzca oneill OR o neill para

recuperar O'Neill.

Introduzca delarosa OR de la rosa para

recuperar artículos por de la Rosa.

Introduzca yen sw OR shi wy para recuperar artículos por Shi-Wa Yen.
Documento

Original

Lord Duvall

Edwards

W. Brumfitt, Jr.
Base de Datos

ISI

Edwards d

Brumfitt w 


\section{Autor Colectivo}

Introduzca el nombre del autor del grupo y las iniciales del nombre. Utilice el Índice del autor del grupo (Search Aid)) para ubicar otras versiones del nombre del autor del grupo.

\begin{tabular}{|c|c|}
\hline & \\
\hline Regla & Ejemplo \\
\hline
\end{tabular}

1. Use comodines y caracteres de truncamiento en este campo. Ingrese múltiples nombres abreviados unidos Introduzca women* interag* HIV* or WIHS* para ubicar artículos de por el operador de búsqueda OR.

\section{Año de Publicación}

Introduzca el año completo del año de publicación.

\begin{tabular}{|l|l|}
\hline \multicolumn{1}{|c|}{ Regla } & \multicolumn{1}{|c|}{ Ejemplo } \\
\hline 1. & $\begin{array}{l}\text { No utilice truncamiento. Se permite un } \\
\text { máximo de 10 años en el campo de } \\
\text { año de publicación. Ingrese el año de } \\
\text { publicación completo o un rango de } \\
\text { años (menos de 10). Combine una } \\
\text { búsqueda por año de publicación con } \\
\text { otros campos de búsqueda. }\end{array}$ \\
\hline
\end{tabular}




\begin{tabular}{|cc|}
\hline \multicolumn{2}{|c|}{ Título Original } \\
Introduzca el título completo o parcial (truncado) de una revista. \\
\hline \multicolumn{1}{|c|}{ Regla } & \multicolumn{1}{c|}{ Ejemplo } \\
1. Use comodines y caracteres de & Introduzca science OR nature para \\
truncamiento en este campo. & recuperar artículos de ambas revistas. \\
Ingrese múltiples títulos abreviados & Introduzca nature* para recuperar \\
unidos por el operador OR. & artículos de las revistas Nature, Nature \\
& \& Resources, Nature Biotechnology, \\
& Nature Genetics, etc. \\
\hline
\end{tabular}

\section{Dirección}

Web of Science Group captura todas las direcciones de los autores. Introduzca el nombre de la institución o del lugar

\section{Regla}

1. Utilice comodines y truncamiento en este campo.

2. Utilice el operador SAME para buscar dos o más palabras que aparecen en la misma dirección.

\begin{tabular}{l}
\multicolumn{1}{c}{ Ejemplo } \\
Introduzca university penn* para \\
recuperar univ penn, la forma \\
abreviada de University of \\
Pennsylvania. \\
Introduzca university penn* SAME \\
anthro* para recuperar documentos \\
cuyos autores pertenecen al \\
Departamento de Antropología de \\
University of Pennsylvania
\end{tabular}

- Si el nombre tiene más de 15 caracteres, trunque después del quinceavo carácter. Deje un espacio después del apellido y luego ingrese la primera inicial y un asterisco.

Ejemplo: C.A. CHATZIDIMITRIOU-DREISMANN se truncaría de la siguiente manera: CHATZIDIMITRIOU* C*

\section{Autor Citado}

Web of Science Group captura el apellido y hasta 3 iniciales del primer autor listado en la cita. Utilice las reglas de autor listadas bajo Autor del Original. 


\section{Trabajo Citado}

Web of Science Group captura hasta 20 caracteres del trabajo citado.

- Para revistas, introduzca variaciones abreviadas de títulos de revistas.

- Para libros, introduzca la primera palabra o palabras significativas del título. Trunque para ver variaciones ortográficas. Los títulos de los trabajos citados pueden estar en un idioma diferente al inglés. Siempre trunque la última palabra del título de un libro.

- Para patentes, introduzca el número de la patente. No especifique ningún código de país.

\section{Regla}

1. Use comodines y caracteres de truncamiento en este campo. Ingrese múltiple títulos abreviados unidos por el operador OR.

\section{Ejemplo}

Introduzca j am chem soc* OR j amer chem soc* OR jacs* para recuperar artículos de Journal of the American Chemical Society.

\section{Año Citado}

Introduzca los cuatro dígitos de un año o una serie de años separados por el operador OR. Para patentes, utilice la fecha de emisión.

- Utilice un rango de años alrededor del año de publicación para tener en cuenta errores de citas.

Ejemplo: para un trabajo escrito en 1992, es recomendable introducer: 1992 OR 1991 OR 1993 


\section{Introducción a Incites Journal Citation Reports}

Incites Journal Citation Reports (JCR) es una base de datos que ofrece un amplio espectro de aplicaciones prácticas para los profesionales de la información. Presenta datos estadísticos que permiten una manera sistemática y objetiva de determinar la importancia relativa de revistas dentro de sus categorías temáticas.

\begin{tabular}{|l|c|c|} 
& $\begin{array}{c}\text { Edición de Ciencias } \\
(2017)\end{array}$ & $\begin{array}{c}\text { Edición de Ciencias } \\
\text { Sociales (2017) }\end{array}$ \\
\hline Frecuencia: & Anual & Anual \\
\hline Número de revistas cubiertas: & 9.015 & 3.312 \\
\hline Número de categorías (disciplinas) & 177 & 57 \\
\hline
\end{tabular}

\section{Usos de Incites JCR}

La información de JCR incluye el Factor de Impacto, Índice de Inmediatez e información sobre tendencia de citas y datos fuente. Los datos proporcionados por JCR tienen numerosas aplicaciones prácticas.

Profesionales de la - Manejar las colecciones de revistas. Constituye una herramienta de Información decisión para la inclusión y exclusión de revistas en las colecciones.

Editoriales - Determinar la influencia de revistas en el mercado

- Revisar las decisiones editoriales

Autores - Identificar las revistas de mayor influencia para decidir la publicación de artículos

- Confirmar el status de las revistas donde hayan publicado

Profesores y Estudiantes - Descubrir donde hallar la información actualizada en sus áreas de especialización

Analistas de Información - Rastrear las tendencias bibliométricas

- Estudiar los patrones de citación

Para más información sobre Incites JCR, visite la página Web:

https://clarivate.com/products/journal-citation-reports/ 


\section{Usos Principales de Journal Citation Reports}

\section{'Contar la historia de una revista y comparar su impacto con revistas en el mismo campo científico'}

- Necesitamos evidencia sobre el impacto de una revista para que se pueda tomar decisiones (decisiones de la valoración de la producion científica, decisiones de donde publicar, decisiones de suscripciones y colecciones de revistas)

- La JCR nos da la evidencia. Nosotros (investigadores, bibliotecarios, agencias de financiación, evaluadores) tomamos las decisiones

\section{¿Por qué es necesario evaluar revistas?}

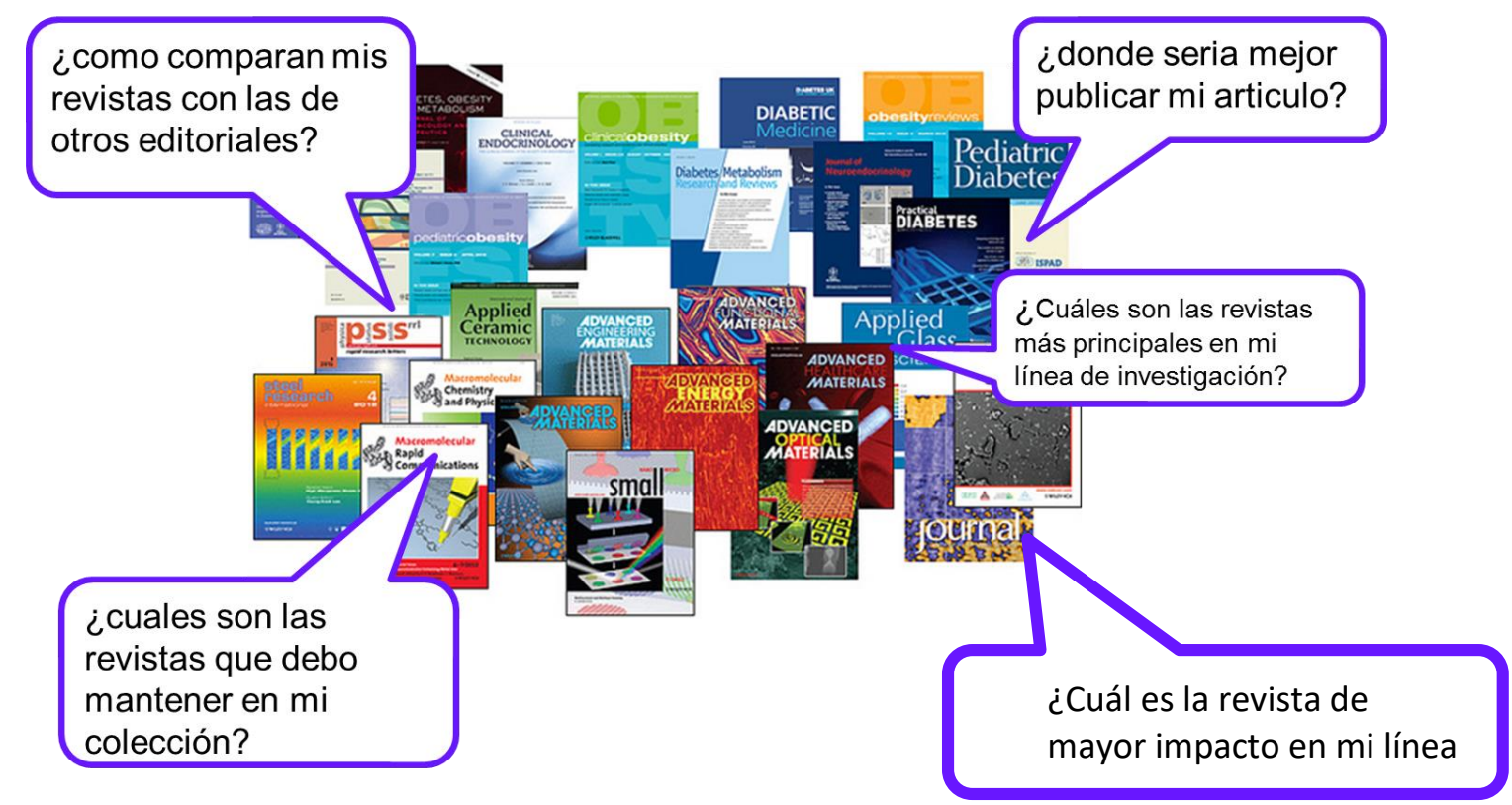

Grafica para ilustrar la evolución de JCR a lo largo de los años (de 1975 a 2018)

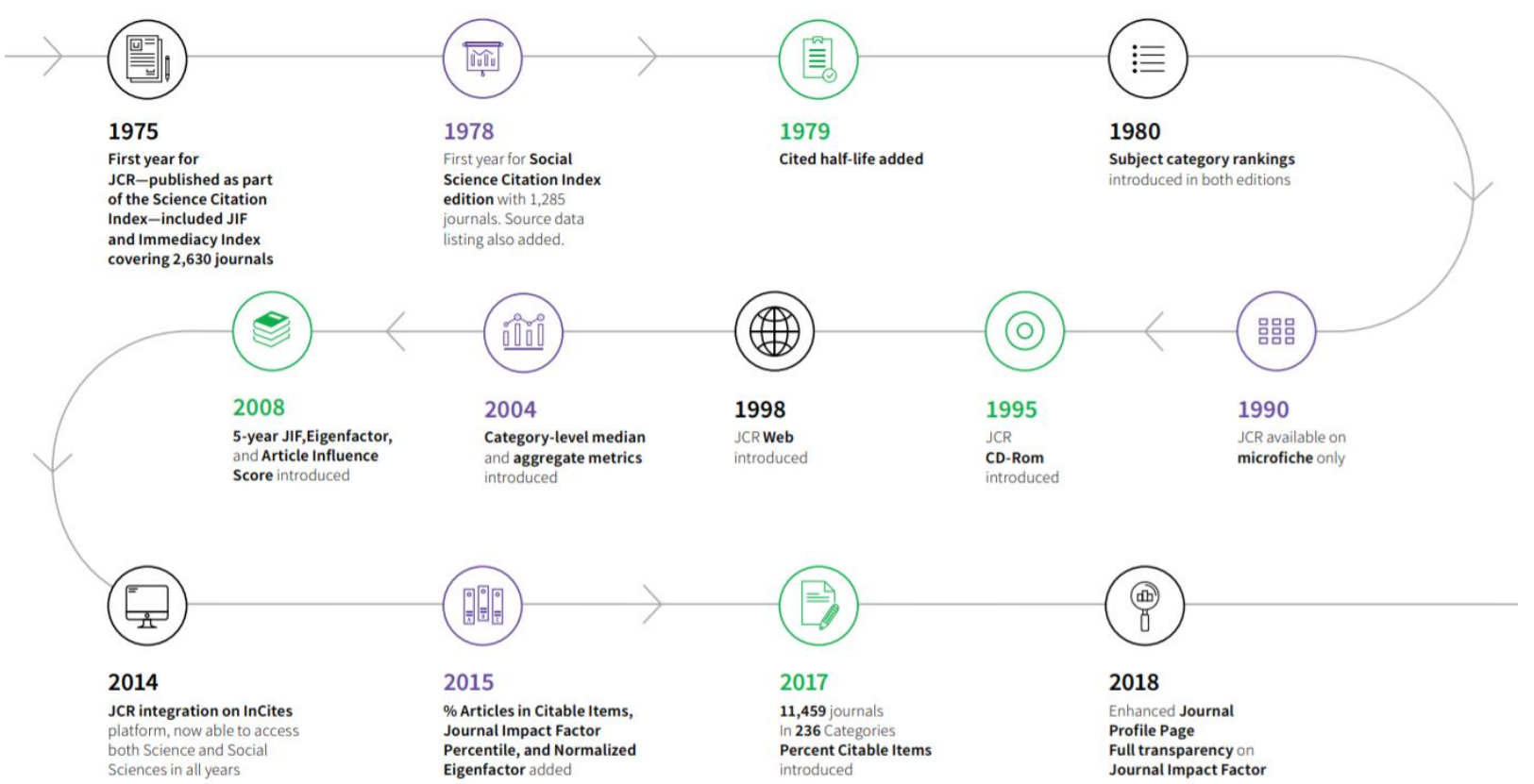




\section{Integración de Datos de Impacto de JCR en la Web of Science}

1. En la página de resultados. Haga clic sobre el título de una revista de la cual su título está en color azul (hiperenlace)

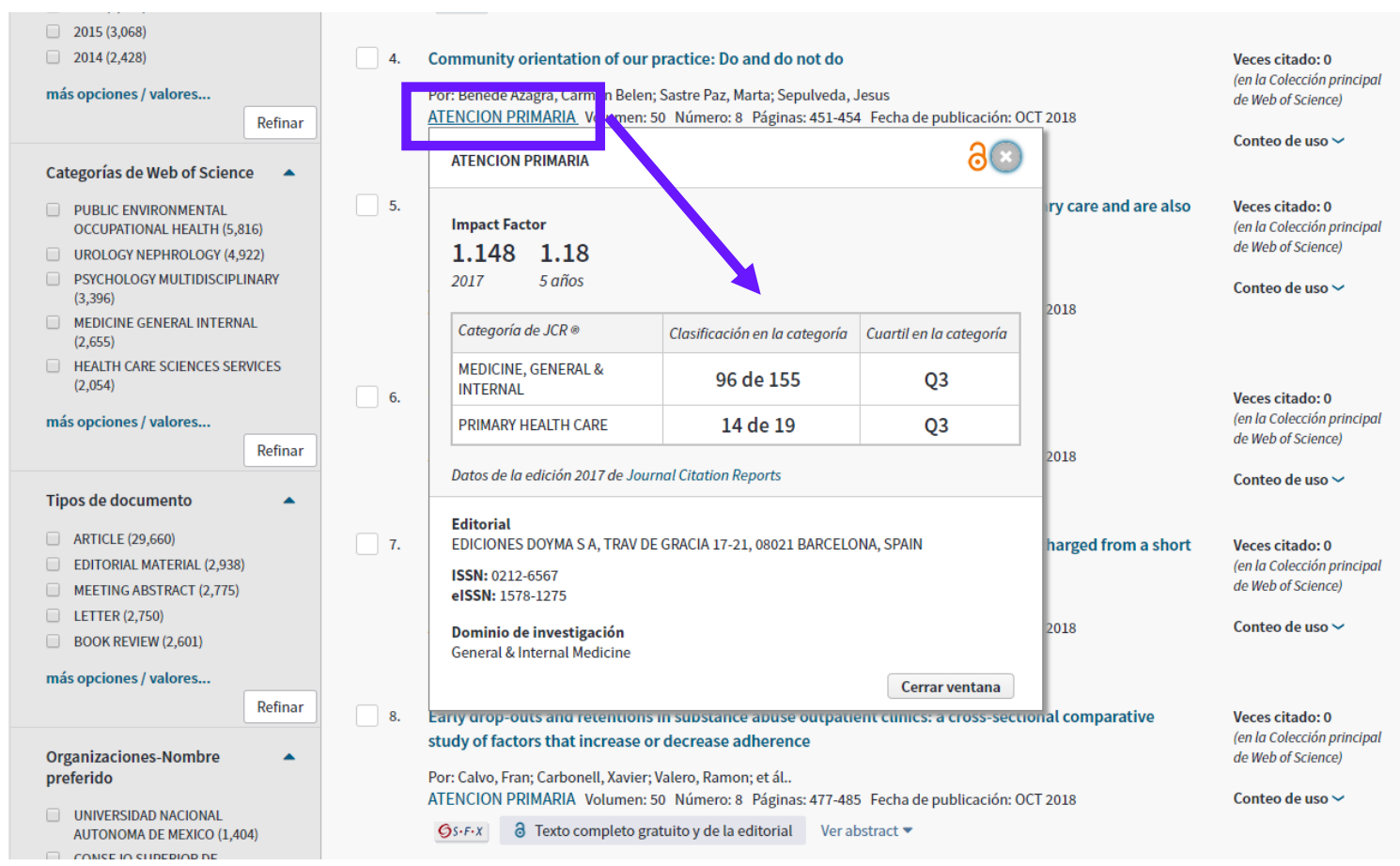

2. En un registro fuente. Haga clic sobre 'ver impacto de revista'

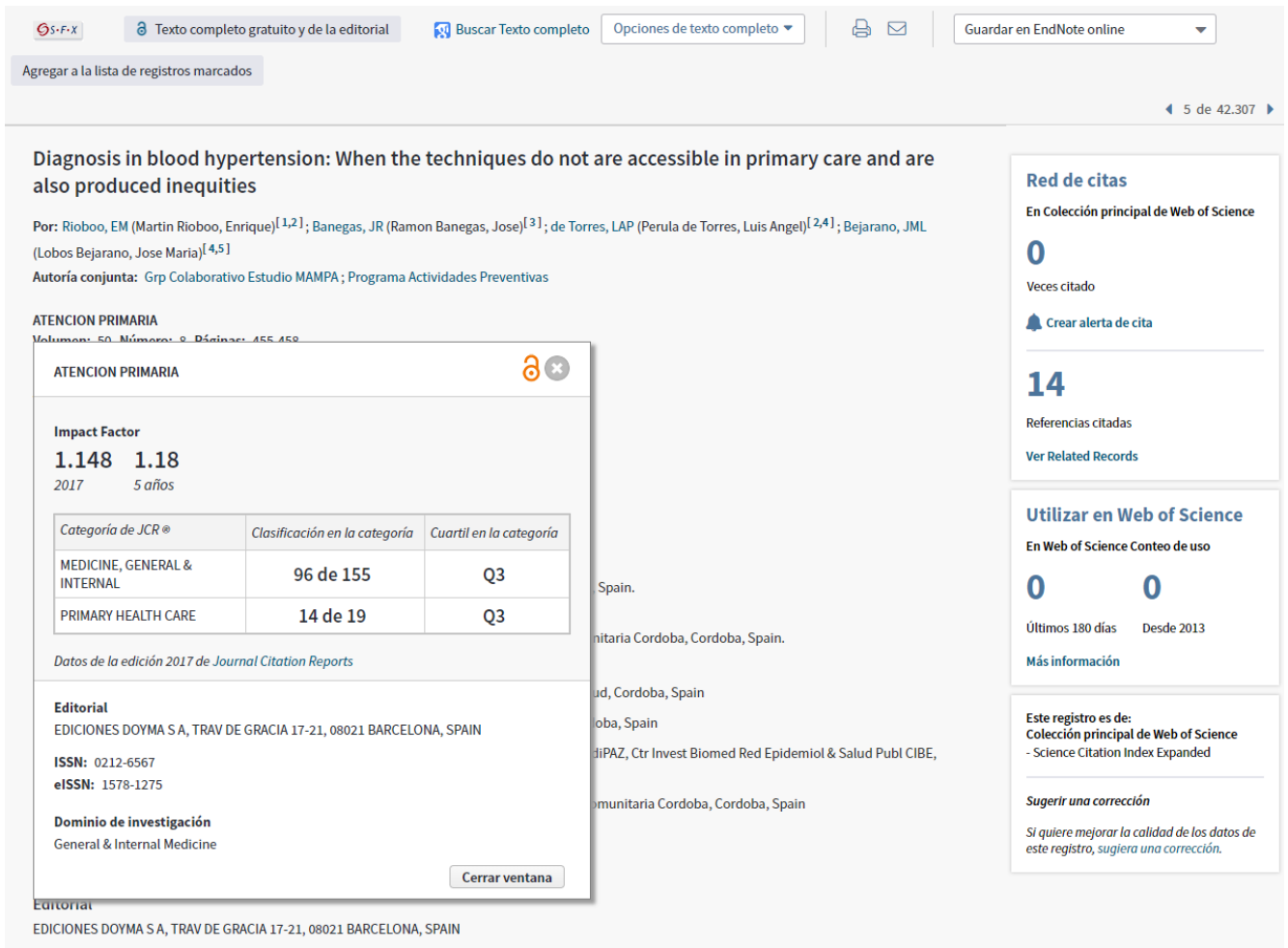


Página de Inicio Nueva de Incites JCR

$\leftarrow \rightarrow$ C $\quad$ A Not secure / jcr.incites.thomsonreuters.com/JCRLandingPageAction.actio

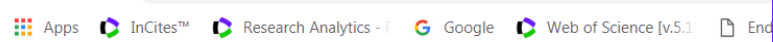

Welcome to Journal Citation Reports

Search a journal title or select an option to get started

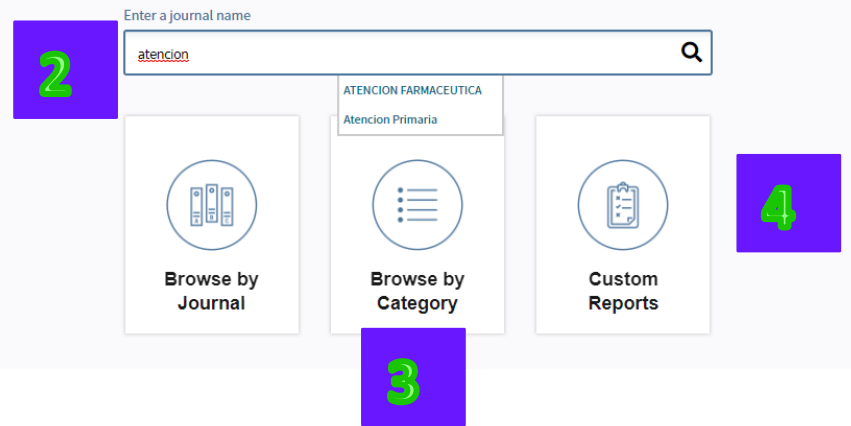

1. URL directo: $\underline{\text { http://icr.incites.thomsonreuters.com }}$

2. Busca una revista. Si figura en la lista de revistas de 2017 la página del perfil nuevo presentará. Si no está en 2017, la página antigua presentará.

3. Buscar categorías de las revistas

4. Vaya a sus informes guardados y sus listas personalizadas de revistas. Es necesario iniciar una sesión personalizada (Sign In) para acceder a información guardada. 


\section{Acceso a la Página Nueva del Perfil de una Revista}

1. Busca la revista en el campo de búsqueda por ejemplo 'Atención Primaria'

2. El sistema de auto sugerencia le presentara el nombre de la revista en el listado patrón de revistas. Hay que hacer clic sobre el nombre de la revista.

Welcome to Journal Citation Reports

Search a journal title or select an option to get started

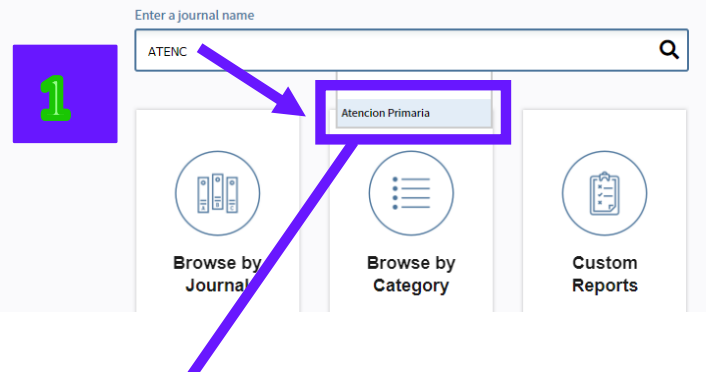

InCites Journal Citation Repor's

1 Clarivate Analytics

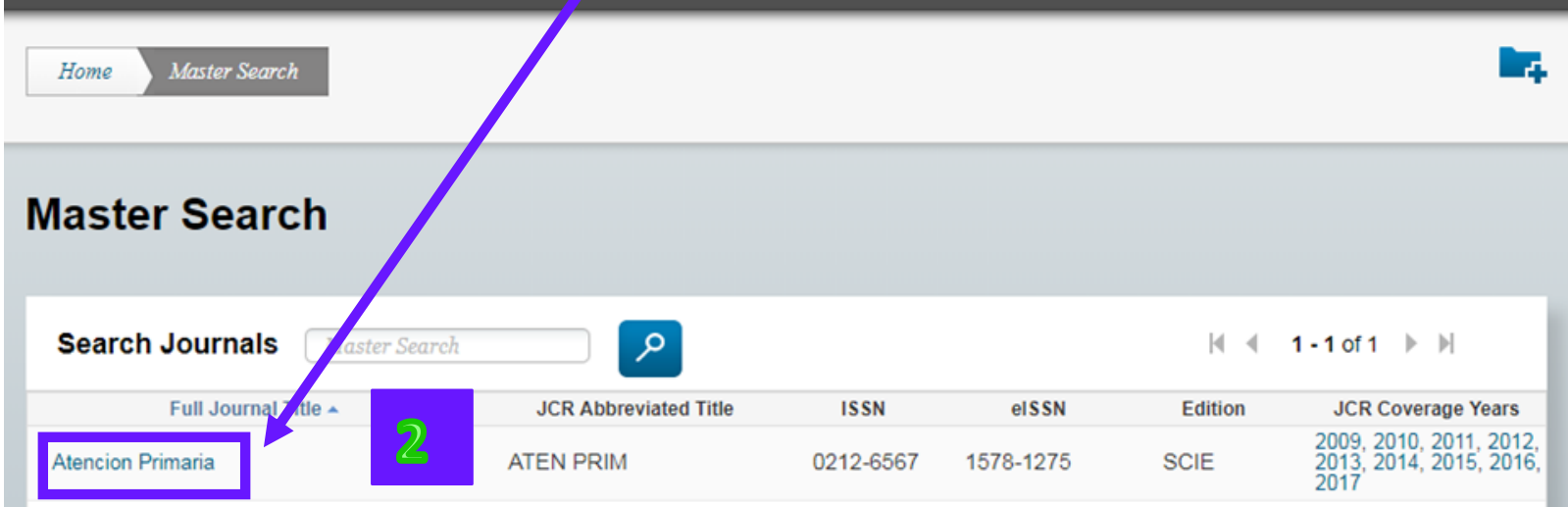


Página Nueva del Perfil de una Revista
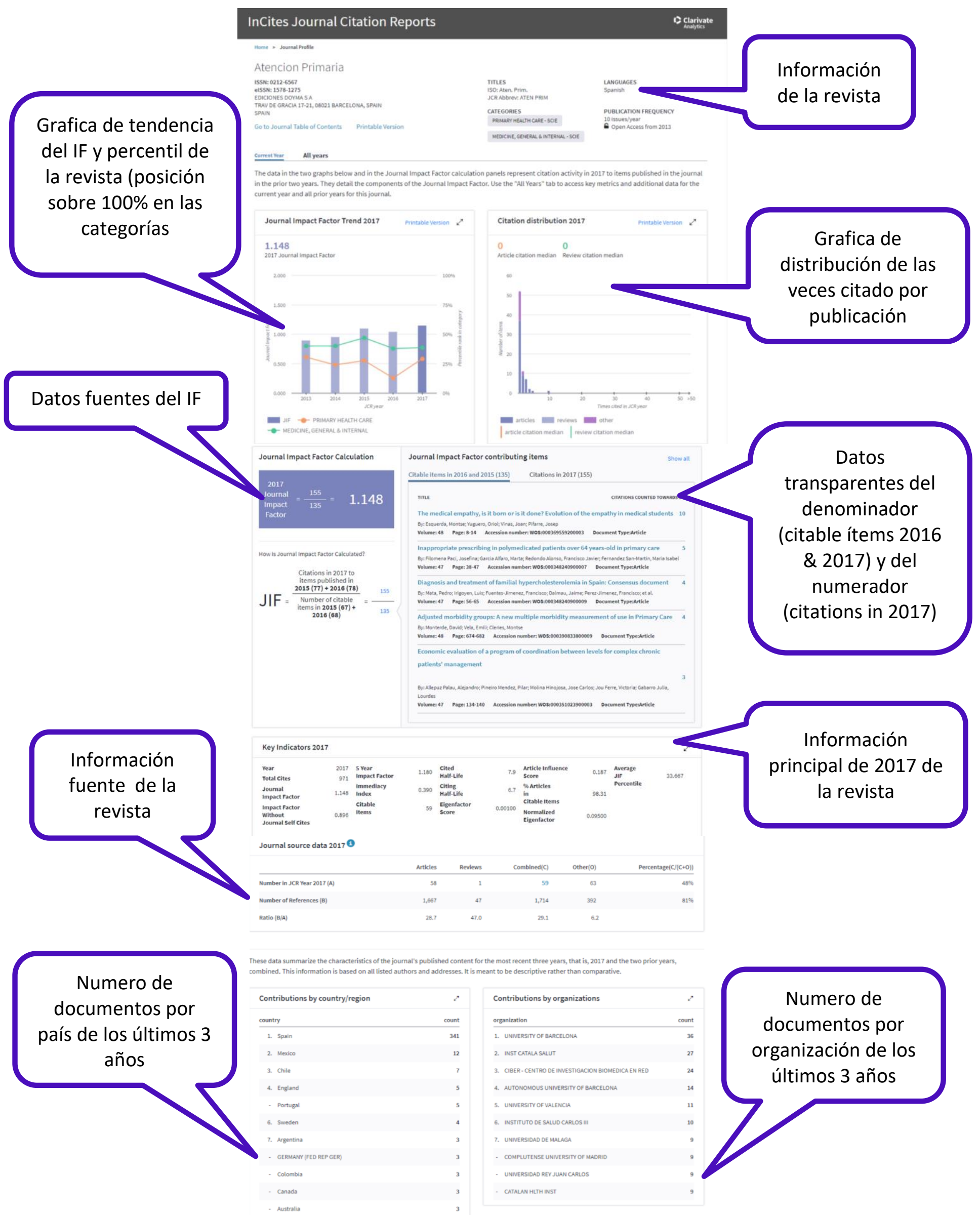


\section{Infografía de datos de Tendencia del Factor de Impacto}

Datos en la infografía:

1. El factor de impacto de 2017

2. Una gráfica de barras del FI de todos los años (índice del FI a mano izquierda)

3. Una gráfica de líneas que representa el percentil en categoría de la revista a lo largo de los años. (índice del percentil en categoría a mano derecha). La leyenda de las categorías se sitúa a mano derecha.
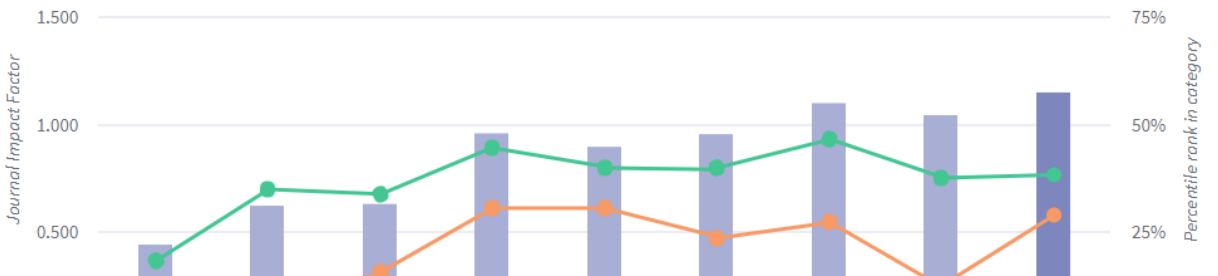

0.000

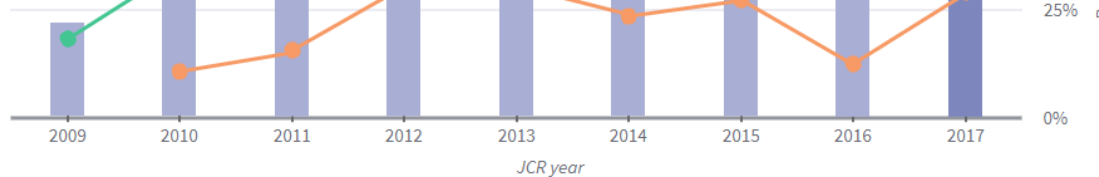

\section{Grafica de la distribución de las veces citado por publicación}

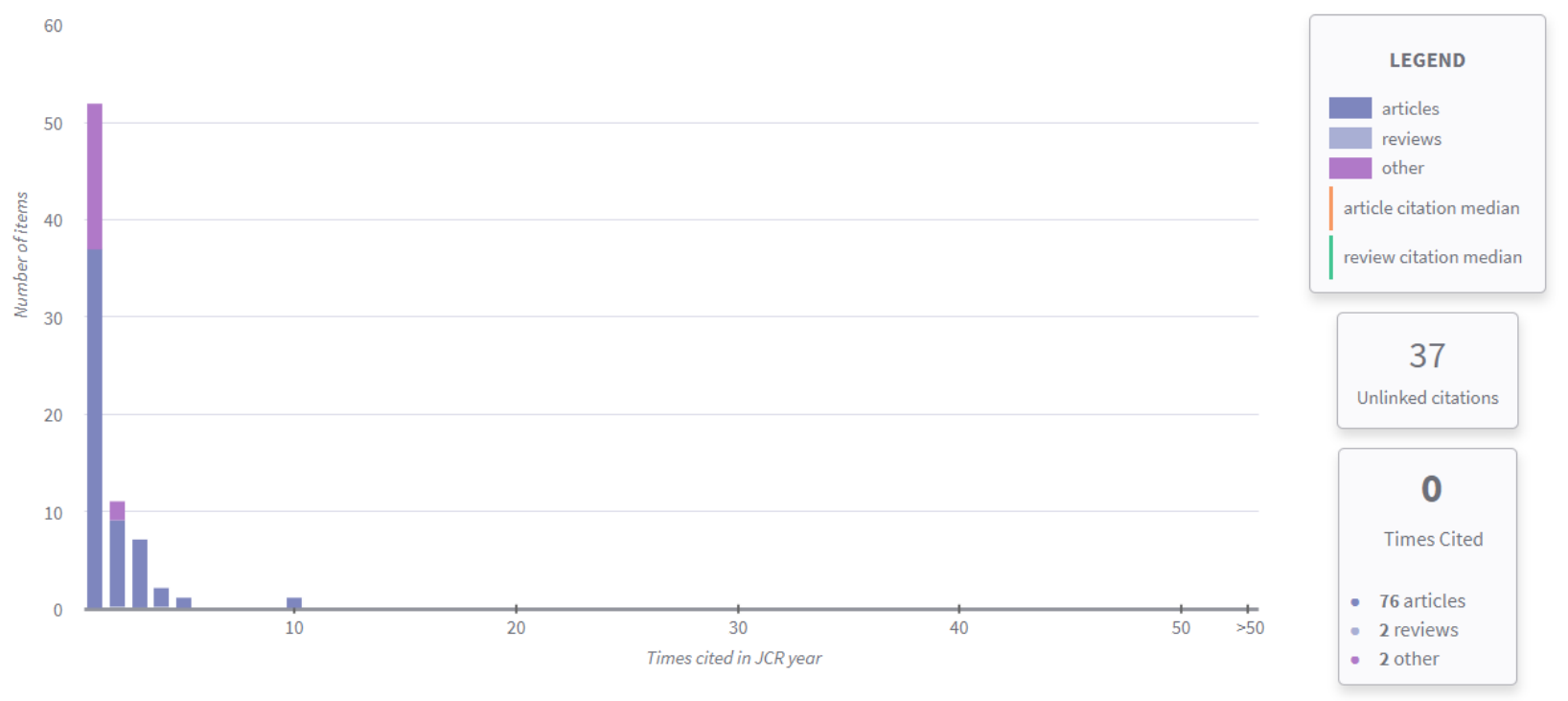


Datos incluidos en la gráfica:

1. La distribución de veces citado y el número y tipo de publicación con tal número de citas. Por ejemplo,

- un artículo recibió 10 veces citado

- nueve artículos y dos otros recibieron 2 veces citado

2. La mediana de las veces citado de los artículos (línea en color naranja)

3. La mediana de las veces citado de las revisiones (línea en color verde)

4. La leyenda de los tipos de publicaciones (artículo, revisión, otro)

5. El número de citas sin conexión a un registro fuente. Son referencias que citan a la revista (Atención Primaria, por ejemplo) pero debido a un motivo no ha sido posible vincular la referencia un registro fuente.

\section{El Factor de Impacto}
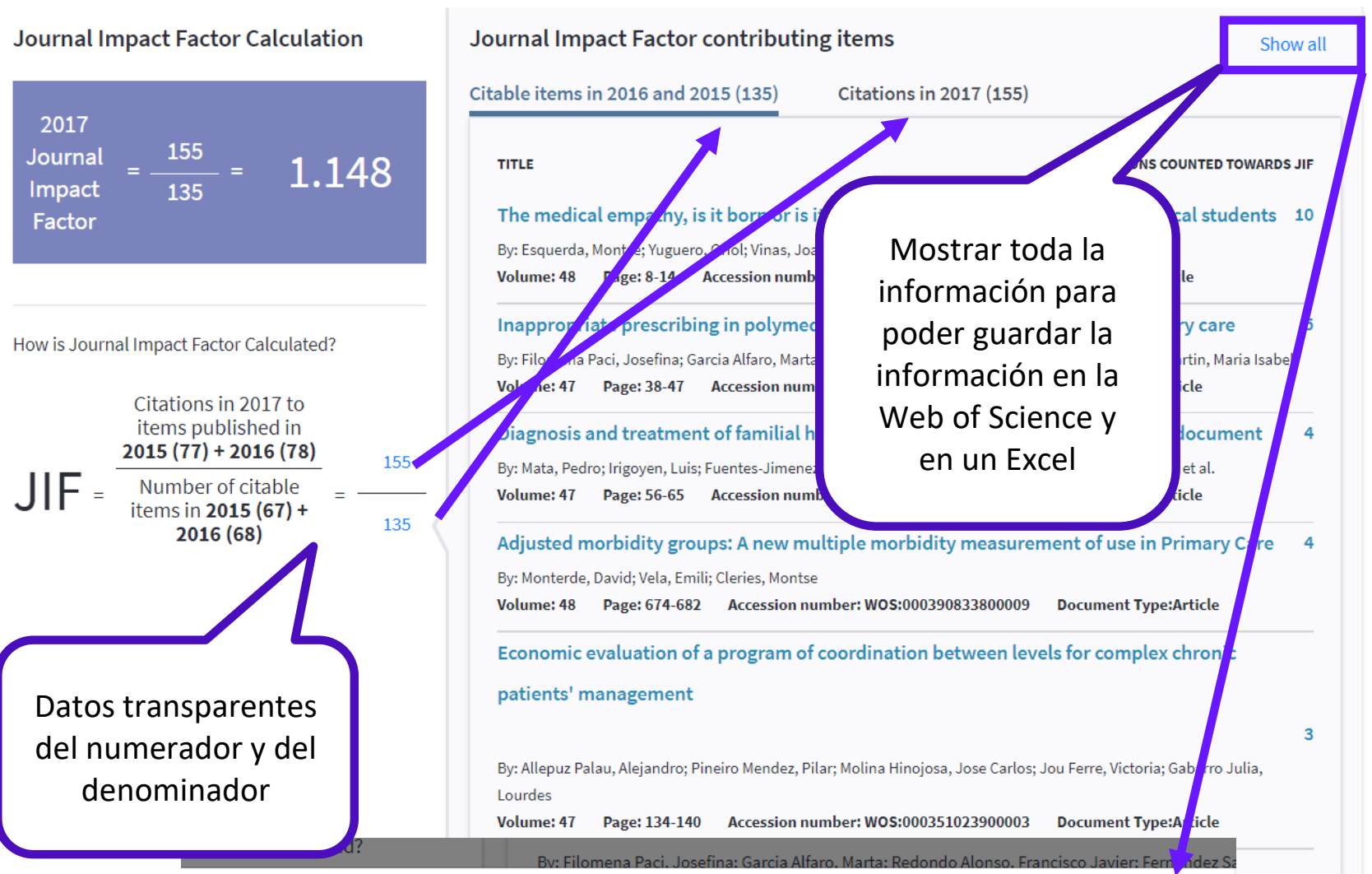

How is Journal Impact Factor Calculated?

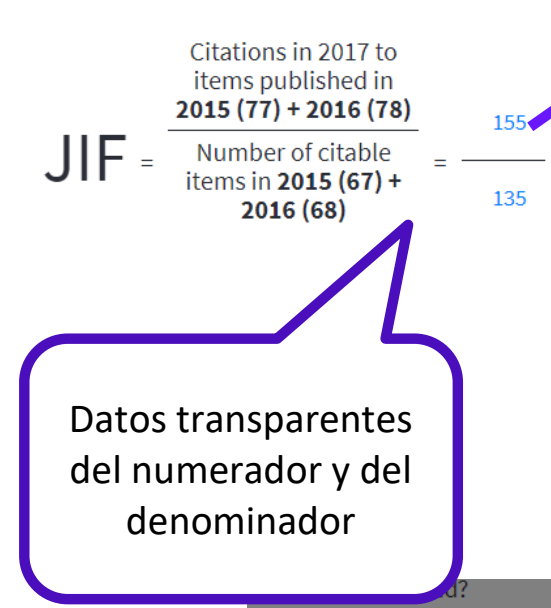

View in Web of Science Export

Showing 135 citable items in 2016 and 2015

CITATIONS COUNTED TOWARDS JIF

TITLE

By: Esquerda, Montse; Yuguero, Oriol; Vinas, Joan; Pifarre, Josep

Volume: 48 Page: 8-14 Accession number: wos:000369559200003 Document Type:Article

Inappropriate prescribing in polymedicated patients over 64 years-old in primary care

By: Filomena Paci, Josefina; Garcia Alfaro, Marta; Redondo Alonso, Francisco Javier; Fernandez San-Martin, Maria Isabel

Volume: 47 Page: 38-47 Accession number: WoS:000348240900007 Document Type:Article

Diagnosis and treatment of familial hypercholesterolemia in Spain: Consensus document 


\section{Ver información del Denominador del IF en la Web of Science Colección Principal}

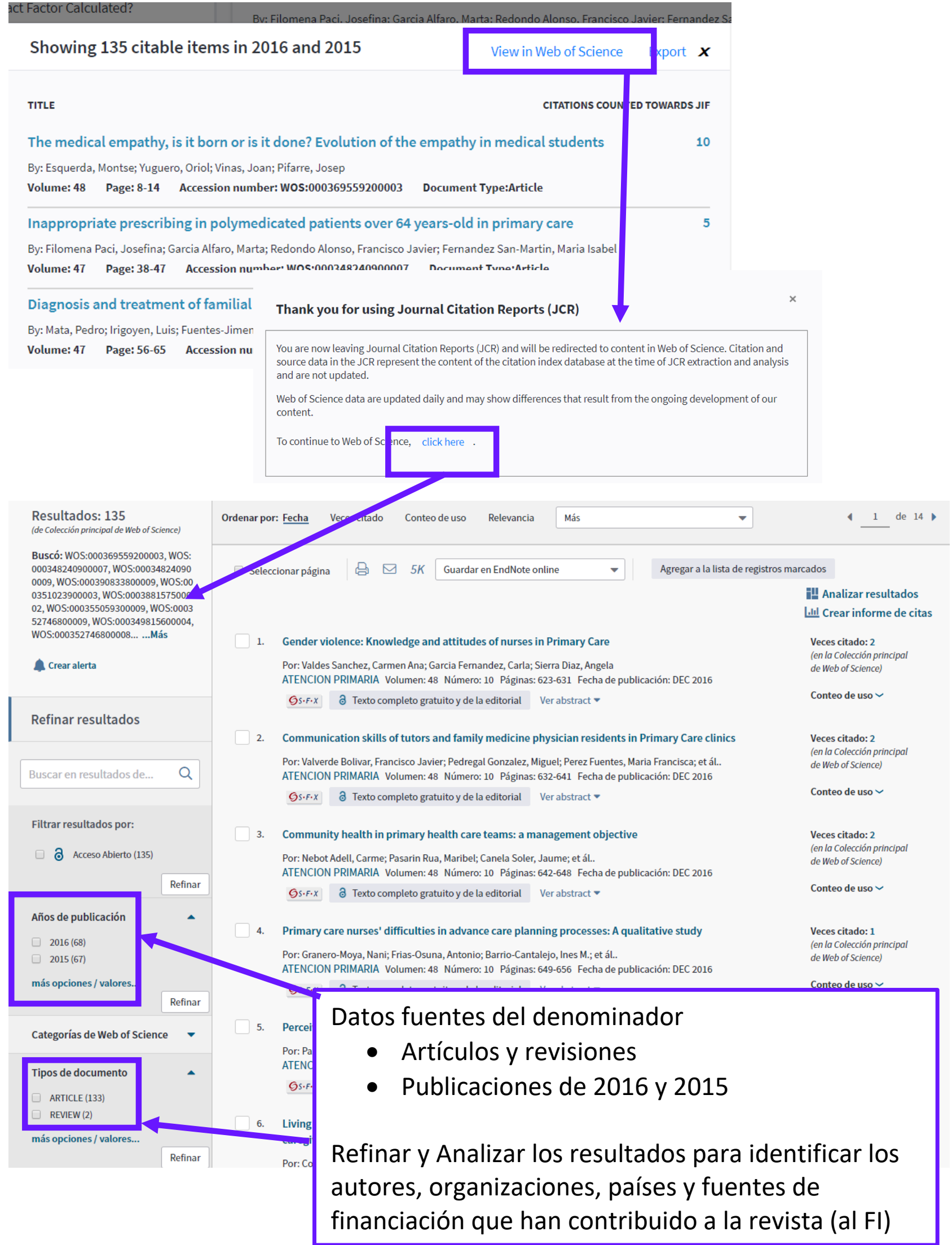




\section{Ver información del Numerador del IF en la Web of Science Colección Principal}

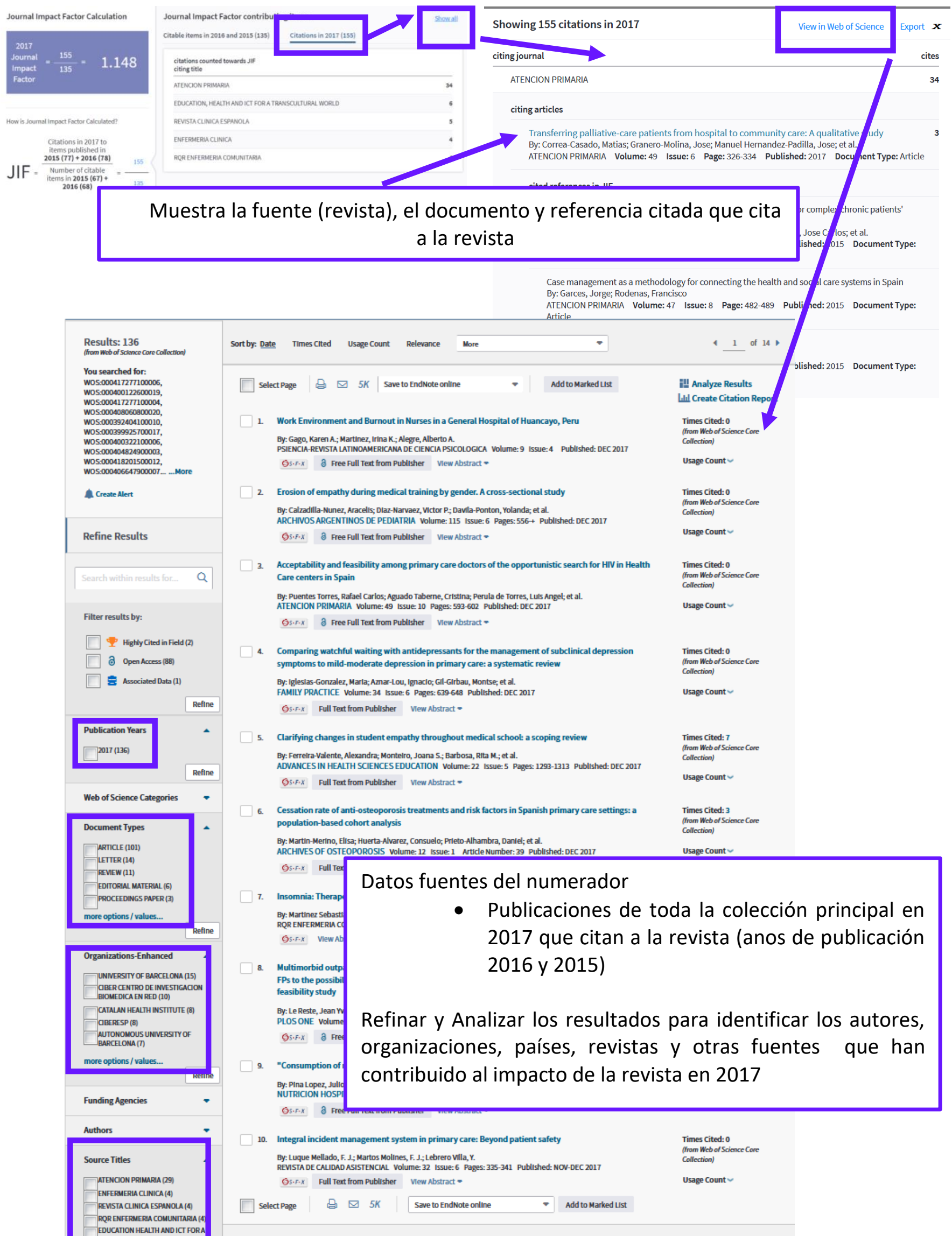


Guardar información a un fichero de cálculo (Excel)

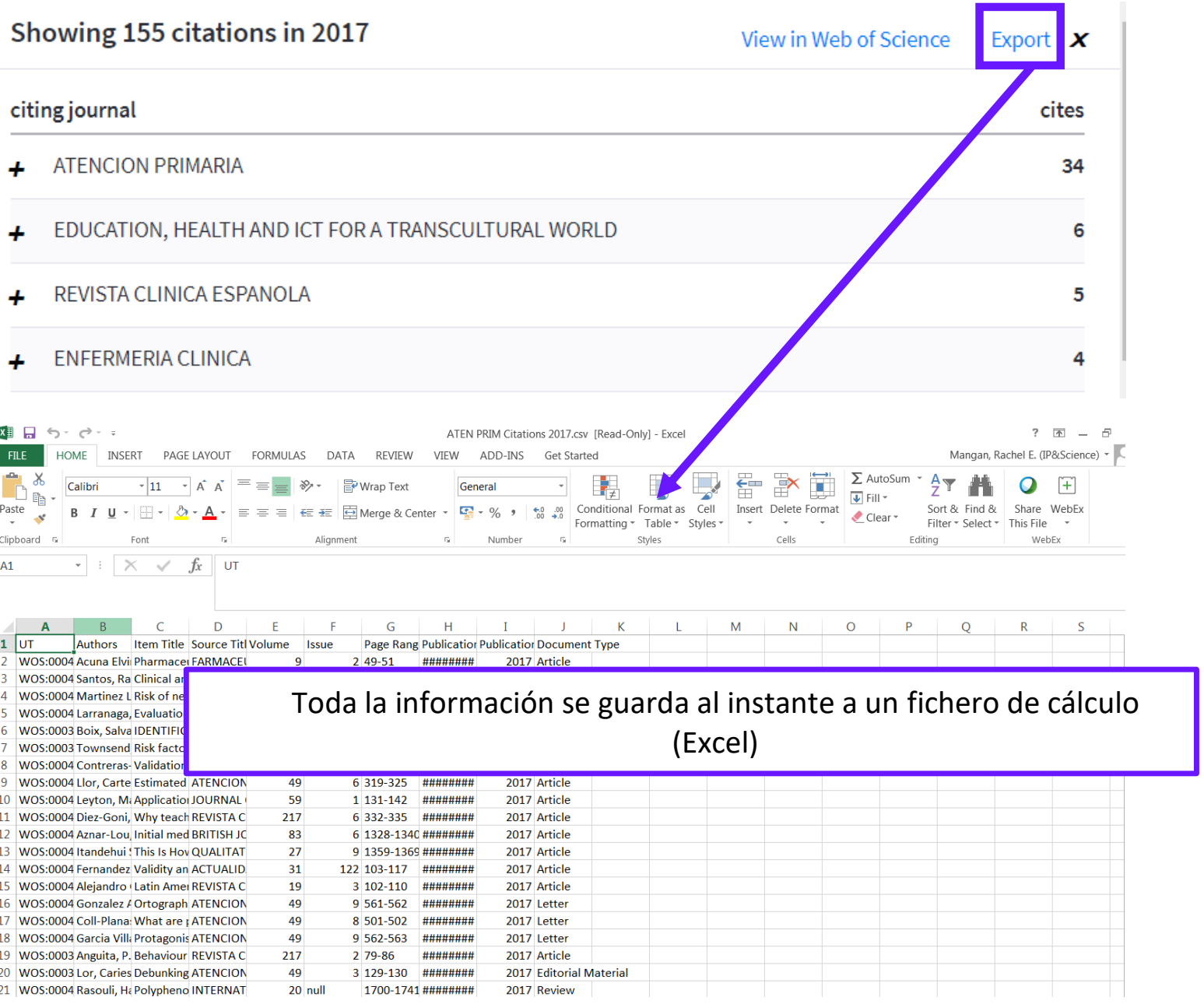

\section{Calculo del Factor de Impacto}

Journal Impact Factor Calculation

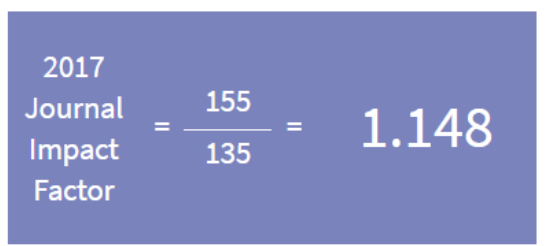

How is Journal Impact Factor Calculated?

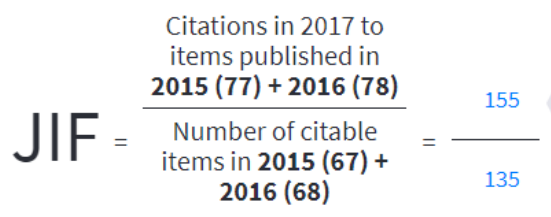

- El factor de impacto mide la frecuencia con la cual ha sido citado el "artículo promedio" de una revista en un año en particular.

- El factor de impacto de JCR se calcula dividiendo el número de citas actuales a todo tipo de publicación de los dos años anteriores (155 citas), por el número total de artículos y revisiones publicados en dicho período (135). 
El Factor de Impacto de 5 Años

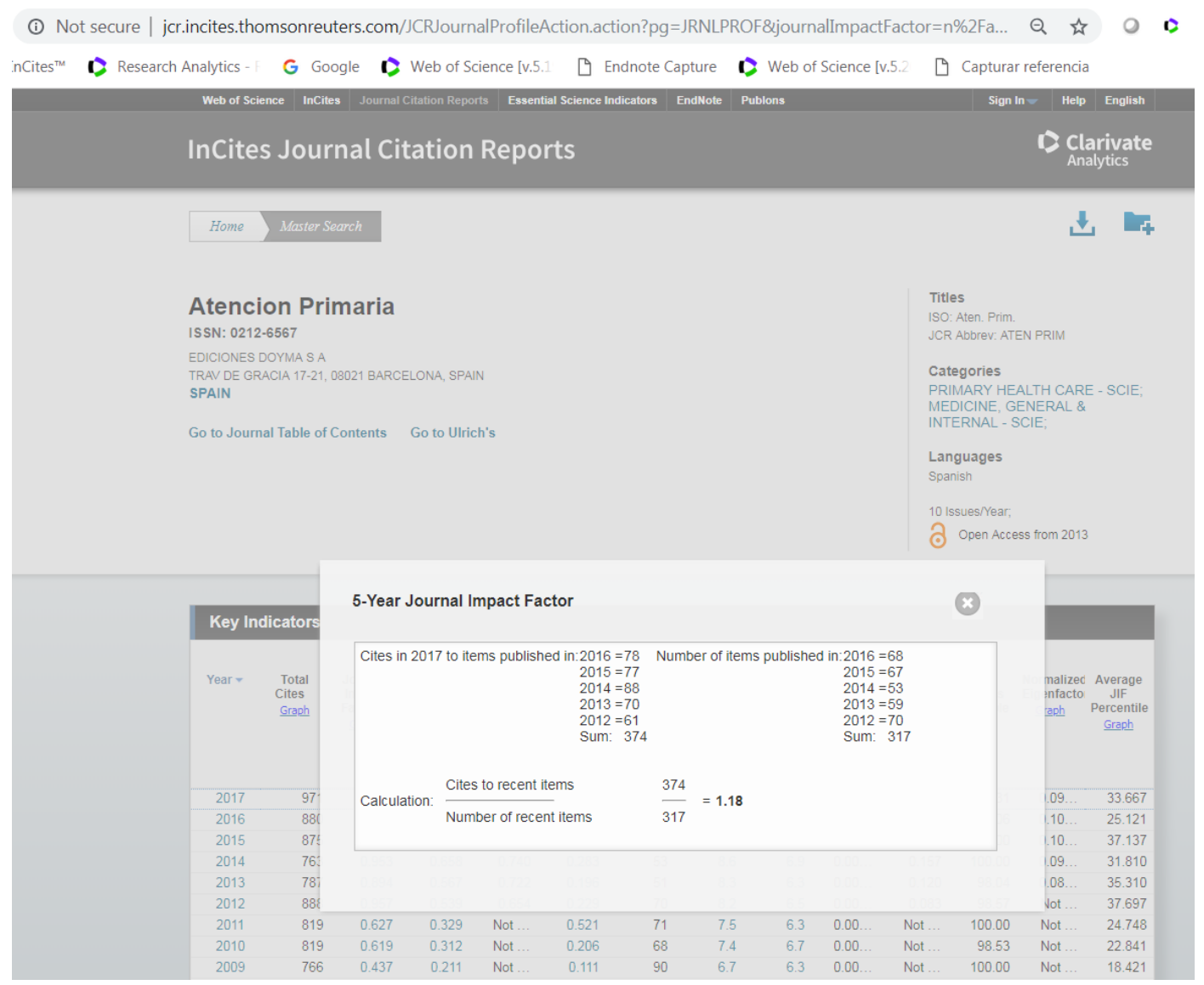

- Para evaluar mejor del impacto de revistas en campos determinados donde la influencia de la investigación publicada crece a lo largo de un tiempo más prolongado en comparación con los dos años del factor de impacto.

- El factor de impacto de cinco años se refiere a citas en el año actual a contenido publicado en revistas en los cinco años anteriores.

- El factor de impacto de 5 años se calcula dividiendo el número de citas actuales a artículos publicados en los cinco años anteriores (el numerador), por el número total de artículos y revisiones publicados en dicho período (el denominador).

- Según este ejemplo del JCR de 2017, la revista publicó 317 artículos en los cinco años anteriores. La revista recibió un total de 374 citas en el año 2017 a todo tipo de publicación de los últimos 5 años. Se divide el número total de citas en 2017 (374) por el número de artículos publicados en los 5 años anteriores (317) para llegar al factor de impacto de cinco años con un valor de 1.18. Se puede concluir que un artículo promedio publicado en cualquier de los 5 años anteriores ha recibido una media de 1.18 citas en el año 2017. 


\section{Auto Citas de la Revista}

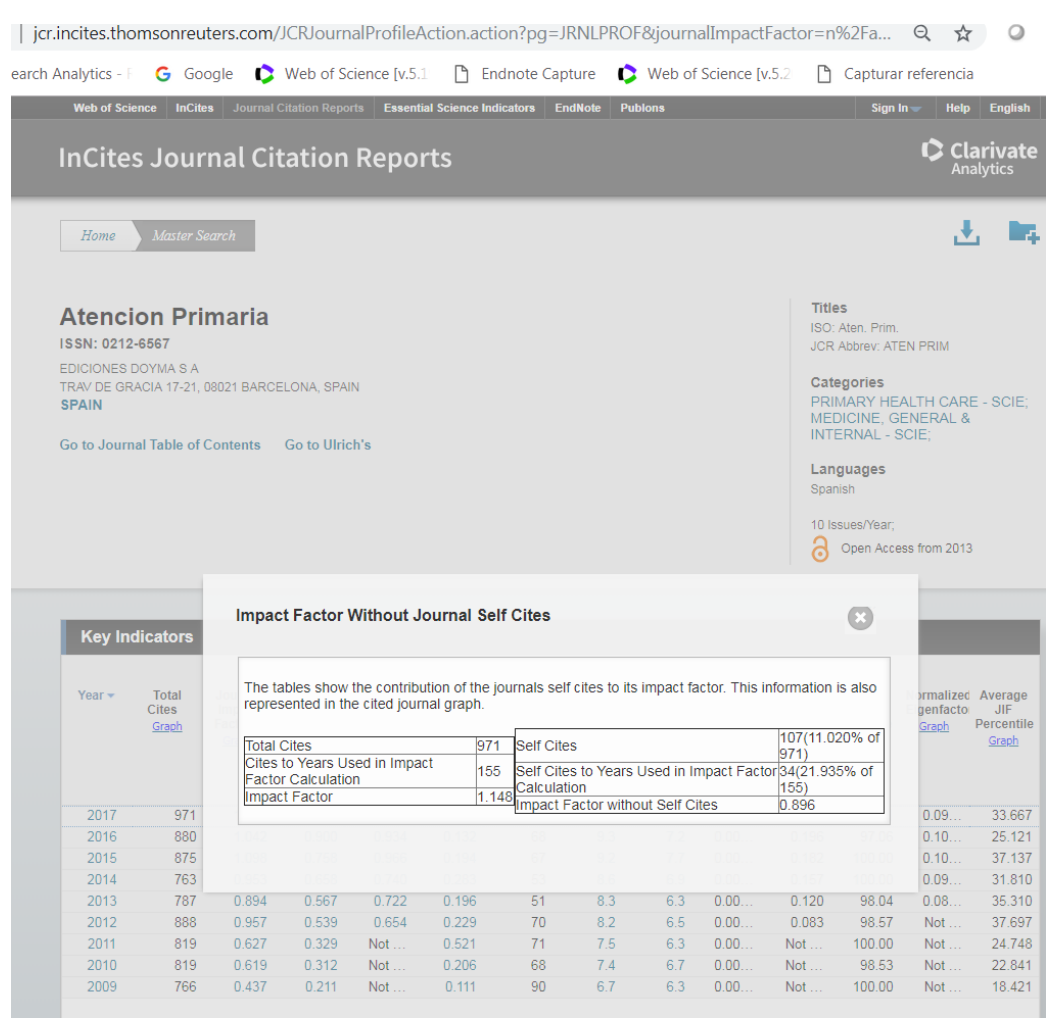

- Auto citas de las revistas- Las auto citas de las revistas no es una costumbre necesariamente negativa.

Los autores por supuesto citan investigación relacionada y ésta puede haber sido publicada en una revista en la que uno somete un trabajo para publicar.

$>$ Las revistas con un contenido especializado naturalmente exhiben niveles elevados de auto citas

- No obstante, $80 \%$ del total de las revistas incluidas en la edición de las ciencias de JCR tiene ritmos de auto citar inferior al 20\%. Basándose en las tendencias dentro de una categoría se puede formarse una idea de lo que puede ser un nivel elevado de auto citas y puede resultar en el debilitamiento de la integridad de una revista.

En el cuadro se puede ver:

1. Total de citas

2. Número de citas en el periodo considerado para calcular el factor de impacto

3. Factor de impacto de la revista

4. Total de Auto citas y por \% (Atención Primaria cita a Atención Primaria)

5. Número de auto citas en el periodo considerado para calcular el factor de impacto (total de citas y por \%)

6. Factor de impacto recalculado eliminando las auto citas 
Índice de Inmediatez

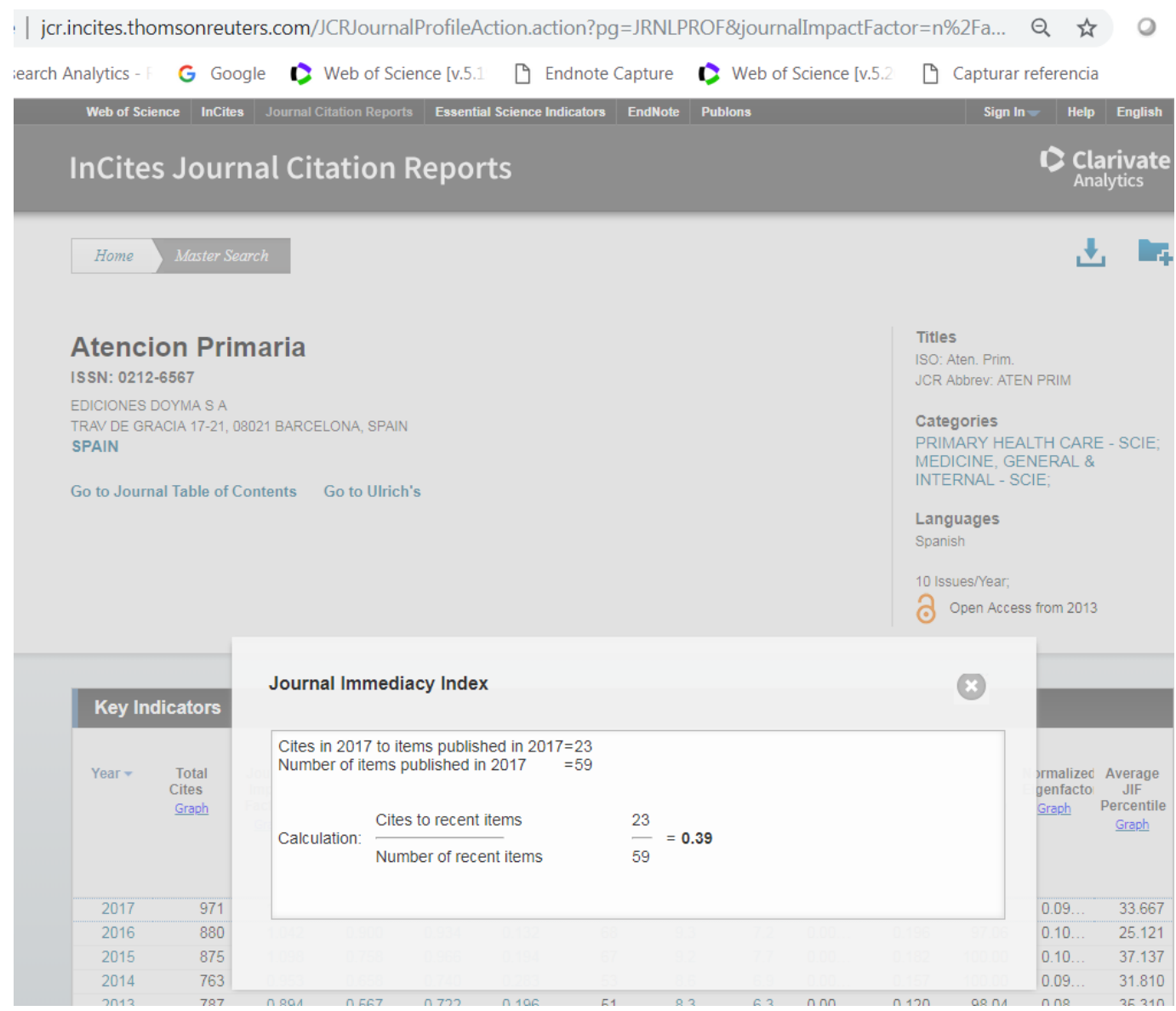

- El Índice de Inmediatez mide la rapidez con la cual es citado el "artículo promedio" de una revista. El Índice de Inmediatez le dirá con qué frecuencia los artículos publicados en una revista son citados en el mismo año.

- El Índice de Inmediatez se calcula dividiendo el número de citaciones a artículos publicados en un año dado, por el número de artículos publicados en ese mismo año.

\section{Suspensión de Revistas de JCR}

El equipo editorial de JCR evalúa todas las revistas cada año y suspendan revistas por dos motivos:

- \% muy alto de auto citas

- Citation Stacking (dos revistas colaboran de forma intencional para aumentar sus factores de impacto)

Vaya a la noticia en el archivo de soporte y consulte el listado de las revistas suspendidas y los datos que detallan de porque suspendan las revistas.

La suspensión de una revista significa que no recibe un factor de impacto. No significa que la revista ha sido eliminada de la WOS CC. La revista puede volver a recibir un factor de impacto en años posteriores si la revista resuelva la situación.

http://ipscience-help.thomsonreuters.com/incitesLiveJCR/JCRGroup/titleSuppressions.html 


\section{Evaluar Revistas en una Categoría}

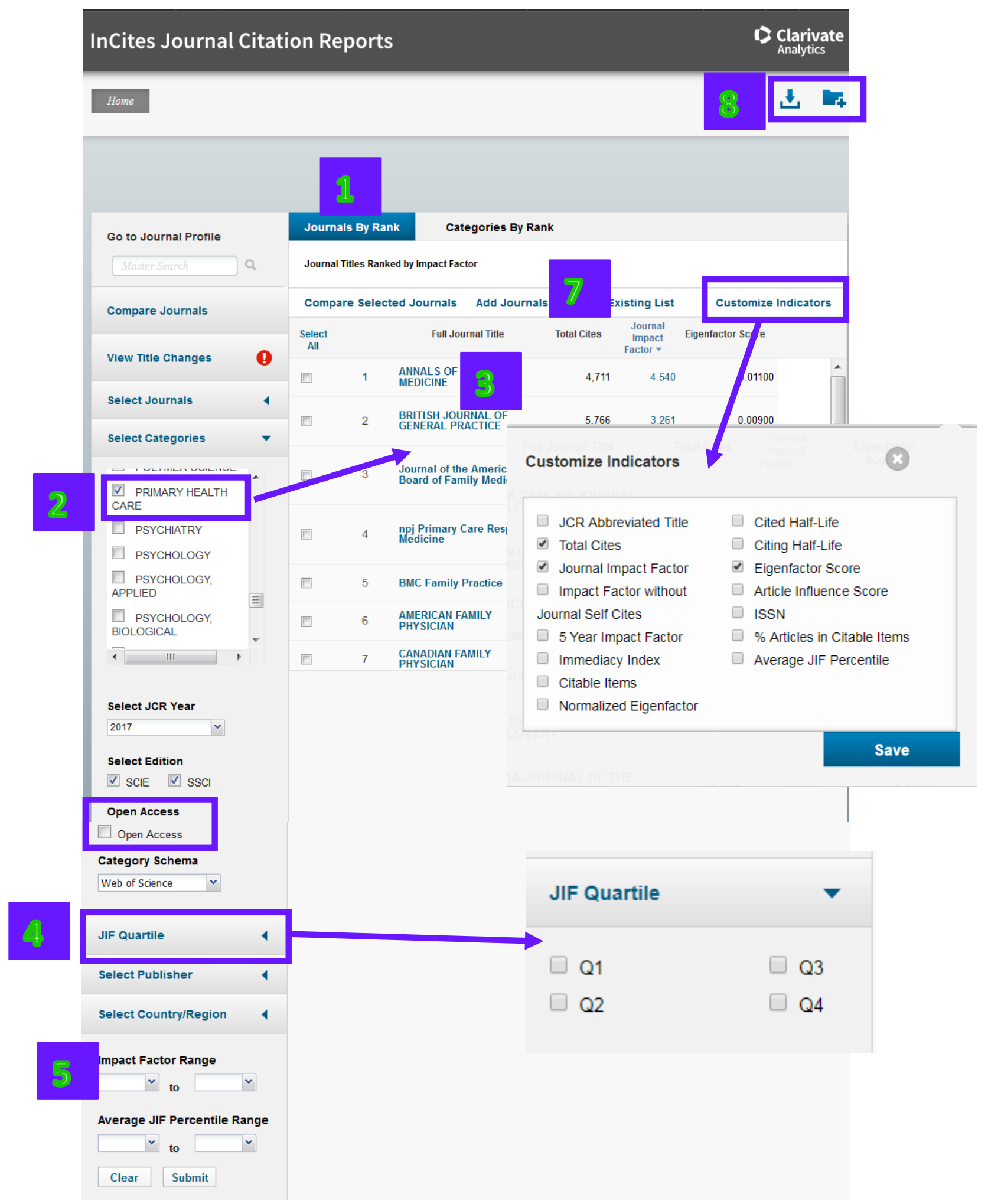

1. Selecciona 'Journals by Rank'.

2. Selecciona 'Select Categories'. La lista de categorías de JCR abra en una nueva casilla. Usando las casillas de verificación, selecciona la categoría de interés. La lista resumen de revistas actualiza para coincidir con la categoría seleccionada. Haga clic en 'Submit' para incorporar los cambios. 
3. Las revistas ordenan de manera automática por el factor de impacto, de lo más alto a lo más bajo.

4. Limita las revistas según el cuartil.

5. Limita las revistas que tienen un factor de impacto mínimo o máximo.

6. Para visualizar otros indicadores ofrecidos por JCR haga clic en 'Customize Indicatros' y selecciona los indicadores de interés.

7. Para cambiar el orden de las revistas, haga clic sobre el encabezamiento del indicador de interés.

8. Descargar y guardar datos. 


\section{Personalizar la Lista Resumen}

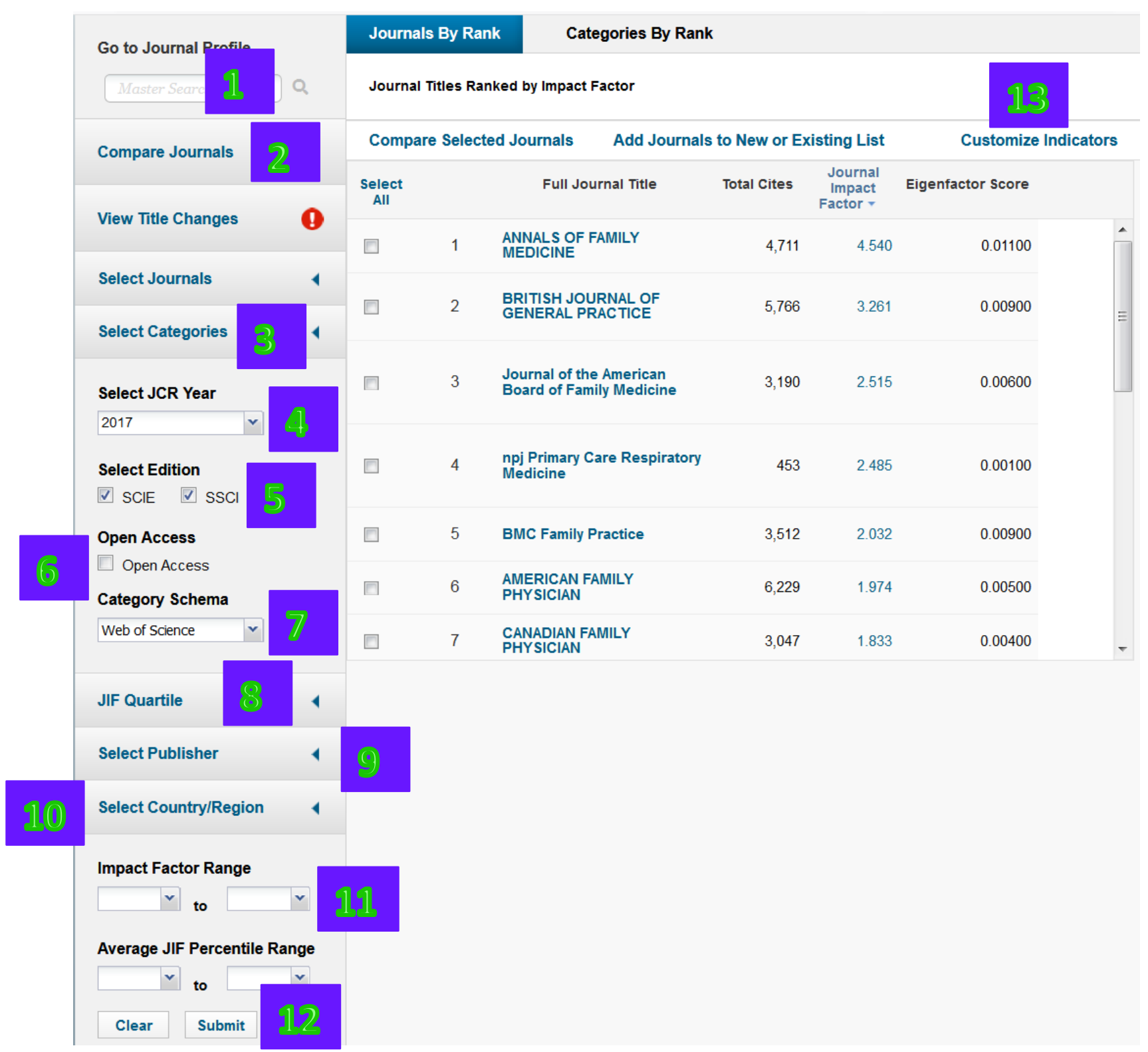

1. Buscar revistas individuales e ir a su perfil.

2. Puede comparar revistas y realizar un análisis sobre revistas de interés.

3. Evalúa revistas según una categoría preferida.

4. Selecciona el año de JCR (desde 1997 al 2017).

5. Limitar las revistas por edición de JCR (Ciencias o Ciencias Sociales).

6. Limitar las revistas por acceso abierto.

7. Selecciona la clasificación (por categorías de Web of Science o por los 22 campos de investigación de Essential Science Indicators).

8. Limitar las revistas por los cuartiles.

9. Limitar las revistas por un editorial de interés. Busca y selecciona el editorial en el índice.

10. Limitar las revistas por un país de la editorial. Selecciona el país en el índice. 
11. Introduce un valor mínimo o máximo del factor de impacto o del Average JIF Percentile (por ejemplo; quiero ver revistas que se situan en el primer $10 \%$ de su campo científico).

12. Haga clic en 'Submit' para realizar la personalización.

13. Haga clic en 'Customize Indicators' para seleccionar los indicadores. 


\section{Perfil Antigua de una Revista}

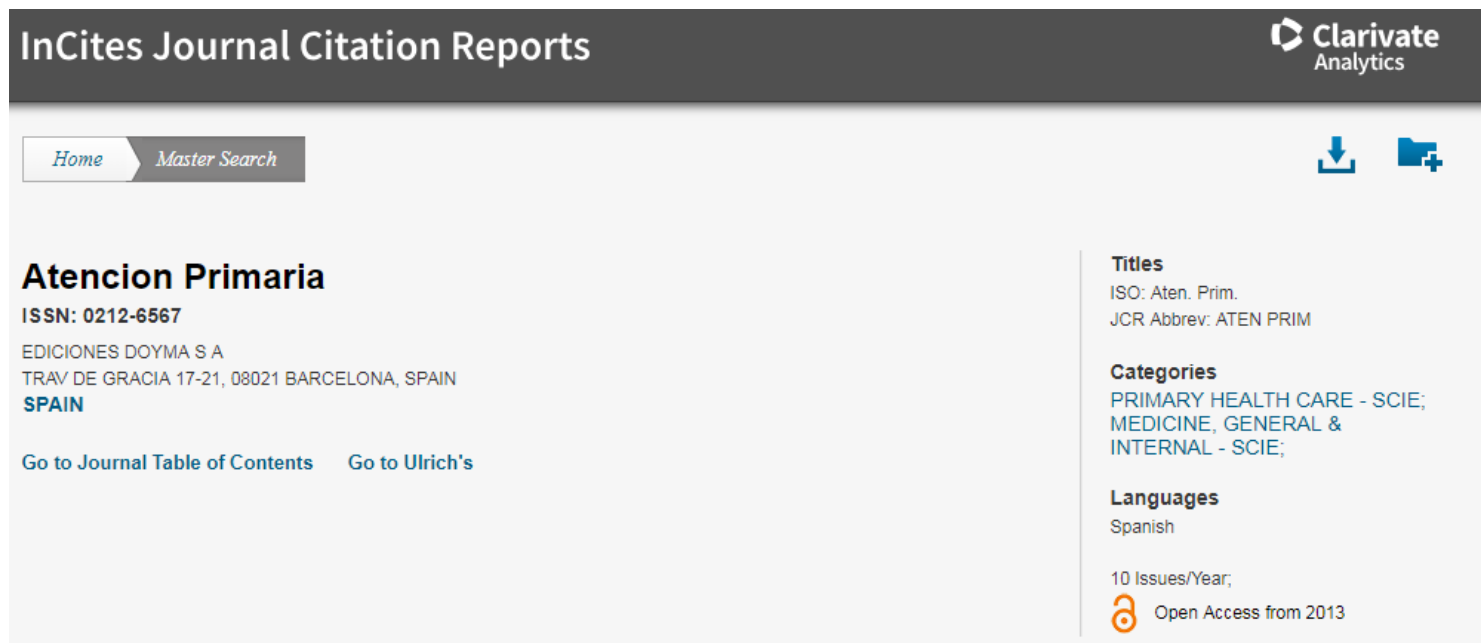

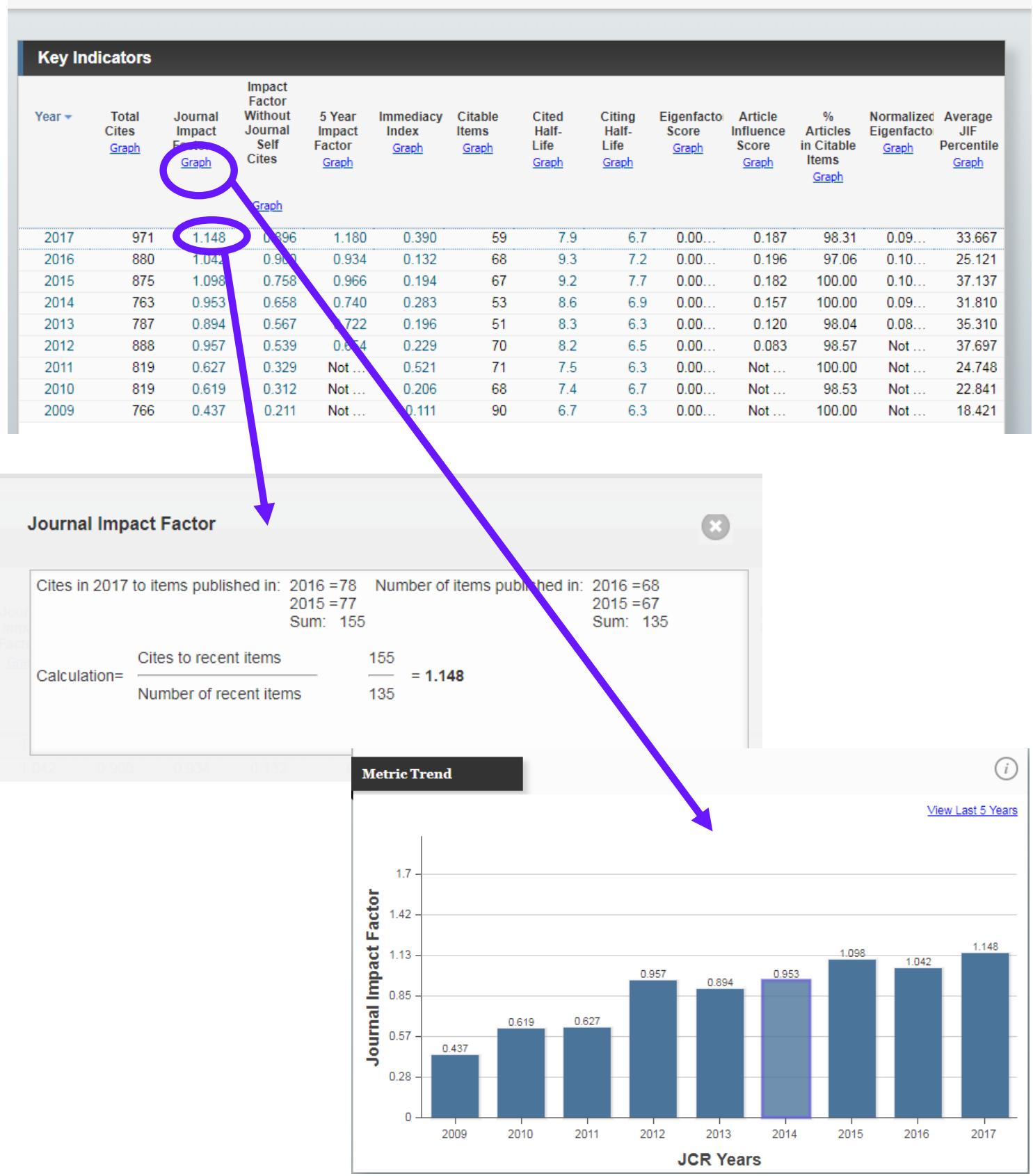




\section{Ranking de una Revista}

\begin{tabular}{|c|c|c|c|c|c|c|c|}
\hline \multicolumn{8}{|c|}{ JCR Impact Factor } \\
\hline \multirow{4}{*}{ Cited Joumal Data } & \multirow{2}{*}{$\begin{array}{c}\text { JCR } \\
\text { Year - }\end{array}$} & \multicolumn{3}{|c|}{ PRIMARY HEALTH CARE } & \multicolumn{3}{|c|}{ MEDICINE, GENERAL \& INTERNAL } \\
\hline & & Rank & Quartile & JIF Percentile & Rank & Quartile & JIF Percentile \\
\hline & 2017 & $14 / 19$ & Q3 & 28.947 & $96 / 155$ & Q3 & 38.387 \\
\hline & 2016 & $18 / 20$ & Q4 & 12.500 & $97 / 155$ & Q3 & 37.742 \\
\hline \multirow{2}{*}{ Citing Journal Data } & 2015 & $15 / 20$ & Q3 & 27.500 & $83 / 155$ & Q3 & 46.774 \\
\hline & 2014 & $15 / 19$ & Q4 & 23.684 & $93 / 154$ & Q3 & 39.935 \\
\hline \multirow{2}{*}{ Box Plot } & 2013 & $13 / 18$ & Q3 & 30.556 & $94 / 156$ & Q3 & 40.064 \\
\hline & 2012 & $13 / 18$ & Q3 & 30.556 & $86 / 155$ & Q3 & 44.839 \\
\hline \multirow{3}{*}{ Journal Relationships } & 2011 & $14 / 16$ & Q4 & 15.625 & $103 / 155$ & Q3 & 33.871 \\
\hline & 2010 & $13 / 14$ & Q4 & 10.714 & $100 / 153$ & Q3 & 34.967 \\
\hline & 2009 & NA & undefined & & $109 / 133$ & Q4 & 18.421 \\
\hline
\end{tabular}

Haga clic sobre 'Rank' para presentar:

$>$ los cuartiles de la revista por año y por categoría

$>$ el JIF Percentile por año y por categoría. (Posición de la revista sobre 100\%)

\section{Journal Relationships}

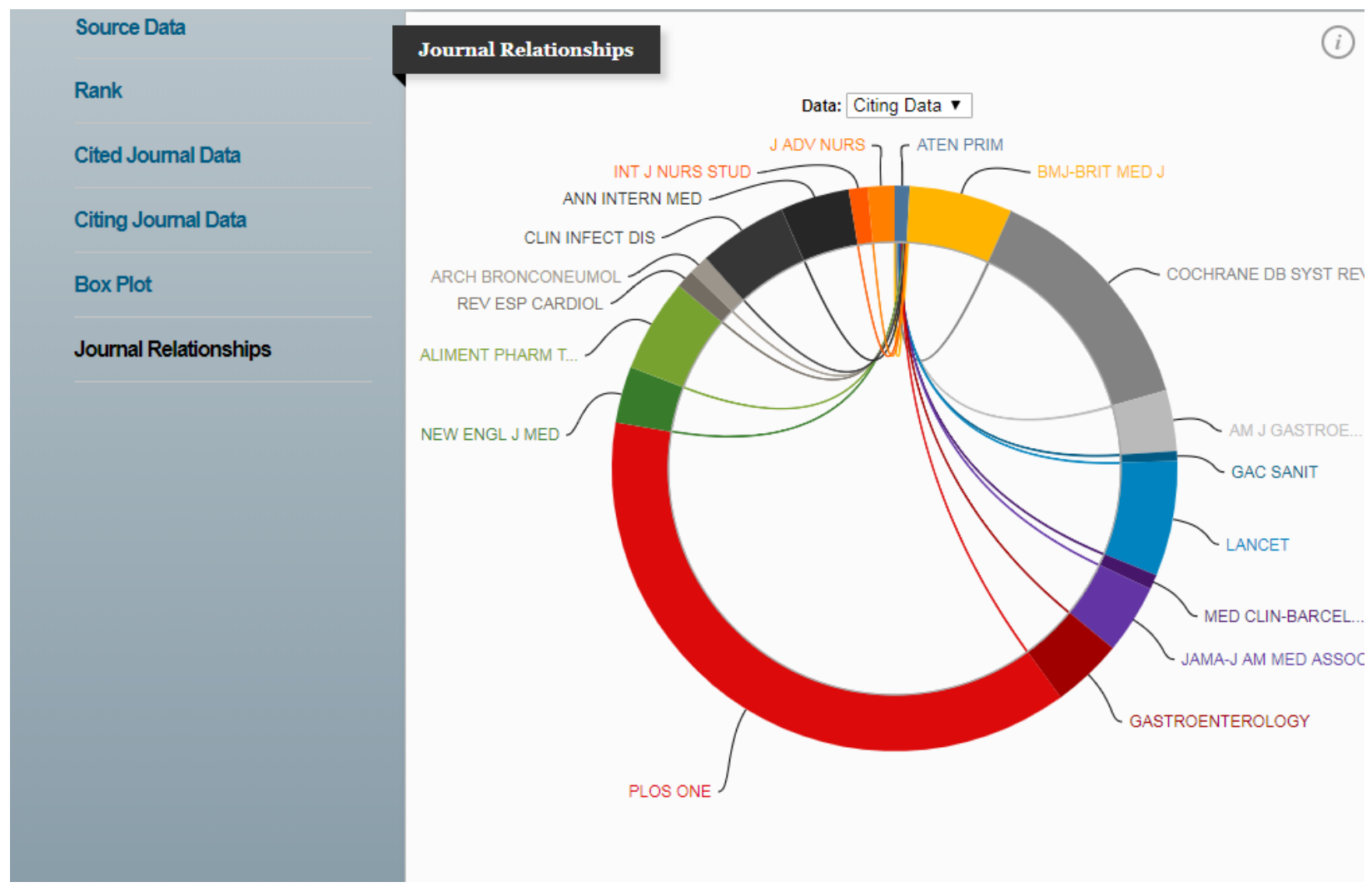

La visualización ilustra la relación entre las principales revistas que citan a la revista seleccionada (cited data) o son las principales revistas citas por la revista seleccionada (citing data). 


\section{La Vida Media de Citas Recibidas (Cited Half-Life Data)}

¿Las publicaciones citas en esta revista por los registros de 2017 son de años recientes o son de años más anteriores?

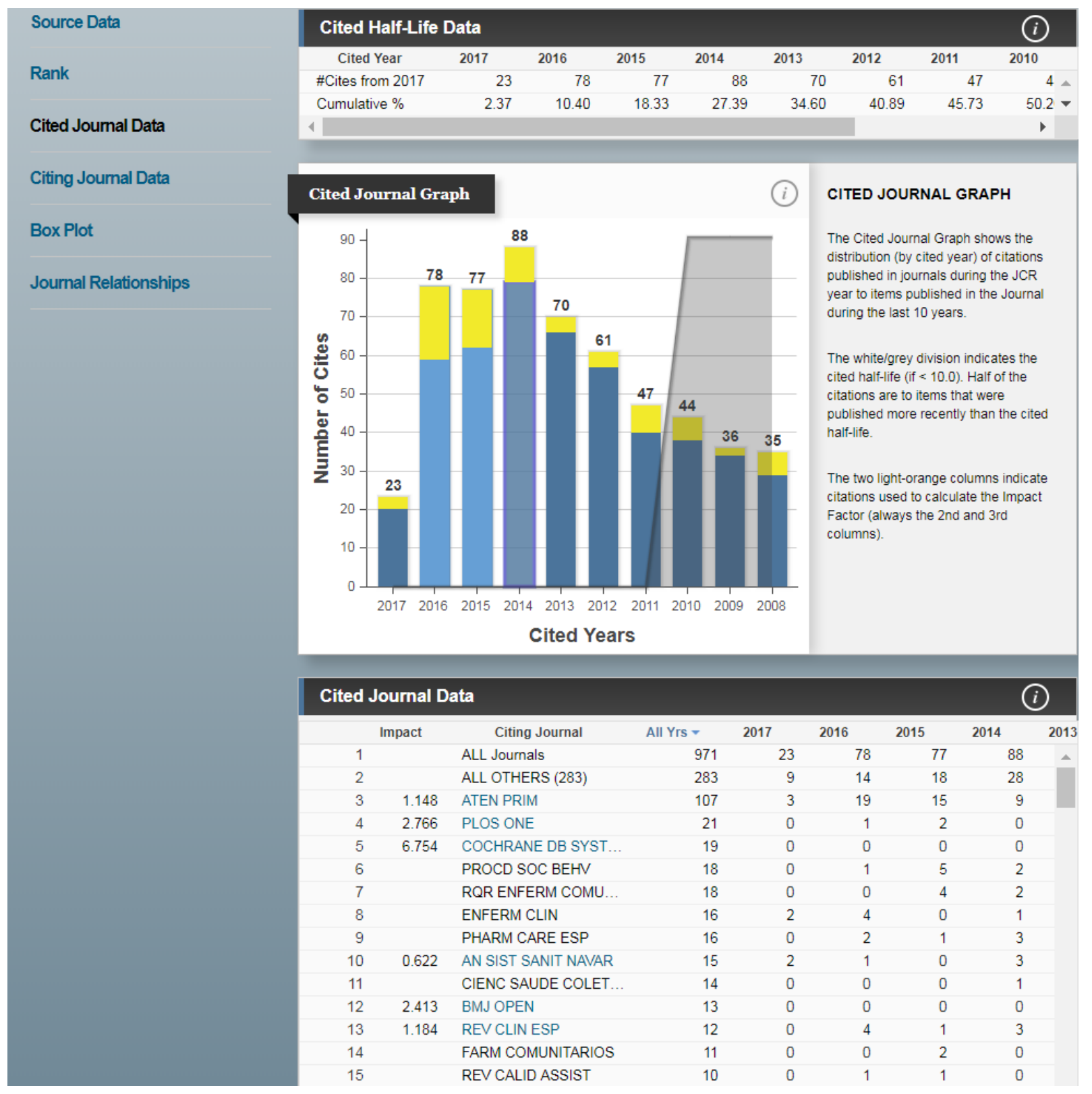

La información muestra en la gráfica de barras es la distribución por año citado de citas a artículos publicados en la revista.

1. La vida media de las citas recibidas (Cited Half Life) indica la edad de los artículos citados al mostrar el número de años a partir del año en curso que representan el $50 \%$ del número total de veces que se citó la revista en el año de curso.

2. Esta cifra le ayuda a evaluar la antigüedad de los artículos de la revista que han sido citados y puede ser utilizada para tomar decisiones de gestión y organización de colecciones. 
3. La parte en color amarillo de cada columna indica la proporción de auto citas (citas a artículos en la revista por artículos en la misma revista) para un año particular.

4. La división blanca/gris en el gráfico indica la vida media de las citas recibidas de la revista.

5. La segunda y la tercera columna (de color más claro) indican las citas utilizadas para calcular el factor de impacto de la revista.

6. La parte en color azul de cada columna indica citas que no son auto citas (citas a la revista por artículos en otras revistas).

\section{La Vida Media de Citas Incluidas (Citing Half-Life Data)}

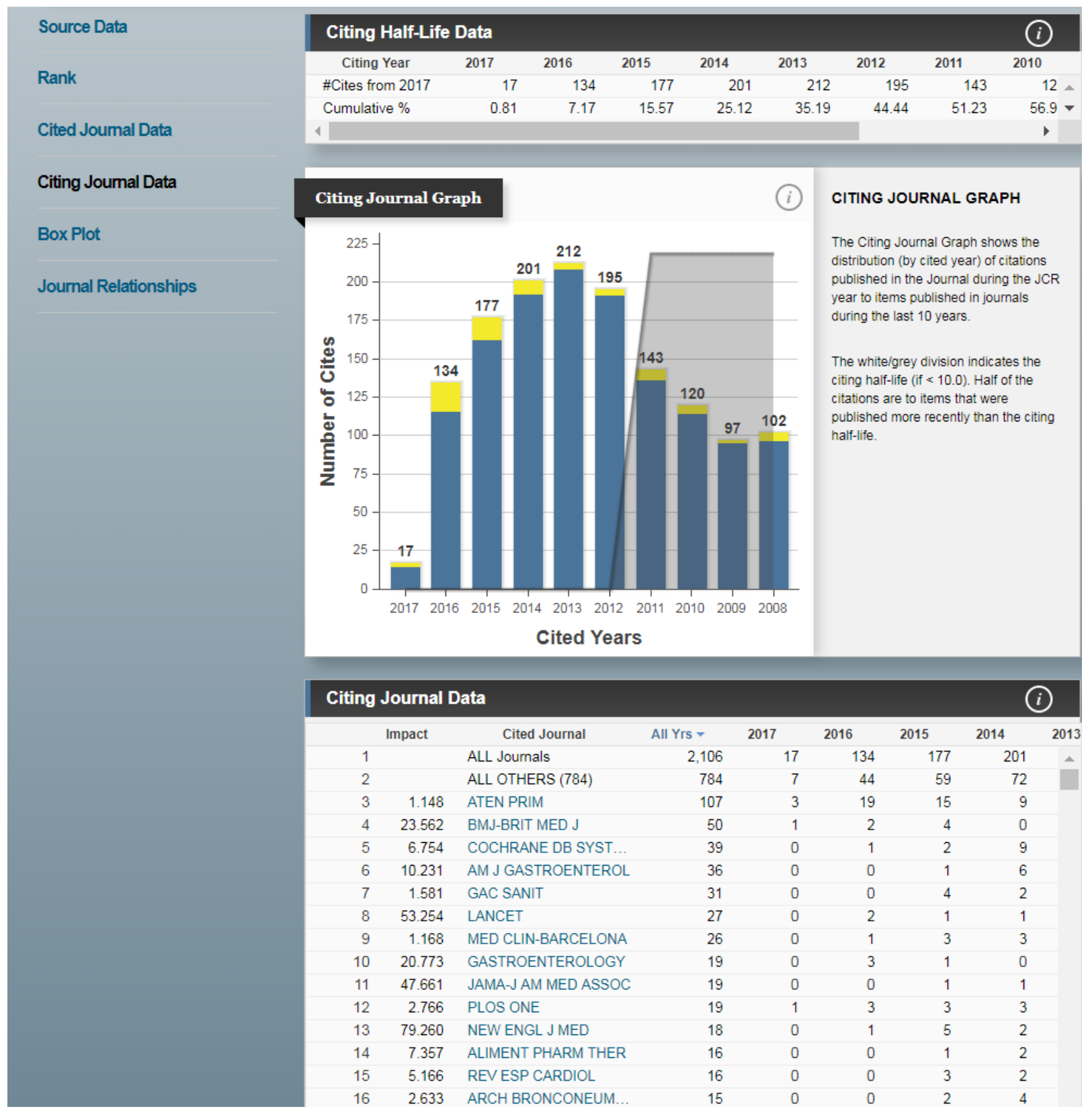

La gráfica de barras muestra la distribución por año citado de citas de artículos del año actual en la revista Atención Primaria. 
1. La vida media de citaciones incluidas es el número de años de publicación, a partir del año en curso, que representa el $50 \%$ de las actuales citaciones publicadas por una revista en las referencias de sus artículos.

2. Esta cifra le ayuda a evaluar la antigüedad de la mayoría de los artículos citados por una revista.

3. La división blanca/gris indica la vida media de las citas incluidas de la revista.

4. La parte superior (dorada) de cada columna indica la proporción de citas auto citas (citas de artículos en la revista por artículos en la misma revista) para un año particular.

5. La parte inferior (azul) de cada columna indica citas que no son autocitas (citas de la revista a artículos en otras revistas).

\section{Datos Fuente}

\begin{tabular}{lccccr} 
Journal source data 2017 ( & & & & & \\
& Articles & Reviews & Combined(C) & Other(O) & Percentage(C/(C+O)) \\
\hline Number in JCR Year 2017 (A) & 58 & 1 & 59 & 63 & $48 \%$ \\
Number of References (B) & 1,667 & 47 & 1,714 & 392 & $81 \%$ \\
Ratio (B/A) & 28.7 & 47.0 & 29.1 & 6.2 &
\end{tabular}

- Los Datos Fuente corresponden al número de artículos (solamente artículos de investigación originales y artículos de revisión) y al número de referencias que publicó una revista en el año en curso y dan el número promedio de referencias por artículo.

- Ya que los artículos de revisión son frecuentemente más citados que los artículos de investigación originales, es aconsejable tener en cuenta los datos fuente de las revistas por tipo de documento cuando se comparan los índices de citas de estas.

- Las revistas sólo citadas son aquellas que aparecen en JCR pero para las cuales Web of Science Group no ha procesado Datos Fuente.

- Haga clic en el número de registros combinado (Combined) para visualizarlos. Es posible limitar por el tipo de documento- por artículo o por revisión o por los dos

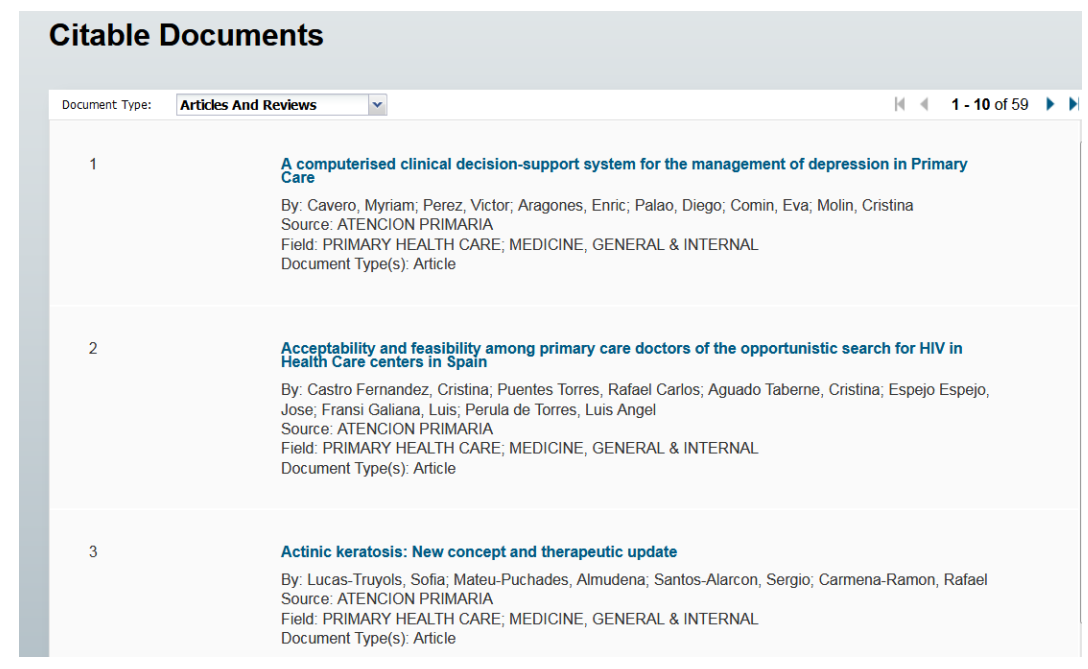


Revista Citada: La revista seleccionada recibe citas por las revistas de la lista

\begin{tabular}{|c|c|c|c|c|c|c|c|c|}
\hline \multicolumn{9}{|c|}{ Cited Journal Data } \\
\hline & Impact & Citing Journal & All Yrs - & 2017 & 2016 & 2015 & 2014 & 201 \\
\hline 1 & & ALL Journals & 971 & 23 & 78 & 77 & 88 & , \\
\hline 2 & & ALL OTHERS (283) & 283 & 9 & 14 & 18 & 28 & $\equiv$ \\
\hline 3 & 1.148 & ATEN PRIM & 107 & 3 & 19 & 15 & 9 & 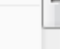 \\
\hline 4 & 2.766 & PLOS ONE & 21 & 0 & 1 & 2 & 0 & \\
\hline 5 & 6.754 & COCHRANE DB SYST ... & 19 & 0 & 0 & 0 & 0 & \\
\hline 6 & & PROCD SOC BEHV & 18 & 0 & 1 & 5 & 2 & \\
\hline 7 & & RQR ENFERM COMU... & 18 & 0 & 0 & 4 & 2 & \\
\hline 8 & & ENFERM CLIN & 16 & 2 & 4 & 0 & 1 & \\
\hline 9 & & PHARM CARE ESP & 16 & 0 & 2 & 1 & 3 & \\
\hline 10 & 0.622 & AN SIST SANIT NAVAR & 15 & 2 & 1 & 0 & 3 & \\
\hline 11 & & CIENC SAUDE COLETI... & 14 & 0 & 0 & 0 & 1 & \\
\hline 12 & 2.413 & BMJ OPEN & 13 & 0 & 0 & 0 & 0 & \\
\hline 13 & 1.184 & REV CLIN ESP & 12 & 0 & 4 & 1 & 3 & \\
\hline 14 & & FARM COMUNITARIOS & 11 & 0 & 0 & 2 & 0 & \\
\hline 15 & & REV CALID ASSIST & 10 & 0 & 1 & 1 & 0 & \\
\hline 16 & 1.675 & FAM PRACT & 9 & 0 & 1 & 1 & 0 & \\
\hline 17 & 1.581 & GAC SANIT & 8 & 0 & 2 & 2 & 0 & - \\
\hline 1 & & III & & & & & & 1 \\
\hline
\end{tabular}

- La revista cuyo nombre aparece en la parte superior de la página recibió citas por parte de las revistas de la tabla. Éstas están ordenadas por número de citas dadas a la revista especificada en la parte superior.

- La tabla muestra una distribución en 10 años de artículos citados por año de publicación. Las referencias a artículos más antiguos están en la columna "Rest."

- Esta lista puede revelar la orientación temática de una revista, indicar la publicación competidora más cercana a la misma y describir las redes de revistas de temas especializados. 
La Revista da citas a otras revistas: La revista seleccionada cita a las revistas de la lista

\begin{tabular}{|c|c|c|c|c|c|c|c|c|}
\hline \multicolumn{9}{|c|}{ Citing Journal Data } \\
\hline & Impact & Cited Journal & All Yrs - & 2017 & 2016 & 2015 & 2014 & 2013 \\
\hline 1 & & ALL Journals & 2,106 & 17 & 134 & 177 & 201 & $\triangle$ \\
\hline 2 & & ALL OTHERS (784) & 784 & 7 & 44 & 59 & 72 & $\equiv$ \\
\hline 3 & 1.148 & ATEN PRIM & 107 & 3 & 19 & 15 & 9 & \\
\hline 4 & 23.562 & BMJ-BRIT MED J & 50 & 1 & 2 & 4 & 0 & \\
\hline 5 & 6.754 & COCHRANE DB SYST ... & 39 & 0 & 1 & 2 & 9 & \\
\hline 6 & 10.231 & AM J GASTROENTEROL & 36 & 0 & 0 & 1 & 6 & \\
\hline 7 & 1.581 & GAC SANIT & 31 & 0 & 0 & 4 & 2 & \\
\hline 8 & 53.254 & LANCET & 27 & 0 & 2 & 1 & 1 & \\
\hline 9 & 1.168 & MED CLIN-BARCELONA & 26 & 0 & 1 & 3 & 3 & \\
\hline 10 & 20.773 & GASTROENTEROLOGY & 19 & 0 & 3 & 1 & 0 & \\
\hline 11 & 47.661 & JAMA-J AM MED ASSOC & 19 & 0 & 0 & 1 & 1 & \\
\hline 12 & 2.766 & PLOS ONE & 19 & 1 & 3 & 3 & 3 & \\
\hline 13 & 79.260 & NEW ENGL J MED & 18 & 0 & 1 & 5 & 2 & \\
\hline 14 & 7.357 & ALIMENT PHARM THER & 16 & 0 & 0 & 1 & 2 & \\
\hline 15 & 5.166 & REV ESP CARDIOL & 16 & 0 & 0 & 3 & 2 & \\
\hline 16 & 2.633 & ARCH BRONCONEUMOL & 15 & 0 & 0 & 2 & 4 & \\
\hline 17 & & REV ESP SALUD PUBLIC & 15 & 0 & 2 & 1 & 2 & $r$ \\
\hline
\end{tabular}

- La lista muestra que la revista especificada en la parte superior de la página cita a las publicaciones de la tabla. Las publicaciones citadas están ordenadas según el número de citaciones recibidas.

- La tabla muestra una distribución en 10 años de artículos citados por año de publicación. Las referencias a artículos más antiguos están en la columna "Rest."

- La lista puede revelar la orientación temática de una revista, indicar la publicación competidora más cercana a la misma y describir las redes de revistas de temas especializados. 


\section{Comparar Revistas}

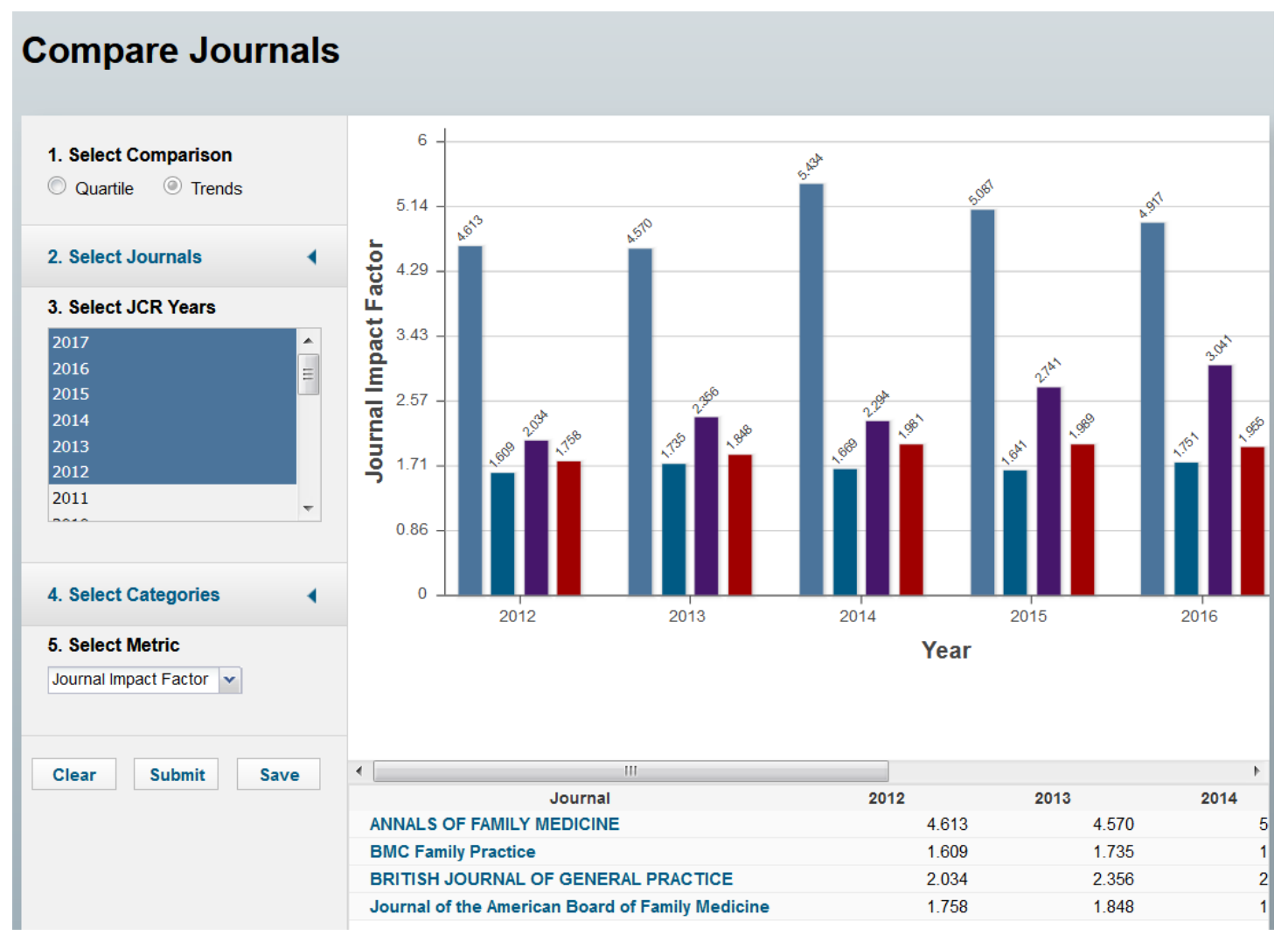

La herramienta 'Comparar revistas' le permite comparar revistas de interés para poder examinar tendencias y predeterminar la repercusión de una revista.

1. Selecciona el indicador que desea comparar entre los cuartiles o datos a lo largo del tiempo.

2. Busca las revistas que desea comparar.

3. Selecciona los años de evaluación. Pulse en 'control' con su teclado para seleccionar un rango de años.

4. Si ha optado a comparar datos a lo largo del tiempo, puede seleccionar la métrica con la cual se desea comparar las revistas.
a. Factor de impacto
b. Factor de impacto de la categoría
c. Factor de impacto de 5 años
d. Índice de inmediatez
e. Eigenfactor Score
f. Article Influence Score
5. Selecciona la categoría.
6. Haga clic en 'Submit' para realizar la comparación de revistas. 
Journal Ranking

Rank in Category Table:

JCR Impact Factor

\begin{tabular}{r|c|c|c|c|c|c|}
\multirow{2}{*}{$\begin{array}{l}\text { JCR } \\
\text { Year }\end{array}$} & \multicolumn{3}{l}{ PRIMARY HEALTH CARE } & \multicolumn{3}{l|}{ MEDICINE, GENERAL \& INTERNAL } \\
\cline { 2 - 7 } 2017 & Rank & Quartile & JIF Percentile & Rank & Quartile & JIF Percentile \\
\hline 2016 & $14 / 19$ & Q3 & 28.947 & $96 / 155$ & Q3 & 38.387 \\
2015 & $18 / 20$ & Q4 & 12.500 & $97 / 155$ & Q3 & 37.742 \\
2014 & $15 / 20$ & Q3 & 27.500 & $83 / 155$ & Q3 & 46.774 \\
2013 & $15 / 19$ & Q4 & 23.684 & $93 / 154$ & Q3 & 39.935 \\
2012 & $13 / 18$ & Q3 & 30.556 & $94 / 156$ & Q3 & 40.064 \\
2011 & $13 / 18$ & Q3 & 30.556 & $86 / 155$ & Q3 & 44.839 \\
2010 & $14 / 16$ & Q4 & 15.625 & $103 / 155$ & Q3 & 33.871 \\
2009 & $13 / 14$ & Q4 & 10.714 & $100 / 153$ & Q3 & 34.967 \\
\hline
\end{tabular}

Una tabla síntesis de su posición por factor de impacto en las categorías temáticas a la que pertenece, que resulta práctica para enterarse rápidamente de su situación relativa respecto a los demás títulos, sin tener que ir a localizarla en cada lista.

Para mejor entender la influencia de una revista dentro de todas las categorías en que está clasificado el cuadro nos permitirá.

-Visualizar el ranking que tiene una revista entre las categorías en que está clasificada. -Visualizar en que cuartil de la categoría está situada la revista con respecto a su factor de impacto.

\section{La tabla indica}

- Las categorías en las que la revista tiene clasificación en JCR.

- Ranking de la revista dentro de la categoría.

- Número total de revistas en la categoría.

- Cuartil de la revista.

- JIF Percentile 


\section{Diagrama de Cajas}

El diagrama de cajas es una gráfica ilustrando la distribución de los valores del factor de impacto para las categorías a las que pertenece una revista.

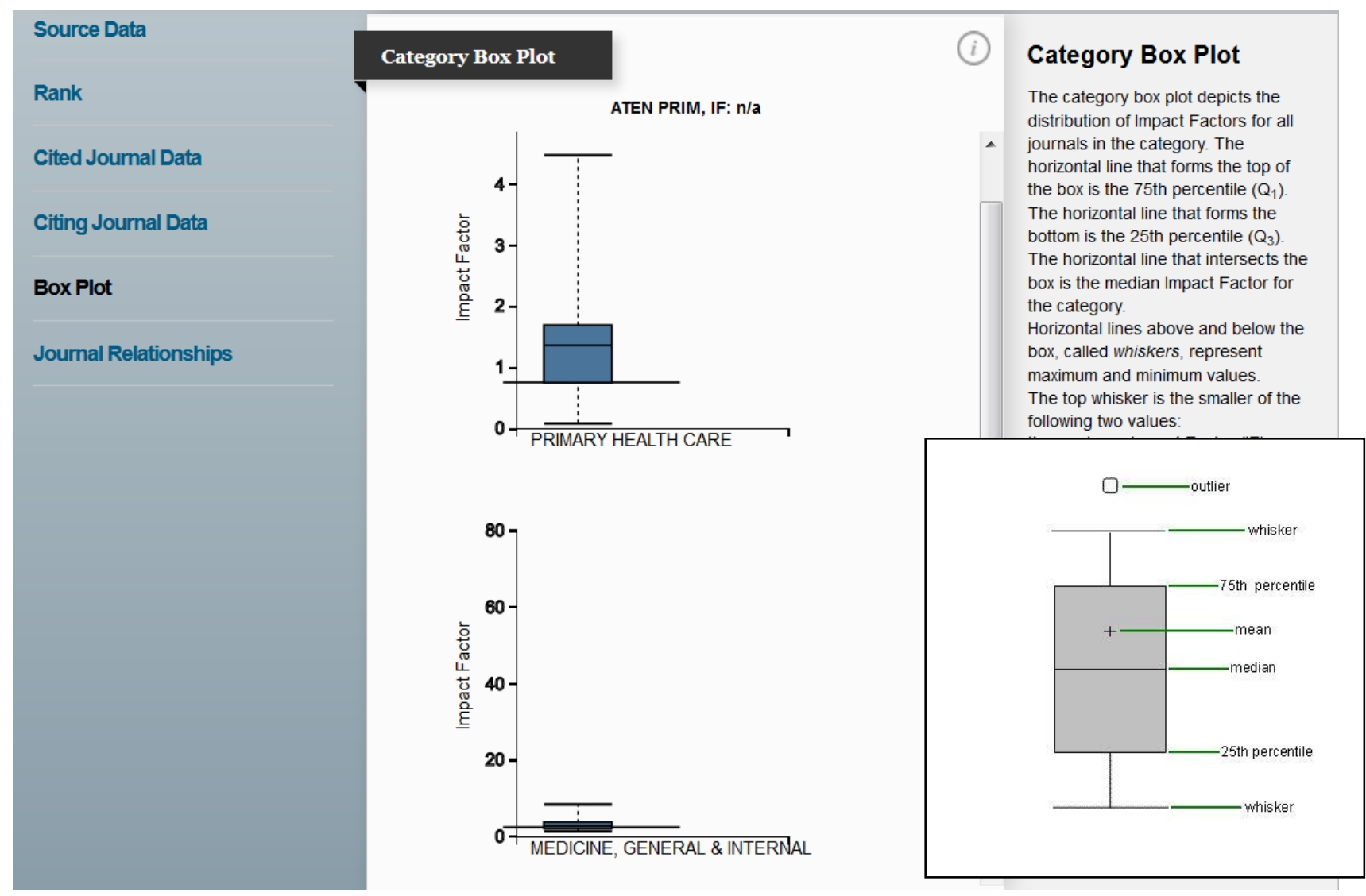

- El espacio entre los partes diferentes del diagrama de cajas, los cuartiles, ayudan a indicar el grado de dispersión del impacto de las revistas dentro de una categoría.

- Se puede visualizar el factor de impacto de una revista en el contexto de todos los factores de impacto de una categoría como indicado en el gráfico. Hace falta imaginar una línea en el diagrama que representa el factor de impacto de la revista de interés. Nos permite entender mejor la información representada en el diagrama

- En este ejemplo, se puede ver que el factor de impacto en la categoría C, zoología, está en la parte superior de los límites superiores.

- Para explicar los detalles del diagrama hace falta darse cuenta de que el propio diagrama representa un cuarto $(25 \%)$ al tercer cuarto $(75 \%)$ de los valores y la mediana $(50 \%)$. La línea horizontal dentro de la caja representa el mediano del factor de impacto y el símbolo (+) representa el promedio del factor de impacto. Las líneas al superior y al inferior del diagrama representan los bigotes y significan los extremos de ciertos valores. Los círculos representan las revistas atípicas que están situadas fuera de los bigotes. 


\section{Eigenfactor Metrics}

- Eigenfactor Score

- Normalized Eigenfactor

- Article Influence Score

\begin{tabular}{|c|c|c|c|c|c|c|c|c|c|c|c|c|c|}
\hline \multicolumn{14}{|c|}{ Key Indicators } \\
\hline Year $>$ & $\begin{array}{c}\text { Total } \\
\text { Cites } \\
\text { Graph }\end{array}$ & $\begin{array}{c}\text { Journal } \\
\text { Impact } \\
\text { Factor } \\
\text { Graph }\end{array}$ & $\begin{array}{c}\text { Impact } \\
\text { Factor } \\
\text { Without } \\
\text { Journal } \\
\text { Self } \\
\text { Cites } \\
\\
\text { Graph }\end{array}$ & $\begin{array}{c}5 \text { Year } \\
\text { Impact } \\
\text { Factor } \\
\text { Graph }\end{array}$ & $\begin{array}{l}\text { Immediacy } \\
\text { Index } \\
\text { Graph }\end{array}$ & $\begin{array}{l}\text { Citable } \\
\text { Items } \\
\underline{\text { Graph }}\end{array}$ & $\begin{array}{c}\text { Cited } \\
\text { Half-Life } \\
\text { Graph }\end{array}$ & $\begin{array}{c}\text { Citing } \\
\text { Half-Life } \\
\text { Graph }\end{array}$ & $\begin{array}{l}\text { Eigenfactc } \\
\text { Score } \\
\text { Graph }\end{array}$ & $\begin{array}{c}\text { Article } \\
\text { Influence } \\
\text { Score } \\
\text { Graph }\end{array}$ & $\begin{array}{c}\% \\
\text { rrticles } \\
\text { in } \\
\text { Citable } \\
\text { tems } \\
\text { Graph }\end{array}$ & $\begin{array}{c}\text { Normalizeı } \\
\text { Eigenfactc } \\
\text { Graph }\end{array}$ & $\begin{array}{l}\text { Average } \\
\text { JIF } \\
\text { ercentile } \\
\text { Graph }\end{array}$ \\
\hline 2017 & 971 & 1.148 & 0.896 & 1.180 & 0.390 & 59 & 7.9 & 6.7 & 0.00100 & 0.187 & 98.3 & 0.09500 & 33.667 \\
\hline 2016 & 880 & 1.042 & 0.900 & 0.934 & 0.132 & 68 & 9.3 & 7.2 & 0.00090 & 0.196 & 97.0 & 0.10377 & 25.121 \\
\hline 2015 & 875 & 1.098 & 0.758 & 0.966 & 0.194 & 67 & 9.2 & 7.7 & 0.00089 & 0.182 & 100.0 & 0.10091 & 37.137 \\
\hline 2014 & 763 & 0.953 & 0.658 & 0.740 & 0.283 & 53 & 8.6 & 6.9 & 0.00089 & 0.157 & 100.0 & 0.09992 & 31.810 \\
\hline 2013 & 787 & 0.894 & 0.567 & 0.722 & 0.196 & 51 & 8.3 & 6.3 & 0.00077 & 0.120 & 98.0 & 0.08518 & 35.310 \\
\hline 2012 & 888 & 0.957 & 0.539 & 0.654 & 0.229 & 70 & 8.2 & 6.5 & 0.00064 & 0.083 & 98.5 & Not A... & 37.697 \\
\hline 2011 & 819 & 0.627 & 0.329 & Not A... & 0.521 & 71 & 7.5 & 6.3 & 0.00065 & Not A... & 100.0 & Not A... & 24.748 \\
\hline 2010 & 819 & 0.619 & 0.312 & Not A... & 0.206 & 68 & 7.4 & 6.7 & 0.00067 & Not A... & 98.5 & Not A... & 22.841 \\
\hline 2009 & 766 & 0.437 & 0.211 & Not A... & 0.111 & 90 & 6.7 & 6.3 & 0.00070 & Not A... & 100.0 & Not A... & 18.421 \\
\hline
\end{tabular}

Las métricas de Eigenfactor sirven para complementar el factor de impacto y otros indicadores del JCR por que proporcionan una perspectiva más amplia sobre la influencia de revistas mediante mediciones específicas aceptadas por la comunidad de investigación.

Estas mediciones han sido desarrolladas por el proyecto Eigenfactor- un proyecto sin ánimo de lucro y académico patrocinado por el laboratorio Bergstrom en el departamento de biología en la universidad de Washington.

\section{www.eigenfactor.org}




\section{Eigenfactor $^{\mathrm{TM}}$ Score}

- Referencias académicas se unen a las revistas en una amplia red de citas. El algoritmo de la puntuación del Eigenfactor utiliza la estructura de la red entera para evaluar la importancia de cada revista, tocando cada disciplina. Se excluyen las auto citas.

- Este corresponde a un modelo básico de investigación en que los lectores siguen cadenas de citas al mover de una revista a otra.

- Los cálculos del Eigenfactor considera un período de 5 años de actividad de citas utilizando datos del Journal Citation Report

- Se considera que una revista es influyente si recibe citas de otras revistas influyentes.

- Eigenfactor considera que una cita de una revista de alta calidad puede ser de más valor que muchas citas de revistas periféricas.

- Para realizar estos cálculos, hay que tener en cuenta que calculando el Eigenfactor resulta más complejo y menos transparente en comparación con los cálculos del factor de impacto. Y sobre todo, el Eigenfactor se ocupa de medir la contribución/ valor de una revista a la comunidad científica mientas el factor de impacto mide el impacto promedio de un trabajo publicado en una revista determinada.

- El factor de impacto considera más el elemento de puntualidad, dado que considera dos años de trabajo citado y concentra en las relaciones de una cita a otra dentro de las revistas. Directo, sencillo y fácil entender describen las fuerzas del factor de impacto y también el factor de impacto de cinco años que considera un periodo más amplio de trabajo citado que el clásico factor de impacto.

- No obstante, se puede describir el Eigenfactor de otra manera- el Eigenfactor mide la influencia total de una revista sobre la literatura erudita. $O$ en comparación el valor total proporcionado por todos los artículos publicados en una revista determinada

- Para entender mejor hacemos un contraste del Eigenfactor con el factor de impacto. EI Eigenfactor proporciona la influencia completa que tiene la revista, más bien que la influencia por artículo individual. El factor de impacto presenta la influencia media de una revista determinada.

- El Eigenfactor Score mide la importancia completa de una revista dentro de la comunidad científica

- La suma de todos los resultados (Score) de todas las revistas en JCR resulta en 100.

- En 2017 la revista con el Eigenfactor Score más alto fue PLOS ONE con un resultado de 1.86200
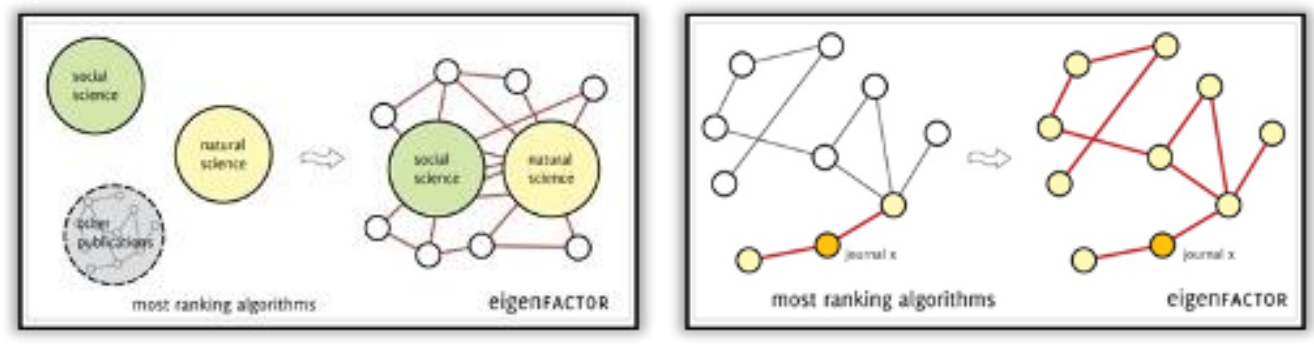


\section{Article InfluenceTM Score:}

- Como indicado en el Eigenfactor Score, el Article Influence Score :

- utiliza el cuerpo entero de la red de citas para evaluar la importancia de cada revista, basándose en datos del JCR

- No considera las autocitas.

- Los cálculos para el Articule Influence Score en realidad incorporan la puntuación del Eigenfactor.

- Mientras tanto, la puntuación del Eigenfactor puede considerarse como representación del valor global proporcionado por todos los artículos publicados en una revista en un año. - El Article Influence Score mide la influencia media de artículos individuales que se presentan en la misma revista, es decir representa la importancia de un artículo publicado en dicha revista.

- Como representa el promedio de influencia al nivel del artículo, el Article Influence parece más como el factor de impacto que el Eigenfactor Score. Hay que tener en cuenta que la metodología es muy diferente y por lo tanto proporciona una perspectiva diferente al factor de impacto, aunque sirve también como un complementario.

- Eigenfactor normaliza los Scores para que el artículo promedio en la JCR completa tenga una influencia de 1.00 .

- En 2017 la revista con el Article Influence Score más alto fue CA-A Cancer Journal for Clinicians con una influencia de 40.950. Significa que un artículo promedio de esta revista tiene una influencia 40 veces mayor que un artículo promedio en JCR. 


\section{Introducción a Incites Essential Science Indicators}

Incites Essential Science Indicators es una compilación global y exclusiva de estadísticas sobre el desempeño científico y datos sobre tendencias de la ciencia, derivados de las bases de datos de la Colección Principal de la Web of Science. Essential Science Indicators utiliza datos de citas recopilados de las publicaciones incluidas en los índices de $\mathrm{SCl}$ y $\mathrm{SSCl}$, a fin de clasificar autores, instituciones, países y publicaciones.

- Incites Essential Science Indicators es un archivo dinámico que abarca la última década de datos.

- Se actualiza cada dos meses.

- En el análisis de datos se incluyen artículos, resúmenes, documentos de reuniones y notas de investigación provenientes de más de 12.700 revistas indexadas en los índices de $\mathrm{SCl}$ y $\mathrm{SSCl}$ de la Colección Principal de la Web of Science.

\section{Usos de Incites Essential Science Indicators}

Incites Essential Science Indicators permite realizar análisis complejos de literatura científica que le asistirán para:

- Evaluar el rendimiento de la investigación de investigadores, instituciones, países y revistas. Entre las clases de análisis figuran los siguientes:

- Identificar a los investigadores o instituciones de primera línea en un campo o disciplina específicas.

- Determinar áreas importantes de investigación que se desarrollan en universidades o instituciones específicas.

- Identificar tendencias significativas y áreas emergentes de investigación.

- Clasificar países, publicaciones, científicos, documentos e instituciones de primera línea por campo de investigación.

- Comparar impacto con media de citas por campo científico (Baselines)

- Evaluar posibles empleados, colaboradores, críticos y colegas.

- Determinar quién publica los documentos más importantes o relevantes en un determinado campo.

Mas información:

http://clarivate.libguides.com/esi 


\section{Campos de Investigación}

- Incites Essential Science Indicators es una herramienta multidisciplinaria que incluye 22 campos de investigación.

- Las revistas pertenecen a un campo solo de investigación

- Es el campo de investigación de la revista donde se publica el artículo que determina en que campo está clasificado un autor, institución, país y publicación.

\begin{tabular}{|l|l|l|}
\hline Biología Molecular y Genética & Farmacología & Medio Ambiente/Ecología \\
\hline Biología y Bioquímica & Física & Microbiología \\
\hline Botánica y Zoología & Geociencias & Multidisciplinar \\
\hline Ciencia Espacial & Informática & $\begin{array}{c}\text { Neurociencia y } \\
\text { Comportamiento }\end{array}$ \\
\hline Ciencias Agrícolas & Ingeniería & Psiquiatría/Psicología \\
\hline Ciencias de los Materiales & Inmunología & Química \\
\hline Ciencias Sociales (general) & Matemática & \\
\hline Economía y Negocios & Medicina Clínica & \\
\hline
\end{tabular}




\section{Científicos}

Las citas de un documento se acreditan igualmente para cada uno de los autores, no sólo para el que se detalla primero. Se pueden buscar todos los autores.

\section{Instituciones}

Los conteos de las instituciones se basan en las afiliaciones de los autores presentados en los documentos publicados. Un documento se acredita a una institución si incluye, como mínimo, una dirección de autor de dicha institución. Se consideran todas las direcciones listadas. Las direcciones institucionales que aparecen más de una vez en un documento sólo se cuentan una vez.

\section{Países}

Al igual que las instituciones, los países se acreditan con las citas cuando aparecen en las afiliaciones de los autores que suministra la publicación. Asimismo, los países sólo se cuentan una vez por documento, incluso si en más de una dirección de autor se detalla el nombre del país

\section{Publicaciones}

Los documentos se atribuyen a la publicación original. Todas las citas que recibe un documento en una publicación se acreditan a ésta.

\section{Documentos}

Los documentos se definen como artículos científicos comunes, resúmenes, documentos de reuniones y notas de investigación. No se consideran cartas, correcciones o resúmenes. Sólo se analizan y cuentan los artículos de publicaciones incluidas en los índices de Web of Science.

Nota: Es importante tener en cuenta que los datos de Essential Science Indicators se limitan sólo a los artículos de las revistas que figuran en los índices de Web of Science. En este caso, no se toman en cuenta los libros, capítulos de libros o artículos de publicaciones que no se incluyen en los índices de Web of Science, ya sea en función de su publicación o de las citas. 


\section{Umbrales de Citas para incluirse en ESI}

Para ser incluidos en Incites Essential Science Indicators, los científicos, instituciones, países y publicaciones, así como los documentos más citados y los más relevantes, deben cumplir con umbrales específicos de citas. Estos umbrales los identifican como artículos con mérito suficiente para figurar en Incites Essential Science Indicators dentro del plazo en cuestión.

\begin{tabular}{|c|c|c|}
\hline & Percentiles de citas & $\begin{array}{l}\text { Años de datos } \\
\text { examinados }\end{array}$ \\
\hline Científicos & $1 \%$ & 10 \\
\hline Instituciones & $1 \%$ & 10 \\
\hline Países & $50 \%$ & 10 \\
\hline Revistas & $50 \%$ & 10 \\
\hline $\begin{array}{l}\text { Documentos muy citados } \\
\text { (Highly cited papers) }\end{array}$ & $1 \%$ & 10 \\
\hline $\begin{array}{l}\text { Documentos Recientes muy citados (Hot } \\
\text { Papers) }\end{array}$ & $0,1 \%$ & 2 \\
\hline
\end{tabular}




\section{Integración de Indicadores de 'Incites Essential Science Indicadores' en la Colección Principal de Web of Science}

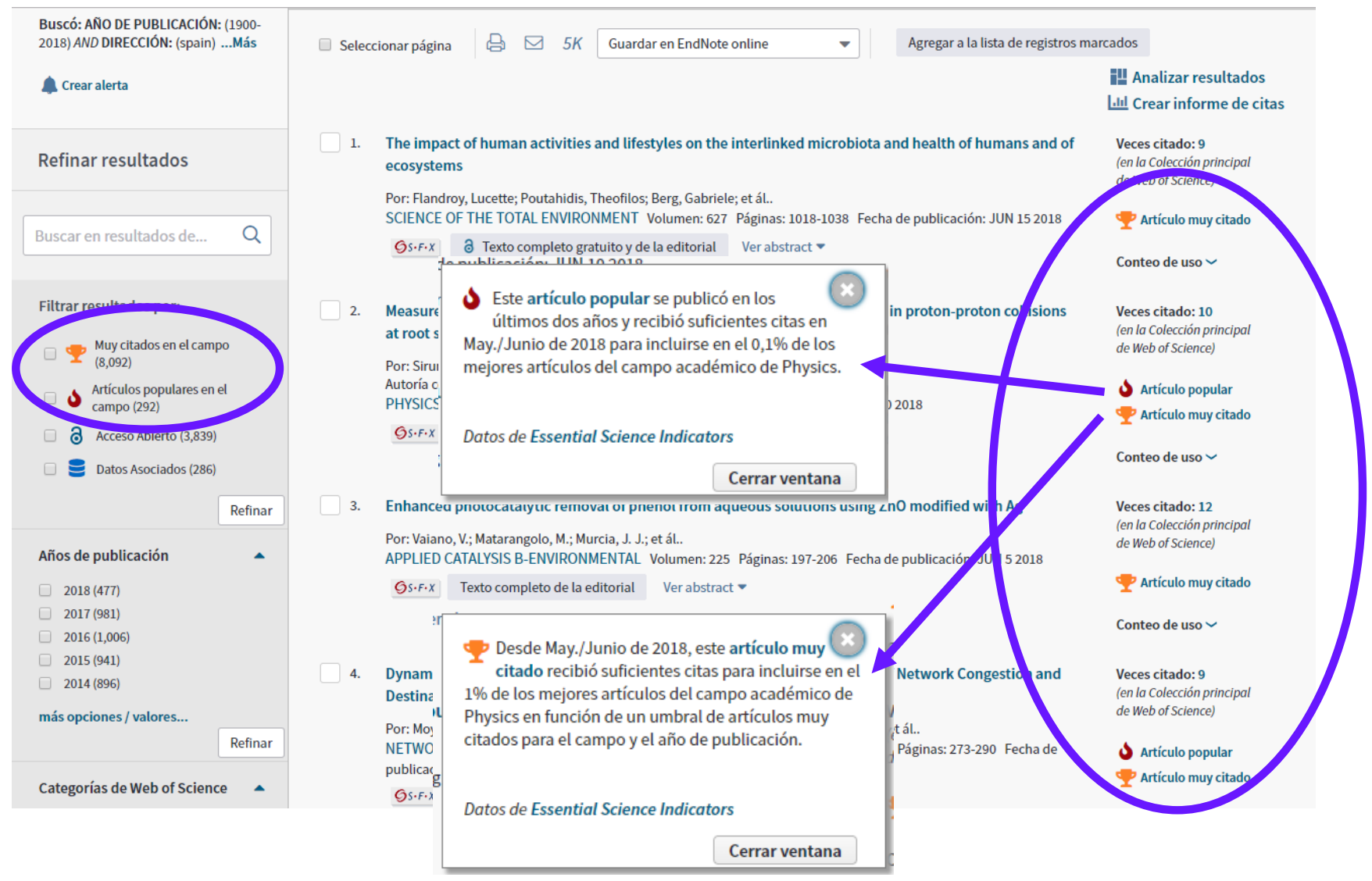

En la página de resultados en la Colección Principal, en un registro completo o en otra base de datos incluso Todas Las Bases de Datos, podrá ver los artículos que son trabajos altamente citados en el campo (Highly Cited), trabajos populares en el campo (Hot Papers). 


\section{Incites Essential Science Indicators: Consultas}

1. Quiero ver las líneas de investigación de excelencia de España.

a. Selecciona 'Reseach Field' del campo 'Results List'.

b. Añade el filto 'Countries' y busque 'Spain'.

c. Incluye 'Trabajos muy citados'.

d. Es posible ordenar las disciplinas por total de citas, número de documentos WOS, citas por trabajo o número de trabajos muy citados.

e. Haga clic en el número de artículos (trabajos muy citados o trabajos candentes) para visualizarlos.

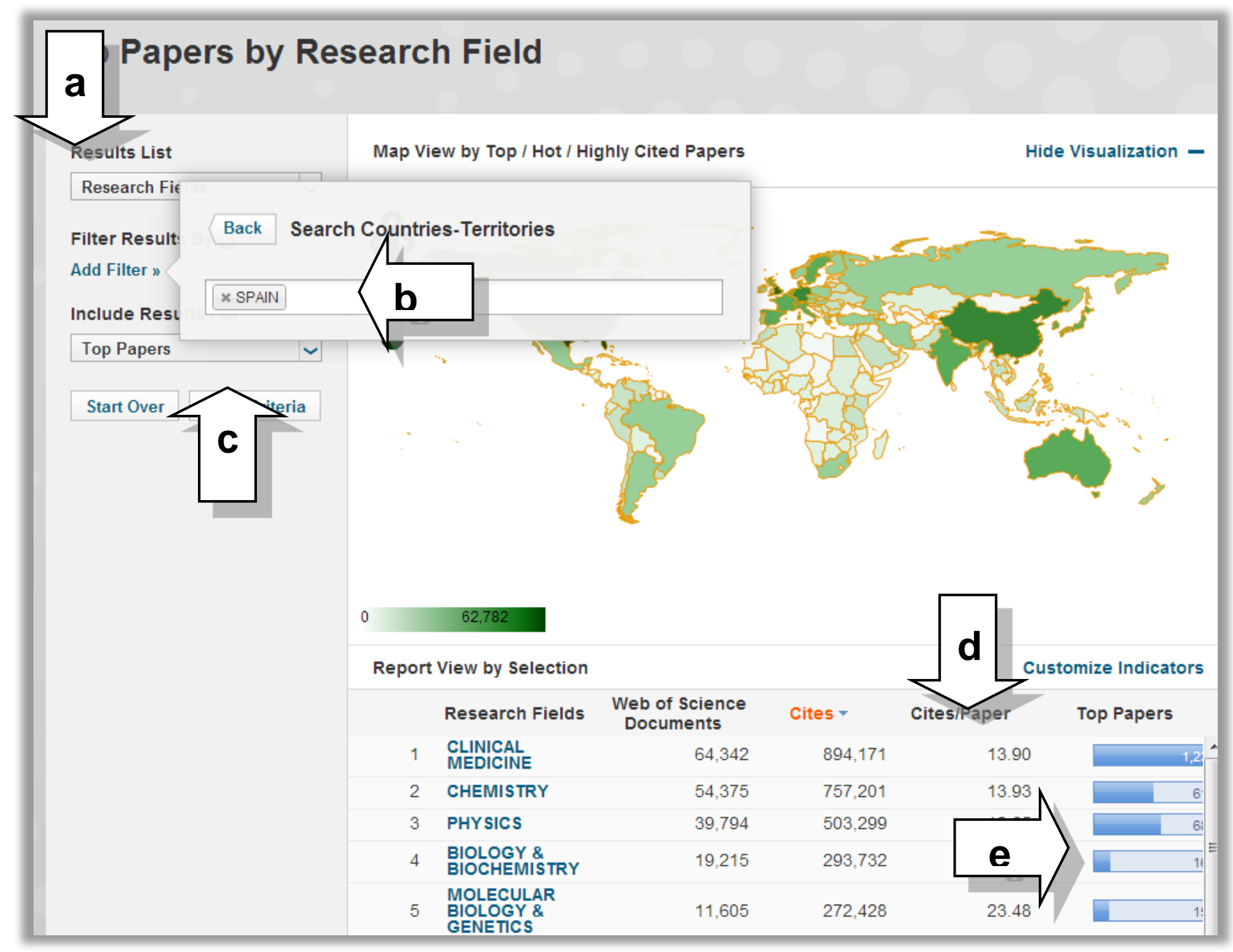

- Según los datos, con respecto a la produccion cientifica de produce España, el campo que ha accumulado el mayor número de citas durante los ultimos 10 años de datos de la WOS CC es la Medicina Clinica. 
2. Quiero ver las instituciones más citadas en un campo de investigación.

a. Selecciona 'Institutions' en el campo 'Results List'.

b. Añade el filto 'Research Field' y selecciona el campo de interés.

c. Incluye 'Trabajos muy citados' o 'trabajos candentes'.

d. Es posible ordenar las instituciones por el total de citas, el número de documentos de WOS, citas por trabajo o número de trabajos muy citados/trabajos candentes.

e. Haga clic en el número de articulos para visualizarlos.

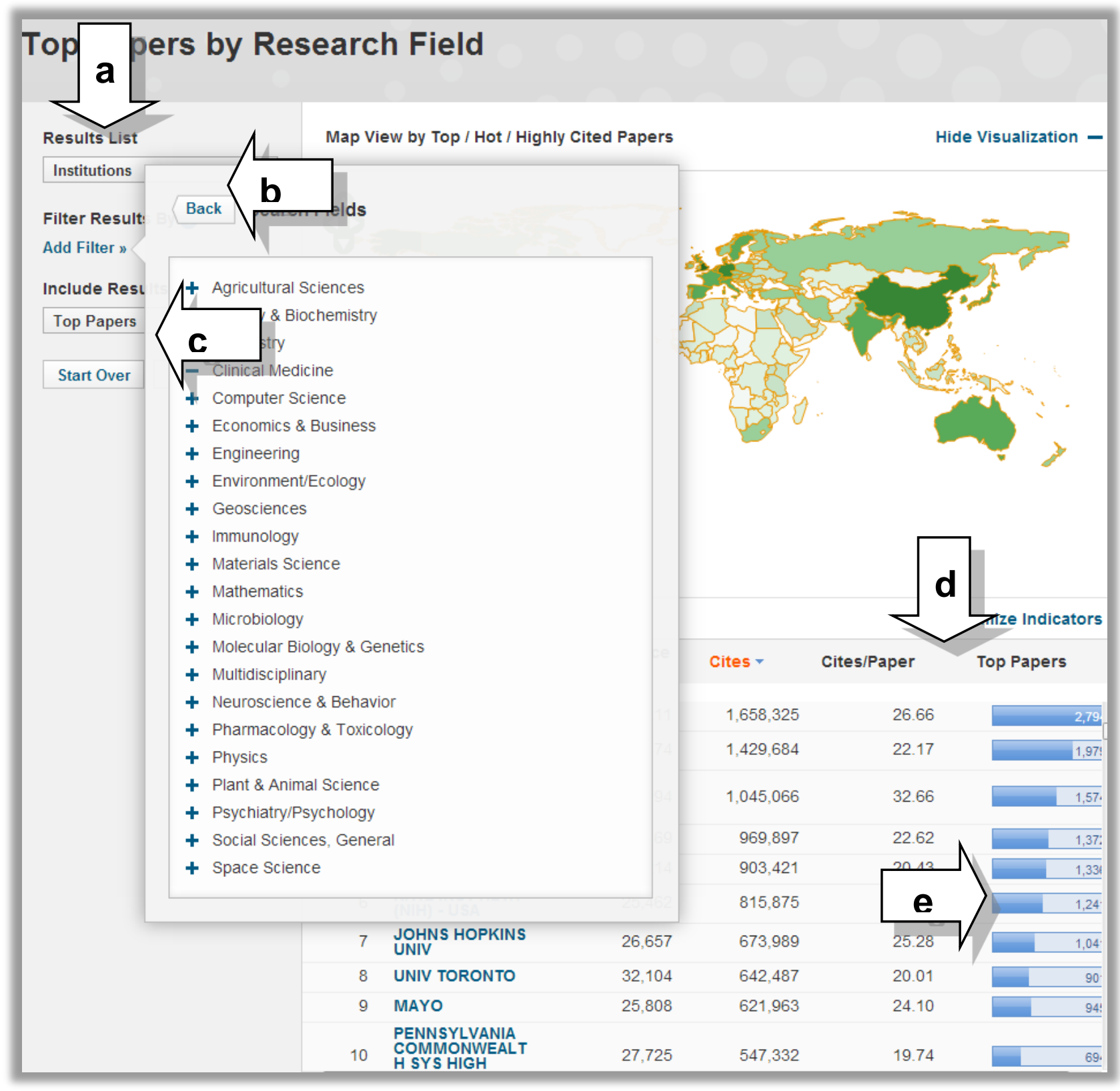


3. Quiero ver los países más citados en un campo de investigación.

a. Selecciona 'Countries' en el campo 'Results List'.

b. Añade el filto 'Research Field' y selecciona el campo de interés.

c. Incluye 'Trabajos muy citados' o 'trabajos candentes'.

d. Es posible ordenar los paises por el total de citas, número de documentos de WOS, citas por trabajo o número de trabajos muy citados/trabajos candentes.

e. Haga clic en el número de articulos para visualizarlos.

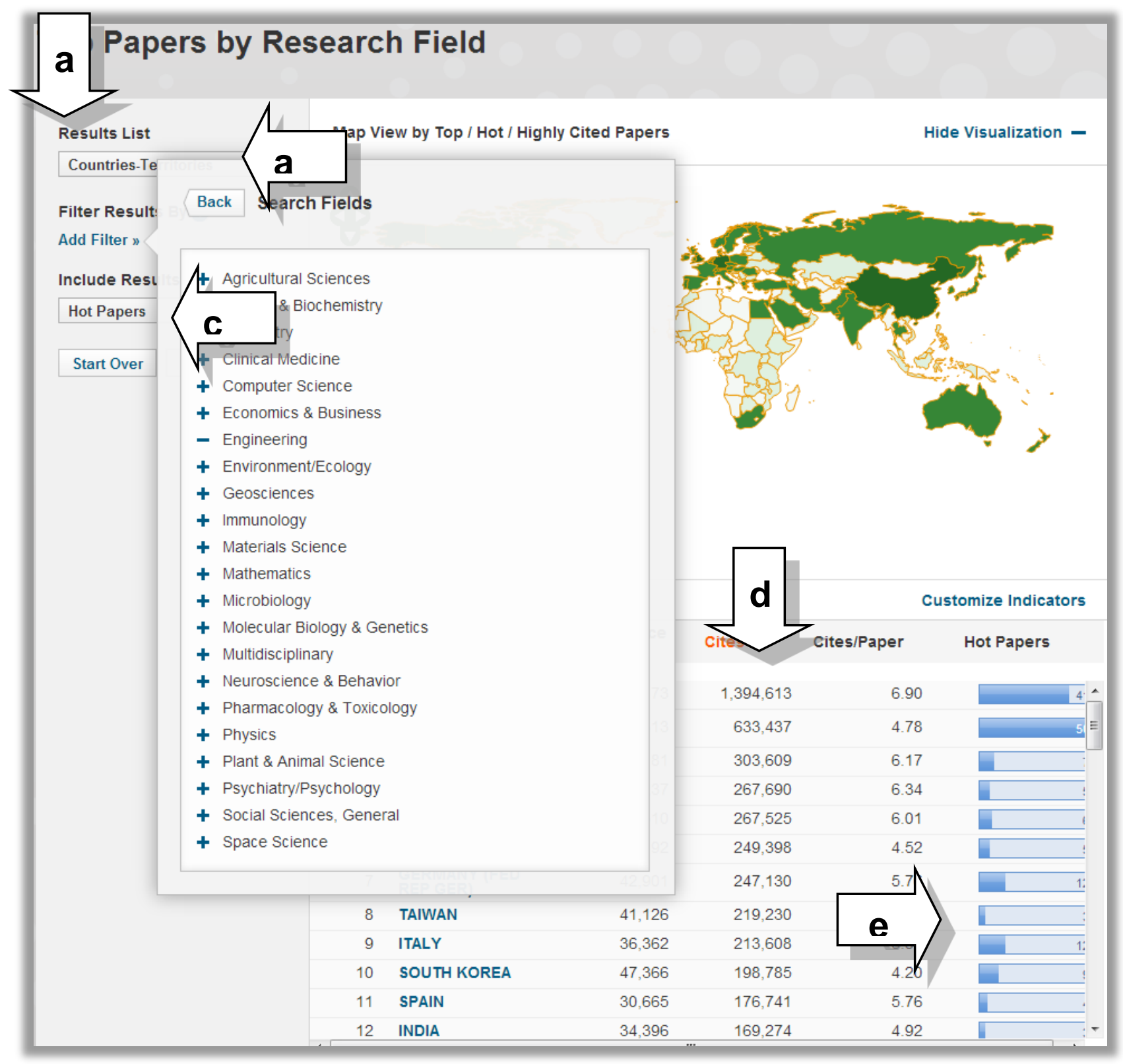


4. Quiero ver los autores más citados en un campo de investigación.

a. Selecciona 'Author' en el campo 'Results List'.

b. Añade el filto 'Research Field' y selecciona el campo de interés .

c. Incluye 'Trabajos muy citados' o 'trabajos candentes'.

d. Es posible ordenar los autores por el total de citas, número de documentos de WOS, citas por trabajo o número de trabajos muy citados/trabajos candentes.

e. Haga clic en el número de articulos para visualizarlos.

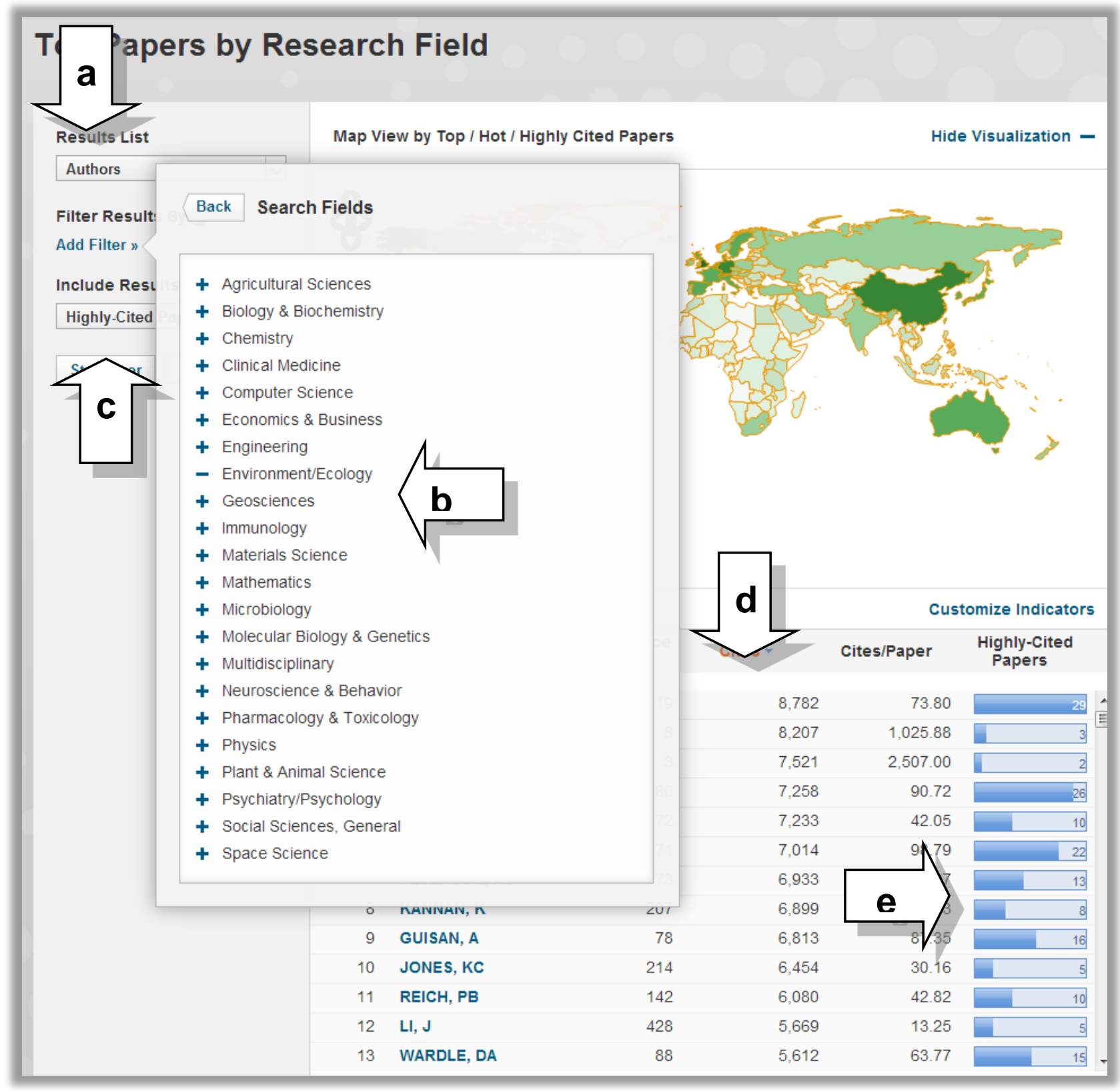


5. Quiero identificar las líneas de investigación de alto impacto de mi institución

a. Selecciona 'Research Field' en el campo 'Results List'.

b. Añade el filto 'Institutcion' y busque la institucion de interés.

c. Incluye 'Trabajos muy citados' o 'trabajos candentes'.

d. Es posible ordenar los campos por total de citas, número de documentos de WOS, citas por trabajo o número de trabajos muy citados/trabajos candentes.

e. Haga clic en el número de articulos para visualizarlos.

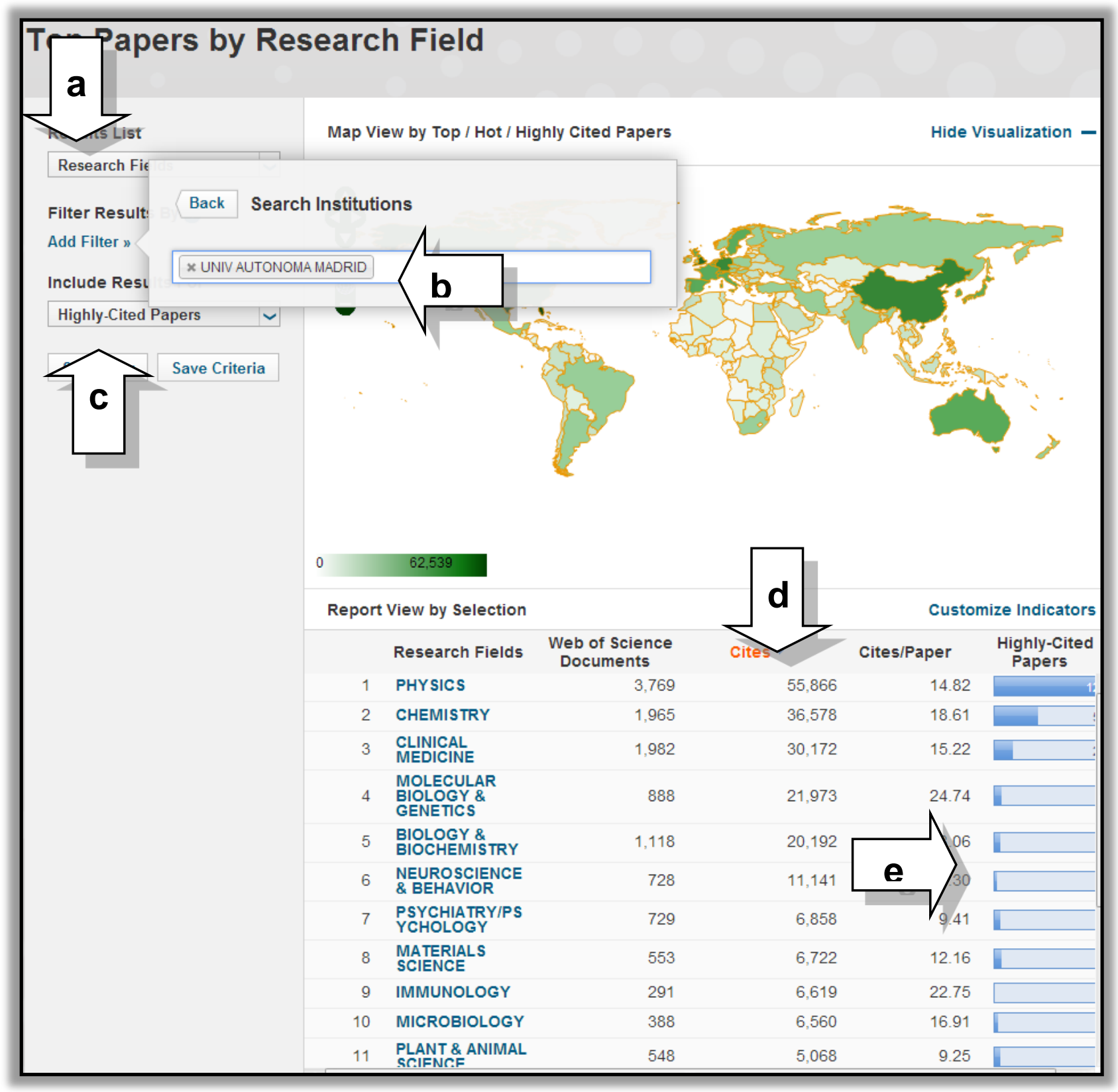




\section{Field Baselines}

Los Field Baselines son puntos de referencia basados en promedias de citas calculados por campo científico y por año de publicación que sirven para entender mejor el desempeño de un artículo en su campo científico. Incites ESI ofrece y calcula cada actualización:

Información contextual

- las promedias de citas por campo científico y por año (medias de citas mundiales)

- posicionamiento en el campo científico : las citas por percentile (primer $1 \%, 10 \%, 20 \%$ y \% 50)

Los puntos de referencia reflejan la actualidad del impacto científico y la producción científica global y se actualizan cada dos meses.

Los puntos de referencia le permiten comparar el impacto actual de una publicación con el impacto esperado de publicaciones de los 22 campos científicos. También, los percentiles de ESI le permiten evaluar la posición de una publicación dentro de su categoría (su posición sobre $100 \%)$.

Los Field Baselines (Puntos de referencia de los campos científicos) ofrecen...

- Las medias de citas por disciplina y por año de publicación

- Los umbrales de citas de cada rango de percentile calculado por disciplina y por año de publicación

- Las citas globales de cada campo de investigación de ESI 
6. Quiero ver las medias de citas de cada campo de investigación durante los últimos 10 años.

La tabla más abajo indica las medias de citas por año de cada campo de investigación. Podemos usar las medias para determinar si nuestro artículo tiene un impacto inferior o superior a la media del campo científico.

Por ejemplo, tengo un artículo clasificado en el campo 'Environment/Ecology' y es del año 2011. De momento, las veces citado de mi artículo son 30 citas. La media de citas del aquel año y campo es 20.55. Concluyo que mi artículo tiene un impacto superior a lo de la media del mismo campo.

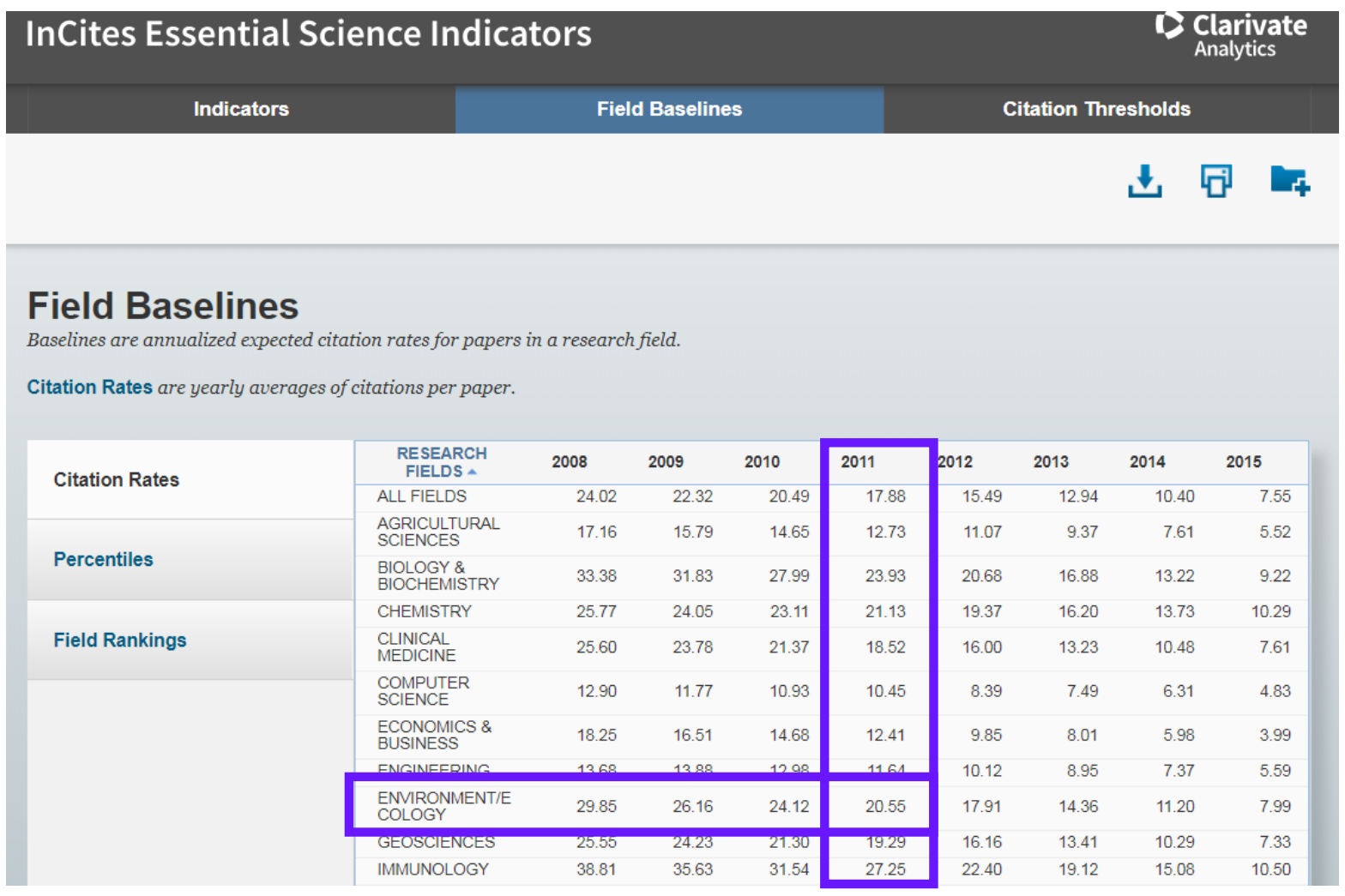


7. Quiero ver las citas necesarias para incluirse en el primer $1 \%$ (highly cited paper) o para incluirse en el primer $0.1 \%$ (hot paper) de un campo científico.

\section{InCites Essential Science Indicators}

\section{Field Baselines}

Baselines are annualized expected citation rates for papers in a research field.

Percentiles define levels of citation activity. The larger the minimum number of citations, the smaller the peer group.

\begin{tabular}{|c|c|c|c|c|c|c|c|c|c|c|c|}
\hline \multirow{2}{*}{ Citation Rates } & $\begin{array}{l}\text { RESEARCH } \\
\text { FIELDS }\end{array}$ & 2008 & 2009 & 2010 & 2011 & 2012 & 2013 & 2014 & 2015 & 2016 & 2017 \\
\hline & \multicolumn{10}{|l|}{ ALL FIELDS } & $\Delta$ \\
\hline \multirow{3}{*}{ Percentiles } & $0.01 \%$ & 1,931 & 1,958 & 1,668 & 1,368 & 1,253 & 916 & 737 & 503 & 299 & \\
\hline & $0.10 \%$ & 663 & 607 & 563 & 477 & 403 & 321 & 257 & 178 & 108 & \\
\hline & $1.00 \%$ & 205 & 187 & 172 & 147 & 125 & 102 & 81 & 59 & 36 & \\
\hline \multirow{17}{*}{ Field Rankings } & $10.00 \%$ & 54 & 50 & 46 & 40 & 35 & 29 & 24 & 17 & 11 & \\
\hline & $20.00 \%$ & 32 & 30 & 28 & 24 & 21 & 18 & 15 & 11 & 7 & \\
\hline & $50.00 \%$ & 11 & 11 & 10 & 9 & 8 & 7 & 6 & 4 & 3 & \\
\hline & \multicolumn{10}{|c|}{ AGRICULTURAL SCIENCES } & \\
\hline & $0.01 \%$ & 526 & 642 & 612 & 415 & 334 & 353 & 185 & 141 & 88 & \\
\hline & C.100/ & בחס & (4) & سمتف & 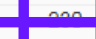 & 169 & 142 & 101 & 74 & 42 & \\
\hline & $1.00 \%$ & 130 & 108 & 108 & 86 & 73 & 61 & 48 & 35 & 22 & \\
\hline & Tu.00\% & 45 & 38 & 35 & 31 & 27 & 23 & 19 & 14 & 9 & \\
\hline & $20.00 \%$ & 26 & 24 & 22 & 20 & 17 & 15 & 12 & 9 & 6 & \\
\hline & $50.00 \%$ & 9 & 9 & 8 & 7 & 7 & 6 & 5 & 4 & 2 & \\
\hline & \multicolumn{10}{|c|}{ BIOLOGY \& BIOCHEMISTRY } & \\
\hline & $0.01 \%$ & 2,200 & 5,136 & 2,763 & 1,652 & 2,629 & 1,451 & 1,326 & 986 & 455 & \\
\hline & $0.10 \%$ & 785 & 739 & 668 & 552 & 479 & 403 & 314 & 203 & 122 & \\
\hline & $1.00 \%$ & 258 & 235 & 205 & 171 & 144 & 119 & 91 & 65 & 38 & \\
\hline & $10.00 \%$ & 71 & 66 & 59 & 50 & 44 & 35 & 28 & 20 & 12 & \\
\hline & $20.00 \%$ & 44 & 42 & 38 & 32 & 28 & 23 & 18 & 13 & 8 & \\
\hline & $50.00 \%$ & 18 & 17 & 16 & 14 & 12 & 10 & 8 & 6 & 4 & \\
\hline
\end{tabular}

Como interpretar los percentiles:

Mi artículo ha sido clasificado en el campo 'Agricultural Sciences' y es del año 2011 Las veces citado actual de mi artículo son 50 citas.

- Para ser clasificado un trabajo muy citado mi artículo necesita recibir 86 citas. Mi artículo no está en el primer $1 \%$ del campo y por lo tanto no es un trabajo muy citado.

- Mi artículo figura en el primer $10 \%$ del campo porque el artículo ha recibido mayor que 31 citas. 


\section{Medline}

MEDLINE es la base de datos bibliográfica dedicada a la biomedicina y a la literatura de la investigación de la salud producida por de la Biblioteca Nacional de Medicina de Los Estados Unidos (Nacional Library of Medicine, NLM). Medline abarca temas de la biomedicina y de las ciencias de la vida que tienen un gran uso para los investigadores, los médicos y los profesores. Encontrará también literatura en los campos de la medicina, la biología, las ciencias de la vida, la enfermería, la veterinaria, y temas de otros campos relevantes por ejemplo las ciencias medioambientales, las ciencias de las plantas y los animales, biología marina, química, y biofísica.

La indexación especializada le permite profundizar en temas específicos utilizando opciones de búsqueda incluyendo lenguaje natural, términos de MeSH o números de CAS.

Medline a través de la Web of Science ofrece:

- Contenido de más de 5.300 revistas publicadas en más de 30 idiomas, incluso contenido relevante de prensa y noticias.

- Más de 17 millones de registros de publicaciones del mundo

- Se añade aproximadamente 600.000 registros anualmente

- Verán vínculos de los registros de Medline a las bases importantes de proteína de la NCBI y a la secuencia de la ADN y a registros relacionados de PubMed.

- Vínculos a sus suscripciones al texto completo

- Contenido totalmente indexado de artículos desde el año 1950 hasta la actualidad.

- Las fuentes de publicaciones incluyen entre otros: artículos de revistas, periódicos, ensayos clínicos, estudios de evaluación, biografías, bibliografías, conferencias y actas de congresos.

Se puede consultar Medline según un rango amplio de temas de búsqueda. En la página de una búsqueda general se puede buscar por:

1. tema (recupera sus términos de búsqueda en los títulos, los campos temáticos, y resúmenes)

2. los títulos MeSH,

- autores

- título del artículo

- título de la fuente

- año de publicación

- tipo de publicación

- idioma

- dirección

- datos de química

- códigos de identificación.

- Base de citas

También consultar directamente el índice de vocabulario controlado de Medline (MeSH headings/ títulos MeSH). 
Web of Science

Selecionar una basededatos MEDLINE⿱日十)

Búsqueda básica Búsqueda avanzada

Ejemplo: "skin graft" reject*

And $>$ Ejemplo: Vonwald $L^{*}$ or Von wald $L^{*} \quad \boldsymbol{*}$ Seleccionar del índice

And $\rightarrow$ Ejemplo: Br J Dermatol Seleccionar del índice

x

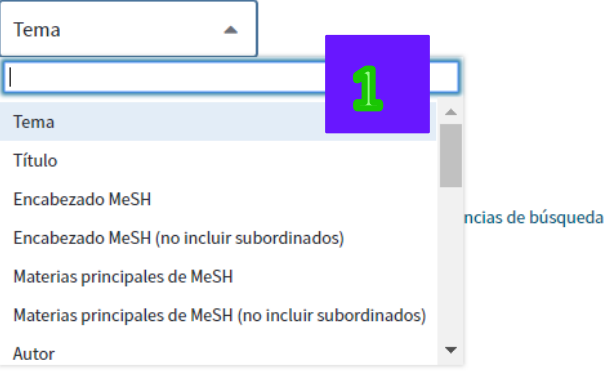
Todos los años (1950 - 2018) -

MÁS AJUSTES •

índice

MEDLINE --1950-presente

Fecha de última actualización de los datos: 2018-10-30

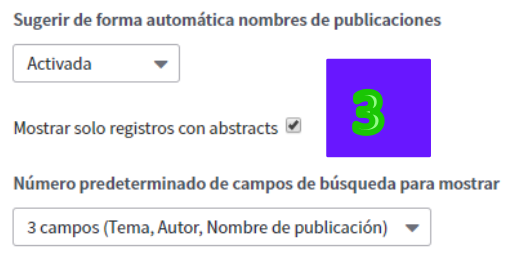

1. Abra el menú desplegable para seleccionar un tipo de búsqueda: Una búsqueda por tema incluye varias opciones para la recuperación de registros. Una búsqueda por tema recupera sus términos de búsqueda en los campos siguientes: en los títulos, campos temáticos y resúmenes de los artículos. Existen más opciones de una búsqueda por tema y por título que le permite asociar sus términos de búsqueda con los títulos MeSH.

2. Seleccione aquí los años que desea incluir en su búsqueda. Por defecto todos los años están seleccionados. Se puede seleccionar un rango de años o un periodo de años entre los a que su institución está suscrita.

3. Seleccione la casilla para recuperar únicamente registros con resúmenes. 
Búsquedas de Medline

\begin{tabular}{|c|c|c|}
\hline Tipo de Búsqueda & & Ejemplo \\
\hline Tema & $\begin{array}{l}\text { - } \quad \text { Titulo } \\
\text { - } \quad \text { Título en idioma original } \\
\text { - } \quad \text { Abstract } \\
\text { - } \text { Otro Abstract } \\
\text { - } \quad \text { Términos de MeSH } \\
\text { - } \quad \text { Las palabras claves } \\
\text { - } \quad \text { Química } \\
\text { - Símbolos de Genes } \\
\text { - Personal Name Subject } \\
\text { - } \quad \text { Space Flight Mission }\end{array}$ & "vitamin a" \\
\hline Tema más MeSH & $\begin{array}{l}\text { Le permite incluir el término MeSh a } \\
\text { su búsqueda. Esta búsqueda mapea } \\
\text { automáticamente un término } \\
\text { común a su término MeSh e incluye } \\
\text { términos subordinados al termino } \\
\text { principal }\end{array}$ & $\begin{array}{l}\text { Tema=(“Nose Bleed") OR MeSH } \\
\text { Heading:exp=(Epistaxis) }\end{array}$ \\
\hline $\begin{array}{l}\text { Tema más MeSH (no } \\
\text { explode) }\end{array}$ & $\begin{array}{l}\text { Le permite incluir el término MeSh a } \\
\text { su búsqueda. Esta búsqueda mapea } \\
\text { automáticamente un término } \\
\text { común a su término MeSh. Puede } \\
\text { recuperar resultados que no } \\
\text { contienen los términos buscados. }\end{array}$ & 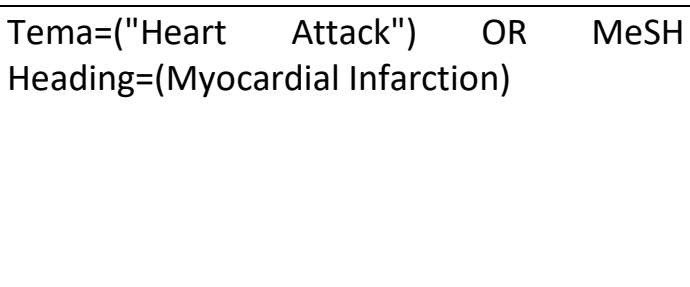 \\
\hline MeSh & $\begin{array}{l}\text { Le permite recuperar resultados que } \\
\text { contienen los títulos MeSh } \\
\text { seleccionados. Consulte el índice de } \\
\text { los términos MeSH. El tesauro } \\
\text { contiene cientos de términos en } \\
\text { vocabulario controlado. Es posible } \\
\text { 'explotar' la búsqueda para incluir } \\
\text { términos subordinados. }\end{array}$ & 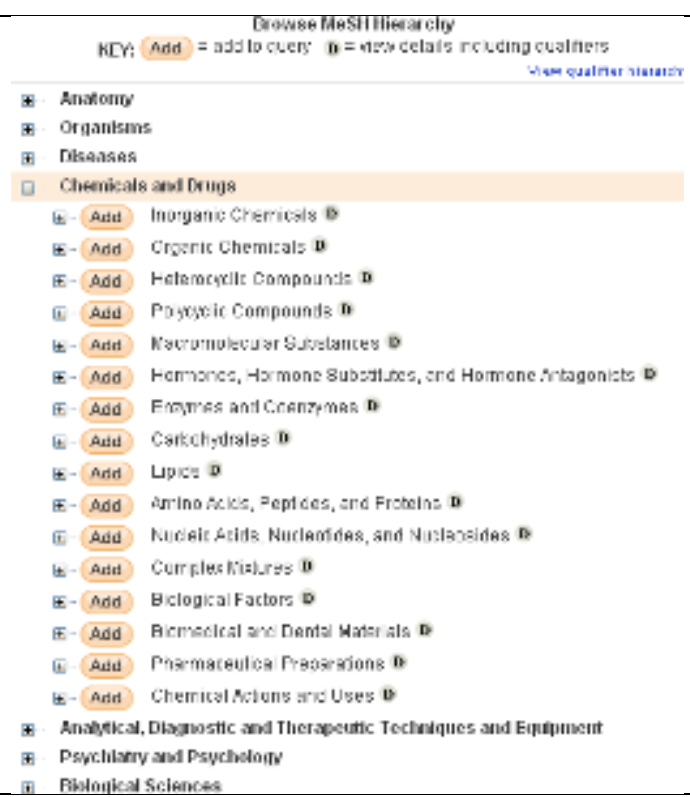 \\
\hline MeSh Major Topics & $\begin{array}{l}\text { Le permite recuperar resultados de } \\
\text { lo cual su contenido principal está } \\
\text { tratado por el título MeSH e incluye } \\
\text { títulos subordinados }\end{array}$ & \\
\hline $\begin{array}{l}\text { MeSH Major Topics } \\
\text { (No Explode) }\end{array}$ & $\begin{array}{l}\text { Le permite recuperar resultados de } \\
\text { lo cual su contenido principal esta } \\
\text { tratado por el título. Un asterisco }\left({ }^{*}\right) \\
\text { en el titulo MeSh en el registro } \\
\text { significa que el título es un tema } \\
\text { principal. }\end{array}$ & \\
\hline
\end{tabular}




\section{Página de Resultados Medline}

\section{Web of Science}

\section{Buscar}

Resultados: 3.295

(de MEDLINE)

Buscó: (TEMA: ("zika virus") AND ISO Buscó: (IEMA: ("Zika virus") ANDS

...Más

4 crear alerta

Refinar resultados

Buscar en resultados de $\quad Q$

Filtrar resultados por:

1 Muy citados en

- Artículos populares en el

campo (14)

¿. Acceso Abierto $(1,942)$

을 Datos Asociados (21)

Años de publicación

$2018(1,100)$

$2017(1,273)$

2016 (855)

2015 (22)

$2014(12)$

más opciones / valores..
Ordenar por: Fecha Vecescitado Conteo de uso Relevancia Más $\quad-7$ de 4 a la lista de registros marcados

FII Analizar resultados

Monitoring arbovirus in Thailand: Surveillance of dengue, chikungunya and zika virus, with a focus on coinfections.

Por: Suwanmanee, San; Surasombatpattana, Pornnapat; Soonthornworasiri, Ngamphol; et ál.. Acta tropica Volumen: 188 Páginas: 244-250 Fecha de publicación: 2018-Dec (Epub 2018 Sep 21) Gs.F.X Texto completo de la editorial Ver abstract -

Arch-shaped multiple-target sensing for rapid diagnosis and identification of emerging infectious pathogens.

Por: Koo, Bonhan; Hong, Ki Ho; Jin, Choong Eun; et ál..

Biosensors \& bioelectronics Volumen: 119 Páginas: 79-85 Fecha de publicación: 2018-Nov-15 (Epub 2018 Aug 08) GS.F.X Texto completo de la editorial Ver abstract -

3. Zika Virus and Neurologic Disease.

Veces citado: 0 (en la colección principa de Web of Science)

Conteo de uso $\sim$

Veces citado: 0 (en la Colección principal de Web of Science)

Conteo de uso $\sim$

Por: Reid, Savina; Rimmer, Kathryn; Thakur, Kiran

Neurologic clinics Volumen: 36 Número: 4 Páginas: 767-787 Fecha de publicación: 2018-Nov

SS.F.X Texto completo de la editorial Ver abstract -

Veces citado: 0
(en la colección principa de Web of Science)

Conteo de uso $\sim$

One in Seven Babies Exposed to Zika Virus In Utero Has Birth Defects.

Por: Potera, Carol

The American journal of nursing Volumen: 118 Número: 11 Páginas: 12 Fecha de publicación: 2018-Nov

QS.F.X Texto completo de la editorial Ver abstract -

Veces citado: 0

(en la colección principa

de Web of Science)

Conteo de uso $\checkmark$

Therapeutic treatment of Zika virus infection using a brain-penetrating antiviral peptide.

Veces citado: 0

(en la colección principal

de Web of Science)

Por: Jackman, Joshua A; Costa, Vivian V; Park, Soohyun; et ál.

Nature materials Volumen: 17 Número: 11 Páginas: 971-977 Fecha de publicación: 2018-Nov (Epub 2018 Oct 22) Gs.F.X Texto completo de la editorial Ver abstract -

1. Se puede refinar los resultados por los campos que aparecen en el menú a mano izquierda. Se puede refinar los resultados por título Articulo Muy Citado, Articulo Popular, Acceso Abierto, Datos Asociados, MeSH, MeSH Qualifier (temas más específicos dentro de un área de investigación), título de las publicaciones, tipo de publicación, autor y año de publicación.

2. Abra el menú desplegable para cambiar el orden de visualización de los resultados en la página. Inicialmente los resultados ordenan por su año de publicación. También se puede ordenarlos por relevancia, primer autor, título de la fuente y año de publicación.

3. Utilice la herramienta 'Analizar' para analizar todos los registros por varios campos y para poder exportar posteriormente su análisis a una hoja de cálculo.

4. Opciones de exportación. Se puede exportar los resultados a un gestor de referencias, a su perfil de ResearcherID o enviarlos por correo electrónico o hacer una impresión. 


\section{Un Registro Completo en Medline}

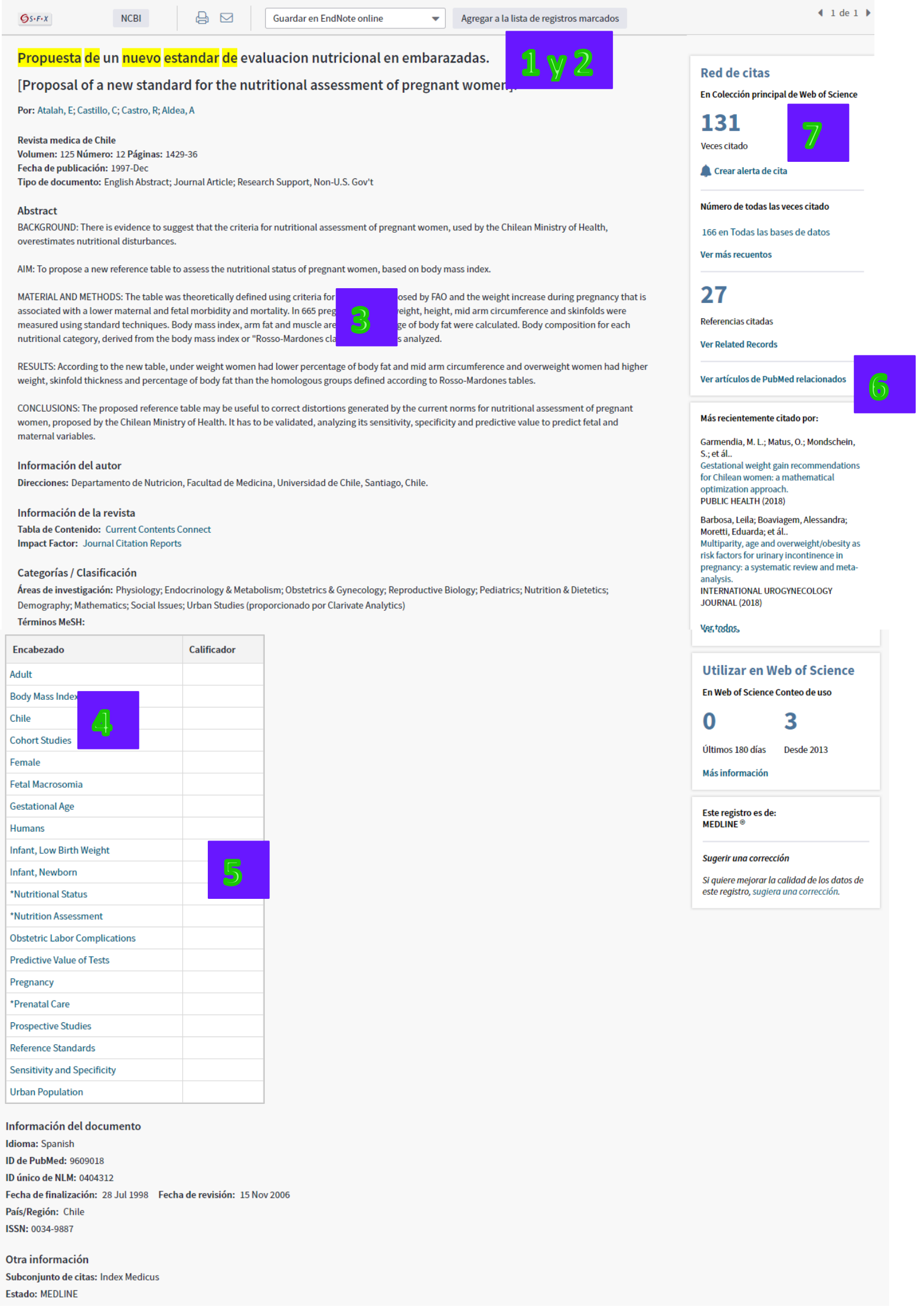


1. Se indexa el título completo del documento original. Se traduce los títulos de idiomas extranjeros al inglés estadounidense.

2. El título completo en idioma original.

3. Existen dos tipos de resúmenes. El primer tipo de resumen se refiere al resumen completo del documento original. El segundo tipo de resumen 'Other Abstract' se refiere a un resumen escrito por un colaborador y no está presente en el documento original.

4. El campo de los títulos MeSH. Los títulos MeSH son temas importantes tratados por el artículo y derivan del vocabulario controlado de terminología de las ciencias de la salud de la NML y sirven para hacer búsquedas.

5. Calificador o subtítulos se refieren a términos asociados con los temas importantes que aclaran el significado de los temas principales en el artículo.

6. Buscar registros relacionados de Pubmed.

7. Las veces citado ( de la Colección Principal de la Web of Science) y crear una alerta de cita (recibir un aviso en cuanto este articulo este citado por otro en la Web of Science) 


\section{El Tesauro de Medline}

El tesauro de Medline contiene la terminología de las ciencias de la salud en vocabulario controlado proporcionado por la NLM. El tesauro ofrece más de 22.000 títulos. También el tesauro incluye subtítulos (Qualifiers) que son títulos adicionales que se puede asociar a los títulos principales, pero no sirven como títulos principales de búsqueda. El tesauro es dinámico y se puede desplazarse de títulos generales a títulos más específicos. Existen dos maneras para recuperar los títulos MeSH

1. Introduzca una palabra en la casilla para recuperar términos que contienen o están relacionados con la palabra.

2. Los títulos están ordenados por una jerarquía. Abra el menú para mover de temas generales a temas más específicos.

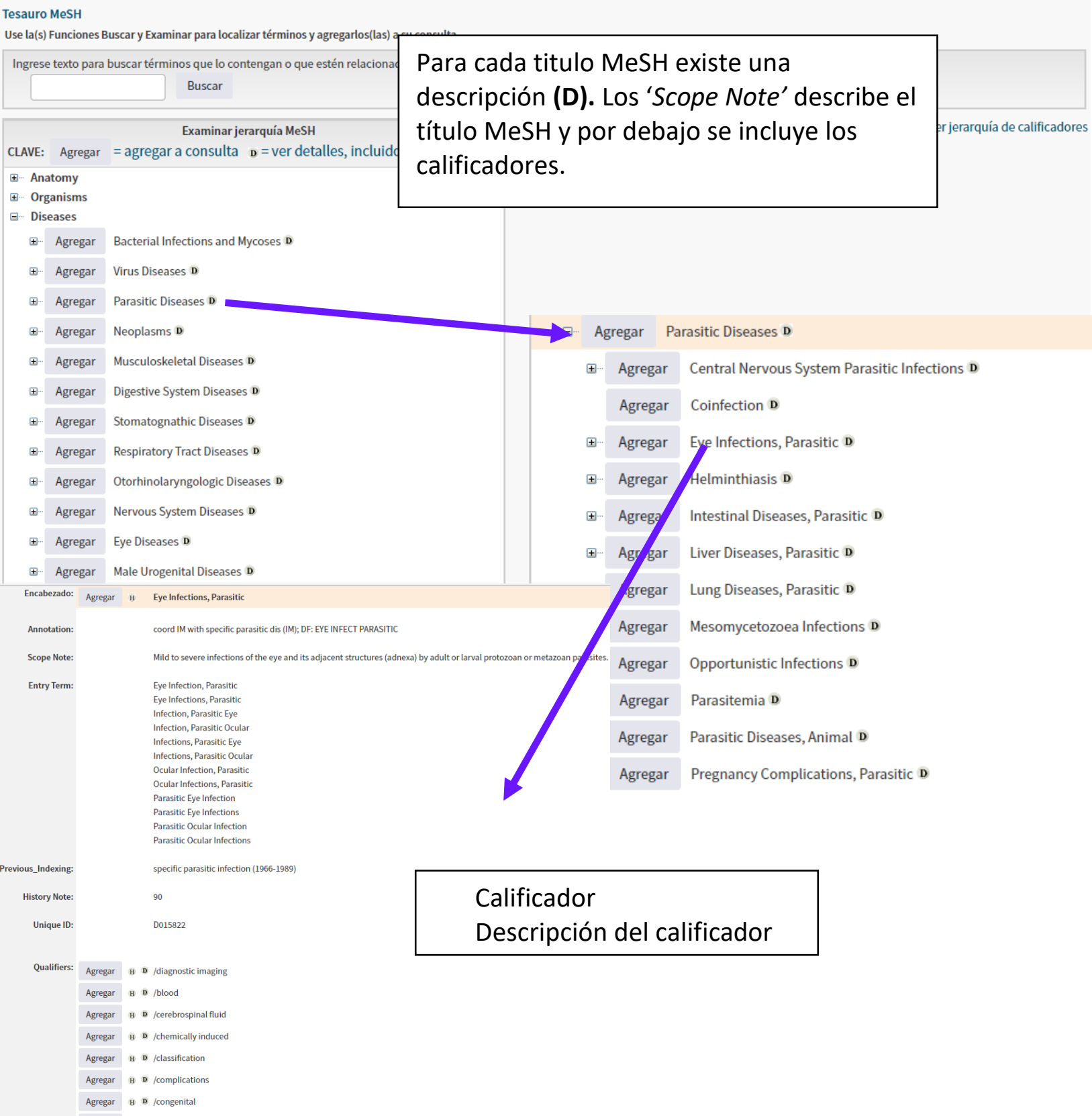




\section{SciELO Citation Database}

\section{http://www.scielo.org}

La Web of Science ofrece a todos sus usuarios acceso a la investigación de países con economías en desarrollo, sobre todo en América Latina, el Caribe y Sud África. También incluye contenido de España y Portugal.

\section{Sobre SciELO}

- SciELO - Scientific Electronic Library Online (Biblioteca Científica Electrónica en Línea) es un modelo para la publicación electrónica cooperativa de revistas científicas en Internet. Especialmente desarrollado para responder a las necesidades de la comunicación científica en los países en desarrollo y particularmente de América Latina y el Caribe, el modelo proporciona una solución eficiente para asegurar la visibilidad y el acceso universal a su literatura científica, contribuyendo para la superación del fenómeno conocido como 'ciencia perdida'. Además, el Modelo SciELO contiene procedimientos integrados para la medida del uso y del impacto de las revistas científicas

1. El Modelo SciELO es el producto de la cooperación entre FAPESP (http://www.fapesp.br ) - la Fundación de Apoyo a la Investigación del Estado de São Paulo, BIREME (http://www.bireme.br) - Centro Latinoamericano y del Caribe de Información en Ciencias de la Salud, así como instituciones nacionales e internacionales relacionadas con la comunicación científica y editores científicos. Un proyecto piloto, envolviendo 10 revistas brasileñas de diferentes áreas del conocimiento, fue llevado a cabo con éxito entre Marzo de 1997 y Mayo de 1998, con el desarrollo y la evaluación de una metodología adecuada para la publicación electrónica en Internet. Desde junio de 1998 el proyecto opera regularmente, incorporando nuevos títulos de revistas y expandiendo su operación para otros países. A partir de 2002, el Proyecto cuenta con el apoyo del CNPq (http://www.cnpq.br ) - Conselho Nacional de Desenvolvimento Científico y Tecnológico. 
Sobre SciELO

\section{Colecciones de revistas y temas}

Por tema - todos

Ciencias Agrícolas

Ciencias Biológicas

Ciencias de la Salud

Ciencias Exactas y de la Tierra

Ciencias Sociales Aplicadas

Humanidades

Ingenierias

Lingüistica, Letras y Artes
$\Rightarrow$ Red SciELO

colecciones de Libros

ㅇ) Brasil

colecciones de Revistas

- Argentina

(-) Brasil

므 Chile

- Colombia

프 Costa Rica

E Cuba

프 España

- México

- Portugal

DE Sudáfrica

Venezuela

9 Salud Pública

7 Social Sciences

en desarrollo

- Bolivia

들 Paguay

7.] Perú

$\triangleq \equiv$ Uruguay

A West Indian Medical Journal

7 Brasil Proceedings

divulgación científica

7. Ciência e Cultura

9 ComCiência

1 Conhecimento e Inovação

A Pesquisa FAPESP

4 Revista USP

A. Revista Virtual de Química

\section{SciELO Características}

- Todo el contenido es de carácter acceso abierto (open access)

- SciELO mantiene su propia selección de contenido que es distinta a la de la WOS CC

- Los criterios por la indexación de contenido incluyen:

- Contenido científico

- Peer Review

- Editorial Board

- Frecuencia

- Historial (debe haber publicado más que 4 publicaciones)

- Puntualidad de publicación

- Títulos de artículos, resúmenes, y palabras claves en inglés

- Normalización

- Afiliaciones de autores 


\section{Cobertura de SciELO}

- El SCIELO Citation Index incluye aproximadamente 600 títulos.

- Incluye más de 6 millones de Referencias Citadas.

- 217 de las revistas coinciden con la Web of Science CC.

- 298 de las revistas coinciden con la Web of Science.

- Todas las revistas con de carácter libre acceso con vínculos al texto completo situado en la página web de SciELO.

- SciELO mantiene las mismas características que otros índices en la WOS.

- Actualizaciones semanalmente según la recepción de datos de SciELO a Web of Science Group.

\section{Página de Búsqueda de SciELO}

Web of Science

Búsqueda básica Búsqueda de referencia citada Búsqueda avanzada

"breast cancer" or "cancer de mama"

(1)

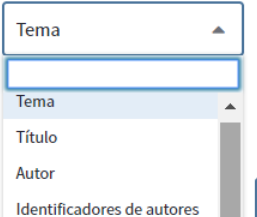

Editor

Nombre de publicación

Colecciones SciELO

\section{Todos los años (2002 - 2018) -}

MÁS AJUSTES *

Índice de citas

SCiELO Citation Index (SCIELO) -2002-presente

Fecha de última actualización de los datos: 2018-10-29

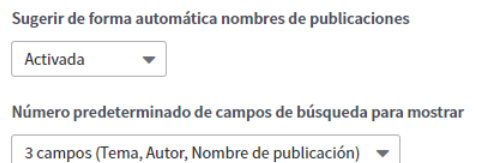

3 campos (Tema, Autor, Nombre de publicación) -

Guardar configuración

1. La página principal de SciELO le permite seleccionar entre la búsqueda básica, la búsqueda avanzada o la búsqueda de referencias citadas.

2. También se puede seleccionar el período de búsqueda. Es posible limitar por años individuales entre el año 2002 al año actual. O se puede seleccionar períodos predeterminados (semana actual, año actual, últimos 5 años etc). 


\section{Normas de una Búsqueda en Scielo}

\begin{tabular}{|c|c|c|}
\hline $\begin{array}{l}\text { Campo de } \\
\text { búsqueda }\end{array}$ & Norma & Índice \\
\hline Tema & Consulte la sección 'Normas de Web of Science CC & \\
\hline Autor & $\begin{array}{l}\text { Ingrese nombres de autores para buscar en el } \\
\text { campo Autor(es) de un registro. Puede introducer } \\
\text { los nombres de autor con o sin signos diacríticos. } \\
\text { Ingrese primero el (los) apellido(s) seguido(s) de un } \\
\text { espacio y de las iniciales del autor. }\end{array}$ & $\mathrm{Si}$ \\
\hline $\begin{array}{l}\text { Identificadores } \\
\text { de autores }\end{array}$ & Introduce el numero de RID o ORCID & $\begin{array}{l}\text { Vaya a } \\
\text { www.researcherid.com }\end{array}$ \\
\hline Editor & $\begin{array}{l}\text { Ingrese el nombre de un editor para buscar en el } \\
\text { campo Editor de un registro. Tenga en cuenta que } \\
\text { una autoría corporativa también puede ser un } \\
\text { editor. } \\
\text { Ingrese nombres completos o parciales } \\
\text { usando comodines (* } \$ \text { ?). Conecte varios } \\
\text { nombres con los operadores booleanos (AND, OR, } \\
\text { NOT). } \\
\text { Las páginas de resultados y de registro completo } \\
\text { muestran primero el apellido de los editores } \\
\text { seguido del nombre y/o de las iniciales. }\end{array}$ & $\overline{\text { No }}$ \\
\hline $\begin{array}{l}\text { Nombre de } \\
\text { publicación }\end{array}$ & $\begin{array}{l}\text { Ingrese un nombre de publicación para buscar en } \\
\text { el campo Fuente de un registro. El producto } \\
\text { recupera nombres de publicaciones con un título } \\
\text { tanto extranjero como en inglés }\end{array}$ & $\mathrm{Si}$ \\
\hline $\begin{array}{l}\text { Año de } \\
\text { publicación }\end{array}$ & $\begin{array}{l}\text { Ingrese un año de cuatro dígitos o un rango de } \\
\text { años para encontrar registros publicados en una } \\
\text { revista específica. }\end{array}$ & No \\
\hline Dirección & $\begin{array}{l}\text { Busque en el campo Dirección introduciendo el } \\
\text { nombre completo o parcial de una institución o } \\
\text { ubicación de la dirección de un autor. Por } \\
\text { ejemplo, Univ y University busca instituciones en } \\
\text { las que el término "Univ" aparece en el campo } \\
\text { Dirección de un registro. } \\
\text { Cuando ingrese nombres completos, no use } \\
\text { artículos (a, an, the) ni preposiciones (of, in, for) } \\
\text { en el nombre. Por ejemplo, la búsqueda de UNIV } \\
\text { Pennsylvania es correcta, pero si } \\
\text { introduce University of Pennsylvania, aparecerá } \\
\text { un mensaje de error. } \\
\text { Tenga en cuenta que los términos de direcciones } \\
\text { habituales pueden estar abreviados en la base de } \\
\text { datos del producto. Por ejemplo, la palabra }\end{array}$ & Ver lista de abreviaturas \\
\hline
\end{tabular}




\begin{tabular}{|c|c|c|}
\hline & $\begin{array}{l}\text { Department puede estar abreviada como Dept o } \\
\text { Dep }\end{array}$ & \\
\hline Organización & $\begin{array}{l}\text { Ingrese el nombre de una organización para } \\
\text { buscar en el campo Direcciones de un registro. } \\
\text { Puede buscar una corporación, una universidad y } \\
\text { otros tipos de nombres de organizaciones. } \\
\text { Ejemplo: una búsqueda sobre Univ* Fed* puede } \\
\text { devolver los siguientes resultados de un registro } \\
\text { específico. } \\
\text { Direcciones: } \\
\text { [ } 1 \text { ] Universidade Federal de Viçosa, Viçosa, Brasil } \\
\text { [ } 2 \text { ] Universidade Tecnológica Federal do Paraná, } \\
\text { Pato Branco, Brasil } \\
\text { [ } 3 \text { ] Universidade Federal Rural do Semi-Árido, } \\
\text { Mossoró, Brasil } \\
\text { Ingrese nombres completos o parciales } \\
\text { usando comodines (* } \$ \text { ?). Conecte varios } \\
\text { nombres con el operador booleano OR. }\end{array}$ & No \\
\hline Idioma & $\begin{array}{l}\text { Los registros de este producto incluyen un } \\
\text { indicador de idioma que categoriza los } \\
\text { documentos por el idioma en que se redactaron. } \\
\text { Para restringir su búsqueda, seleccione uno o } \\
\text { varios idiomas en la lista. La selección } \\
\text { predeterminada es Todos los idiomas. }\end{array}$ & $\mathrm{Si}$ \\
\hline $\begin{array}{l}\text { Tipo de } \\
\text { docuemento }\end{array}$ & $\begin{array}{l}\text { Al limitar una búsqueda por tipo de documento, } \\
\text { solo recuperará aquellos registros que contengan } \\
\text { el (los) término(s) de búsqueda que ingresó en los } \\
\text { campos de búsqueda y el (los) tipo(s) de } \\
\text { documento que seleccionó en la lista. } \\
\text { Para restringir su búsqueda, seleccione uno o } \\
\text { varios documentos en la lista Documento. La } \\
\text { selección predeterminada es Todos los tipos de } \\
\text { documentos. }\end{array}$ & $\mathrm{Si}$ \\
\hline $\begin{array}{l}\text { Numero de } \\
\text { accceso }\end{array}$ & $\begin{array}{l}\text { El número de acceso es un número de } \\
\text { identificación único asociado a cada registro del } \\
\text { producto. Está formado por un número de acceso } \\
\text { (un código de identificación de producto) y un } \\
\text { número secuencial. }\end{array}$ & No \\
\hline
\end{tabular}




\begin{tabular}{|l|l|l|}
\hline & $\begin{array}{l}\text { Conecte siempre varios números con el } \\
\text { operador booleano OR. No use los operadores } \\
\text { AND, NOT, NEAR y SAME al buscar números de } \\
\text { acceso, ya que el producto devolverá un mensaje } \\
\text { de error. }\end{array}$ & \\
& \\
\hline
\end{tabular}




\section{Página de Resultados de SciELO}

\section{Web of Science}

\section{Buscar}

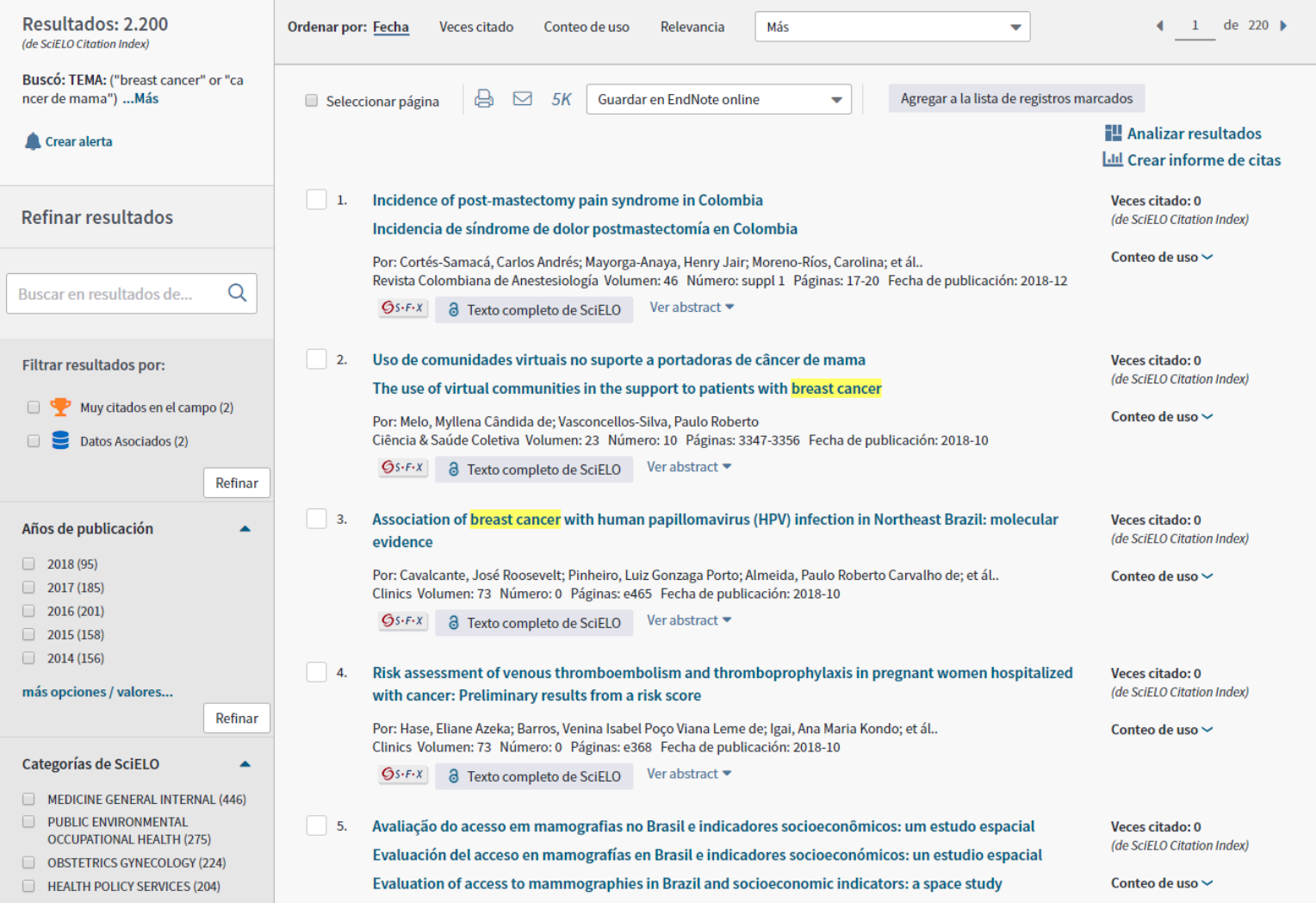

La página de resultados ofrece varias herramientas para que se pueda explorar los resultados e identificar temas de interés.

1. Ordenar los resultados por las opciones en el menú desplegable.

2. Refinar los resultados por campos temáticos (categorías de SciELO, tipo de documento, áreas de investigación de Web of Science, autor, título de la fuente, ano de publicación, instituciones, idiomas y países)

3. Haga clic en 'Analizar resultados' para realizar un análisis sobre los resultados para identificar datos más precisos

4. Haga clic en 'Crear informe de citas' para ver métricas de citas y graficas de tendencia basadas en los artículos recuperados. Incluye el índice h y el promedio de citas por artículo.

5. Las veces de citas de SciELO. Haga clic en este número para examinar más totales de citas de la Web of Science.

6. Haga clic en 'Texto completo de la editorial' para acceder al texto completo en el sitio web de SciELO.

7. Haga clic en 'ver abstract' para visualizar el resumen al instante.

8. El título de artículo se presenta en idioma original y en inglés. 


\section{Registro Completo de SciELO}

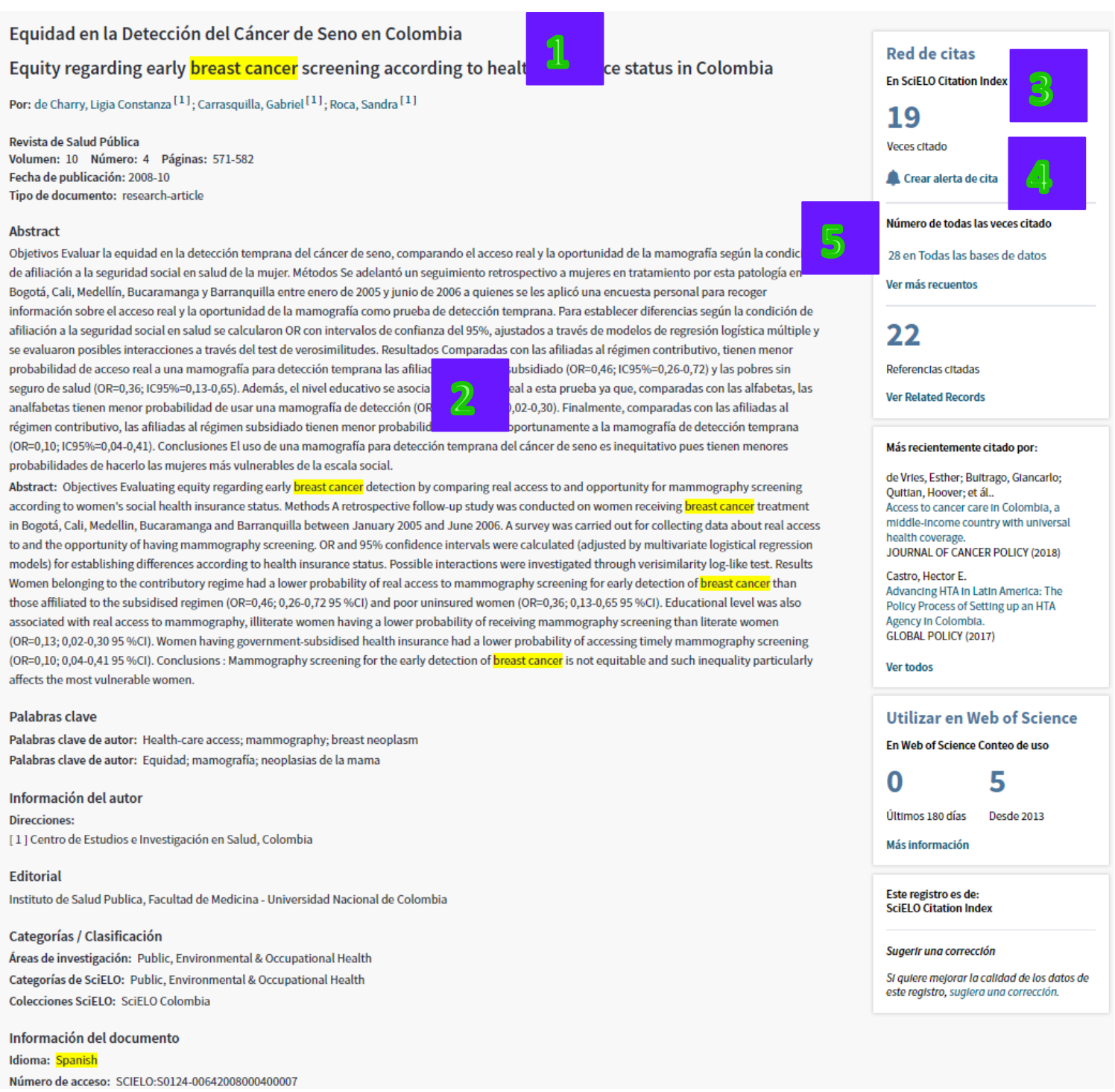

1. El título en idioma original, en inglés y/o en portugués.

2. Resumen original y en inglés.

3. Red de citas. Puede ver el total de citas (de SciELO), el número de referencias citadas, y ver los registros relacionados. Los registros relacionados citan por lo menos una de las referencias incluidas en la bibliografía del artículo.

4. Crear alerta de cita para recibirá notificación en cuanto este articulo este citado por otro (en SciELO).

5. Ver aquí totales de citas de otras bases incluidas en la Web of Science. 


\section{Búsqueda Avanzada de SciELO}

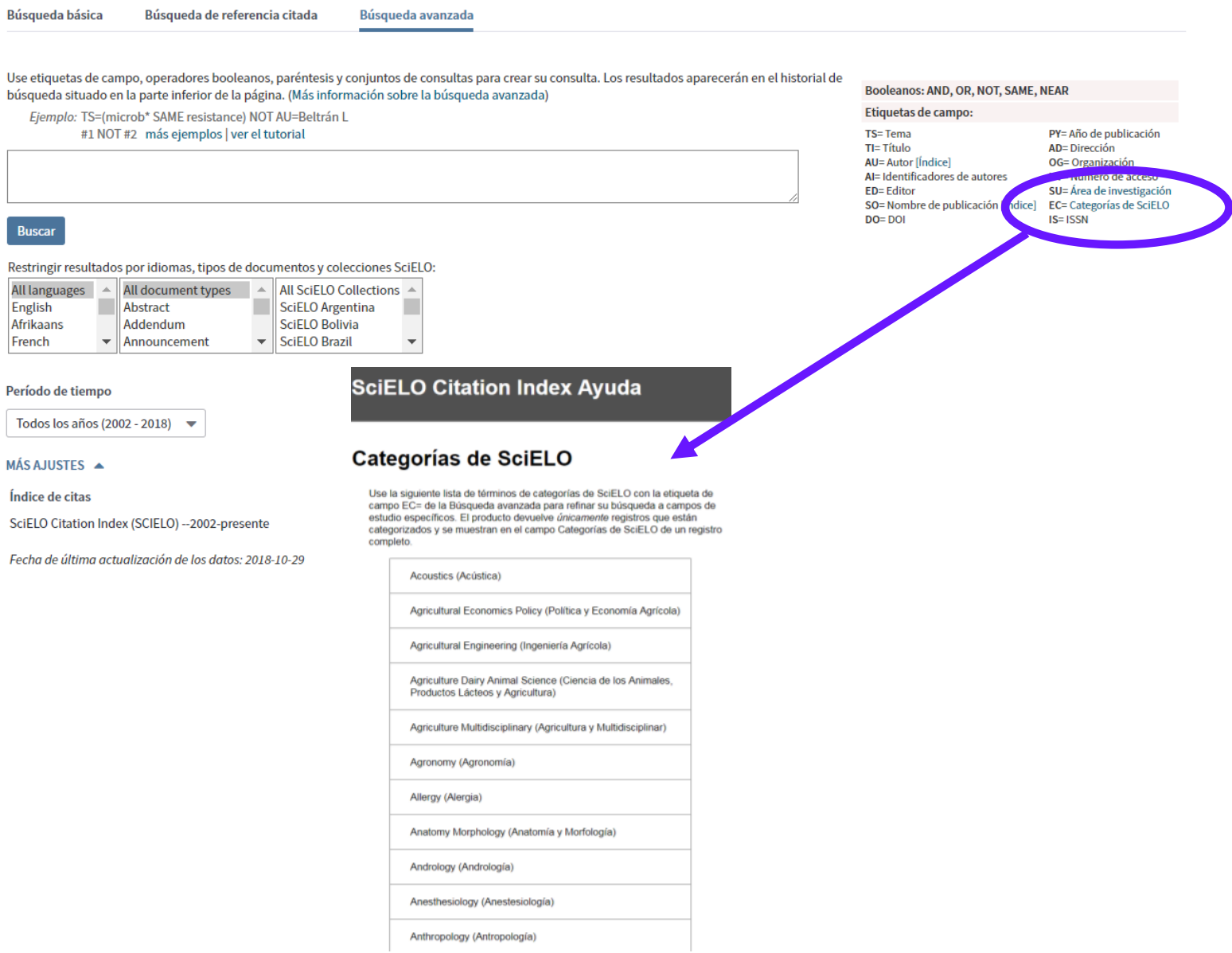

La búsqueda avanzada de SciELO le permite buscar en campos adicionales no disponibles a través de la búsqueda básica.

Seleccionar la etiqueta 'EC=' para buscar en el campo 'Categorías de SciELO.

En el campo de búsqueda introduce las etiquetas de campo y combina sus búsquedas con los operadores booleanos (AND,OR, NOT, SAME y NEAR) 


\section{Korean Journal Database}

La Web of Science ofrece a sus usuarios acceso a un índice regional. Se trata de la Korean Journal Database $(\mathrm{KCl})$ una base de datos basada en una selección de 2.000 revistas coreanas de alto impacto de las cuales 1.500 son nuevas en Web of Science, presentándose su contenido también en inglés. Esta base de datos presenta información de alto valor añadido especialmente para Ingeniería.

\section{Características}

- La base se desarrolló de una colaboración entre Web of Science Group y la Fundación Nacional de Investigacion de Corea.

- Aumenta la visibilidad de la investigación en Corea del Sur y su impacto global.

- Facilita la colaboración internacional.

- Ofrece las mismas capacidades y funcionalidades de otras bases en la plataforma de Web of Science.

\section{Korean Journal Database Página Principal}

$$
\text { Web of Science } \quad \text { clarivate }
$$

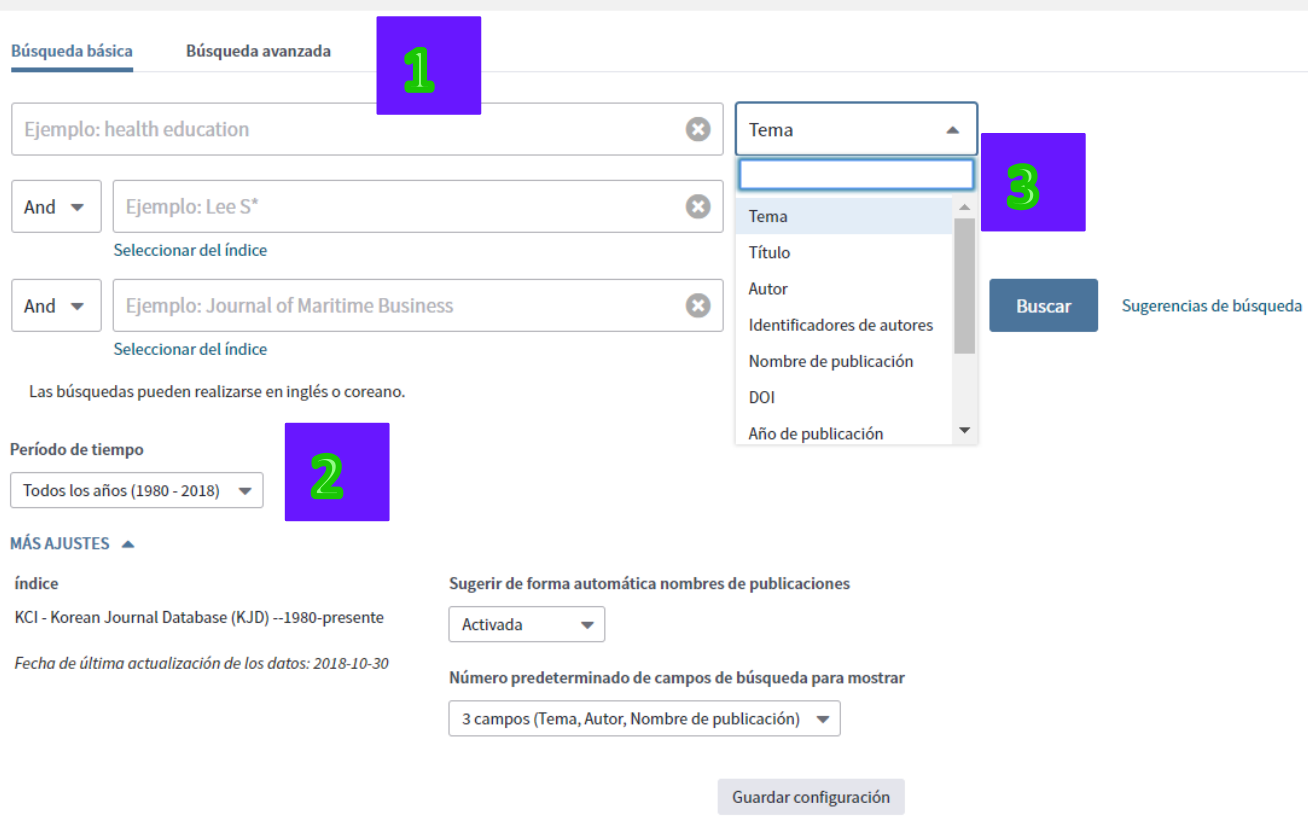

1. La página principal del Korean Journal Database le permite seleccionar entre la búsqueda básica y la búsqueda avanzada. 
2. También se puede seleccionar el período de búsqueda. Es posible limitar por años individuales entre el año 1980 al año actual. O se puede seleccionar períodos predeterminados (semana actual, año actual, últimos 5 años etc).

3. La búsqueda básica le permite buscar en campos bibliográficos y seleccionar el tipo de documento e idioma.

4. Es posible buscar en inglés o en coreano.

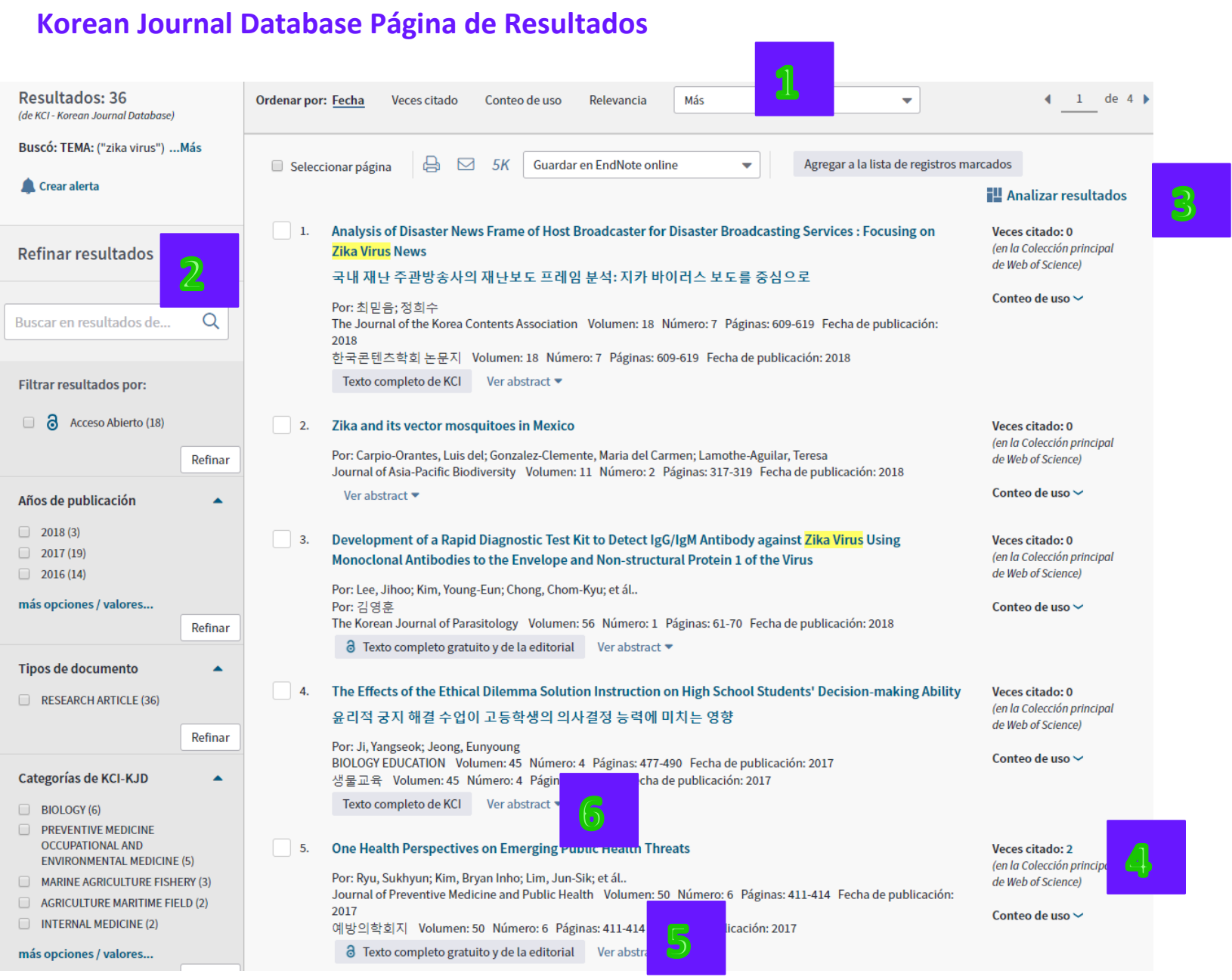

La página de resultados ofrece varias herramientas para que se pueda explorar los resultados e identificar temas de interés.

1. Ordenar los resultados por las opciones en el menú desplegable.

2. Refinar los resultados por campos temáticos (categorías de KCl-KJD, tipo de documento, áreas de investigación de Web of Science, autores, título de la fuente, año de publicación e idiomas) 
3. Haga clic en 'Analizar resultados' para realizar un análisis sobre los resultados para identificar datos más precisos

4. Las veces de citas de Colección Principal de la Web of Science. Haga clic en este número para examinar más totales de citas en la Web of Science.

5. Haga clic en 'Texto completo de la editorial' para acceder al texto completo en el sitio web del 'National Research Foundation of Korea'.

6. Haga clic en 'ver abstract' para visualizar el resumen al instante.

\section{Korean Journal Database Registro Completo}
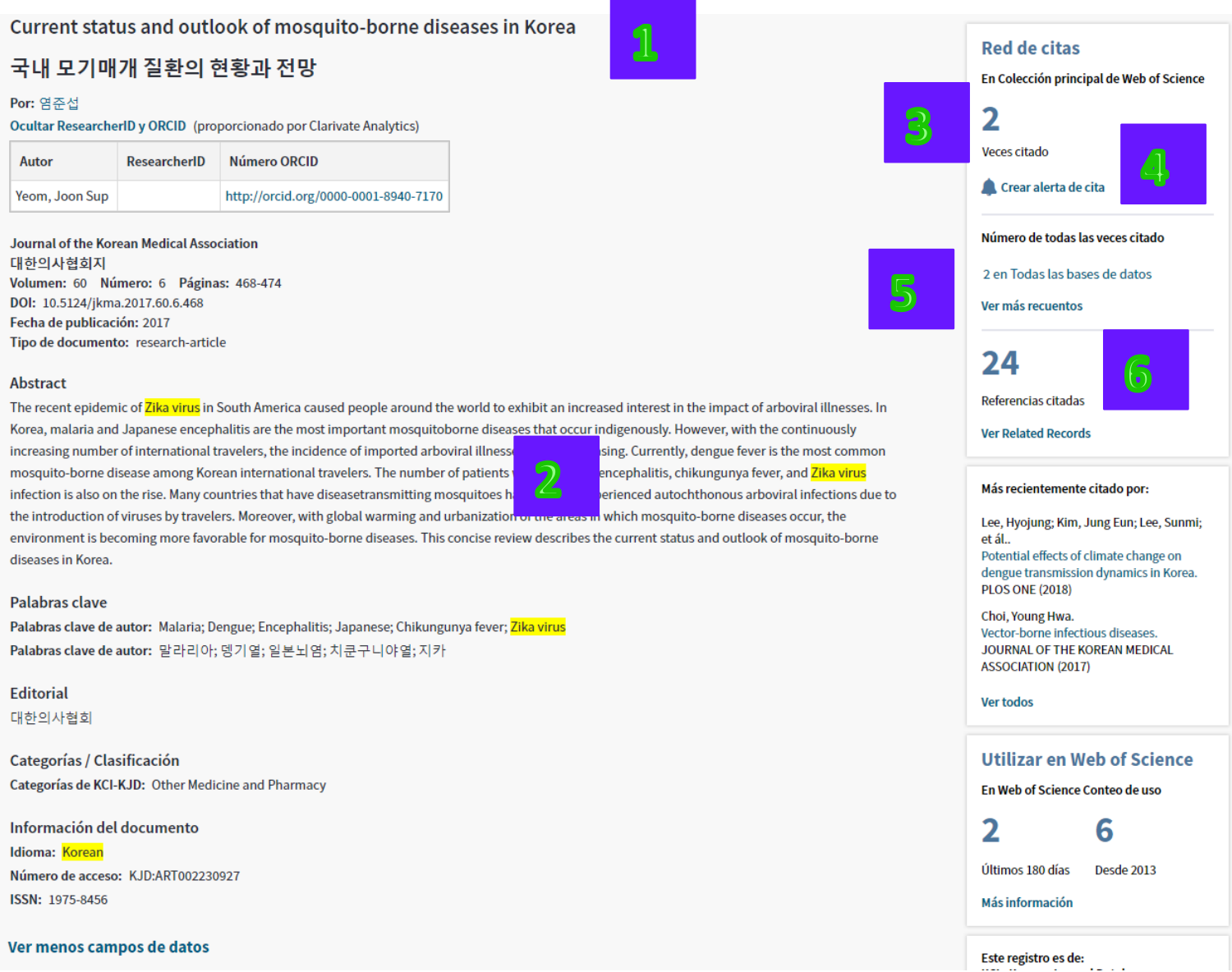

1. El título en idioma original (en coreano) y en inglés.

2. Resumen original en coreano y en inglés.

3. La red de citas proporciona datos de citas originados de la Colección Principal de Web of Science. Puede ver el total de citas, el número de referencias citadas (y ver los registros relacionados. Los registros relacionados citan por lo menos una de las referencias incluidas en la bibliografía del artículo.

4. Crear alerta de cita para recibirá notificación en cuanto este artículo este citado por otro (de la Colección Principal de Web of Science).

5. Ver aquí totales de citas de otras bases incluidas en la Web of Science.

6. Las referencias citas (de la Web of Science colección principal) 